\title{
RESPONSABILIDAD SOCIAL DE LAS ORGANIZACIONES (RSO)
}

Estudios desde la mirada de la Responsabilidad Social hacia los Objetivos de Desarrollo Sostenible en América Latina

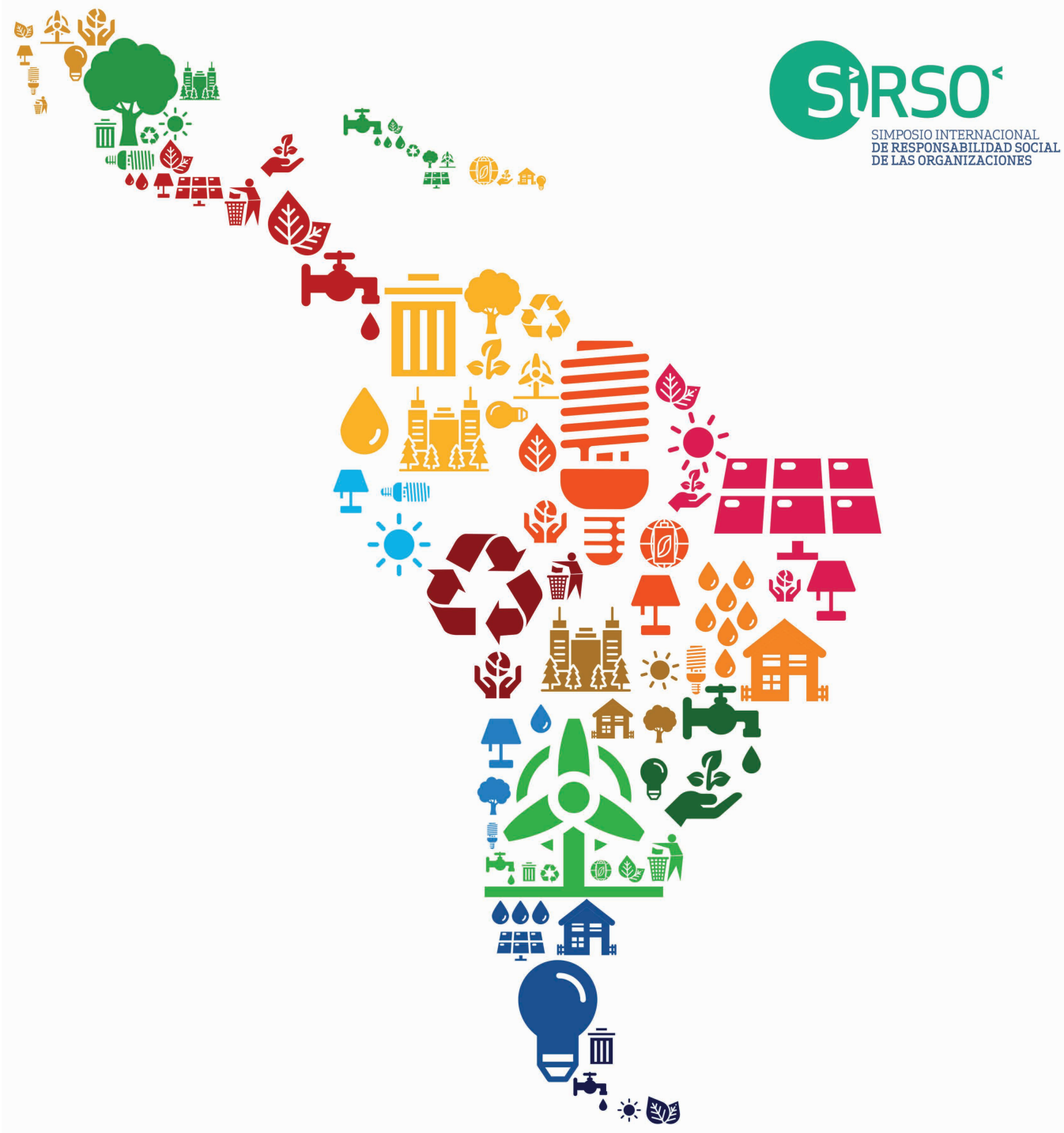

NORA GORROCHATEGUi

Valmir Martins de Oliveira

Nelson Stevenson Palamara

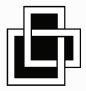

RiL editores 


Responsabilidad Social DE las Organizaciones (RSO) 



\author{
Nora Gorrochategui \\ Valmir Martins de Oliveira \\ Nelson Stevenson Palamara \\ Compiladores
}

\title{
RESPONSABILIDAD SOCIAL DE LAS ORGANIZACIONES (RSO)
}

Estudios desde la mirada de la Responsabilidad Social hacia los Objetivos del Desarrollo Sostenible en América Latina

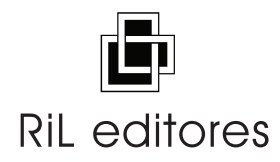




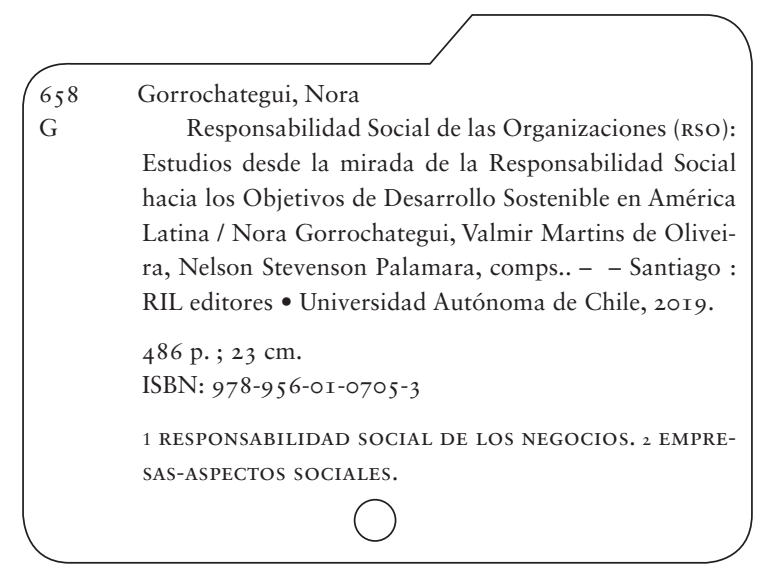

Responsabilidad Social de las Organizaciones (RSO). Estudios desde la miRAda de la Responsabilidad Social hacia los Objetivos de Desarrollo Sostenible en América latina

Primera edición: agosto de 2019

(C) Nora Gorrochategui, Valmir Martins de Oliveira

y Nelson Stevenson Palamara, 2019

Registro de Propiedad Intelectual

$\mathrm{N}^{\circ} 306.966$

(C) RIL ${ }^{\circledR}$ editores, 2019

Sede Santiago:

Los Leones 2258

CP 75 I1055 Providencia

Santiago de Chile

(d) (56) 222238 100

ril@rileditores.com・www.rileditores.com

Sede Valparaíso:

Cochrane 639, of. 92

CP 236I80I Valparaíso

(d) (56) 322746203

valparaiso@rileditores.com

Sede España:

europa@rileditores.com・Barcelona

(C) Centro de Comunicación de las Ciencias, 2019

Universidad Autónoma de Chile

https://ciencias.uautonoma.cl I ciencias@uautonoma.cl

ISBN Universidad Autónoma 978-956-8454-38-8

Composición, diseño de portada e impresión: RIL $®$ editores

Impreso en Chile $\bullet$ Printed in Chile

ISBN 978-956-OI-0705-3

Derechos reservados. 


\section{ÍNDICE}

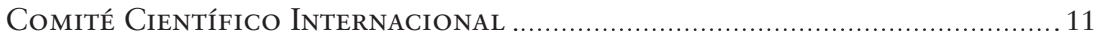

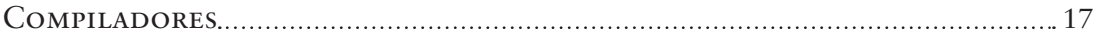

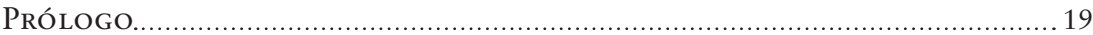

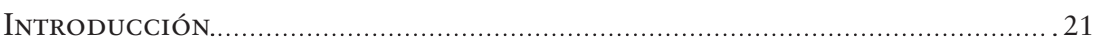

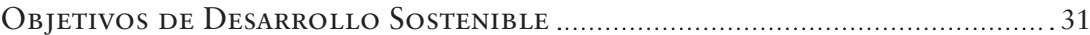

SECCIÓn I: CONFEREnCIAS Y MENSAJES de LOS COORdinAdoreS............. 33

El ROL DE LA UNIVERSIDAD EN AMÉRICA LATINA SOBRE FORMACIÓN E INVESTigación en Responsabilidad Social y Sustentabilidad

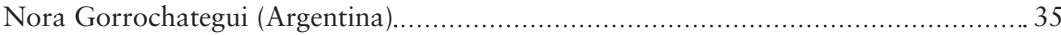

LAS NUEVAS GENERACIONES DE PROFESIONALES PREFIEREN A LAS EMPRESAS SOCIALMENTE RESPONSABLES

Valmir Martins de Oliveira (Chile).

Mensaje de apertura, decano Facultad de Administración y Negocios De la Universidad Autónoma de Chile en el V Simposio Internacional DE Responsabilidad SOCIAL de las Organizaciones y I CONGRESO INTERNACIONAL DE GESTIÓN ORGANIZACIONAL

Nelson Stevenson Palamara (Chile)

Sección II: Responsabilidad Social Empresarial (RSE) 55

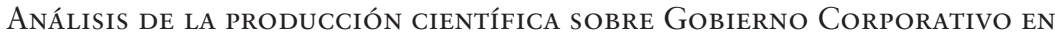
LATINOAMÉRICA Y ESPAÑA

Walter Daniel Ovelar Fernández (Paraguay).

GOBERNANZA DE LA SUSTENTABILIDAD EN CADENAS DE VALOR INDUSTRIALES en Córdoba, Argentina

María Florencia Peretti, Mónica Buraschi, Celina N. Amato (Argentina). 81

CREACIÓN DE VALOR COMPARTIDO COMO ESTRATEGIA DE COMPETITIVIDAD Y RESPONSABILIDAD SOCIAL EN LAS ORgANIZACIONES

Manuel Méndez Pinzón, Marcela Gómez Osorio (Colombia).

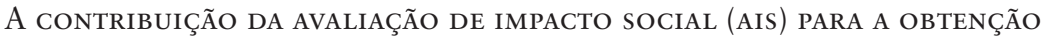
DA LICENÇA SOCIAL PARA OPERAR (LSO) NA MINERAÇÃO

Ana Lúcia Frezzatti Santiago, Jacques Demajorovic, Antonio Aledo Tur (Brasil y España). 
LA INCIDENCIA DE LA RSE EN LA REPUTACIÓN CORPORATIVA Y SU MEDICIÓN EN EMPRESAS DE COMUNICACIÓN

Jaime Alberto Orozco-Toro (Colombia).

Consumo Responsable: PERfil DEL CONSUMidor SANTAFESINO

Graciela Kosiak de Gesualdo, Horacio Alesandria,

Enrique Carlos Bianchi (Argentina).

LA Responsabilidad Social de los destinos turí́sticos: IMPACTO EN LA PERCEPCIÓN DE CALIDAD DE SERVICIO Y EN LA IMAGEN DEL DESTINO

Enrique Carlos Bianchi, Juan Manuel Bruno, Carolina Sánchez (Argentina). 161

A CONTRIbuiÇão DOS PACOTES SALARIAIS NA AMPLIAÇÃO DA

RESPONSABILIDADE SOCIAL EMPRESARIAL

Katia de Rezende Maia Cruz, Emmanuel Paiva de Andrade,

David Barbosa Souza Junior (Brasil).

Políticas de Diversidad en las empresas argentinas

Emmanuel Oliverio, Emiliano Sebastián Consoli, Paula Colacioppo (Argentina)....... 209

REFLEXIONES SOBRE LA DIVISIÓN SEXUAL DEL TRABAJO Y LA

Responsabilidad Social Empresarial en Chile

Hernán Riquelme Brevis, Matías Riquelme Brevis (Chile).

DiRECTIVOS GENERACIÓN CONFIANZA: PERSPECTIVA DE GÉNERO EN PYMES SECTOR SERVicios, Bogotá D.C.

Marta Gisela Durán Gamba, Luz Janeth Lozano Correa, Myriam Sosa Espinosa (Colombia).

SECCIÓN III: RESPONSABILIDAD SOCIAL DE LAS COOPERATIVAS 261

INFORME SOBRE EL ACCIONAR SOCIALMENTE RESPONSABLE DE UNA COOPERATIVA ARgENTINA. CASO CEB

Oscar Alcides Zapata (Argentina).

Responsabilidad SOCIAL EMPRESARIAL y LA RENTABILIDAD EN LAS COOPERATIVAS DE AHORRO Y CRÉDITO DEL ECUADOR

Juanita García Aguilar, Aníbal Altamirano Salazar (Ecuador)

SEcción IV: Responsabilidad Social Universitaria (RSU). 305

LA SIMULACIÓN COMO ESTRATEGIA EDUCATIVA PARA LA ENSEÑANZA DE LA SUSTENTABILIDAD EN INGENIERÍA, EN FRBA (UTN)

Diana Rut Schulman, Milena Ramallo, Hugo Alejandro Izaguirre (Argentina). 307 
RESPONSABILIDAD SOCIAL UNIVERSITARIA Y VINCULACIÓN CON EL MEDIO: CONSTRUCCIÓN DE UNA METODOLOGÍA PARA DESARROLLAR PROYECTOS DE A+S

Gracia Navarro Saldaña, Verónica González Navarro,

Jorge Maluenda Albornoz (Chile).

Sección V: Responsabilidad Social Pública (RSP).

Herramienta de ANÁlisis DEl ROL GUbernamental PARA PROMOVER LA Responsabilidad SOCIAL EN LA PRODUCCIÓN SOSTENIBLE DE LAS PYMES COLOMBIANAS

Luis Fernando Moreno Garzón (Colombia)

Principios de Responsabilidad Social: UnA MIRAdA Desde EL CONTROL

Daniela Alejandra Giordano (Argentina).

ÍNDICE DE PERCEPCIÓN DE TRANSPARENCIA PARA LA OBRA PÚBLICA

Carlos Nelson Rubín (Argentina).

Sección VI: Objetivos de desarrollo sostenible 401

ESTRATEGIAS DE GESTIÓN TERRITORIAL BAJO LOS PRECEPTOS DE LA Responsabilidad SOCIAL

Silvia Susana Vega, Marcela Vanesa Céspedes, Graciela Laplagne (Argentina)...... 403

AVAliaÇÃO DA SUSTENTABILIDAdE DE MUNICÍPIOS BRASILEIROS PELOS OBJETIVOS DO DESENVOLVIMENTO SUSTENTÁVEL

Ronaldo Ferreira da Silva, Leonardo de Lima Moura, Luiz Octávio Gavião (Brasil)

Microgobernanza PARA LOS EMPRENDIMIENTOS DE CALIDAD EN ECUAdOR acorde al objetivo 8 de Desarrollo Sostenible

Gino Geovanny Cornejo Marcos (Ecuador) 441

CALIdAd de VIDA y Responsabilidad Social EN NiÑos INdígenaS MEXICANOS: CONDUCTA PROAMBIENTAL

Santa Magdalena Mercado Ibarra, María Teresa Fernández Nistal, Joanna Mariby Cota Beltrán (México). 



\section{Comité Científico InTernacional}

JuAn José Almagro

Universidad Rey Juan Carlos

España

José Antonio Ariza Montes

Universidad Loyola Andalucía

España

Alberto Edgardo Barbieri

Universidad de Buenos Aires

Argentina

EUGENIO BISAMA

Universidad Tecnológica de Chile

Chile

ISABEL BLANCO

Universidad de Buenos Aires

Argentina

Vivian Aparecida Blaso Souza Soares Cesar

Fundação Armando Alvares Penteado (FAAP)

Brasil

Norma Lucía Bonilla Londoño

Universidad Piloto de Colombia

Colombia

María Teresa CASPARri

Universidad de Buenos Aires

Argentina 


\section{Aldo CeA}

Universidad Autónoma de Chile

Chile

Luis CERDA

Universidad Autónoma de Chile

Chile

Luciana de Araujo Gil

Universidad Diego Portales

Chile

Julio Domínguez Granda

Universidad de Los Ángeles de Chimbote

Perú

Armindo dos Santos de Sousa Teodósio

Pontificia Universidad Católica de Minas Gerais

Brasil

Alejandro Miguel Estévez

Universidad Torcuato Di Tella

Argentina

LILIANA GALÁN

Universidad Nacional de La Plata

Argentina

Teresa del Pilar García García

Universidad de Los Ángeles de Chimbote

Perú

JUAN José GILLI

Universidad de Buenos Aires

Argentina

Juan Carlos Gómez Fulao

Universidad de Buenos Aires

Argentina 
Helena Maria Gomes Queiroz

Fundação Dom Cabral

Brasil

Osvaldo Luiz Goncalves Quelhas

Universidad Federal Fluminense

Brasil

Nora Gorrochategui

Universidad de Buenos Aires

Argentina

Ana Patricia Hernández Bernal

Universidad Católica de Colombia

Colombia

Rene Hernández

Universidad Del Zulia

Venezuela

LUIS IRRIBARREN

Universidad Autónoma de Chile

Chile

Patricia Kent

Universidad Nacional de la Patagonia San Juan Bosco

Argentina

Silvia Carolina Martino

Universidad Austral

Argentina

Valmir Martins de Oliveira

Universidad Autónoma de Chile

Chile 
Marcelo Jasmin Meiriño

Universidad Federal Fluminense

Brasil

Luis Fernando Moreno Garzón

Universidad Santo Tomás

Colombia

Gracia Navarro Saldaña

Universidad de Concepción

Chile

Sasquia Obata

Facultad de Tecnología Victor Civita-Centro Paula Souza

Brasil

Teresa Pérez Cosgaya

Universidad Miguel de Cervantes

Chile

María Marta Preciosa

Pontificia Universidad Católica Argentina

Argentina

Adriana Balbina Riquelme Miranda

Universidad Autónoma de Chile

Chile

Guillermo Sabbioni Pérez

Universidad Católica Argentina

Argentina

Diana Rut Schulman

Universidad Nacional de Luján

Argentina

Eduardo Rubén Scarano

Universidad de Buenos Aires

Argentina 
Graciela Scavone

Universidad del Salvador

Argentina

María JoÃo SANTOS

Universidad de Lisboa

Portugal

Fernando Miguel Seabra

Instituto Superior de Contabilidade e Administração de Lisboa (ISCAL)

Portugal

Antonio Sianes Castaño

Universidad Loyola Andalucía

España

Elsa BeAtriz Suárez Kimura

Universidad de Buenos Aires

Argentina

Nilda TAÑSKI

Universidad Nacional de Misiones

Argentina

Mario Henrique Uribe Macías

Universidad de Tolima

Colombia

Jeannette Valverde Chaves

Universidad Nacional en Costa Rica

Costa Rica

Alejandro Vega

Universidad Autónoma de Chile

Chile 
Otto Villaprado Chávez

Universidad de Guayaquil

Ecuador

Mario Villar

Universidad Autónoma de Chile

Chile

Alberto Willi

Universidad Austral

Argentina 


\section{Compiladores}

\section{Nora Gorrochategui (Argentina)}

- Postdoctorado en Ciencias Económicas, Universidad de Buenos Aires (UBA).

- Doctora en Administración, Universidad de Buenos Aires (UBA)

- Magister Scientiarum en Administración Pública, Universidad de Buenos Aires (UBA).

- Licenciada en Ciencia Política, Universidad del Salvador.

- Ha sido la primera subdirectora de la Oficina de Ética Pública de su país.

- Cofundadora y Coordinación General SIRSO.

- Docente e investigadora de la Facultad de Ciencias Económicas de la Universidad de Buenos Aires (UBA).

\section{Valmir Martins de Oliveira (Chile)}

- Doctor en Estudios Americanos (especialidad: Estudios Internacionales) en Instituto de Estudios Avanzados (IDEA), Universidad de Santiago de Chile (USACH). Título convalidado como Doctor en Integración de América Latina, Universidade de São Paulo, USP.

- Magíster en Planificación y Gestión Estratégica en Hospitalidad, Universidad Anhembi-Morumbi (UAM), Brasil.

- Postgrado (lato sensu) en Turismo, Universidade de São Paulo (USP).

- Administrador de Empresas, Universidade São Judas Tadeu (USJT) Brasil.

- Cofundador y Coordinación General SIRSO.

- Académico docente-investigador, Facultad de Administración y Negocios, Universidad Autónoma de Chile (UA). 


\section{Nelson Stevenson Palamara (Chile)}

- Doctor@ en Procesos de Integración, Universidad de Lleida, España.

- Máster en Dirección y Organización de Empresas, Universidad de Lleida, España.

- Máster en Dirección General de Empresas, Institute for Executive Development, IEDE-España.

- Diplomado en Administración de Educación Superior, CT-INTRA-BID, Universidad de Los Andes, Colombia, y Universidad de Costa Rica, Costa Rica.

- Diplomado en Estudios Avanzados en Procesos de Integración en Europa y América Latina, Universidad de Lleida, España.

- Ingeniero comercial, Universidad Católica del Norte.

- Decano de la Facultad de Administración y Negocios, Universidad Autónoma de Chile (UA). 


\section{Prólogo}

Desde la perspectiva de la Responsabilidad Social de las organizaciones en América Latina, el presente libro tiene el desafío de avanzar en la discusión del tema frente a la necesidad de lograr un mayor desarrollo socioeconómico para nuestra región, ofreciendo un diálogo compartido entre los autores de esta obra, que van desde reflexiones, presentaciones de marcos teóricos y propuestas metodológicas, hasta los más relevantes resultados de los proyectos de investigación sobre esta materia.

La Responsabilidad Social de las organizaciones no está limitada de manera exclusiva a las entidades privadas, sino que abarca también al Estado y a todo tipo de organización humana. Por tal razón, es un tema instalado en la agenda académica latinoamericana.

El debate acerca de la responsabilidad social en conjunto con los Objetivos de Desarrollo Sostenible (ODS) de la Organización de Naciones Unidas abre una visión de futuro que requiere, además de un enfoque multidimensional, concentración de esfuerzos e integración del trabajo realizado por diferentes actores sociales a nivel global. La cooperación y el rol de la educación en el proceso de garantizar una mejor calidad de vida para hoy y para las futuras generaciones posibilitan la generación de iniciativas que estén alineadas a una realidad social.

Los ODS cobran sentido si los consideramos como una guía para que las organizaciones puedan gestionar sus actividades de impacto social, económico y medioambiental, reconocer cómo están aportando valor a la sociedad, así como establecer sus agendas de acción y fortalecer los vínculos con sus grupos de interés.

En este escenario, la decisión de nuestra universidad de acoger como sede la quinta edición del Simposio Internacional de Responsabilidad Social de las Organizaciones (SIRSO) y de inaugurar el primer Congreso Internacional de Gestión Organizacional converge con el trabajo realizado para profundizar el posicionamiento institucional en el ámbito nacional e internacional, consolidando un compromiso con la sociedad como parte de su desarrollo académico y profesional.

Un ejemplo de esta línea de actuación es nuestro Modelo Educativo, que ostenta la Responsabilidad Social como uno de sus cuatro ejes, 
junto con la Centralidad en el Estudiante, Aprendizajes Transversales y Aprendizaje Continuo. El eje de la Responsabilidad Social busca en su principio «conducir una visión integradora que, a partir del valor de la dignidad de las personas, contribuya a la comprensión y solución de problemas sociales, para generar condiciones más justas y plenamente humanas».

Vivimos un presente y vislumbramos un futuro en que la discusión pública sea una alternativa para avanzar en la construcción de un país más equitativo, donde sus habitantes tengan mejores competencias y sea posible la convivencia en un mundo de constante cambio. Así, la Responsabilidad Social se constituye en herramienta importante para combatir la pobreza y la desigualdad en conjunto con las políticas públicas de los países y regiones, viabilizando la construcción del futuro deseado.

Expreso mi esperanza de que los contenidos de esta publicación sean una contribución relevante para los investigadores, gestores e interesados en la Responsabilidad Social y la sostenibilidad, involucrados en distintos ambientes organizacionales.

De este modo se reafirmaría, una vez más, el rol protagónico de la academia como un conjunto de instituciones generadoras de conocimientos para los procesos de transformación de nuestro entorno.

Dr. Teodoro Ribera Neumann Rector Universidad Autónoma de Chile Santiago, marzo de 2019 


\section{INTRODUCCIÓN}

América Latina está trabajando para el logro de los Objetivos del Desarrollo Sostenible (ODS) con una orientación multidimensional que transforme los modelos tradicionales de desarrollo. Ello implica, a nivel organizacional, modificar la gestión en búsqueda de un arquetipo que conjugue la racionalidad técnica y la visión humanista. En este sentido, los principios y materias de la Responsabilidad Social (RS) ofrecen el marco adecuado para la gobernanza organizacional que contribuya a alcanzar algunas de las metas que se ha planteado la ambiciosa agen$\mathrm{da}$ internacional.

Desde la academia, el Simposio Internacional de Responsabilidad Social de las Organizaciones (SIRSO) viene construyendo una comunidad epistémica para América Latina, que permita la expresión de los avances y reflexiones sobre las nuevas formas de gestión, «a favor de las personas, el planeta y la prosperidad», tal como se sostiene en los ODS.

Para ello, los investigadores enfrentan los desafíos de los abordajes transdisciplinares que se encuentran sujetos a las limitaciones de las unidades académicas, en las que prevalecen las visiones disciplinares. Gestión responsable para el logro de objetivos de carácter integrado e indivisible que conjugue las dimensiones económicas, sociales y ambientales es materia de análisis y estudio para las universidades.

Esta introducción tiene el propósito tradicional de efectuar una presentación del contenido del libro y, además, de hacer explícitos los objetivos y o metas a los que apuntan los distintos autores con sus trabajos, para comenzar a corporizar la intangibilidad de la contribución de la academia al logro de los ODS en la región.

La Sección I está dedicada a las conferencias y mensajes que los compiladores del libro expusimos en la apertura del SIRSO. Nora Gorrochategui reflexiona sobre el rol de la universidad en América Latina sobre formación e investigación en Responsabilidad Social y Sustentabilidad. Valmir Martins de Oliveira llama la atención sobre la tendencia de que las nuevas generaciones de profesionales prefieren a las empresas socialmente responsables. Nelson Stevenson Palamara expone 
la significación del evento en el marco de la Facultad de Administración y Negocios de la Universidad Autónoma de Chile.

Las otras cinco secciones contienen veintidós de los trabajos presentados en el evento y preseleccionados por el Comité Científico Internacional. Su clasificación ha resultado compleja, dado que los temas abordados corresponden a uno o más asuntos mutuamente interrelacionados. Los documentos se han ordenado teniendo en cuenta, principalmente, el tipo de organización sobre el que se aplica la responsabilidad social, ya sean empresas, cooperativas, universidades, así como agencias del sector público. En la sección dedicada a los ODS, se han presentado temáticas puntuales, que responden a las preocupaciones universales con las características propias de la realidad en la que se producen. Cada uno de los trabajos se pueden encuadrar en algunos de los objetivos y metas y en el espíritu general de los ODS y, aunque los autores no lo hayan destacado específicamente, respondieron a la consigna de convocatoria del V SIRSO, realizado en la Universidad Autónoma de Chile. Esta es la que refleja el título del libro: Estudios desde la mirada de la Responsabilidad Social hacia los Objetivos del Desarrollo Sostenible.

La Sección II, Responsabilidad Social Empresarial (RSE), abarca once capítulos en los que se refleja la orientación pragmática de su contenido, tanto en algún trabajo que puede ser calificado como estado del arte, como en aquellos que consisten en aplicaciones a realidades locales, de materias o asuntos de la RS y de modelos teóricos, así como los que pueden ser considerados como investigaciones propiamente dichas.

Los ODS (ver p. 31) que se revelan más frecuentemente asociados a las temáticas incluidas en la sección son los ODS 5 y el 9. Luego, en orden decreciente similar se ubican los ODS 8, 10, 11, 16 y 17.

El primer trabajo, titulado "Análisis de la producción sobre gobierno corporativo en Latinoamérica y España» y elaborado por Walter Daniel Ovelar Fernández, aborda el tema del gobierno corporativo, analizando noventa artículos de la producción científica en Latinoamérica y España en el período 2008-2017. El tema relevante para la gestión de las empresas en un mercado libre se condice con el ODS 16 y su meta 16.6: «Crear a todos los niveles instituciones eficaces y transparentes que rindan cuentas».

La propuesta operativa "Gobernanza de la sustentabilidad en cadenas de valor industriales en Córdoba, Argentina», cuyas autoras son María Florencia Peretti, Mónica Buraschi y Celina Noé Amato, analiza 
la influencia de la gobernanza de las «cadenas de valor» en la adopción de criterios de sostenibilidad; identifica los principales impactos derivados de sus actividades y analiza los mecanismos que emplean las empresas y el gobierno para la adopción de dichos criterios. El modelo utilizado permite predecir cómo los distintos nodos de agregación de valor de una actividad productiva se vinculan dentro de una economía a nivel territorial-espacial. Claramente, se relaciona con el ODS 9 y con la meta 9.3: aumentar la integración en las cadenas de valor y los mercados para las pequeñas industrias y otras empresas, particularmente en los países en desarrollo.

El trabajo "Creación de valor compartido como estrategia de competitividad y RSE en las organizaciones», escrito por Manuel Méndez Pinzón y Marcela Gómez Osorio, destaca que el concepto de valor compartido genera beneficios para las empresas en las dimensiones social, ambiental y económica. Además, identifica factores que inciden en su creación y los principales obstáculos y facilitadores de la implementación de este tipo de estrategias. Así, el trabajo se relaciona con el ODS 9 en cuanto a la innovación, en el plan de la gestión de las empresas y con el ODS 17 y su respectiva meta 17, al promover la constitución de alianzas eficaces en las esferas pública, público-privada y de la sociedad civil, aprovechando la experiencia y las estrategias de obtención de recursos de las alianzas.

El capítulo «A contribuição da Avaliação de Impacto Social (AIS) para a obtenção da Licença Social para Operar (LSO) na mineração», cuyos autores son Ana Lúcia Frezzatti Santiago, Jacques Demajorovic y Antonio Aledo, plantea que los desafíos de la LSO van más allá de la gestión de conflictos, discute sus límites y señala que se demandan cambios en la gestión social de los riesgos en las empresas, evolucionando de un modelo reactivo para un proactivo, proponiendo la AIS como una contribución. Así, el ODS 9 en cuanto a la innovación, en este caso en el plano de la gestión de las empresas. También este trabajo tiene relación con el ODS 17 y su respectiva meta 17.

La propuesta operativa que realiza Jaime Alberto Orozco-Toro expresa en el título del trabajo su propósito, «La incidencia de la RSE en la reputación corporativa y su medición en empresas de comunicación», focalizando la atención en la necesidad de crear índices. Esto está en línea con el reconocimiento de que no existen datos de referencia para varias metas de los ODS, contenido en el párrafo 57 del documento de Naciones Unidas «Transformar nuestro mundo: la Agenda 2030 para 
el Desarrollo Sostenible«. Ademá, el ODS 17, con su meta 19 señala: "Aprovechar las iniciativas existentes para elaborar indicadores que permitan medir los progresos en materia de desarrollo sostenible (...)».

La investigación "Consumo pesponsable: perfil del consumidor santafesino», elaborada por Graciela Kosiak de Gesualdo, Horacio Alesandria y Enrique Bianchi, analiza la percepción de los consumidores acerca de la problemática social y ambiental, el conocimiento que tienen sobre consumir en forma responsable, su opinión sobre el comportamiento socialmente responsable de las empresas, y define una tipología de los mismos. La bibliografía especializada coincide en señalar que el consumo responsable es uno de los motores de la RSE. El ODS 12 es una aspiración que comienza a concretarse a partir de diagnósticos locales que permiten conocer mejor a sus consumidores.

La investigación «La responsabilidad social de los destinos turísticos: impacto en la percepción de calidad de servicio y en la imagen del destino", llevada adelante por Enrique Carlos Bianchi, Juan Manuel Bruno y Carolina Sánchez, pretende conocer el impacto que tienen las acciones de RSE que implementa un «destino turístico» sobre sus visitantes en términos de imagen global y calidad percibida de los servicios, como de la satisfacción experimentada — afectiva y cognitiva-. Dos ODS tienen relación directa con la investigación, 8 y el 12. Ambos están entrelazados por sus metas 8.4 y 12.1, respectivamente, por las que se propone la aplicación del Marco Decenal de Programas sobre Modalidades de Consumo y Producción Sostenibles. Además, las meta 8.9 y 12.b hacen mención específica a la promoción del «turismo sostenible que cree puestos de trabajo y promueva la cultura y los productos locales».

El capítulo «A contribuição dos pacotes salariais na ampliação da Responsabilidade Social Empresarial», realizado por Katia de Rezende Maia Cruz, Emmanuel Paiva de Andrade y David Barbosa Souza Junior a través del análisis de la literatura, investigó sobre los principales factores que llevan a la desigualdad social, contribuyendo a la reflexión de los profesionales de Recursos Humanos, y hace emerger los temas de RSE no solamente relacionados con el género, sino también a la jerarquía organizacional. Este trabajo se vincula con el ODS 10, también con el ODS 5. En sentido lato, igualmente tiene relación con el ODS 16.7. «Garantizar la adopción en todos los niveles de decisiones inclusivas, participativas y representativas que respondan a las necesidades».

La investigación «Políticas de diversidad en las empresas argentinas», cuyos autores son Emmanuel Oliverio, Emiliano Sebastián Consoli 
y Paula Colacioppo, contextualiza el ámbito de las empresas argentinas explorando la gestión de la diversidad e identificando las políticas que aplican. Los temas abordados tienen relación con varios ODS. Algunos de ellos son el 3, el 5, especialmente con la meta ODS 5.1: «Poner fin a todas las formas de discriminación contra todas las mujeres» y el ODS 10, relativo a la reducción de la desigualdad, considerando especialmente la meta 10.2, que tiende a "potenciar y promover la inclusión social, económica y política de todas las personas, independientemente de su edad, sexo, discapacidad, raza, etnia, origen, religión o situación económica u otra condición».

El análisis «Reflexiones sobre la división sexual del trabajo y la responsabilidad social empresarial en Chile», realizado por Hernán Brevis y Matías Riquelme Brevis, consiste en una reflexión crítica sobre las desigualdades sociales a las que se ven enfrentadas las mujeres al momento de insertarse en los espacios productivos. En este sentido, se integran categorías históricas de las ciencias sociales para problematizar el escenario laboral chileno desde el papel de la Responsabilidad Social Empresarial. Se vincula con el ODS 5 y con la meta 5.c, que específicamente señala la aprobación y fortalecimiento de políticas acertadas para promoverla. También tiene relación con el ODS 8 y su meta 8.5, que aspira a lograr el trabajo decente, entre otros, para todas las mujeres, así como la igualdad de remuneración por trabajo de igual valor.

El trabajo «Directivos generación confianza: Perspectiva de género en pymes sector servicios, Bogotá D.C.», producido por Marta Gisela Gamba, Luz Janeth Lozano Correa y Myriam Sosa Espinosa, aborda empíricamente el establecimiento de las relaciones de confianza desde la óptica del género, evidenciando el valor de las habilidades de relacionamiento y características propias de los hombres y mujeres en cargos directivos, frente al desarrollo organizacional. Este trabajo tambén se encuadra en el ODS 5.

La Sección III, Responsabilidad Social de las Cooperativas, consta de dos trabajos, que se constituyen en evidencia de que el concepto de RSE está incorporado definitivamente a la gestión de este tipo de organizaciones, dejando de lado el debate que dominó casi las dos primeras décadas del nuevo milenio, sobre si era pertinente adoptarlo o no, dado que la finalidad social y económica que define la esencia de las cooperativas ya contemplaba dos de las dimensiones de la responsabilidad social, restando solo incorporar la dimensión medioambiental. 
El caso «Informe sobre el accionar socialmente responsable de una cooperativa argentina. Caso CEB», cuyo autor es Oscar Alcides Zapata, estudia el accionar de una cooperativa argentina (CEB) en función de los principios y las áreas del Pacto Global, en el marco de la filosofía de la Responsabilidad Social, teniendo presentes los Objetivos del Desarrollo Sostenible aplicables al caso. Cabe señalar que se identifican relaciones de las acciones de RS en ocho de los diecisiete ODS: 3, 4, 6, 8, 9, 11, 15 y 16.

La investigación «Responsabilidad Social Empresarial y la rentabilidad en las cooperativas de ahorro y crédito del Ecuador», elaborada por Juanita García y Aníbal Altamirano, determina la incidencia de la Responsabilidad Social Empresarial en la rentabilidad aplicando el modelo de ecuaciones estructurales. La dimensión económica tiene una relación positiva y estadísticamente significativa con la rentabilidad, no así las dimensiones medioambiental y social. El trabajo tiene un vínculo directo con el ODS 8 y, especialmente, con la meta 8.2, relativa a lograr niveles más elevados de productividad económica mediante la diversificación, la modernización tecnológica y la innovación, entre otras cosas, centrándose en los sectores con gran valor añadido y un uso intensivo de la mano de obra.

La Sección IV, Responsabilidad Social Universitaria (RSU), consta de dos trabajos de corte metodológico, que abordan el «cómo hacer» plausible la responsabilidad en la universidad. Uno se focaliza en la enseñanza de la sustentabilidad y el otro, en el diseño de proyectos que vinculen a la universidad con su comunidad. El ODS 4 que trata de tema de Educación está en el espíritu de los capítulos incluidos en esta sección.

El estudio de caso «La simulación como estrategia educativa para la enseñanza de la sustentabilidad en ingeniería», realizado por Diana Rut Schulman, Milena Ramallo y Hugo Alejandro Izaguirre, desarrolla una experiencia de simulación como estrategia educativa para la enseñanza de la sustentabilidad en la carrera de Ingeniería Mecánica de la Facultad Regional Buenos Aires (UTN, Argentina) del 2016 al 2018. El ODS 4 con sus metas: 4.3 , relativo a la enseñanza universitaria y la 4.7 , que tiende a "asegurar que todos los alumnos adquieran los conocimientos teóricos y prácticos necesarios para promover el desarrollo sostenible, entre otras cosas mediante la educación para el desarrollo sostenible y los estilos de vida sostenibles, los derechos humanos, la igualdad de género, la promoción de una cultura de paz y no violencia, la ciudadanía mundial y la valoración de la diversidad cultural y la contribución de la cultura al desarrollo sostenible». 
La propuesta contenida en el trabajo «Responsabilidad social universitaria y vinculación con el medio: construcción de una metodología para desarrollar proyectos de $\mathrm{A}+\mathrm{S}$ » ha sido elaborada por Gracia Navarro, Verónica González y Jorge Maluenda. Se describe y evalúa, desde los participantes, la metodología construida en la Universidad de Concepción, Chile, para formar y mantener alianzas sociales a fin de diseñar proyectos de aprendizaje y servicio para avanzar en los ODS en la comuna de Cabrero (Chile). En este trabajo, además de su relación con ODS 4 vinculado a educación, es destacable su aporte al ODS 17 con su meta 17. «Fomentar y promover la constitución de alianzas eficaces en las esferas pública, público-privada y de la sociedad civil, aprovechando la experiencia y las estrategias de obtención de recursos de las alianzas».

La Sección V, Responsabilidad Social Pública (RSP), se compone de tres trabajos, dos propuestas metodológicas y un estudio de caso. La incorporación de la temática de la responsabilidad social en las organizaciones públicas hace cada vez más necesario el desarrollo de instrumentos que permitan operacionalizar sus principios y materias. Así, cobra importancia el análisis de la especificidad de política pública de responsabilidad social, en sus fases de implementación, y el diseño de herramental técnico que permita la medición de fenómenos tales como la corrupción. El ODS 16 se asocia con la problemática general de la gobernanza, dominante en el sector público.

El capítulo denominado «Herramienta de análisis del rol gubernamental para promover la Responsabilidad Social en la producción sostenible de las pymes colombianas» consiste en una propuesta de su autor, Luis Fernando Moreno Garzón, para analizar el rol gubernamental para la promoción de la Responsabilidad Social en la Producción Sostenible, con la finalidad de identificar barreras culturales existentes entre políticas públicas ambientales y las prácticas responsables de los empresarios de las pymes colombianas. El instrumento se basa en cuatro variables, en las que cada una tiene relación con algún ODS. Las variables «comando y control», «incentivos económicos» e "inversión» se relacionan con el ODS 9.4, vinculado a la modernización de la infraestuctura y a la reconversión de las industrias para que sean sostenibles, promoviendo la adopción de tecnología y procesos industriales limpios y ambientalmente racionales. También se vinculan con el ODS 12.4, que aspira a «lograr la gestión ecológicamente racional de los productos químicos y de todos los desechos a lo largo de su ciclo de vida, (...) y reducir significativamente su liberación a la atmósfera, el agua y el suelo a fin de minimizar sus 
efectos adversos en la salud humana y el medio ambiente». La variable «información» está asociada al ODS 12.6. "Alentar a las empresas, en especial las grandes empresas y las empresas transnacionales, a que adopten prácticas sostenibles e incorporen información sobre la sostenibilidad en su ciclo de presentación de informes».

En el análisis «Principios de Responsabilidad Social: una mirada desde del control», realizado por Daniela Alejandra Giordano, se reflexiona sobre prácticas para integrar la Responsabilidad Social a las organizaciones desde la función del control (interno o externo) en la Administración Pública Nacional en la Argentina, considerando los principios y materias de la Responsabilidad Social enmarcados en la norma ISO 26000. El trabajo se relaciona directamente con el ODS 16.

La propuesta que se realiza en el trabajo «Índice de percepción de transparencia para la obra pública», elaborado por Carlos Nelson Rubín, consiste en el desarrollo de un modelo que evalúa la transparencia de la gestión pública, en relación con una obra o compra pública en particular. Permite monitorear la gestión pública y ayuda a formular sus políticas, a fin de prevenir la «gran corrupción». El trabajo se inscribe en el ODS 16. Las metas relacionadas son tres: 16.4, en lo relativo a luchar contra todas las formas de delincuencia organizada; 16.5, «Reducir considerablemente la corrupción y el soborno en todas sus formas», y 16.6, "Crear a todos los niveles instituciones eficaces y transparentes que rindan cuentas».

La Sección VI:, Objetivos del Desarrollo Sostenible, contiene cuatro trabajos, en los que los autores hacen referencia expresa a los ODS. Todos los trabajos tienen relación directa con el territorio y con las comunidades, lo que es una prueba de que la academia reconoce el carácter integrado e indivisible de los ODS, pero trabaja teniendo en cuenta las diferentes realidades y capacidades.

El capítulo «Estrategias de gestión territorial bajo los preceptos de la Responsabilidad Social», cuyas autoras son Silvia Vega, Marcela Céspedes y Graciela Laplagne, tiene como objetivo formular lineamientos estratégicos para proyectos innovadores de territorios emergentes que posibiliten la construcción del sentido de gobernanza y Responsabilidad Social. La idea de «territorio socialmente responsable» que plantean las autoras tiene relación con el ODS 11 y con la meta 11.3 , «(..) aumentar la urbanización inclusiva y sostenible y la capacidad para la planificación y la gestión participativas, integradas y sostenibles de los asentamientos humanos (...)». 
La investigación "Avaliação da sustentabilidade de municípios brasileiros pelos Objetivos do Desenvolvimento Sustentável», llevada adelante por Ronaldo Silva, Leonardo Moura y Luiz Gavião, evalúa, a través de un método de multicriterio de apoyo a la decisión, veintidós ciudades de las regiones del Nordeste y Sur de Brasil, utilizando indicadores alineados con los Objetivos de Desarrollo Sostenible, y establece una ordenación en función del nivel de sostenibilidad. Los criterios de ordenamiento han seguido las dimensiones clásicas de la RS y se han ordenado los ODS en función de ellas. Las dimensiones social y ambiental quedan enlazadas en el trabajo por el ODS 6. Para la dimensión social se consideran las metas 6.1 , «(..) lograr el acceso universal y equitativo al agua potable a un precio asequible para todos» y $6 \mathrm{a}$, relativa a la creación de capacidad en actividades y programas relativos al agua y el saneamiento, así como la $6 \mathrm{~b}$, que tiende a fortalecer la participación de las comunidades locales en la mejora de la gestión del agua y el saneamiento. Para la dimensión ambiental se consideran especialmente las metas 6.4, que pretenden asegurar la sostenibilidad de la extracción y el abastecimiento de agua dulce, la meta 6.6, proteger y restablecer los ecosistemas relacionados con el agua, y la meta 6a, la creación de capacidad en actividades y programas relativos al agua y el saneamiento. Además del ODS 6, en la dimensión social se considera el ODS 3, con sus metas 3.8 y $3 c$, que se refieren, respectivamente, al logro de una cobertura sanitaria universal y al aumento de la financiación para la salud y la capacitación y retención del personal sanitario.

En la dimensión económica, el trabajo se vincula con cuatro ODS: 8, 6,12 y 2 . El ODS 8 menciona especialmente algunas de sus metas, tales como 8.2, realtivo al logro de niveles más elevados de productividad; 8.3, «(...) la creación de puestos de trabajo decentes, el emprendimiento, la creatividad y la innovación, y fomentar la formalización y el crecimiento de las microempresas y las pequeñas y medianas empresas (...)», y 8.4, relacionado con la mejora de la producción y consumo eficientes. En cuanto al ODS 6 se consideran tres metas, que son: meta 6.3, relativa a la mejora de la calidad del agua; 6.5 , que propone implementar la gestión integrada de los recursos hídricos a todos los niveles, y la 6.6, que tiende a proteger y restablecer los ecosistemas relacionados con el agua. Los otros dos objetivos que se mencionan vinculados con la dimensión económica se enuncian en su forma general. Ellos son el ODS 12 y 2.

El trabajo «Microgobernanza para los emprendimientos de calidad en Ecuador acorde al Objetivo de Desarrollo Sostenible», realizado 
por Gino Cornejo Marcos, consiste en una propuesta para establecer estrategias de microgobernanza que redunden en la creación, impulso y fortalecimiento de emprendimientos, para paliar la situación de que muy pocos de ellos logran constituirse en un negocio establecido. El autor señala la vinculación directa con el ODS 8.

La investigación "Calidad de vida y Responsabilidad Social en niños indígenas mexicanos: conducta proambiental», cuyos autores son Santa Magdalena Mercado Ibarra, Joanna Mariby Cota Beltrán y María Teresa Fernández Nistal, evalúa la conducta en pro del cuidado del medioambiente en treinta y seis niños indígenas de Sonora, México, para delinear estrategias de intervención que sean socialmente responsables y contribuir al bienestar personal y social, se requieren programas multidisciplinarios de intervención y que abarcan varios ODS. El trabajo se vincula con numerosos objetivos que abarcan amplias problemáticas. Una de ellas son las cuestiones ambientales en su más amplio sentido, estableciéndose relación con los ODS 6 y 11. También se consideran, en sentido amplio, el ODS 4 y el 10 en su meta 10.2, que tiende a "potenciar y promover la inclusión social, económica y política de todas las personas, independientemente de su edad, sexo, discapacidad, raza, etnia, origen, religión o situación económica u otra condición».

Los trabajos que se presentan son una muestra de la producción académica de América Latina sobre responsabilidad social, sustentabilidad y ODS. Sirven de referencia para la propia comunidad académica, con la finalidad de determinar sobre qué se está trabajando y cuáles son los temas aún no abordados. Las propuestas metodológicas y estratégicas son de utilidad, por su potencial de distinto tipo: a) potencial práctico, como instrumento de resolución de problemas; b) potencial de aplicación, por parte de quienes tienen responsabilidades de gerenciamiento en todo tipo de organizaciones, y c) potencial de innovación, por la utilidad metodológica que surge del propio diseño de un instrumento de gestión.

En tal sentido, la relevancia social de la incipiente producción académica de nuestra región quedará demostrada en la medida que los lectores de estas páginas capten las ideas centrales, las difundan y se conviertan paulatinamente en prácticas responsables para organizaciones concretas.

Nora Gorrochategui Valmir Martins de Oliveira Nelson Stevenson Palamara 


\section{Objetivos de Desarrollo Sostenible}

\begin{tabular}{|c|c|}
\hline ODS 1 & Poner fin a la pobreza en todas sus formas en todo el mundo. \\
\hline ODS 2 & $\begin{array}{l}\text { Poner fin al hambre, lograr la seguridad alimentaria y la mejora de } \\
\text { la nutrición y promover la agricultura sostenible. }\end{array}$ \\
\hline ODS 3 & $\begin{array}{l}\text { Garantizar vida sana y promover el bienestar de todos a todas las } \\
\text { edades. }\end{array}$ \\
\hline ODS 4 & $\begin{array}{l}\text { Garantizar una educación inclusiva, equitativa y de calidad y } \\
\text { promover oportunidades de aprendizaje durante toda la vida para } \\
\text { todos. }\end{array}$ \\
\hline ODS 5 & $\begin{array}{l}\text { Lograr la igualdad entre los géneros y empoderar a todas las mu- } \\
\text { jeres y las niñas. }\end{array}$ \\
\hline ODS 6 & $\begin{array}{l}\text { Garantizar la disponibilidad de agua y su gestión sostenible y el } \\
\text { saneamiento para todos }\end{array}$ \\
\hline ODS 7 & $\begin{array}{l}\text { Garantizar el acceso a una energía asequible, segura, sostenible y } \\
\text { moderna para todos. }\end{array}$ \\
\hline ODS 8 & $\begin{array}{l}\text { Promover el crecimiento económico sostenido, inclusivo y sosteni- } \\
\text { ble, el empleo pleno y productivo y el trabajo decente para todos. }\end{array}$ \\
\hline ODS 9 & $\begin{array}{l}\text { Construir infraestructuras resilientes, promover la industrializa- } \\
\text { ción inclusiva y sostenible y fomentar la innovación. }\end{array}$ \\
\hline ODS 10 & Reducir la desigualdad en y entre los países. \\
\hline ODS 11 & $\begin{array}{l}\text { Lograr que las ciudades y los asentamientos humanos sean inclusi- } \\
\text { vos, seguros, resilientes y sostenibles. }\end{array}$ \\
\hline ODS 12 & Garantizar modalidades de consumo y producción sostenibles. \\
\hline ODS 13 & $\begin{array}{l}\text { Adoptar medidas urgentes para combatir el cambio climático y } \\
\text { sus efectos. }\end{array}$ \\
\hline ODS 14 & $\begin{array}{l}\text { Conservar y utilizar en forma sostenible los océanos, los mares y } \\
\text { los recursos marinos para el desarrollo sostenible. }\end{array}$ \\
\hline ODS 15 & $\begin{array}{l}\text { Promover el uso sostenible de los ecosistemas terrestres, luchar } \\
\text { contra la desertificación, detener e invertir la degradación de las } \\
\text { tierras y frenar la pérdida de la diversidad biológica. }\end{array}$ \\
\hline ODS 16 & $\begin{array}{l}\text { Promover sociedades pacíficas e inclusivas para el desarrollo sos- } \\
\text { tenible, facilitar el acceso a la justicia para todos y crear institucio- } \\
\text { nes eficaces, responsables e inclusivas a todos los niveles. }\end{array}$ \\
\hline ODS 17 & $\begin{array}{l}\text { Fortalecer los medios de ejecución y revitalizar la Alianza Mundial } \\
\text { para el Desarrollo Sostenible. }\end{array}$ \\
\hline
\end{tabular}





\section{Sección I: \\ Conferencias y mensajes de los coordinadores}





\section{EL ROL DE LA UNIVERSIDAD EN AMÉRICA LATINA SOBRE FORMACIÓN E INVESTIGACIÓN EN RESPONSABILIDAD SOCIAL Y SUSTENTABILIDAD"}

\section{Nora Gorrochategui"* Argentina}

La reunión de docentes e investigadores en el marco del V Simposio Internacional de Responsabilidad Social de las Organizaciones (SIR$\mathrm{SO}$ ) es una oportunidad para reflexionar acerca de la enseñanza y la investigación sobre la Responsabilidad Social (RS) en nuestra región.

Hoy, la RS está incorporada en el espíritu de nuestras universidades.

Cicerón decía: "No saber lo que ha ocurrido antes de nosotros es como seguir siendo niños». Una mirada atrás nos lleva a comprender que el proceso ha sido lento y los avances se han asociado a cambios en las condiciones contextuales.

Algunos temas centrales de la RS han formado parte de los programas de las universidades desde siempre. La ética es el ejemplo más claro, ya que ha sido incluida en los planes de estudio desde el momento mismo en que podemos ubicar la creación de la universidad como institución moderna en la Europa medieval, con la fundación de la Universidad de Bolonia alrededor del 1300.

En el siglo XVIII, la relación entre ética y problemas económicos era tema de debate en las universidades. Baste mencionar solamente un ejemplo.

El profesor Francis Hutchenson, de la Universidad de Glasgow, dedicaba una parte de sus clases a la moral práctica, lo que influenció

Conferencia dictada en el marco del V Simposio Internacional de Responsabilidad Social de las Organizaciones, I Congreso Internacional de Gestión Organizacional. Universidad Autónoma, Santiago de Chile, 6 y 7 de septiembre de 2018.

** Posdoctora en Ciencias Económicas, Universidad de Buenos Aires. Correo electrónico: noragorrochategui@gmail.com 
luego el pensamiento de su alumno Adam Smith, enseñanzas que quedaron reflejadas en su libro La riqueza de las naciones.

Los especialistas coinciden en señalar que el hito que marca el punto de partida del desarrollo de teorías sobre la Responsabilidad Social Corporativa es la aparición de la obra de Howard Bowen, Social Responsabilities of the Businessman, en 1953. La pregunta que subyacía el libro sigue teniendo vigencia hoy: ¿qué responsabilidades se puede esperar razonablemente que asuman los empresarios con respecto a la sociedad?

Después de la II Guerra Mundial comienza un proceso de profundos cambios contextuales, que quedan plasmados en numerosas normativas internacionales, las que sirven de orientaciones a los gobiernos para que las incorporen en sus legislaciones nacionales.

Primero, los derechos denominados de primera generación, o sea, los derechos civiles y políticos, y luego, durante las décadas del 50 y del 60, los derechos de segunda generación, o sea, derechos económicos, sociales y culturales. La universidad va incorporando esas orientaciones no solamente desde el campo del derecho, sino que también cobran fuerza en los programas de las carreras de ciencias sociales y humanas.

Al finalizar la década del 80, en 1987, el informe «Nuestro futuro común» marca un hito para la RS. Por un lado, incorpora la cuestión medioambiental y, por otro, introduce el concepto de «desarrollo sostenible», como "aquel que garantiza satisfacer las necesidades de las generaciones presentes sin comprometer las posibilidades de las del futuro para atender sus propias necesidades».

De este modo, se delinean los fundamentos de los derechos de tercera generación, que surgen de la necesidad de cooperación entre naciones y grupos y hacen referencia a tres tipos de bienes: paz, desarrollo y medioambiente.

La respuesta de la universidad no se hace esperar. En 1990, veintidós autoridades de universidades firman la Declaración de Talloires. Es una manifestación expresa a favor de la sostenibilidad y un llamamiento a las instituciones de educación superior para el establecimiento de medidas para que se conviertan en ejemplo de responsabilidad ambiental.

En 1999, el secretario general de las Naciones Unidas pone en marcha la iniciativa del Pacto Global, en la que se invita a empresas a adherir voluntariamente a incorporar en la gestión, diez principios que versan sobre cuatro áreas temáticas: derechos humanos, normas laborales, medioambiente y anticorrupción. 
A partir de aquí, destaco tres tipos de factores que incidieron en la expansión de la RS en el ámbito de la universidad: a) la incorporación de la RS en las agendas de las Conferencias Mundiales de Educación Superior (CMES), b) el desarrollo de iniciativas que se originan en los propios países o en organismos internacionales, y c) la generación de redes.

Así, la Declaración Mundial sobre Educación Superior de la UNESCO, en 1998, planteó los ejes temáticos de la educación superior para el siglo XXI: justicia, equidad, información, ciencia y sabiduría, construcción de la cultura de la paz, fraternidad y convivencia.

En 2009, en la Conferencia Mundial de Educación Superior de París, se reafirma que la educación superior es un bien público. Ante la complejidad de los desafíos mundiales, la educación superior tiene la «responsabilidad social» de hacer avanzar la comprensión de problemas polifacéticos con dimensiones sociales, económicas y culturales. En el desempeño de sus funciones esenciales de «enseñanza, investigación y servicio a la comunidad», la universidad debería centrarse en aspectos interdisciplinarios y promover el pensamiento crítico y la ciudadanía activa.

En América Latina, la actividad de los organismos internacionales para vigorizar estas ideas es significativa. Baste mencionar, a título de ejemplo, la Iniciativa de Capital Social, Ética y Desarrollo del Banco Interamericano de Desarrollo (BID). Su propósito consistió en expandir el concepto y la práctica de la RS dentro de las universidades y sobre la toma de conciencia acerca de que la universidad responde a las necesidades de su sociedad, a través de su misión. Así, se espera que las universidades identifiquen medidas para mejorar su contribución al desarrollo económico, político y social. La Responsabilidad Social Universitaria (RSU) ayuda a la universidad a reconectarse con el contexto social y a reencontrar su identidad.

También, se destaca el Proyecto Cátedra Iberoamericana de Responsabilidad Social Empresarial (RSE), un proyecto del Programa de Naciones Unidas para el Desarrollo (PNUD) en asociación con el Programa Universidades del Banco Santander, que tuvo una duración de siete años y dejó su impronta en América Latina. El Programa tuvo diferentes etapas. Apuntó a fortalecer a las universidades en el cumplimiento de un rol decisivo en RS, al integrar activamente la temática a sus planes de estudio, incorporando y apoyando la investigación en RSE y vinculándola con la docencia y la extensión. Un logro significativo se alcanzó durante la primera etapa del proyecto (2008-2011), dedicada al 
Programa de Formación de Formadores en RSE, que, bajo la modalidad de educación virtual, se dirigió a crear masa crítica de docentes en RSE.

En cuanto a la formación de redes, Naciones Unidas ha promovido, por lo menos tres redes de universidades: a) la REDUNIRSE; 2) la red Principios para una Educación Responsable en Management (PRME), promovida por el Pacto Global, y c) la red Impacto Académico (UNAI), fomentada por la Dirección de Información del Secretariado de las Naciones Unidas.

Varían en grado de formalidad, entendido como costos de membresía y obligaciones de reporte. La más informal es REDUNIRSE, que no requiere pagos de membresía ni obligaciones de reporte. Le sigue Impacto Académico, con obligación de reporte. PRME es la más formal, puesto que requiere costos de membresía y obligación de reporte, estando especialmente orientado a escuelas de negocios.

El SIRSO es una red de docentes e investigadores que se reúne bianualmente, de forma itinerante, en distintas universidades; genera un ámbito propicio para que sus miembros presenten sus trabajos e intercambien propuestas de investigación y capacitación conjuntas, sobre Responsabilidad Social empresarial, universitaria, pública y sobre los Objetivos del Desarrollo Sostenible (ODS).

Esta evolución nos reafirma que:

- Existe un cuerpo temático que se ha formado lentamente respondiendo al ambiente de época con aportes de distintas disciplinas.

- Las responsabilidades de la educación superior son educar, investigar, servir a la comunidad y hacer avanzar en la comprensión de problemas polifacéticos en sus dimensiones social, económica, cultural y medioambiental.

- Existe una estructura de docentes e investigadores que posibilita corporizar la RS en las universidades.

Cabría preguntarse: ¿por qué?, ¿qué? y ¿cómo? educar en la universidad sobre RS.

¿Por qué educar en la universidad sobre RS?

La universidad es un actor comprometido con su realidad. Dispone del conocimiento científico y técnico de distintas disciplinas, que le permiten interpretar problemas complejos y buscar soluciones. Cuenta con personas dedicadas a la producción de conocimiento y a su transmisión. La universidad es un agente de cambio.

San Agustín decía: «El pasado ya no es y el futuro no es todavía». 
La universidad aporta su conocimiento para contribuir al logro del objetivo explícito de la comunidad internacional: la construcción de una sociedad sustentable.

La sociedad sustentable es aquella en la que el hombre focaliza la atención en dos dimensiones: su relación con otros hombres y su relación con la naturaleza.

Así, la relación entre los hombres, o sea, la dimensión humana se fundamenta en la noción de la dignidad y libertad de las personas, la sociabilidad humana y los derechos humanos; se basa en los principios del bien común, subsidiariedad, participación, solidaridad y en los valores de verdad, libertad, justicia y caridad.

La relación del hombre con la naturaleza tiene en cuenta postulados tales como: la regeneración de los recursos renovables, la sustitución de recursos no renovables por los renovables, la utilización de recursos considerando la capacidad global de su generación, y la integración y compatibilización de necesidades humanas, económicas y ecológicas.

Esta idea de sociedad sustentable se ha ido generando a lo largo del tiempo y reconoce múltiples antecedentes que han quedado plasmados en recomendaciones de normativas internacionales y que paulatinamente han sido reflejadas en las legislaciones nacionales.

La universidad educa sobre RS porque contribuye a construir ese futuro que todavía no es.

¿Qué enseñar sobre RS en la universidad? En esta pregunta subyace el problema de los contenidos que abarca la RS.

El contenido de la RS quedó expresado en 2010, con la ISO 26000.

La ISO 26000 es una guía de consensos con numerosos acuerdos que establecen denominadores mínimos en diversos temas y una base de partida para la acción organizacional. Se establecieron principios: rendición de cuentas, transparencia, comportamiento ético y respeto a las partes interesadas.

Se delimitaron materias fundamentales: gobernanza de la organización, derechos humanos, prácticas laborales, medioambiente, prácticas justas de operación, asuntos de consumidores, participación activa y desarrollo de la comunidad.

No resulta suficiente, también hay que reflexionar sobre los problemas que se enfrenta la comunidad internacional y ofrecer soluciones. La guía es la Agenda 2030, que se fija un horizonte temporal para transformar el mundo y lograr el desarrollo sostenible. Los Objetivos del Desarrollo Sostenible (ODS) abarcan los problemas sociales más 
acuciantes: pobreza, hambre, salud, educación, igualdad entre los géneros, agua, energía, empleo, cambio climático y también vivir en sociedades pacíficas, inclusivas y justas «sin dejar a nadie atrás».

El listado de temas es muy amplio, su abordaje requiere múltiples matices y saberes, que provienen de diferentes campos del conocimiento, entre otros, administración, contabilidad, economía, derecho, sociología, biología y ciencias naturales. Parece importante señalar, que una sola disciplina no reúne todos los conocimientos necesarios para conceptualizar problemas complejos y aportar soluciones. Por lo tanto, es necesario adoptar primero una perspectiva interdisciplinaria y luego, avanzar con una visión transdisciplinaria.

Pero el análisis de sobre qué debe educar la universidad en materia de RS no se agota en los principios y materias que propone la ISO 26000, ni tampoco con la comprensión de los problemas que subyacen en los ODS.

Es necesario entender que estos problemas, materias y principios se deben adaptar a las realidades en las que operamos, a fin de que puedan estar contextualizados. Esto es, la comprensión de los problemas debe adaptarse al contexto en el que estamos operando. ¿Cuál es nuestro contexto? América Latina, nuestro país, nuestra ciudad, nuestro pequeño territorio.

Pero esta contextualización de los problemas significa buscar soluciones en el plano de las organizaciones. O sea, es la empresa, es la organización pública, es la cooperativa, es la propia universidad, que da vida a la idea de RS, de sustentabilidad.

Así, incorporando la RS en el plano organizacional, tenemos la RSE, la RSP, la RSU. Es la RS la que se incorpora a la gestión de las distintas organizaciones. Es necesario entender cómo los diferentes tipos de organizaciones se vinculan con el sistema social, económico y cultural del que forman parte y cómo su comportamiento incide en el sistema más amplio. Entonces, debemos comprender cómo se vinculan los elementos contextuales con las prácticas operacionales, a fin de poder transmitir conocimientos valiosos.

En síntesis, para decidir «sobre qué debe educar la universidad», parece importante entender las características del campo de estudio de la RS.

La RS como campo de estudio es multidimensional, multidisciplinario, multiparadigmático, diversificado en métodos de abordaje, 
temas focales y consecuencias operacionales. Su tratamiento requiere un enfoque transdisciplinario, sistémico y contextualizado.

A esta altura de la exposición, ya tenemos un listado de temas que deberían convertirse en contenidos de RS y también, de alguna manera, en la definición de las características del campo de estudio.

Avancemos un paso más, y reflexionemos sobre cómo se debería enseñar la RS en la universidad.

El desafío consiste en la formulación de áreas o bloques temáticos a ser incluidos en programas, currículos y aun en debates académicos sobre el tema.

Uno de los mayores problemas que existe a la hora de establecer programas formativos en materia de RS es cierto desconocimiento de los fundamentos teóricos y su procedencia disciplinar.

Básicamente, la RS es un concepto de gestión, que implica principios, dimensiones de trabajo y consta de numerosas herramientas operacionales, ya diseñadas y en constante elaboración.

La RS como concepto de gestión ha sido abordada por la Sociedad Americana de Management, creando una División Especial que trata específicamente los aspectos sociales del management. Hace ya unos años que estoy dando una materia en distintos doctorados con este nombre, que es una síntesis de todo el conjunto de temas que tendrían que incluirse en los currículos de RS.

Sin embargo, persisten una serie de cuestiones:

¿En las universidades se debería incluir la RS en todas las carreras, al menos un módulo sintético que dé cuenta de los temas y problemas que abarca la RS?

¿En las carreras de administración, debería incorporarse el tema de la RS en cada materia que se imparte en la carrera o debería darse como una materia con entidad propia, que abarcara todos los temas, denominada Aspectos Sociales del Management?

¿Qué concepción paradigmática, marcos teóricos y herramental tecnológico debería incluirse en la enseñanza de la RS?

¿La RS debería ser enseñada en un curso de capacitación?, ¿en un curso de posgrado?, ¿en una maestría? En caso de que fuera una maestría, ¿debería tener una orientación profesional o académica?

Todos estos son temas por resolver.

Parto del convencimiento de que educar sobre RS es educar sobre el futuro.

Entonces, surge otra interrogante: ¿cómo educar en RS? 
Howard Gardner, el psicólogo creador de la teoría de las inteligencias múltiples, planteó en su libro Las cinco mentes del futuro (2008) cinco tipos de mentes necesarias para el futuro: la mente disciplinada, la mente sintética, la mente creativa, la mente respetuosa y la mente ética.

La mente disciplinada es aquella que, al menos, domina un modo de pensar: un tipo significativo de cognición que caracteriza una disciplina académica, un oficio, una profesión. Se requieren al menos diez años para el dominio de una disciplina. La mente disciplinada sabe cómo trabajar de manera constante a lo largo del tiempo para mejorar las habilidades y la comprensión.

La mente sintética recaba información de fuentes dispares, comprende y evalúa esa información con objetividad y la reúne de forma que adquiere sentido, no solo para quien la ha sintetizado, sino también para los demás. La capacidad de sintetizar, tan valiosa en el pasado, es aún más decisiva a medida que la información se acumula e incrementa a ritmo vertiginoso.

La mente creativa, tomando como base la disciplina y la síntesis, presenta nuevas ideas, plantea preguntas con las que no estamos familiarizados, invoca nuevas formas de pensar y llega a respuestas imprevistas.

El cuarto tipo de mente, la mente respetuosa, es aquella que reconoce que en la actualidad nadie puede permanecer ya encerrado en su caparazón o en su territorio particular, observa y acepta las diferencias entre individuos y grupos, al tiempo que trata de comprender a esos «otros» y procura trabajar con todos en forma efectiva. En un mundo en el que todo está interrelacionado, la intolerancia o la falta de respeto han dejado de ser una opción viable.

El quinto tipo de mente, la mente ética se ubica a un nivel más abstracto y reflexiona acerca de la naturaleza de su propio trabajo y sobre las necesidades y deseos de la sociedad en que vivimos. La mente ética actúa sobre el análisis acerca de la manera en que, desde su lugar, su puesto de trabajo, su ámbito de influencia, cada persona puede servir a fines y propósitos que trascienden los intereses personales, así como del modo en que los ciudadanos pueden actuar de forma desinteresada para mejorar su entorno.

Si el objetivo es incentivar estos tipos de mentes, el «cómo se aprende» tiene que ser un aspecto importante al momento de desarrollar programas de formación.

Si pensamos en cómo aprendemos los seres humanos, comenzaremos a entender también cómo debemos enseñar la RS en la universidad. 
Los seres humanos aprendemos mediante la observación, el análisis, la contrastación entre lo conocido y lo nuevo por conocer, creando aprendizajes a partir de la experiencia, a través del cuestionamiento de hechos y por intereses personales, mediante la acción (aprender haciendo), la experimentación y el descubrimiento, la discusión y la negociación de los conocimientos con los pares, estableciendo semejanzas y diferencias, evaluando y buscando la solución de los problemas.

Esta forma de aprender nos obliga a utilizar todos los métodos y técnicas de enseñanza y aprendizaje tradicionales y otros más nuevos.

La lección magistral, el trabajo en grupo, el estudio de caso «con vías de solución, con "valoración de la solución», de "creación situacional o incompleto", la resolución de problemas, el desarrollo de proyectos y el capstone.

También, tendríamos que pensar en métodos de autoanálisis, que sensibilicen sobre los propios valores y favorezcan la adopción de valores sociales deseables, en aprendizajes cooperativos, trabajando juntos y en el análisis interdisciplinario de problemas. En esta misma línea, Mañoz de Balanzó (2000) plantea propuestas en un proceso de participación: hacer, hacer con los otros, hacer con los otros ante problemas comunes, hacer con los otros ante problemas comunes para transformar la sociedad disfrutando y creciendo desde el diálogo.

El preguntarnos sobre cómo enseñar también nos obliga a pensar en los «proyectos de cátedra». El proyecto de cátedra anticipa las grandes decisiones de los docentes, las más relevantes, las que se asientan en "papel», como un documento para el trabajo cotidiano; la programación del diseño de las actividades docentes que se plasma en un programa.

¿Qué tipo de programa es más adecuado para enseñar RS y Sustentabilidad?

¿El programa centrado en la disciplina académica? ¿El programa centrado en grandes libros e ideas? ¿El programa centrado en problemas sociales?

¿El programa centrado en competencias?

El hecho es que, en América Latina, las especializaciones, posgrados y maestrías son limitados e incipientes. La oferta de capacitación es menor que la demanda, por lo cual, he aquí un curso de acción indispensable para ser abordado.

Hasta aquí las reflexiones sobre educación en RS, ahora la pregunta es: ¿qué características presenta la investigación sobre RS en nuestra región? 
1. La producción es abundante y revela interés por la temática, aunque el avance del conocimiento sustantivo es escaso y poco sistematizado, con baja consolidación de marcos teóricos aceptados ampliamente por la comunidad académica.

2. Existen escasos centros de referencia académica en la región.

3. No hay líneas de investigación definidas.

4. Se presentan limitaciones, no exclusivas de la temática de la RS, que son comunes a la investigación en la región, tales como: acceso a fuentes de financiamiento, reducidas dedicaciones docentes para investigación, escasos programas de formación de posgrado dedicados a la investigación sobre RS. Entonces, ¿qué líneas de investigación se proponen?

Presento tres líneas de investigación que pueden generar múltiples proyectos. Los elementos inspiradores son fundamentalmente, la ISO 26000 y los ODS.

La primera línea es la "gobernanza de las organizaciones», entendida como la capacidad de conducir organizaciones de todo tipo de manera cooperativa en relación con sus partes interesadas, preocupada por los impactos de sus actividades y por su contribución a los ODS.

Algunos proyectos de interés pueden ser los relativos al diseño y arreglos organizacionales, de mecanismos y tecnologías compatibles con principios y orientaciones de la gobernanza moderna, que permitan solucionar problemas y generar oportunidades. Así como la creación de un banco de experiencias exitosas que puedan ser comunicadas al interior de la comunidad epistémica y que también puedan ser transferidas y aplicables en otras organizaciones, más allá del ámbito en el que se generan.

La segunda línea versa sobre los ODS: relativo a los temas sustantivos que plantea cada uno de ellos, así como a la resolución de situaciones de su gestión, implementación, seguimiento, control y medición de resultados.

Los proyectos pueden estar relacionados con los problemas de coordinación que derivan de la gestión horizontal y vertical, así como la transversalidad de cada uno de los asuntos de los ODS, al desarrollo de estadísticas e índices en las metas que todavía no cuentan con ello, y de los sistemas de medición y comunicación sobre cómo cada tipo de organización puede demostrar su contribución al logro de un ODS específico, relacionado con su actividad central.

Sobre las dos líneas de investigación mencionadas anteriormente, se señalan dos enfoques que pueden adoptar los proyectos. Uno, el 
enfoque organizacional, centrado en el tipo de organización sobre la cual se pretende trabajar: empresas, organismos públicos, universidades, cooperativas, organizaciones no gubernamentales. El otro, el enfoque tecnológico, centrado en el diseño o aplicación de tecnologías de gestión, metodologías, modelos o procedimientos sobre la implementación, comunicación, control de acciones y proyectos de responsabilidad social o vinculados a las temáticas de los ODS.

La tercera línea de investigación es la «conceptualización del campo de estudio", con el propósito de hacer avanzar el conocimiento útil socialmente sobre RS y sustentabilidad. Los proyectos pueden referirse a diversos asuntos: análisis de sus núcleos temáticos, sistematización de los principales marcos conceptuales aplicables a diferentes problemáticas, recolección de las conclusiones sobre experiencias empíricas que permitan conceptualizar los hallazgos y formularlos en términos de proposiciones e hipótesis que posibiliten ser sometidas a verificación empírica, dando lugar al avance del campo de conocimiento.

Cabe formularse aún otra pregunta: ¿qué cursos de acción son posibles de desarrollar en el futuro?

El contexto para desarrollar iniciativas de capacitación e investigación está signado por limitaciones y restricciones en materia de recursos institucionales, infraestructura, recursos financieros, así como de personas que puedan llevarlas adelante.

En tal sentido, los cursos de acción que se proponen están inspirados en los principios de la gestión moderna y reflexiva que impone la construcción de una sociedad sustentable. Así, la colaboración, la participación, los esfuerzos mancomunados y el trabajo en red de personas y organizaciones deben inspirar la acción.

Parece indispensable innovar en la forma de gestionar las actividades de capacitación e investigación.

Tal vez ha llegado el momento de dejar de pensar que lo mejor es que cada organización cuente con «su» curso de capacitación, «su» centro de investigación, «su» revista, lo cual implica esfuerzos y aplicación de recursos que no abundan y generan fragmentación.

Tal vez ha llegado el momento de pensar que la comunidad académica latinoamericana cuente con «un» programa de maestría y doctorado, «un» centro de investigación, «una» revista de nivel reconocido sobre la temática, en la que todos puedan participar; eso parece ser más viable y posible de lograr. 
Las tecnologías de la información y la comunicación (TIC) permiten hoy avanzar en iniciativas de este tipo. Cursos de acción centralizados en su concepción, que contemplen módulos que respondan a realidades locales, desconcentrados en su ejecución, con sistemas de coordinación y reconocimiento de titulaciones en diferentes países, pueden ser criterios que se impongan en el mediano plazo.

Sin duda, estas modalidades requieren esfuerzos de coordinación importantes y desafíos a la articulación de intereses y la superación de formas tradicionales de gestión.

El SIRSO ha crecido como una red de personas, y mucho puede hacer para generar y propiciar estas formas de gestión, pero la red tiene sus límites si no se cuenta con la voluntad de las organizaciones que posibiliten fortalecer las realizaciones.

Articulación de personas y organizaciones, trabajo en alianza que reúna intereses y necesidades comunes, complementando competencias y recursos posibilitarán la generación de una producción académica que observe estándares internacionales de calidad y, al mismo tiempo, adecúe las tendencias de época, compatibilizándolas con las necesidades del contexto en el que se producen.

En síntesis, el resultado, aunque por el momento no sea más que una aspiración, será la construcción de la «identidad» de la producción académica latinoamericana en la temática específica de responsabilidad social y sustentabilidad.

En este espíritu presento algunos cursos de acción, que no agotan las posibilidades y que agrupo en tres categorías:

- Definir prioridades sobre áreas temáticas.

- Generar de condiciones favorables a la investigación.

- Difusión.

Es fundamental definir áreas de interés común que permitan establecer programas de investigación conjunta.

Se propone crear un "observatorio" sobre RS y sustentabilidad latinoamericano, entendido como un centro de información, intercambio y colaboración, que aprovechando las ventajas de las tecnologías de la información y la comunicación (TIC), permita recopilar, tratar y difundir la temática.

En cuanto a la generación de condiciones favorables a la investigación, se considera necesario: 
- Formar y consolidar grupos de investigación en la temática en cada universidad, dotándolos de dedicaciones horarias que permitan la especialización en el tema.

- Generar condiciones propicias para el intercambio de información, estadías, pasantías, actividades docentes y de investigación en las temáticas sustantivas.

La difusión de los resultados de las investigaciones a distintos públicos es esencial. Difundir a los colegas, con propósitos académicos; a quienes pueden convertirse en usuarios, con propósito de transferencia, y a instituciones nacionales e internacionales, con propósito de obtención de financiamiento.

Como última idea, les quiero reiterar el convencimiento sobre el hecho de que cada uno de nosotros puede hacer mucho, como integrantes de una red para generar cambios, solo es necesario aglutinar voluntades orientadas a la acción.

El futuro lo estamos imaginando... ahora hay que construirlo. 



\title{
LAS NUEVAS GENERACIONES DE PROFESIONALES PREFIEREN A LAS EMPRESAS SOCIALMENTE RESPONSABLES*
}

\section{Valmir Martins de Oliveira** Chile}

\begin{abstract}
Aunque la Responsabilidad Social viene ganando un espacio dentro de la problemática general del consumo, hay un largo camino por recorrer para lograr cambios significativos en la conducta de los consumidores. Esto implica un despertar consciente y el desarrollo de sentido crítico sobre cómo la Responsabilidad Social puede impactar en la preferencia de productos y servicios vinculados a una propuesta más global de sostenibilidad y asociada a los valores que han sido transmitidos a través de su marca.
\end{abstract}

Esta circunstancia, unida al agravamiento de la situación económica de varios países y de regiones, afecta esta dinámica responsable y conlleva decisiones de consumo por precios más accesibles. Además, el desconocimiento de la esencia de la responsabilidad social, confundiéndola con filantropía o caridad, impacta en la adopción de acciones que se fundamentan en visiones restrictivas de lucratividad y en logro de resultados a corto plazo.

Este escenario despierta el espíritu crítico, particularmente en los jóvenes que están formándose profesionalmente en el área de administración y negocios. Sus experiencias como ciudadanos y consumidores confluyen, por un lado, con los lineamientos de la Responsabilidad Social y el desarrollo sostenible y, por otro lado, con el debate académico, que amplía la discusión sobre cómo las decisiones estratégicas de su actuación profesional influyen en la sociedad globalizada.

\footnotetext{
* Ideas centrales de la conferencia académica en V Simposio Internacional de Responsabilidad Social de las Organizaciones (SIRSO) y I Congreso Internacional de Gestión Organizacional.

** Doctor en Estudios Americanos, Unversidad de Santiago de Chile (USACH). Académico docente-investigador de la Universidad Autónoma de Chile. Cofundador y cocoordinador general del SIRSO.
} 
Los estudios sobre el avance del engagement de las organizaciones empresariales con los jóvenes profesionales o, en otros términos, el grado de atractividad de las empresas en retenerlos en su organizaciones dan cuenta de esta problemática.

Baste mencionar un ejemplo, el proyecto de la Berlin School of Economics and Law titulado «MitCSR - Mitarbeiter finden und binden» (Atracción y retención de talentos), con la participación de más de veinte países, entre ellos, Chile. En líneas generales, los resultados han mostrado que se percibe en empleados un mayor interés por los atributos relacionados con el trabajo, tales como el ambiente, la variedad de tareas o la viabilidad a largo plazo de la empresa.

En este sentido, el desafío está en que las organizaciones empresariales, especialmente las grandes corporaciones nacionales e internacionales, dentro del escenario de competitividad y de atracción de talentos, avancen en el diseño e implementación de programas de RSE y ecoeficiencia, muchas veces presionadas por sus stakeholders. La universidad también tiene un rol fundamental en la formación de los aspectos de gestión relacionados con el tema.

Además, el interés de los potenciales empleados está cada vez más vinculado con el posicionamiento de la marca de la empresa en el mercado y con la determinación de si el tema de Responsabilidad Social es un factor estratégico para su actuación global, hecho este que puede justificar la interacción a través de sus redes sociales que las propias compañías promueven y que son canales más inmediatos de su gestión.

Las operaciones empresariales que generan impacto negativo afectan su reputación a una velocidad mayor que otros factores. La interactividad tecnológica registra una tendencia exponencial que ya está impactando en los planes de jóvenes profesionales, quienes estarán cada vez más interesados sobre el actuar empresarial.

Como tendencia se visualiza que es indispensable avanzar en el tema de Responsabilidad Social como el ADN de cualquier agenda de comunidad internacional y que, junto con el crecimiento sostenible vinculado con la Cuarta Revolución Industrial, son factores que estimularán el comportamiento e interés de los jóvenes para identificar a las empresas más atractivas, especialmente a través de las actividades vinculadas a las plataformas digitales que permitirán una mayor diversidad de opciones y la sistematización inteligente de las informaciones empresariales y de los propios profesionales. 


\title{
Mensaje de apertura, decano Facultad \\ DE AdMINistración Y Negocios DE LA Universidad Autónoma de Chile
}

\author{
EN EL V Simposio INTERNACIONAL DE Responsabilidad \\ Social de las Organizaciones y I CONGRESO \\ INTERNACIONAL DE GESTIÓN ORGANIZACIONAL
}

Nelson Stevenson Palamara

Chile

Sin duda, la presencia de académicos de Argentina, Brasil, Chile, Colombia, Ecuador, España, Honduras, México, Paraguay, Perú y Venezuela, quienes además han presentado sus ponencias, es muy relevante porque validan la convocatoria y el contexto en el cual se desarrolla este encuentro internacional.

En nuestra facultad cultivamos las artes, las ciencias y las técnicas de la administración y los negocios, para formar profesionales y graduados competentes y emprendedores en las carreras de Ingeniería Comercial, Auditoría e Ingeniería en Control de Gestión, y Técnico en Administración de Empresas.

Somos una comunidad de 2.700 estudiantes, 270 profesores y 4.000 titulados, que opera académicamente en las ciudades de Temuco, Talca y Santiago.

La esencia de nuestra facultad se define por la existencia, evolución y desarrollo de los mercados y empresas, privadas y públicas; ello nos genera la necesidad de construir y mantener una profunda vinculación con las características de la realidad en que esos mercados se desarrollan.

En nuestro ethos y dimensión trascendente está la actitud emprendedora; ello nos obliga a estar a la vanguardia del conocimiento y desarrollo de las competencias necesarias para la innovación, el mayor argumento de competitividad del siglo XXI. 
Consistente con la concepción educativa que motiva a la Universidad Autónoma de Chile, la Facultad de Administración y Negocios ofrece oportunidades de formación a todos los sectores sociales y orienta su quehacer a partir de una visión de futuro compartida por su comunidad académica.

Estamos comprometidos con el desafío de la búsqueda rigurosa de la verdad y el respeto de la libertad de todas las personas que interactúan con nosotros.

Nuestros valores son los declarados por la Universidad Autónoma de Chile, fundamento de la actuación de todos y cada uno de sus miembros: formación integral de personas; ética y responsabilidad social; comprensión global de la sociedad; espíritu reflexivo y capacidad analítica; respeto; calidad en todo el quehacer.

Nuestro hábitat es el de las organizaciones sociales, el mundo de las empresas, el mundo de los negocios. A ello nos debemos.

Así procuramos honrar nuestra misión, que es formar profesionales y graduados en administración y negocios, competentes, social y éticamente responsables, y orientados hacia una educación permanente.

En nuestro quehacer promovemos un entorno académico de calidad, a través de la docencia, la investigación y una efectiva vinculación con el medio, contribuyendo al bienestar de la sociedad.

Lo anterior, por un sentido ético y de responsabilidad social, correspondiente con la confianza que tanto nuestros estudiantes como las organizaciones en las que ellos se desempeñan han depositado en nosotros.

Atendiendo a dichas premisas, y dado que los objetivos de este simposio son concordantes con nuestro quehacer estratégico, asumimos el desafío de organizar esta quinta versión y a partir de ella, continuar en 2019 con el II Congreso Internacional de Gestión Organizacional.

El objetivo del simposio es debatir y proyectar investigaciones avanzadas sobre el tema de responsabilidad social de las organizaciones y desarrollo sostenible, desde la perspectiva económica, ambiental y social, para contribuir a la generación de lineamientos de acción y elementos de sustentabilidad para organizaciones de todo tipo.

La convocatoria ha sido muy relevante: se seleccionaron 157 resúmenes de autores de 12 países, para finalmente contar, hoy día, con 103 ponencias, paneles y conferencias académicas de autores provenientes de los 11 países iberoamericanos ya mencionados.

Con mucha satisfacción debo informarles que hemos recibido el patrocinio del Comité de CONICYT, Comisión Nacional de Investigación 
Científica y Tecnológica de Chile, dando su apoyo científico al simposio y al congreso.

Las ponencias han sido aceptadas por un comité científico internacional, posteriormente una proporción de ellas serán seleccionadas para recomendarlas tanto a las revistas indexadas asociadas, Ambiente y Sociedad, de Scopus, y Visión de Futuro, de Scielo, para ser publicadas.

El ministro de Desarrollo Social, Sr. Alfredo Moreno, que nos acompaña, expondrá los lineamientos del Gobierno de Chile acerca de los Objetivos de Desarrollo Sostenible de Naciones Unidas.Por otra parte, el padre Felipe Berríos S.J. compartirá su visión en esta materia junto al ministro.

Esperamos que este espacio de análisis y reflexión pueda constituirse en un real aporte para cada uno de ustedes. Queremos hacer de nuestra patria una mejor sociedad y de la Universidad Autónoma de Chile, una universidad de calidad, comprometida y vinculada efectiva y activamente con nuestro medio relevante y la comunidad toda. En otras palabras, «Más Universidad».

Finalmente, agradezco a todos quienes han hecho posible la realización de este gran encuentro internacional. Muchas gracias. 



\section{Sección II: Responsabilidad Social Empresarial (RSE)}





\title{
ANÁlisis DE LA PRODUCCIÓN CIENTÍfICA SOBRE GOBIERNO CORPORATIVO EN LATINOAMÉRICA Y ESPAÑA
}

\author{
Walter Daniel Ovelar Fernández"
}

Paraguay

\section{INTRODUCCIÓN}

Gobierno es la acción y efecto de gobernar o gobernarse (RAE). Mientras que Gobierno Corporativo (GC) es el ejercicio del poder en el ámbito de las organizaciones, ya sean estás con fines de lucro, sin fines de lucro o hasta públicas. El estudio del poder en las organizaciones en la actualidad cobra importancia en un entorno caracterizado por ser dinámico, globalizado y muy competitivo (Acosta Palomeque, 2018). Charreaux (2004) afirma que la expresión "Gobierno Corporativo» puede ser ambiguo porque su objetivo no es estudiar la manera en que los directivos gobiernan sino más bien como son gobernados.

La relación entre propiedad y dirección de una empresa, desde hace años, constituye un tema de investigación de gran interés en el ámbito de la economía y las empresas (Richart-Ramon et al., 2011). Lavoie (1992, p. 107), citado por Dallery (2008), niega la capacidad de los accionistas de influir la orientación estratégica de las empresas porque en los modelos de Galbraith y de la empresa postkeynesiana, los accionistas tienen un rol pasivo, en el sentido de que esta concepción es heredada de una configuración institucional específica en la cual los accionistas están dispersos. Dallery (2008) dice que Galbraith describe una era de tecnoestructura en la cual las empresas son manejadas por el espíritu de la búsqueda de crecimiento, donde el control supera a la propiedad. Pero también para Dallery (2008) esta teoría de la empresa

Maestría en Contabilidad y Sistemas de Información. Universidad Autónoma de Asunción.wovelar@uaa.edu.py 
parece haber parado en los a inicio de los años ochenta y a partir de ahí, la financiación de las empresas ha cambiado las reglas de juego y los accionistas pueden ya reclamar que sus demandas sean cumplidas. Si los directivos de las empresas desean financiación, deberán compartir la gestión y el control con sus accionistas.

La relación que se da entre accionistas y empresa intenta ser explicada por la Teoría de la Agencia. Ya en el año 1976, Jensen y Meckling definen la relación de agencia de la siguiente manera: un contrato bajo el cual una o varias personas (el principal) contratan a otra persona (el agente) para que realicen ciertos servicios en su nombre, los que envuelven la delegación de decisiones dando autoridad al agente. Pero esta delegación de autoridad nuevamente crea conflictos o dilemas.

Es decir, al existir la delegación de autoridad de los propietarios o accionistas a los gerentes, estos últimos deben ser gobernados de alguna manera. Es así que se consolida el GC, basado en tres principios fundamentales: transparencia, integridad y responsabilidad.

La transparencia implica una actitud abierta hacia la divulgación de información, lo que contribuye a la mayor eficiencia de los mercados, impulsa a los miembros del directorio a decidir acciones y a los demás accionistas y otros a monitorear con mayor énfasis a la empresa. El directorio debe actuar de manera completamente íntegra. La integridad de los informes financieros depende de la integridad de quienes los preparan y presentan. Finalmente, la responsabilidad significa que los miembros del directorio son responsables de la información que presentan a los demás accionistas y a las otras partes (Informe Cadbury, 1992).

Por lo tanto, según Acosta Palomeque (2018), un buen GC proporciona los mecanismos que permitan un equilibrio entre la gestión y el control de dicha gestión mediante sistemas de pesos y contrapesos, con el fin de que las decisiones adoptadas se realicen de acuerdo al mejor interés de la organización y accionistas, respetando los derechos de los grupos de interés.

\section{Metodología}

Aquí se describe el proceso seguido para elaborar esta investigación acerca de la producción científica sobre GC en la base de datos Web of Science (WoS) de Clarivate Analytics. Como método de investigación se han utilizado técnicas bibliométricas, en decir, se analizaron los registros bibliográficos que se incluyen en esta base de datos. A través de estas referencias se valoró cómo las distintas áreas de conocimiento 
han contribuido a la formación del concepto del GC. Asimismo, se seleccionaron artículos con la presencia de este término en el título del articulo y/o como palabra clave. La base de datos mencionada posee una cobertura temática amplia y ha sido colectada en línea a través de Centro de Información Científica del CONACYT (CICCO) del Paraguay en el mes de mayo de 2018.

Se pretende estudiar la producción científica biliométrica sobre GC a nivel de los países latinoamericanos y España, realizando un análisis descriptivo-cuantitativo desde el 2008 al 2017.

El proceso de producción científica no está concluido si los resultados obtenidos por la investigación no se publican en una revista especializada. Cualquier contribución a la ciencia solamente es reconocida después de haber sido publicada, juzgada, criticada y agrupada en una disciplina del conocimiento (Oliveira Neto et al., 2017). La publicación es la salida (output) del proceso investigativo.

La bibliometría fue inicialmente utilizada por Alan Pritchard en 1969 para conceptualizar una nueva disciplina, en la cual los métodos cuantitativos son usados para analizar procesos de comunicación científica midiendo varios aspectos de los documentos publicados (Sanku y Moutusi, 2013).

Para Guedes y Borschiver (2005), la bibliometría, cienciometría, infometría y actualmente la webometría se basan en tres leyes o principios:

- Ley de Bradford: mide la productividad de periódicos (revistas) estimando su relevancia dentro de una determinada área del conocimiento.

- Ley de Lotka: mide la productividad científica de autores, identifica centros de investigación y busca reconocer la solidez de un determinado campo científico.

- Ley de Zipf: mide la frecuencia de aparición de determinadas palabras en textos, produciendo así una lista de términos dentro de una disciplina, conforme a su relevancia, para que, de esta forma, una concentración de palabras con un alto contenido semántico pueda ser usada como forma de indexación.

\section{CUESTIONES CLAVES SOBRE EL GOBIERNO CORPORATIVO.}

Dos definiciones del concepto de GC son las siguientes:

- El Informe Cadbury (1992) entiende el GC como aquel sistema por el cual los negocios corporativos de las empresas son 
dirigidos y controlados y donde se establecen derechos y obligaciones entre las diferentes personas involucradas en la empresa: propietarios, consejeros, administradores, accionistas y simples empleados, así como también las reglas y los procedimientos para la toma de decisiones sobre esos negocios.

- La Organización para la Cooperación Económica y Desarrollo Económicos (2004) define gobierno corporativo como los medios internos por los cuales las corporaciones son operadas y controladas.

Asimismo, en línea con Acosta Palomeque (2012) que, basándose en los Principios del Gobierno Corporativo (OCDE/G20, 2015), señala seguidamente los seis principios clave que hacen al buen GC:

1. La base para un buen marco de gobierno corporativo: el marco del gobierno corporativo debe promover mercados justos y transparentes y una eficiente asignación de recursos. Ello debería ser consistente con el marco legal y soportado por una efectiva aplicación de la supervisión.

2. Los derechos y trato equitativo de los accionistas y las funciones principales de la propiedad: el marco de referencia del gobierno corporativo debe proteger y facilitar el ejercicio de los derechos de los accionistas y asegurar un tratamiento equitativo de todos, incluyendo accionistas minoritarios y extranjeros. Todos deben tener la oportunidad de obtener una efectiva compensación por la violación de sus derechos.

3. Inversionistas institucionales, mercado de valores y otros intermediarios: el marco del gobierno corporativo debería proveer importantes incentivos a lo largo de la cadena de inversión y aporte al funcionamiento del mercado de valores, de manera que contribuya al buen gobierno corporativo.

4. El papel de los grupos de interés en el gobierno corporativo: el marco del gobierno corporativo debería reconocer los derechos de los grupos de interés establecidos por la ley o a través de acuerdos mutuos, y alentar una cooperación activa entre corporaciones y grupos de interés en la creación de riqueza, empleo y en la sostenibilidad de las empresas financieramente sólidas. Se reconoce que los mecanismos de participación de los empleados contribuyen a mejorar la rentabilidad corporativa. 
5. Divulgación de la información y transparencia: el marco del gobierno corporativo debería asegurar la oportuna y precisa divulgación de la información de todos los asuntos importantes con respecto a la corporación, incluyendo la situación financiera, actuación, propiedad y gobierno de la compañía.

6. Las responsabilidades del órgano de administración: el marco del gobierno corporativo debería asegurar una orientación estratégica de la compañía, el efectivo monitoreo por parte de la administración de la estrategia y la rendición de cuentas a la compañía y a los grupos de interés.

Por lo tanto, las investigaciones sobre Gobierno Corporativo deberían estar encuadradas en una combinación de estos principios clave.

\section{ESTUdios BIBLIOMÉTRICOS PREVIOS SOBRE GOBIERNO COR- PORATIVO}

Se ha realizado una búsqueda de estudios bibliométricos anteriores en español y portugués sobre el Gobierno Corporativo en las siguientes bases de datos: Web of Science, Scielo, Google Académico y Red de Revistas Científicas de América Latina y el Caribe, España y Portugal (Redalyc).

Para considerar a un estudio bibliométrico como antecedente a esta investigación, se estableció que la palabra clave "Gobierno Corporativo» debe estar incluida ya sea en el título del artículo o como palabra clave. En el cuadro siguiente se observan que los resultados obtenidos fueron los siguientes:

CuAdro i. Estudios bibliométricos Previos sobre el Gobierno Corporativo

\begin{tabular}{|c|c|c|c|}
\hline $\begin{array}{c}\text { AÑO DE } \\
\text { PUBLICACIÓN }\end{array}$ & AuTOR/ES & $\begin{array}{l}\text { Título del } \\
\text { ARTí́CUlo }\end{array}$ & BREVE DESCRIPCIÓN DE LOS ESTUdIOS \\
\hline 2008 & $\begin{array}{l}\text { Cristián Berrío } \\
\text { Zapata }\end{array}$ & $\begin{array}{l}\text { Revisión Bibliométri- } \\
\text { ca del Concepto de } \\
\text { Gobierno Corporativo }\end{array}$ & $\begin{array}{l}\text { Se realizó un análisis estadístico descrip- } \\
\text { tivo no correlacional de las tendencias } \\
\text { conceptuales subyacentes al desarrollo } \\
\text { investigativo en Gobierno Corporativo, } \\
\text { sobre una muestra de } 1.114 \text { artículos } \\
\text { científicos. Cubre el periodo de } 1996 \\
\text { a } 2008 \text {. }\end{array}$ \\
\hline
\end{tabular}




\begin{tabular}{|c|c|c|c|}
\hline $\begin{array}{c}\text { AÑO DE } \\
\text { PUBLICACIÓN }\end{array}$ & Autor/es & $\begin{array}{c}\text { Título DEL } \\
\text { ARTículo }\end{array}$ & BREVE DESCRIPCIÓN DE LOS ESTUdIOS \\
\hline 2011 & $\begin{array}{l}\text { Richart- } \\
\text { Ramón et al. }\end{array}$ & $\begin{array}{l}\text { Análisis de la produc- } \\
\text { ción científica sobre } \\
\text { Gobierno Corporativo } \\
\text { a través de ISI Web of } \\
\text { Science }\end{array}$ & $\begin{array}{l}\text { Este trabajo ha analizado } 2.147 \text { publi- } \\
\text { caciones sobre buen gobierno empre- } \\
\text { sarial incluidas en la base de datos ISI } \\
\text { Web of Science y sus correspondientes } \\
79.635 \text { referencias, con el objetivo } \\
\text { principal de identificar las pautas } \\
\text { sobre las que se basa la investigación. } \\
\text { Cubre el periodo de } 1977 \text { a } 2008 \text {. }\end{array}$ \\
\hline 2012 & $\begin{array}{l}\text { Vivas-Crisol } \\
\text { et al. }\end{array}$ & $\begin{array}{l}20 \text { años de investiga- } \\
\text { ción sobre Gobierno } \\
\text { Corporativo Interna- } \\
\text { cional }\end{array}$ & $\begin{array}{l}\text { El presente artículo analiza la produc- } \\
\text { ción científica sobre Gobierno Corpora- } \\
\text { tivo internacional desde que se publicó } \\
\text { el primer artículo en } 1992 \text { hasta } 2010 . \\
\text { Los datos se han obtenido de la base } \\
\text { de datos ISI Web of Science, dando por } \\
\text { resultado } 338 \text { artículos. }\end{array}$ \\
\hline 2017 & $\begin{array}{l}\text { Maia \& Di } \\
\text { Serio }\end{array}$ & $\begin{array}{l}\text { Governança corpora- } \\
\text { tiva e estratégia em- } \\
\text { presarial: mapeamento } \\
\text { bibliométrico da pro- } \\
\text { dução na área }\end{array}$ & $\begin{array}{l}\text { Se realizó un estudio bibliométrico de } \\
496 \text { artículos en los que se analizan las } \\
\text { relaciones existentes entre el Gobierno } \\
\text { Corporativo y la estrategia empresarial, } \\
\text { con el fin de elaborar un panorama } \\
\text { inicial de la producción científica en el } \\
\text { área. Cubre el periodo de } 1996 \text { a } 2015 \text {. }\end{array}$ \\
\hline 2017 & $\begin{array}{l}\text { Oliveira Neto } \\
\text { et al. }\end{array}$ & $\begin{array}{l}\text { Agency Theory: a } \\
\text { Study about scientific } \\
\text { research in Brazilian } \\
\text { Journals }\end{array}$ & $\begin{array}{l}\text { Se realizó una investigación descriptiva } \\
\text { usando un enfoque cuantitativo de } \\
\text { aplicación bibliométrica. El análisis } \\
\text { se concentró en la formación de la } \\
\text { estructura social del conocimiento } \\
\text { científico. Se seleccionaron } 74 \text { artículos } \\
\text { publicados en } 26 \text { revistas brasileras de } \\
\text { administración y contabilidad entre los } \\
\text { años } 2002 \text { y } 2015 \text {. }\end{array}$ \\
\hline
\end{tabular}

FuENTE: ElABORACión PROPIA.

Tal como se observa en el cuadro anterior, no se han identificado estudios previos de producción científica sobre GC enfocados exclusivamente a países de Latinoamérica y España. 


\section{PROCEDIMIENTOS UTILIZADOS PARA CLASIFICAR LOS ARTÍ́CULOS}

Sobre la base de la revisión de la literatura se han seleccionado diez maneras para clasificar los noventa artículos seleccionados y son los siguientes:

Cuadro 2: Procedimientos utilizados para Clasificar los artículos

\begin{tabular}{|c|c|c|c|c|}
\hline $\mathrm{N}^{\circ}$ & $\begin{array}{c}\text { CLASIFICACIÓN } \\
\text { POR }\end{array}$ & DESCRIPCIÓN & ОвјетіVоs & INTERPRETACIÓN \\
\hline 1 & $\begin{array}{l}\text { Áreas de } \\
\text { investigación }\end{array}$ & $\begin{array}{l}\text { Cantidad de artí- } \\
\text { culos publicados } \\
\text { por áreas de in- } \\
\text { vestigación }\end{array}$ & $\begin{array}{l}\text { Identificar las } \\
\text { áreas de inves- } \\
\text { tigación de los } \\
\text { artículos publi- } \\
\text { cados }\end{array}$ & $\begin{array}{l}\text { Predominancia en } \\
\text { áreas de investiga- } \\
\text { ción en los artículos } \\
\text { publicados }\end{array}$ \\
\hline 2 & $\begin{array}{l}\text { Métodos de } \\
\text { investigación }\end{array}$ & $\begin{array}{l}\text { Cantidad de artí- } \\
\text { culos publicados } \\
\text { por métodos de } \\
\text { investigación }\end{array}$ & $\begin{array}{l}\text { Identificar los } \\
\text { métodos de } \\
\text { investigación } \\
\text { utilizados en los } \\
\text { artículos publi- } \\
\text { cados }\end{array}$ & $\begin{array}{l}\text { Predominancia en } \\
\text { métodos científicos } \\
\text { utilizados por los } \\
\text { autores }\end{array}$ \\
\hline 3 & $\begin{array}{l}\text { Años de } \\
\text { publicación }\end{array}$ & $\begin{array}{l}\text { Cantidad de artí- } \\
\text { culos publicados } \\
\text { por año }\end{array}$ & $\begin{array}{l}\text { Identificar diná- } \\
\text { mica de los artí- } \\
\text { culos }\end{array}$ & $\begin{array}{l}\text { Aumento en el inte- } \\
\text { rés en el } \\
\text { área de investigación }\end{array}$ \\
\hline 4 & $\begin{array}{l}\text { Idiomas de } \\
\text { publicación }\end{array}$ & $\begin{array}{l}\text { Cantidad de artí- } \\
\text { culos publicados } \\
\text { por idioma }\end{array}$ & $\begin{array}{l}\text { Identificar la } \\
\text { concentración } \\
\text { lingüística en los } \\
\text { artículos }\end{array}$ & $\begin{array}{l}\text { Predominancia lin- } \\
\text { güística en el área de } \\
\text { investigación }\end{array}$ \\
\hline 5 & $\begin{array}{l}\text { Productividad } \\
\text { de países }\end{array}$ & $\begin{array}{l}\text { Países en donde } \\
\text { se ubican las pu- } \\
\text { blicaciones }\end{array}$ & $\begin{array}{l}\text { Identificar la } \\
\text { concentración } \\
\text { por países de los } \\
\text { artículos }\end{array}$ & $\begin{array}{l}\text { Predominancia de } \\
\text { países en el tema } \\
\text { investigado }\end{array}$ \\
\hline 6 & $\begin{array}{l}\text { Productividad } \\
\text { de revistas }\end{array}$ & $\begin{array}{l}\text { Cantidad de re- } \\
\text { vistas con más } \\
\text { publicaciones } \\
\text { para corrobo- } \\
\text { rar la Ley de } \\
\text { Bradford }\end{array}$ & $\begin{array}{l}\text { Identificar la con- } \\
\text { centración por } \\
\text { revistas de los } \\
\text { artículos }\end{array}$ & $\begin{array}{l}\text { Predominancia de } \\
\text { revistas en el total de } \\
\text { artículos }\end{array}$ \\
\hline
\end{tabular}




\begin{tabular}{|l|l|l|l|l|}
\hline No & $\begin{array}{l}\text { ClasificACIóN } \\
\text { POR }\end{array}$ & \multicolumn{1}{|c|}{ Descripción } & \multicolumn{1}{|c|}{ OBJETIVos } & InTERPRETACIón \\
\hline 7 & $\begin{array}{l}\text { Productividad } \\
\text { de autores }\end{array}$ & $\begin{array}{l}\text { Cantidad autores } \\
\text { con más artículos } \\
\text { para corroborar } \\
\text { la Ley de Lotka }\end{array}$ & $\begin{array}{l}\text { Identificara los } \\
\text { autores con el } \\
\text { mayor número } \\
\text { de artículos, los } \\
\text { que por ende son } \\
\text { autoridades en el } \\
\text { área }\end{array}$ & $\begin{array}{l}\text { Predominancia de } \\
\text { autores con una sola } \\
\text { publicación en el } \\
\text { total de artículos }\end{array}$ \\
\hline 8 & $\begin{array}{l}\text { Artículos más } \\
\text { citados }\end{array}$ & $\begin{array}{l}\text { Corroborar el } \\
\text { factor de impacto } \\
\text { de los artículos } \\
\text { con más citas }\end{array}$ & $\begin{array}{l}\text { Identificar los } \\
\text { artículos con más } \\
\text { citas }\end{array}$ & $\begin{array}{l}\text { Predominancia de } \\
\text { artículos citados en } \\
\text { el total de artículos } \\
\text { publicados }\end{array}$ \\
\hline 9 & Palabras clave & $\begin{array}{l}\text { Cantidad de pa- } \\
\text { labras clave para } \\
\text { corroborar la Ley } \\
\text { de Zipf }\end{array}$ & $\begin{array}{l}\text { Identificar las } \\
\text { palabras clave } \\
\text { más utilizadas en } \\
\text { los artículos para } \\
\text { descubrir tenden- } \\
\text { cias en el área de } \\
\text { investigación }\end{array}$ & $\begin{array}{l}\text { Predominancia de } \\
\text { palabras clave }\end{array}$ \\
\hline 10 & $\begin{array}{l}\text { Colaboración } \\
\text { científica }\end{array}$ & $\begin{array}{l}\text { Corroborar el } \\
\text { grado de colabo- } \\
\text { ración científica } \\
\text { entre los autores }\end{array}$ & $\begin{array}{l}\text { Identificar el } \\
\text { grado de colabo- } \\
\text { ración científica } \\
\text { entre los autores } \\
\text { de los artículos }\end{array}$ & $\begin{array}{l}\text { Predominancia o no } \\
\text { de la colaboración } \\
\text { científica }\end{array}$ \\
\hline
\end{tabular}

Fuente: Elaboración propia A PARTir de Berrío Zapata (2008).

\section{Resultados}

Los resultados obtenidos en la investigación sobre el análisis de la producción científica sobre Gobierno Corporativo se presentan seguidamente:

\section{ClasificaCión DE ARTÍ́CUlos POR ÁREAS DE INVESTIGACIÓN}

Tal como se observa en el Gráfico 1, la cantidad de artículos en el área de investigación científica de Business \& Economics asciende a 62 de los 90 analizados en este estudio. Esta cifra da fe de la predominancia o superioridad de esta área científica sobre las demás. También estos resultados corroboran que el Gobierno Corporativo es un área temática propia de las ciencias empresariales. Las áreas de Government \& Law 
y Arts \& Humanities ocupan un distante segundo y tercer lugar, con siete y cinco artículos respectivamente.

GrÁFICO i. CANTIDAD DE ARTí́culos PUblicados POR ÁREA CIENTífica

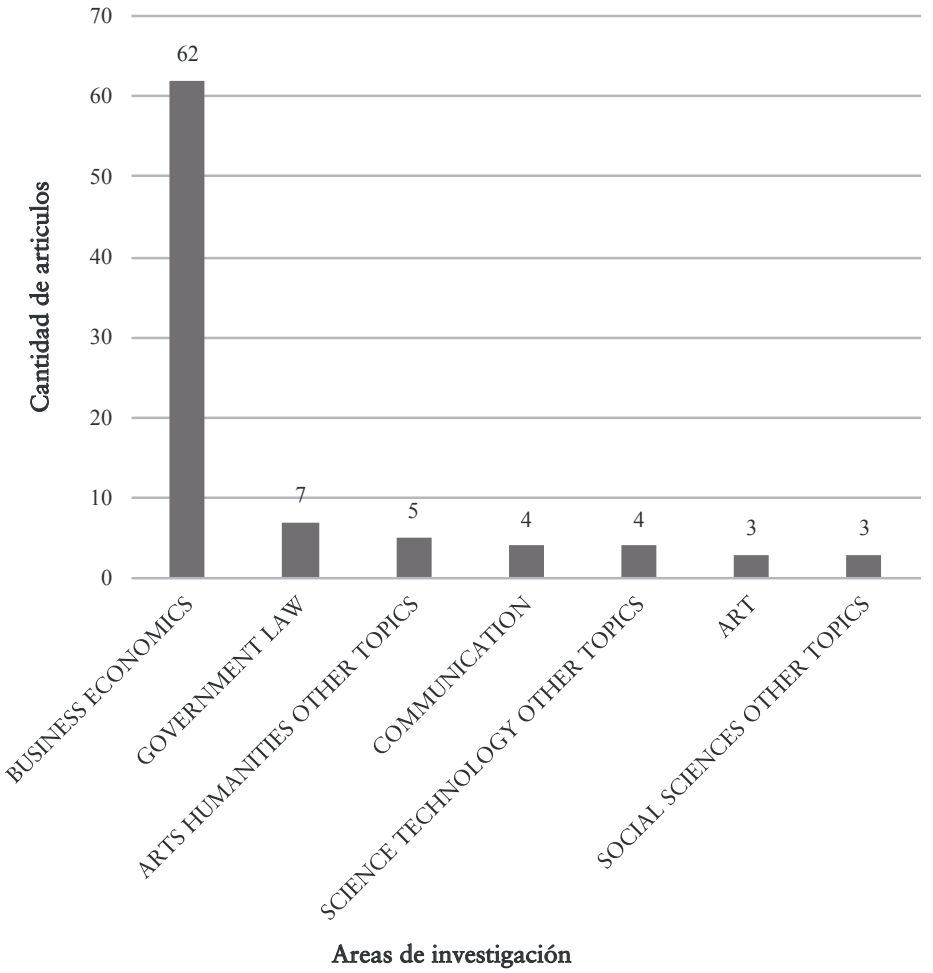

Fuente: Elaboración propia a partir de Web of SCience.

\section{CLASIFICACIÓN POR MÉTODOS DE INVESTIGACIÓN}

Los métodos de investigación no muestran cuál ha sido el camino seguido por los autores para obtener los resultados en sus investigaciones. Lunkes (2001) cita a Birnberg et al. (1990) y a Hesford et al. (2007) para clasificar los métodos de investigación en nueve categorías, las que se describen seguidamente: 
CuAdro 3. Clasificación y definiCión de MÉTOdos de InVESTIGACIÓN

\begin{tabular}{|l|l|}
\hline \multicolumn{1}{|c|}{ MÉTodos } & \multicolumn{1}{c|}{ DEFInICIón } \\
\hline Analítica & $\begin{array}{l}\text { Se trata de la evaluación y el estudio detallado de la } \\
\text { información disponible en un intento de explicar el } \\
\text { contexto de un fenómeno. }\end{array}$ \\
\hline Archivo/documental & $\begin{array}{l}\text { Implica el uso de la información que no ha tenido } \\
\text { un tratamiento científico. }\end{array}$ \\
\hline Caso & $\begin{array}{l}\text { Se trata de la investigación de los fenómenos, inclu- } \\
\text { yendo a las personas, procedimientos y estructuras } \\
\text { en una sola organización. }\end{array}$ \\
\hline Experimental & $\begin{array}{l}\text { Implica el tratamiento de la información en un } \\
\text { intento de establecer causa-efecto de las variables } \\
\text { investigadas. }\end{array}$ \\
\hline Campo & $\begin{array}{l}\text { Se trata de la investigación de los fenómenos, inclu- } \\
\text { yendo a las personas, procedimientos y estructuras } \\
\text { en dos o más organizaciones. }\end{array}$ \\
\hline Framework & $\begin{array}{l}\text { Implica el desarrollo de un nuevo concepto y nue- } \\
\text { vas perspectivas. }\end{array}$ \\
\hline Revisión & $\begin{array}{l}\text { Básicamente, consiste en la síntesis y la revisión de } \\
\text { la literatura ya conocida. }\end{array}$ \\
\hline Survey (encuesta) & $\begin{array}{l}\text { Se trata de la investigación de un grupo de perso- } \\
\text { nas, a menudo llevado a cabo a través de un cues- } \\
\text { tionario. }\end{array}$ \\
\hline No encaja en ninguno de los otros métodos. \\
\hline
\end{tabular}

Fuente: Lunkes ET AL. (20I I), SObRe LA BASE DE Birnberg ET AL. (I990) Y HESFORD ET AL. (2007).

En este estudio se ha corroborado la gran predominancia de los métodos de investigación analítica y experimental, con el $38 \%$ y el $47 \%$, respectivamente, sobre los demás tipos de métodos. Esto se puede observar en el gráfico siguiente. Ambos métodos fueron utilizados en el $85 \%$ del total de artículos analizados. Los resultados obtenidos no han podido ser comparados contra los estudios bibliométricos previos utilizados en esta investigación, porque los mismos no han investigado cuáles han sido los métodos de investigación utilizados en los artículos que han seleccionado. 


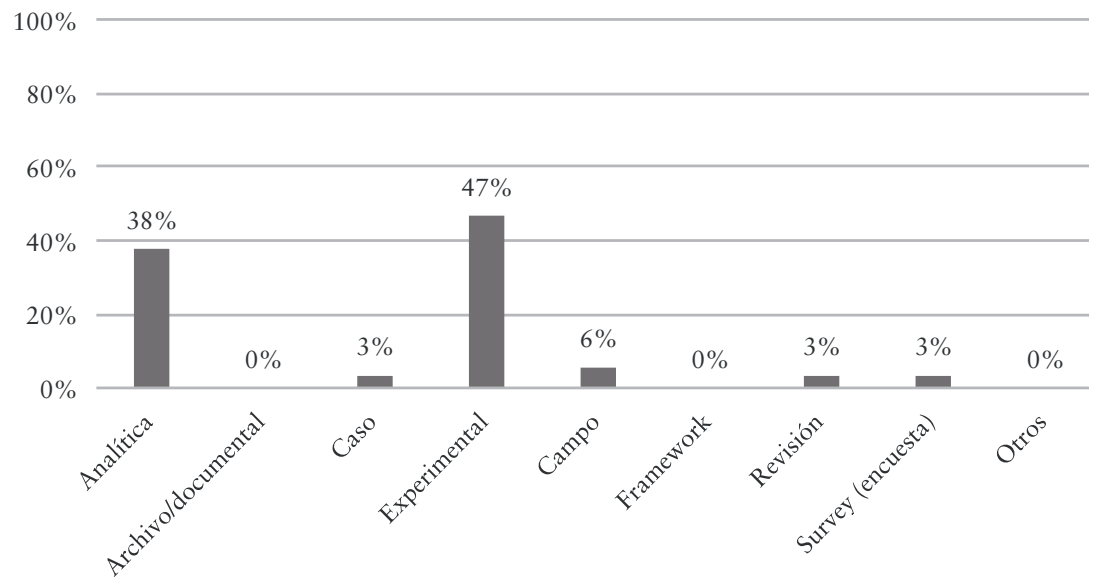

FUENTE: ElABORACIÓN PROPIA.

Finalmente, existe un gran potencial en Latinoamérica y España para realizar estudios sobre el GC con métodos de investigación de casos y campo.

\section{ClasificaCión de ARTículos POR AÑOS DE PUBLICACIÓN}

La producción sobre el tema de investigación ha sido irregular a lo largo de los diez años analizados. El promedio de artículos publicados por año es nueve. Es así que en el año 2010 se publicaron once artículos para descender a cinco en el año 2011. En el año 2012 se vuelven a publicar once artículos, pero en los años 2013 y 2014, la producción decrece a diez y nueve, respectivamente. Sin embargo, se nota un impulso en el año 2015 con doce artículos publicados y un gran salto en el año 2016 con dieciséis, pero en el último año de análisis, el 2017, vuelve a decrecer a once. Obsérvense estos datos en el gráfico siguiente: 
Gráfico 3. Artículos por años de publicación

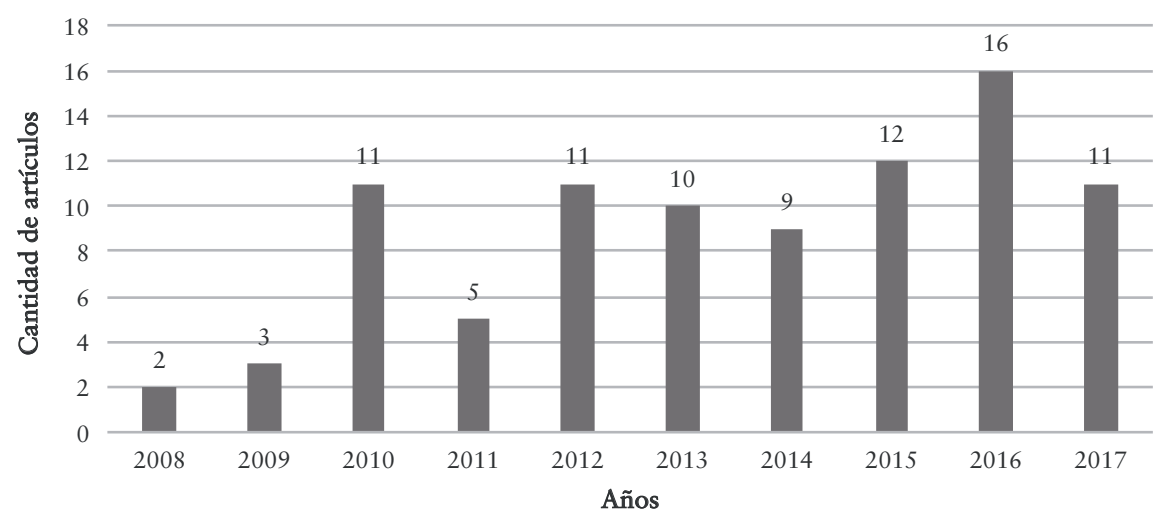

Fuente: Elaboración propia, sobre la base de Web of Science (WoS).

\section{ClasificACIÓN DE ARTíCUlos POR IDIOMAS DE PUBLICACIÓN}

Al ser este un estudio sobre la producción de artículos científicos relacionados con el Gobierno Corporativo en Latinoamérica y España, se corrobora el predominio del idioma español sobre el inglés y portugués. Tal como se observa en el gráfico 4, el español se utilizó en el $63 \%$, el inglés en el 19\% y finalmente el portugués en el 17\% del total de artículos analizados.

En el estudio realizado por Berrio Zapata (2008), el predominio del inglés sobre el español fue muy pronunciado.

\section{GrÁfico 4. CANTIDAd DE ARTí́culos POR IDiomas}

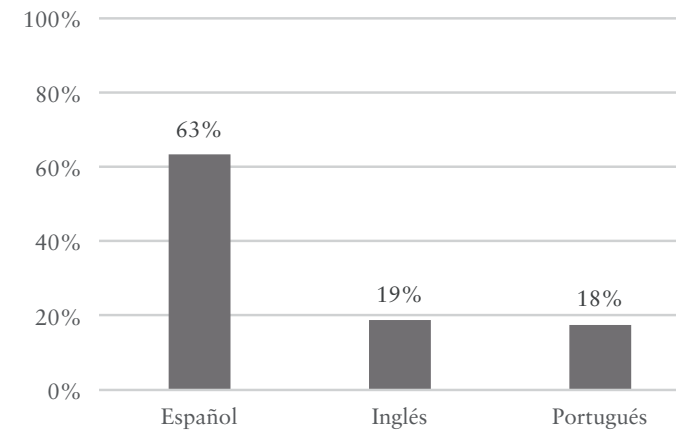

Fuente: Elaboración propia, sobre la base de Web of Science. 


\section{Clasificación DE ARTículos POR PRODUCTIVIDAD DE PAÍSES}

En total se han publicado noventa artículos científicos sobre Gobierno Corporativo en veinticuatro países de Latinoamérica y España. Los cuatro países más productivos identificados son Colombia con $28 \%$, España con el $20 \%$, Brasil con 18,8\%, México con el $11 \%$ y otros países con el $22 \%$. Se corrobora la ventaja de tres países latinoamericanos (Colombia, Brasil y México) sobre los demás porque producen en conjunto el $58 \%$ del total de los artículos científicos analizados.

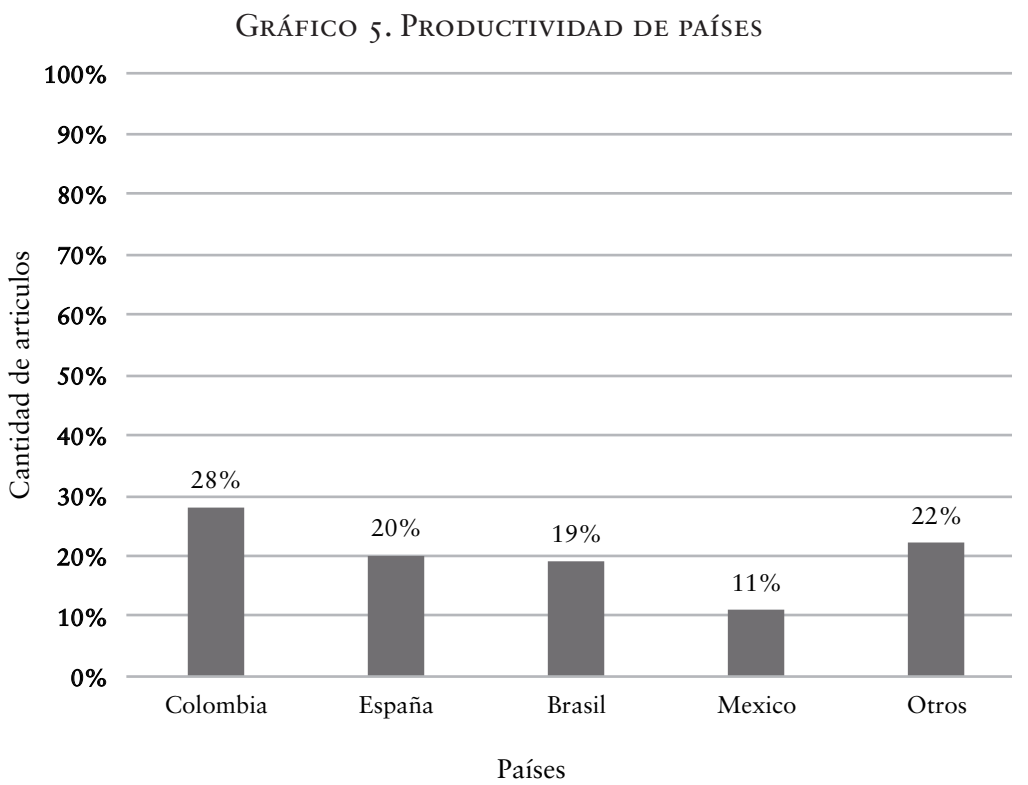

Fuente: Elaboración propia, sobre la base de Web of Science.

\section{ClasificACIÓN DE ARTÍCULOS POR PRODUCTIVIDAD DE REVISTAS}

Es la Ley de Bradford la que posibilita estimar el grado de relevancia de las revistas que actúan en un área determinada del conocimiento científico. Para Machado Junior et al. (2014), revistas con mayor cantidad de artículos publicados sobre un determinado tema tenderán a establecer un núcleo con una supuesta calidad superior y con una mayor relevancia en esta área del conocimiento. Es en este contexto 
que se constituye un conjunto de tres zonas, cada cual con un tercio de los artículos relevantes. La primera contiene un número de revistas altamente productivas; la segunda, un número mayor de revistas con menor productividad, y la tercera incluye a un volumen aún mayor de revistas con una reducida productividad sobre el tema (Machado Junior et al., 2014).

En esta investigación no se ha podido corroborar la Ley de Bradford porque no existen tres zonas o núcleos con revistas altamente, medianamente o poco productivas. Sin embargo, las primeras cuatro revistas más productivas, con veintisiete artículos publicados, casi alcanzan el primer tercio. Obsérvese sobre el particular en el gráfico siguiente:

Gráfico 6. Productividad DE REVISTAS

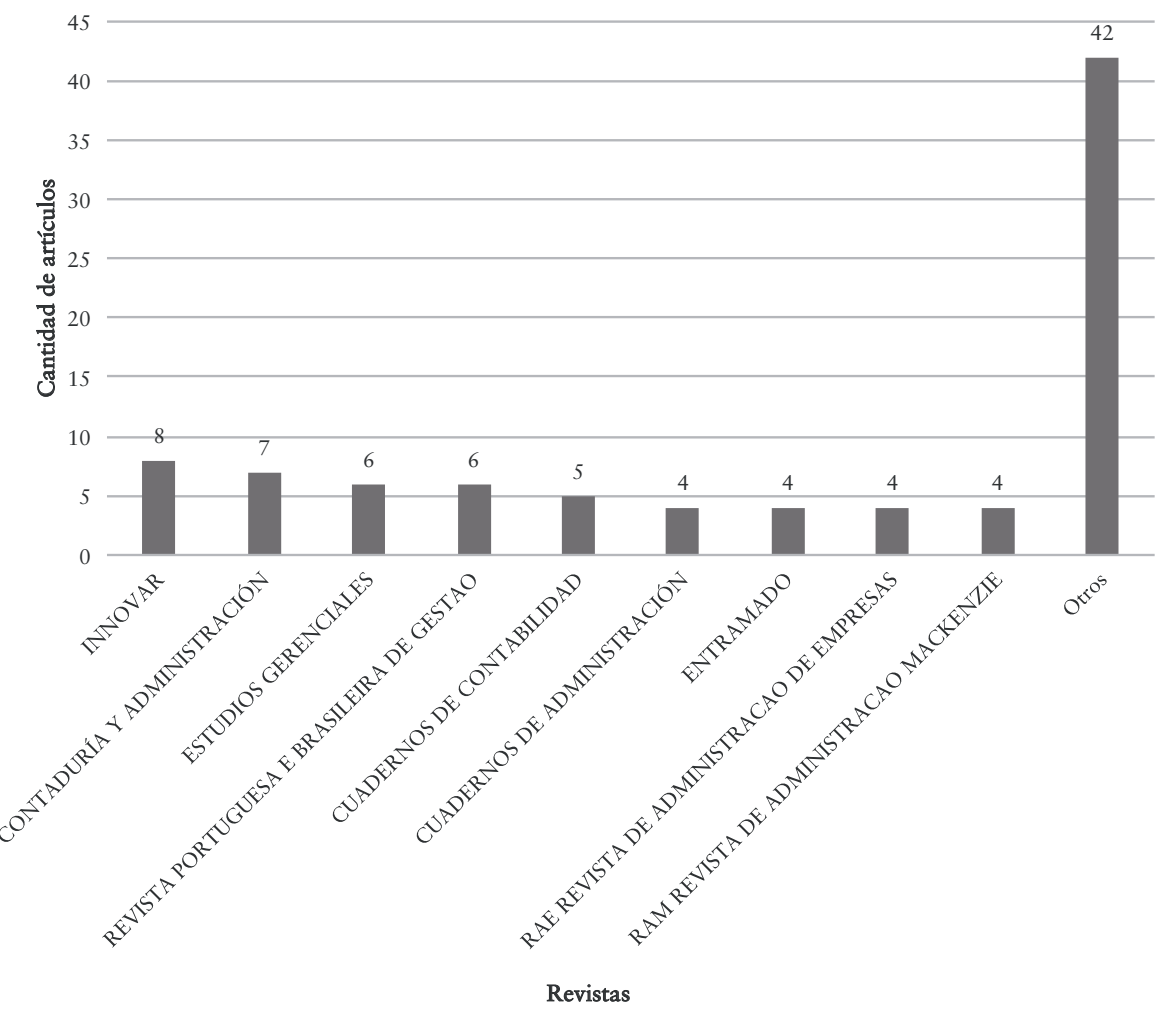

Fuente: Elaboración propia, sobre la base de Web of Science. 


\section{ClasificaCión DE ARTículos POR PRODUCTIVIDAD DE AUTORES}

Lotka (1926) estableció los fundamentos de la Ley del Cuadrado Inverso, afirmando que el número de autores que hacen $n$ contribuciones en un determinado campo científico es de aproximadamente $1 / n 2$ de los que realizan una sola contribución y da como porcentaje más o menos $60 \%$ (Urbizagástegui, 2002). En este aspecto, varios estudios bibliométricos la utilizan para describir la productividad de investigadores en determinado campo científico. Urbizagástegui (2002) afirma que varios estudios bibliométricos realizados en el Brasil arrojaron resultados contradictorios al aplicar la Ley de Lotka.

Se ha realizado una búsqueda de los autores con mayor volumen de publicaciones en el periodo de análisis. En total se ha identificado que 201 autores han publicado 90 artículos, siendo el promedio de autores/artículos de 2,333. Obsérvese en el resultado que se expone en el gráfico 6, que solamente tres autores (Gómez-Betancourt Gonzalo; Lagos Cortes Diógenes y Betancourt Ramírez José Bernardo) han publicado cuatro artículos cada uno. Once han publicado dos artículos, y son los denominados medianos autores, los demás tan solo un artículo. Si aplicásemos la Ley de Lokta, dividiendo 56 (cantidad de autores con un solo artículo publicado) por 90 (cantidad total de artículos investigados), el resultado obtenido es del $62 \%$, porcentaje cercano al $60 \%$ postulado por Lotka. Por lo tanto, se corrobora la predominancia de autores con una sola publicación en este estudio.

Conforme Vivas-Crisol et al. (2012), los tres autores con cuatro artículos son los más productivos y por lo tanto son grandes autores; los con dos artículos son medianos autores, mientras que los con un solo artículo son autores ocasionales. 


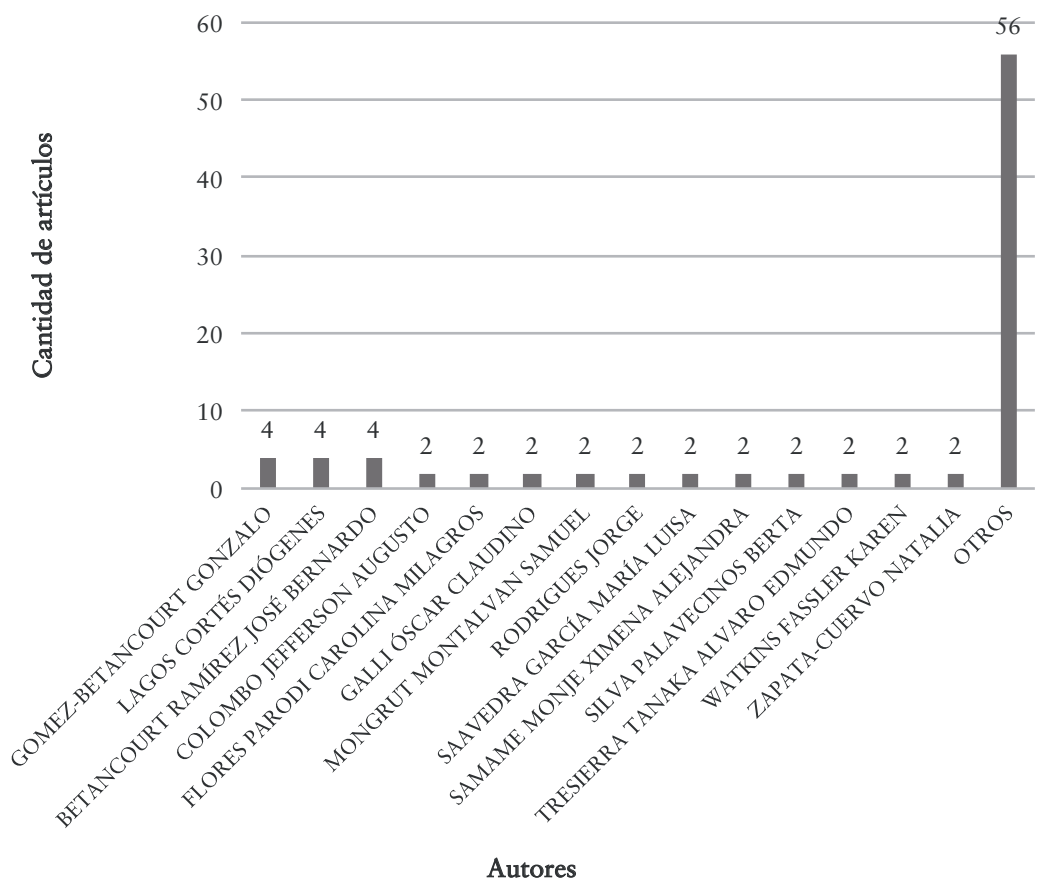

Fuente: Elaboración propia, sobre la base de Web of Science.

\section{ClasificACión POR ARTÍ́CUlos MÁs CITADOS}

Si un artículo científico no es citado es como si no existiese. Cuando un artículo de una revista científica es muy citado, representa la aceptación de parte de la comunidad que lo cita (Guedes y Borschiver, 2005). A efectos de identificar a los artículos más relevantes, se ha utilizado el criterio habitual para determinar el impacto de una publicación, como es el «número de citas» (Vivas-Crisol et al., 2011). Para ello, sobre la base de los datos obtenidos de la WoS se ha elaborado el siguiente cuadro, en el cual se exponen los diez artículos más citados de entre los noventa analizados. 


\section{Cuadro 4. Artículos más citados}

\begin{tabular}{|c|c|c|c|c|c|}
\hline $\begin{array}{l}\text { Título DEL } \\
\text { ARTí́culo }\end{array}$ & Autores & $\begin{array}{l}\text { REVISTA DE } \\
\text { PUBLICACIÓN }\end{array}$ & $\begin{array}{c}\text { AÑO DE } \\
\text { PUBLICACIÓN }\end{array}$ & $\begin{array}{c}\text { Total } \\
\text { DE CITAS }\end{array}$ & $\begin{array}{l}\text { Prome- } \\
\text { DIO/AÑO }\end{array}$ \\
\hline $\begin{array}{l}\text { Efectos del accio- } \\
\text { nario activista en } \\
\text { las políticas de }\end{array}$ & $\begin{array}{l}\text { Prado-Lorenzo } \\
\text { José Manuel; Gar- } \\
\text { cía-Sánchez, Isabel } \\
\text { María; gallego- } \\
\text { Álvarez, Isabel }\end{array}$ & $\begin{array}{l}\text { Journal of } \\
\text { Economics, } \\
\text { Finance and } \\
\text { Administrative } \\
\text { Science }\end{array}$ & 2012 & 12 & 1,71 \\
\hline Introducción & Luttuada, Paola & $\begin{array}{l}\text { Cuadernos del } \\
\text { Centro de Estu- } \\
\text { dios en Diseño } \\
\text { y Comunica- } \\
\text { ción. Ensayos }\end{array}$ & 2010 & 12 & 1,33 \\
\hline $\begin{array}{l}\text { Gobierno } \\
\text { Corporativo y } \\
\text { Comunicación } \\
\text { Empresarial ¿Qué } \\
\text { papel cumplen los } \\
\text { directores? }\end{array}$ & $\begin{array}{l}\text { Gutiérrez-García, } \\
\text { Elena }\end{array}$ & Palabra Clave & 2010 & 11 & 1,22 \\
\hline $\begin{array}{l}\text { Legitimacy, cor- } \\
\text { porate governance } \\
\text { and performance } \\
\text { in bm } \$ f \text { bovespa }\end{array}$ & $\begin{array}{l}\text { Rossoni, Luciano; } \\
\text { Machado-da-Silva, } \\
\text { Clovis }\end{array}$ & $\begin{array}{l}\text { Rae-revista de } \\
\text { administracao } \\
\text { de mepresas }\end{array}$ & 2013 & 8 & 1,33 \\
\hline $\begin{array}{l}\text { Empresas fami- } \\
\text { liares; revisao da } \\
\text { literatura desde } \\
\text { una perspectiva } \\
\text { de agencia }\end{array}$ & $\begin{array}{l}\text { González Ferrero, } \\
\text { Maximiliano; } \\
\text { Guzmán Vázquez, } \\
\text { Alexander; Pombo } \\
\text { Bejarano, Carlos; } \\
\text { Trujillo Dávila; } \\
\text { María Andrea }\end{array}$ & $\begin{array}{l}\text { Cuadernos de } \\
\text { Administración }\end{array}$ & 2010 & 6 & 0,67 \\
\hline $\begin{array}{l}\text { Gobierno corpo- } \\
\text { rativo: considera- } \\
\text { ciones y cimientos } \\
\text { teóricos. Corpora- } \\
\text { te Governance: }\end{array}$ & $\begin{array}{l}\text { Ganga Contreras, } \\
\text { Francisco Aníbal; } \\
\text { Vera Garnica, José } \\
\text { Ricardo }\end{array}$ & $\begin{array}{l}\text { Cuadernos de } \\
\text { Administración }\end{array}$ & 2006 & 6 & 0,55 \\
\hline $\begin{array}{l}\text { Gobierno cor- } \\
\text { porativo: Una } \\
\text { comparación de } \\
\text { códigos de gobier- } \\
\text { no en el mundo, } \\
\text { un modelo para } \\
\text { empresas latinoa- } \\
\text { mericanas familia- } \\
\text { res y no }\end{array}$ & $\begin{array}{l}\text { Gómez-Betancurt, } \\
\text { Gonzalo; Zapata- } \\
\text { Cuervo, Natalia }\end{array}$ & Entramado & 2013 & 4 & 0,57 \\
\hline
\end{tabular}




\begin{tabular}{|l|l|l|l|l|l|}
\hline \multicolumn{1}{|c|}{$\begin{array}{c}\text { Título del } \\
\text { ARTículo }\end{array}$} & \multicolumn{1}{|c|}{ Autores } & $\begin{array}{c}\text { Revista de } \\
\text { PUblicación }\end{array}$ & $\begin{array}{c}\text { AÑo DE } \\
\text { PUblicación }\end{array}$ & $\begin{array}{c}\text { Total } \\
\text { DE Citas }\end{array}$ & $\begin{array}{c}\text { Prome- } \\
\text { Dio/Año }\end{array}$ \\
\hline $\begin{array}{l}\text { Supervisores bur- } \\
\text { sátiles, gobierno } \\
\text { corporativo y } \\
\text { cumplimiento de } \\
\text { las NIIF: el caso } \\
\text { de la CNMV }\end{array}$ & $\begin{array}{l}\text { Villanueva García, } \\
\text { José; Zorio Grima, } \\
\text { Ana; García Ben- } \\
\text { au; M. Antonia }\end{array}$ & Innovar & 2015 & 3 & 0,75 \\
\hline $\begin{array}{l}\text { El gobierno cor- } \\
\text { porativo en el } \\
\text { sector público: } \\
\begin{array}{l}\text { Un estudio de las } \\
\text { universidades pú- } \\
\text { blicas españolas }\end{array}\end{array}$ & $\begin{array}{l}\text { Flórez-Parra, Jesús } \\
\text { M. }\end{array}$ & $\begin{array}{l}\text { Cuadernos de } \\
\text { Administración } \\
\text { (Universidad } \\
\text { del Valle) }\end{array}$ & 2013 & 3 & 0,5 \\
\hline
\end{tabular}

Fuente: Web of SCIENCE.

\section{ClasificaCión de los artículos pOR PAlabras Clave}

Las palabras clave o descriptores son términos o frases cortas (lexemas) que permiten clasificar y direccionar las entradas en los sistemas de indexación y de recuperación de la información en las bases de datos de un manuscrito o área temática en particular (González y Salim, 2012). Según las normas APA, las palabras claves suelen ser palabras o frases cortas que deben condensar los temas más importantes que se presentan en el artículo.

Por otro lado, para Guedes y Borschiver (20015), la Ley de Zipf o del Mínimo Esfuerzo consiste en medir la frecuencia de la aparición de las palabras en varios textos, generando una lista ordenada de términos en una disciplina o tema.

En los 90 artículos científicos analizados se han identificado y extraído un total de 449 palabras clave, lo que da un promedio de cinco palabras clave por cada artículo. De estas 449 palabras clave, 165 han sido agrupadas por similitudes, mientras que no se han podido agrupar 284 por ser las mismas muy inusuales. En el cuadro 5 se observan estos datos.

En cuanto a la cantidad de palabras clave, estas varían de una revista científica a otra, pero en la mayoría de los casos oscilan de tres a diez. El rango de las palabras clave de este estudio es de tres a 42. Las normas APA establecen que deben ser alrededor de cinco. 
ANÁLISIS DE LA PRODUCCIÓN CIENTÍFICA SOBRE GOBIERNo CORPORATIVO EN LATINOAMÉRICA Y ESPAÑA

Cuadro 5. Agrupamiento de palabras clave (TOdAs las palabras Clave ESTÁN EN MINÚSCULAS Y SEPARADAS POR PUNTO Y COMA)

\begin{tabular}{|c|c|c|}
\hline $\mathrm{N}^{\circ}$ & PALABRAS ClaVE & PALABRAS CLAVE AGRUPADAS POR SIMILITUd \\
\hline 1 & $\begin{array}{l}\text { gobierno } \\
\text { corporativo }\end{array}$ & $\begin{array}{l}\text { gobiernos corporativos; gobernanza; gobernanza corpo- } \\
\text { rativa; gobernabilidad empresarial; códigos de gobierno } \\
\text { corporativo, códigos }\end{array}$ \\
\hline 2 & $\begin{array}{l}\text { comunicación } \\
\text { corporativa }\end{array}$ & $\begin{array}{l}\text { comunicación empresaria; comunicación estratégica; co- } \\
\text { municación organizacional; comunicación institucional }\end{array}$ \\
\hline 3 & empresa familiar & $\begin{array}{l}\text { empresas de familia; empresas familiares; propiedad } \\
\text { familiar }\end{array}$ \\
\hline 4 & $\begin{array}{l}\text { desempeño } \\
\text { financiero }\end{array}$ & $\begin{array}{l}\text { desempeño empresarial; desempeño; desempeño econó- } \\
\text { mico; economic performance; performance }\end{array}$ \\
\hline 5 & $\begin{array}{l}\text { consejo de } \\
\text { administración }\end{array}$ & $\begin{array}{l}\text { junta directiva; directorio; board of directors; board } \\
\text { composition }\end{array}$ \\
\hline 6 & $\begin{array}{l}\text { responsabilidad } \\
\text { social empresarial }\end{array}$ & $\begin{array}{l}\text { responsabilidad social; responsabilidad social empresa- } \\
\text { ria; corporate social responsability; información sobre } \\
\text { responsabilidad social corporativa }\end{array}$ \\
\hline 7 & $\begin{array}{l}\text { estructura de } \\
\text { propiedad }\end{array}$ & $\begin{array}{l}\text { Estructura de capital; ownership structure; capital pro- } \\
\text { perty structure; concentración de propiedad }\end{array}$ \\
\hline 8 & género & mujer; diversidad de género \\
\hline 9 & grupos de interés & stakeholders; teoría de los stakeholders \\
\hline 10 & teoría de la agencia & \\
\hline 11 & $\begin{array}{l}\text { asimetría de } \\
\text { información }\end{array}$ & información asimétrica \\
\hline 12 & redes sociales & social networks \\
\hline 13 & transparencia & índice de transparencia \\
\hline 14 & dividendos & política de dividendos \\
\hline
\end{tabular}

FUENTE: ElABORACIÓN PROPIA.

Asimismo, se han observado palabras clave que no han podido ser agrupadas por similitud al ser las mismas muy inusuales, genéricas o sin relación directa o indirecta con el concepto o los principios del Gobierno Corporativo. Como ejemplos citamos las siguientes: contabilidad crítica; agency dilema; fraccionamiento de voto; implantación; implementación; DIRCOM; empresa ciudadana; Colombia; México; patrocinio; reemplazos; apercibimiento; adquisición de tierras; Universidades en Latinoamérica; autonomía; precisión; medición del gobierno corporativo; accionariado familiar. 
Lo afirmado anteriormente indica que los autores no están adheridos a un sistema de clasificación estándar de palabras clave con el JEL del Journal of Economic Literature o el Tesaurus de la UNESCO. También significa que los editores de las revistas científicas no obligan a los autores a utilizar algún tipo de estándar.

En el gráfico 8 se expone la frecuencia de aparición o repetición de las palabras clave más usuales. Lógicamente, el término Gobierno Corporativo, con setenta y cuatro apariciones, es la palabra clave con mayor repetición. Las demás se relacionan de manera directa con principios o conceptos del Gobierno Corporativo, tales como Responsabilidad Social Corporativa, Consejo de Administración, estructura de propiedad, dividendos y transparencia.

Gráfico 8. Frecuencia de palabras Clave

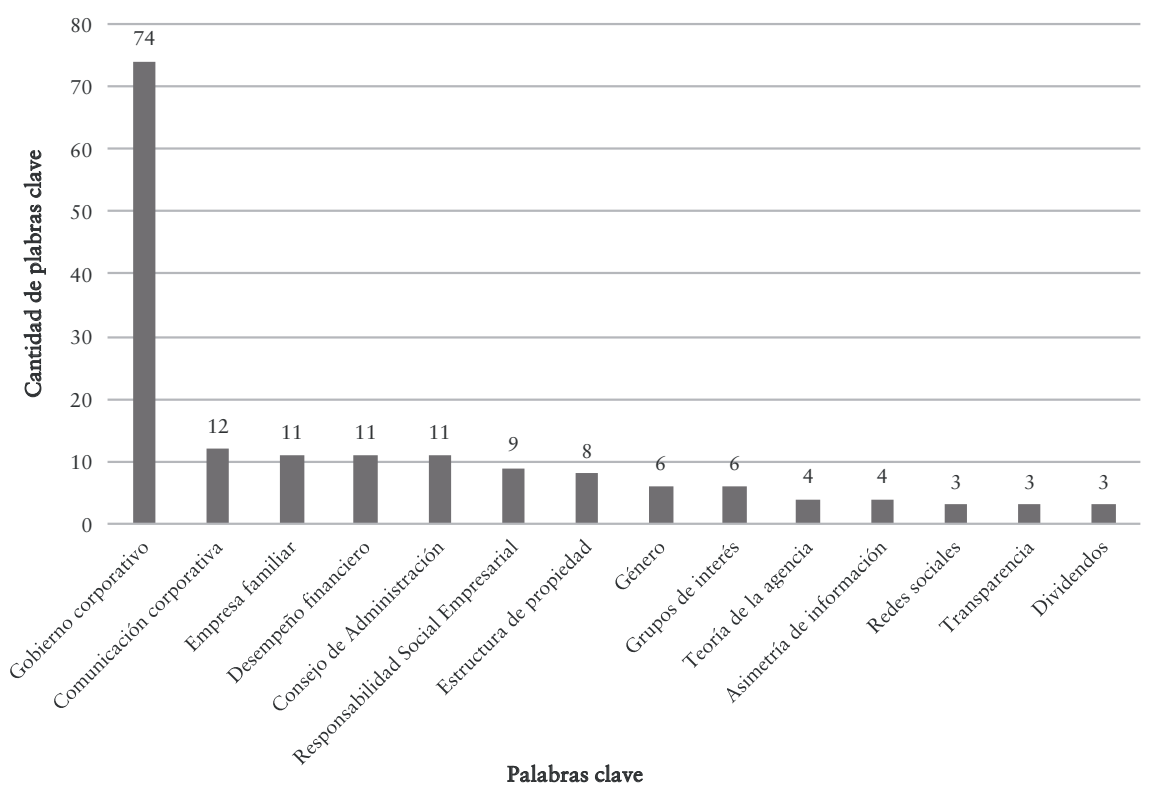

Fuente: Elaboración propia, sobre la base de Web of Science.

A partir de los resultados obtenidos, las palabras clave con repeticiones superiores a ocho y en línea con lo afirmado por Lunkes et al. (2011) son las que suscitan mayor atención de parte de los investigadores y son temas de investigación consolidados del Gobierno Corporativo. Por otra parte, las palabras clave con repeticiones superiores a tres pero 
inferiores a ocho constituyen temas emergentes, aún poco explorados en la región y que potencialmente serán objeto de mayor atención a futuro.

\section{CLASIFICACIÓN DE ARTÍCULOS POR COLABORACIÓN CIENTÍFICA}

Para Alcaide et al. (2014), la colaboración científica es un proceso de interacción entre dos o más individuos con el propósito de lograr el fin común de generar nuevo conocimiento. Por lo tanto, toda revisión de literatura debe incorporar el análisis de la colaboración científica para validar la pertinencia o no de misma (Vivas-Crisol et al., 2012). La colaboración científica es a las ciencias lo que el trabajo en equipos es a las organizaciones.

Para poder estudiar la colaboración científica y su evolución se ha obtenido el número de autores firmantes por cada uno de los 90 artículos analizados. Obsérvese para ello el cuadro 6, en el cual se han agrupado los resultados obtenidos. En total se ha identificado que 201 autores han firmado 90 artículos, siendo el promedio de autores/artículos de 2,333.

Cuadro 6. Colaboración Científica

\begin{tabular}{|l|l|l|}
\hline \multicolumn{1}{|c|}{ Número DE AUTORES FIRMANTES } & \multicolumn{1}{|c|}{$\begin{array}{c}\text { CANTIDAD DE } \\
\text { ARTículOS }\end{array}$} & PORCENTAJES \\
\hline Artículos con un autor firmante & 24 & $27 \%$ \\
\hline Artículos con dos autores firmantes & 34 & $38 \%$ \\
\hline Artículos con tres autores firmantes & 22 & $24 \%$ \\
\hline Artículos con cuatro autores firmantes & 7 & $8 \%$ \\
\hline Artículos con cinco autores firmantes & 3 & $3 \%$ \\
\hline Total artículos & 90 & $100 \%$ \\
\hline
\end{tabular}

Fuente: Elaboración propia, Sobre la base de Web of SCience.

La colaboración científica se verifica cuando dos o más autores son los firmantes de un artículo y como el porcentaje de artículos con dos o más autores firmantes asciende al 77\%, se puede afirmar que existe colaboración científica entre ellos. 


\section{LIMITACIONES Y LÍNEAS FUTURAS DE INVESTIGACIÓN}

Como en todo estudio de producción científica, existen limitaciones, siendo las principales las siguientes: a) se seleccionaron exclusivamente artículos indexados por la base de datos Web of Science y, por lo tanto, pueden existir más artículos publicados sobre el tema investigado en los países de América Latina y España que no fueron seleccionados, y b) no se ha realizado el análisis de la calidad de los artículos seleccionados.

Por otro lado, para Levy y Ellis (2006), citados por Carneiro Moro et al. (2015), la revisión de literatura de un conjunto de artículos permite analizar un determinado tema e identificar tendencias de investigaciones y posibles brechas que podrían resultar en nuevos estudios y descubrimientos. En este aspecto, existen grandes oportunidades de investigaciones futuras tanto en la metodología de investigación que será utilizada como temas que a la fecha han sido poco investigados, entre ellos: transparencia informativa obligatoria y voluntaria; género, redes sociales y rendición de cuentas. Asimismo, faltarían estudios bibliométricos que utilicen minería de textos (Text Mining) o el modelo de categorías Latent Dirichlet Allocation (LDA).

\section{Conclusiones}

El estudio sobre Gobierno Corporativo y temas afines en Latinoamérica y España es incipiente y ofrece grandes oportunidades de investigación futura a los académicos del área. Se ha identificado el predominio de dos métodos de investigación (analítica y experimental) sobre los demás. Es decir, existe concentración en los temas investigados. Además, se verifica un buen grado de colaboración científica. También se ha identificado el mal uso de las palabras clave en los artículos analizados, lo cual indica la necesidad de que los editores y sus respectivos comités editoriales extremen sus controles de calidad en este aspecto.

\section{BibLIOGRAFÍA}

Acosta Palomeque, G. R. (2018). Gobierno Corporativo y Poder desde la perspectiva de la Teoría de Agencia. Ciencias Administrativas, 6, 11.

Berrio Zapata, C. (2008). Revisión Bibliometrica del Concepto de Gobierno Corporativo. Revista Management, XVII, 30, 73-100. 
Carneiro Moro, S. M.; Ribeiro Cortez, P. A. y Ferreira Rita, P. M. R. (2015). Business Intelligence in Banking: a Literature Analysis from 2002 to 2013 using Text Mining and Latent Dirichlet Allocation. Expert Systems with Applications, 42, 3, 1314-1324.

Charreaux, G. (2004). Corporate Governance Theories: From Micro Theories to National Systems Theories. Working paper of FARGO 1041202.

Dallery, T. (2008). Post-Keynesian Theories of the Firm under Financialization. Workshop Financialization: PostKeynesian Approaches. Lille, France.

De Oliveira Neto, J. F.; De Lacerda Moreira, R. y Barbosa Neto, J. E. (2017). Agency Theory: a Study about scientific research in Brazilian Journals. Revista de Gestão, Finanças e Contabilidade, 7, 3, 379-396.

De Oliveira Neto, J.; De Lacerda Moreira, R. y Barbosa Neto, J. (2017). Teoria da agencia: um estudo da producao cientifica nos periodicos Brasileiros. Revista De Gestao, Financas e Contabilidade, 3, 379.

Ferreira Mainardi, C. y De Morán Suárez, M. A. (2011). La Responsabilidad Social Corporativa (RSC) en las bases de datos Scopus y Wos (estudio bibliométrico). Revista EDICIC, 1, 4, 141-160.

González Alcaide, G. y Gómez Ferri, J. (2014). La colaboración científica: principales líneas de investigación y retos de futuro. Revista Española de Documentación Científica, 37 (4): e062. doi: http://dx.doi. org/10.3989/redc.2014.4.1186

González Tous, M. y Mattar V. S. (2012). Las claves de las palabras clave en los artículos científicos. Revista MVZ Córdoba, 17, 2, 2955-2956.

Guedes, V. y Borschiver, S. (2005). bibliometria: uma ferramenta estatística para a gestão da informação e do conhecimento, em sistemas de informação, de comunicação e de avaliação científica e tecnológica. VI Encontro Nacional de Ciencia da Informacao. Salvador, Bahía, Brasil. Informe Cadbury (1992). Inglaterra.

Jensen, M. C. y Meckling, W. H. (1976). Theory of the Firm: Managerial behavior, Agency Costs and Ownership structure. Journal of Financial Economics, 3, 305-360.

Lunkes, R. J.; Ripoll-Feliu, V. M. y Silva da Rosa, F. (2011). Contabilidad de Gestión: un estudio en revistas de Brasil, España y de Lengua España. Revista de Contabilidade e Organizações, 5, 13, 132-150.

Machado Júnior, C.; Saraiva de Souza, M. T.; Palmisano, A.; Abreu Campanário, M. y Dos Santos Parisotto, I. R. (2014). Análise de Viabilidade de Utilizar as Leis da Bibliometria em Diferentes Bases de Pesquisa. XXXVIII Encontro da ANPAD. Rio de Janeiro, Brasil.

Maia, J. L. y Di Serio, L. C. (2017). Governança corporativa e estratégia empresarial: mapeamento bibliométrico da produção na área. Revista Gestão \& Tecnologia, Pedro Leopoldo, 17, 2, 160-185. 
OECD (2015). Principios de Gobierno Corporativo de la OCDE y del G20. Paris: OECD Publishing. http://dx.doi.org/10.1787/9789264259171-es Richart-Ramón, A.; Martínez-Blasco, M. y García-Blandón, J. (2011). Análisis de la producción científica sobre Gobierno Corporativo a través de ISI Web of Science. Revista Española de Documentación Cientifica, 34, 1 79-101. doi: 10.3989/redc.2011.1.776

Sanku Bilas, R. y Moutusi, B. (2013). "Journal of Documentation: a Bibliometric Study». Library Philosophy and Practice (e-journal), 945.

The OECD Principles of Corporate Governance (2004).

Urbizagástegui Alvarado, R. (2002). A Lei de Lotka na bibliometria brasileira. Ci. Inf., Brasília, 31, 2, 14-20.

Vivas-Crisol, L.; Martinez-Blasco, M. y Garcia-Blandón, J. (2012). 20 años de investigación sobre Gobierno Corporativo Internacional. Revista General de Información y Documentación, 22, 267-278. http:// dx.doi.org/10.5209/rev_RGID.2012.v22.39657 


\title{
GOBERNANZA DE LA SUSTENTABILIDAD EN CADENAS DE VALOR INDUSTRIALES EN Córdoba, Argentina"
}

\author{
María Florencia Peretti"* \\ Mónica Buraschi" $i^{* * *}$ \\ Celina N. Amato**** \\ Argentina
}

\section{INTRODUCCIÓN}

Es habitual encontrar en la literatura que la adopción de criterios de sustentabilidad en las organizaciones es resultado de su interacción con los diversos stakeholders o partes interesadas (Freeman, 1984), entre los que se cuentan clientes, proveedores y gobierno, por mencionar algunos. Numerosos autores vinculan a la Responsabilidad Social Empresaria (RSE) con una actitud comprometida hacia sus stakeholders (Dahlsrud, 2006). Sin embargo, identificar al stakeholder relevante es muchas veces un proceso complejo en aquellas actividades que presentan encadenamientos múltiples.

Por su parte, el enfoque de Cadena de Valor (CV) resulta de utilidad cuando se desea representar la complejidad de los procesos productivos actuales a fin de identificar puntos de intervención, lograr la inserción

* Investigación realizada con subsidio de la Secretaría de Ciencia y Tecnología de la Universidad Nacional de Córdoba, período 2016-2017. Córdoba, Argentina.

* Especialista en Ingeniería en Calidad, Universidad Nacional de Córdoba. Correo electrónico: florencia.peretti@unc.edu.ar

*** Magíster en Relaciones Internacionales, Universidad Nacional de Córdoba. Correo electrónico: monica.buraschi@gmail.com

**** Doctora en Ciencias Económicas, Consejo Nacional de Investigaciones Científicas y Técnicas (U. A. Cs. Soc. y Hum.-Universidad Católica de Córdoba). Correo electrónico: amatocelina@hotmail.com 
de las pymes en los procesos productivos, fortalecer el tejido industrial y mejorar la relación entre los sectores público y privado (CEPAL, 2014).

En la literatura sobre CV se distinguen dos enfoques principales: un enfoque horizontal, que se centra en la relación entre las diferentes etapas, los procesos y los actores que intervienen desde la producción hasta el consumo final de un determinado producto, y un enfoque vertical, que se ocupa de temas específicos tales como la eficiencia o la gobernanza (Scott, 2014).

Desde el enfoque horizontal, el concepto de sustentabilidad fue relacionado con el de CV en el ámbito de la logística a través del Sustainable Supply Chain Management o Gestión Sustentable de la Cadena de Suministros, que implica «la gestión de los materiales, la información y los flujos de capital, así como, la cooperación entre empresas a lo largo de la cadena de suministro, a la vez que toman en cuenta los objetivos de las tres dimensiones del desarrollo sostenible, es decir, económica, ambiental y social» (Seuring y Müller, 2008 p. 1700), con el fin de «satisfacer las necesidades de las partes interesadas y mejorar la rentabilidad, la competitividad y la capacidad de recuperación de la organización en el corto y largo plazo» (Ahi y Searcy, 2013, p. 339).

Desde el enfoque vertical, el aspecto de la gobernanza de la CV resulta de especial interés para identificar aquellos eslabones que ejercen el poder de "configurar activamente la distribución de ganancias y riesgos en una industria» (Gereffi, 2014, p. 13), que presumiblemente serán los mismos que determinen los criterios de sustentabilidad de toda la cadena. En este sentido, los tipos de gobernanza según Gereffi, Humphrey y Sturgeon (2005) son: de mercado, modular, relacional, cautiva y de jerarquía.

En este marco, la pregunta de investigación que se busca responder es: ¿cómo influyen la gobernanza y los stakeholders en la adopción de criterios de sustentabilidad en las CV?

Este trabajo tiene como objetivos: a) analizar la influencia de la gobernanza de las CV en la adopción de criterios de sostenibilidad; b) identificar los principales impactos en la sostenibilidad derivados de sus actividades y c) analizar los mecanismos que emplean las empresas y el gobierno para la adopción de dichos criterios.

Las proposiciones ${ }^{1}$ planteadas para el desarrollo de la investigación son las siguientes:

1 Se habla de proposiciones y no de hipótesis dado que se trabaja con metodología cualitativa. 
- P1: El eslabón de la CV que ejerce la gobernanza es el que determina los criterios de sustentabilidad a adoptar por el resto de los eslabones de la cadena.

- P2: La aplicación de criterios de sustentabilidad es afectada por las demandas de los stakeholders y los impactos económicos, sociales y ambientales.

- P3: Los mecanismos más utilizados para garantizar el cumplimiento de los criterios de sustentabilidad se refieren a la exigencia de estándares con auditoría externa.

\section{Metodología}

El modelo de Cadenas Globales de Valor (CGV) (Gereffi, Humphrey y Sturgeon, 2005) busca explicar o predecir cómo los distintos nodos de agregación de valor de una actividad productiva se vinculan dentro de una economía a nivel territorial-espacial. Las cadenas de valor locales y regionales también se encuadran dentro de cadenas de valor globales, por lo que el enfoque es aplicable en cualquiera de estas escalas, sea esta local, regional o global (Sturgeon, 2011). La metodología utilizada por los autores de CGV es naturalmente de tipo cualitativa, ya que cada CV comprende un caso de estudio que se analiza de manera descriptiva.

Existen diversos criterios para la selección de los casos. Para la presente investigación fueron seleccionados especialmente para reflejar los contrastes entre cadenas globales y locales en materia de gobernanza de la sustentabilidad. Así, se eligieron dos cadenas globales (embotelladoras de gaseosas y automotriz) y dos cadenas locales (hortícola y maderera).

Los casos se abordaron mediante una metodología común de análisis que integra las propuestas de Gereffi y Fernández-Stark (2011), CEPAL (2014) y Kaplinsky y Morris (2010) para caracterizar las CV y su gobernanza, consistente de tres etapas: a) descripción de la CV y su gobernanza; b) identificación de los principales impactos de sustentabilidad y c) relevamiento de los mecanismos por los cuales se transmiten los criterios de sustentabilidad a lo largo de la CV.

Para ello se efectuaron entrevistas a diversos actores de la cadena y se realizó investigación documental sobre la normativa vigente, los reportes de sustentabilidad publicados por las empresas líderes y diversas fuentes institucionales relacionadas con cada una de las cadenas. 


\section{Resultados}

Se resumen a continuación los principales aspectos relevados para cada uno de los casos, los cuales fueron luego sistematizados e integrados en un cuadro comparativo.

\section{Caso i: Embotelladoras de bebidas gaseosas en Córdoba, Argentina}

La CV del embotellado de bebidas gaseosas en Córdoba, Argentina, está configurada principalmente por las características del mercado interno (dado que la exportación es escasa) y conformada por dos grandes grupos de empresas, según elaboren marcas locales o globales. Existen unas veintitrés plantas embotelladoras, destacándose las empresas líderes del mercado Coca-Cola y Pepsi con nueve y seis plantas, respectivamente. Con relación a las principales embotelladoras de marcas nacionales, Pritty es la más importante y posee dos plantas. Tres de estas plantas embotelladoras más importantes se encuentran en la Provincia de Córdoba, donde se centra este caso de estudio.

En el cuadro 1 se detallan los actores clave en las cadenas de valor global de las empresas de marcas internacionales.

\section{Cuadro i. Actores clave en las CADENAS globales de VAlor DE LAS EMBOTELLADORAS}

\begin{tabular}{|l|}
\hline \multicolumn{1}{|c|}{ ACTORES CLAVE EN LAS CADENAS DE LAS EMBOTELLADORAS } \\
\hline Empresas líderes (multinacionales con casa matriz en el extranjero) \\
\hline Embotelladoras (subsidiarias de las primeras, con asiento en Argentina) \\
\hline $\begin{array}{l}\text { Proveedores (entre los que se cuenta también a la empresa líder que provee del } \\
\text { jarabe básico para la elaboración de algunos de los productos) }\end{array}$ \\
\hline Distribuidores \\
\hline Clientes (grandes superficies como supermercados, hipermercados, mayoristas) \\
\hline Consumidores finales \\
\hline
\end{tabular}

FUENTE: ElABORACIÓN PROPIA.

Esta cadena posee rasgos de tipo cautiva, caracterizada por un alto seguimiento y control por parte de las empresas líderes (Peretti, Amato y Buraschi, 2017). Se observa que la empresa líder logra permear la adopción de criterios de sostenibilidad en la totalidad de su cadena 
debido al poder que ejerce. En la gobernanza de la cadena predomina la influencia de las empresas líderes de manera individual, sin encontrarse iniciativas de cooperación de relevancia ni actores externos a la cadena que tengan una influencia determinante en la adopción de criterios de sustentabilidad, más allá de una regulación ambiental y laboral básica.

Con relación a los principales impactos relacionados con la sustentabilidad, la regulación ambiental que enfrenta la CGV del embotellado de gaseosas se refiere principalmente a la sanidad del producto y al tratamiento de residuos, es decir, los impactos en el eslabón de producción. Todos estos aspectos son regulados y certificados por la propia empresa líder, que establece protocolos con los parámetros mínimos exigidos relacionados con cada uno de ellos para poder operar como embotelladora de la marca.

También para el caso de Investigación y Desarrollo existen impactos importantes, a cargo de la empresa líder, relacionados con nuevas tecnologías de envases y empaques primordialmente.

En el caso de los proveedores, la provisión del jarabe es realizada por la casa matriz, quien debe tener en cuenta las consideraciones sobre los efectos en la salud. Otro de los insumos esenciales del proceso, el agua, si bien no es provisto por la empresa líder, sino por las jurisdicciones del sitio donde opera la planta, debe cumplir con una serie de criterios y especificaciones relacionados con la sustentabilidad que vienen dados por la casa matriz.

También la CGV se enfrenta a la ausencia de normativas y leyes en Argentina en algunos aspectos medioambientales, lo cual genera diferencias importantes entre el objetivo de la casa matriz y los de la subsidiaria, como es el caso de los envases cuando se transforman en "productos fuera de uso" y los sistemas de logística inversa asociados (Amato, 2015). Estos aspectos que no han sido todavía reglamentados quedan en el ámbito voluntario de las empresas.

En lo que respecta a impactos en otros stakeholders, las gaseosas se encuentran en el centro de un debate mundial liderado por la Organización Mundial de la Salud (OMS) acerca de la responsabilidad de las bebidas azucaradas en la epidemia de la obesidad y otras enfermedades asociadas.

En cuanto a los mecanismos para transmisión de la sustentabilidad, al ser la CGV del embotellado de gaseosas de tipo cautiva, el poder que ejerce la empresa líder sobre el resto de la cadena se observa también al analizar las estrategias o mecanismos de sustentabilidad. Puntualmente en el caso estudiado existe un importante grado de asimetría de poder 
entre la empresa líder y las subsidiarias, ejerciendo la primera un control significativo en diversos aspectos que atañen a la sustentabilidad.

Este control se perfecciona a través de diversas estrategias de largo plazo que se traducen en planes y programas de mediano y corto plazo en las subsidiarias para la incorporación de los preceptos establecidos desde la compañía líder (incluso desde la declaración de visión y misión de cada una de las empresas).

Uno de los medios de comunicación de estos mecanismos son los reportes de sustentabilidad, en los que se pudo observar que los lineamientos que se establecen en la casa matriz son seguidos y respetados por las subsidiarias locales. En aquellos aspectos cuya gestión reviste un mayor nivel de complejidad y que no se condicen con las prioridades del entorno local, es la empresa líder quien se pone al frente de su cumplimiento. En algunos casos, las subsidiarias locales reciben las acciones a modo de manual a seguir, como por ejemplo en los principios rectores para proveedores, y en otros casos la subsidiaria directamente no aplica o no reporta acciones, como en lo que respecta a trabajo infantil o esclavo.

\section{CASO 2: INDUSTRIA AUTOMOTRIZ Y AUTOPARTISTA en Córdoba, Argentina}

El sector automotriz está caracterizado por la reconversión productiva de la década de los noventa, donde desaparecieron las empresas nacionales y las multinacionales tomaron el control generando una estrategia de CV para el Mercosur. Es así que hay un fuerte comercio intrasectorial, donde distintos eslabones de la cadena de producción del mismo vehículo se van realizando alternadamente cruzando la frontera Argentina-Brasil varias veces. Las ventas están orientadas al mercado interno de la zona.

La industria trabaja íntimamente con el sector autopartista, siendo esta relación de carácter simbiótica. Este sector, a diferencia, se caracteriza por empresas locales de menor tamaño, en su mayoría mipymes (micro, pequeñas y medianas empresas).

En el cuadro 2 se destacan los principales eslabones de la CGV de la industria. 
CUAdro 2. Eslabones de LA CGV DE LA INDUSTRIA AUTOMOTRIZ y AUTOPARTISTA

\begin{tabular}{|l|}
\hline \multicolumn{1}{|c|}{ EsLABONES EN LA CGV AUTOMOTRIZ Y AUTOPARTISTA } \\
\hline $\begin{array}{l}\text { Proveedores de insumos tales como el acero, aluminio, productos plásticos y } \\
\text { petroquímicos, vidrio, caucho, etc. }\end{array}$ \\
\hline $\begin{array}{l}\text { Empresas autopartistas, cuya función es transformar los insumos para la ela- } \\
\text { boración de partes, piezas y sistemas. }\end{array}$ \\
\hline $\begin{array}{l}\text { Empresas terminales, encargadas de las actividades de ensamblaje y termina- } \\
\text { ción de los vehículos automotores (automóviles, utilitarios, furgones, camione- } \\
\text { tas, transporte de carga y de pasajeros). }\end{array}$ \\
\hline Clientes: mercado externo (exportación) o interno (concesionarios). \\
\hline Consumidores finales \\
\hline
\end{tabular}

Fuente: Elaboración PROPIA.

Las empresas del sector automotor en Argentina presentan rasgos de cadena cautiva (Amato, Romero y García, 2016). Las terminales ejercen un control significativo sobre la producción, introduciendo exigencias específicas para la producción de cada pieza o parte a la industria autopartista. Se observa una gran asimetría de poder entre estas terminales y sus proveedoras, que son en general mipymes y, por lo tanto, reciben una gran cantidad de auditorías y controles por parte de las empresas terminales. El intercambio del conocimiento se centra en la mejora de la eficiencia, en especial, en cuestiones de impacto ambiental.

En el caso de las empresas del sector autopartista, estas tienen una gran fragmentación explicada a través de la cercanía con las terminales. Esta división permite la coexistencia de eslabones fuertes y débiles en la misma cadena. Las más débiles son las mipymes, que tienen una relación indirecta con las terminales y que abastecen piezas básicas con menor tecnología, con condiciones laborales más precarias que en el resto de la cadena. En el medio están los proveedores con relación directa a las terminales, pero con capacidades de diseño e innovación más limitado. Por otro lado, hay proveedores globales que abastecen a las terminales los conjuntos de piezas, siguiendo órdenes detalladas, pero usando tecnología propia.

A su vez, las empresas terminales siguen los requerimientos de las casas matrices (extranjeras), que adquieren la función de empresas líderes en el marco de la CGV de la industria automotriz, ejerciendo la gobernanza de la sustentabilidad. Estas se rigen por los marcos 
normativos de sus países en materia de sustentabilidad y de las organizaciones internacionales de las que forman parte.

En relación con los impactos relacionados con la sustentabilidad, tres aspectos son fundamentales en el análisis de la actividad de la industria automotriz (e indirectamente en la industria autopartista): la cuestión ambiental en general, la eficiencia energética en particular y la seguridad.

Los problemas ambientales a nivel global han motivado la adopción de estándares cada vez más estrictos en materia de eficiencia energética y emisiones de contaminantes, lo que impone retos a la industria automotriz, que se traducen en oportunidades para su transformación estructural y desarrollo hacia nuevas tecnologías que permitan mejorar la eficiencia energética de los vehículos.

La dimensión social de la sustentabilidad se relaciona principalmente con la seguridad. La Unión Europea (UE), por ejemplo, obliga a los fabricantes a que diseñen los vehículos futuros teniendo como objetivo reducir al mínimo las víctimas mortales en los accidentes en que se ven involucrados los peatones, factor que influirá en el diseño de los vehículos en todo el mundo, dado que la UE forma parte del mercado de vehículos fabricados en la mayor parte de los países y que la legislación relativa a la seguridad y a las emisiones tiende a converger en el plano nacional e internacional.

En cuanto a los mecanismos de transmisión de los criterios de sustentabilidad, en el caso de las empresas automotrices las casas matrices (empresas líderes) tienen un rol fundamental en el desarrollo de la estrategia corporativa a nivel global, inversión en I+D, control de calidad y homologación de partes, piezas y accesorios de los vehículos, entre otras. Esos son los mecanismos utilizados para la transmisión de los criterios a las terminales argentinas.

En el caso de las empresas autopartistas, entre los mecanismos utilizados por las terminales para la transmisión de criterios de sustentabilidad se encuentran auditorías, exigencia de requisitos, capacitación, transferencia de recursos y otros.

También se pueden mencionar mecanismos de otros actores en relación con la sustentabilidad de la cadena, que se vinculan con la gobernanza económica que ejerce el Estado argentino en esta CV. A nivel nacional, se puede destacar que en el año 2016 se sancionó en Argentina la Ley $\mathrm{N}^{\circ} 27.263$ de fortalecimiento del autopartismo, con 
el cual se establecieron una serie de beneficios fiscales a las empresas que cumplan con el contenido mínimo nacional de autopartes; también, en 2017, el gobierno reglamentó la reducción y la eliminación de los aranceles de importación para autos híbridos, eléctricos y aquellos propulsados por celdas de combustible; otra medida que tendrá impacto en el sector, relacionada con el pilar social de la sustentabilidad, es la implementación del control electrónico de estabilidad, un dispositivo de seguridad recomendado por la OMS en el año 2012 y que en Argentina aún está en vías de ser legislado.

A nivel internacional, existen otras organizaciones que influyen directamente en las decisiones de las casas matrices y que se transfieren a las terminales locales, en relación con la sustentabilidad; se puede mencionar a Drive Sustainability (grupo de empresas en el que participan las automotrices líderes mundiales, facilitado por CSR Europe), Automotive Industry Action Group (AIAG), European Automobile Manufacturers Association (ACEA), entre las más importantes.

\section{Caso 3: Sector hortícola de la CiUdad de Córdoba, Argentina}

La actividad hortícola en la Argentina se desarrolla sobre una superficie de 250 mil hectáreas y logra una producción anual que supera los 5 millones de toneladas, generando empleo directo a más de 200 mil personas y de manera indirecta a un número importante de trabajadores involucrados en la industria de la maquinaria agrícola, agroquímicos, herramientas, materiales de embalaje, plásticos, transporte y distribución (mayorista y minorista).

Los productores hortícolas de la ciudad de Córdoba han venido enfrentando una serie de problemas que provocaron una declinación en la producción, entre ellos, el avance inmobiliario (que elevó el valor de las tierras y corrió la frontera urbana) y la falta de infraestructura, obligando a muchos productores a migrar hacia otras zonas productivas o bien dedicarse a otras actividades (Ortiz y Peretti, 2016).

En el cuadro 3 se destacan los principales eslabones de la CV de esta industria. 
Cuadro 3. Eslabones de la CV hortícola

\begin{tabular}{|l|}
\hline \multicolumn{1}{|c|}{ EsLABONES DE LA CV HoRTícola } \\
\hline $\begin{array}{l}\text { Establecimientos de producción: preparación del suelo, desmalezamiento, } \\
\text { riego y cosecha. Todas estas etapas están atravesadas por controles sanita- } \\
\text { rios y de calidad. }\end{array}$ \\
\hline $\begin{array}{l}\text { Plantas procesadoras y envasadoras: comercialización de hortalizas lavadas } \\
\text { y cortadas, listas para consumir. }\end{array}$ \\
\hline $\begin{array}{l}\text { Mercado de frutas y verduras donde se concentra la producción de todo el } \\
\text { cinturón verde de la Ciudad de Córdoba, tanto las frutas y verduras en fres- } \\
\text { co como de las verduras procesadas. }\end{array}$ \\
\hline $\begin{array}{l}\text { Comercios minoristas: verdulerías, restaurantes y Comercios mayoristas: su- } \\
\text { permercados, hipermercados. Acercan el producto hasta el consumidor final. }\end{array}$ \\
\hline Consumidores finales.
\end{tabular}

FUENTE: ELABORACIÓN PROPIA.

La gobernanza de esta CV es de tipo de mercado, en la cual el regulador de las relaciones es el precio y el costo por cambiar la relación con otro proveedor es bajo. Está liderada por los grandes comercios mayoristas que utilizan su poder para fijar precios y políticas de entrega, tales como el abastecimiento continuo o el transporte con cámaras de frío, lo que aumenta los costos del productor hortícola.

Con respecto a los principales impactos de la sustentabilidad, en la dimensión social se destaca una alta participación de la mujer en el trabajo, especialmente en la etapa de cosecha. La labor de quienes producen no está compensada con un salario justo en relación a sus esfuerzos. La fuerza laboral está compuesta por algunos profesionales (ingenieros agrónomos, biólogos) que participan en diversos programas de capacitación e investigación, pero la mano de obra en sí disminuye a medida que desaparece la cuarta generación que enseñaba este oficio a sus descendientes.

La industria produce algunos impactos ambientales positivos sobre los recursos naturales. En la ciudad de Córdoba, la actividad hortícola se concentra en los cinturones verdes norte y sur situados en zonas rurales 
que son considerados también los pulmones de la ciudad. El valor de la biodiversidad está dado por el ecosistema que predomina, como la baja densidad de la población, entre otros. Debemos destacar que en este sector los campos están rodeados por cortinas rompe vientos formadas por árboles que sirven de cerca y reparo, lo que crea sitios de diversidad biológica animal y vegetal.

En cuanto a impactos ambientales negativos, los insumos más cuestionados en la etapa de siembra son los plaguicidas, mientras que en la etapa de recolección y comercialización se utilizan cajones de medida estándar de plástico; otras hortalizas se comercializan en fardos, por lo que se utiliza hilo plástico o mimbre para atarlos. La actividad productiva no demanda energía eléctrica, que solo se utiliza para las instalaciones donde se realiza la preparación, embalaje o procesamiento de las hortalizas y para las cámaras de frío. Por otra parte, el agua es un recurso crítico para la actividad económica y se utiliza en forma intensiva para el riego.

En cuanto a los mecanismos de transmisión de criterios de sustentabilidad, el Estado Nacional los establece a través de diversas leyes. El Servicio Nacional de Sanidad y Calidad Agroalimentaria (SENASA) es la autoridad de aplicación, que interviene regulando y auditando el cumplimiento de las numerosas normativas de seguridad agroalimentaria, tanto para las actividades de producción de frutas y hortalizas como para las actividades de procesamiento y empaque de las mismas. También este organismo regula el cumplimiento de la Ley $\mathrm{N}^{\circ} 25.127$ de Producción Ecológica, Biológica u Orgánica, la cual promueve un marco sustentable para dicha producción mediante el manejo racional de los recursos naturales y sin la utilización de productos de síntesis química (herbicidas, fertilizantes, pesticidas) u otros de efecto tóxico real o potencial para la salud humana. Esta norma establece además un sistema de certificación para la producción que se considere ecológica, biológica u orgánica.

La gobernanza de la sustentabilidad es compartida con el gobierno municipal de la ciudad de Córdoba para los mercados concentradores mayoristas a través de ordenanzas que regulan verdulerías y ferias. Un caso especial lo constituyen las grandes cadenas de supermercados en las cuales no se verifican acciones de sustentabilidad respecto a las hortalizas. En el eslabón de envasado y procesamiento se agregan además otras normas de calidad. 


\section{Caso 4: Sector maderero en valle de Punilla}

La industria forestal-industrial de Argentina enfrenta a partir de 2013 una etapa de contracción, producto de la apertura de las importaciones y de una reducción en el consumo. Las empresas que han logrado permanecer en el mercado del mueble compiten a través de la calidad, del aprovechamiento de nichos o de nuevos canales de venta como Internet (FAIMA, 2018).

El estudio de esta cadena se focalizó en el análisis de las carpinterías ubicadas en la localidad de Valle Hermoso, provincia de Córdoba. La región tiene una gran actividad turística, la cual impulsa también a la construcción, especialmente en lo que se refiere a cabañas de madera y casas prefabricadas.

La cadena es corta; cuenta con solo tres eslabones principales (Mondino y Buraschi, 2016). La misma se detalla en el cuadro 4.

\section{Cuadro 4. Eslabones de la CV de la madera}

Eslabones DE LA CV DE LA MADERA

Aserraderos: el principal aserradero es Lendaro, de Valle Hermoso, quien obtiene la madera a partir de la deforestación local. Se ocupa de la extracción, corte y transporte de los árboles, principalmente ciprés y olmo. Otros proveedores están radicados en la provincia de Misiones, en el noreste del país, y proveen principalmente madera de eucaliptus y pino elliotis.

Carpinterías: existen tres carpinterías importantes, que realizan trabajos de envergadura, y otras tres que realizan trabajos menores. Se producen muebles rústicos de ciprés, cabañas de eucaliptus y preparación de tablones y retazos a pedido. Se trata de micro y pequeñas empresas familiares que tienen menos de diez empleados y trabajan a un nivel de subsistencia.

Clientes: son principalmente dueños de cabañas y complejos turísticos radicados en la zona y en segundo lugar los turistas. Las carpinterías pequeñas son a su vez clientes de las carpinterías grandes, a quienes les compran la madera semi-procesada.

Fuente: ELABORACión PROPia.

La gobernanza de la cadena es de mercado, ejercida por los proveedores, quienes determinan el costo y calidad de los materiales y los 
trasladan a lo largo de la cadena. El principal costo del aserradero local es el corte de la madera. Una de las carpinterías intentó integrarse verticalmente incorporando la actividad de corte mediante una máquina propia, pero no pudo resolver los inconvenientes que le proporcionaba esta tecnología, más rudimentaria. Con respecto a los proveedores de Misiones, el principal costo es el flete, ya que la distancia a cubrir supera los mil kilómetros. Este costo se reduce realizando menos cantidad de pedidos de mayor volumen, pero a costa de una mayor demora en las entregas. Ambas situaciones ejemplifican la configuración de poder de la cadena en torno al primer eslabón.

Con relación a la identificación de los principales impactos de la sustentabilidad, en lo que se refiere a la dimensión ambiental están dados por la deforestación y la generación de residuos. Este impacto se encuentra atenuado en la cadena bajo estudio, ya que la mayor parte de las maderas que se utilizan son especies introducidas. La generación de residuos implica tres clases de desperdicios: los retazos de leña, la viruta y el aserrín. Los retazos de leña son en general reutilizados en artesanías o reciclados como leña para calefacción de las propias empresas. La viruta es aprovechada por los lugareños para acondicionar los corrales de sus animales, pero muchas veces queda acumulada largos períodos hasta que es retirada. El aserrín es reutilizado en talleres mecánicos para la absorción de grasas en los pisos, o como abono para las plantas.

Con respecto a la dimensión social, el principal impacto está dado por las precarias condiciones de trabajo que caracterizan la actividad. En la cadena analizada los galpones son pequeños, con techos de chapa y contrapiso, poca iluminación y ventilación. Solo una de las carpinterías cuenta con un local de exposición y venta de muebles rústicos. En general, las máquinas son antiguas y no hay extractores de polvillo; los operarios no utilizan protectores auditivos ni mascarillas. La inhalación de partículas representa un riesgo serio de salud para los trabajadores.

En cuanto a los mecanismos de transmisión de criterios de sustentabilidad, a nivel nacional, la gobernanza de la sustentabilidad de la industria maderera es desempeñada por la Federación Argentina de la Industria Maderera y Afines (FAIMA) en la cual se encuentran representados, a través de sus veintisiete cámaras, los aserraderos, carpinterías, productores de aberturas, maderas para la construcción y otros. Su principal función es brindar representación gremial ante el gobierno, dar servicio a los recursos humanos (capacitación técnica, 
mejoramiento social y económico), estimular el desarrollo industrial en foros regionales e internacionales, promover nuevos mercados y contribuir a la preservación del medio ambiente. A partir de 2010 se implementó el Sistema Argentino de Certificación Forestal (CERFOAR), que está administrado por la FAIMA. Bajo esta certificación, un tercero audita que la gestión de una superficie forestal implementada por un productor se ajuste a los requisitos establecidos en las normas. La cadena bajo estudio no participa de estos mecanismos, ya que el aserradero local no cuenta con certificación y ninguna de las empresas intervinientes se encuentra afiliada a la FAIMA.

La Municipalidad de Valle Hermoso regula a través de sus ordenanzas cuestiones de sustentabilidad relacionadas con la deforestación, uno de los principales impactos ambientales de esta $\mathrm{CV}$. $\mathrm{Al}$ respecto, limita la superficie edificable hasta el $40 \%$ del terreno y las clases de árboles a deforestar, defendiendo el cuidado de árboles nativos (molle, tala, algarrobo) y permitiendo la extracción de especies invasoras (siempreverde, olmo, paraíso, ciprés, mora, acacia). El gobierno municipal también se ocupa de regular el otro gran impacto ambiental de esta $\mathrm{CV}$, que es la gestión de residuos, exigiendo a las empresas que no acumulen cantidades excesivas de desperdicios dentro de los predios y que se hagan cargo de la limpieza de los espacios públicos que utilizan.

\section{INTEGRACIÓN DE LOS RESULTADOS}

A los fines de facilitar la comparación entre los casos, se elaboró el cuadro 5 con las principales categorías analizadas.

De la misma se desprende que se verifican las proposiciones planteadas inicialmente. Las CV analizadas se corresponden con dos tipos de gobernanza: las cadenas globales poseen una gobernanza cautiva, mientras que las dos cadenas locales tienen una gobernanza de mercado. 
Cuadro 5. Comparación de la gobernanza de la SUSTENTABILIDAd EN LAS CADENAS DE VALOR OBJETO DE ESTUDIO.

\begin{tabular}{|c|c|c|c|c|}
\hline Caso & $\begin{array}{l}\text { EMBOTELLADO- } \\
\text { RAS DE GASEOSAS }\end{array}$ & $\begin{array}{c}\text { AUTOMOTRIZ } \\
\text { Y AUTOPARTISTA }\end{array}$ & Hortícola & MADERERA \\
\hline $\begin{array}{l}\text { Alcance } \\
\text { geográfico de } \\
\text { la cadena }\end{array}$ & Global & Global & $\begin{array}{l}\text { Local (Ciudad de } \\
\text { Córdoba, Argen- } \\
\text { tina) }\end{array}$ & $\begin{array}{l}\text { Local (Valle de } \\
\text { Punilla, Argen- } \\
\text { tina) }\end{array}$ \\
\hline $\begin{array}{l}\text { Eslabones } \\
\text { identificados }\end{array}$ & $\begin{array}{l}\text { 1. Empresas } \\
\text { líderes } \\
\text { (casa matriz) } \\
\text { 2. Embotella- } \\
\text { doras } \\
\text { (subsidiarias) } \\
\text { 3. Proveedores } \\
\text { 4. Distribuidores } \\
\text { 5. Clientes } \\
\text { 6. Consumido- } \\
\text { res finales }\end{array}$ & $\begin{array}{l}\text { 1. Proveedores de } \\
\text { insumos } \\
\text { 2. Empresas auto- } \\
\text { partistas } \\
\text { 3.Empresas termi- } \\
\text { nales } \\
\text { 4.Destino: expor- } \\
\text { tación o concesio- } \\
\text { narios } \\
\text { 5. Consumidores } \\
\text { finales }\end{array}$ & $\begin{array}{l}\text { 1. Pequeños pro- } \\
\text { ductores } \\
\text { 2. Plantas procesa- } \\
\text { doras } \\
\text { 3. Mercado de } \\
\text { frutas } \\
\text { y verduras } \\
\text { 4. Comercios mi- } \\
\text { noristas y mayo- } \\
\text { ristas } \\
\text { 5. Consumidores } \\
\text { finales }\end{array}$ & $\begin{array}{l}\text { 1. Aserraderos } \\
\text { locales y de } \\
\text { Misiones } \\
\text { 2. Carpinterías } \\
\text { 3. Clientes }\end{array}$ \\
\hline $\begin{array}{l}\text { Otros stake- } \\
\text { holders que } \\
\text { inciden en la } \\
\text { cadena }\end{array}$ & OMS & $\begin{array}{l}\text { Gobierno } \\
\text { Organizaciones } \\
\text { internacionales } \\
\text { OMS }\end{array}$ & $\begin{array}{l}\text { SENASA } \\
\text { Municipalidad de } \\
\text { Córdoba }\end{array}$ & $\begin{array}{l}\text { FAIMA } \\
\text { Municipalidad } \\
\text { de Valle Her- } \\
\text { moso }\end{array}$ \\
\hline $\begin{array}{l}\text { Tipo de } \\
\text { gobernanza }\end{array}$ & Cautiva & Cautiva & De mercado & De mercado \\
\hline $\begin{array}{l}\text { Principales } \\
\text { impactos de } \\
\text { sustentabilidad }\end{array}$ & $\begin{array}{l}\text { Sanidad del pro- } \\
\text { ducto } \\
\text { Uso intensivo de } \\
\text { agua } \\
\text { Tratamiento de } \\
\text { residuos } \\
\text { Producto fuera } \\
\text { de uso (envase) } \\
\text { Efectos en la } \\
\text { salud }\end{array}$ & $\begin{array}{l}\text { Eficiencia energé- } \\
\text { tica y emisiones de } \\
\text { contaminantes } \\
\text { Seguridad }\end{array}$ & $\begin{array}{l}\text { Plaguicidas } \\
\text { Desplazamiento de } \\
\text { mano de obra } \\
\text { Condiciones de } \\
\text { trabajo precarias } \\
\text { Uso intensivo de } \\
\text { agua }\end{array}$ & $\begin{array}{l}\text { Deforestación } \\
\text { Residuos } \\
\text { Condiciones } \\
\text { de trabajo pre- } \\
\text { carias } \\
\text { Efectos nocivos } \\
\text { para la salud }\end{array}$ \\
\hline $\begin{array}{l}\text { Actor que } \\
\text { ejerce la } \\
\text { gobernanza } \\
\text { económica }\end{array}$ & Empresa líder & $\begin{array}{l}\text { Empresa líder } \\
\text { Gobierno nacional }\end{array}$ & $\begin{array}{l}\text { Supermercados y } \\
\text { grandes superficies }\end{array}$ & Aserraderos \\
\hline
\end{tabular}




\begin{tabular}{|c|c|c|c|c|}
\hline Caso & $\begin{array}{l}\text { EMBOTELLADO- } \\
\text { RAS DE GASEOSAS }\end{array}$ & $\begin{array}{c}\text { AUTOMOTRIZ } \\
\text { Y AUTOPARTISTA }\end{array}$ & Hortícola & MADERERA \\
\hline $\begin{array}{l}\text { Actor que ejer- } \\
\text { ce la gobernan- } \\
\text { za de la susten- } \\
\text { tabilidad }\end{array}$ & Empresa líder & $\begin{array}{l}\text { Empresa líder } \\
\text { Gobierno (nacio- } \\
\text { nal y extranjeros) } \\
\text { Organizaciones } \\
\text { internacionales: } \\
\text { Drive Sustainabili- } \\
\text { ty, AIAG, ACEA }\end{array}$ & $\begin{array}{l}\text { SENASA } \\
\text { Gobierno provin- } \\
\text { cial y municipal }\end{array}$ & $\begin{array}{l}\text { FAIMA } \\
\text { Municipalidad } \\
\text { de Valle Her- } \\
\text { moso }\end{array}$ \\
\hline Mecanismos & $\begin{array}{l}\text { Estrategias, pla- } \\
\text { nes y programas } \\
\text { de la empresa } \\
\text { líder } \\
\text { Reportes de } \\
\text { sustentabilidad }\end{array}$ & $\begin{array}{l}\text { Estrategias, planes } \\
\text { y programas de la } \\
\text { empresa líder } \\
\text { Leyes nacionales } \\
\text { Estándares y } \\
\text { normas de organi- } \\
\text { zaciones interna- } \\
\text { cionales }\end{array}$ & $\begin{array}{l}\text { Normativa de } \\
\text { seguridad agroali- } \\
\text { mentaria } \\
\text { Leyes Nacionales } \\
\text { Normas de Cali- } \\
\text { dad }\end{array}$ & $\begin{array}{l}\text { Ordenanzas } \\
\text { sobre urbaniza- } \\
\text { ción, deforesta- } \\
\text { ción y manejo } \\
\text { de residuos } \\
\text { Capacitación } \\
\text { técnica } \\
\text { Certificaciones } \\
\text { específicas }\end{array}$ \\
\hline
\end{tabular}

FUENTE: ELABORACión PROPIA

En los casos de CGV cautivas, el eslabón que ejerce la gobernanza económica es la empresa propietaria de la marca, radicada en países desarrollados, quien también ejerce la gobernanza de la sustentabilidad. En el caso de la CV automotriz, también el Estado influye en esta gobernanza por su poder normativo respecto de beneficios económicos para estas firmas. En las cadenas locales de tipo de mercado, la gobernanza de la sustentabilidad es ejercida por el Estado y por diversas iniciativas de cooperación, mientras que otros eslabones tienen a su cargo la gobernanza económica.

Los actores que ejercen la gobernanza de la sustentabilidad responden en diferente medida a las demandas de los stakeholders y a los impactos de sustentabilidad de la actividad correspondiente. En las CGV es muy amplia la gama de asuntos considerados en los criterios de sustentabilidad, mientras que en las cadenas locales la gobernanza de la sustentabilidad se focaliza en unos pocos temas, dejando muchas demandas e impactos sin atender.

Con respecto a los mecanismos a través de los cuales se transmiten los criterios de sustentabilidad a lo largo de la cadena, en las CGV se recurre principalmente a la aplicación de estándares con auditoría externa con capacitación específica por parte de la empresa líder o a 
mecanismos de acción propios de las firmas, como estrategias. En las cadenas locales, el gobierno aplica mecanismos normativos (leyes y ordenanzas), mientras que las iniciativas de cooperación recurren a sugerencias de buenas prácticas y certificaciones que aún no tienen un grado de aceptación suficiente.

\section{Conclusiones}

A partir de los casos analizados, se puede inferir que las cadenas globales de valor son más exitosas que las locales en la transmisión de los criterios de sustentabilidad, ya que tienen en cuenta más demandas de sus stakeholders e impactos de sustentabilidad y poseen mecanismos más evolucionados para garantizar el cumplimiento de estos criterios a lo largo de la cadena. El fundamento podría asociarse a una motivación utilitarista de la sustentabilidad a través de la cual la empresa líder obtiene un beneficio de imagen para su marca global. Pero también es evidente que la participación en CGV pone a la industria completa en un escenario mundial en donde surgen otros actores con demandas y exigencias específicas relacionadas con la sustentabilidad, como es el caso de los organismos internacionales (como OMS) y organizaciones específicas (como Drive Sustainability en el caso de la industria automotriz). En estas cadenas se verifica lo resaltado por Gorrochategui (2011) con relación a la coincidencia de la agenda internacional y la operativa de las empresas en la atención prioritaria de la cuestión medioambiental, en particular el cambio climático, como un indicador de la adaptabilidad de las empresas al adoptar temas críticos de carácter global.

Las cadenas locales, en cambio, no tienen un incentivo tan claro para la fijación de criterios de sustentabilidad ni para la instrumentación de mecanismos de transmisión hacia los demás eslabones. Como se concluyó en una investigación anterior (Amato et al., 2016), en estas cadenas son más evidentes las barreras que impiden a las organizaciones pasar de una percepción ideal de la sustentabilidad a las acciones concretas en ese sentido. La obligación de fijar estándares recae casi exclusivamente en el Estado, cuyos mecanismos resultan más acotados e ineficientes que los instrumentos de mercado para lograr la adopción de criterios a lo largo de la CV. 


\section{BiBLIOGRAFÍA}

Amato, C. N.; Buraschi, M. y Peretti, M. F. (2016). Orientación de los empresarios de Córdoba-Argentina hacia la sustentabilidad y la Responsabilidad Social Empresaria: identificación de variables asociadas a cada constructo. Contaduría y Administración, 61, 1, 84-105.

Ahi, P. y Searcy, C. (2013). A comparative literature analysis of definitions for green and sustainable supply chain management. Journal of Cleaner Production, 52, 329-341.

Amato, C. (2015). La logística inversa como estrategia para el logro de un desempeño superior (económico, social y ambiental). Estudio de casos de empresas embotelladoras de gaseosas en Argentina. Tesis doctoral. Córdoba: UNC.

Amato, C.; Romero, M. y García, L. (2016). Gobernanza e impactos en la sostenibilidad de la cadena de valor de la industria automotriz en Argentina. XXII Jornadas de Epistemología de las Ciencias Económicas. UBA. Ciudad Autónoma de Buenos Aires, Argentina. Octubre.

CEPAL-Comisión Económica Para América Latina y el Caribe (2014). Fortalecimiento de las cadenas de valor como instrumento de la política industrial. Santiago de Chile.

Dahlsrud, A. (2006). How Corporate Social Responsibility is defined: an Analysis of 37 Definitions. Corporate Social Responsibility and Environmental Management, 15, 1-13.

FAIMA-Federación Argentina de la Industria Maderera y Afines (2018). Muebles: el desafío de competir. Revista Pymes, abril.

Freeman, R. E. (1984). Strategic Management: a Stakeholder Approach. Boston: Pitman.

Gereffi, G. (2014). Global value chains in a post-Washington Consensus world. Review of International Political Economy, 21(1), 9-37.

Gereffi, G. y Fernández-Stark, K. (2011). Global value chain analysis: a primer. Center on Globalization, Governance and Competitiveness, USA.

Gereffi, G.; Humphrey, J. y Sturgeon, T. (2005). The governance of global value chains. Review of International Political Economy, 12(1), 78-104.

Gorrochategui, N. (2011). Responsabilidad Social Empresaria en Argentina después de la crisis del 2008. Contrastación de la agenda internacional con la agenda real de las empresas. En N. Gorrochategui y V. Martins de Oliveira (comps.), Responsabilidad Social de las Organizaciones. Perspectivas de nuevos marcos institucionales en América Latina. Ciudad Autónoma de Buenos Aires: Ediciones Cooperativas. Kaplinsky, R. y Morris, M. (2010). A Handbook for Value Chain Research. Brighton: Instituto de Estudios de Desarrollo. 
Mondino, A. J. y Buraschi, M. (2016). El enfoque de la cadena de valor y la gobernanza de la sustentabilidad: caso Sector Maderero en Argentina. XXII Jornadas de Epistemología de las Ciencias Económicas. UBA. Ciudad Autónoma de Buenos Aires, Argentina. Octubre.

Ortiz, A. y Peretti, M. F. (2016). Gobernanza en las cadenas de valor sustentables. Estudio de casos en el sector hortícola de la ciudad de Córdoba. XXII Jornadas de Epistemología de las Ciencias Económicas. UBA. Ciudad Autónoma de Buenos Aires, Argentina. Octubre.

Peretti, M. F.; Amato, C. y Buraschi, M. (2017). La cadena de valor del embotellado de bebidas gaseosas en Córdoba, Argentina. En P. Vera (coord.), Cadenas de valor y sostenibilidad en Latinoamérica (pp. 145-171). Ciudad de México: Publicaciones Empresariales UNAM.

Scott, G. (2014). Agregando valor a las cadenas de valor. Revista de Administração de Empresas, 54(1), 67-79.

Seuring, S. y Müller, M. (2008). From a literature review to a conceptual framework for sustainable supply chain management. Journal of Cleaner Production, 16(15), 1699-1710.

Sturgeon, T. (2011). De cadenas de mercancías (commodities) a cadenas de valor: construcciones teóricas en una época de globalización. Eutopía, (2), 11-38. 



\title{
CREACIÓN DE VALOR COMPARTIDO COMO ESTRATEGIA DE COMPETITIVIDAD Y RESPONSABILIDAD SOCIAL EN LAS ORGANIZACIONES
}

\author{
Manuel Méndez Pinzón" \\ Marcela Gómez Osorio"* \\ Colombia
}

\section{INTRODUCCIÓN}

Ante los cambios que enfrentan las organizaciones, es necesario que las empresas, además de satisfacer las necesidades del mercado, incluyan la creación de valor compartido en su desarrollo y crecimiento, de tal modo que les permita mejorar tanto sus condiciones dentro de la competencia como la realidad del entorno del que forman parte, alcanzando un progreso que además de económico sea social y ambiental.

Este proyecto muestra cómo la implementación de estrategias para la generación de valor compartido impacta el desarrollo económico, conllevando la construcción de estrategias esenciales para crear impactos tangibles e intangibles en el corto, mediano y largo plazo, esto se plantea en el marco del concepto de Porter y Kramer (2011).

Mientras la Responsabilidad Social implica el desembolso de dineros sin esperar un retorno económico para la empresa, el valor compartido (VC) mejora la actividad empresarial generando riqueza para ella con la ventaja de que identifica oportunidades de negocio en

MBA, Magíster en Administración de Empresas, ESAN Graduate School of Business. Correo electrónico: mlmendezp@gmail.com

** Gerente de Investigación y Estudios Empresariales de Uniempresarial, Magíster en Gestión Ambiental para el Desarrollo Sostenible de la Pontificia Universidad Javeriana. Correo electrónico: mgomez@uniempresarial.edu.co 
la resolución de las problemáticas sociales y ambientales, con lo cual todos se benefician.

En este sentido, el valor compartido tiene el potencial de convertirse en un fenómeno que facilita la innovación y la competitividad por parte de las empresas y, al mismo tiempo, contribuir al desarrollo de una región tras la mitigación de las problemáticas socioeconómicas y medioambientales, dado que las compañías la satisfacen obteniendo utilidad (Porter y Kramer, 2011).

La metodología empleada en esta investigación se inició con una búsqueda preliminar de información para la elaboración de un modelo teórico y continuó con la formulación de un instrumento para la toma de datos, el cual fue validado y aplicado en campo, y a partir de los datos obtenidos, se diseñó y estimó un modelo estadístico, que muestra la relación y correlación existentes entre las variables analizadas.

\section{VALOR COMPARTIDO}

Históricamente, se han generado diferentes puntos de vista sobre el valor compartido, como el enfoque propuesto por el sistema capitalista, los estudios sobre la ética, el accionar de la filantropía y, no muy lejos, la concepción de la Responsabilidad Social. Estos enfoques, opuestos entre sí, analizan el concepto desde diferentes puntos: por un lado, se quiere priorizar una visión productiva y rentable de la empresa, y por el otro, el deber ético y moral de la empresa de favorecer a las personas y comunidades del entorno. A lo anterior se suma un tercer aspecto: la bien conocida responsabilidad frente al impacto ambiental.

Estas perspectivas intentan responder preguntas sobre los conceptos de responsabilidad y competitividad que conforman el valor compartido: ¿cuál es la motivación empresarial para la creación de valor compartido?, ¿por qué las empresas deben crear valor compartido?, y ¿crean las empresas valor compartido?

De la interacción entre la empresa y la comunidad surgió la Responsabilidad Social Corporativa (RSC), que apunta al deber que tienen las organizaciones de generar acciones que beneficien a sus grupos de interés, aunque las acciones adelantadas sean ajenas al negocio mismo de la organización. Esto, a su vez, genera críticas desde los diferentes actores involucrados. Al respecto, Porter y Kramer (2011) manifiestan: 
Mientras más las empresas han comenzado a adoptar la responsabilidad corporativa, más se las ha culpado por las fallas de la sociedad. La legitimidad de las empresas ha caído a niveles inéditos en la historia reciente. Esta pérdida de confianza en las compañías lleva a que los líderes políticos tomen medidas que socavan la competitividad y minan el crecimiento económico. (p. 11)

Ante esta situación, los mismos autores proponen «la creación de valor compartido» (CVC), que consiste en que las organizaciones puedan desarrollar acciones a favor de sus grupos de interés y que en ese proceso ambas partes obtengan beneficios. Es así como las empresas hallan un beneficio económico, no se desvían de su propósito fundamental y mantienen la dinámica en el sector organizacional. En ese sentido, el valor compartido busca sustituir la visión tradicional y filantrópica de las organizaciones, que realizan donaciones sin buscar un rendimiento financiero.

La CVC genera un impulso hacia la innovación y un aumento de la competitividad global, y Porter y Kramer (2011) proponen tres formas mediante las cuales una empresa puede hacerlo: a) reconcebir los productos y mercados, b) redefinir la productividad en la cadena de valor, y c) desarrollar un clúster local (p. 36).

Con el fin de lograr beneficios tanto económicos y sociales para la empresa, se esperan obtener los siguientes resultados empresariales al establecer las formas de generar valor compartido expuestas por Porter y Kramer (2011), las que se encuentran consolidadas en el cuadro 1.

\section{CUADRO I. RESULTADOS EMPRESARIALES Y SOCIALES ILUSTRATIVOS POR NIVEL DE VALOR COMPARTIDO}

\begin{tabular}{|c|c|c|}
\hline $\begin{array}{l}\text { NivELES DE VALOR } \\
\text { COMPARTIDO } \\
\end{array}$ & $\begin{array}{c}\text { RESULTADOS DE LA EM- } \\
\text { PRESA }\end{array}$ & $\begin{array}{l}\text { RESULTADOS } \\
\text { SOCIALES }\end{array}$ \\
\hline $\begin{array}{l}\text { Reconcibiendo produc- } \\
\text { tos y servicios: }\end{array}$ & \multirow{2}{*}{$\begin{array}{l}\text { Aumento de los ingresos } \\
\text { Aumento de la cuota de } \\
\text { mercado } \\
\text { Mayor crecimiento del } \\
\text { mercado } \\
\text { Mejora de la rentabi- } \\
\text { lidad }\end{array}$} & \multirow{2}{*}{$\begin{array}{l}\text { Mejora de la atención al } \\
\text { cliente } \\
\text { Reducción huella de car- } \\
\text { bono } \\
\text { Mejor nutrición } \\
\text { Mejor educación }\end{array}$} \\
\hline $\begin{array}{l}\text { ¿Cómo focalizar las ne- } \\
\text { cesidades no satisfechas } \\
\text { impulsa los ingresos y } \\
\text { las ganancias incremen- } \\
\text { tales? }\end{array}$ & & \\
\hline
\end{tabular}




\begin{tabular}{|c|c|c|}
\hline $\begin{array}{l}\text { Redefiniendo la produc- } \\
\text { tividad en la cadena de } \\
\text { valor: }\end{array}$ & \multirow{2}{*}{$\begin{array}{l}\text { Mejora la productividad } \\
\text { Reducción de los costos } \\
\text { logísticos y operativos } \\
\text { Suministro asegurado } \\
\text { Calidad mejorada } \\
\text { Mejora de la rentabi- } \\
\text { lidad }\end{array}$} & \multirow{2}{*}{$\begin{array}{l}\text { Uso reducido de recursos } \\
\text { (agua, energía) } \\
\text { Uso eficiente de materias } \\
\text { primas } \\
\text { Mejoras en las habilida- } \\
\text { des del trabajo } \\
\text { Mejora en los ingresos a } \\
\text { los empleados }\end{array}$} \\
\hline $\begin{array}{l}\text { ¿Cómo una mejor } \\
\text { administración de las } \\
\text { operaciones internas } \\
\text { aumenta la produc- } \\
\text { tividad y reduce los } \\
\text { riesgos? }\end{array}$ & & \\
\hline $\begin{array}{l}\text { Permitiendo el desarro- } \\
\text { llo de clústeres: }\end{array}$ & \multirow{2}{*}{$\begin{array}{l}\text { Reducción de costos } \\
\text { Suministro asegurado } \\
\text { Mejora de la infraes- } \\
\text { tructura } \\
\text { Mejor acceso a la fuerza } \\
\text { de trabajo } \\
\text { Mejora la rentabilidad }\end{array}$} & \multirow{2}{*}{$\begin{array}{l}\text { Mejor educación } \\
\text { Aumento en la creación } \\
\text { de puesto de trabajo } \\
\text { Mejora de la salud } \\
\text { Mejores ingresos }\end{array}$} \\
\hline $\begin{array}{l}\text { ¿Cómo las cambiantes } \\
\text { condiciones sociales } \\
\text { fuera de la compañía } \\
\text { desatan crecimiento y } \\
\text { productividad? }\end{array}$ & & \\
\hline
\end{tabular}

Fuente: Elaboración propia, sobre la base De Porter et AL., 20 i I.

Cantor et al. (2017) aseguran que, de acuerdo con documentos escritos por Porter y Kramer, la competitividad de la empresa y la prosperidad de las comunidades donde opera están fuertemente entrelazadas, ya que una compañía necesita una comunidad exitosa no solo para crear demanda de sus productos, sino también para brindar activos públicos cruciales y un entorno que apoye al negocio. Asimismo, la comunidad necesita empresas exitosas que ofrezcan empleos y oportunidades de creación de riqueza para sus ciudadanos.

En ese mismo orden de ideas, Vélez (2015) menciona en su artículo que las instituciones de educación superior juegan un papel importante en este sentido, ya que estas deben asumir responsabilidades y proporcionar soluciones para que un modelo de desarrollo sostenible sea posible. Además, en los resultados de su investigación concluye que los estudiantes asocian la sostenibilidad a conceptos relacionados al desarrollo económico, pero no perciben la responsabilidad frente a la sociedad, encontrando en las propuestas tecnológicas la única solución a los problemas sociales y ambientales propiciados por el sector empresarial, atribuido en parte a la ausencia del tema en los programas académicos y a la limitada exigencia que tienen las empresas frente al tema.

Para conocer cuál ha sido la evolución de la CVC, es importante analizar las teorías y estudios propuestos por otros autores, con el fin 
de identificar qué se pretende o qué alternativas existen para la creación de valor compartido en las empresas.

Kania y Kramer (2011) introdujeron un movimiento conocido como «impacto colectivo", cuya finalidad es que cada uno de los actores de la sociedad intervenga para generar un cambio en el sistema con el cual todos se beneficien, a la vez que las empresas redireccionen sus esfuerzos colectivos y obtengan mayores oportunidades de crecimiento y competitividad. Para este movimiento, cinco son las condiciones fundamentales que conllevan al éxito: a) agenda y enfoque común, b) medición compartida, c) actividades que se refuerzan mutuamente, d) comunicación constante, y e) respaldo de un eje central.

El valor compartido tiene en cuenta diversos aspectos que en la actualidad carecen de mejoras para que una empresa logre aplicarlos en su core de negocio. Spitzeck y Chapman (2012) proponen seguir determinadas reglas en cuanto a la implementación de estrategias, innovación y manejo en las relaciones con los stakeholders para que esta alternativa sea exitosa. Resaltaron a su vez, que, cuando una empresa aplica el valor compartido, es necesario que tenga en cuenta los siguientes aspectos: a) conocer las políticas, así como las prácticas de funcionamiento que se tienen en la empresa, b) aumento de la competitividad, se mejoran las condiciones sociales de las comunidades que estuvieran cercanas, c) definir cuáles son los proyectos estratégicos para la empresa y sus grupos de interés y, por último, d) entender la forma en que pueden medirse las demandas de los stakeholders.

\section{VALOR COMPARTIDO FRENTE A LA RESPONSABILIDAD SOCIAL EMPRESARIAL}

Una polémica que se ha generado durante los últimos años ha sido por las diferencias que existen en cuanto a que una empresa implemente en su estrategia de negocio la RSE y el VC, aunque estas dos pretenden generar valor para la misma, la forma en que lo generan es diferente. Asimismo, las organizaciones deben ser sostenibles dando importancia e incluyendo tres aspectos importantes: el ambiente económico, la estabilidad ambiental y el panorama social, siendo estas características de una empresa responsable o de un buen ciudadano corporativo (Sierra, 2007).

También, se afirma que hay dos tipos de empresas, la tradicional y la sostenible. Donde la primera «sólo cumple con lo que dice la ley, sobre todo en beneficio de sus accionistas y, si mucho, de empleados y 
clientes, pensando únicamente en el corto plazo» y la segunda empresa define que «no considera que deba crear valor para esos tres factores, especialmente los accionistas, sino que intenta dar valor a otros grupos de interés, no por motivos oportunistas sino como una auténtica estrategia corporativa, de cuyo éxito depende el futuro mismo de la empresa. Le apuesta al largo plazo» (Sierra, 2007).

Sin embargo, la RSE enfrentada con la creación de valor compartido tiene más debilidades que fortalezas. En el cuadro 2 se analizan y comparan estos dos términos que actualmente se encuentran en controversia en cuanto a los objetivos que persigue cada uno.

Cuadro 2. Valor compartido vs. Responsabilidad Social Empresarial

\begin{tabular}{|l|l|}
\hline \multicolumn{1}{|c|}{ RESPONSABILIDAD SOCIAL } & \multicolumn{1}{c|}{ VALOR COMPARTIDO } \\
\hline $\begin{array}{l}\text { Beneficios para la comunidad del } \\
\text { entorno }\end{array}$ & $\begin{array}{l}\text { Beneficios económicos y sociales para la } \\
\text { empresa, el entorno y el ambiente }\end{array}$ \\
\hline Filantropía (gasto para la empresa) & Genera utilidades para la empresa \\
\hline Respuesta a la presión externa & $\begin{array}{l}\text { Creación conjunta de valor entre la em- } \\
\text { presa y la comunidad }\end{array}$ \\
\hline $\begin{array}{l}\text { Impacto limitado por la huella de la } \\
\text { empresa }\end{array}$ & $\begin{array}{l}\text { Genera desarrollo en las comunidades } \\
\text { donde opera }\end{array}$ \\
\hline $\begin{array}{l}\text { Se limita a los recursos destinados de } \\
\text { la empresa para el fin }\end{array}$ & Aumenta la competitividad \\
\hline $\begin{array}{l}\text { Sostenible mientras esté la empresa en } \\
\text { la zona }\end{array}$ & $\begin{array}{l}\text { Hace sostenible el negocio y el beneficio } \\
\text { para el entorno y el ambiente }\end{array}$ \\
\hline $\begin{array}{l}\text { Acción de la empresa que requiere } \\
\text { inversión constante }\end{array}$ & Hace parte de la estrategia del negocio \\
\hline
\end{tabular}

Fuente: Elaboración propia, sobre la base de Porter y Kramer (2OII).

\section{Metodología}

La metodología empleada para esta investigación consistió en la búsqueda preliminar de información, a partir de la cual se elaboró un modelo teórico desde el cual se detectaron factores de incidencia en la creación de valor compartido. Con estos factores determinados, se desarrolló un instrumento para la toma de datos. El diseño del instrumento fue realizado entre la Cámara de Comercio de Bogotá, a través 
de su Dirección de Valor Compartido, y la Dirección de Investigaciones y Estudios Empresariales de Uniempresarial.

Dicho instrumento busca analizar diferentes factores en la empresa, como son: la relación de las empresas y el entorno, la reconcepción de productos y mercados, el fortalecimiento de su cadena de valor, igualmente si desarrollan proveedores y, por último, si la empresa tiene motivación para crear valor compartido.

Cada una de las partes inicia con una afirmación que aclara al encuestado el sentido de las preguntas que se le solicita responder, de acuerdo con las prácticas de su empresa. Las respuestas se ubican en una escala que va de «totalmente en desacuerdo» hasta «totalmente de acuerdo». Este instrumento fue validado en cuatro grupos focales, en el cual participaron diez empresas, y se aplicó una prueba piloto a veinticinco compañías.

Luego fue aplicado a altos directivos de 140 empresas de la ciudad de Bogotá de todos los sectores de producción y de todos los tamaños, lo cual ha permitió recoger información en fuentes primarias. Posteriormente se diseñó y estimó un modelo usando la técnica de las ecuaciones estructurales (SEM), con el propósito de identificar los factores que pueden desencadenar la creación de valor compartido en las empresas de Bogotá, y se procedió a diseñar un modelo que fue evaluado mediante la técnica SEM.

\section{El MOdelo de ECUACIONES ESTRUCTURALES (SEM)}

Este modelo permite verificar las relaciones causales o no causales entre un conjunto de variables y ha sido recientemente usado en diferentes investigaciones sobre índices de producción y las cadenas de valor en distintos sectores productivos (García-Alcaraz, 2015).

El modelo, al igual que la técnica de la regresión, permite examinar el efecto de una variable o de un conjunto de variables explicativas sobre una ya explicada y estimar en qué medida los cambios en esta última son causados por las primeras. Sin embargo, la razón de por qué este tipo de modelo se ajusta de manera correcta a la presente investigación es que permite involucrar un conjunto de variables observables o medibles (preguntas del cuestionario) y otras no medibles de manera directa (variables latentes), que resultan de relacionar las observables. Así, se descubren procesos subyacentes que se generan entre las variables y la flexibilidad a la hora de proponer dichas relaciones. 


\section{Resultados}

El diseño de este modelo refiere a una relación de tipo causal entre cinco variables latentes: entorno, reconcepción de productos, cadena de valor, proveedores y motivación, así como de otra variable latente, denominada para este trabajo creación de valor compartido. El gráfico 1 muestra la especificación del modelo propuesto.

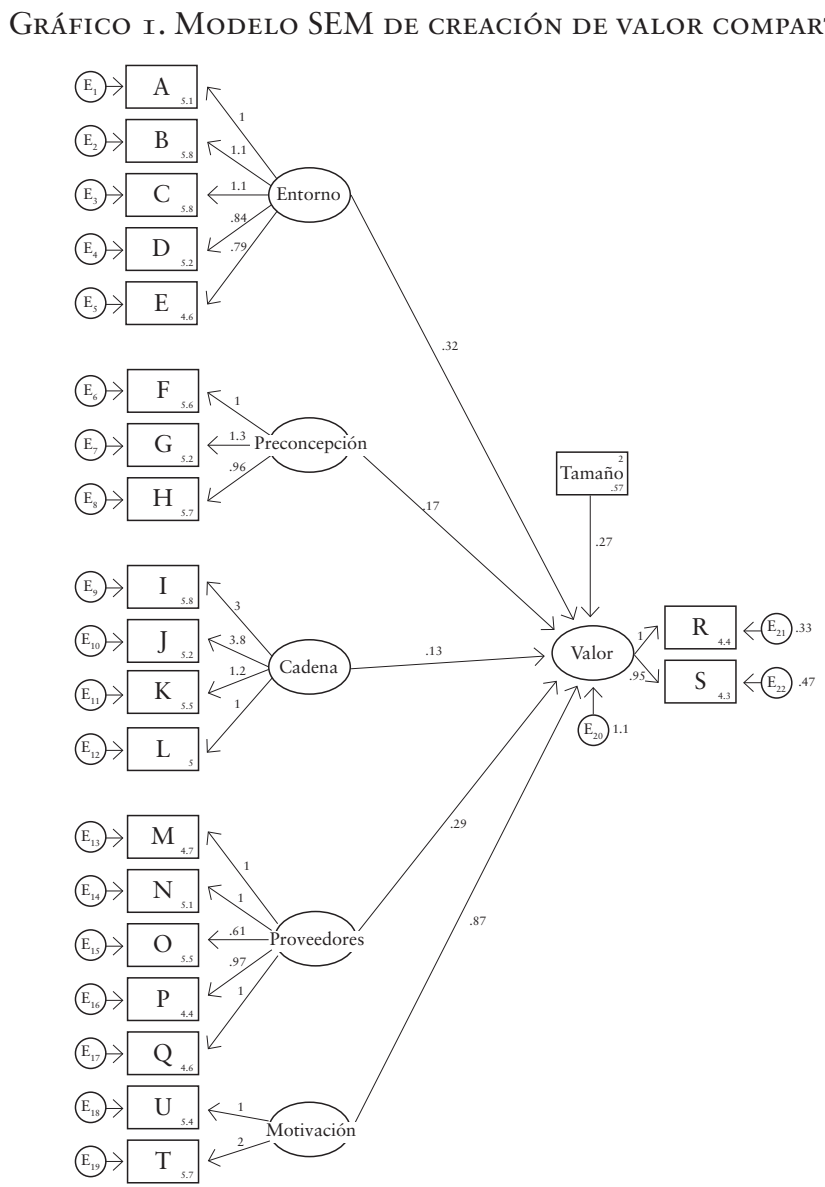

FuENTE: Elaboración PROPIA.

Las variables latentes descritas corresponden a un conjunto de variables que no se pueden medir de manera directa, pero sí inferir a partir de otras variables, las ordinales, que sí son observables. Las 
variables latentes son presentadas en elipses. Al observar el número de varianzas y los coeficientes a estimar, y comparándolas con el número de variables incluidas en el modelo, se encuentra que el modelo está claramente identificado.

El primer criterio de análisis fue la fiabilidad del cuestionario por medio del cálculo del Alpha de Cronbach. Para que un cuestionario presente una buena consistencia entre sus preguntas, es decir, que sea fiable, se estima que el Alpha de Cronbach debe tener un mínimo rango entre 0,6 y 0,7 (Hair, Hult, Ringle y Sarstedt, 2014). En el caso de esta encuesta, el resultado fue de 0,829 , lo cual indica que es más que satisfactorio, según lo presenta el cuadro a continuación.

Cuadro 3. Fiabilidad del Cuestionario

\begin{tabular}{|c|c|}
\hline Alpha de Cronbach & Número de Ítems \\
\hline 0,829 & 140 \\
\hline
\end{tabular}

FUENTE: ElABORACIÓN PROPIA.

Una vez aplicado el cuestionario a la muestra de empresas seleccionada, se obtuvo un total de 140 entrevistas válidas. En el cuadro 4 se presenta la frecuencia de empresas clasificadas según su tamaño.

Cuadro 4. Empresas encuestadas, SEgún tamaño

\begin{tabular}{|l|c|}
\hline \multicolumn{1}{|c|}{ TAMAÑo } & FreCUENCIA \\
\hline Micro & 47 \\
\hline Pequeña & 54 \\
\hline Mediana & 24 \\
\hline Grande & 12 \\
\hline
\end{tabular}

FUENTE: Elaboración PROPIA.

Se puede evidenciar como consecuencia del cuestionario que en las empresas existe un interés por satisfacer las necesidades sociales en la población. En ese sentido, el gráfico 2 muestra la frecuencia con la que 
las empresas de la ciudad diseñan programas sociales o ambientales que benefician a la comunidad. Se diferencian de acuerdo con su tamaño.

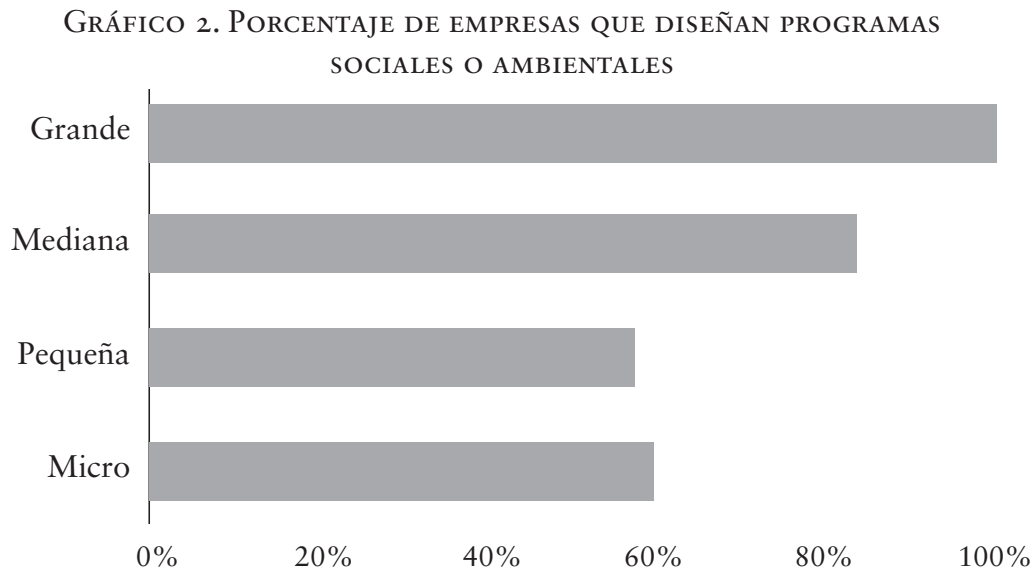

FUENTE: ELABORACIÓN PROPIA.

Ahora bien, el diseño de programas sociales o ambientales puede ser de diferente índole; esto es, se puede tratar de un nuevo producto o servicio, de una iniciativa de inversión social, del desarrollo de proveedores o de prácticas ambientales eficientes. En las empresas encuestadas, ¿cuál es el tipo de programa o de proyecto que se ejecutó en el 2015? El gráfico 3 nota que el ejecutado con mayor frecuencia corresponde a la creación de nuevos productos y servicios.

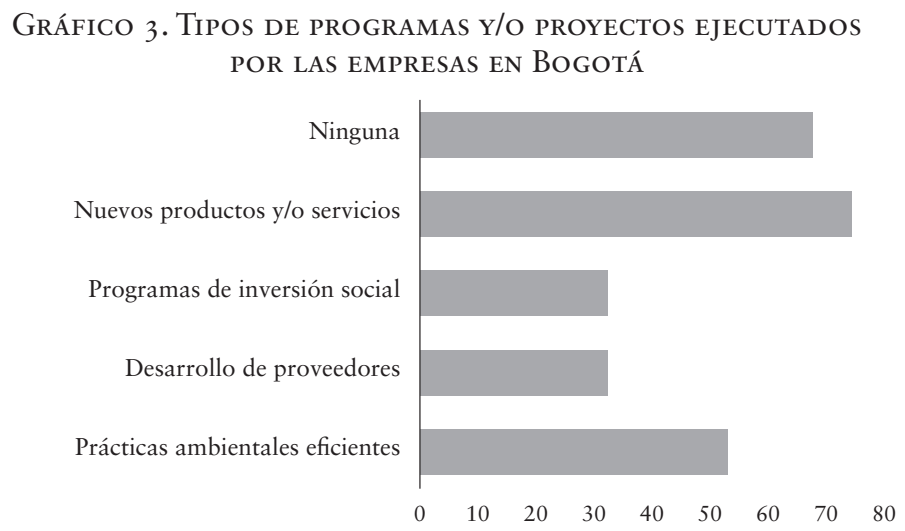

FUENTE: ELABORACIÓN PROPIA.

Un modelo en el que se relacionan cinco variables latentes, correspondientes a cada uno de los componentes de la encuesta, con la 
capacidad de creación de valor compartido de las empresas, fue usado para la aplicación de la técnica SEM, cuyos resultados son presentados en el cuadro 5. En él se puede evidenciar que todos los coeficientes obtenidos son significativos y cuentan con la robustez necesaria.

En primer lugar, los coeficientes obtenidos para los efectos directos, presentados en la primera parte de la tabla mencionada, permiten inferir que el conjunto de variables que miden la motivación de las empresas para la creación de valor compartido es el de mayor peso sobre esta misma capacidad de las compañías. Por lo tanto, cuando la desviación estándar se incrementa en un punto, la capacidad para crear valor compartido sube 0,91, el reconocimiento del entorno se incrementa 0,38 , mientras que, con la relación con los proveedores, el aumento en la capacidad de creación de valor es de 0,26. Por el contrario, las variables latentes de menor efecto son la reconcepción de los productos y la cadena de valor.

Cuadro 5. Coeficientes estructurales

\begin{tabular}{|l|l|}
\hline & CAPACIDAD DE CREACIÓN DE VALOR COMPARTIDo \\
\hline Tamaño & $0,2746 * *(2,40)$ \\
\hline Entorno & $0,3189 * * *(1,96)$ \\
\hline Reconcepción del producto & $0,1738 * *(1,01)$ \\
\hline Cadena de valor & $0,1339 *(0,78)$ \\
\hline Proveedores & $0,2924 * * *(2,53)$ \\
\hline Motivación & $0,8680 * * *(2,87)$ \\
\hline
\end{tabular}

Nota: Coeficientes obtenidos en la regresión del modelo de ecuaciones estructurales, valores del estadístico z en paréntesis. $* *$ Coeficientes válidos al $95 \%$ de confianza. * Coeficientes válidos al $90 \%$ de confianza.

FUENTE: ELABORACión PROPIA.

De otra parte, en cuanto a los efectos indirectos, como se ha presentado en el gráfico 1 (Modelo SEM de creación de valor compartido), todas las variables latentes dependen del comportamiento de 
otras variables observables; asimismo, la variable latente se define en dependencia de las demás latentes.

Los coeficientes observados permiten observar que son las variables vinculadas a la motivación las que mayor relación expresan; entre ellas, es la reflexión constante sobre cómo impactar positivamente el entorno la de mayor relevancia. A su vez, en el grupo de entorno, la identificación acertada de los grupos de interés y la ejecución constante de programas para contribuir a la solución de problemas sociales son las variables de mayor peso.

\section{Conclusiones}

El valor compartido es una herramienta valiosa para mejorar la competitividad de las organizaciones y para generar beneficios sociales $\mathrm{y}$ ambientales en el entorno del mismo.

Las tendencias de certificación y requerimientos en acciones responsables y alineadas a los intereses de las comunidades y el ambiente son cada vez más rigurosas para las organizaciones y exigen acciones más profundas y definitivas. Si bien es cierto que un posicionamiento de la imagen de la organización orientada a la satisfacción de necesidades de la sociedad y el medioambiente genera una ventaja competitiva en los mercados en los que se desenvuelve, también es un hecho que las estrategias de valor compartido, además de lograrlo, permiten que las incorporen en su estrategia de negocio, logrando un beneficio para ellas que les permite ser más competitivos y darles mayor alcance y sostenibilidad a estas acciones.

Los resultados obtenidos en esta investigación muestran que para las organizaciones de Bogotá medidas, es la motivación la que incide de manera definitiva en que las organizaciones creen valor compartido.

El factor de la motivación está determinado por la ampliación del mercado y el posicionamiento de la imagen de la compañía, y refuerza el hecho de que las acciones de las organizaciones están encaminadas a lograr su permanencia en el mercado.

Los resultados también muestran que tanto las micro como las grandes empresas diseñan y ejecutan programas de corte ambiental y social, lo cual representa un beneficio para la implementación del valor compartido porque las compañías están sensibilizadas frente a dichas necesidades. En la misma medida, significa una ventaja, pues existe una conciencia sobre la importancia de que la empresa identifique y 
trabaje estos aspectos. Ello supone que el objetivo sea que implementar la creación de valor compartido en las empresas sea visto como una utilidad para el negocio y que, por esta misma razón, sea incluido entre sus estrategias de mercado.

Adicionalmente, se evidenció que las organizaciones seleccionan sus proveedores teniendo como criterio fundamental los beneficios que estos representan para mejorar la gestión propia del negocio a partir de políticas de competitividad, y de manera específica, incluyen criterios de certificaciones y posicionamiento de estos en temas ambientales y sociales. Esto evidencia que la oportunidad de crear valor compartido se extiende a todas las partes interesadas en el negocio.

Finalmente, resulta importante resaltar que no importa el tamaño de las inversiones que tenga que realizar la organización para crear valor compartido, pues estas redundan en beneficio del negocio al incorporarse como parte de su estrategia y consecuentemente generando riqueza y competitividad para la organización.

El concepto de valor compartido logra articular los intereses de la organización con los de su entorno, permite dinamizarlos en torno a una generación de beneficios mutuos que mejora la competitividad y las condiciones sociales y ambientales.

\section{BiBLIOGRAFÍA}

Cantor, C.; Forero, G.; Perdomo, R. y Montenegro, W. (2017). Diagnóstico sobre la generación de Valor Compartido en las Empresas Líderes. Abril. Disponible en: http://tesis.pucp.edu.pe/repositorio/bitstream/ handle/123456789/8702/CANTOR_FORERO_DIAGNOSTICO_ PLASTICOS.pdf? sequence $=3 \&$ isAllowed $=\mathrm{y}$.

García-Alcaraz, J. L.-L. (2015). Structural equation modeling to identify the human resource value in the JIT implementation: case maquiladora sector. International Journal of manufactural technology, 1483-1497.

Hair, J. F. (2014). A Primer on Partial Least Squares Structural Equation Modelling (PLS-SEM). S. Publications.

Méndez Pinzón, M. y Gómez Osorio, M. (2017). Factores incidentes para crear valor compartido en las mipymes de Bogotá. Suma de Negocios, 8(18), 96-105.

Porter, M. y Kramer, M. (2011). La creación de valor compartido. Harvard Business Review, 6. 
Porter, M. E.; Hills, G.; Pfitzer, M.; Patscheke, S. y Hawkins, E. (2011). Measuring shared value: How to unlock value by linking social and business results.

Sierra, J. (2007). RSE Responsabilidad Social Empresarial: lecciones, casos y modelos de vida. Bogotá: Seguros Bolívar.

Spitzeck, H. y Chapman, S. (2012). Creating shared value as a differentiation strategy - the example of BASF in Brazil. Corporate Governance: The international journal of business in society, 499-513.

Rolón, A. M. V. (2015). Formación de estudiantes de administración Para generar valor compartido en el sector empresarial desde el marco de la sostenibilidad. Revista ESPACIOS, 36, 21. 


\title{
A CONTRIBUiÇÃO DA AVALIAÇÃO DE IMPACTO SOCIAL (AIS) PARA A OBTENÇÃO DA LICENÇA SOCIAL PARA OPERAR (LSO) NA MINERAÇÃO
}

\author{
Ana Lúcia Frezzatti Santiago" \\ Jacques Demajorovic" \\ Antonio Aledo Tur"** \\ Brasil \\ España
}

\section{INTRODUÇÃO}

O conceito de LSO surge no contexto das engenharias da indústria extrativista, quando os especialistas se dão conta da necessidade de responder aos desafios sociais, além dos habituais desafios tecnológicos e de gestão. De acordo com Franks e Cohen (2012) há uma tendência dos setores de engenharia, sustentabilidade, segurança e principalmente das áreas de mapeamento de risco tratarem as questões tecnológicas de forma neutra, separando os projetos de pesquisa tecnológica das influências sociais. A LSO traz para a pauta das engenharias que atuam na área de gestão de risco, a necessidade de também considerarem o viés social do risco. Apesar da nomenclatura «licença», a LSO não se trata de um documento que pode ser concedido pelas autoridades civis, estruturas políticas ou sistema jurídico, mas sim de um processo de negociação contínua com a sociedade (Franks e Cohen, 2012). Fundamenta-se na

Profa. Dra. Administração e Sociedade. Univers. Alicante, Espanha e FEI SP, Brasil. analucia@fei.edu.br

** Prof. Dr. Pós-Graduação em Administração. Centro Universitário FEI, SP, Brasil. jacquesd@fei.edu.br

*** Prof. Dr. Departamento Sociologia I. Universidade de Alicante. Espanha. antonio. aledo@ua.es 
ideia de que a sociedade pode dar ou recusar o apoio para uma empresa e suas operações (Santiago, 2016). O nível de apoio concedido está diretamente relacionado com as expectativas da sociedade sobre a forma como a empresa conduz as suas atividades (Gunningham, Kagan e Thornton, 2004). A LSO passa a integrar a estratégia de negócio das empresas, o planejamento e desenvolvimento das operações produtivas e sendo vista como necessária para a redução dos riscos associados à resistência e conflitos com a sociedade, os quais podem afetar a reputação da empresa provocando o aumento dos níveis de regulamentação governamental (Parsons; Lacey; Moffat, 2014). Conflitos entre empresas e comunidades locais representam riscos para o negócio e decorrem da percepção cada vez maior por parte das empresas dos custos associados aos conflitos (Franks et al., 2014). Nesse contexto o presente artigo apresenta conceitos e discute os limites da LSO. Discute estudos de casos e propõem a adoção da AIS como contribuição para a obtenção e manutenção de uma LSO mais efetiva. Agregando ao tradicional ponto de vista tecnológico utilizado pelas empresas, o ponto de vista a partir da percepção da comunidade local. Propõem o preenchimento de uma lacuna, uma limitação, que é identificar os riscos somente pela ótica do negócio em detrimento dos riscos das operações minerais para a comunidade como um todo, considerando que o entendimento de situações de risco da empresa nem sempre são os mesmos dos seus stakeholders e da comunidade em geral.

\section{LSO IMPLEMENTAÇÃO, ETAPAS E NÍVEIS DE ACEITAÇÃO}

Em especial no setor de mineração, caracterizado pelo potencial impacto das suas operações, o risco de conflitos com comunidades representado pela não obtenção da LSO foi classificado como o $7^{\circ}$ principal risco para o negócio (EY, 2018), já no ranking 2019-2020foi classificado como o risco número 1 (EY, 2019). Pesquisa realizada por Franks et al. (2014) demostra uma escala dos custos para apaziguar conflitos com comunidades locais em empresas do setor mineral, evidenciando as principais questões de disputa e a necessidade de adotar novas práticas para a gestão social do risco. A primeira descoberta empírica da pesquisa é que as questões ambientais foram as questões mais comuns para precipitar o conflito. 
A CONTRIbUiÇão DA AVALIAÇÃo DE IMPACTO SOCIAL (AIS) PARA A OBTENÇÃo DA LICENÇA SOCIAL PARA OPERAR (LSO) NA MINERAÇÃO

Figura i. Conflitos entre Mineração e Comunidades /

Questões de Disputa $(\mathrm{N}=50)$

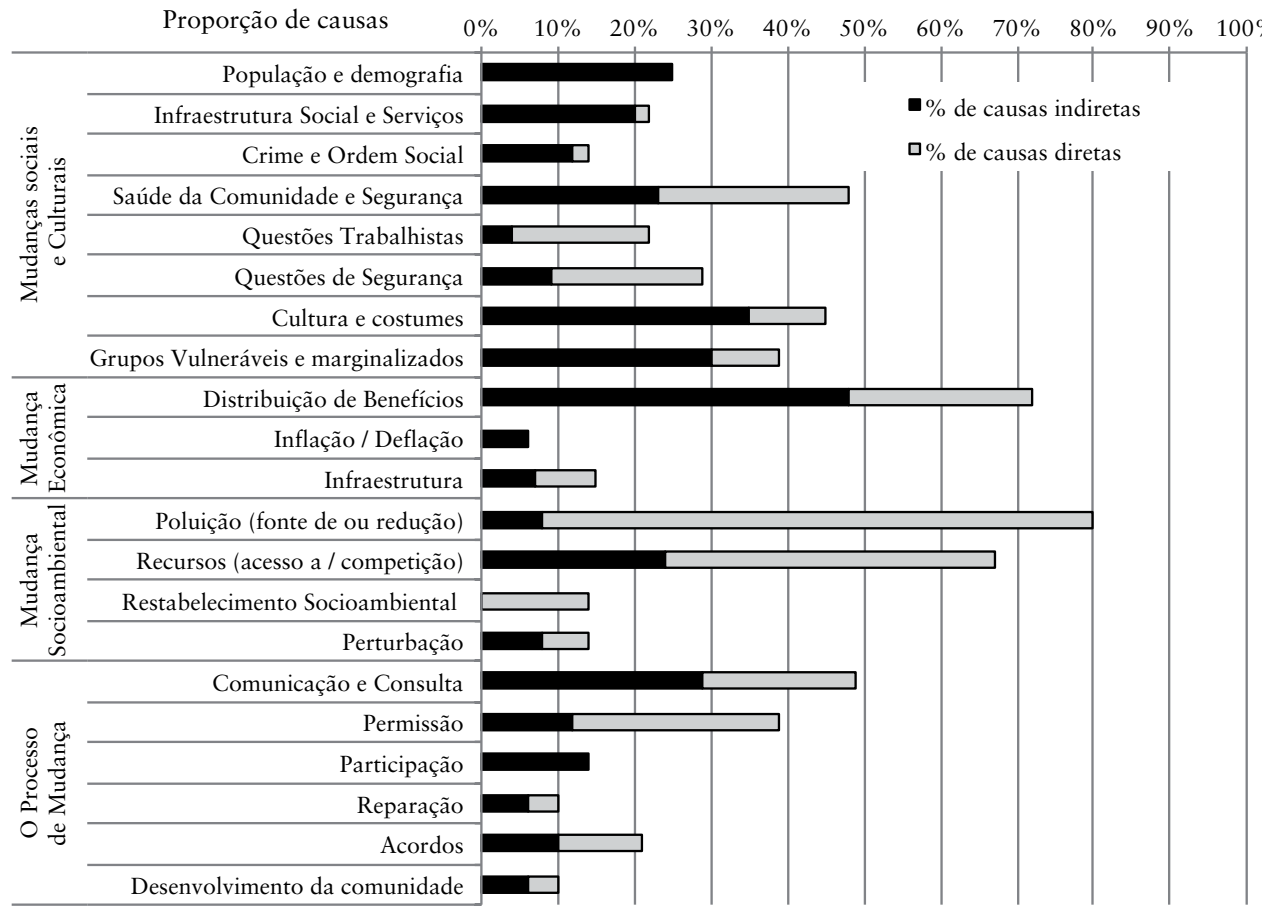

Fonte: Autores «Adaptado De» Franks et Al. (2OI4).

A implementação da LSO é proposta em diversos estudos e envolve diferentes modelos de acordo com a ótica dos estudos de caso e pesquisas realizadas. LSO é um termo que reflete a percepção de que a conformidade com os regulamentos legais é muitas vezes insuficiente para atender às demandas da sociedade, sendo que as expectativas das comunidades afetadas pelo empreendimento frequentemente excedem as questões legais (Gunningham, Kagan e Thornton, 2004). A LSO refere-se ao intangível, à parte não tácita do contrato realizado com a sociedade ou grupo social, que permite uma operação de extração ou de processamento iniciar e continuar as suas operações (Franks e Cohen, 2012.) Os requisitos para a LSO são reconhecidamente de difícil possibilidade de modelagem e métrica, alguns autores propõem modelos para um melhor entendimento do termo e suas variáveis. No entanto, é um consenso que os princípios de sustentabilidade devem 
ser cumpridos antes que haja uma concessão de LSO, ou seja, as comunidades locais devem acreditar que os benefícios sociais, ambientais e econômicos de uma empresa superam os seus potenciais impactos legais (Gunningham, Kagan e Thornton, 2004; Franks e Cohen, 2012; Prno e Slocombe, 2012; Parsons, Lacey e Moffat, 2014).

Thomson e Boutilier (2011) sistematizaram um processo para conquistar e manter a LSO, conforme apresentado a seguir: a) Entrevistas com os stakeholders da empresa, para entender a sua percepção do projeto, preocupações e aspectos positivos; b) Construir mapas de stakeholders da empresa, indicando quem são os mais influentes e que nível de licença social concede; c) Desenvolver uma estratégia alinhada as percepções dos stakeholders; d) Construir acordo em torno de objetivos compartilhados com a comunidade; e) Construir apoios para a mineração desempenhar o seu papel junto à comunidade. Trabalhando juntos Thomson e Boutilier (2011) propõem uma modelagem para a LSO com escalas de níveis de aceitação da empresa pela comunidade local, sendo que o nível de LSO concedido a uma empresa está diretamente relacionado com o nível de risco sociopolítico que ela enfrenta. Uma LSO inferior indica um risco mais elevado para a empresa, que pode ter a sua licença social suspensa ou revogada, restringindo o seu acesso aos recursos essenciais, como financiamento, licenças legais, matéria-prima, mão de obra, mercados e infraestrutura pública. Representando um risco sociopolítico extremamente elevado para a empresa. Um nível mais alto de LSO, por sua vez, sinaliza a confiança institucional no projeto empresarial. $\mathrm{O}$ modelo distingue por meio da legitimidade os projetos que foram rejeitados, nos quais a LSO foi retida daqueles que foram aceitos pelas partes interessadas por meio do envolvimento. Propõe três fronteiras, nas quais se a empresa estabelece sua credibilidade, a licença social sobe para o nível de aprovação. Se a confiança for estabilizada ao longo do tempo, a licença social pode subir para o nível de identificação psicológica, baixando o risco sociopolítico.

A figura a seguir apresenta os níveis de aceitação da empresa pela comunidade proposto por Thomson e Boutilier (2011), organizado por meio da categorização de riscos sociais enfrentados pelas empresas de mineração América Latina. 
A CONTRIbUição DA AVALIAÇÃo DE IMPACTO SOCIAL (AIS) PARA A OBTENÇÃo DA LICENÇA SOCIAL PARA OPERAR (LSO) NA MINERAÇÃO

Figura 2. Níveis de aCEITAÇÃo da EMPRESA PEla COMUNidAde PARA a LSO

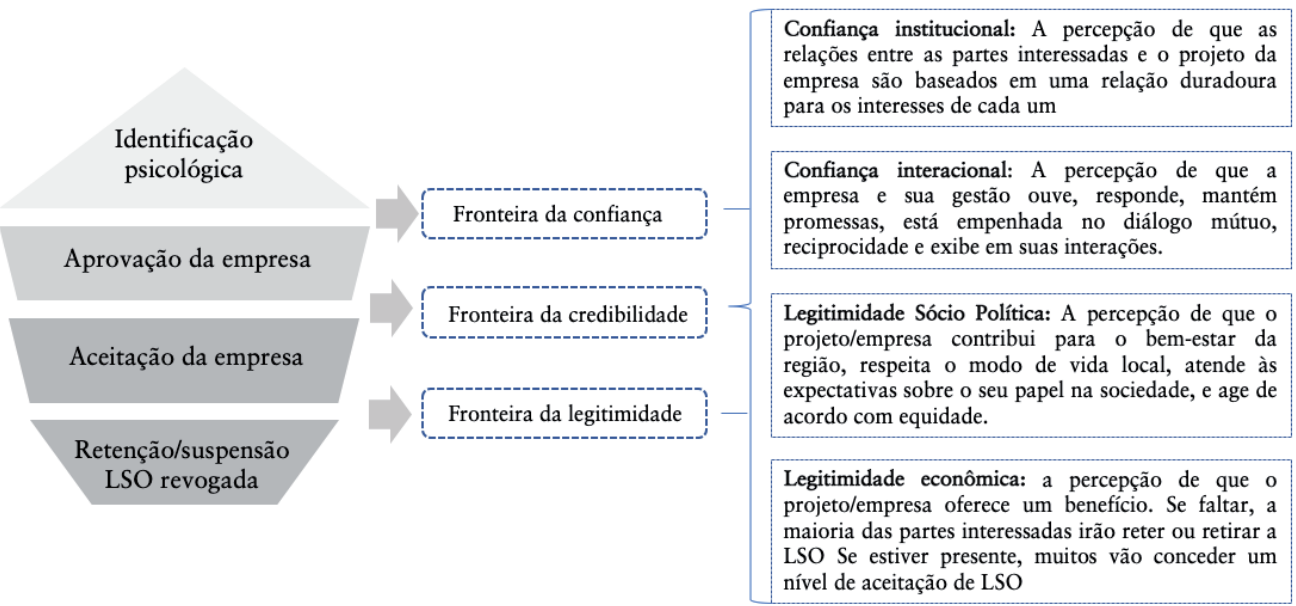

Fonte: Autores, «ADAPTADo DE» Thomson E Boutilier (20II).

Em se tratando de modelos para a implementação da LSO, Prno (2014) destaca como pré-requisitos a análise do contexto local, a existência de uma relação transparente entre a mineradora e a comunidade e o fortalecimento das instituições locais, para que possam integrar e participar dos diálogos com a empresa. Enfatiza um modelo de LSO que denomina como «resiliente», ou seja, implementado com base em um relacionamento mais sólido entre a empresa e a comunidade local, capaz de suportar momentos críticos frequentemente motivados pela transformação profunda causada nos ambientes natural, econômico e social. 
Figura 3. BASES DA LSO

\section{BASES DA LICENÇA SOCIAL PARA OPERAR}

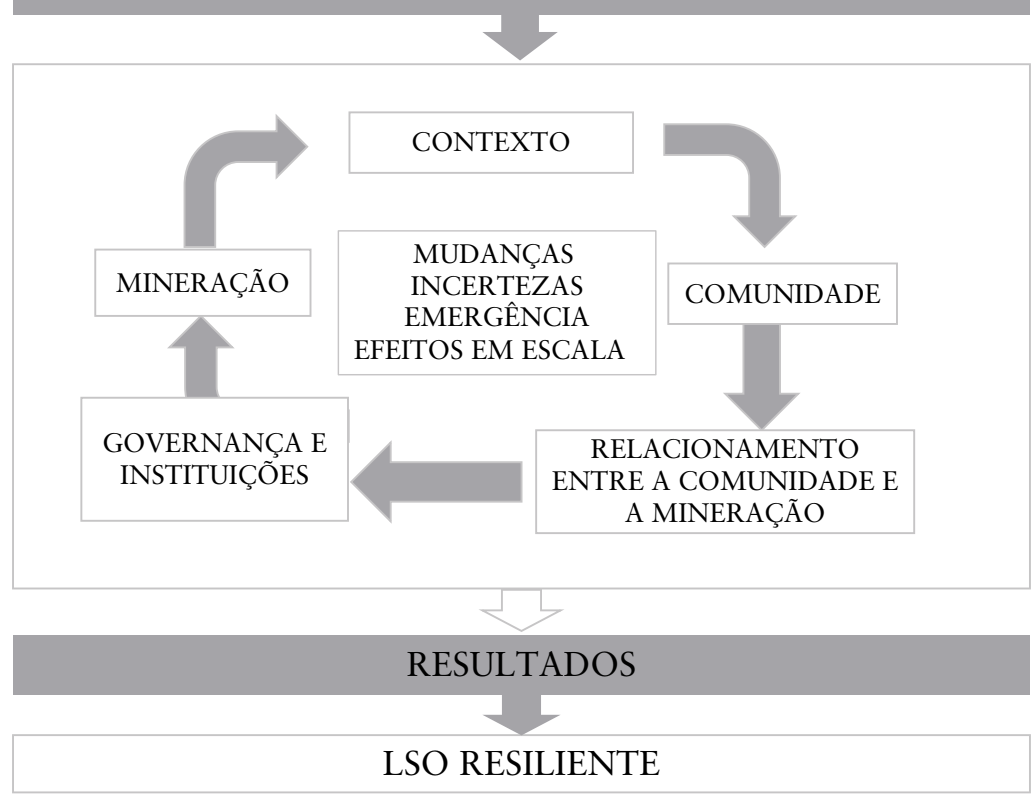

Fonte: Autores «Adaptado De» Prno (2OI4).

A Licença social, de acordo com Lancey et al. (2012), é um futuro indicador que irá sustentar a qualidade das relações entre as partes interessadas. Para Moffat e Zhang (2014) a LSO é proposta como uma forma de criar consenso entre diversas perspectivas, contribuindo para o diálogo e construção de confiança nas relações entre as empresas e demais partes envolvidas ou afetadas pelo desenvolvimento dos empreendimentos. Indicando que as práticas da empresa influenciam diretamente a confiança, influenciando por sua vez a aprovação e a aceitação. Para demostrar o proposto desenvolveram um modelo integrativo para o entendimento das etapas da aceitação das operações minerais pela comunidade local. Destacam que a construção da confiança com as comunidades locais é crucial para as empresas de mineração obterem e manterem uma LSO. O modelo proposto por Moffat e Zhang (2014) é representado na figura a seguir. 
Figura 4. Modelo integrativo para A CONSTRUÇão Da CONFIANÇA Na LSO

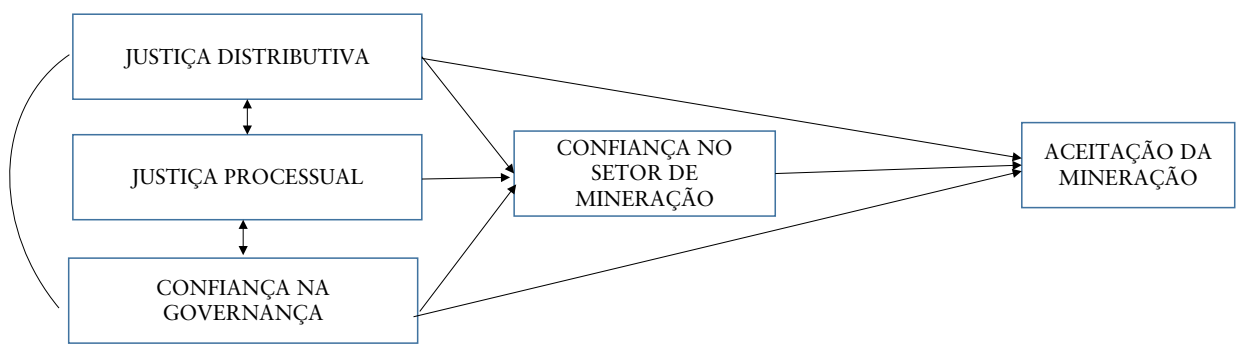

Fonte: Autores, «Adaptado De» Moffat e Zhang (2OI4).

O conceito da LSO é amplamente adotado pelas empresas do setor mineral e reflete a aceitação das operações da empresa pela comunidade impactada (positiva e negativamente). Entretanto o conceito apresenta limites se adotado somente a partir da ótica da empresa, tendo em vista ser imprescindível agregar a ótica das demais partes envolvidas e ou impactadas pelo empreendimento. Os processos de LSO tendem a privilegiar ou fazer o que é necessário para evitar a perda da aceitação da comunidade em detrimento de focar na melhoria de padrões de desempenho ambientais e sociais. Nesse contexto o risco social no setor de mineração é frequentemente confundido com riscos para o negócio promovido pelos stakeholders em detrimento dos riscos das operações minerais para a comunidade como um todo. A maior articulação das partes interessadas ampliou a variedade dos atores no processo de governança corporativa. A solução de conflitos relacionados a impactos ambientais e sociais, entendidos como responsabilidade do Estado e empresas, demandam uma gestão colaborativa, mediante acordos, consensos e participação pública (Ansell e Gash, 2008) envolvendo também a sociedade civil (Prno e Slocombe, 2012). Para a mineração, particularmente, este argumento se justifica, pois, apesar de sua importância para a atividade industrial, o setor está sujeito a elevado escrutínio da sociedade e a críticas devido aos impactos negativos de suas operações (Lamontagne, 2015). Sendo assim, o processo de tomada de decisão neste setor não pode mais privilegiar os avanços tecnológicos na busca pela produtividade em detrimento de uma abordagem social que valorize o diálogo, absorvendo diferentes pontos de vista e interesses coletivos (Franks e Cohen, 2012). O diálogo, segundo Frank (2014) deve ser mantido em todas as etapas de operação da mina, desde 
o início do projeto mineral, quando surgem as primeiras expectativas locais e podem ocorrer ajustes na atuação da empresa, até o momento do encerramento das operações. Esta mudança, no entanto, não é simples, pois predomina no setor ações reativas, como resposta a momentos de conflitos e pressão de grupos da sociedade, associados a impactos socioambientais significativos gerados pela extração mineral (Campos e Carillo, 2008; Koivurova et al., 2015; Ruesga e Durán, 1995). A LSO emerge como um elemento complementar aos mecanismos formais de controle das empresas, como por exemplo a legislação ambiental, de forma a assegurar a legitimidade das organizações. A proposta de uma LSO baseia-se na ideia de que a sociedade pode dar ou recusar o apoio à uma empresa e suas operações (Prno, 2013; Moffat e Zhang, 2014), sendo necessário que empresas de mineração avancem para além das obrigações formais (Santiago e Demajorovic, 2016). A LSO nesse contexto é ressaltada pelas empresas como um elemento estratégico de sua responsabilidade corporativa, contribuindo para minimizar riscos aos negócios e garantir sua reputação (Owen e Kemp, 2013).

\section{LIMITES DA LSO E CONTRIBUIÇÕES DA AIS}

Muitos dos desafios da LSO estão associados a forma como a comunidade local percebe o risco e como estes são gerenciados (Business Council of British Columbia, 2015). A confiança do público é a base da aceitação social. Sendo assim, assume-se para este trabalho que identificação, gestão e a comunicação efetiva e transparente dos riscos seria o elemento essencial para construir a confiança entre projetos minerais e a comunidade. Isto significa que o engajamento da comunidade local nas questões der risco é o elemento chave dos processos de LSO. Para a que a avaliação de risco social possa cumprir este papel rumo a legitimação de empreendimentos minerais, é essencial ir além da forma tradicional dos processos de avaliação de riscos. É necessário agregar ao tradicional ponto de vista tecnológico, que envolve métricas e cálculos matemáticos, o ponto de vista a partir da percepção da comunidade local. A contribuição da Avaliação de Impacto Social (AIS) para o processo de LSO, propõem o preenchimento de uma lacuna, uma limitação, que é identificar os riscos somente pela ótica do negócio, em detrimento dos riscos das operações minerais para a comunidade como um todo (Kemp, Worden e Owen, 2016), considerando que o entendimento de 
situações de risco da empresa nem sempre são os mesmos dos seus stakeholders e da comunidade em geral (Ower e Kemp, 2013).

A ênfase nas medidas que garantam manter a reputação das organizações levaria as empresas a escolher as ações que resultem em menor oposição ao projeto, uma vez que a resistência das comunidades pode afetar diretamente sua rentabilidade, seja por atrasos na produção ou aumento dos níveis de regulamentação governamental (Parsons, Lacey e Moffat, 2014). Neste processo, empresas procuram por meio do diálogo com a comunidade assegurar sua capacidade de controlar eventuais riscos e exaltar os benefícios econômicos do projeto de forma a diminuir a resistência da população local aos potenciais riscos (Campbel e Roberts 2010). Nesse contexto, ações que promovam ganhos econômicos em comunidades locais aparecem, de acordo com Meesters e Behagel (2017) como centrais nos processos de LSO. Em contraparte, Kemp e Owen (2018) enfatizam a necessidade de a empresa ter um profundo nível de compreensão das expectativas da população local, cumprindo as obrigações de desenvolvimento sustentável, respeitando os direitos humanos e promovendo benefícios sociais. Quanto mais bem-sucedidos nesta estratégia, mas próximo as empresas poderiam estar do estágio copropriedade psicológica proposto por Thomson e Boutilier (2011). Gaviria (2014, p. 12) sugere que o estágio de copropriedade psicológica é «o melhor cenário possível para os gestores do risco social para exaltar sua LSO, uma vez que o elevado grau de confiança previne eventuais conflitos entre comunidade e empresa». No entanto, utilizar a ausência de contestação de projetos como uma legitimidade de sua LSO é criticada por Owen e Kemp (2013), propondo que tal situação seria um indicador de resistência mínima da comunidade, sendo necessário entender o que está abaixo da superfície neste processo. Frente a tal realidade é necessário diferenciar o processo de legitimação organizacional normativa, da prática empresarial (Demuijnk e Fasterling, 2016). O primeiro depende de um contrato social em que a aprovação da empresa é resultado do fato que todos os grupos estejam perfeitamente informados sobre as práticas organizacionais. No entanto, na prática o processo de legitimidade pode ser alcançado justamente porque alguns grupos não estão informados ou parcialmente informados sobre as práticas efetivas da empresa. Meesters e Behagel (2017) sugerem que técnicas de neutralização de ideias que não estejam alinhadas com o discurso dominante podem ser usadas pelas organizações de forma a assegurar sua LSO. Empresas podem utilizar seus instrumentos de relação com a 
comunidade e sua estratégia de investimentos para ganhar a confiança dos stakeholders locais ao mesmo tempo que impactos na comunidade podem ser desconsiderados.

Um exemplo prático é tratado por Santiago (2016) durante o processo de fechamento de mina no Brasil, o qual demostrou que a postura assistencial adotada pela empresa e pelo governo local para com a comunidade e a dependência econômica da mineração durante a operação velaram os reais impactos ocorridos após o encerramento das atividades. O fechamento da mina indicou que o elevado grau de dependência pela comunidade da empresa e escondeu não apenas riscos para a comunidade, mas também para o próprio negócio. O contexto resultou no estabelecimento de uma LSO instável firmada durante as atividades da mina, que não se manteve sendo revogada após as transformações econômicas sofridas pelo município com o encerramento das operações da mina. Conflitos e manifestações locais foram empreendidos pela comunidade em resposta aos impactos socioeconômicos, tendo a empresa a sua Licença social revogada (Santiago, 2016). Ainda no Brasil, Lopes e Demajorovic (2016) mostram o recente exemplo do rompimento da barragem da Mineradora Samarco, localizada no município de Mariana. Por se tratar da maior tragédia socioambiental causada por vazamento de rejeitos em nível mundial envolvendo o setor de mineração (Fernandes et al., 2016). Para manter a percepção positiva da comunidade em relação à segurança, de acordo com Lopes e Demajorovic (2016), a empresa reforçava em seu diálogo com a comunidade a sua capacidade de minimizar riscos. No entanto, o rompimento da barragem que matou 19 pessoas e gerou um mar de lama que se estendeu por $600 \mathrm{~km}$ contaminando diversos ecossistemas foi caracterizado por uma ausência de plano efetivo de gestão de risco que pudesse minimizar os impactos da tragédia. Já na mina Tambogrande no Peru, a polarização das posições empresa, governo e comunidade local e a baixa confiança na segurança das operações minerais resultaram no não estabelecimento da LSO e suspensão das operações minerais (Prno, 2014). Os casos mostram os limites de uma LSO quando a legitimidade da empresa não é construída por um processo efetivo de avaliação e gestão de impactos socioambientais causados pela empresa (Nelsen e Scoble, 2006) encobrindo conflitos que poderiam motivar ações mitigadoras. A conquista e a manutenção da LSO se alicerça como resultado da adequada gestão dos impactos socioambientais das operações da empresa, e nas condições nas quais a empresa opera 
(Kokko, 2014). Se uma empresa não segue a legislação ou não opera de acordo com os regulamentos estabelecidos pode perder a credibilidade e a confiabilidade conquistados em uma LSO (Franks e Cohen, 2012). A principal contribuição da AIS para a LSO é aumentar a credibilidade e efetividade do processo. Ao reconhecer e atuar sobre impactos identificados pelos indivíduos e grupos que sentem as consequências positivas e negativas de projetos minerais amplia-se a possiblidade de que a LSO seja um instrumento efetivo da legitimidade da operação e não apenas uma reduzir resistências a implantação e operação de projetos. A AIS pode alicerçar os principais fatores determinantes para a obtenção da LSO, de acordo com Santiago (2016): a) conhecer e gerir os impactos socioambientais das operações da empresa; b) conhecer as percepções e expectativas das comunidades impactadas.

\section{CONClusÃo}

A conquista e manutenção de uma LSO deve ser resultado de uma adequada gestão dos impactos socioambientais e no entendimento, por parte da empresa, de como estes impactos são sentidos. Para tanto, é necessário que a compreensão dos impactos sociais não seja apenas retrospectiva da empresa, mas planejada e proativa, antecipando-se à ocorrência dos impactos (Vanclay, 2002a) e definindo a população que sofre o impacto direto das operações, principais atores na concessão de uma LSO (Campbell e Roberts, 2010; Thomson e Boutilier, 2011; Prno e Slocombe, 2012; Falck e Spangenberg, 2014; Vanclay, 2016). Ressalta-se, portanto, a relevância da LSO estar baseada em uma prévia AIS para a gestão dos projetos minerais. Agregando aos riscos relacionados ao negócio, a partir da ótica da empresa, os potenciais riscos das operações minerais, a partir da ótica da população impactada. Em se tratando dos impactos socioambientais da mineração tanto a empresa como a população local são afetadas, em primeiro lugar, a população situada no entorno das áreas de extração, que sofre diretamente os impactos das atividades produtivas. E um segundo momento, caso os impactos não sejam gerenciados, a própria empresa é afetada, quando emergem conflitos com a população local, além de legislações mais restritivas, resultando em limitações para operar e diversos custos para a empresa (Franks et al., 2014). O desafio para se obter e manter uma LSO vai além da gestão dos conflitos, demanda mudanças no enfoque da gestão social dos riscos nas empresas, evoluindo de um modelo reativo, com 
respostas a riscos primários que surgem em momentos de conflitos e pressão de grupos da sociedade, como a probabilidade de interromper as operações e as consequências para a reputação e posse, para um modelo proativo, buscando compreender quais são os riscos que a empresa representa para a comunidade, quais são as expectativas locais em relação a empresa, além de um diálogo mais amplo e o cumprimento, por parte da empresa, das obrigações de desenvolvimento sustentável e de direitos humanos.

\section{REFERÊNCIAS}

Ansell, C., \& Gash, A. (2008). Collaborative Governance in Theory and Practice. Journal of Public Administration Research and Theory, 18(4), 543-571. doi:10.1093/jopart/mum032

Business Council of British Columbia (2015). Disponível em: < http://www. bcbc.com/publications > Acesso em: 2 mar. 2018.

Campbell, G. N. \& Roberts, M. (2010). Permitting a new mine: Insights from the community debate. Resources Policy, 35, 210-217.

Campos, A., \& Carillo, M. (2008). Minería, derechos humanos y medio ambiente en Perú. In M. A. Zegarra (Ed.), Impactos económicos sociales y politicos de las industrias extractivas (pp. 149-166). Barcelona: Icaria.

Demuijnck, G. \& Fasterling, B. (2016). The social License to Operate. Journal of Business Ethics, 136, 41, 675-685.

Ernest and Young. EY (2017). Business risks facing mining and metals 2017-2018. Disponível em: http://www.ey.com/gl/en/industries/ mining---metals/business-risks-in-mining-and-metals (acesso em: 2 mar 2018).

Falck, A. W. E.; Spangenberg, J. H. (2014). Selection of social demand-based indicators: eo-based indicators for mining. Journal of Cleaner Production, 84, 193-203.

Fernandes et al. (2016). Deep in the mud: ecological and social economic impacts of the dan breach in mariana, Brazil. Brasilian Journal of Nature Conservation, 14, 35-45.

Franks, D. M., \& Cohen, T. (2012). Social licence in design: constructive technology assessment within a mineral research and development institution. Local: University of Queensland. et al. (2014). Conflict translates environmental and social risk into business costs. Proceedings of the National Academy of Sciences of the United States of America, 111, 21, 7576-7581, 10 jan. 
Gaviria, E. M. A. (2015). «Licença social para operar» na indústria da mineração: uma aproximação a suas apropriações e sentidos. Estudos Urbanos e Regionais, 17, 2, 138-154.

Gunningham, N.; Kagan, R. A. \& Thornton, D. (2004). Social licence and environmental protection: why businesses go beyond compliance. Law \& Social Inquiry, 29, 307-341.

Kemp, D.; Worden S., \& Owen J. R. (2016). Differentiated social risk: Rebound dynamics and sustainability performance in mining. ResourcesPolicy, 50, 19-26.

Kemp, D., \& J.R. Owen (2018). Social performance gaps in the global mining industry: A position paper for executives. Centre for Social Responsibility in Mining, Sustainable Minerals Institute, The University of Queensland: Brisbane.

Kokko, K. et al. (2014). Sound Mining in the North. A Guide to Environmental Regulation and Best Practices Supporting Social Sustainability. Tekes - the Finnish Funding Agency for Technology and Innovation European Union, ERDF. Electronic version: ISBN 978-951-40-2464-1 (PDF).

Koivurova, T.; Buanes, A.; Riabova, L.; Didyk, V.; Ejdemo, T.; Poelzer, G.;... Lesser, P. (2015). «Social license to operate»: a relevant term in Northern European mining? Polar Geography, 38(3), 194-227. doi:10.1080/1088937X.2015.1056859

Lacey J.; Parsons R., \& Moffat, K. (2012). Exploring the Concept of a Social Licence to Operate in the Australian Minerals Industry: Results From Interviews With Industry Representatives. CSIRO.

Lamontagne, A. (2015). A configuração institucional da responsabilidade social empresarial nas relações capital/trabalho: empresas multinacionais de mineração no Brasil e no Canadá

(Doutorado Tese), Universidade de Brasília, Brasília.

Lopes, J., \& Demajorovc, J. A. (2017). Tragédia da Samarco a Luz da Licença Social para Operar: Uma Análise de Conteúdo das Publicações na Mídia de 2007 a 2015. ANPAD.

Meesters. M. E., \& Behagel, J. H. (2017). The social license to operate: ambiguities and the neutralization of harm in Mongolia. Resources Policy, 53, 274-282.

Moffat, K.; Zhang, A., \& Boughen, N. (2014). Australian attitudes toward mining: Citizen survey -2014 results. Australia: CSIRO.

Nelsen, J., \& Scoble, M. (2006). Social Licence to Operate Mines: Issues of Situational Analysis and Process: Department of Mining Engineering. Vancouver: University of British Columbia.

Owen, J. R, \& Kemp, D. (2013). Social licence and mining: A critical perspective. Resources Policy, 38, 29-35. 
Parsons, R.; Lacey, J., \& Moffat, K. (2014). Maintaining legitimacy practice: How the minerals industry understands its social licence to operate. Resources Policy, 41, 83-90.

Prno, J. (2014). Establishing a social licence to operate amidst complexity: issues and opportunities for mining industry. Tese (Doutorado em Geografia), Wilfrid Laurier University, Canada. , \& Slocombe, D. S. (2012). Exploring the origins of «social license to operate» in the mining sector: Perspectives from governance and sustainability theories. Resources Policy, 37, 346-357.

Ruesga, S. M., \& Durán, G. (1995). Empresa y medio ambiente. Madrid: Pirámide-

Santiago, A. L. F. (2016). Licença social para operar relacionamento da empresa com a comunidade local: critérios de influência para a concessão da LSO. Um estudo de caso da mineração brasileira. Doctoral Thesis. FEI Sao Paulo University, Brazil and Alicante University, Spain.

Santiago, A. L. F., \& Demajorovic, J. (2016). Social license to operate: A case study from Brazilian mining industry. Latin American Journal of Management for Sustainable Development, 3, 19-34.

Thomson, I., \& Boutilier, R. G. (2016). Social license to operate. In: P. Darling (Ed.), SME Mining Engineering Handbook. http://socialicense. com/publications.html. 2011. Acesso em janeiro de 2016.

Vanclay, F. (2002). Conceptualising social impacts. Environ Imp. Assess Rev., 22, 3, 183-211.

(2016). Legitimacy, credibility and trust as the key components of a social licence to operate: An analysis of BP's projects in Georgia. Journal of Cleaner Production, Oct.. 


\title{
LA INCIDENCIA DE LA RSE EN LA REPUTACIÓN CORPORATIVA Y SU MEDICIÓN EN EMPRESAS DE COMUNICACIÓN
}

\author{
Jaime Alberto Orozco-Toro" \\ Colombia
}

\section{INTRODUCCIÓN}

Los estudios que relacionan la Responsabilidad Social Empresarial (RSE) con la economía, la estrategia empresarial, el marketing, entre otros, son numerosos, en especial en los países anglosajones. Sin embargo, aquellas investigaciones sobre la comunicación de la RSE son mucho menos prolíficas. Aún más, si la intención es indagar sobre el vínculo entre la comunicación de la RSE y sus efectos en la Reputación Corporativa (RC), los estudios son más que escasos.

Hasta el momento, las exploraciones realizadas sobre la incidencia de la RSE en la RC no son concluyentes e incluso en algunos casos son contradictorias. Quizá una de las justificaciones a este hecho es que no se haya abordado a toda la cadena de valor. Si bien es cierto que los stakeholders cobran cada vez más importancia para las empresas, la mayoría de los procesos investigativos se centran en empleados y usuarios. Dadas estas circunstancias, el enfoque de este artículo se dirige hacia la manera en que la RSE afecta o incide en la RC y la forma en que se puede medir dicha incidencia en empresas de comunicación.

\section{Herramientas de COMUNiCACión DE LA RSE}

El advenimiento de las TIC y los procesos de globalización de los modelos tradicionales de comunicación, como la publicidad, les han

Doctor en Medios, Comunicación y Cultura. Universidad Pontificia Bolivariana. Correo electrónico: jaime.orozco@upb.edu.co 
ido abriendo campo a medios no convencionales como los sitios web, blogs, redes sociales, informes anuales, gabinetes de prensa, memorias de sostenibilidad, entre otros. En este orden de ideas, uno de los aspectos importantes radica en que la comunicación ya no fluye en la dirección tradicional, de arriba abajo (Hollender y Breen, 2010), sino que los stakeholders tienen la potestad de participar en los procesos de comunicación y diálogo. Esta es una condición sine qua non para el éxito, ya que como lo aseguran Cantó-Milà y Lozano (2008), el diálogo «it is the only way for any CSR initiative to be successful» (p. 165). Inclusive la propia comunicación cambia cuando se trata de la RSE, pues se tienen herramientas y condiciones propias para su materialización.

Las empresas emplean tradicionalmente tres tipos de herramientas de comunicación para dar a conocer sus actividades de RSE: informes sociales, informes temáticos e informes anuales (Illia, Rodríguez, González y Romenti, 2010). Específicamente, la memoria anual (también llamada memoria de sostenibilidad), el balance social y la página web son los documentos que se han convertido en los principales instrumentos de comunicación de la RSE.

\section{ESTRATEGIAS DE COMUNICACIÓN DE LA RSE}

Las estrategias de comunicación institucional o comercial de una organización difieren en gran medida de las estrategias de comunicación de la RSE. Las bases de la publicidad y la comunicación comercial de la marca que han definido importantes autores (Aaker, 2002; Sanz de la Tajada, 1996; Van Riel, 1997; Cerviño, 2002; Borrini, 2006; Cooper, 2006) están mediadas por una relación directa con los públicos objetivos a través de la promoción de productos y servicios. Estos han sido tradicionalmente los que han acaparado el espectro de la comunicación entre las marcas y sus consumidores. En contraposición, la comunicación de la RSE está orientada a la identidad y a los valores corporativos que comparte con todos sus grupos de interés.

Además de la complejidad de la comunicación de la RSE, uno de los mayores retos a los que se enfrentan los encargados de estas estrategias es la decisión de si es correcto o no difundir las acciones de RSE $\mathrm{y}$, posteriormente, establecer la intensidad de dicho vínculo con los stakeholders. La discusión de comunicar o no tiene menores implicaciones, pues instituciones públicas y privadas como el Global Compact de las Naciones Unidas, el Libro Verde de la Comisión Europea, o el 
Global Reporting Initiative recomiendan dar a conocer los esfuerzos que en materia de RSE desarrollan las empresas. El meollo de la situación radica en definir la intensidad de esta relación.

Para algunos autores, una comunicación excesiva de la RSE ha sido interpretada por los públicos como una acción de maquillaje (Villagra, 2007). Aunque no existe una fórmula mágica o una medida estándar que determine la intensidad de la comunicación, la clave está en la realización de una comunicación transparente (Epstein y Birchard, 2001). Aquí emerge uno de los mayores paradigmas de la comunicación de la RSE: no existe una mejor estrategia corporativa que la transparencia y el diálogo con los stakeholders.

Ahora bien, en la actualidad, la saturación de mensajes que impactan diariamente a la audiencia se convierte en un obstáculo para que los públicos comprendan mejor lo que la compañía quiere comunicar. Por eso, Azuero (2009) propone la combinación de aspectos de fondo, racionales, técnicos y de largo plazo con otros más atractivos y emocionales. Esta estrategia puede ser interesante en el caso de que la información que se debe entregar a los stakeholders no implique altos niveles de atención o una comprensión mayor, por ejemplo, de cifras y justificantes de una labor materializada cuantitativamente.

Por último, la comunicación estratégica de la RSE en la que se valora la transparencia y el diálogo con los stakeholders requiere, aunque parezca obvio, una comunicación responsable, que anteponga los valores corporativos, y que siempre esté en consonancia con la misión y la visión de la organización.

\section{INVESTIGACIONES SOBRE LA COMUNICACIÓN DE LA RSE}

Si bien la comunicación de la RSE ha recibido una mayor atención en los últimos años, tradicionalmente ha sido uno de los renglones más olvidados dentro de las investigaciones que vinculan la empresa con sus stakeholders a través de estrategias corporativas. En alusión a la comunicación de la RSE, Morsing et al. (2008) optaron por analizar la manera en que las empresas danesas comunicaban su responsabilidad social. Los resultados demostraron que la comunicación de la RSE impactaba directamente sobre una amplia variedad de stakeholders, lo que favorecía su reputación. Por su parte, Sweeney y Coughlan (2008) tomaron como base los reportes anuales de RSE, encontrando que se trata de herramientas que permiten el contacto con una amplia variedad 
de grupos de interés, situación que era igualmente bien valorada por Morsing et al. (2008).

Una posición contradictoria sobre este tipo de comunicación proviene de Baghi et al. (2009). Estos investigadores, luego de analizar mensajes sobre la RSE y el marketing con causa, concluyeron que "CSR communication is a very delicate matter. While stakeholders claim they want to know about the good deeds of the companies they interact with, they can easily become leery of extrinsic motives when companies promote their CSR efforts» (p. 17). Esta aseveración puede llegar a ser una verdad bien conocida por quienes trabajan en el sector de la comunicación, sin embargo, este factor no significa que la RSE no genere impactos positivos sobre la audiencia, sino que se sabe con anterioridad que es una práctica comunicativa que debe realizarse con sumo cuidado.

Se encuentran otros resultados divergentes, como aquellos que plantean la dificultad de las pequeñas empresas para poner en práctica estrategias de comunicación de la RSE (Ziek, 2009). Las empresas deben hacer cada día un esfuerzo más grande para convencer a los stakeholders sobre su responsabilidad, debido a los escándalos de multinacionales acaecidos alrededor del mundo (Arvidsson, 2010).

En una banda diferente está la investigación llevada a cabo por Kim (2011). Sus postulados sugieren que la comunicación de la RSE debe ser más congruente con los mensajes y la relación con sus stakeholders para generar algún resultado positivo, de lo contrario, se elevará la suspicacia de los públicos, disminuyendo la efectividad de la comunicación. En contraposición, Sohn et al. (2012) sugieren que para que la eficiencia de la comunicación de la RSE aumente, se deben realizar campañas publicitarias con un importante contenido explicativo, de tal forma que se den a conocer todos los aspectos que puedan vincular la marca con los grupos de interés.

Tanto Sohn et al. (2012) como otros investigadores hacen recomendaciones a las empresas sobre la forma en que deben realizar la comunicación de la RSE. Así lo sugieren Amaladoss y Manohar (2013), pues para ellos las estrategias que se deben implementar deben corresponder a un modelo previamente establecido.

Aunque los resultados de estas indagaciones sean de alguna manera contradictorias, lo interesante de las investigaciones relacionadas con la comunicación de la RSE está en advertir que esta actividad cobra cada vez mayor importancia, dado que investigadores y directivos han entendido la enorme relevancia de un vínculo transparente con los stakeholders. 


\section{VÍNCULO RSE CON EMPRESAS DE COMUNICACIÓN}

Las empresas de comunicación pertenecen a uno de los ámbitos empresariales donde menos acciones de RSE se desarrollan. Una de las formas para comprobar esta afirmación es que, ante la verificación de las empresas adheridas al Pacto Mundial de las Naciones Unidas, el renglón perteneciente a las empresas de comunicación es uno de los que menos participación tiene (Ferré Pavia y Orozco, 2011, p. 101).

Las investigaciones vinculantes con las empresas de comunicación se suscriben en su mayoría a los medios de comunicación masivos, en especial los medios impresos (Paz, 2010), o los que analizan los reportes anuales de agencias de publicidad (Waller y Lanis, 2009).

Entre los descubrimientos más importantes están los que precisan que las empresas de comunicación utilizan una amplia variedad de conceptos e iniciativas de RSE, entre los cuales están los derechos humanos, la relación con los trabajadores, el cuidado del medioambiente o la diversidad (Hou y Reber, 2011) los que denuncian que las empresas de comunicación no implementan acciones estratégicas con al menos varios tipos de stakeholders (Orozco y Ferré Pavia, 2011), o la investigación de Ingenhoff y Koelling (2012), que evidencia cómo las empresas de comunicación están utilizando la Responsabilidad Social Corporativa (RSC) con el objetivo de mostrarse ante la sociedad como buenos ciudadanos corporativos.

Otra investigación sobre la RSE de las empresas de comunicación revela que «es palpable el desconocimiento que las empresas tienen del uso de las nuevas tecnologías de comunicación de masas y autocomunicación» (Fernández, 2013, p. 105). Este autor, que analiza el uso de la Web 2.0 para comunicar la RSC, además denuncia que «queda un largo camino para que las corporaciones de radiotelevisión públicas encuentren la senda correcta para comunicar sus acciones de responsabilidad social, para hacer atractivos sus datos y para lograr retroalimentación con los grupos de interés» (p. 108).

\section{MEDICIÓN DE LA REPUTACIÓN CORPORATIVA}

Evaluar la reputación corporativa (RC) se ha convertido en una gestión indispensable para organizaciones e investigadores. Esta necesidad proviene de la idea que señala Lizcano (2006), de que «los recursos y actividades intangibles han de poder ser representados en una 
serie de indicadores que hagan posible su medición y comparabilidad» (p. 165). La valoración de la RC ha sido un tema recurrente a partir de la década de 1990, debido a la evidencia de que los intangibles tienen un valor financiero (Olins, 2000) y que una buena reputación es la base para hacer frente a la creciente competitividad de los mercados globales (Fombrun y Rindova, 2000; Sarstedt, Wilczynski y Melewar, 2013). Adicionalmente, hay quienes consideran que el mayor interés acerca de la RC es su posibilidad de medición, razón por la cual se ha convertido en una oportunidad para la generación de nuevos índices de medición (Sanna, 2013).

Las posiciones más significativas de investigadores proponen la utilización de métodos cualitativos y cuantitativos para evaluar la reputación. Una de las propuestas se encamina a la combinación de diferentes modelos de otros investigadores, para luego preguntar a los grupos de interés por sus percepciones directamente sobre la reputación (Earl y Waddington, 2012), entretanto Hannington (2006) es quien mejor desarrolla una propuesta de evaluación de los intangibles con el fin de conocer la reputación de una compañía. Para este investigador, se deben cumplir ciertas circunstancias básicas. La primera es evaluar a todos los stakeholders. Esta recomendación es muy importante, pues muchos de los métodos que existen en la actualidad para medir la reputación de las empresas se basan en las percepciones de un solo grupo de interés (Ruiz, Esteban y Gutiérrez, 2014).

Desde la perspectiva de dichas herramientas de medición de la RC, se cuenta con diferentes modelos de evaluación (Raithel y Schwaiger, 2015). Los modelos vinculados con la comunicación se han desarrollado desde dos perspectivas: una académica y otra desde la consultoría; ambas buscan mejorar la gestión empresarial (Garrido, 2004). Debido a la dificultad que conlleva esta actividad, los medios de comunicación han optado por realizar únicamente mediciones de audiencia (Orozco-Toro, 2018). A pesar de las dificultades propias de la creación de herramientas que determinen los efectos de la comunicación de las organizaciones, no se pueden escatimar esfuerzos en la búsqueda de instrumentos de evaluación.

\section{INCIDENCIA DE LA RSE EN LA RC DE LAS EMPRESAS DE COMUNICACIÓN}

Una de las mayores problemáticas en torno a la RSE es la dificultad para medir y evaluar la incidencia que tienen dichas acciones sobre la 
RC. En este sentido, se ha desarrollado una propuesta de índice de medición que permita evaluar la influencia de las acciones de RSE y de otros aspectos del devenir de las empresas en su reputación. Este índice, denominado como Índice de Reputación Corporativa para Empresas de Comunicación (IRCEC), posee cinco dimensiones y diecisiete atributos, en los que se han tenido en cuenta las condiciones más importantes de las empresas de comunicación en su relación con los stakeholders.

Para el caso del IRCEC, las dimensiones representan las magnitudes o tópicos generales del aspecto que se evaluará, es decir, la medida orientativa que determina los atributos. También se pueden interpretar las dimensiones como la materialización de los aspectos preponderantes de la actuación de la organización con relación a sus stakeholders. Asimismo, los atributos serán las cualidades y propiedades específicas de cada una de las dimensiones, lo que equivale a decir que los atributos son representaciones concretas de cada dimensión (cuadro 1).

CuAdro I. ÍNDICE DE RC PARA EMPRESAS DE COMUNICACIÓN

\begin{tabular}{|c|c|}
\hline DIMENSIONES & Atributos \\
\hline \multirow{4}{*}{ Autonomía } & Transparencia \\
\hline & Honestidad \\
\hline & Independencia \\
\hline & Confianza \\
\hline \multirow{3}{*}{ Vínculo } & Diálogo \\
\hline & Empatía \\
\hline & Percepción \\
\hline \multirow{3}{*}{ Calidad } & Calidad percibida \\
\hline & Garantía y atención \\
\hline & Acceso a información \\
\hline \multirow{4}{*}{ RSC } & Responsabilidad social \\
\hline & Responsabilidad económica \\
\hline & Responsabilidad ambiental \\
\hline & Responsabilidad legal \\
\hline \multirow{3}{*}{ Gestión } & Gestión estratégica \\
\hline & Estructura empresarial \\
\hline & Cultura organizacional \\
\hline
\end{tabular}

FUENTE: ElaboraCión PROPIA. 


\section{DiMENSIÓN AUTONOMÍA}

La dimensión autonomía dentro del IRCEC se definirá bajo la perspectiva y concepción griega que la cataloga como la capacidad de gobernarse a sí mismo, es decir, el propio autogobierno en función del sistema de valores que posea la organización. Los atributos que definen y caracterizan esta dimensión son transparencia, honestidad, independencia y confianza. Con el objetivo de aplicar el IRCEC, se han relacionado ocho preguntas que permitirán conocer las percepciones de los stakeholders respecto de la autonomía de las empresas de comunicación (cuadro 2).

Cuadro 2. Preguntas correspondientes a la autonomía

\begin{tabular}{|l|l|}
\hline \multicolumn{1}{|c|}{ Autonomía } \\
\hline \multirow{4}{*}{ La empresa: } \\
\hline \multirow{3}{*}{ Honestidad } & Informa a sus stakeholders de todas sus acciones. \\
\cline { 2 - 2 } & $\begin{array}{l}\text { Da a conocer a sus stakeholders informes con sus cuentas } \\
\text { anuales. }\end{array}$ \\
\hline \multirow{3}{*}{ Independencia } & Demuestra ser una organización con claridad informativa. \\
\cline { 2 - 2 } & No emite información falsa. \\
\cline { 2 - 3 } Confianza & Es una organización neutral e imparcial. \\
\hline \multirow{2}{*}{ Es una organización que respeta a sus stakeholders. } \\
\cline { 2 - 3 } & Es una organización en la que se puede creer. \\
\hline
\end{tabular}

FueNTE: ELABORACIÓN PROPIA.

\section{Dimensión VÍNCULO}

Se interpreta el vínculo dentro del desarrollo del índice como la interacción entre dos o más personas u organizaciones, de manera que se sostiene una conexión dinámica a través de una conducta específica que está determinada por los intereses de cada una de las partes. Los atributos que forman parte del vínculo son diálogo, empatía y percepción. Para cada uno de estos tres atributos se proponen dos preguntas (cuadro 3). 
LA INCIDENCIA DE LA RSE EN LA REPUTACIÓN CORPORATIVA Y SU MEDICIÓN EN EMPRESAS DE COMUNICACIÓN

Cuadro 3. Preguntas correspondientes al vínculo

\begin{tabular}{|l|l|}
\hline \multicolumn{2}{|c|}{ La empresa: } \\
\hline \multirow{2}{*}{ Diálogo } & Dispone de canales de comunicación bilateral. \\
\cline { 2 - 3 } & Es una organización que acepta opiniones contrarias. \\
\hline \multirow{2}{*}{ Empatía } & Es una buena compañía para trabajar. \\
\cline { 2 - 2 } & Es una organización que demuestra familiaridad. \\
\hline \multirow{2}{*}{ Percepción } & Es una organización que transmite respeto. \\
\cline { 2 - 3 } & Es una organización con una buena imagen. \\
\hline
\end{tabular}

Fuente: Elaboración Propia.

\section{DiMENSIÓN CALIDAD}

La calidad se entenderá como las características cualitativas de una organización que le confieren la aptitud de satisfacer de la mejor manera posible las expectativas y necesidades de los stakeholders con los que tiene un vínculo. Los atributos que hacen parte de la dimensión calidad son calidad percibida, garantía y atención y acceso a información. Para cada uno de los atributos se han construido dos preguntas que permitirán la valoración completa de la calidad de la empresa de comunicación (cuadro 4).

Cuadro 4. Preguntas correspondientes a la calidad

\begin{tabular}{|l|l|}
\hline \multicolumn{2}{|c|}{ CALIDAD } \\
\hline \multirow{2}{*}{ Calidad percibida } & $\begin{array}{l}\text { Offece a sus stakeholders productos que cumplen sus } \\
\text { expectativas. }\end{array}$ \\
\cline { 2 - 2 } & Desarrolla productos innovadores. \\
\hline \multirow{2}{*}{ Garantía y atención } & Dispone de productos para diversos stakeholders. \\
\cline { 2 - 2 } Acceso a información & Responde a las exigencias de los stakeholders. \\
\hline & $\begin{array}{l}\text { Ofrece facilidades de acceso a la información a sus } \\
\text { stakeholders. }\end{array}$ \\
\cline { 2 - 2 } & $\begin{array}{l}\text { Comunica a los stakeholders los canales disponibles } \\
\text { para el diálogo. }\end{array}$ \\
\hline
\end{tabular}

FUENTE: ElABORACIÓN PROPIA. 


\section{Dimensión RSC}

La responsabilidad social corporativa se representa dentro del análisis del IRCEC como el cumplimiento de las obligaciones de la organización con cada uno de sus stakeholders en los ámbitos económicos, sociales, medioambientales y legales. Ya que esta es una de las dimensiones más importantes del IRCEC para los efectos de la investigación, se han creado diez preguntas que dan cuenta de los cuatro atributos mencionados (cuadro 5).

Cuadro 5. Preguntas correspondientes a la RSC

\begin{tabular}{|l|l|}
\hline \multicolumn{2}{|c|}{ RSC } \\
\hline \multirow{2}{*}{$\begin{array}{l}\text { Responsabilidad } \\
\text { social }\end{array}$} & Respeta los derechos humanos. \\
\cline { 2 - 2 } & Apoya las buenas causas. \\
\cline { 2 - 2 } $\begin{array}{l}\text { Responsabilidad } \\
\text { económica }\end{array}$ & Promueve condiciones de equidad con sus stakeholders. \\
\cline { 2 - 2 } & Combate la corrupción. \\
\cline { 2 - 2 } $\begin{array}{l}\text { Responsabilidad } \\
\text { ambiental }\end{array}$ & Contribuye al desarrollo del país. \\
\cline { 2 - 2 } Responsabilidad & Es una organización respetuosa con el medioambiente. \\
\hline \multirow{2}{*}{$\begin{array}{l}\text { Regal } \\
\text { Resarrolla campañas para la conservación ambiental. }\end{array}$} & Cumple las leyes. \\
\cline { 2 - 2 } & $\begin{array}{l}\text { Dispone de códigos de conducta que aplica en toda la } \\
\text { organización. }\end{array}$ \\
\hline
\end{tabular}

FueNTE: ELABORACIÓN PROPIA.

\section{DiMENSIÓN GESTIÓN}

La gestión está representada por las acciones que desarrolla la organización con el objetivo de brindar un producto o servicio de calidad y que, además, mejore las condiciones de competitividad y productividad. Para esta dimensión se relacionan siete preguntas, correspondientes a tres atributos: gestión estratégica, estructura empresarial y cultura organizacional (cuadro 6). 
Cuadro 6. Preguntas correspondientes a la gestión

\begin{tabular}{|l|l|}
\hline \multicolumn{2}{|c|}{ Gestión } \\
\hline \multirow{4}{*}{$\begin{array}{l}\text { Gestión } \\
\text { estratégica }\end{array}$} & $\begin{array}{l}\text { Lesarrolla su labor basada en procesos de planeación } \\
\text { estratégica. }\end{array}$ \\
\cline { 2 - 2 } & Es una organización con una gestión financiera sólida. \\
\cline { 2 - 2 } & Es líder dentro de su sector. \\
\hline \multirow{2}{*}{$\begin{array}{l}\text { Estructura } \\
\text { empresarial }\end{array}$} & Posee una estructura empresarial que favorece su desarrollo. \\
\cline { 2 - 2 } $\begin{array}{l}\text { Cultura } \\
\text { organizacional }\end{array}$ & Se adapta con facilidad a los cambios. \\
\cline { 2 - 2 } & $\begin{array}{l}\text { Promulg con una apropiada cultura organizacional. } \\
\text { nes empresariales. }\end{array}$ \\
\hline
\end{tabular}

FUENTE: ElABORACIÓN PROPIA.

\section{CONCLUSIONES}

Las principales conclusiones de esta investigación están vinculadas a la comunicación de la RSE y al desarrollo de los métodos de evaluación de la RC en empresas de comunicación. Sin embargo, se pueden evidenciar aspectos relacionados con los stakeholders y la misma RC de las empresas de comunicación. En este aspecto, el Índice De Reputación Corporativa En Empresas De Comunicación (IRCEC) se convierte en una herramienta que permite medir la RC en empresas de comunicación, tomando como base factores decisivos y específicos para este tipo de organizaciones. El estudio de las dimensiones y atributos genera un instrumento que no solo pretende determinar la RC de las empresas de comunicación, sino que además da una mayor relevancia a variables como la RSE y puede aplicarse en toda la cadena de valor.

Aunque en la actualidad existe una importante cantidad de investigaciones que abordan el tema de la RSE, este acercamiento a la comunicación de la RSE permite una visión desde los vínculos con la cadena de valor y el diálogo transparente con los stakeholders.

Pero el error más grave en el que puede incurrir una empresa no es equivocarse en la implementación de las acciones de RSE, sino intentar hacerlo con el objetivo de mejorar su RC o resarcirse de una situación pasada a través de una estrategia de «lavado de cara». Los stakeholders cada vez mejor informados son también más escépticos ante las acciones 
empresariales. Por estas razones, una acción de lavado de cara terminará por empeorar la relación con los grupos de interés y deteriorar la propia RC. En este sentido, un paradigma importante es que la RSE y la ética empresarial no deben utilizarse como herramientas para el beneficio de la RC.

La comunicación de la RSE genera impactos decisivos en la RC de las organizaciones, bien sean estos positivos o negativos. La marca, como parte fundamental de los activos empresariales, es quizá el elemento sobre el que más influencia se ejerce.

\section{BiBLIOGRAFÍA}

Aaker, D. (2002). Construir marcas poderosas. Barcelona: Gestión.

Amaladoss, M. y Manohar, H. (2013). Communicating corporate social responsibility - a case of CSR communication in emerging economies. Corporate Social Responsibility and Environmental Management, 20, 65-80.

Arvidsson, S. (2010). Communication of corporate social responsibility: a study of the views of management teams in large companies. Journal of Business Ethics, 96, 339-354.

Azuero, D. (2009). La comunicación de la RSE. Propuestas para un modelo de comunicación responsable. Madrid: Forética.

Baghi, I.; Rubaltelli, E. y Tedeschi, M. (2009). A strategy to communicate corporate social responsibility. Corporate Social Responsibility and Environmental Management, 16, 15-26.

Borrini, A. (2006). Publicidad, diseño y empresa. Buenos Aires: Infinito.

Cerviño, J. (2002). Marcas internacionales. Cómo crearlas y gestionarlas. Madrid: Pirámide.

Cantó-Milá, N. y Lozano, J. (2008). The Spanish discourse on corporate social responsibility. Journal of Business Ethics, 87, 157-171.

Cooper, A. (2006). Planning: cómo hacer el planteamiento estratégico de las comunicaciones. Buenos Aires: Thomson.

Epstein, M. y Birchard, B. (2001). La empresa honesta. Cómo convertir la responsabilidad corporativa en ventaja competitiva. Barcelona: Paidós.

Fernández, T. (2013). Las corporaciones de radiotelevisión pública de la Unión Europea y el incipiente uso de la web 2.0 para comunicar RSC. Journal of Communication, 6, 86-110.

Fombrun, C. y Rindova, V. (2000). The road to transparency: reputation management at Royal Dutch/Shell. En M. Schultz, M. Hatch y M. Larsen (Eds.), The expressive organization. Linking identity, 
reputation, and the corporate brand (pp. 77-96). Nueva York: Oxford University Press.

Garrido, F. (2004). Auditorías de comunicación. En J. Losada (Ed.), Gestión de la comunicación en las organizaciones (pp. 73-100). Barcelona: Ariel. Hannington, T. (2006). Cómo medir y gestionar la reputación de su empresa. Barcelona: Deusto.

Hollender, J. y Breen, B. (2010). The responsibility revolution. How the next generation of businesses will win. San Francisco: Jossey-Bass.

Ingenhoff, D. y Koelling, M. (2012). Media governance and corporate social responsibility of media organizations: an international comparison. Business Ethics: A European Review, 21(2), 154-167.

Kim, S. (2011). Transferring effects of CSR strategy on consumer responses: the synergistic model of corporate communication strategy. Journal of Public Relations Research, 23(2), 218-241.

Lizcano, J. (2006). Información empresarial sobre responsabilidad social. En J. Benavides, J. Fernández y N. Villagra (Eds.), La ética y la responsabilidad social de las empresas y organizaciones (pp. 121-140). Madrid: Universidad Pontificia Comillas.

Morsing, M.; Schultz, M. y Nielsen, K. (2008). The catch 22 of communicating CSR: Findings from a Danish study. Journal of Marketing Communications, 14(2), 97-111.

Olins, W. (2000). How brands are taking over the corporation. En M. Schultz M. Hatch y M. Larsen (Eds.), The expressive organization. Linking identity, reputation, and the corporate brand (pp. 51-65). Nueva York: Oxford University Press.

Orozco, J. y Ferré Pavia, C. (2011). Los stakeholders de las empresas de comunicación en el ámbito de la responsabilidad social corporativa. Folios, 25, 107-125.

Orozco-Toro, J. (2018). Reputación Corporativa. Gestión y comunicación de los valores intangibles de marca. Medellín: Editorial UPB.

Paz, V. (2010). Características de la cobertura informativa de la responsabilidad social empresarial. Cuadernos de Información, 27, 123-135.

Raithel, S. y Schwaiger, M. (2015). The effects of corporate reputation perceptions of the general public on shareholder value. Strategic Management Journal, 36(6), 945-956.

Sanna, D. (2013). Desafíos actuales frente a la medición de la reputación corporativa. Austral Comunicación, 2(1), 79-104.

Sanz de la Tajada, L. (1996). Auditoría de la imagen de empresa. Métodos y técnicas de estudio de la imagen. Madrid: Síntesis.

Sarstedt, M.; Wilczynski, P. y Melewar, T. C. (2013). Measuring reputation in global markets-A comparison of reputation measures' convergent and criterion validities. Journal of World Business, 48(3), 329-339. 
Sohn, Y.; Han, J. y Lee, S. (2012). Communication strategies for enhancing perceived fit in the CSR sponsorship context. International Journal of Advertising, 31(1), 133-146.

Sweeney, L. y Coughlan, J. (2008). Do different industries report corporate social responsibility differently? An investigation through the lens of stakeholder theory. Journal of Marketing Communications, $14(2), 113-124$.

Van Riel, C. (1997). Comunicación corporativa. Madrid: Prentice Hall.

Villagra, N. (2007). ¿Por qué tenemos miedo de comunicar la responsabilidad social corporativa? En A. Bajo y N. Villagra (Eds.), Evolución conceptual y práctica de una gestión responsable (pp. 77-91). Madrid: Universidad Pontificia Comillas.

Waller, D. y Lanis, R. (2009). Corporate social responsibility (CSR) disclosure of advertising agencies: an exploratory analysis of six holding companies anual reports. Journal of Advertising, 38(1), 109-121.

Ziek, P. (2009). Making sense of CSR communication. Corporate Social Responsibility and Environmental Management, 16, 137-145. 


\title{
Consumo Responsable: PERFIL DeL CONSUMIDOR SANTAFESINO
}

\author{
Graciela Kosiak de Gesualdo* \\ Horacio Alesandria" \\ Enrique Carlos Bianchi"** \\ Argentina
}

\section{INTRODUCCIÓN}

Hay coincidencia en los autores al señalar que el Consumo Responsable es uno de los motores de la Responsabilidad Social de la empresa. Según Díaz (2011), es posible hablar de «consumo y consumidor responsable, crítico, ético, político, consciente y transformador, ciudadano de mercado» $y$, aunque no existe unanimidad dentro de la comunidad científica sobre su significado, todas estas denominaciones vienen a abrazar un concepto de consumo que va más allá del acto dirigido a la mera satisfacción de unos intereses o necesidades individuales. Consumir de manera responsable significa aplicar criterios de responsabilidad a la decisión de consumo, es decir, criterios éticos, sociales y medioambientales.

La inclusión de estos criterios en la decisión de compra y consumo deberían llevar al decisor a sopesar las alternativas, en términos de sus consecuencias, en cada uno de los ámbitos señalados y a decidir en función de su racionalidad, su capacidad económica y su grado de implicación con el entorno y consigo mismo (Peiró Barra, 2013).

Los consumidores tienen en general una valoración positiva de cuestiones relativas a preservación del medioambiente por parte de

\footnotetext{
Magíster en Administración de Empresas, Universidad Nacional del Litoral. Correo electrónico: graciegesualdo@hotmail.com

** Magíster en Administración de Empresas, Universidad Nacional del Litoral. Correo electrónico:. haletcsf@gmail.com

*** Doctor en Ciencias Económicas, orientación Administración, Universidad Nacional de Córdoba. Correo electrónico: enriquecarlosbianchi@gmail.com
} 
las empresas; sin embargo, esto se manifiesta escasamente al momento de comprar productos ecológicos. Esto puede ser debido a que existe una falta de sensibilización por los aspectos ecológicos y es de esperar que el impacto de los problemas ambientales en la sociedad dará lugar en el futuro al desarrollo de un consumidor verde (Sánchez García y Gil Roig, 1998).

Asimismo, si bien por un lado los consumidores aceptan racionalmente la importancia de la Responsabilidad Social y conductas éticas de las empresas, esto no siempre se refleja en sus comportamientos, donde siguen primando factores tales como el precio, la imagen de marca, la disponibilidad del producto, etc., como determinantes de la decisión final de consumo. En diferentes estudios se menciona a la falta de información como el principal problema a la hora de elegir en forma responsable una marca.

Al respecto, Valor y Calvo (2009) señalan la existencia de fallas de mercado, que bloquean una expresión adecuada del consumidor socialmente responsable, dado que es predominante la falta de información y la escasa disponibilidad de productos y servicios responsables que afectan la posibilidad misma de que los consumidores puedan tomar decisiones responsables de consumo.

En este trabajo se analiza la percepción de los consumidores sobre la problemática social y ambiental, y el nivel de conocimiento que tienen sobre lo que implica consumir en forma responsable, definiendo una tipología de consumidores sobre la base de una escala de actitudes hacia el Consumo Responsable y su opinión sobre el comportamiento socialmente responsable de las empresas.

Los resultados empíricos surgen de una investigación de tipo descriptiva-explicativa realizada en la Ciudad de Santa Fe (Argentina) en 2015, por un equipo de investigación formado por profesores y tesistas de la Facultad de Ciencias Económicas de la UNL.

\section{MARCo TEÓRICO CONCEPTUAL}

\section{Consumo}

Según Cortina y Carreras (2004), puede caracterizarse el momento actual como la «era del consumo» porque en ella se ha aumentado esta práctica vertiginosamente. Una sociedad consumista es una sociedad en la que se consume no lo necesario para la vida, sino lo superfluo, donde 
el consumo legitima la política y la economía, y en la que, además, las personas miden su éxito y su felicidad en ese consumo.

Este modelo al que hemos migrado en las últimas décadas, dominado por la idea de tenerlo todo, lo mejor y lo antes posible, ha ido paulatinamente provocando crisis económica, social y ambiental, desempleo creciente, aumento de la pobreza y exclusión social, sostiene Cucco (2014).

Como consecuencia de esta situación se producen, por un lado, desequilibrios medioambientales: el agotamiento de los recursos naturales, la degradación del medioambiente, deforestación, calentamiento global, la inmensa cantidad de desechos y desperdicios, la contaminación. Por el otro, el sistema crea grandes injusticias y desigualdades sociales; distribución desigual de la riqueza y violación de derechos humanos fundamentales.

En la recordación del Día Mundial del Medio Ambiente 2015, la Organización de las Naciones Unidas (ONU) promovió el Consumo Sostenible y el director del Programa para el Medio Ambiente, A. Steiner, sostuvo que las actuales pautas de consumo y producción no son sostenibles y que son una de las mayores causas del continuo deterioro del medioambiente mundial. Pidió a la gente ser más consciente del impacto ecológico de su comportamiento y pensar más en las consecuencias e imaginar cómo sería el mundo si cada uno de sus siete mil millones de habitantes llevara a cabo un cambio hacia un consumo más sostenible de los recursos.

Debeljuh (2009) sostiene que, si bien la primera responsabilidad en la ética del producto recae sobre el empresario y/o directivos de una empresa, también existe una responsabilidad del consumidor, quien asumiendo un rol activo puede denunciar aquellos productos que van en contra de la dignidad de la persona y alentar la compra de los buenos productos. «El cliente tiene en sus manos el poder para no caer en las tentaciones que le propone el consumismo, induciéndole a dejarse llevar por modas o gastos superfluos o innecesarios». 


\section{CONCIENCIA AMBIENTAL Y SOCIAL FRENTE A LA URGENCIA DEL CAMBIO CLIMÁTICO}

La creciente preocupación de la sociedad por la preservación del medioambiente está forzando a las empresas a incorporar los aspectos ecológicos en su estrategia de marketing (Calomarde, 2000).

Inicialmente, los trabajos académicos se centraron en la preocupación ambiental o ecológica, dando lugar al surgimiento del marketing ecológico, entendido como «el estudio de los aspectos positivos y negativos de las actividades de marketing en la contaminación, el agotamiento de la energía y de los recursos no energéticos» (Henion y Kinnear, 1976), en el contexto de la crisis del petróleo mundial. Posteriormente creció la conciencia en la problemática ambiental (Kilbourne y Beckmann, 1998) y se estudiaron las primeras conductas de reciclado y de compra verde. Se identificó un «nuevo segmento verde» (green segment) y se estudió cómo definir su perfil y su medición.

Hasta hace pocos años, la preocupación medioambiental era menor, pero a medida que los recursos naturales han dejado de considerarse ilimitados, los activos medioambientales son considerados como un patrimonio que necesariamente hay que conservar para mantener el crecimiento económico sostenible (Calomarde, 2005) y garantizar la vida de las generaciones futuras.

En el nuevo milenio, resurge el tema ambiental como problemática, pero bajo el paradigma de las «sustentabilidad» y de la «conciencia ética», y un intento por generar modelos más holísticos e integrales respecto del comportamiento del consumidor que contemplen no solo la dimensión ambiental o ecológica, sino también la social y ética.

La Responsabilidad Social Empresaria (RSE), por su parte, es vista como la contribución de la empresa a la sostenibilidad y una estrategia para conseguir las metas de cohesión social y competitividad (Comisión Europea, 2002).

Kuhn y Deetz (2008) argumentan que las iniciativas de sustentabilidad de las empresas no vienen desde un compromiso serio, sino de las regulaciones, ventajas competitivas, o bien de la necesidad de afianzar una imagen pública. Ellos declaran que hay muy poca esperanza de que las mejoras en el medioambiente se tomen en serio, a menos de que haya un cambio ideológico. La RSE es un acto voluntario, la regulación del Estado a través de normas legales es una obligación a cumplir, por lo que el debate ideológico sobre los alcances de la regulación, desregulación o autorregulación es sumamente importante (Villarreal y Martínez, 2000). 


\section{Consumo Responsable y Sustentable}

En la comunidad científica no existe unanimidad de criterio al conceptualizar el consumo y consumidor responsable; sin embargo, todas las definiciones son abarcativas de un concepto de consumo que va más allá del acto dirigido a la mera satisfacción de unos intereses o necesidades individuales. Se puede entender por consumidor responsable a aquella persona que, siendo consciente de sus hábitos de consumo, conoce y exige sus derechos como consumidor, y además busca y elige (o reclama o propone a las empresas) opciones que tienen un menor impacto negativo y un mayor efecto positivo en la sociedad, el medioambiente y los animales no humanos (Díaz, 2011).

En 1999, la ONU enunciaba como parte de sus Directrices para la Protección del Consumidor, que el consumo sostenible significa que las necesidades de bienes y servicios de las generaciones presentes y futuras se satisfacen de modo tal que puedan sustentarse desde el punto de vista económico, social y ambiental (ONU 2003, versión ampliada 1999).

En 2012, la Comisión para el Desarrollo Sostenible de la ONU plantea que el Consumo Responsable y Sustentable es un término sombrilla que reúne en sí mismo toda una serie de factores, como satisfacción de necesidades, mejoramiento de la calidad de vida, eficiencia de los recursos, incremento en el uso de recursos energéticos renovables, reducción de desperdicios, adopción de una perspectiva responsable del ciclo de vida y consideración por la dimensión de equidad. Integrar estos componentes es una cuestión central de cómo brindar los mismos o mejores servicios para satisfacer las necesidades básicas de la vida y las aspiraciones de las mejoras de las generaciones presentes y futuras, mientras se continúa reduciendo el daño ambiental y el riesgo de salud humana.

El consumo consciente y responsable aboga por la elección de productos no solo guiándose por la relación calidad-precio, sino también basándose en la historia de los productos y la conducta de las empresas que los ofrecen.

Desde esta perspectiva, el consumidor responsable es aquel que puede realizar un análisis introspectivo de sus hábitos de compra y de sus valores. Es decir que, a la hora de decidir la compra de un producto, realiza un ejercicio de reflexión sobre diversas cuestiones, como, por ejemplo: «¿Necesito lo que voy a comprar? ¿Quiero satisfacer un deseo? ¿Estoy eligiendo libremente o es una compra compulsiva? ¿Cuántos tengo ya? ¿Cuánto lo voy a usar? ¿Cuánto me va a durar? ¿Podría 
pedirlo prestado a un amigo o a un familiar? ¿Voy a poder mantenerlo/ limpiarlo/repararlo yo mismo? ¿Tengo ganas de hacerlo? ¿He buscado información para conseguir mejor calidad y menor precio? ¿Cómo me voy a deshacer de él una vez que haya terminado de usarlo? ¿Está hecho con materiales reciclables? ¿Las materias primas que se usaron son renovables? ¿Hay algo que yo posea que pueda reemplazarlo? ¿He buscado información acerca de quién y cómo ha realizado el producto?» (ECODES, citado en Bianchi, 2014).

Carrero Bosch, Martínez y Rosa Durán (2010) caracterizan el consumo responsable y sustentable como aquel que tiene los siguientes rasgos: es un consumo consciente y deliberado; se realiza de forma rutinaria, siendo un hábito; se actúa buscando el interés externo, centrado en otros; se busca, como fin último, modificar el contexto o las estructuras de mercado. Según Iglesias (2009), puede sintetizarse en tres ejes: ético o consciente, ecológico y solidario.

Consumir en forma sustentable no se limita a reducir los deseos, sino a poder dominarlos. El hecho de consumir no es malo ni bueno, sencillamente es necesario, $y$ por eso debemos hacerlo en forma eficiente y responsable, de manera tal que haya lugar para el placer, pero con mesura y consciencia ambiental y social sobre nuestro actuar (Cortes Funes, 2011).

La persona con un comportamiento responsable de consumo pone su acento, fundamentalmente, en su bienestar moral. Se trata de solucionar situaciones muy claras de disonancia entre lo que se espera de una persona y lo que realmente le apetece. Quizás esto pueda explicarse, una vez más, a través de la coherencia entre lo que uno piensa y como actúa (Ballesteros, 2011).

\section{Segmentación y tipología de CONSUMidores}

Considerando los cambios habidos en los patrones de consumo, el marketing ha ido evolucionado al considerar no solo la satisfacción de los consumidores a corto plazo, sino también el bienestar a largo plazo; incluyendo la preocupación ambiental por la contaminación y el agotamiento de los recursos naturales; ampliando la mirada estratégica de manera de contemplar no solo la satisfacción de los deseos de los consumidores, sino también los intereses de la sociedad en su conjunto, en el presente y en el largo plazo.

Kotler (2013) sostiene que es necesario pensar no únicamente en la satisfacción del cliente y el rendimiento del negocio, sino planear 
estrategias que preserven el mundo para las generaciones futuras y plantea que «el marketing sustentable implica acciones social y ambientalmente responsables que satisfagan las necesidades actuales de los consumidores y los negocios, y al mismo tiempo conserven o mejoren la capacidad de las generaciones futuras para satisfacer sus propias necesidades».

En las sociedades occidentales se ha producido un desplazamiento de las prioridades valorativas desde un énfasis casi exclusivo en el bienestar material y la seguridad personal hacia la preocupación destacada por la calidad de vida, la satisfacción de las necesidades sociales y la autorrealización. El Consumo Responsable habría surgido en el cambio de una cultura materialista a otra cultura postmaterialista, en el tránsito de la modernización a la postmodernización (Inglehart, 1991).

$\mathrm{El}$ «nuevo consumidor» se vincula, por un lado, con una transformación de las significaciones y valoraciones del consumo; el consumidor involucra en sus compras valores éticos. Por el otro, el consumidor responsable aparece como respuesta a la crisis del modelo de desarrollo capitalista que tiende a no considerar los impactos sociales y ambientales de producción y consumo (Ubeira, 2010).

Además, el efecto de las constantes crisis económicas mundiales constituye otro factor clave que vuelve al consumidor más prudente, ahorrativo y selectivo a la hora de consumir, de modo que cada compra que realice sea realmente justificada (Redondo, Escudero y Ordóñez, 2013).

En relación con el tema de consumo responsable y sustentable (CRS), en América Latina en general y en Argentina en particular, existen escasos estudios del comportamiento de los consumidores y de las actitudes hacia el CRS y sus repercusiones éticas, ecológicas y sociales, que permitan reconocer grupos o segmentos con opiniones heterogéneas.

Dentro de la Red Educa-Al (Encuentro de Docentes Universitarios de Comercialización de Argentina y América Latina) de CRS, se llevó a cabo en el año 2011 una investigación para conocer la percepción de las políticas de Responsabilidad Social de las empresas y las actitudes de las personas ante el CRS. A partir de una muestra de 1.700 casos conformada por personas de diez ciudades argentinas, se utilizó un cuestionario estructurado con una escala de Likert para medición de actitudes diseñada al efecto. La escala incluyó proposiciones para detectar el nivel de conocimiento de los consumidores, conocer el componente afectivo y algunas acciones específicas de comportamiento.

Como resultado de la investigación y el análisis estadístico de Cluster se definieron cuatro segmentos y se conformó una tipología de CRS: 
Indiferentes/Apáticos, Anticonsumistas Conscientes, Consumidores Responsables y Shopper Impulsivos. Dicha tipología es la que se aplica en esta ponencia para definir el perfil del consumidor santafesino en relación con el CRS.

\section{Trabajo DE CAMpo}

OBjetivos

- Conocer la percepción de la población sobre problemática ambiental y social.

- Relevar el nivel de conocimiento sobre el concepto Consumo Responsable.

- Definir una tipología de consumidores, según sus actitudes hacia el Consumo Responsable.

- Conocer la opinión de los consumidores acerca del comportamiento socialmente responsable de las empresas.

\section{Metodología}

- Tipo de estudio: descriptivo-explicativo.

- Población en estudio: personas de 18 a 75 años de la ciudad de Santa Fe (Argentina).

- Diseño muestral: probabilístico polietápico por conglomerados; se estratificaron los sectores medios y altos (con capacidad de consumo) dada la naturaleza del objetivo de la investigación.

- Tamaño de la muestra: 445 casos.

- Herramienta de recolección de datos: encuesta personal.

- Variables de clasificación: edad-sexo-nivel de instrucción.

- Técnicas de análisis de datos: univariante, bivariante y multivariante.

\section{Resultados}

\section{Problemática AMbiental y SOCIAL}

En relación con el objetivo de conocer la percepción de la problemática ambiental por parte de la población en estudio, se puede observar que la mayor preocupación aparece en cuanto a la contaminación de 
las aguas, la pobreza y la exclusión, con valores superiores al $65 \%$. Luego, las opciones de contaminación del aire, el cambio climático, la contaminación de la agricultura, el impacto de los productos químicos en la salud y el agotamiento de los recursos naturales obtienen valores cercanos al $50 \%$.

Con la finalidad de sondear el nivel de «conciencia» o preocupación por el ambiental, se aplicó un indicador de "Conciencia Ambiental» (Kosiak de Gesualdo y Etcheverría, 2015) sobre la base de la identificación de las opciones seleccionadas por los entrevistados. El indicador consta de tres niveles, a partir de la cantidad de variables identificadas por el encuestado como preocupantes para él: entre 9 y 12 opciones, Conciencia Ambiental Alta; entre 5 a 8 opciones, Conciencia Ambiental Media, y hasta 4 variables, Conciencia Ambiental Baja.

$\mathrm{Al}$ aplicar este indicador, el 54\% de los santafesinos puede categorizarse como de Baja Conciencia Ambiental, el 18\% con Conciencia Ambiental Media y el 28\% con Conciencia Ambiental Alta.

Cuadro i. Problemática ambiental y social

\begin{tabular}{|l|l|}
\hline & Porcentaje \\
\hline La contaminación de las aguas & 67,19 \\
\hline La pobreza y la exclusión & 65,17 \\
\hline La contaminación del aire & 52,81 \\
\hline El cambio climático & 51,46 \\
\hline La contaminación de la agricultura & 48,99 \\
\hline Impacto de los productos químicos en la salud & 47,19 \\
\hline El agotamiento de los recursos naturales & 46,97 \\
\hline El impacto de los medios de transporte & 37,98 \\
\hline La pérdida de biodiversidad & 36,40 \\
\hline La distribución del ingreso & 36,40 \\
\hline El derretimiento de los glaciares & 34,16 \\
\hline El excesivo consumismo actual & 33,26 \\
\hline Ninguno & 1,80 \\
\hline Otros problemas & 1,35 \\
\hline
\end{tabular}

FuENTE: ELABORACIÓN PROPIA. 


\section{Consumo Responsable}

En cuanto a relevar el nivel de conocimiento de la población del concepto de Consumo Responsable, se trabajó sobre la base de tres niveles: ha oído alguna vez la expresión Consumo Responsable; ha utilizado alguna vez la expresión Consumo Responsable y con qué conceptos lo asocia para indagar el nivel de conocimiento.

Seis de cada diez individuos han oído alguna vez el término, uno de cada diez individuos lo ha usado con frecuencia (17\% de los que la han oído), en tanto que tres de cada diez individuos lo han usado «a veces» ( $47 \%$ de los que la oyeron alguna vez).

\section{GrÁfico I}

Ha oído alguna vez la expresión

«Consumo Responsable»

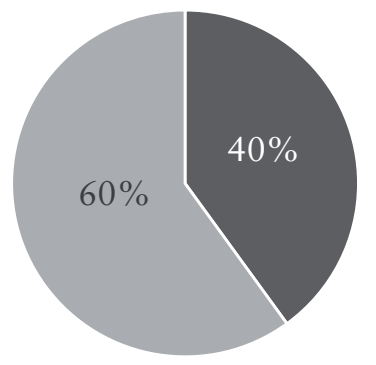

- No ha oído " Ha oído

Ha utilizado alguna vez la expresión «Consumo Responsable»

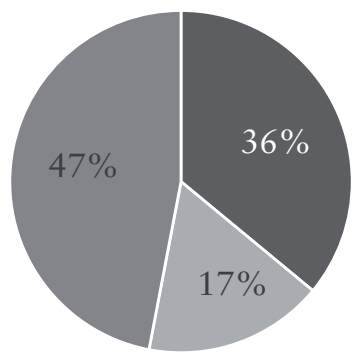

- No. Nunca la utilizo $\rightleftharpoons$ Sí. Muchas veces

- Sí. A veces

FuENTE: ELABORACIÓN PROPIA. 
Cuando se pidió asociar el término Consumo Responsable con los conceptos que lo representan, el 29\% lo relacionó con la afirmación «reducir, reutilizar y reciclar»; con porcentajes menores se mencionaron el estilo de vida saludable $(20 \%)$, compra reflexiva (18\%) y estilo de vida ahorrativo (13\%). El concepto Consumo Responsable abarca todos los ítems enunciados y solo el $12 \%$ de los encuestados reconoció el concepto correcto.

Gráfico 2. Conceptos con los que asocia el Consumo Responsable

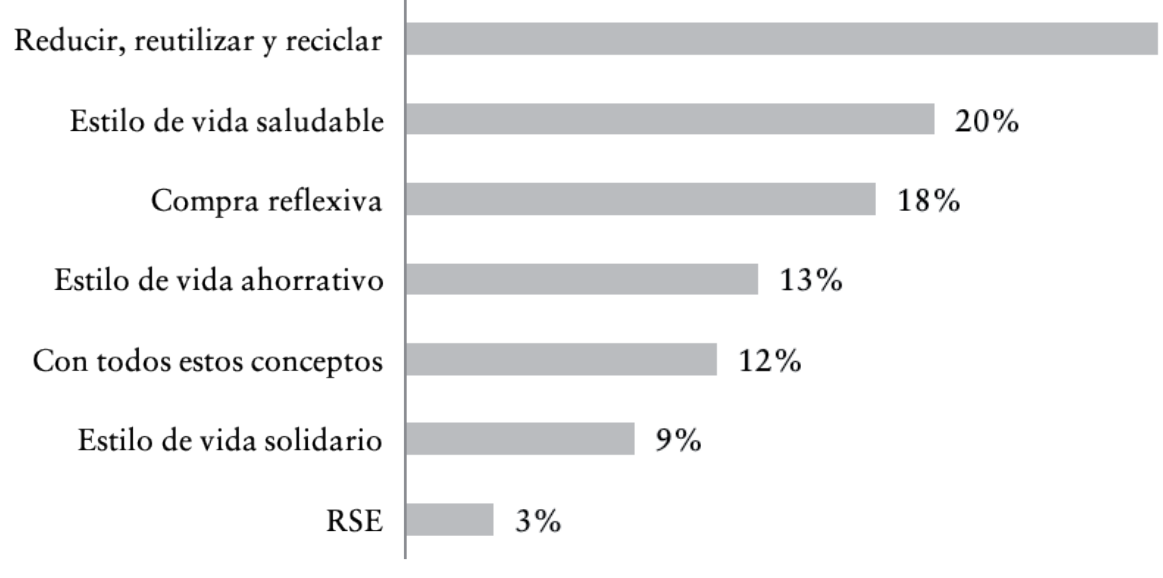

FueNTE: ELABORACIÓN PROPIA.

\section{EL COMPORTAMIENTO SOCIALMENTE RESPONSABLE DE LAS EMPRESAS}

En cuanto al objetivo de conocer la opinión de los consumidores acerca del comportamiento social y ambiental de las empresas, se utilizaron en el cuestionario preguntas con escalas numéricas (puntajes de 1 a 10) para que los encuestados dieran su opinión, como así también para conocer qué importancia le asigna la población a la información que le brindan las empresas respecto a sus políticas de RSE. 
Gráfico 3. Difusión COMPORTAMIENTO SOCIALMENTE RESPONSABle: IMPORTANCIA QUE LE OTORGAN LOS CONSUMIDORES

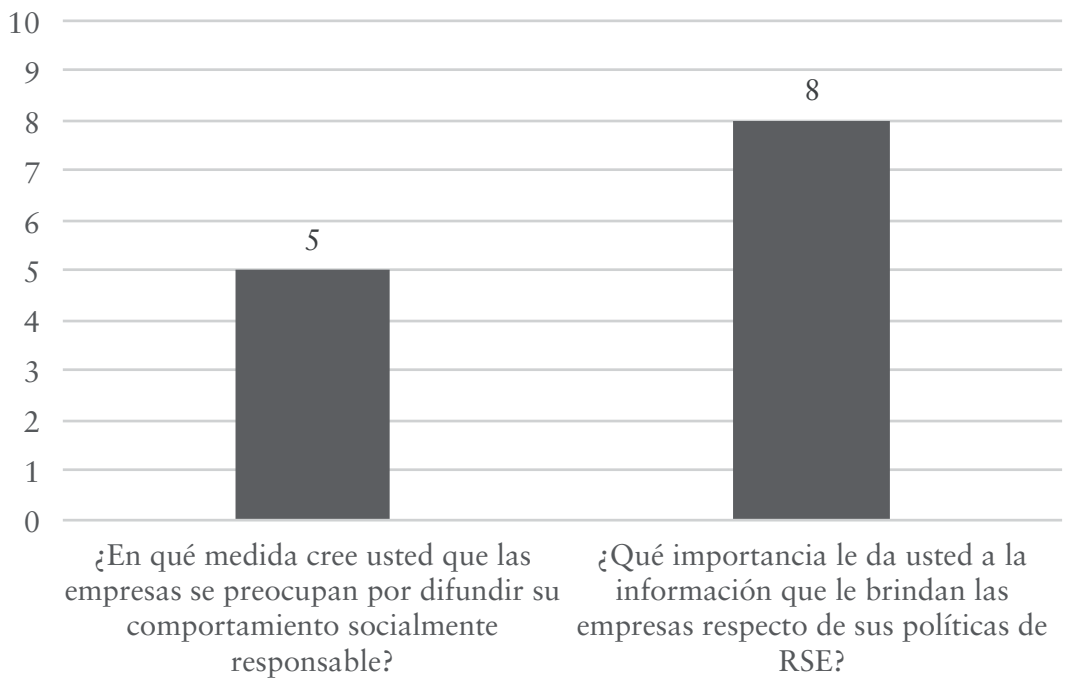

Fuente: Elaboración PROPIA.

El valor 5 de la moda que indica que, según la percepción de los consumidores, las empresas tienen una baja preocupación por difundir su comportamiento socialmente responsable. A su vez, el valor 8 indica que los encuestados le asignan mucha importancia a la información que le brindan las empresas sobre sus políticas de RSE.

\section{Tipología de CONSUMidoRES}

A efectos de definir una tipología de consumidores santafesinos según sus actitudes hacia el Consumo Responsable y Sustentable, se utilizó el marco conceptual de la Red Educa-Al de CRS, según se explicó previamente. Se pueden comparar los resultados obtenidos en Santa Fe con los de Argentina (presentados por la Red en 2012). 
Cuadro 2. Tipología de CONSumidores

\begin{tabular}{|c|c|c|c|}
\hline \multirow{2}{*}{ Tipología } & \multirow{2}{*}{ Características/Descripción } & \multicolumn{2}{|l|}{$\%$} \\
\hline & & Santa Fe & Argentina \\
\hline $\begin{array}{l}\text { Indiferentes/ } \\
\text { Apáticos }\end{array}$ & $\begin{array}{l}\text { Los consumidores de este grupo son los que menos guardan los } \\
\text { tickets de compras y dicen que no planifican la compra de ali- } \\
\text { mentos. Desconocen las políticas ambientales de las empresas a } \\
\text { las que compran sus productos y no creen que los consumidores } \\
\text { puedan influir para que las compañías tengan un comportamiento } \\
\text { socialmente responsable. Sin embargo, entienden que estas no } \\
\text { deben contaminar el medioambiente. } \\
\text { Creen que antes de comprar hay que analizar si el producto es ne- } \\
\text { cesario, comparar precios, leer la fecha de vencimiento al comprar } \\
\text { alimentos e informarse de ofertas y promociones. En cuanto a los } \\
\text { recursos naturales, son los que menos cuidan el agua en la ducha. }\end{array}$ & $21 \%$ & $25 \%$ \\
\hline $\begin{array}{l}\text { Anticonsumistas/ } \\
\text { Conscientes }\end{array}$ & $\begin{array}{l}\text { Es el grupo más numeroso. A este grupo de consumidores no los } \\
\text { hace feliz el consumo, les agobian los centros comerciales y no } \\
\text { sienten la ansiedad o necesidad de salir a comprar. Son los que } \\
\text { menos se arrepienten de las compras que hacen. } \\
\text { Son los que más cuidan el agua en la ducha y reutilizan papel } \\
\text { en la impresión de documentos, como así también planifican la } \\
\text { compra de alimentos y guardan el ticket de compra por cualquier } \\
\text { reclamo. Siempre guardan algo de dinero para hacer frente a im- } \\
\text { previstos. } \\
\text { De manera similar al grupo de Apáticos, creen que antes de } \\
\text { comprar hay que analizar si el producto es necesario, comparar } \\
\text { precios, leer la fecha de vencimiento al comprar alimentos e infor- } \\
\text { marse de ofertas y promociones. }\end{array}$ & $32 \%$ & $32 \%$ \\
\hline $\begin{array}{l}\text { Consumidores } \\
\text { Responsables }\end{array}$ & $\begin{array}{l}\text { Son los que más se preocupan por elegir productos de pack ecoló- } \\
\text { gicos, separar residuos y aprovechar al máximo la luz solar; tam- } \\
\text { bién dicen cuidar el agua en la ducha, Se preocupan por conocer } \\
\text { las políticas ambientales de las empresas, creen que se desconoce } \\
\text { el comportamiento ético de las empresas y son los que más se } \\
\text { encargan de difundirlas cuando conocen de casos no éticos. Ex- } \\
\text { presan que el Estado debe tener un rol activo para apoyar e incen- } \\
\text { tivar la actuación responsable de empresas que los consumidores } \\
\text { pueden influir al respecto. Reclaman la factura de compra y en } \\
\text { forma similar a los grupos de Apáticos y Anticonsumistas creen } \\
\text { que antes de comprar hay que analizar si el producto es necesario, } \\
\text { comparar precios, leer la fecha de vencimiento al comprar alimen- } \\
\text { tos e informarse de ofertas y promociones. } \\
\text { Sin embargo, a pesar de ser conscientes, tienen en claro que son } \\
\text { consumistas: dicen sentirse en gran parte más feliz cuando más } \\
\text { compran y consumen y sienten fuertemente la necesidad de com- } \\
\text { prar. }\end{array}$ & $24 \%$ & $25 \%$ \\
\hline
\end{tabular}




\begin{tabular}{|c|c|c|c|}
\hline \multirow[b]{2}{*}{ Tipología } & \multirow{2}{*}{ Características/Descripción } & \multicolumn{2}{|l|}{$\%$} \\
\hline & & Santa Fe & Argentina \\
\hline $\begin{array}{l}\text { Shopper/ } \\
\text { Impulsivos }\end{array}$ & $\begin{array}{l}\text { Este grupo es el que presenta un perfil más diferente a los demás. } \\
\text { Les encanta ver tiendas en la ciudad, le gustan los centros comer- } \\
\text { ciales, compran todos los meses alguna ropa o calzado, cuando } \\
\text { ven algo que les gusta, no se lo pueden sacar de la cabeza. Las } \\
\text { marcas son en parte determinantes a la hora de comprar indu- } \\
\text { mentaria. } \\
\text { Lo que lo caracteriza es su baja implicación en la compra desde } \\
\text { el punto de vista racional y ético, pues les interesa poco el com- } \\
\text { portamiento de las empresas y no difunden los comportamientos } \\
\text { negativos de estas. Son los que menos conocen las entidades de } \\
\text { defensa del consumidor. Su nivel de impulsividad en la compra } \\
\text { hacen que sean los/las que más se arrepienten de las compras } \\
\text { inútiles que hacen. Debido a su bajo nivel de conciencia social res- } \\
\text { pecto del impacto del consumo, no separan residuos en sus casas, } \\
\text { no aprovechan la luz solar ni les preocupa reclamar factura, leer } \\
\text { la fecha de vencimiento al comprar alimentos, comparar precios e } \\
\text { informarse de precios y promociones. }\end{array}$ & $22 \%$ & $18 \%$ \\
\hline
\end{tabular}

FuENTE: ELABORACIÓN PROPIA.

Del análisis cualitativo surgen dos ejes que se sintetizan en el gráfico siguiente:

a) El eje vertical muestra la conciencia-inconciencia en la compra.

b) El eje horizontal muestra la actitud consumista-anticonsumista.

GrÁfico 4. Tipología de consumidores

\begin{tabular}{|c|c|}
\hline \multicolumn{2}{|c|}{ CONSCIENTES } \\
\hline $32 \%$ & $24 \%$ \\
\hline Anticonsumistas/Conscientes & Consumidores Responsables \\
\hline Anticonsumo & $\underset{\text { Consumo }}{\longrightarrow}$ \\
\hline $21 \%$ & $22 \%$ \\
\hline Indiferentes/Apáticos & Shopper/Impulsivo \\
\hline & CIENTES \\
\hline
\end{tabular}

FueNTE: ELABORACIÓN PROPIA. 
En cuanto a la conformación demográfica de los grupos, las mujeres tienen mayor participación en Anticonsumistas y Apáticos (55\% y $52 \%$, respectivamente) y los hombres en el grupo de Shopper Impulsivos $(54 \%)$. En el grupo de Consumidores Responsables tienen similar participación, cercana al 50\%.

En relación con la edad, los jóvenes (entre 18 y 25 años) tienen mayor participación en el grupo de Shopper Impulsivos (32\%). Las personas de mayor edad (entre 26 y 40 años) conforman el 34\% de los Anticonsumistas y el 28\% de los Consumidores Responsables.

Si se realiza un análisis bivariante entre los Cluster y el nivel de conocimiento de las personas sobre Consumo Responsable, el resultado de la tabulación cruzada indica que existe relación de asociación entre el nivel de conocimiento y la pertenencia a los diferentes grupos: aquellas personas que conocen con precisión el concepto de Consumo Responsable integran el grupo de Consumidores Responsables, Anticonsumistas y Apáticos, en porcentajes superiores al valor de la media de la muestra.

\section{Conclusiones}

Hay coincidencia en los autores al señalar que el Consumo Responsable es uno de los motores de la Responsabilidad Social de la Empresa (Fielding, 2007).

El proceso de decisión de compra es un fenómeno complejo, dado que intervienen variables racionales, emocionales, la familia, amigos, grupos de pertenencia y cuestiones culturales. En el caso de la compra responsable, el consumidor debe ir superando, además, las numerosas barreras u obstáculos que se le presentan a lo largo de las distintas etapas del proceso de compra responsable, una de las cuales es la falta de información sobre las mejores marcas en estos atributos sociales o ambientales.

A la luz de los datos arrojados por el trabajo empírico en la ciudad de Santa Fe y habiendo constatado que son similares a los que se registran en otras partes del mundo, se puede decir que en nuestra región el nivel de preocupación o conciencia ambiental está en un estadio incipiente, con límites difusos entre los temas ambientales y sociales.

Existe poca o escasa disponibilidad de información sobre el comportamiento socialmente responsable de las empresas, al menos desde la percepción de los consumidores. Sin embargo, expresan que sería importante para ellos contar con dicha información. 
El nivel de conocimiento del concepto Consumo Responsable y Sustentable es bajo y en la mayoría de los casos se lo asocia a las $3 \mathrm{R}$ (reducir, reutilizar y reciclar).

Respecto de la tipología de consumidores, se puede observar que la población santafesina muestra un perfil bastante parecido respecto de la población nacional, con una mayor cantidad de Shopper Impulsivos (+4\%) y menos de Apáticos/Indiferentes (-3\%).

Las empresas deberían aplicar esfuerzos mayores para mejorar los canales de comunicación con la sociedad, ya que los ciudadanos no disponen de suficiente información sobre el CSR de las mismas. A su vez, invertir en mejorar su nivel de credibilidad y encontrar el equilibrio entre las acciones de RSE y el precio de los productos.

En todas estas acciones, el consumidor percibe un Estado poco involucrado en las cuestiones medioambientales, de baja credibilidad en la información sobre RSE que emite, por lo que se considera tiene como asignatura pendiente asumir una política activa que incentive la RSE y el Consumo Responsable.

Los dos actores centrales que tiene la Responsabilidad Social —Estado y empresas- tienen, desde la óptica del consumidor, un largo camino por recorrer para estar a la altura de lo que la temática les exige.

En línea con lo que señalan Sánchez García y Gil Roig (1998), los consumidores santafesinos manifiestan una alta preocupación por los temas ambientales, sin embargo, les falta pasar a la acción. Esto se puede explicar por la escasa presencia en las góndolas de productos «verdes» o, muchas veces, ausencia de información y disponibilidad como continuidad de ofertas (Valor y Calvo, 2009), por lo que es necesario remover estos obstáculos cognitivos y estas fallas de mercado.

Se puede afirmar que el comportamiento general de los santafesinos se caracteriza por ser, en palabras de Cortes Funes (2011), un consumidor donde "hay lugar para el placer, pero con mesura y conciencia ambiental y social sobre nuestro actuar", ya que la mayoría de ellos forma parte de los grupos Anticonsumistas, Responsables y Apáticos, siendo solo un quinto de ellos de perfil Shopper Impulsivo. Sin embargo, aún queda mucho por lograr en términos de coherencia entre lo que uno piensa y cómo actúa (Ballesteros, 2011).

No obstante lo señalado, es de esperar que el «nuevo consumidor santafesino" esté en proceso de incorporación paulatina de valores éticos y sociales en sus compras, con mayor conciencia para valorar los 
impactos sociales y ambientales que su elección de consumo presupone (Ubeira, 2010).

\section{BibLIOGRAFÍA}

Alesandria, H. y Kosiak, G. (2013). ¿Puede la Responsabilidad Social Empresaria incrementar la competitividad de las PyMEs? En N. Gorrochategui, V. Martins de Oliveira y O. Licandro (Comp.), Responsabilidad Social de las Organizaciones(RSO): Panorama de la agenda académica de América Latina. Investigaciones, Casos y Reflexiones (pp. 68-84). Buenos Aires: Ediciones Cooperativas.

Ballesteros, C. (2011). Soberanía consumidora. Más allá del consumo responsable. ¿Cambiar el Mundo desde el Consumo? Economistas sin Fronteras. Dossieres EsF, 2.

Bianchi, E. (2014). ¿Qué es un consumidor responsable y sustentable? Reflexiones y consideraciones para cómo medirlo. XXVI Congreso de AEMARK. Elche. Editorial ESIC.

Bianchi, E.; Ferreyra, A. y Kosiak, G. (2014). Consumo responsable: diagnóstico y análisis comparativo en la Argentina y Uruguay. Escritos Contables y de Administración, 4(1).

Calomarde, J. (2005) Marketing Ecológico. Madrid: Universidad Politécnica de Madrid.

Carrero Bosch, I.; Martínez, C. y Durán, J. (2010). La relación del consumidor con las etiquetas sociales y medioambientales. Madrid: Universidad Pontificia Comillas.

Cortes Funes, E. (2011). Consumo responsable, el rol de las empresas, del Estado y del Consumidor. Fundación Ambiente y Recursos Naturales Informe 2011.

Cortina, A. y Carreras, I. (2004) Consumo...1 uego existo. Cuad. Cristianisme i Justícia 123.

Cucco, P. (2014). Una nueva forma de ser ciudadano. Evolución IARSE, $3,26$.

Debeljuh, P. (2009). Ética empresarial: en el núcleo de la estrategia corporativa. Buenos Aires: Cengage Learning.

Díaz, E. (2011). Abanico de opciones para ciudadanos responsables. $¿$ Cambiar el Mundo desde el Consumo? Economistas sin Fronteras. Dossieres EsF, 2.

Fielding, M. (2007). Companies that Behave Responsibly Earn Good Rep, Consumers' Attention. Marketing News, 41, 8, 17-18.

Henion, A. y Kinnear, A. (Ed.) (1976). Ecological marketing. Chicago: American Marketing Association. 
Iglesias, J. (2009). La irresponsabilidad del consumo responsable como propuesta transformación social. Kaos en la red.

Ingleharht, R. (1991). El cambio cultural en las sociedades industriales avanzadas. En R. Llopis- Goig R. (2009), Consumo responsable y globalización reflexiva (pp. 145-165). Valencia: CIS/Siglo XXI.

Kilbourne, A. y Beckmann, A. (1998). Review and critical assessment of research on marketing and the environment. Journal of marketing management, 14.

Kosiak, G. y Etcheverría, M. (2015). La influencia del acceso a la información en la compra responsable. 3ras. Jornadas de Gestión Ambiental y Urbana. Gobierno de la ciudad de Santa Fe.

Kotler, D. y Armstrong, A. (2013). Fundamentos de marketing. Edición 11. México: Always Learning Pearson.

Kuhn, T. y Deetz, S. (2008). Critical theory and corporate social responsibility. The Oxford handbook of corporate social responsibility.

Naciones Unidas (2003). Directrices para la Protección del Consumidor. Nueva York.

Peiró Barra, A. (2013). RSE + RSC: las responsabilidades de la empresa y el consumidor. IESE Business School. Disponible en: http://www. iese.edu/research/pdfs/ESTUDIO-274.pdf.

Redondo, A.; Escudero, A. y Ordóñez, A. (2013). El dilema del consumidor en España. Fundación Entorno y Deloitte.

Sánchez García, A. y Gil Roig, A. (1998). Frenos al crecimiento del mercado ecológico. Revista Española de Investigación de Marketing, 2, 2.

Ubeira, F. (2010). Caracterización del consumo responsable en Chile. Fundación Ciudadano Responsable.

Valor, A. y Calvo, A. (2009). Compra Responsable en España. Comunicación de atributos sociales y ecológicos. Boletín Económico de ICE, 2971.

Villarreal, C. y Martínez, A. (2000). Economía, sociedad y medio ambiente: reflexiones y avances hacia un desarrollo sustentable en México. Instituto Nacional de Ecología. 


\title{
LA Responsabilidad Social de los \\ DESTINOS TURÍSTICOS: IMPACTO EN LA \\ PERCEPCIÓN DE CALIDAD DE SERVICIO Y EN \\ LA IMAGEN DEL DESTINO
}

\author{
Enrique Carlos Bianchi" \\ Juan Manuel Bruno"* \\ Carolina Sánchez"*** \\ Argentina
}

\section{INTRODUCCIÓN}

Tradicionalmente, el marketing turístico buscaba incrementar el número de visitas. Sin embargo, este enfoque tiene una orientación miope, ya que también debe identificar la satisfacción de las necesidades de los turistas y la comunidad local. En definitiva, el marketing de destinos no solo debería ser considerado como una herramienta para atraer más visitantes a una región, sino que debería operar como un mecanismo para facilitar los objetivos de desarrollo regional y racionalizar la provisión de turismo, con el fin de asegurar que los objetivos estratégicos de los destinos se cumplan (Bigné Alcañiz, Font y Andreu Simó, 2000).

Los destinos turísticos (DT) son combinaciones de productos turísticos que ofrecen una experiencia integrada a los turistas. Son un área que presenta características percibidas por los visitantes potenciales, es decir, que puede interpretarse subjetivamente por los consumidores

Doctor en Ciencias Económicas. Universidad Nacional de Córdoba. Correo electrónico: enriquecarlosbianchi@gmail.com

** Doctor en Ciencias Económicas. Universidad Nacional de Córdoba. Correo electrónico: jmbruno.mkt@gmail.com

*** Licenciada en Administración. Universidad Nacional de Córdoba. Correo electrónico: licsanchezc@yahoo.com.ar 
en función de su itinerario de viaje, formación cultural, motivo de la visita, nivel de educación y experiencia previa.

Por otro lado, es importante considerar la sustentabilidad de los DT. Alrededor de la industria del turismo existe una gran diversidad de intereses y las relaciones de la comunidad local son muy complejas. En este sentido, las acciones y estrategias deberían considerar los deseos de todos los participantes del sistema turístico (residentes, empresarios, inversores, turistas, intermediarios y otros grupos de interés). Quizá el problema más difícil sea asegurar el uso racional de los bienes públicos como paisajes, montañas y playas en beneficio de todos los interesados (Bigné Alcañiz et al., 2000).

Por ello, surge la inquietud de estudiar el turismo en el paradigma de la sustentabilidad, más específicamente la relación entre Responsabilidad Social Empresarial (RSE), turismo, la percepción de la RSE de los DT que tienen los turistas y el impacto de la RSE en las decisiones $\mathrm{y}$ acciones de los consumidores.

El objetivo de la presente investigación es conocer el impacto, sobre los turistas, que tienen las acciones de RSE que implementa un destino turístico ${ }^{1}$, y analizar si las acciones de RSE influyen en la percepción de la imagen del DT, la calidad percibida de los servicios ofrecidos y la satisfacción experimentada. Además, se buscará analizar si la percepción del DT de aquellos turistas, con un perfil de consumidores responsables, cuya demanda de turismo responsable creciente (Goodwin y Francis, 2003; citado por Zanfardini, Tamagni y Bigné, 2014) difiere respecto de aquellos turistas cuyo comportamiento de consumo no se enmarca en el perfil indicado.

Por ello, se realizó un estudio cuantitativo para indagar acerca de la percepción de la Responsabilidad Social de los Destinos Turísticos y su impacto en los turistas.

A partir de los resultados obtenidos, se pudieron validar las hipótesis que indican que cuanto mayor es la percepción de RS del destino turístico, mayor es la Percepción de Calidad, la Satisfacción y la Imagen. Sin embargo, no se hallaron diferencias significativas según el perfil del consumidor responsable.

Las conclusiones están en sintonía con los trabajos previos que señalan que asociar una localidad con un destino responsable genera

1 Por destino turístico, se refiere a lugar o zona geográfica, que desarrolla acciones de responsabilidad social, cuyos efectos sobre el turista desean conocerse. 
mayor intención de volver a visitarlo, pero, sobre todo, mayor predisposición para recomendarlo (Zanfardini et al., 2014).

Este trabajo busca contribuir a la literatura creciente en el ámbito del marketing turístico y de la RSE. Primero, se presenta la revisión de la literatura respecto del paradigma de la RSE y la sustentabilidad que nos ha permitido plantear una serie de hipótesis a contrastar, luego, se presenta la metodología de investigación realizada y los resultados encontrados. Para finalizar, se plantean las principales conclusiones, limitaciones y líneas futuras de investigación que se derivan del presente trabajo.

\section{REVISIÓN DE LA LITERATURA}

\section{LA Responsabilidad SOCIAl EMPRESARIAL y LA SUSTENTA- BILIDAD DE LOS DESTINOS TURÍSTICOS}

La conceptualización de la responsabilidad social, basándose en el paradigma desarrollo sostenible, establece que la responsabilidad de las empresas es un constructo multidimensional, formado por las dimensiones medioambiental, social y económica. (Panapanaan y Linnanen, 2002; Panwar, Rinne, Hansen y Juslin, 2006, citado por García de Leaniz, Pérez Ruiz y Rodríguez del Bosque, 2012).

La Organización Mundial del Turismo (2004) describe cada una de estas facetas: la dimensión medioambiental implica dar un uso óptimo a los recursos ambientales, los cuales son un elemento esencial del desarrollo turístico, protegiendo los procesos ecológicos esenciales y ayudando a conservar los recursos naturales y la diversidad biológica; la dimensión social hace referencia al respeto de la autenticidad sociocultural de las comunidades anfitrionas, a la conservación de sus activos culturales arquitectónicos y vivos y de sus valores tradicionales, así como a la contribución, al entendimiento y a la tolerancia intercultural; y la dimensión económica se basa en asegurar unas actividades económicas viables a largo plazo, que reporten a todos los agentes unos beneficios socioeconómicos correctamente distribuidos.

Si nos posicionamos desde el punto de vista del consumidor, resulta interesante conocer cómo percibe el comportamiento responsable de los DT y qué efectos tiene esto sobre sus propias acciones, ya sea antes de tomar una decisión de elegir viajar o visitar, o luego de la misma, para evaluar el resultado de dicha acción. 
La percepción es «el proceso mediante el cual un sujeto selecciona, organiza e interpreta los estímulos para formarse una imagen significativa y coherente del mundo» (Schiffman y Kanuk, 2010, p. 157). Por lo tanto, la percepción de la RSE puede llegar a adquirir una gran importancia y tener una consecuencia directa en la valoración del servicio y calidad percibida por el cliente (Sureshchandar, Rajendran y Kamalanabhan, 2001). Sin embargo, Pérez Ruiz, García de los Salmones Sánchez y Rodríguez del Bosque (2008) advierten que estudios de la percepción social del consumidor sugieren que el efecto de estas acciones de marketing en el comportamiento del consumidor —el acto de compra y la posterior sensación pos compra- no es directo. Por el contrario, viene mediado por una serie de actitudes y sentimientos que condicionan el papel de la Responsabilidad Social.

En este contexto, resulta fundamental estudiar la percepción de RSE de un destino turístico. Tal como lo explica Campell (2007, citado por García de Leaniz et al., 2012), el significado de la RSE varía en función de las distintas percepciones de los grupos de interés y del sector de actividad al que nos refiramos. Zanfardini et al. (2014) concluyen que percepciones de los turistas sobre actividades de un DT, en relación con la RSE, afectan el valor que le otorgan a esa marca, debido a que influyen en su percepción de la imagen, en la satisfacción con el DT, en su nivel de lealtad y en recomendación de boca-en-boca. Incluso, estos autores señalan que asociar un DT con un destino responsable genera mayor intención de volver a visitar el destino, pero sobre todo mayor predisposición para recomendarlo.

\section{VAloración de LA CALIDAd DEL SERVICIO DEL DT Y SATISFACCIÓN DEL TURISTA}

¿Qué es la satisfacción del cliente? Es definida «como la valoración del consumidor de una característica del producto o servicio, o el producto o servicio en sí mismo, proporciona (o está proporcionando) un resultado de agrado derivado del consumo, incluyendo niveles por debajo o por encima de lo esperado» (Oliver 1997, citado por Bigne Alcañiz y Andreu Simó, 2004).

La satisfacción del consumidor de servicios turísticos se comienza a construir, según lo explican Velázquez, Saura y Molina (2009), desde el momento mismo de la prestación, es decir, en el momento de encuentro con el cliente, en el cual empresa y consumidor interactúan. 
Es aquí cuando el cliente comienza a dar valor al servicio y a construir su satisfacción.

La satisfacción tiene dos dimensiones: cognitiva y afectiva. La perspectiva cognitivista sostiene que la satisfacción resulta de un procesamiento cognitivo de la información, es una evaluación poscompra o posuso que resulta de un procesamiento de información relevante, el cual puede consistir en una comparación entre las expectativas del consumidor y el rendimiento del producto o servicio recibido, en la comparación de costos, beneficios y de procesos de atribución que realizan los consumidores (Velandia Salazar, Ardón Centeno y Jara Navarro, 2007). En cambio, la perspectiva afectiva considera fundamental la presencia del componente afectivo, expresado en fenómenos mentales relacionados con sentimientos subjetivos, emociones y estados de ánimo; estos son distintos de la satisfacción y la anteceden (Velandia et al., 2007).

Vale agregar que una corriente integradora considera que la satisfacción obedece a una doble vertiente: tanto los constructos afectivos como cognitivos contribuyen a su formación (Velandia et al., 2007). En este sentido, Bigné Alcañiz y Andreu Simó (2004, p. 95) explican que «la satisfacción presenta un carácter dual, es decir, afectivo y cognitivo (Oliver, 1997), y es relativa, es decir, es el resultado de la comparación entre una experiencia subjetiva y una base previa de referencia. Este principio de comparación ha sido bien establecido en el paradigma de la disconfirmación (Oliver, 1980)». Este enfoque indica que la satisfacción es el resultado de un proceso de comparación entre la percepción del resultado o el rendimiento y algún estándar (Velázquez et al., 2009). El resultado del servicio es inferior (o superior) a lo que un consumidor esperaba cuando realiza una decisión de compra (Oliver, 1997), con implicaciones negativas (o positivas) para la experiencia del servicio (Bigné Alcañiz y Andreu Simó, 2004).

En síntesis, la satisfacción del consumidor se define como un estado cognitivo-afectivo resultante de evaluaciones cognitivas (incluyendo la disconfirmación), así como de las emociones provocadas, a su vez, por las evaluaciones cognitivas y, todo ello, incitando respuestas de comportamiento (Bigné Alcañiz y Andreu Simó, 2004). La satisfacción del cliente puede verse influida por muchas variables. Una de ellas es la valoración de la calidad del servicio, la cual es definida como el juicio que tienen los clientes o usuarios sobre un producto o servicio; es el punto en el que sienten que sobrepasa sus necesidades y expectativas. Esta percepción favorece los comentarios boca-oreja y contribuye a la 
repetición de compra (Cole e Illum, 2006). Aplicado al ámbito de servicios, incluidos los servicios turísticos, la calidad posee una dimensión técnica y una dimensión funcional que se asocian al resultado («qué» está recibiendo el consumidor) y al proceso ( «cómo» se está recibiendo el servicio), respectivamente (Gronroos, 1984). Existen investigaciones que sostienen una relación causal entre satisfacción al cliente y calidad del servicio, mientras que otras contradicen estos resultados y no muestran una relación directa (Velázquez et al., 2009).

\section{IMAGEN DE LOS DESTINOS TURÍSTICOS}

Tradicionalmente se ha establecido que la imagen de un destino turístico se basa en las creencias y conocimientos del individuo sobre los atributos o características de ese lugar (San Martín Gutiérrez, Rodríguez del Bosque y Vázquez Casielles, 2006). Sin embargo, en la actualidad existe un convencimiento cada vez mayor de la presencia no solo de creencias, que determinan el componente cognitivo de la imagen, sino también de evaluaciones afectivas en la percepción del individuo del destino turístico (Kim y Richardson, 2003; Pike y Ryan, 2004). Estas últimas se corresponden en realidad con los sentimientos del individuo hacia el lugar (Chen y Uysal, 2002). La coexistencia de las dimensiones cognitiva y afectiva en el estudio de la imagen de destino turístico permite explicar mejor la representación que tiene el turista de un lugar cuyo significado no se limita solo a sus propiedades físicas (Baloglu y Brinberg, 1997). Más bien, los destinos turísticos evocan todo un conjunto de experiencias emocionales, tales como la excitación o el agrado, entre otras (Walmsley y Young, 1998).

Estudios recientes muestran una fuerte relación entre RSE e imagen del DT. Los impactos más importantes de un destino asociado a RSE se observan en la imagen percibida, es decir, en el significado que se le otorga a la marca (Zanfardini et al., 2014).

En síntesis, la imagen de un DT puede describirse como la percepción global sobre un destino la representación en la mente del turista de lo que conoce y siente sobre destino, evocando así a cualquier idea, creencia, sentimiento o actitud que los turistas asocian con el lugar (Bigné Alcañiz, Sánchez y Sanz, 2005). 


\section{CONSUMIDOR SOCIALMENTE RESPONSABLE (CSR)}

Un consumo responsable se centra en un consumo ético y solidario y no en un consumo por el consumo. Ese cambio de actitud es el que nos propicia una relación sana con nuestro propio ambiente y con nosotros mismos (Moltedo Perfetti, 2007, citado por Bianchi, Ferreyra y Gesualdo, 2013).

Desde esta perspectiva, Bianchi et al. (2013) describen al consumidor responsable como aquel que puede realizar un análisis introspectivo de sus hábitos de compra y de sus valores. Es decir que, a la hora de decidir la compra de un producto, realiza un ejercicio de reflexión sobre diversas cuestiones, como, por ejemplo: «¿Necesito lo que voy a comprar? ¿Cuánto lo voy a usar? ¿Cuánto me va a durar? ¿He buscado información para conseguir mejor calidad y menor precio? ¿Está hecho con materiales reciclables? ¿Hay algo que yo posea que pueda reemplazarlo?». En definitiva, los consumidores responsables no solo toman en cuenta el beneficio inmediato que les pueden brindar los productos o servicios, sino la procedencia y los efectos directos o indirectos que dichos productos o servicios pueden tener (Ocampo, Ortiz y Castaño, 2014).

Finalmente, en los últimos años, al concepto de CSR se agrega contexto particular en el cual el consumidor toma las decisiones de compra. Así lo explican Ocampo et al. (2014, p. 289): «Hoy el consumo responsable empieza a ser considerado como un fenómeno colectivo y dependiente de los grupos sociales con los que el consumidor interactúa». Las investigaciones identifican una "distancia entre las actitudes de los consumidores y sus comportamientos reales de compra. Las razones de estas distancias se deben a diferentes factores, entre los cuales se encuentran fallas de mercado, costos de transacción, la calidad de la información en un momento específico, el contexto cultural y la identidad, entre otros».

En ese sentido, y dada la variedad de dimensiones del consumidor socialmente responsable, se presenta a continuación la clasificación propuesta por Iglesias (2009, citado por Bianchi et al., 2013): Consumo Ético (basado en valores, deliberado, consciente), Consumo Ecológico (incluye las famosas «erres» del movimiento ecologista: Reducir, Reutilizar y Reciclar), y Consumo Social o Solidario (vinculado a las relaciones sociales, laborales y el comercio justo. 
A partir de todo lo expresado, se pueden expresar las siguientes hipótesis:

- $\mathrm{H}_{1}$ : La Percepción de Responsabilidad Social del Destino Turístico influye de manera directa y positiva sobre la Percepción de Calidad de Servicio del Destino Turístico, la Imagen del Destino Turístico, la Satisfacción Cognitiva y Afectiva.

- $\mathrm{H}_{2}$ : El Perfil Responsable de los Turistas influye de manera directa y positiva en la Percepción de Calidad de Servicio del Destino Turístico, la Imagen del Destino Turístico, la Satisfacción Cognitiva y Afectiva.

- $\mathrm{H}_{3}$ : El impacto de la Percepción de Responsabilidad Social del Destino Turístico directo y positivo, sobre la Percepción de Calidad de Servicio del Destino Turístico, la Imagen del Destino Turístico, la Satisfacción Cognitiva y Afectiva, depende del Perfil Responsable de los Turistas, de modo que cuanto más responsable, mayor impacto de la PRSE del Destino Turístico.

\section{Metodología de inVestigación}

\section{DiseÑo DE LA INVESTIGACIÓN}

Este estudio es de tipo cuantitativo, cuya población fueron mayores de 18 años de edad, que habitan en el departamento Capital, ciudad de Córdoba, y que hubiesen viajado - y pernoctado- a un Destino Turístico de la provincia de Córdoba.

Se diseñó un muestreo no probabilístico por cuota de edad y sexo, siendo la muestra final de 256 casos. El trabajo de campo se realizó durante de los meses de agosto hasta diciembre de 2016. La ficha técnica de la investigación se muestra en el cuadro 1.

CuAdro I

\begin{tabular}{|l|l|}
\hline \multicolumn{1}{|c|}{ CARACTERística } & \\
\hline Universo & $\begin{array}{l}\text { Habitantes mayores de 18 años de edad, que hayan } \\
\text { visitado, en el último año, algún Destino Turístico de la } \\
\text { Provincia de Córdoba. }\end{array}$ \\
\hline Ámbito geográfico & Córdoba, Capital - Argentina \\
\hline Tipo de muestreo & Muestreo no probabilístico por conveniencia. \\
\hline
\end{tabular}


La Responsabilidad SOCIAL de los DEsTinos turísticos:

IMPACTO EN LA PERCEPCIÓN DE CALIDAD DE SERVICIO Y EN LA IMAGEN DEL DESTINO

\begin{tabular}{|l|l|}
\hline \multicolumn{1}{|c|}{ CARACTERística } & \\
\hline Trabajo de campo & Encuestas personales \\
\hline Tamaño de muestra & $\begin{array}{l}360 \text { encuestas relevadas, } \\
256 \text { casos válidos pos depuración de datos. }\end{array}$ \\
\hline $\begin{array}{l}\text { Fecha de } \\
\text { realización }\end{array}$ & Agosto a Octubre de 2016. \\
\hline
\end{tabular}

FuENTE: ElABORACión PROPIA

Se elaboró un cuestionario semiestructurado que incluyó las siguientes variables: destinos turísticos visitados en la provincia de Córdoba en 2016, percepción del Destino Turístico, percepción de la Calidad del Destino Turístico, Imagen, Evaluación/Satisfacción con el Destino Turístico.

Los datos se recogieron por medio de entrevistas personales y encuestas, distribuidas a través de correo electrónico, enviadas a base de datos de referidos, a ser contestadas por medio de la descarga de un cuestionario en Word, o desde un link a una plataforma web.

\section{ESCALAS UTILIZADAS}

El cuadro siguiente muestra las fuentes de las escalas de medición utilizadas, que fueron medidas en una escala de Likert de cinco puntos, y el indicador de confiabilidad inicial.

CUAdro 2. Resumen DE VARIABles y ESCALAS DE MEDIDA

\begin{tabular}{|c|c|c|c|c|}
\hline \multicolumn{2}{|c|}{ VARIABLES } & Fuente & \multicolumn{2}{|c|}{$\begin{array}{l}\text { Alpha DE } \\
\text { CRONBACH }\end{array}$} \\
\hline \multicolumn{2}{|c|}{$\begin{array}{l}\text { Responsabilidad Social del } \\
\text { Destino Turístico }\end{array}$} & $\begin{array}{l}\text { Brown y Dancin (1997) } \\
\text { Bigné, Aldas, Alvarado } \\
\text { y Currás (2011) }\end{array}$ & \multicolumn{2}{|l|}{0,817} \\
\hline \multirow[t]{4}{*}{$\begin{array}{l}\text { Percepción de } \\
\text { calidad: }\end{array}$} & $\begin{array}{l}\text { Confiabili- } \\
\text { dad }\end{array}$ & $\begin{array}{l}\text { Zeithaml, Parasuraman } \\
\text { y Berry (1985) } \\
\text { Cronin y Taylor (1994) }\end{array}$ & 0,761 & \multirow{4}{*}{0,928} \\
\hline & Seguridad & Cronin y Taylor (1994) & 0,834 & \\
\hline & Tangibilidad & Cronin y Taylor (1994) & 0,756 & \\
\hline & Empatía & $\begin{array}{l}\text { Zeithaml, Parasuraman } \\
\text { y Berry (1985) } \\
\text { Cronin y Taylor (1994) }\end{array}$ & 0,872 & \\
\hline
\end{tabular}




\begin{tabular}{|c|c|c|c|}
\hline \multicolumn{2}{|c|}{ VARIABLES } & FuENTE & $\begin{array}{l}\text { Alpha de } \\
\text { CronbaCH }\end{array}$ \\
\hline \multicolumn{2}{|c|}{$\begin{array}{l}\text { Imagen Global del Destino } \\
\text { Turístico }\end{array}$} & $\begin{array}{l}\text { San Martín Gutiérrez, } \\
\text { Rodríguez del Bosque. } \\
\text { Vázquez Casielles } \\
(2006)\end{array}$ & 0,876 \\
\hline \multicolumn{2}{|c|}{ La calidad percibida del DT } & $\begin{array}{l}\text { García de los Salmones } \\
\text { y otros }(2015)\end{array}$ & 0,909 \\
\hline \multirow[t]{2}{*}{ Satisfacción } & Cognitiva & \multirow{2}{*}{$\begin{array}{l}\text { Cronin et al. (2010), en } \\
\text { Bigné, Aldas, Alvarado } \\
\text { y Curras (2011) }\end{array}$} & 0,909 \\
\hline & Afectiva & & 0,962 \\
\hline \multicolumn{2}{|c|}{$\begin{array}{l}\text { Consumidor Responsable y } \\
\text { Sustentable }\end{array}$} & Bianchi et al. (2013) & 0,701 \\
\hline
\end{tabular}

FUENTE: ELABORACIÓN PROPIA

\section{CARACTERÍsticAs DE LA MUESTRA}

En el cuadro 3 se visualiza el perfil de la muestra junto con el destino turístico elegido agrupado por regiones turísticas, la época del año en que fue visitado y el tipo de alojamiento escogido.

Cuadro 3. Perfil de la muestra

\begin{tabular}{|l|l|l|}
\hline \multicolumn{2}{|l|}{} & Porcentaje \\
\hline Sexo & Masculino & 61,3 \\
& Femenino & 38,7 \\
\hline Estudios & Secundario incompleto o inferior & 2,7 \\
& Secundario completo & 13,8 \\
& Terciario/Universitario incompleto & 46,1 \\
& Terciario/Universitario completo & 37,4 \\
\hline \multirow{2}{*}{ Región visitada } & Punilla & 30,9 \\
& Calamuchita & 26,2 \\
& Translasierras & 15,2 \\
& Paravachasca & 7,8 \\
& Sierras Chicas & 7,0 \\
& Capital & 6,6 \\
& Otras regiones turísticas & 6,3 \\
\hline \multirow{2}{*}{ éca visitada } & Verano & 34,0 \\
& Primavera & 36,0 \\
& Invierno & 21,3 \\
& Otoño & 8,7 \\
\hline
\end{tabular}


La Responsabilidad Social de los destinos turí́sticos:

IMPACTO EN LA PERCEPCIÓN DE CALIDAD DE SERVICIO Y EN LA IMAGEN DEL DESTINO

\begin{tabular}{|l|l|l|}
\hline \multicolumn{2}{|l|}{} & Porcentaje \\
\hline $\begin{array}{l}\text { Alojamiento ele- } \\
\text { gido }\end{array}$ & Hotel 4 o 5 estrellas & 4,6 \\
& Hotel 3 o 2 estrellas & 12,2 \\
& Casa propia & 28,1 \\
& Casa alquilada & 25,5 \\
& Cabaña & 29,6 \\
\hline
\end{tabular}

FUENTE: ElABORACIÓN PROPIA

\section{RESUlTADOS OBTENIDOS}

\section{Principales indicadores Del Destino Turístico}

Los resultados obtenidos al aplicar el cuestionario ofrecen un primer diagnóstico general de la percepción de los turistas respecto del Destino Turístico (véase cuadro 4). Cada una de las variables reciben puntuaciones globales positivas (la media observada es entre 3,4 y 4,3) y con escasa variabilidad (desviación típica de 0,5 a 0,9 puntos).

La dimensión mejor valorada fue la satisfacción afectiva, seguida muy de cerca por la satisfacción cognitiva. En efecto, los entrevistados indicaron sentirse satisfechos con la selección del Destino Turístico, lo que puede observarse en ambas dimensiones de la satisfacción —cognitiva y afectiva-, ya que el $71 \%$ y $84 \%$ de los encuestados, respectivamente, les otorgaron un valor mayor a cuatro puntos (ver figura 1).

Cuadro 4. Principales indicadores del Destino Turístico: media Y DESVIACIÓN ESTÁNDAR

\begin{tabular}{|l|l|l|l|}
\hline & N & Media & \multicolumn{1}{|c|}{$\begin{array}{c}\text { DeSviACión } \\
\text { ESTÁNDAR }\end{array}$} \\
\hline Responsabilidad Social del DT & 256 & 3,63 & 0,81 \\
\hline $\begin{array}{l}\text { Percepción Global de la Calidad } \\
\text { de Servicio }\end{array}$ & 256 & 3,86 & 0,73 \\
\hline Satisfacción Cognitiva del DT & 256 & 4,08 & 0,90 \\
\hline Satisfacción Afectiva con el DT & 256 & 4,36 & 0,87 \\
\hline Consumidor Responsable & 256 & 3,35 & 0,70 \\
\hline Imagen del DT & 256 & 3,85 & 0,55 \\
\hline
\end{tabular}

FUENTE: ElABORACIÓN PROPIA 
La siguiente variable con mejor puntuación fue la percepción de calidad del DT. El 52\% de los participantes consideró que el destino turístico les ofreció servicios con una buena calidad, y estuvo a la altura de sus expectativas; el $10 \%$ indicó lo contrario y el 38\% restante se mantuvo en una posición neutral. Tal como se indicó en el marco teórico, algunas investigaciones sostienen una relación causal entre satisfacción al cliente y calidad del servicio, mientras que otras contradicen estos resultados. En este caso puede observarse que ambas variables tuvieron una valoración positiva, aunque no se mantuvieron los mismos porcentajes.

Figura i. Principales indicadores del Destino Turístico

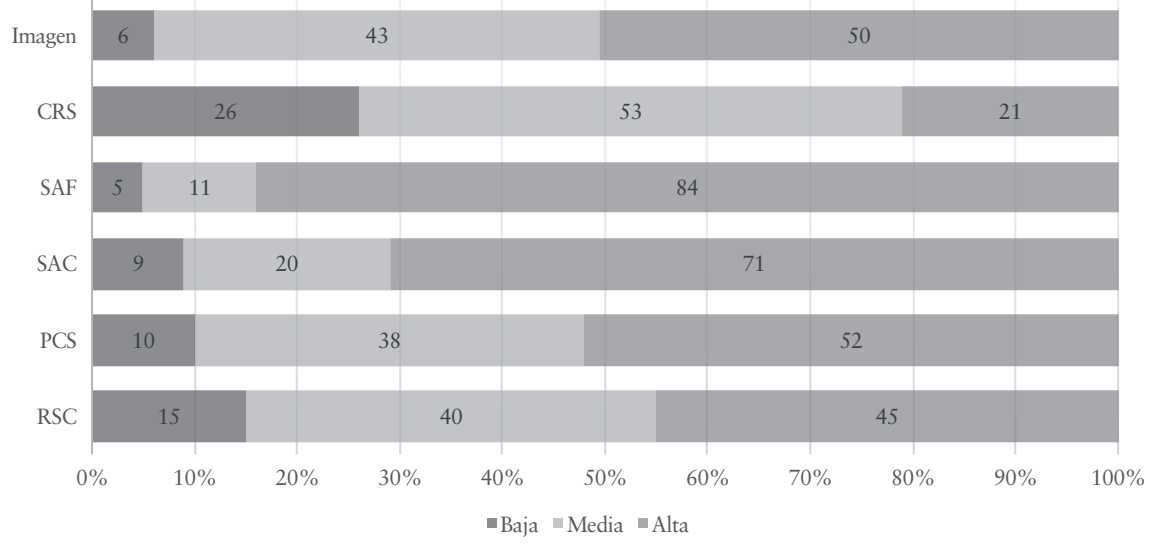

Por otro lado, la mitad de los encuestados evaluó positivamente la imagen del DT, el $43 \%$ se mantuvo indiferente, y el restante $6 \%$ indicó que es negativa.

Además, los datos obtenidos indican que el $45 \%$ está de acuerdo en considerar que el destino visitado es responsable socialmente; el $15 \%$ opinó que el DT, en su percepción global, no es socialmente responsable, y el $40 \%$ restante, un porcentaje significativo de los entrevistados, expresó una posición intermedia entre las dos posturas anteriores.

Finalmente, para conocer el perfil de la muestra y detectar si en ella hay consumidores responsables (en el sentido expresado teóricamente), se consultó su comportamiento frente al consumo eléctrico y de agua, consumo de productos reciclados, separación de residuos y la filantropía. Pudo observarse, claramente, que solo el $21 \%$ de ellos 
tiene un perfil de consumidor responsable, el 53\% tiene algunos comportamientos responsables y otros no, mientras que el $26 \%$ no tiene el perfil de consumo responsable.

\section{LA GeStión Responsable Del Destino Turístico}

Resulta interesante observar si la percepción de RSE de un DT influye en la valoración de cada una de las variables analizadas, es decir, si existe un rol moderador de la PRSE. Para ello, se comparan las respuestas de aquellas personas con una percepción de RSE del DT alta y baja frente a cada dimensión analizada (figura 2).

Figura 2. Responsabilidad Social del Destino Turístico. Principales indicadores de gestión del Destino Turístico

Percepción global de la Calidad del Servicio
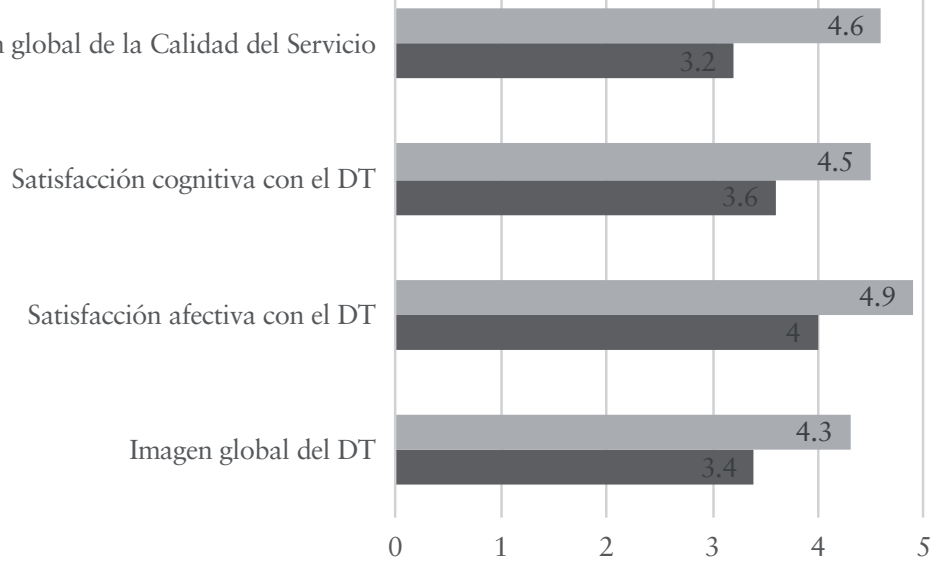

Para ello, se utilizó el procedimiento utilizado por Homburg y Giering (2001) y Wangenheim (2003), que consiste en conformar dos grupos a partir de la mediana de la variable como valor de corte, desechando aquellos casos cuya mediana está contenida en el intervalo comprendido entre la mediana menos la desviación típica ( «baja») y la mediana más la desviación típica ( «alta»), identificándose veinticuatro casos de alta PRSE y treinta y nueve casos de baja PRSE.

En general, se observa que las personas con un nivel alto de percepción de RSE tienden a otorgar mayor puntaje a cada una de las variables analizadas (imagen del DT, satisfacción y calidad percibida), en 
contraste con las personas que tienen una baja percepción de RSE. Las personas con una alta PRSE evalúan, en promedio, con 0,88 puntos más cada una de las dimensiones analizadas que sus pares con baja PRSE.

La mayor diferencia puede observarse en la variable percepción global de la calidad del servicio. Las personas con una percepción de RSE alta otorgaron una puntuación positiva de 4,59 (en una escala de 5 puntos), mientras que quienes tienen una percepción de RSE baja, tuvieron una percepción de calidad del servicio mucho más baja, y la valoraron con 3,2 puntos.

Figura 3. Responsabilidad Social del Destino Turístico.

Principales indicadores de gestión del Destino Turístico
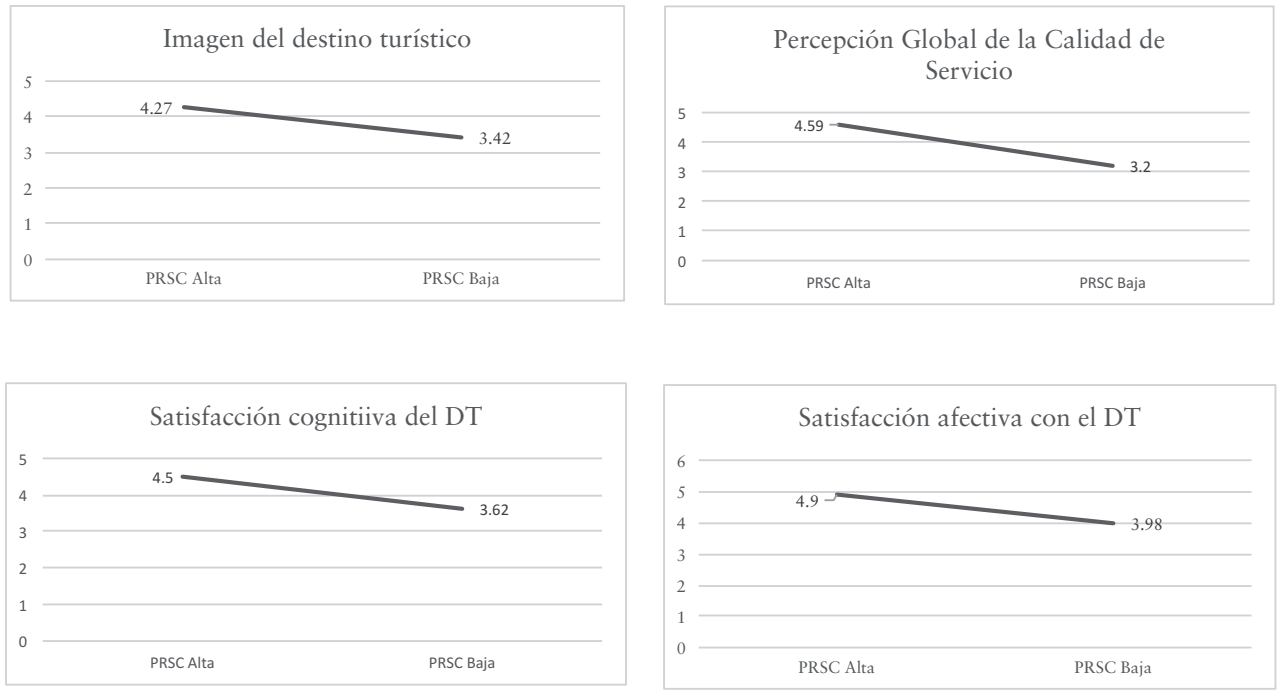

\section{EL CONSUMIDOR RESPONSABLE Y SUSTENTABLE (CRS)}

A continuación, surge la inquietud de observar si los consumidores que tienen un alto perfil de consumo responsable y sustentable evalúan al DT visitado de un modo diferente respecto a los encuestados que no tienen ese perfil. Los resultados se reflejan en la figura 4. Para ello, se utilizó el procedimiento citado anteriormente (Homburg y Giering, 2001; Wangenheim, 2003), identificándose treinta y ocho casos de alta CRS y cuarenta y dos casos de baja CRS. 
A diferencia del apartado anterior, aquí no se observan prácticamente diferencias. Los entrevistados, sean consumidores responsables o no, coincidieron en sus evaluaciones respecto a la imagen global del DT, satisfacción en sus dos dimensiones y en la percepción de RSE del destino turístico visitado. Únicamente difirieron respecto a la percepción global de calidad del servicio, donde el test de diferencia de media-ANOVA es significativo estadísticamente $(\mathrm{F}=2,853 ; \mathrm{p}<0,095)$.

Los CSR consideraron que el destino turístico les ofreció, en general, un nivel alto de calidad, valorando esta variable con 4 puntos; mientras que los consumidores que no tienen hábitos de consumo responsable fueron más exigentes y percibieron menor calidad en los servicios, otorgando en promedio 3,7 puntos. Es en esta variable donde se observa la mayor distancia entre ambos perfiles de consumidores, aunque cabe mencionar que la diferencia no resulta muy significativa ( 0,3 puntos.)

Figura 4. CONSUMIDOR RESPONSABLE Y SUSTENTABLE. Principales indicadores de gestión del Destino Turístico

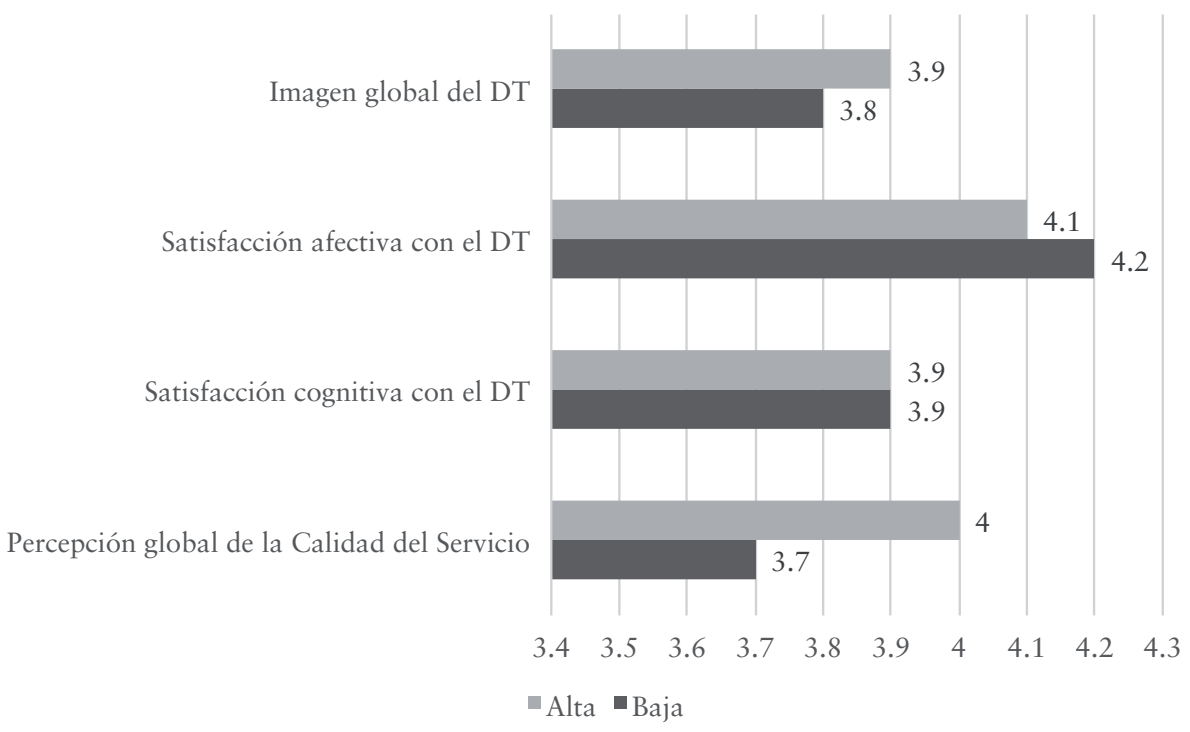

Por lo tanto, podemos decir que el perfil de consumidor socialmente responsable (alto o bajo) no presenta variaciones en la evaluación de la PRSE del Destino Turístico. Por lo tanto, no se pueden afirmar que los turistas con hábitos de consumo responsable valoran diferente la percepción de RSE del destino turístico que aquellos que no lo son. Este 
resultado es llamativo, ya que intuitivamente se podría pensar que las personas que tienen un alto perfil de consumo responsable tenderían a valorar más un destino que implemente acciones de RSE. Pero esta idea no es respaldada por los resultados de estudio.

Figura 5. Consumidor Responsable y SUSTENTABle.

Principales indicadores de gestión del Destino Turístico.

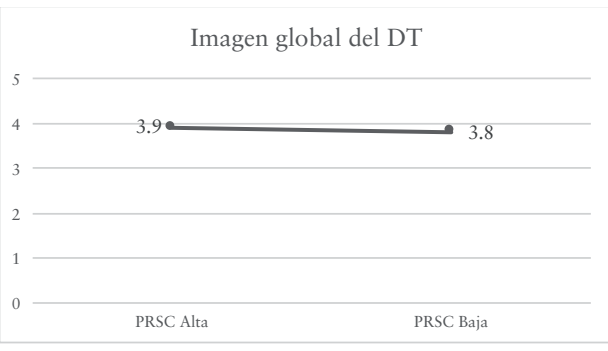

Satisfacción cognitiiva del DT

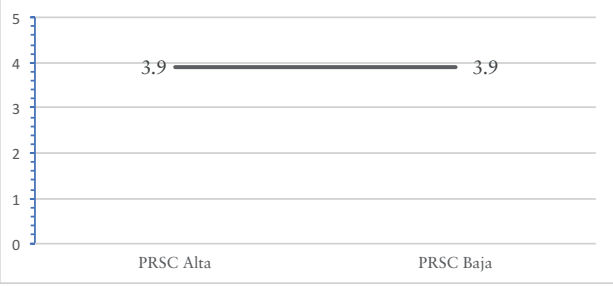

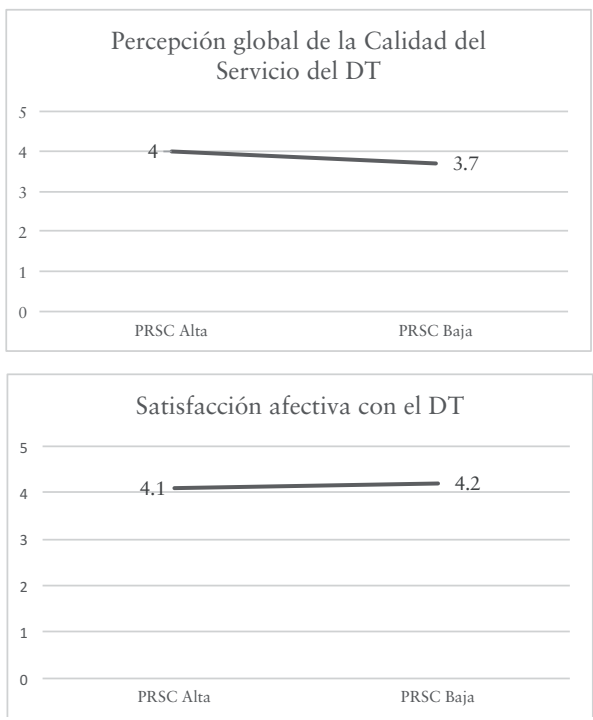

La Responsabilidad Social del Destino Turístico (PRSE) y su impacto en los indicadores de gestión de un Destino Turístico: el rol moderador del comportamiento responsable del turista

Finalmente, se analizará qué sucede cuando comparamos las respuestas de los turistas que tienen un perfil responsable (o no) junto con los que tienen una percepción de RSE alta (o baja); ¿surgirán diferencias significativas en las valoraciones que realicen respecto de cada una de las variables de gestión de los destinos turísticos?

En primer lugar, es interesante observar (véase figura 6) que cuando la PRSE es alta, todas las variables muestran una mayor puntuación que cuando la PRSE es baja, es decir, que la PRSE del Destino Turístico tiene efecto en cada uno de los indicadores de gestión, como se ha afirmado anteriormente. En segundo lugar, respecto del rol moderador del perfil del turista responsable sobre la relación entre la PRSE del Destino 
Turístico de las variables de gestión, cuando esta es alta o baja, se puede afirmar, a partir de los resultados obtenidos, lo siguiente.

Los participantes con alta percepción de RSE otorgan casi la misma valoración a cada variable estudiada, independientemente de que tengan o no un perfil de CRS. Para ser más específicos, si los encuestados tienen alta percepción de RSE y alto perfil de CRS, su evaluación será más exigente, pero por una diferencia mínima, en promedio, de 0,2 puntos. Por ejemplo, los participantes con perfil de CSR y alta percepción de RSE evalúan con 4,2 puntos la imagen global del DT, mientras que le otorgan 4,4 puntos (levemente superior) a la imagen del destino si los consumidores no tienen el perfil responsable. El mismo patrón se observa para las variables de percepción global de la calidad del DT, satisfacción cognitiva, y se mantienen los mismos valores para la variable de satisfacción afectiva. Las diferencias son mínimas y tienden a incrementar las valuaciones de los encuestados que no tienen un perfil de consumidor responsable, es decir, resultan más benevolentes en sus apreciaciones.

Figura 6. RSE DEL DT y CONSUMIDOR RESPONSABLE y SUSTENTABLE

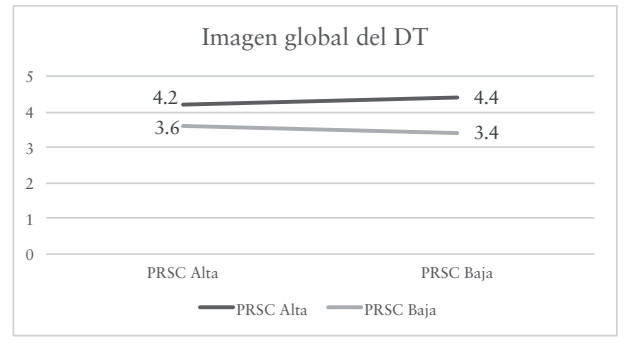

Satisfacción cognitiiva del DT

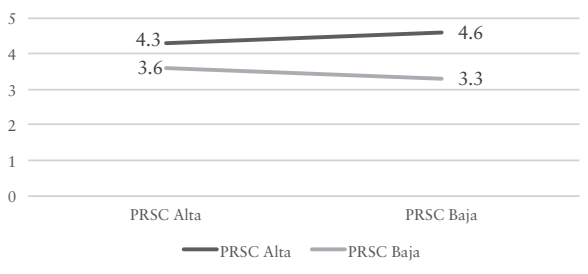

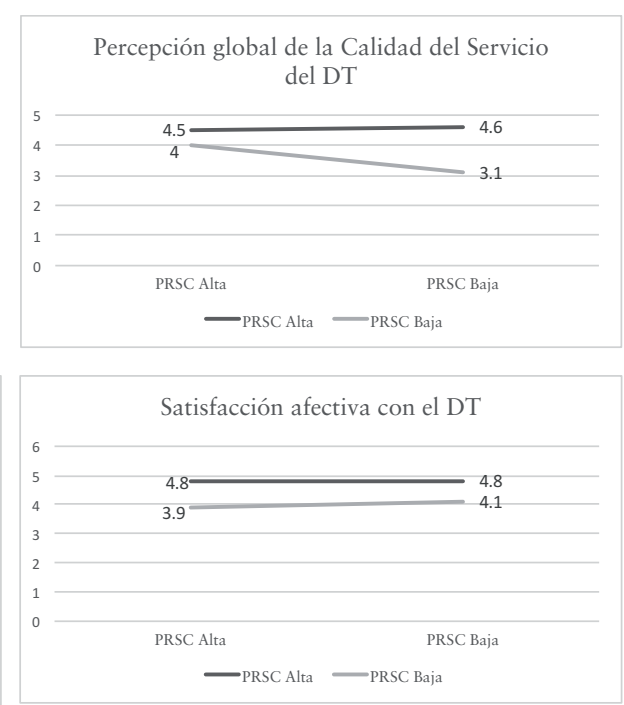

En cambio, sí se observan diferencias más significativas cuando es baja la percepción de RSE, combinado con el perfil de CSR. La mayor diferencia se registra frente a la variable percepción global de la calidad del DT. Los CSR alto otorgan 4 puntos a la calidad del destino, mientras que los CSR bajo le dan un menor puntaje, 3,1. Respecto a las 
variables imagen global del DT y satisfacción cognitiva, los resultados son similares: los consumidores con perfil alto de CRS le otorgan 3,6 puntos, mientras que los CRS bajo le dan 3,4. Finalmente, la tendencia se revierte frente a la variable satisfacción afectiva. Aquí, el mayor puntaje lo otorgan los CSR bajo $(4,1)$ contra los CSR alto $(3,9)$.

\section{Conclusiones}

Tal como se indicó al comienzo, el presente trabajo pretende indagar acerca de la influencia que ejercen en los turistas las acciones de Responsabilidad Social que emprenden los Destinos Turísticos en la provincia de Córdoba, Argentina. Respecto de nuestras hipótesis de investigación, podemos decir que:

La hipótesis H1 fue confirmada. La Percepción de Responsabilidad Social del Destino Turístico influye de manera directa y positiva sobre la Percepción de Calidad de Servicio del Destino Turístico, la Imagen del Destino Turístico, la Satisfacción Cognitiva y Afectiva. La PRSC influye de manera positiva en la imagen del destino. Es decir, los turistas que perciben que los lugares visitados tienen conciencia ambiental y cuidan el medioambiente, tienden a generar una mejor percepción de imagen sobre el mismo. Sin embargo, no se hallaron diferencias significativas según el perfil del consumidor responsable. No se pudo confirmar una asociación entre los hábitos de consumo responsable y las percepciones del turista respecto del destino visitado en cada una de las variables analizadas. Razón por la cual, la hipótesis $\mathrm{H} 2$ fue rechazada, pues no se verifica que el perfil responsable de los turistas influya en la Percepción de Calidad de Servicio del Destino Turístico, la Imagen del Destino Turístico, la Satisfacción Cognitiva y Afectiva.

La hipótesis H3, de la moderación del perfil del turista responsable, es confirmada parcialmente, en el caso de los consumidores con bajo perfil de "consumidor responsable». La relación entre la Percepción de Responsabilidad Social del Destino Turístico y la Percepción de Calidad de Servicio del Destino Turístico, y la Percepción de Responsabilidad Social del Destino Turístico y la Satisfacción Cognitiva, implica que en estos grupos menos conscientes y comprometidos, la inversión en PRSE del DT para lograr una alta percepción impacta de manera mayor en la Calidad de Servicio del DT y en la Satisfacción Cognitiva, que cuando se efectúa en turistas responsables. Esto puede deberse a las menores 
expectativas de ese perfil de turista menos comprometido y a un efecto de «novedad» o «sorpresa».

Estos resultados están en sintonía con las investigaciones que indican que el impacto más importante de un destino asociado a RSE se observa en la imagen percibida, es decir, en el significado que se le otorga a la marca (Zanfardini, Tamagni y Bigné, 2014). Las conclusiones están en sintonía con los trabajos previos que señalan que asociar una localidad con un destino responsable genera mayor intención de volver a visitarlo, pero sobre todo mayor predisposición para recomendarlo (Zanfardini, Tamagni y Bigné, 2014). Por lo tanto, quienes gestionan y ofrecen servicios turísticos en la provincia de Córdoba deben saber que las acciones de RSE generan un efecto positivo y directo en la imagen que los visitantes tengan del destino turístico.

\section{BiBLIOGRAFÍA}

Baloglu, S. y Brinberg, D. (1997). Affective Images of Tourism Destinations. Journal of Travel Research, 35 (4), 11-15.

Bianchi, E. C.; Ferreyra, S., y De Gesualdo, G. K. (2013). Consumo responsable: diagnóstico y análisis comparativo en la Argentina y Uruguay. Escritos Contables y de Administración, 4(1), 43-79.

Bigné Alcañiz, E.; Font, X. y Andreu Simó, L. (2000). Marketing de los destinos turísticos: Análisis y estrategias de desarrollo. Madrid: Esic.

Bigné Alcañiz, E. y Andreu Simó, L. (2004). Modelo cognitivo-afectivo de la satisfacción en servicios de ocio y turismo. Cuadernos de Economía y Dirección de la Empresa, (21), 89-120.

Bigné Alcañiz, E.; Sánchez García, I., y Sanz Blas, S. (2005). La imagen de un destino como variable de segmentación: un modelo de relaciones post-compra. En XVII Encuentro de Profesores Universitarios de Marketing (pp. 689-704). Madrid: Escuela Superior de Marketing y ESIC.

Campbell, J. L. (2007). Why would corporations behave in socially responsible ways? An institutional theory of corporate social responsibility. The Academy of Management Review, 32(3), 946-963.

Chen, J. S. y Uysal, M. (2002). Market Positioning Analysis: A Hybrid Approach. Annals of Tourism Research, 29(4), 987-1003.

Cole, S. T. e Illum, S. F. (2006). Examining the mediating role of festival visitors satisfaction in the relationship between service quality and behavioral intentions. Journal of Vacation Marketing, 12 (2), 160-173.

García de Leaniz, P. M.; Pérez Ruiz, A. y Rodríguez del Bosque, I. (2012). Análisis de la práctica corporativa de la responsabilidad social en 
el sector turístico: un estudio de casos. Cuadernos de Turismo, (30), 145-164.

Goodwin, H. y Francis, J. (2003). Ethical and responsible tourism: Consumer trends in the UK. Journal of Vacation Marketing, 9 (3), 271-284.

Grönroos, C. (1984). A service quality model and its marketing implications. European Journal of Marketing, 18(4), 36-44.

Homburg, C. y Giering, A. (2001). Personal characteristics as moderators of the relationship between customer satisfaction and loyalty-an empirical analysis. Psychology \& Marketing, 18(1), 43-66.

Iglesias Fernández, J. (2009). La irresponsabilidad del consumo responsable como propuesta transformación social. En J. Iglesias Fernández, Sobre el decrecimiento y otras rendiciones. Interpretación crítica sobre el decrecimiento y el consumo responsable. Barcelona.

Kim, H. y Richardson, S. L. (2003). Motion Picture Impacts on Destination Images. Annals of Tourism Research, 30 (1), 216-237.

Moltedo Perfetti, P. (2007). Reflexiones en torno al Marketing y la Felicidad. Actualizaciones para el Management y el Desarrollo Organizacional. Disponible en: http://www.eumed.net/librosgratis/2007a/223/pmp.htm.

Ocampo, S.; Ortiz, J. y Castaño, L. (2014). El concepto de consumo socialmente responsable y su medición. Una revisión de la literatura. Estudios Gerenciales, 30, 287-300.

Oliver, R. L. (1980). A Cognitive Model of the Antecedents and Consequences of Satisfaction Decisions. Journal of Marketing Research, 17 (4), 460-469.

(1997). Satisfaction: A behavioral perspective on the consumer. Boston: Irwin/McGraw-Hill.

Organización Mundial del Turismo. (2001/2004). Declaraciones de la Organización Mundial del Turismo en relación con el desarrollo sostenible del turismo: conceptos y definiciones. Disponible en: http:// www2.unwto.org/es/content/acerca-de-la-omt.

Panapanaan, V. y Linnanen, L. (2002). Management of corporate responsibility towards sustainability: triple bottom line approach. Oikos $\mathrm{PhD}$ summer academy 2002. University of St. Gallen, Suiza.

Panwar, R.; Rinne, T., Hansen, E. y Juslin, H. (2006). Corporate responsibility: Balancing economic, environmental, and social issues in the forest products industry. Forest Products Journal, 56(2), 4-12.

Pérez Ruiz, A.; García de los Salmones Sánchez, M. y Rodríguez del Bosque, I. (2008). Las dimensiones de la responsabilidad social de las empresas como determinantes de las intenciones de comportamiento del consumidor. Revista Asturiana de Economía, 41, 127-147. 
Pike, S. y Ryan, C. (2004). Destination positioning analysis through a comparison of cognitive, affective, and conative perceptions. Journal of Travel Research, 42 (4), 333-342.

San Martín Gutiérrez, H.; Rodríguez del Bosque Rodríguez, I. A. y Vázquez Casielles, R. (2006). Análisis de la imagen en turismo mediante técnicas estructuradas y no estructuradas: Implicaciones competitivas para los destinos turísticos. Revista Asturiana de Economía, 35, 69-91.

Schiffman, L. G. y Kanuk, L. L. (2010). Consumer Behaviour (10a ed.). México: Pearson Education.

Sureshchandar, G. S.; Rajendran, C. y Kamalanabhan, T. J. (2001). Customer perceptions of service quality: A critique. Total quality management, 12(1), 111-124.

Velandia Salazar, F.; Ardón Centeno, N. y Jara Navarro, M. (2007). Satisfacción y calidad: análisis de la equivalencia o no de los términos. Revista Gerencia y Políticas de Salud, 6(13), 139-168.

Velázquez, B.; Saura, I. y Molina, M. (2009). La formación de la lealtad y su contribución a la gestión de destinos turísticos. Cuadernos de Administración, 22(39), 75-98.

Walmsley, D. J. y Young, M. (1998). Evaluative Images and Tourism: The Use of Personal Constructs to Describe the Structure of Destinations Images. Journal of Travel Research, 36(3), 65-69.

Wangenheim, F. (2003). Situational characteristics as moderators of the satisfaction-loyalty link: an investigation in a business-to-business context. Journal of Consumer Satisfaction, Dissatisfaction and Complaining Behavior, 16, 145-156.

Zanfardini, M.; Tamagni, L. y Bigné, E. (2014). ¿Cómo impacta la RSE en el valor de las marcas turísticas? La percepción de los turistas en San Martín de los Andes. VI Congreso Latinoamericano de Investigación Turística. Neuquén. 



\title{
A CONTRIBUIÇÃO DOS PACOTES SALARIAIS NA AMPLIAÇÃO DA RESPONSABILIDADE SOCIAL EMPRESARIAL
}

\author{
Katia de Rezende Maia Cruz" \\ Emmanuel Paiva de Andrade"* \\ David Barbosa Souza Junior ${ }^{* * *}$ \\ Brasil
}

\section{INTRODUÇÃO}

Não é de hoje que a classe trabalhadora clama por melhores salários e menor desigualdade. Segundo Hobsbawm (2015), após 1815 havia um sentimento geral de desarmonia entre a classe trabalhadora e a aristocracia, o que ainda se mantém quando comparamos salários dos executivos, ou seja, membros de diretoria e presidência, e não executivos na maioria dos países, segundo a OIT (2017). Se vê, portanto, até os dias atuais, a necessidade de rever práticas salariais para que sejam sustentáveis, evitando que haja uma maior disparidade na diferença salarial, a qual poderia contribuir, entre outros fatores, para o aumento da desigualdade social.

A diferença salarial entre os executivos e não executivos faz emergir questões não somente relacionadas às práticas salariais, mas também, de Responsabilidade Social relacionadas às oportunidades no mercado de trabalho. Com base neste enfoque, em 1919 foi criada a OIT - Organização Internacional do Trabalho, cuja missão é «promover

\footnotetext{
Mestranda em Sistemas de Gestão. Universidade Federal Fluminense. cmte. katiamaia@gmail.com

** Doutor em Engenharia de Produção. Universidade Federal Fluminense. emmanueluff@gmail.com

**** Mestrando em Sistemas de Gestão. Universidade Federal Fluminense. dbsjunior@ id.uff.br
} 
oportunidades para que homens e mulheres possam ter acesso a um trabalho decente e produtivo, em condições de liberdade, equidade, segurança e dignidade» (OIT, 2018).

Segundo Seixas et al. (2017), as organizações podem ter diferentes níveis de dificuldade para incorporar Responsabilidade Social em seus negócios, porém se não atingirem determinados patamares de justiça social estão fadadas ao insucesso.

Percebe-se, entretanto, na literatura, grande foco na diferença salarial entre homens e mulheres (Manning e Swaffield, 2008; Cha e Weeden, 2014; Kampelmann et al., 2018).

Por um longo período, segundo Judge y Livingston (2008), os estudos ficaram concentrados nas diferenças entre os gêneros e, segundo Shin (2014), há poucos estudos que visam identificar os principais fatores de diferenças salariais dentro da hierarquia organizacional.

Portanto, o objetivo deste trabalho é realizar uma análise da literatura para investigar os principais fatores que levam a desigualdade salarial, não só nos países em desenvolvimento, mas também nos países desenvolvidos, contribuindo para a reflexão dos profissionais de $\mathrm{RH}$ e fazendo emergir questões sobre Responsabilidade Social não somente ligadas ao gênero, mas também à hierarquia organizacional.

\section{EVOLUÇÃO DOS PACOTES SALARIAIS}

A palavra salário tem origem na Roma antiga onde os pagamentos eram feitos com sal. Hoje, de acordo com Aulete (2018), a palavra salário tem conotação de dinheiro, onde é «remuneração paga ao empregado em troca do seu trabalho» (Aulete, 2018). Segundo Hipólito e Dutra (2012), o salário base deve ser suficiente para suprir as necessidades básicas das pessoas e para sua capacidade de reprodução.

Entretanto, outros componentes de remuneração foram incorporados, ao longo do tempo, aos chamados pacotes salariais, tais como bonificações e benefícios. No início do século XX, os pacotes salariais eram compostos basicamente de salário fixo, sendo definido por dia de trabalho ou de acordo com a produção individual. Este último conceito, segundo Hipólito e Dutra (2012), foi introduzido por Taylor, que pregava que para o trabalhador manter seu nível de remuneração deveria ter maior produtividade. Todavia, tal conceito não era bem aceito por todos pois alguns tinham a percepção de que produtividade e remuneração não avançavam na mesma proporção. Por outro lado, 
Piketty (2014) destaca que promovendo o aumento da produtividade, os salários também se elevarão (Hipólito e Dutra, 2012; Piketty, 2014).

De acordo com os estudos realizados pela OIT (2017), percebe-se, nos dias atuais, a mesma tendência de que o aumento da produtividade reflete em aumento salarial, porém eles não avançam na mesma proporção, conforme gráfico 1 .

GRÁfICO I. TENDÊNCIA DO CRESCIMENTO DOS SALÁRIOS MÉdIOS REAIS E DA PRODUTIVIDADE DO TRABALHO NAS ECONOMIAS DESENVOLVIDAS

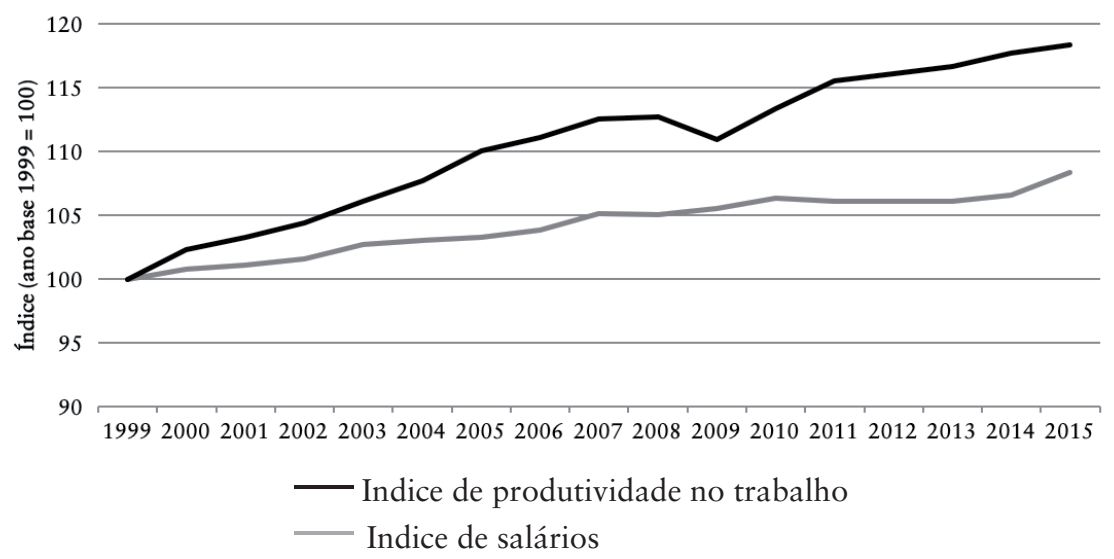

Fonte: OIT - Relatório global SObRe os SALÁrios 20I6/I7: Desigualdade SALARIAL NO LOCAL DE TRABALHO (2OI7, P. I 5 ).

Foi então que os pacotes salariais ficaram mais rígidos e buscavam a imparcialidade, sendo estas as características do modelo tradicional de remuneração de acordo com Hipólito e Dutra (2012), o qual é conhecido como remuneração funcional, que utiliza o cargo como base de diferenciação, ou seja, a remuneração é pelo cargo e não pelo indivíduo. Segundo Malferrari (1970), apesar das primeiras metodologias de avaliação de cargo terem surgido na década de 1920, somente após 1960 as organizações começaram a implementar planos de cargos e salários (Malferrari, 1970; Hipólito, 2006; Hipólito e Dutra, 2012).

Diversos autores como Wood Jr. e Picarelli Filho (2004), Hipólito (2006), Marras e Neto (2012) e Lima (2014) destacam que o método funcional, ou seja, baseado em cargos, já não atende às necessidades das organizações por ser um método inflexível e burocrático, porém ainda é utilizado pela maioria das empresas pois é um método muito 
bem aceito por elas (Wood Jr. e Picarelli Filho, 2004; Hipólito, 2006; Marras e Neto, 2012; Lima, 2014).

Surge então, na década de 1990, no Brasil, um novo conceito chamado de remuneração por habilidades, o qual já estava sendo praticado em outros países, como Estados Unidos desde a década de 1970. Este método, segundo Mitra et al. (2011) reconhece as habilidades do indivíduo e sua capacidade de ocupar outros cargos dentro da organização. Entretanto, segundo Hipólito y Dutra (2012), ao longo do tempo constatou-se que este método estava restrito aos cargos mais operacionais e técnicos e dependia que a área de RH estivesse bem estruturada para treinar e monitorar o desenvolvimento do indivíduo.

Este método, no Brasil, ainda gerava um outro desafio para as organizações, segundo Hipólito (2006), pois era muito mais suscetível a reclamações trabalhistas, já que remunerava de maneira diferente indivíduos que ocupavam o mesmo cargo, principalmente no nível operacional.

Outro desafio apontado por Wood Jr. e Picarelli Filho (2004) é com relação ao equilíbrio externo. Os pacotes salarias são desenhados com o intuito de garantir que haja equilíbrio interno em uma mesma organização e que os trabalhadores sejam remunerados de maneira justa. Entretanto, não se pode deixar de observar a prática salarial e avaliar a competitividade das empresas que possam concorrer na busca por profissionais. Esta análise é realizada através de pesquisa salarial, a qual, ainda nos dias atuais, segundo Wood Jr. e Picarelli Filho (2004), é baseada na descrição de cargo e não na comparação de habilidades em trabalhos equivalentes.

Em função da restrição da aplicação do método de remuneração por habilidades, e com o avanço da tecnologia, onde trabalhos mais operacionais começaram a ser migrados para países com salários mais baixos, foi desenvolvido um novo método, conhecido por remuneração por competência, o qual é tido como uma evolução do método de remuneração por habilidades (Wood Jr. e Picarelli Filho, 2004; Hipólito, 2006; Marras e Neto, 2012).

De acordo com Wood Jr. e Picarelli Filho (2004), remunerar por competência traz um desafio adicional para o time de Recursos $\mathrm{Hu}$ manos, de definir um painel de competências adequado, de maneira a agregar valor aos produtos e serviços requeridos pelos clientes e que esteja alinhado com a estratégia da organização.

Marras e Neto (2012) ressaltam que os pacotes salariais baseados no modelo por competência são mais aplicáveis aos níveis de liderança, 
enquanto que Wood Jr. e Picarelli Filho (2004) apontam que também podem ser aplicados aos níveis mais operacionais/técnicos.

Segundo Hipólito e Dutra (2012), os pacotes salariais neste modelo são aplicados com base nas competências e podem ser totalmente desvinculados da hierarquia organizacional.

Além dos modelos funcional, por habilidade e por competência, ainda há um outro modelo sob o qual os pacotes salariais podem ser desenvolvidos, conhecido como remuneração por desempenho.

O modelo de remuneração por desempenho tem como base, segundo Nyberg et al. (2016), remunerar pelo atingimento de metas pré-acordadas, reconhecendo o resultado passado. Além do salário base, há o pagamento de um bônus o qual é chamado nas organizações de remuneração variável. Este método é muito usado atualmente nas organizações (Hipólito e Dutra, 2012; Marras e Neto, 2012; Lima, 2014; Nyberg, 2016).

Wood Jr. e Picarelli Filho (2004) ressaltam que neste modelo, remuneração deve estar totalmente relacionada ao desempenho do trabalhador. Entretanto, não há impacto no salário base, somente na remuneração variável. A WorldatWork (2007) ainda destaca que para o sucesso deste modelo, o trabalhador precisa entender claramente o que é esperado dele para que ele veja valor no recebimento da remuneração variável.

\section{Responsabilidade Social EMPRESARIAL}

O estudo realizado por Seixas et al. (2017), foi importante para este trabalho por ter organizado, de maneira cronológica, a evolução do conceito de Responsabilidade Social Empresarial, desde a década de 1950, considerando o contexto do pós-guerra, das lutas pelos direitos humanos e movimentos em favor das mulheres, negros e homossexuais.

Segundo Seixas et al. (2017), a discussão sobre Responsabilidade Social traz diversos conceitos onde, no início, as empresas eram o centro do poder, em que as decisões dos empresários impactavam diretamente a vida dos cidadãos. Um dos objetivos dos empresários era reduzir custos sem muita preocupação com impacto social, econômico e ambiental.

Os anos 1960 tiveram grande importância pois o conceito de Responsabilidade Social Empresarial foi formalizado de maneira mais precisa (Carroll, 1999). Carroll (1999) destaca que nesta época já havia decisões tomadas com base em interesses além dos puramente 
econômicos e os que tinham como base a Responsabilidade Social, impactavam não somente na vida dos cidadãos, mas também no resultado dos seus negócios, trazendo ganhos econômicos a longo prazo.

Porém, a visão da empresa socialmente responsável surge na década de 1970 quando há o entendimento sobre a integração e equilíbrio de «[...] múltiplos interesses, que inclui o lucro para os acionistas e as necessidades dos funcionários, fornecedores, comunidades e a nação» (Seixas et al., 2017, p. 35). Este novo conceito emergiu, possivelmente, em função das manifestações em prol do meio ambiente e de melhores condições de trabalho que aconteceram na época.

Responsabilidade Social evoluiu de um conceito relacionado à caridade para um conceito mais voltado para o comportamento das empresas onde se espera, de maneira voluntária, que as decisões tomadas não se limitem aos interesses dos acionistas e nem fiquem restritas à aplicação das leis (Lázaro e Gremaud, 2016). Entretanto, de acordo com Cohen et al. (2009) e Seixas et al. (2017), o comportamento das empresas é reflexo das atitudes e ações de seus líderes, os quais são responsáveis por criar as políticas internas e direcionar a cultura organizacional.

Liang e Renneboog (2017) definem Responsabilidade Social como sendo um termo usado frequentemente para descrever comportamentos de uma empresa voltados para os stakeholders. Por outro lado, o conceito mais amplo de Responsabilidade Social, de acordo com Rodrigues e Mendes (2018), é a maneira voluntária e ética de uma empresa contribuir para o desenvolvimento econômico, tendo compromisso com trabalhadores, suas famílias, a comunidade local e a sociedade em geral por melhor qualidade de vida (Seixas et al., 2017; Rodrigues e Mendes, 2018).

Entretanto, percebe-se, pelos estudos de Rodrigues e Mendes (2018) que as empresas estão em evolução, ou seja, em estágios diferentes de maturidade com relação ao conceito e aplicação da Responsabilidade Social (Lázaro e Gremaud, 2016; Liang e Renneboog, 2017; Seixas et al., 2017).

\section{PACOTES SALARIAIS E RESPONSABILIDADE SOCIAL EMPRESARIAL}

Uma das dimensões da Responsabilidade Social abraça temas ligados ao trabalho e, portanto, à desigualdade salarial. A desigualdade salarial pode gerar profundos impactos na desigualdade social 
e percebe-se, de acordo com Piketty (2014), que ao longo dos séculos houve períodos de maior desigualdade social e outros com redução desta desigualdade.

Piketty (2014) aponta que logo após as duas grandes guerras, no século XX, houve uma redução significativa da desigualdade salarial, porém, em seguida essa desigualdade voltou a ampliar. Com a retomada da economia pós-guerra, segundo Piketty (2014), percebe-se o crescimento dos salários mais altos de maneira mais acelerada do que o dos salários mais baixos, contribuindo para o aumento da desigualdade social.

O Gráfico 2 mostra que entre os anos 2000 e 2015 houve crescimento da desigualdade social em mais de $50 \%$ dos países membros da OCDE - Organização para Cooperação e Desenvolvimento Econômico, incluindo países como a Noruega que possuía uma das menores desigualdades no mundo. Por outro lado, países como Chile, Estônia e Hungria mostraram grande evolução da redução da desigualdade social.

\section{Gráfico 2. Desigualdade social nos Países da OCDE}

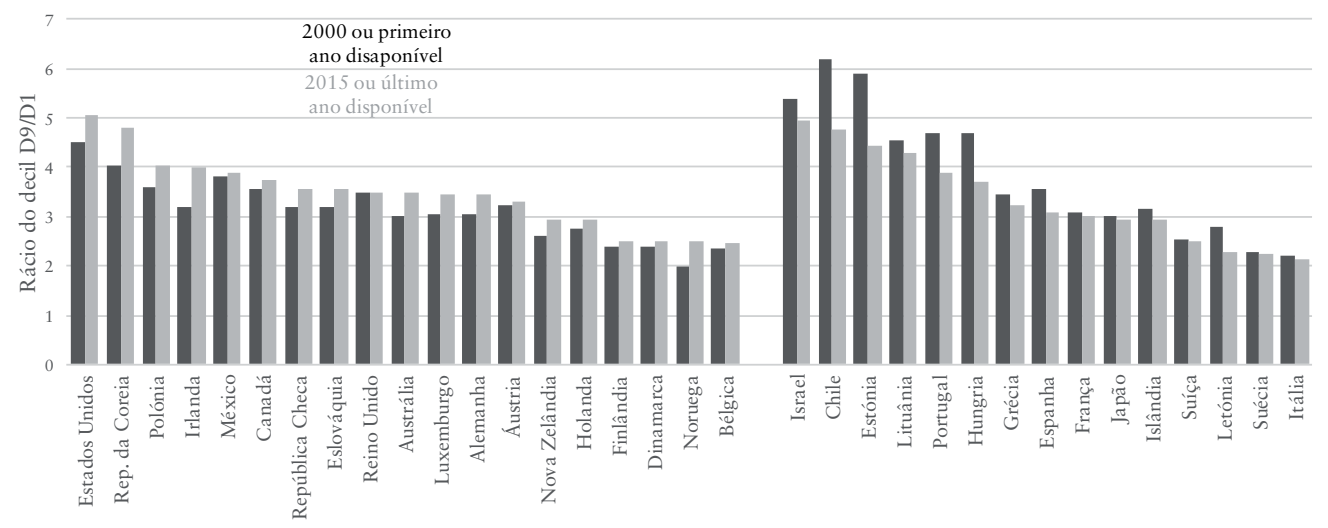

FONTE: OIT (2017, P. 22).

Com o intuito, entre outros, de garantir melhores condições de trabalho e reduzir a desigualdade salarial, diversos organismos foram criados ao longo do século XX, tais como a OIT - Organização Internacional do Trabalho, WEF - World Economic Forum e a GRI - Global Reporting Initiative.

A OIT, criada em 1919, visa criar mecanismos para reduzir a desigualdade social e garantir o desenvolvimento sustentável, definindo 
normas e princípios e direitos fundamentais no trabalho. Seu último relatório global sobre salários traz uma análise detalhada sobre as práticas salariais de países de todos os continentes, ressaltando a disparidade salarial entre os gêneros e entre os menores e maiores salários (OIT, 2017).

Em 1971, foi criado o WEF cujo objetivo é fornecer uma plataforma para líderes de todos os grupos de stakeholders —empresas, governo e sociedade civil - para se unirem em prol de um mundo melhor. O Fórum «afirma que uma organização é responsável perante todas as partes da sociedade» (WEF, 2018). Seus últimos relatórios têm foco no desenvolvimento do capital humano e nas desigualdades entre homens e mulheres no que tange à participação econômica, educação, oportunidades, entre outros (WEF, 2017).

Em 1997, foi criada a GRI, um trabalho em conjunto da Coaliation for Environmentally Responsible Economies (CERES) e do Instituto Tellus, além do envolvimento do Programa das Nações Unidas para o Meio Ambiente (PNUMA), com o objetivo, também, de criar um mecanismo para garantir que as empresas estivessem seguindo uma conduta ambiental responsável. Em 2000, foi lançado o primeiro relatório com as diretrizes de Responsabilidade Social e, a partir de 2002, a GRI incorporou indicadores ambientais, econômicos e sociais. Os indicadores sociais englobam, entre outros aspectos, as práticas salariais das organizações (GRI, 2018).

A revisão dos tipos de pacotes salariais e dos conceitos de Responsabilidade Social, mostra que os modelos de remuneração vêm sofrendo alterações ao longo dos anos com o objetivo de atender tanto às necessidades das organizações, em um ambiente mais tecnológico e cada vez mais competitivo, quanto às necessidades dos indivíduos. Porém, além das fragilidades encontradas em todos os modelos que suportam os pacotes salariais, percebe-se que estes podem contribuir para o aumento da desigualdade salarial. Até mesmo os pacotes de remuneração baseados no cargo, que foram criados com o intuito de serem imparciais, podem gerar certa desigualdade salarial por permitirem reajustes diferenciados, em função da diferença de produtividade individual.

Porém, há uma preocupação, segundo a OIT (2017), com relação à excessiva desigualdade salarial, a qual pode gerar redução do crescimento econômico do país, além de contribuir para a desigualdade social. Daí, a necessidade de investigar os fatores que contribuem para o aumento da desigualdade salarial, principalmente entre os níveis hierárquicos nas organizações. 


\section{Aspectos metodológicos}

Em função da necessidade de investigar os principais fatores que levam a desigualdade salarial, a metodologia utilizada neste artigo foi o estudo bibliométrico utilizando a revisão sistemática da literatura. Segundo Gray (2012), a revisão da literatura tem como objetivo identificar a maneira como outras pessoas pesquisaram o assunto a ser estudado e permitir que o pesquisador possa aprofundar estudos realizados anteriormente.

\section{REVISÃO SISTEMÁTICA DA LITERATURA}

A revisão sistemática da literatura, segundo Gray (2012) deve seguir um roteiro previamente definido. Portanto, a primeira etapa desta pequisa foi definir a base de dados a ser pesquisada. Foram escolhidas a base Scopus e Web of Science por serem as maiores bases de dados de literatura revisada por pares, o que, de acordo com Gray (2012), garante maior probabilidade de qualidade e confiabilidade dos artigos.

A segunda etapa foi determinar as palavras-chave para a busca de artigos nas referidas bases. A pesquisa foi feita de maneira a identificar artigos contendo pelo menos uma das palavras da tabela 1 no resumo, título ou palavras-chave, sem nenhum tipo de filtro aplicado. Foram encontrados mais de 18 mil artigos, considerando a possibilidade de haver artigos em duplicidade.

Tabela i. Seleção de palavras-chave

\begin{tabular}{|l|l|}
\hline \multicolumn{2}{|c|}{ PALAVRAS-CHAVE } \\
\hline Wage inequality & Salay inequality \\
\hline Wage gap & Salary gap \\
\hline $\begin{array}{l}\text { Social Responsibility AND } \\
\text { Wage inequality }\end{array}$ & Social Responsibility AND Salary inequality \\
\hline $\begin{array}{l}\text { Social Responsibility AND } \\
\text { Wage gap }\end{array}$ & Social Responsibility AND Salary gap \\
\hline
\end{tabular}

FONTE: OS AUTORES.

A terceira etapa foi aplicar um filtro temporal, de maneira a obter os artigos publicados no período de 2008 a 2018, onde se obteve cerca de 12 mil artigos. Então, mais um filtro foi aplicado, onde limitou-se 
artigos publicados apenas em journals e nos idiomas inglês, português e espanhol, obtendo-se, portanto, cerca de 10 mil artigos, ainda considerando-se a possibilidade de haver artigos em duplicidade. Através do Excel, foi feita a identificação dos artigos duplicados, expurgando-os, o que resultou em uma base com 3.845 artigos, conforme distribuição por ano de publicação, mostrado no gráfico 3 , onde percebe-se uma certa tendência de crescimento no estudo do tema circunscrito pelas palavras-chave.

GrÁfico 3. Número de artigos Por ano de PUblicação

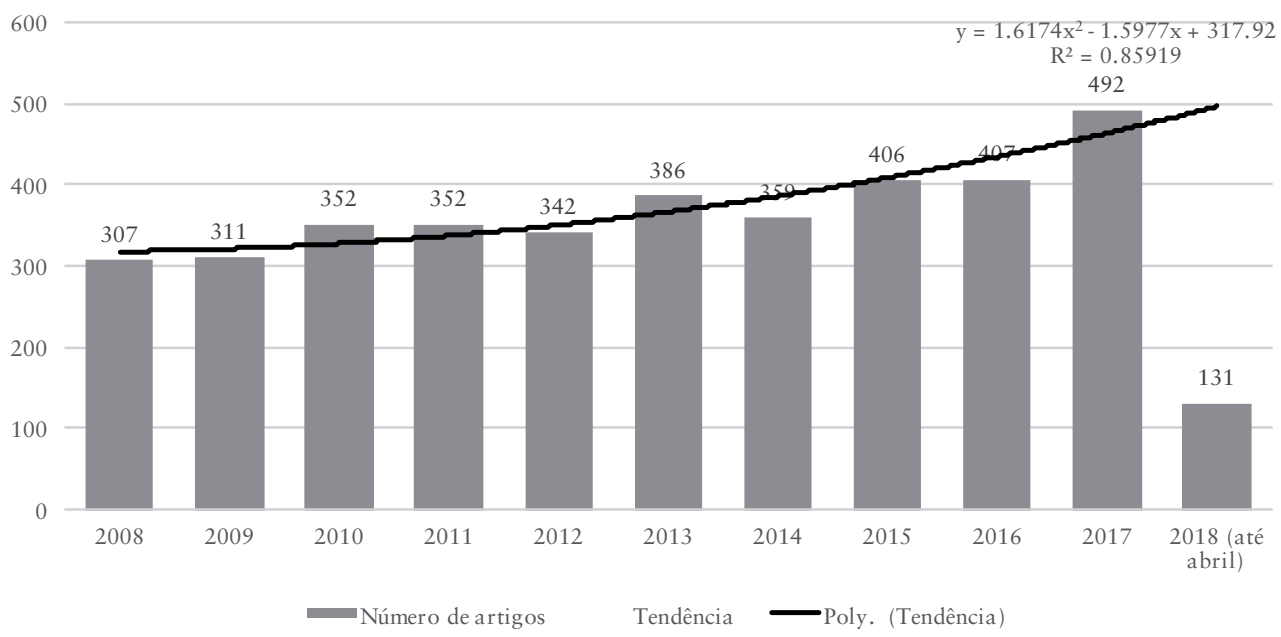

FONTE: OS AUTORES

Os artigos foram, então, ordenados pelos mais citados e, na quarta etapa, foi feita a análise do resumo dos 100 artigos mais citados em cada uma das bases para identificar os que estavam explicitamente relacionados com o tema deste estudo. Ou seja, aqueles artigos que, em seus resumos, eram abordados temas de remuneração tais como desigualdade salarial, incremento salarial, entre outros e temas de Responsabilidade Social, tais como relações do trabalho, gênero, entre outros. O resultado obtido revelou 47 artigos finais para inclusão neste trabalho, conforme figura 1 . 
A CONTRIBUIÇÃO DOS PACOTES SALARIAIS NA AMPLIAÇÃO

DA RESPONSABILIDADE SOCIAL EMPRESARIAL

Figura I. MAPA DA REVISÃo SISTEMÁTICA DA LITERATURA

Processo de Identificação e Seleção

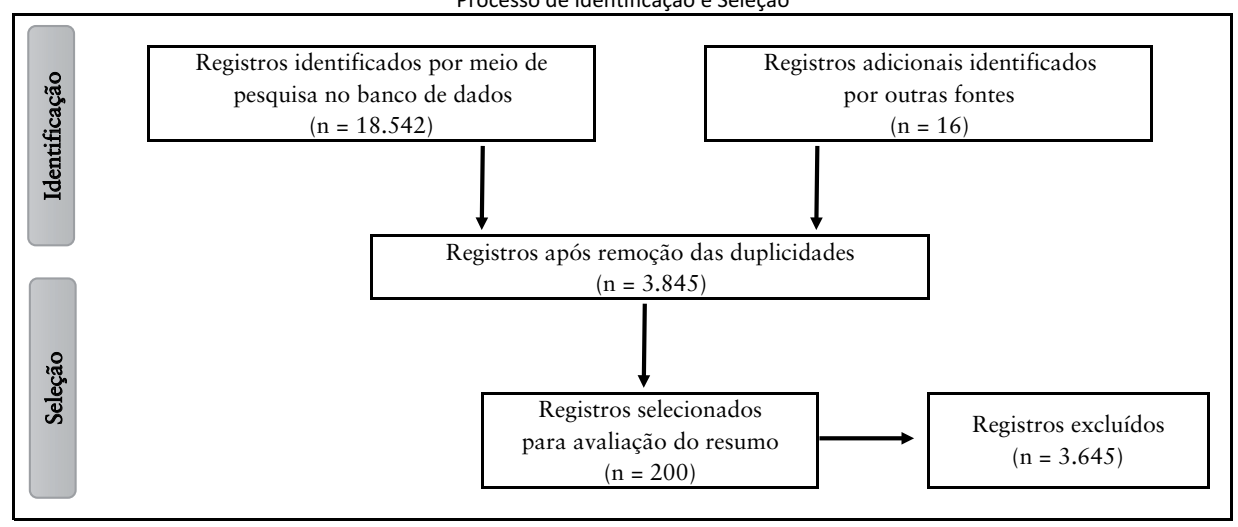

Processo de Elegibilidade e Inclusão

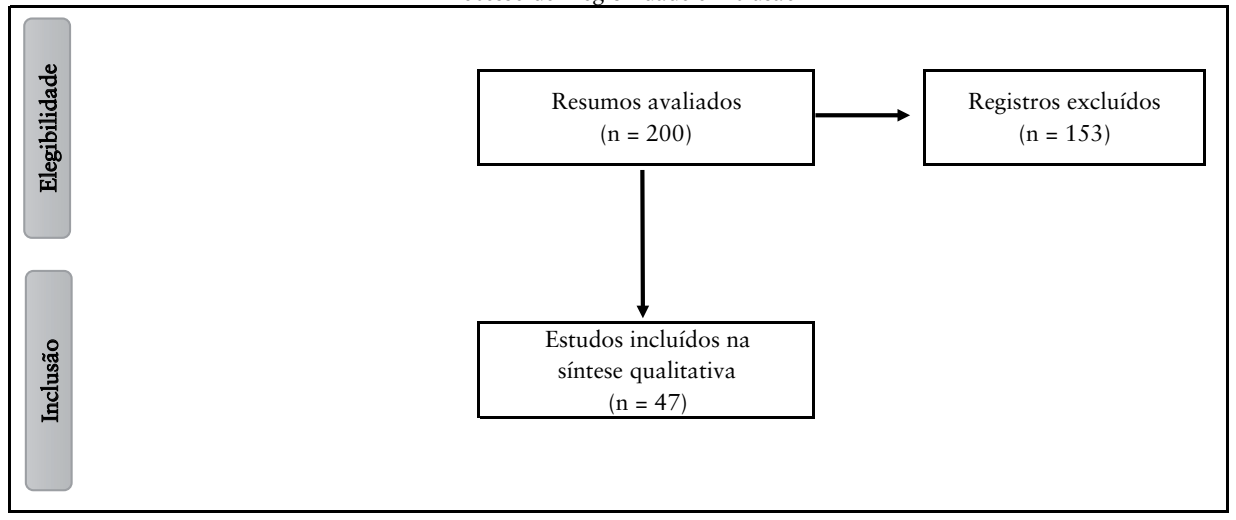

FonTE: OS AUTORES - ADAPTAÇÃO DO DIAGRAMA DE PRISMA.

\section{ANÁlise dos DADOS}

Após a definição dos artigos que seriam incluídos no estudo, foi feita uma análise detalhada de cada um dos 47 artigos de maneira a identificar o objetivo dos estudos e seus achados, classificando os resultados conforme as categorias gênero, escolaridade, hierarquia organizacional e fatores socioeconômicos. 
CATEgorizando A LiTERATURA SOBRE AS DESIGUALDADES SALARIAIS

O gráfico 4 mostra o número de artigos publicados por país, o que revela grande discussão sobre o tema nos Estados Unidos, sendo este o país com maior desigualdade salarial em 2015, de acordo com a OIT (2017).

\section{Gráfico 4. Artigos PUblicados por País}

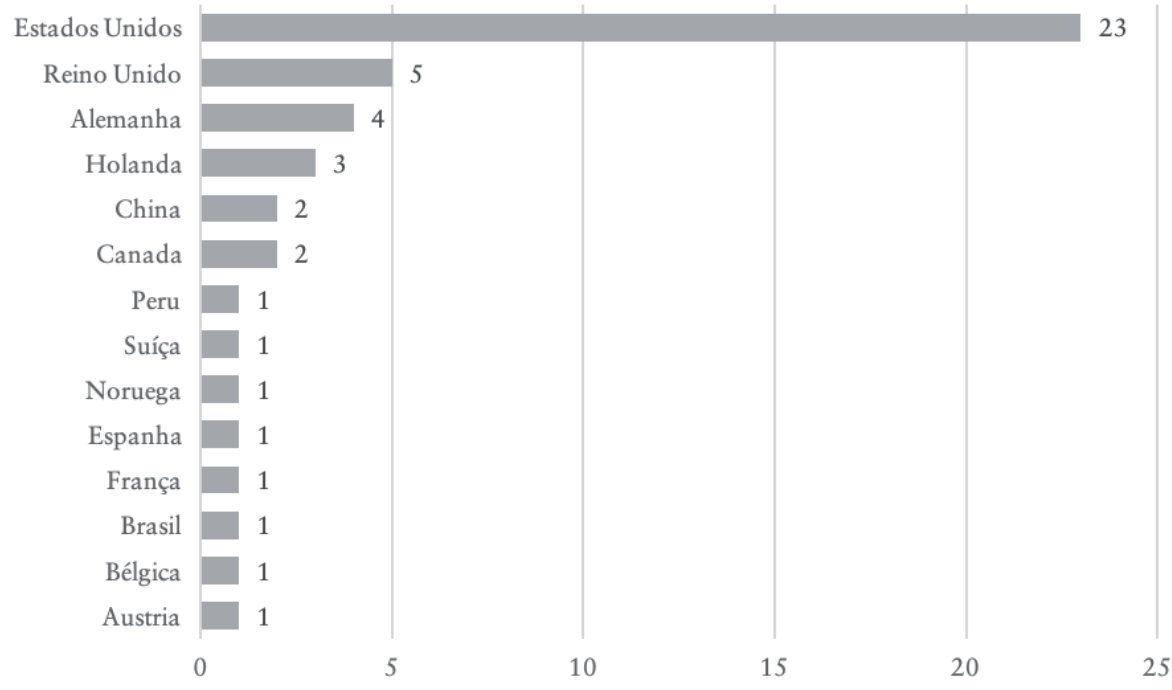

FONTE: OS AUTORES.

Todos os artigos estudados referem-se à desigualdade salarial. Entretanto, com base na análise do objetivo e da conclusão desses artigos, percebe-se que endereçam questões relacionadas à diferentes abordagens de desigualdade tais como, gênero, escolaridade, hierarquia organizacional e fatores socioeconômicos.

Os artigos, portanto, foram classificados de acordo com categorias determinadas pelos autores com base nas diferentes abordagens. A tabela 2 mostra os autores que abordam cada uma dessas categorias, sendo que um mesmo artigo pode tratar de temas relacionados à mais de uma categoria. 
A CONTRIbUiçÃo dos PACOtes SALARIAIS NA AMPLIAÇÃo

DA RESPONSABILIDADE SOCIAL EMPRESARIAL

Tabela 2. Autores por Categorias de Desigualdade

\begin{tabular}{|c|c|c|}
\hline $\begin{array}{l}\text { CATEGORIAS DE } \\
\text { DESIGUALDADE }\end{array}$ & Autores & $\begin{array}{l}\text { Total De } \\
\text { ARtigos }\end{array}$ \\
\hline Gênero & $\begin{array}{l}\text { Castilla, 2008; De la Rica et al., 2008; } \\
\text { Fortin, 2008; Judge e Livingston, 2008; } \\
\text { Manning e Swaffield, 2008; Nopo, 2008; } \\
\text { Zhang et al., 2008; Acker, 2009; Cohen et } \\
\text { al., 2009; Dustmann et al., 2009; Evertsson } \\
\text { et al., 2009; Oostendorp, 2009; Antonczyk } \\
\text { et al., 2010; Kulich et al., 2011; Balafoutas } \\
\text { e Sutter, 2012; Cha e Weeden, 2014; Card et } \\
\text { al., 2015; Geiler e Renneboog, 2015; Bryan } \\
\text { e Bryson, 2016; Silva et al., 2016; Blau e } \\
\text { Kahn, } 2017\end{array}$ & 21 \\
\hline $\begin{array}{l}\text { Fatores } \\
\text { Socioeconômicos }\end{array}$ & $\begin{array}{l}\text { Autor et al., 2008; Carpenter, 2008; Castilla, } \\
\text { 2008; Krugman, 2008; Verhoogen, 2008; } \\
\text { Acker, 2009; Kambourov e Manovskii, } \\
\text { 2009; Oostendorp, 2009; Antonczyk et al., } \\
\text { 2010; Helpman et al., 2010; Oesch e Rodrí- } \\
\text { guez, 2010; Western e Rosenfeld, 2011; Card } \\
\text { et al., 2013; Lustig et al., 2013; Moretti, } \\
\text { 2013; Bol e Weeden, 2014; Shin, 2014; Card } \\
\text { et al., 2015; Kristal e Cohen, 2016; Silva et } \\
\text { al., 2016; Helland et al., } 2017\end{array}$ & 21 \\
\hline Escolaridade & $\begin{array}{l}\text { Autor et al., 2008; Davidson et al., 2008; De } \\
\text { la Rica et al., 2008; Kim e Sakamoto, 2008; } \\
\text { Zhang et al., 2008; Brunello et al., 2009; } \\
\text { Dustmann et al., 2009; Evertsson et al., } \\
\text { 2009; Gathmann y Schönberg, 2010; Mouw } \\
\text { e Kalleberg, 2010; Oesch e Rodríguez, 2010; } \\
\text { Fang e Yang, 2011; Lustig et al., 2013; Mo- } \\
\text { retti, 2013; Autor, 2014; Silva et al., 2016; } \\
\text { Broecke et al., } 2017\end{array}$ & 17 \\
\hline $\begin{array}{l}\text { Hierarquia } \\
\text { Organizacional }\end{array}$ & $\begin{array}{l}\text { Autor et al., 2008; García-Aracil e Van der } \\
\text { Velden, 2008; Kim e Sakamoto, 2008; Noopo, } \\
\text { 2008; Antonczyk et al., 2010; Mouw e } \\
\text { Kalleberg, 2010; Philippon e Reshef, 2012; } \\
\text { Shin, 2014; Helland et al., 2017; Mueller et } \\
\text { al., } 2017\end{array}$ & 10 \\
\hline
\end{tabular}

Fonte: OS AUTORES.

Segue um resumo das principais contribuições da literatura, agrupado pelas categorias descritas anteriormente: 


\section{GÊNERO}

Um dos principais temas discutidos com relação à desigualdade social está diretamente relacionado às diferenças salariais entre homens e mulheres. Acker (2009) destaca que sistemas igualitários são muito difíceis de serem encontrados e que poucas mulheres ocupam posições da alta gerência apesar da substancial igualdade de gênero na educação e da entrada de um número crescente de mulheres em profissões de alto prestígio (De la Rica et al., 2008; Zhang et al., 2008; Oostendorp, 2009; Geiler e Renneboog, 2015; Bryan e Bryson, 2016; Silva et al., 2016).

Balafoutas e Sutter (2012) apontam que apesar de haver programas para incentivar a promoção das mulheres em níveis da alta gerência e reduzir as diferenças salariais entre homens e mulheres em cargos de mesmo nível, problemas em conciliar família e trabalho, tipo de emprego e discriminação são comumente apontados como a causa dessas diferenças. Seus estudos evidenciam que homens aumentam seu desempenho em ambientes competitivos, o que não acontece com as mulheres, gerando menos oportunidades de promoção e, consequentemente, de aumento salarial, contribuindo para o aumento da desigualdade salarial entre os gêneros. Manning e Swaffield (2008) ainda ressaltam que os homens são mais inclinados a tomar mais risco que as mulheres (Fortin, 2008; Judge e Livingston, 2008; Ñopo, 2008; Card et al., 2015).

Segundo Cha y Weeden (2014), apesar da melhora na educação ter reduzido a desigualdade salarial entre homens e mulheres nos Estados Unidos, a prática da sobrejornada é um dos fatores que contribui para o aumento da desigualdade salarial entre os gêneros e que, em sua maioria, é realizada pelos homens.

Kulich et al. (2011) apontam questões ligadas à discriminação, a qual não é possível corrigir somente redesenhando pacotes salariais. Seus estudos constataram que, no Reino Unido, as mulheres em cargos de diretoria possuem salários base inferiores aos de seus colegas homens e sua remuneração variável (gratificações, em particular) corresponde a uma proporção menor desses salários mais baixos. Além disso, Dustmann et al. (2009) destacam que essa diferença é maior nos níveis mais altos. Entretanto, Evertsson et al. (2009) apontam que em níveis mais baixos não se pode deixar de levar em consideração que a força de trabalho feminina é bem menor que a masculina (Castilla, 2008; Cohen et al., 2009; Antonczyk et al., 2010; Blau y Kahn, 2017). 


\section{FATORES SOCIOECONÔMICOS}

Dentre as categorias definidas pelos autores, fatores socioeconômicos, tais como discriminação de gênero, de raça, de orientação sexual, impacto da influência sindical, momento da economia do país, setor da indústria, entre outros, foram tão estudados quanto os impactos das diferenças de gênero. Não do ponto de vista estatístico, mas da relação dos agrupamentos deste estudo.

Segundo Verhoogen (2008), as indústrias com maior produtividade pagam salários mais altos do que as com menor produtividade. Isto deve-se ao fato de que essas indústrias buscam profissionais mais qualificados para, minimamente, garantirem seu nível de produtividade (Kambourov e Manovskii, 2009; Helpman et al., 2010).

Card et al. (2013) ainda destacam que os profissionais mais qualificados, que tenderiam a ter salários mais altos em quaisquer setores da indústria, concentram-se nas empresas que oferecem melhores salários contribuindo para o aumento da desigualdade salarial. Além disso, a relação comercial de países como os Estados Unidos com países que praticam menores salários absolutos, também impactou, apesar de maneira modesta, para o aumento da desigualdade social (Krugman, 2008).

Outro fator destacado por diversos autores é o impacto da força sindical na desigualdade salarial (Antonczyk et al., 2010; Western e Rosenfeld, 2011; Lustig et al., 2013; Bol e Weeden, 2014; Kristal e Cohen, 2016).

Observa-se que empresas mais sindicalizadas tendem a ter menor desigualdade salarial do que as menos sindicalizadas. Kristal y Cohen (2016) apontam que entre 1969 e 2012 houve um enfraquecimento das entidades sindicais nos Estados Unidos, além do achatamento do salário mínimo. Esses foram um dos principais fatores para o aumento da desigualdade social, principalmente nos níveis mais baixos das organizações naquele país.

Estudos realizados por Carpenter (2008) mostram que a orientação sexual também tem impacto na desigualdade salarial. Homens homossexuais têm rendimentos significativamente menores do que os homens heterossexuais, enquanto que as mulheres homossexuais têm rendimentos significativamente maiores do que as heterossexuais. Entretanto, Carpenter (2008) ressalta que são necessários maior aprofundamento no tema para entender os motivos dessas desigualdades. 
De acordo com Castilla (2008), os pacotes salariais que têm como base remunerar por desempenho apresentam certa subjetividade no processo de avaliação. Este fator contribui para que mulheres e outros grupos minoritários, tais como negros, recebam prêmios menores do que os homens brancos na mesma ocupação, demonstrando que a discriminação pode ter profundo impacto no âmbito organizacional.

\section{ESCOLARIDADE}

Outro tema muito discutido com relação à desigualdade salarial é sobre o impacto do nível de escolaridade na remuneração dos trabalhadores. Segundo Silva et al. (2016), a melhoria da escolaridade no Brasil foi um dos principais fatores na contribuição da diminuição da desigualdade salarial de 1995 a 2004. Assim como no Brasil, outros autores também constataram que a educação teve impacto positivo em países como Bélgica, Estados Unidos, Reino Unido e China (Autor et al., 2008; Brunello et al., 2009; Fang e Yang, 2011; Lustig et al., 2013; Autor, 2014; Broecke et al., 2017).

Por outro lado, segundo Davidson et al. (2008), empresas com tecnologia mais moderna tendem a buscar profissionais mais qualificados e, portanto, praticam salários mais altos. Percebe-se, então, um aumento da diferença salarial entre profissionais com alta e baixa qualificação, à medida que os mercados se tornam mais abertos, o que pode, ir na contra mão do que foi identificado por Silva et al. (2016). Autor et al. (2008) ainda destacam que haverá certa desigualdade em função de melhor qualificação não somente nos níveis mais baixos, mas em todos os níveis da hierarquia (Davidson et al., 2008; De la Rica et al., 2008; Dustmann et al., 2009; Mouw e Kalleberg, 2010; Oesch e Rodríguez, 2010; Moretti, 2013).

Dustmann et al. (2009) também destacam que a desigualdade salarial é maior entre os trabalhadores com maior escolaridade do que entre os trabalhadores com menor nível de escolaridade. Gathmann e Schönberg (2010) reforçam essa temática, complementando que os trabalhadores mais qualificados têm mais mobilidade de emprego durante a vida profissional e essa mobilidade faz com que esses trabalhadores tenham seus salários incrementados mais rapidamente do que trabalhadores menos qualificados, contribuindo para a desigualdade salarial não somente dentro das organizações mas também entre as organizações. 
Kim e Sakamoto (2008) observam que a melhora da escolaridade resultou em desigualdade salarial não somente entre níveis, mas também, dentro de um mesmo nível, implicando em melhor produtividade pelos profissionais mais bem qualificados.

\section{HIERARQUIA ORGANIZACIONAL}

Apesar dos principais temas abordados pelos estudos sobre desigualdade salarial estarem atrelados às questões de gênero, fatores socioeconômicos e escolaridade, há uma grande preocupação, de acordo com Shin (2014) com as diferenças salariais dentro da hierarquia organizacional. Mesmo na Noruega, considerado um dos países com menor desigualdade social do mundo, percebe-se, de acordo com Helland et al. (2017), um aumento na desigualdade salarial, principalmente entre os níveis hierárquicos, apesar de ainda modesta. Helland et al. (2017) apontam como um dos fatores para este aumento a redução da força sindical.

De acordo com Shin (2014), empresas muito sindicalizadas tendem a ter uma diferença menor entre o salário dos executivos e dos não executivos do que empresas menos sindicalizadas. Antonczyk et al. (2010) também evidenciaram que o declínio das negociações sindicais teve uma contribuição significativa no aumento da desigualdade salarial entre os níveis hierárquicos na Alemanha.

Por outro lado, Autor et al. (2008), apontam que os sindicatos não têm influência para a redução da disparidade salarial entre executivos e não executivos por defenderem a igualdade entre os níveis mais baixos nas organizações e não se empenharem sobre a remuneração executiva.

Outro fator que contribui para a desigualdade, segundo Mueller et al. (2017) é o tamanho da empresa. Mueller et al. (2017) destacam que em empresas maiores, a desigualdade salarial entre os executivos e não executivos é maior. Percebe-se, portanto, que o tamanho da empresa impacta em maiores diferenças salariais nos níveis mais altos, ao passo que nos níveis mais baixos não tem tanta variação em função do tamanho da empresa.

Segundo García-Aracil e Van der Velden (2008), a capacidade do indivíduo de tomar decisões, gerenciar situações complexas e assumir risco são competências organizacionais que impactam na definição da remuneração do trabalhador. Essas competências são mais valorizadas, gerando diferenciação salarial (Philippon y Reshef, 2012). 


\section{Discussão}

Não é de hoje que há estudos que abordam a desigualdade salarial. $\mathrm{O}$ artigo mais antigo identificado na base Scopus relacionado com estudos salariais, considerando as palavras-chave utilizadas na revisão da literatura para este estudo, data de 1910.

Este trabalho, além de identificar os pacotes salariais praticados nas organizações, também trouxe à tona temas ligados à evolução do conceito de Responsabilidade Social e os principais fatores que podem contribuir com o aumento da desigualdade salarial. Contudo, os estudos revelam que não há um só viés para garantir a redução da desigualdade salarial.

A partir das categorias detalhadas anteriormente, percebe-se que devem haver dois olhares distintos com relação às diferenças salariais, sendo que um deles para dentro da própria organização onde identificam-se diferenças dentro de um mesmo nível e diferenças entre níveis hierárquicos e o outro para fora da organização, onde há diferenças salariais entre organizações para cargos comparáveis. Além disso, nenhuma dessas categorias é totalmente isolada das demais.

Com base na referência teórica sobre a evolução dos pacotes salariais, identifica-se que os mais aplicados atualmente nas organizações baseiam-se na remuneração funcional e na remuneração por desempenho (Hipólito e Dutra, 2012; Nyberg et al., 2016).

A remuneração funcional tem foco no cargo e não no indivíduo. Porém, o diferente nível de escolaridade e as diferenças de produtividade entre trabalhadores em cargos de mesma natureza podem gerar certa desigualdade salarial, conforme evidenciado por Autor et al. (2008), mesmo que a estratégia de remuneração seja remunerar pelo cargo. Tal desigualdade, até certo ponto, pode ser saudável para incentivar que os trabalhadores busquem melhor qualificação profissional e melhor produtividade dentro das organizações. Porém, deve-se ter o cuidado para que essa desigualdade não se torne excessiva.

Já a remuneração por desempenho tem maior subjetividade na avaliação para pagamento de prêmios, a qual depende, na maioria das vezes, da interpretação do gestor direto do trabalhador. As atitudes dos que ocupam tais posições de liderança afetam as práticas de gestão da organização influenciando positiva ou negativamente na desigualdade de gêneros ou outros tipos de desigualdade. Portanto, percebe-se que há fatores que não podem ser controlados por políticas de remuneração (Cohen et al., 2009; Seixas et al., 2017). 
Está nas mãos dos líderes das organizações criarem as políticas de remuneração de maneira a oferecer a mesma oportunidade a todos os trabalhadores, independente de raça, gênero, orientação sexual ou qualquer outro tipo de discriminação. Suas atitudes e ações serão a base para garantir respeito e comprometimento, os quais são uma das dimensões da Responsabilidade Social.

Entretanto, esta precisa ser uma cultura forte na organização pois um dos achados do estudo realizado por Seixas et al. (2017) mostra que não é raro que os líderes não associem sua atividade com a Responsabilidade Social da empresa.

Um outro ponto relevante identificado neste estudo é o impacto de fatores externos às organizações na contribuição para a redução das discrepâncias salariais. Políticas públicas que garantam educação de boa qualidade para todos, que repudiem qualquer tipo de discriminação e garantam salários mínimos adequados são fatores essenciais para contribuir na redução da desigualdade salarial e, consequentemente, contribuir para a redução da desigualdade social.

Além disso, as entidades sindicais mostram-se determinantes na regulação das práticas salariais com significante grau de contribuição na redução da desigualdade salarial, tanto em países em desenvolvimento como em países desenvolvidos, principalmente nos níveis mais baixos das organizações.

\section{Conclusão}

Conforme ficou evidente ao longo do estudo, os pacotes salariais produzem impacto sobre a ideia de Responsabilidade Social, muito embora não seja explorada suficientemente, particularmente no que diz respeito à interação entre as duas temáticas. Parte dessa ausência de estudos aprofundados podem ser originados do fato de que outros fatores assumam maior relevância. Portanto, estudos empíricos devem ser realizados com o intuito de preencher essa lacuna, sedimentando a relação entre as duas temáticas.

No entanto, se pensarmos a Responsabilidade Social como o compromisso ético com o desenvolvimento econômico, que repercuta sobre a qualidade de vida dos trabalhadores, não há como não se pensar de forma mais cuidadosa sobre os efeitos dos pacotes de remuneração sobre a vida dos trabalhadores. Alguns fatores, apesar de estarem relacionados à decisão de líderes nas organizações, podem estar mais bem 
regulamentados nas políticas de remuneração de maneira a reduzir as desigualdades salariais.

Um desafio para estudos futuros é delimitar até onde a desigualdade salarial é saudável para o crescimento e desenvolvimento profissional e a partir de onde ela passa a ser excessiva, podendo gerar profundo impacto sobre a autoestima dos trabalhadores, sobre o espírito de time e sobre a solidariedade social.

\section{REFERÊNCIAS}

Acker, J. (2009). From glass ceiling to inequality regimes. Sociologie $d u$ travail, 51(2), 199-217. doi: 10.1016/j.soctra.2009.03.004

Antonczyk, D.; Fitzenberger, B., \& Sommerfeld, K. (2010). Rising wage inequality, the decline of collective bargaining, and the gender wage gap. Labour economics, 17(5), 835-847. doi: 10.1016/j.labeco.2010.04.008

Aulete, F. J. C. (2018). iDicionário Aulete. Lexikon Editora Digital ltda. Disponible en: http://www.aulete.com.br.

Autor, D. (2014). Skills, Education, and the Rise of Earnings Inequality among the "other 99 percent". Science, 344(1), 843-851. doi: 10.1126/science. 1251868

Autor, D. H.; Katz, L. F., \& Kearney, M. S. (2008). Trends in US wage inequality: Revising the revisionists. The Review of economics and statistics, 90(2), 300-323. doi: 10.1162/rest.90.2.300

Balafoutas, L., \& Sutter, M. (2012). Affirmative action policies promote women and do not harm efficiency in the laboratory. Science, 335(6068), 579-582. doi: 10.1126/science. 1211180

Blau, F. D., \& Kahn, L. M. (2017). The gender wage gap: Extent, trends, and explanations. Journal of Economic Literature, 55(3), 789-865. doi: $10.1257 /$ jel.20160995

Bol, T., \& Weeden, K. A. (2014). Occupational closure and wage inequality in Germany and the United Kingdom. European Sociological Review, 31(3), 354-369. doi: 10.1093/esr/jcu095

Broecke, S.; Quintini, G., \& Vandeweyer, M. (2017). Explaining international differences in wage inequality: Skills matter. Economics of Education Review, 60, 112-124. doi: 10.1016/j.econedurev.2017.08.005

Brunello, G.; Fort, M., \& Weber, G. (2009). Changes in compulsory schooling, education and the distribution of wages in Europe. The Economic Journal, 119(536), 516-539. doi: 10.1111/j.14680297.2008.02244.x 
Bryan, M., \& Bryson, A. (2016). Has performance pay increased wage inequality in Britain? Labour Economics, 41, 149-161. doi: 10.1016/j. labeco.2016.05.002

Card, D.; Cardoso, A. R., \& Kline, P. (2015). Bargaining, sorting, and the gender wage gap: Quantifying the impact of firms on the relative pay of women. The Quarterly Journal of Economics, 131(2), 633-686. doi: 10.1093/qje/qjv038

Card, D.; Heining, J., \& Kline, P. (2013). Workplace heterogeneity and the rise of West German wage inequality. The Quarterly journal of economics, 128(3), 967-1015. doi: 10.1093/qje/qjt006

Carpenter, C. S. (2008). Sexual orientation, work, and income in Canada. Canadian Journal of Economics/Revue canadienne d'économique, 41(4), 1239-1261. doi: 10.1111/j.1540-5982.2008.00502.x

Carroll, A. B. (1999). Corporate Social Responsibility: Evolution of a Definitional Construct. Business \& Society, 38(3), 268-295. DOI:10.1177/000765039903800303

Castilla, E. J. (2008). Gender, race, and meritocracy in organizational careers. American Journal of Sociology, 113(6), 1479-1526.

Cha, Y., \& Weeden, K. A. (2014). Overwork and the slow convergence in the gender gap in wages. American Sociological Review, 79(3), 457-484. doi: 10.1177/0003122414528936

Cohen, P. N.; Huffman, M. L., \& Knauer, S. (2009). Stalled Progress? Gender Segregation and Wage Inequality Among Managers, 1980冈2000. Work and Occupations, 36(4), 318-342. doi: 10.1177/0730888409347582

Davidson, C.; Matusz, S. J., \& Shevchenko, A. (2008). Globalization and firm level adjustment with imperfect labor markets. Journal of International Economics, 75(2), 295-309. doi: 10.1016/j.jinteco.2008.02.004

De la Rica, S.; Dolado, J. J., \& Llorens, V. (2008). Ceilings or floors? Gender wage gaps by education in Spain. Journal of Population Economics, 21(3), 751-776. doi: 10.1007/s00148-006-0128-1

Dustmann, C.; Ludsteck, J., \& Schönberg, U. (2009). Revisiting the German wage structure. The Quarterly Journal of Economics, 124(2), 843-881. doi: 10.1162/qjec.2009.124.2.843

Evertsson, M.; England, P.; Mooi-Reci, I.; Hermsen, J.; De Bruijn, J., \& Cotter, D. (2009). Is gender inequality greater at lower or higher educational levels? Common patterns in the Netherlands, Sweden, and the United States. Social Politics, 16(2), 210-241. doi: 10.1093/ sp/jxp008

Fang, C., \& Yang, D. U. (2011). Wage increases, wage convergence, and the Lewis turning point in China. China Economic Review, 22(4), 601-610. doi: 10.1016/j.chieco.2011.07.004 
Fortin, N. M. (2008). The gender wage gap among young adults in the united states the importance of money versus people. Journal of Human Resources, 43(4), 884-918. doi: 10.2307/40057374

García-Aracil, A., \& Van der Velden, R. (2008). Competencies for young European higher education graduates: labor market mismatches and their payoffs. Higher Education, 55(2), 219-239. doi: 10.1007/ s10734-006-9050-4

Gathmann, C., \& Schönberg, U. (2010). How general is human capital? A task-based approach. Journal of Labor Economics, 28(1), 1-49.

Geiler, P., \& Renneboog, L. (2015). Are female top managers really paid less? Journal of Corporate Finance, 35, 345-369. doi: 10.1016/j. jcorpfin.2015.08.010

Gray, D. E. (2016). Pesquisa no mundo real. Penso Editora.

GRI-Global Reporting Initiative. (2018). GRI's history. Disponible en: https://www.globalreporting.org/information/about-gri/gri-history/ Pages/GRI's\%20history.aspx.

Helland, H.; Bol, T., \& Drange, I. (2017). Wage Inequality Within and Between Occupations. Nordic Journal of Working Life Studies, 7(4), 3-27.

Helpman, E.; Itskhoki, O., \& Redding, S. (2010). Inequality and unemployment in a global economy. Econometrica, 78(4), 1239-1283. doi: 10.3982/ECTA 8640

Hipólito, J. A. M. (2006). Administração salarial: a remuneração por competências como diferencial competitivo. Editora Atlas.

Hipólito, J. A. M., \& Dutra, J. S. (2012). Remuneração e recompensas. Elsevier Brasil.

Hobsbawm, E. (2015). A era das revoluções: 1789-1848. Editora Paz e Terra. Judge, T. A., \& Livingston, B. A. (2008). Is the gap more than gender? A longitudinal analysis of gender, gender role orientation, and earnings. Journal of applied psychology, 93(5), 994. doi: 10.1037/00219010.93.5.994

Kambourov, G., \& Manovskii, I. (2009). Occupational mobility and wage inequality. The Review of Economic Studies, 76(2), 731-759. doi: 10.1111/j.1467-937X.2009.00535.x

Kampelmann, S.; Rycx, F.; Saks, Y., \& Tojerow, I. (2018). Does education raise productivity and wages equally? The moderating role of age and gender. IZA Journal of Labor Economics, 7(1), 1. doi: 10.1186/ s40172-017-0061-4

Kim, C., \& Sakamoto, A. (2008). The rise of intra-occupational wage inequality in the United States, 1983 to 2002. American Sociological Review, 73(1), 129-157. doi: 10.1177/000312240807300107 
Kristal, T., \& Cohen, Y. (2016). The causes of rising wage inequality: the race between institutions and technology. Socio-Economic Review, 15(1), 187-212. doi: 10.1093/ser/mww006

Krugman, P. R. (2008). Trade and wages, reconsidered. Brookings Papers on Economic Activity, (1), 103-154.

Kulich, C.; Trojanowski, G.; Ryan, M. K.; Alexander Haslam, S., \& Renneboog, L. D. (2011). Who gets the carrot and who gets the stick? Evidence of gender disparities in executive remuneration. Strategic Management Journal, 32(3), 301-321. doi: 10.1002/smj.878

Lázaro, L. L. B., \& Gremaud, A. P. (2016). A Responsabilidade Social Empresarial e Sustentabilidade na América Latina: Brasil e México. Revista de Administração da Universidade Federal de Santa Maria, 9(1). doi: 10.5902/19834659 12279

Liang, H., \& Renneboog, L. (2017). On the foundations of corporate social responsibility. The Journal of Finance, 72(2), 853-910.

Lima, L. C. (2014). Remuneração estratégica: Uma análise de sua eficácia na perspectiva dos executivos. Projetos, dissertações e teses do Programa de Doutorado e Mestrado em Administração, 9(1).

Lustig, N., Lopez-Calva, L. F., \& Ortiz-Juarez, E. (2013). Declining inequality in Latin America in the 2000s: the cases of Argentina, Brazil, and Mexico. World Development, 44, 129-141. doi: 10.1016/j. worlddev.2012.09.013

Malferrari, C. J. (1970). Métodos e fases da avaliação de cargos. Revista de Administração de Empresas, 10(3), 11-37.

Manning, A., \& Swaffield, J. (2008). The gender gap in early凶career wage growth. The Economic Journal, 118(530), 983-1024. doi: 10.1111/j.1468-0297.2008.02158.x

Marras, J. P., \& Neto, P. (2012). Remuneração estratégica. Elsevier Brasil. Mitra, A.; Gupta, N., \& Shaw, J. D. (2011). A comparative examination of traditional and skill-based pay plans. Journal of Managerial Psychology, 26(4), 278-296. doi: 10.1108/02683941111124827

Moher, D.; Liberati, A.; Tetzlaff, J.; Altman, D. G., \& Prisma Group (2009). Preferred reporting items for systematic reviews and meta-analyses: the PRISMA statement. PLoS medicine, 6(7). doi: 10.1371/journal. pmed.1000097

Moretti, E. (2013). Real wage inequality. American Economic Journal: Applied Economics, 5(1), 65-103. doi: 10.1257/app.5.1.65

Mouw, T., \& Kalleberg, A. L. (2010). Occupations and the Structure of Wage Inequality in the United States, 1980s to 2000s. American Sociological Review, 75(3), 402-431. doi: 10.1177/0003122410363564

Mueller, H. M.; Ouimet, P. P., \& Simintzi, E. (2017). Wage inequality and firm growth. American Economic Review, 107(5), 379-83. doi: 10.1257/aer.p20171014 
Ñopo, H. (2008). Matching as a tool to decompose wage gaps. The review of economics and statistics, 90(2), 290-299. doi: 10.1162/rest.90.2.290

Nyberg, A. J.; Pieper, J. R., \& Trevor, C. O. (2016). Pay-for-performance's effect on future employee performance: Integrating psychological and economic principles toward a contingency perspective. Journal of Management, 42(7), 1753-1783. doi: 10.1177/0149206313515520

Oesch, D., \& Rodríguez, M. J. (2010). Upgrading or polarization? Occupational change in Britain, Germany, Spain and Switzerland, 1990-2008. Socio-Economic Review, 9(3), 503-531. doi: 10.1093/ ser/mwq029

OIT-Organização Internacional do Trabalho. (2017). Relatório global sobre os salários 2016/17: Desigualdade salarial no local de trabalho. Disponible en: http://www.ilo.org/public/portugue/region/eurpro/ lisbon/pdf/rel_global_salarios_2016_pt_web.pdf.

OIT-Organização Internacional do Trabalho. (2018). Conheça a OIT. Disponible en: http://www.ilo.org/brasilia/conheca-a-oit/lang--pt/ index.htm

Oostendorp, R. H. (2009). Globalization and the gender wage gap. The World Bank Economic Review, 23(1), 141-161. doi: 10.1093/wber/lhn022

Philippon, T., \& Reshef, A. (2012). Wages and human capital in the US finance industry: 1909-2006. The Quarterly Journal of Economics, 127(4), 1551-1609. doi: 10.1093/qje/qjs030

Piketty, T. (2014). O Capital no século XXI; tradução Mônica Baumgarten de Bolle. Rio de Janeiro: Intrínseca.

Rodrigues, M., \& Mendes, L. (2018). Mapping of the literature on social responsibility in the mining industry: A systematic literature review. Journal of Cleaner Production, 181, 88-101. doi: 10.1016/j. jclepro.2018.01.163

Seixas, M. A. C.; Andrade, E. P.; Perez Peña, M. A.; Cândido, J. C., \& Costa, M. R. S. B. (2017). Responsabilidad social y cultura: un estudio fenomenográfico desde el punto de vista del liderazgo en una empresa de ingeniería. Revista Ciencias Económicas, 14(02), 29-52.

Shin, T. (2014). Explaining pay disparities between top executives and nonexecutive employees: A relative bargaining power approach. Social Forces, 92(4), 1339-1372. doi: 10.1093/sf/sou004

Silva, V. H. M. C.; França, J. M. S. D., \& Pinho Neto, V. R. D. (2016). Capital humano e desigualdade salarial no Brasil: uma análise de decomposição para o período 1995-2014. Estudos Econômicos (São Paulo), 46(3), 579-608. doi: 10.1590/0101-416146357vjv

Verhoogen, E. A. (2008). Trade, quality upgrading, and wage inequality in the Mexican manufacturing sector. The Quarterly Journal of Economics, 123(2), 489-530. doi: 10.1162/qjec.2008.123.2.489 
Western, B., \& Rosenfeld, J. (2011). Unions, norms, and the rise in US wage inequality. American Sociological Review, 76(4), 513-537. doi: 10.1177/0003122411414817

Wood Jr., T., \& Picarelli Filho, V. (2004). Remuneração E Carreira Por Habilidades E Por Competências: Preparando a Organização Para a Era Das Empresas de Conhecimento Intensivo. Editora Atlas SA. WorldatWork (2007). The Worldat Work handbook of compensation, benefits \& total rewards: a comprehensive guide for HR professionals. New Jersey: Wiley.

WEF-World Economic Forum (2017a). The global human capital report 2017: Preparing people for the future of work. Disponible en: https:// www.weforum.org/reports/the-global-human-capital-report-2017.

WEF-World Economic Forum (2017b). The global gender gap report 2017. Disponible en: http://www3.weforum.org/docs/WEF_GGGR_2017. pdf.

WEF-World Economic Forum (2018). Our Mission. Disponible en: https:// www.weforum.org/about/world-economic-forum.

Zhang, J.; Han, J.; Liu, P. W., \& Zhao, Y. (2008). Trends in the gender earnings differential in urban China, 1988-2004. ILR Review, 61(2), 224-243. doi: 10.1177/001979390806100205 



\title{
PolíticAS DE DIVERSIDAD \\ EN LAS EMPRESAS ARGENTINAS
}

\author{
Emmanuel Oliverio" \\ Emiliano Sebastián Consoli*" \\ Paula Colacioppo*** \\ Argentina
}

\section{INTRODUCCIÓN}

El presente trabajo ${ }^{1}$ pretende ser un disparador e inspirador acerca de un tema que lleva implícito el respeto entre los seres humanos: la diversidad. En palabras de Amartya Sen (1995, p. 13): «Los seres humanos somos profundamente diversos, cada uno de nosotros es distinto a los demás, no solo por características externas, como el patrimonio heredado o el ambiente natural y social que nos rodea, sino también por nuestras características personales». Podemos decir entonces que la diversidad nos caracteriza.

En consonancia con su abordaje, se plantea como objetivo, en primer lugar, explorar la gestión de la diversidad en las organizaciones; para luego identificar las políticas de diversidad que aplican las empresas en la Argentina.

\footnotetext{
Licenciado en Administración. Universidad de Buenos Aires. Correo electrónico: emmanueloliverio@economicas.uba.ar

** Licenciado en Administración. Universidad de Buenos Aires. Correo electrónico: consoli_emiliano@economicas.uba.ar

*** Licenciada en Administración. Universidad de Buenos Aires. Correo electrónico: paula@econ.uba.ar

1 Este trabajo se encuentra en el marco del Proyecto de Investigación PROIAT (acreditado y financiado por la Facultad de Ciencias Económicas-UBA-Programación Científica 2018), cuyo título es «Las Empresas Recuperadas en el desarrollo económico y social de la Ciudad de Buenos Aires. Una mirada desde la perspectiva de género en relación al poder».
} 
Para comenzar, se expondrán los conceptos que sustentan un adecuado marco teórico, que permita introducirnos en los términos de diversidad, identidad e igualdad, a partir de la idea de gestión de la diversidad en el ámbito organizacional.

Posteriormente se contextualizará el ámbito de la presente investigación, que son las empresas argentinas, para luego exponer los resultados del relevamiento realizado, su análisis y conclusiones.

La muestra fue construida a partir de comparar las COP (Comunicaciones del Progreso, por sus siglas en inglés) de las empresas argentinas que cotizan en bolsa y que adhieren del Pacto Global, con anterioridad al año 2015.

Sin más preámbulos, nos adentramos en un tema tan diverso y enriquecedor como amplio en sus alcances.

\section{PolíticAS DE LA ORGANIZACIÓN}

Desde el punto de vista de los estudios organizacionales, varios enfoques coinciden en observar a las organizaciones como un sistema de relaciones:

Las interacciones o relaciones deben observarse bajo el prisma de los individuos dentro de la organización y los mecanismos que confieren marco a esas relaciones, como la coordinación y el control, los sistemas de autoridad y poder, las normas y los valores compartidos (Gómez Fulao, et al., 2010, p. 26).

En ese sentido, son las políticas organizacionales las que le dan un marco de referencia al comportamiento de las personas. Dicho marco es, según Robbins y Coulter (2010), un condicionamiento político-legal, en cuanto a que se basa en leyes tanto externas como internas.

Así, las políticas organizacionales marcan los lineamientos que orientan la acción, proporcionan una dirección a sus miembros e imprimen los valores centrales de la organización que, a su vez, limitan el comportamiento de los individuos reglando qué se considera ético y aceptable para la actuación (Bohlander y Snell, 2008). Por este motivo, es necesario que las organizaciones definan sus políticas de gestión de la diversidad para obtener avances reales en la materia.

Sobre la base de estos fundamentos, en el presente trabajo se consideran las políticas internas de la organización ligadas a la gestión de la diversidad. 


\section{GESTIÓN DE LA DIVERSIDAD EN LAS ORGANIZACIONES}

Actualmente, el tema de la diversidad se encuentra posicionado al frente de muchos ámbitos, tanto de la vida cotidiana como de la vida académica y profesional. Esto es así debido a que ha ido ganando terreno desde hace tiempo y más aún en las últimas dos décadas, cuando se observa la aparición de áreas de estudio en el ámbito organizacional conocidas como: gestión de la diversidad, multiculturalismo o desarrollo de organizaciones multiculturales (Heller, 2012). El término de diversidad se viene desarrollando desde la década del 70, entendiéndose como la incorporación de mujeres y minorías dentro del mercado laboral (Keil et al., 2007). Desde allí, se contemplaba que la diversidad respondía a la acción de sumar a la plantilla de las empresas a más personas por su género, etnia, rango etario, etc. Sin embargo, es un concepto más amplio, ya que el hecho de reconocer y valorar la diversidad implica el reconocimiento del otro en su diferencia.

En las organizaciones, podemos encontrar diversidad de personas en aspectos muy variados: «Étnicos, religiosos, familiares, de origen social, geográfico o nacionalidad, fisonómicos, corporales, sexo, género, orientación sexual, identidad de género, formación, edad, discapacidad, personalidad, estilo de trabajo, cultura, sistema de creencias, entre muchas otras características que constituyen al ser humano» (R.E.D. de empresas por la diversidad, 2016, p. 7). Dichos factores, visibles y no visibles, son los que conforman la diversidad y dan cuenta de la identidad de las personas.

Es así como la diversidad debe ser gestionada, ya que una «mirada desde la diversidad implica valorar las diferencias y las habilidades de cada individuo, por cuanto la singularidad de cada uno se refleja en la contribución que hace a la organización» (R.E.D. de empresas por la diversidad, 2016, p. 7). Entonces, ¿qué es gestionar la diversidad? «La Gestión de la Diversidad supone fundamentalmente integrar las ideas y la práctica de la Diversidad en la gestión del día a día y los procesos de aprendizaje de la compañía y de su entorno» (Keil et al., 2007,p. 8). Por ello, es importante que las organizaciones tengan en cuenta estas prácticas, ya que la diversidad implica también identidad, respetando las individualidades, y a su vez, por más que suene contradictoria, se relaciona con la igualdad, en el sentido de mejorar las oportunidades para todas las personas dentro del ámbito organizacional. 
Gestionar la diversidad conlleva establecer políticas, específicas o no, para obtener un mejor funcionamiento de la composición diversa del grupo humano que conforma a la organización. Implica realizar actividades que promuevan prácticas no discriminatorias y acciones positivas desde las diferencias de distinta índole, como herramienta útil de desarrollo. Sin embargo, las empresas no siempre las aplican de forma altruista, sino que muchas veces lo hacen para mejorar su imagen o por cuestiones de legalidad.

\section{DIVERSIDAD EN LAS EMPRESAS ARGENTINAS}

En Argentina, existe un espacio dedicado a la investigación y asesoramiento para la implementación de estas cuestiones. Es una iniciativa colectiva formada por organizaciones empresariales, académicas y civiles, que tiene su sede en la Escuela de Negocios de la Universidad Torcuato Di Tella. Se trata de la R.E.D. de empresas por la diversidad, un espacio que desarrolla y promueve la diversidad y la inclusión dentro de las organizaciones empresariales, y las acompaña en la implementación de sus políticas (R.E.D. de empresas por la diversidad, 2017).

Los miembros de la R.E.D. manifiestan tener la convicción de que gestionar la diversidad dentro de una organización puede transformar el mundo del trabajo, brindando oportunidades y beneficios tanto al negocio como a la sociedad en su conjunto. Esa convicción y la idea de igualdad en el ámbito empresarial fueron los ejes convocantes para que se conformara en diciembre de 2012. En la actualidad, está compuesta por treinta y seis empresas miembros (R.E.D. de empresas por la diversidad, 2017).

Lo que aquí se analiza es la implementación de políticas de diversidad en las empresas de la Argentina. Para ello, se han tomado como referencia las declaraciones que cada una de ella realiza al respecto, tomando como ejes de diversidad los diez definidos por la R.E.D. de empresas por la diversidad. Considerando, entonces, a) género, b) diversidad sexual, c) generaciones, d) personas con discapacidad, e) personas en vulnerabilidad socioeconómica, f) cultura país y étnica, g) aspecto físico, h) Salud en general incluyendo VIH, i) pluralidad religiosa y j) pensamiento, opinión y creencias (R.E.D. de empresas por la diversidad, 2017).

A su vez, la forma de recolectar las declaraciones que las empresas realizan al respecto ha sido a través de las COP (Comunicaciones del 
Progreso, por sus siglas en inglés) que deben presentar las organizaciones adheridas al Pacto Global de la Organización de las Naciones Unidas (ONU), un canal que las empresas utilizan para informar sobre sus acciones de RSE, aunque no es el único (Gorrochategui y Krieger, 2012). Su propósito es que las organizaciones miembros incorporen los principios universales de derechos humanos, trabajo, medioambiente y lucha contra la corrupción, a través de acciones que permitan avanzar en los objetivos sociales. Se encuentran alineadas con los Objetivos del Desarrollo Sostenible, estipulados también por la ONU para el año 2030 (United Nations Global Compact, 2017).

Las COP son los informes que deben presentar las organizaciones que se incorporen a la iniciativa del Pacto Global. Su periodicidad es anual y dan cuenta de lo que han realizado en materia de sustentabilidad, así como también lo planificado para el siguiente año. Su formato puede variar, pudiendo presentarse como un documento independiente, parte de un informe de sostenibilidad o responsabilidad social corporativa, parte de un informe financiero anual, una plantilla COP básica (para los nuevos informes que ya no pueden publicar informe oficial), una COP Express (disponible para las pequeñas y medianas empresas). Cabe destacar que su estructura debe estar en consonancia con los diez principios del Pacto Global² (United Nations Global Compact, 2017).

2 Derechos humanos

Principio 1: Las empresas deben apoyar y respetar la protección de los derechos humanos fundamentales, reconocidos internacionalmente; $y$

Principio 2: asegurarse de que no son cómplices en la vulneración de los derechos humanos.

Trabajo

Principio 3: Las empresas deben apoyar la libertad de afiliación y el reconocimiento efectivo del derecho de negociación colectiva;

Principio 4: la eliminación de todas las formas de trabajo forzoso y obligatorio; Principio 5: la abolición efectiva del trabajo infantil; y

Principio 6: la eliminación de la discriminación en materia de empleo y ocupación.

Ambiente

Principio 7: Las empresas deberán mantener un enfoque preventivo que favorezca el medio ambiente;

Principio 8: fomentar las iniciativas que promuevan una mayor responsabilidad ambiental; y

Principio 9: fomentar el desarrollo y la difusión de las tecnologías respetuosas con el medio ambiente.

Anticorrupción

Principio 10: Las empresas deben trabajar contra la corrupción en todas sus formas, incluidas la extorsión y el soborno. 
La primera COP se exige al año de haberse incorporado y tiene plazos para su publicación. En caso de vencerse los mismos, ya no pueden publicarse siendo pasibles de sanción. Actualmente, el Pacto Global cuenta con 12.803 organizaciones miembros en todo el mundo, de las cuales 423 son argentinas y, dentro de ellas, 226 son empresas (United Nations Global Compact, 2017).

Otro criterio a tener en cuenta para la recopilación de información son las empresas que cotizan en bolsa, ya que deben presentar informes de su actividad frente a la Comisión Nacional de Valores de la República Argentina para realizar Oferta Pública. Esto es así porque la CNV debe velar por la transparencia de los mercados de valores, por lo tanto, regula dicha actividad. Su principal razón de ser es velar por los intereses de los inversionistas y accionistas de las empresas. Se encarga de aprobar la publicidad y prospectos de emisiones de oferta pública, autorizar, regular y vigilar el funcionamiento de las bolsas de valores, entre otras funciones. Actualmente, las empresas que emiten Oferta Pública son 209 (Comisión Nacional de Valores, 2017).

\section{UNIVERSO, MUESTRA Y MÉTODO}

A los fines del presente trabajo, se ha establecido como universo a las empresas argentinas. De todo lo expuesto surge que 226 empresas argentinas participan del Pacto Global, 209 cotizan en bolsa y 36 son miembros de la R.E.D. de empresas para la diversidad. A su vez, se han establecido algunos criterios de exclusión, debido a los alcances de la presente investigación, que son los siguientes: empresas que se encuentren participando en el Pacto Global, con una antigüedad anterior a 2015, y que coticen en bolsa. La actividad que realizan, ubicación geográfica y otros datos de las empresas no son relevantes para la presente investigación.

Al realizar el entrecruzamiento de las bases de datos buscando coincidencias y teniendo en cuenta los criterios de exclusión, el tamaño de la muestra nos da un total de 26 empresas argentinas, según se detalla en el cuadro 1 . 
Cuadro i. Detalle de empresas que conforman la muestra.

\begin{tabular}{|l|l|l|}
\hline 1. Aeropuertos Argentina & 10. Disal SA - Pinturas & 19. Pan American \\
2000 & Tersuave & Energy LLC \\
2. Arcor SAIC & 11. EDESA SA & 20. SA San Miguel \\
3. Autopistas del Sol & 12. Grupo Clarín SA & AGICI y F. \\
4. Banco Galicia & 13. Holcim (Argentina) & 21. SanCor Cooperati- \\
5. Banco Macro SA & 14. INVAP SE & vas Unidas Limitada \\
6. Banco Santander Río SA & 15. Ledesma SAAI & 22. Telecom Argentina \\
7. BBVA Banco Francés SA & 16. Mastellone & SA \\
8. Benito Roggio ambiental & Hermanos S. A & 23. Telefónica de Ar- \\
9. Central Costanera SA & 17. Mercedes-Benz & gentina SA \\
& Argentina SA & 24. Transportadora de \\
& 18. Milicic SA & Gas del Norte SA \\
& \multicolumn{2}{|c}{ 25. Transportadora de } \\
& \multicolumn{2}{|l}{ Gas del Sur SA } \\
\hline
\end{tabular}

FUENTE: ElABORACIÓN PROPIA.

El método aplicado ha sido el de explorar las declaraciones de cada una de esas empresas, relevando los datos informados en las COP del año 2015, publicadas en la página web del Pacto Global de la ONU. Allí se buscaba una mención explícita en cuanto a los ejes de la diversidad que ya hemos establecido.

\section{RESULTADOS Y ANÁLISIS}

Del relevamiento realizado, se ha podido observar cuáles son las empresas que declaran explícitamente en sus COP acciones referidas a algunos de los ejes de diversidad. En el cuadro 2 se detallan los resultados obtenidos. Este debe leerse considerando que en la primera columna se listan las empresas incluidas en el análisis, según los criterios anteriormente explicitados. En la fila superior se presentan los ejes de diversidad codificados alfabéticamente de la $\mathrm{A}$ a la J. El cruce entre las filas y columnas mencionadas puede presentar un espacio vacío o una "X". En el primer caso, la empresa no explicita en su COP el eje en cuestión; mientras que en la segunda opción sí explicita el eje en su informe. En el cuadro se exhiben los ejes de diversidad con sus respectivos códigos. 
Cuadro 2. Empresas y eJES DE Diversidad

\begin{tabular}{|c|c|c|c|c|c|c|c|c|c|c|c|}
\hline EMI & $\begin{array}{ll} & \text { EJES DE DIVERSIDAD } \\
\text { RESAS } & \end{array}$ & A & B & $\mathrm{C}$ & $\mathrm{D}$ & $\mathrm{E}$ & $\mathrm{F}$ & G & $\mathrm{H}$ & I & $\mathrm{J}$ \\
\hline 1 & Aeropuertos Argentina 2000 & & & & $\mathrm{x}$ & & $\mathrm{x}$ & & $\mathrm{x}$ & & \\
\hline 2 & Arcor SAIC & $\mathrm{x}$ & & & $\mathrm{x}$ & & $\mathrm{x}$ & & $\mathrm{x}$ & & \\
\hline 3 & Autopistas del Sol & $\mathrm{x}$ & & & & & $\mathrm{x}$ & & $\mathrm{x}$ & $\mathrm{x}$ & $\mathrm{x}$ \\
\hline 4 & Banco Galicia & $\mathrm{x}$ & $\mathrm{x}$ & & & & $\mathrm{x}$ & & $\mathrm{x}$ & $\mathrm{x}$ & \\
\hline 5 & Banco Macro SA & $\mathrm{x}$ & & $\mathrm{x}$ & & & & & $\mathrm{x}$ & & \\
\hline 6 & Banco Santander Río SA & $\mathrm{x}$ & & $\mathrm{x}$ & & & & & & & \\
\hline 7 & BBVA Banco Francés SA & $\mathrm{x}$ & & & $\mathrm{x}$ & & & & & & \\
\hline 8 & Benito Roggio ambiental & & & & $\mathrm{x}$ & $\mathrm{x}$ & & & & & \\
\hline 9 & Central Costanera SA & & & & & & & & $\mathrm{x}$ & & \\
\hline 10 & Disal SA - Pinturas Tersuave & $\mathrm{x}$ & & $\mathrm{x}$ & & & & & & $\mathrm{x}$ & $\mathrm{x}$ \\
\hline 11 & EDESA SA & & & & $\mathrm{x}$ & $\mathrm{x}$ & & & $\mathrm{x}$ & & \\
\hline 12 & Grupo Clarín SA & $\mathrm{x}$ & & & & & $\mathrm{x}$ & & $\mathrm{x}$ & & \\
\hline 13 & Holcim (Argentina) & & & & $\mathrm{x}$ & & & & $\mathrm{x}$ & & \\
\hline 14 & INVAP SE & & & & & & & & $\mathrm{x}$ & & \\
\hline 15 & Ledesma SAAI & & & & & $\mathrm{x}$ & & & $\mathrm{x}$ & & \\
\hline 16 & Mastellone Hermanos S. A & $\mathrm{x}$ & $\mathrm{x}$ & $\mathrm{x}$ & $\mathrm{x}$ & $\mathrm{x}$ & $\mathrm{x}$ & & $\mathrm{x}$ & $\mathrm{x}$ & \\
\hline 17 & Mercedes-Benz Argentina SA & $\mathrm{x}$ & & & & & & & $\mathrm{x}$ & & \\
\hline 18 & Milicic SA & & & & & & & & & & \\
\hline 19 & Pan American Energy LLC & & & & & & $\mathrm{x}$ & & $\mathrm{x}$ & & \\
\hline 20 & SA San Miguel AGICI y F. & $\mathrm{x}$ & & & & & $\mathrm{x}$ & & $\mathrm{x}$ & $\mathrm{x}$ & \\
\hline 21 & $\begin{array}{l}\text { SanCor Cooperativas Unidas } \\
\text { Limitada }\end{array}$ & & & & $\mathrm{x}$ & & & & $\mathrm{x}$ & & \\
\hline 22 & Telecom Argentina SA & $\mathrm{x}$ & $\mathrm{x}$ & $\mathrm{x}$ & $\mathrm{x}$ & & $\mathrm{x}$ & & $\mathrm{x}$ & & \\
\hline 23 & Telefónica de Argentina SA & $\mathrm{x}$ & $\mathrm{x}$ & $\mathrm{x}$ & $\mathrm{x}$ & & $\mathrm{x}$ & & $\mathrm{x}$ & $\mathrm{x}$ & \\
\hline 24 & $\begin{array}{l}\text { Transportadora de Gas del Norte } \\
\text { SA }\end{array}$ & & & & & & & & $\mathrm{x}$ & & \\
\hline 25 & Transportadora de Gas del Sur SA & & & & & $\mathrm{x}$ & & & $\mathrm{x}$ & & \\
\hline 26 & YPF SA & $\mathrm{x}$ & & $\mathrm{x}$ & $\mathrm{x}$ & & $\mathrm{x}$ & & $\mathrm{x}$ & & \\
\hline
\end{tabular}

FuENTE: ElABORACIÓN PROPIA.

Los ejes de diversidad se encuentran codificados según se detalla en el cuadro 3. 
Cuadro 3. Codificación de EJes de Diversidad

\begin{tabular}{|l|c|}
\hline \multicolumn{1}{|c|}{ EJES DE DIVERSIDAD } & Código \\
\hline Género & A \\
\hline Diversidad sexual & B \\
\hline Generaciones & C \\
\hline Personas con discapacidad & D \\
\hline Personas en vulnerabilidad socio-económica & E \\
\hline Cultura país y étnica & F \\
\hline Aspecto físico & G \\
\hline Salud en general incluyendo HIV & H \\
\hline Pluralidad religiosa & I \\
\hline Pensamiento opinión y creencias & J \\
\hline
\end{tabular}

FuENTE: Elaboración PROPIA.

Cabe destacar que en muchos de los casos solo se mencionaba el eje de diversidad, sin profundizar en las acciones que la empresa realiza o planifica realizar. Por otro lado, en materia de salud, se consideró para incluirlo al eje el hecho de que tomaran medidas respecto de salud, seguridad e higiene en el ámbito laboral, aunque las mismas no implicaran una clara alusión a cuestiones de inclusión por cuestiones de salud o enfermedad.

Por otro lado, en la mayoría de los casos, el hecho de que aparezca mencionado un eje determinado no necesariamente conlleva a una política de diversidad. En varios casos se puede observar que figuran allí por una cuestión de cumplimiento normativo y de forma, más que por la responsabilidad real de su aplicación.

Otra cuestión que se debe destacar es que hay casos en que se declaran acciones sobre diversidad y al analizar los datos expuestos, no se logra visualizar su impacto. Esto suele ocurrir en cuanto a diversidad de género, ya que la declaran como importante, describen acciones al respecto, pero al momento de ver el detalle de dotación del personal se puede notar fácilmente una profunda desigualdad. En términos generales, la cantidad de mujeres no suele superar el $30 \%$ del total, habiendo casos en que no llegan ni al $5 \%$, sobre todo en puestos de mayor jerarquía. Algo similar sucede con la diversidad generacional, declarando que la edad no influye en la contratación y se puede observar una fuerte concentración etaria entre los 30 y los 40 años. 
Ahora bien, con el objeto de poder observar el impacto de la diversidad en las empresas relevadas, se agrega el cuadro 4 , donde se ha calculado el porcentaje en que se menciona cada eje, ordenados de mayor a menor.

Cuadro 4. Porcentaje de aparición de cada eje de diversidad

\begin{tabular}{|l|c|}
\hline \multicolumn{1}{|c|}{ EJES DE DIVERSIDAD } & $\%$ \\
\hline Salud en general incluyendo HIV & 81 \\
\hline Género & 54 \\
\hline Personas con discapacidad & 42 \\
\hline Cultura país y étnica & 42 \\
\hline Generaciones & 27 \\
\hline Pluralidad religiosa & 23 \\
\hline Personas en vulnerabilidad socio-económica & 19 \\
\hline Diversidad sexual & 15 \\
\hline Pensamiento opinión y creencias & 8 \\
\hline Aspecto físico & 0 \\
\hline
\end{tabular}

FuENTE: Elaboración PROPIA.

Lo que se observa es que en la mayoría se ha mencionado el tema de la salud, ya que es un tema relevante en los informes. En segundo lugar, aparece la diversidad de género, que es un tema en auge y de gran impacto en la sociedad actual. No obstante, apenas supera el 50\%. Luego, los siguen discapacidad y etnia, para las cuales suele haber políticas en las empresas, según sus declaraciones. El resto de los ejes no supera el $30 \%$ en las empresas relevadas, mostrando una clara falencia en ese aspecto. Esto puede deberse a que los temas de diversidad se suelen concentrar en las cuestiones que encabezan esta lista, invisibilizando otras desigualdades, como las etarias, socioeconómicas, religiosas o de opinión. Incluso las de diversidad sexual (que pueden ir desde la orientación sexual hasta las identidades sexuales), que pueden confundirse con el género. Por último, el eje del cual nada se ha mencionado en los informes es el del aspecto físico, siendo el más invisibilizado de todos y el que tiene mayor recorrido por delante: la diversidad corporal. 


\section{CONCLUSIONES}

El tema de la diversidad en las organizaciones no es nuevo. Sin embargo, puede observarse que aún queda un largo camino por recorrer en busca de la igualdad que la humanidad necesita, respetando la diversidad que nos caracteriza como especie. Como consecuencia de ello, las organizaciones no están excluidas de tal necesidad, si se desea evolucionar como sociedad.

En el presente trabajo, bajo la pretensión de ofrecer un disparador acerca de un tema que lleva implícito el respeto entre los seres humanos: la diversidad, exploró la gestión de la diversidad en las organizaciones para identificar las políticas de diversidad que aplican las empresas en la Argentina.

Así, se relevaron 26 COP's de distintas empresas argentinas (que cotizan en bolsa y adhieren al Pacto Global) y se sistematizaron las referencias explícitas en las mismas acerca de los ejes de diversidad: a) género, b) diversidad sexual, c) generaciones, d) personas con discapacidad, e) personas en vulnerabilidad socioeconómica, f) cultura país y étnica, g) aspecto físico, h) salud en general incluyendo VIH, i) pluralidad religiosa y j) pensamiento, opinión y creencias.

Se desprende del análisis de la información obtenida, que la mayoría de las empresas se declaran conocedoras de la diversidad. Sin embargo, se ha detectado invisibilidad de varios ejes que comprende la misma. Los primeros cuatro temas (salud en general incluyendo VIH, género, personas con discapacidad, cultura país y étnica) concentran la mayor cantidad de repeticiones en los informes, dejando relegados al resto. Por su propia definición, este aspecto de los informes se presenta como falencia para el logro respeto por diversidad.

La formulación de la problemática, poniendo de relieve su importancia, facilitaría a las organizaciones a llevar a la práctica determinadas políticas y acciones sobre el tema de referencia. Aunque la mera formulación no garantiza avances al respecto. La muestra tomada arroja inconsistencias entre la presentación de los ejes de la diversidad y su efectiva aplicación. Por ejemplo, si bien hay empresas que hacen declaraciones acerca de la diversidad etaria, la muestra arroja que la mayor cantidad de trabajadores/as pertenecen al rango etario de 30 a 40 años.

Es deseable que las compañías avancen en mejorar las definiciones atendiendo al concepto de diversidad, dado que, una mala definición de la problemática puede llevar a invisibilizar temas o limitar su análisis. 
Uno de los ejemplos más claro es definir políticas de género limitándose a presentar información acerca del binomio varón-mujer, dejando por fuera del análisis e invisibilizada a la diversidad sexual.

En línea con el análisis presentado, las COP, en la mayoría de los casos, resultan ser una formalidad, al menos en los temas referidos a la diversidad. Respondiendo a una necesidad de mejora de la imagen empresarial, más que en la voluntad de avanzar en lo referido al tema.

Queda de manifiesto que, en esta falta de recorrido en materia de diversidad, las empresas deberían incorporar dichos ejes en su totalidad como herramientas fundamentales en la implementación de dichas políticas, en pos de mejorar la calidad de vida de las personas. El respeto a la diversidad posiblemente se convertiría en una ventaja competitiva empresarial.

\section{BiBLIOGRAFÍA}

Bohlander, G. y Snell S. (2008). Administración de recursos humanos. Decimocuarta edición. Ciudad de México: Cengage Learning Editores.

Gómez Fulao, J. C. et. al. (2010). Las claves de una organización eficiente. Diseño y comportamiento Buenos Aires: Biblos.

Gorrochategui, N. y Krieger, M. (2012). Dimensión Social de la RSE. Acciones de las organizaciones privadas y públicas. Argentina 20012010. Proyecto UBACyT 2010-2012 GEF Buenos Aires: Ediciones Cooperativas.

Heller, L. (2012). Diversidad de género en las organizaciones, empresas globales, culturas locales. Buenos Aires: Universidad de Buenos Aires, Facultad de Ciencias Económicas.

Keil, M. et al. (2007). Manual de Formación en Gestión de la Diversidad, International Society for Diversity Management - idm. Disponible en: http://www.idm-diversity.org/eng/index.html.

R.E.D. de empresas por la diversidad (2016). Guia de diversidad sexual para empresas. Buenos Aires: Escuela de Negocios, Universidad Torcuato Di Tella. Disponible en: http://www.utdt.edu/listado_contenidos. php?id_item_menu=23712.

Robbins, S. y Coulter, M. (2010). Administración. Décima Edición. Ciudad de México: Pearson.

Sen, A. (1995). Nuevo Examen de la Desigualdad. Madrid: Alianza.

United Nations Global Compact (2017). United Nations Global Compact. Disponible en: https://www.unglobalcompact.org/. 


\title{
REFLEXIONES SOBRE LA DIVISIÓN SEXUAL DEL TRABAJO Y LA RESPONSABILIDAD SOCIAL EMPRESARIAL EN CHILE
}

\author{
Hernán Riquelme Brevis" \\ Matías Riquelme Brevis"
}

Chile

\section{INTRODUCCIÓN}

Las mujeres, en el desarrollo histórico de la sociedad, han jugado un rol protagónico, aunque invisibilizado, subestimado y reducido considerablemente al espacio reproductivo y doméstico. Existen profundas dicotomías entre la discriminación que surge en la inserción en el mercado laboral y las políticas de las empresas en esta materia, generando una agudización de las reivindicaciones sociales, lo cual se ha visto materializado en los movimientos sociales y los grupos de presión que exponen sus derechos, dejando entrever problemáticas asociadas a la etnia, el salario y el género en el escenario nacional durante el último tiempo ${ }^{1}$.

\footnotetext{
Doctor en Ciencias Sociales. Investigador en la Unidad de la Vicerrectoría de Investigación, Innovación y Postgrado de la Universidad Arturo Prat (UNAP). Docente e investigador en la Facultad de Ciencias Sociales y Humanidades de la Universidad Autónoma de Chile (UA).Correo electrónico: h.riquelmebrevis@ gmail.com

** Cientista Político, académico, Núcleo de Formación General, Facultad de Estudios Interdisciplinarios Universidad Mayor, Chile. Estudiante Doctorado Ciencias Sociales, Universidad de La Frontera. Correo electrónico: matiasriquelmeb@gmail.com

1 Una parte de este trabajo integra avances de la tesis de magíster del coautor, en el marco de los estudios desarrollados en la Universidad Autónoma de Chile (UA). De igual modo, se incorporan reflexiones de la investigación «Presentación de resultados de informes de cobertura de prensa sobre movimientos sociales y propuesta de investigación participativa con sindicatos de La Araucanía», del
} 
Por un lado, una de las categorías sustanciales del presente trabajo es la desigualdad de género, fenómeno que se manifiesta de múltiples formas. Particularmente en el desarrollo laboral, esto queda expresado en algunos ejes como: contratación de personal, desarrollo profesional, salarios, segregación laboral, introducción de tecnologías, nuevas prácticas de trabajo, aspectos relacionados con la maternidad, flexibilidad laboral y cuidado de los hijos. Por lo mencionado, se torna necesario establecer un diagnóstico y exponer las problemáticas que emergen actualmente en el desarrollo laboral. Gran cantidad de estas temáticas comienzan a considerarse tanto en las organizaciones como en la literatura de Responsabilidad Social Empresarial (RSE), donde se incorporan gradualmente estos elementos en las políticas públicas y prácticas del mercado, con el propósito de avanzar en la igualdad de género en el lugar de trabajo, para así promover el desarrollo de la sociedad de manera integral e inclusiva.

Por otro lado, los grupos económicos dominantes han identificado la necesidad, pero no han dado una respuesta sustancial y clarificadora respecto a las estrategias y tácticas empresariales adoptadas en relación con la temática, así como el papel que debe asumir en la contingencia nacional. Existen profundas diferencias entre hombres y mujeres a nivel económico y cultural en el mercado de trabajo chileno (Fuentes, Palma y Montero, 2005; Fawaz y Soto, 2012; Caamaño, 2010), agudizadas por las figuras contractuales disimiles según el sexo, y exacerbadas producto de las irregularidades a las que se ven sometidas las mujeres en la legislación laboral, y la desprotección en las soluciones institucionales, que están lejos de dar respuesta a estas desigualdades sociales.

Así, parece necesario comprender las particularidades del país. Como antecedente, se puede mencionar que la Región de La Araucanía presenta la mayor tasa de desocupación femenina a nivel nacional, con alrededor de un 8\% (INE, 2017), y la más alta tasa de vulnerabilidad, pobreza y desempleo a nivel nacional. Ante ello, tanto la RSE como la responsabilidad social de género se vuelven necesidad de primer orden para lograr la integración de realidades sociales y operaciones comerciales, contribuyendo positivamente en el ambiente laboral. Algunas preguntas que se trabajarán en el transcurso del texto son las siguientes: ¿de qué manera se está rearticulando el mundo privado ante el nuevo escenario social y cultural? ¿Cómo impactan las prácticas desiguales dentro de un

Observatorio de Medios y Movimientos Sociales (OMMS) de la Universidad de La Frontera (UFRO). 
contexto laboral en temáticas asociadas al género? ¿Cómo las ciencias sociales pueden aportar a mejorar las relaciones sociales y económicas al interior de las empresas desde una perspectiva de género? Este trabajo se enmarca en la necesidad de generar reflexiones en pos de un cambio no solo a nivel de políticas públicas locales y nacionales, sino también dentro del mercado laboral y de las necesidades de reinvención sociocultural al interior de las empresas, enfatizando en su proceder frente a las nuevas necesidades de la mujer y su progresivo empoderamiento.

En términos específicos, este trabajo integra cuatro secciones. En la primera se desarrolla un análisis respecto a la relación entre RSE y género. La segunda sección despliega una descripción de los procesos de sindicalización de la mujer en Chile, como germen constitutivo de la detección y organización de las reivindicaciones sociales y laborales. En el tercer apartado se reflexiona sobre el papel de la empresa en un nuevo escenario político, caracterizado por un malestar social respecto a las diferencias de género en el trabajo y otros espacios de vida. Finalmente, se presentan conclusiones que sintetizan los tópicos tratados a lo largo del trabajo y se exhiben algunas recomendaciones para enfrentar la temática.

\section{UN PRIMER ACERCAMIENTO A LA PROBLEMÁTICA DE GÉNERO Y LA RESPONSABILIDAD SOCIAL EMPRESARIAL}

Este apartado tiene como objetivo describir la relación entre la construcción de la categoría género y su aterrizaje conceptual con los procesos de RSE en contextos laborales. En la sociedad chilena actual, hombres y mujeres no encuentran las mismas oportunidades en el mercado del trabajo. Como señalan las estadísticas del 2016, un 48\% de las mujeres en edad de trabajar participó en el mercado laboral, mientras que un $71 \%$ correspondió a hombres (INE, 2017), cifras que en su máxima expresión se correlacionan con las problemáticas de género. En el léxico genérico, no se comprende a ciencia cierta la noción de género producto de su complejidad y su distanciamiento con los determinismos biologicistas, provocándose una confusión en el mundo cotidiano, donde muchas veces sexo y género se entienden erróneamente como sinónimos. Para avanzar en las igualdades de género, se torna menester aclarar diferencias y establecer parámetros de distinción en función de procesos fidedignos desde las demandas históricas de la mujer y el desarrollo de las femineidades en la sociedad contemporánea. Por lo mencionado, se 
consideran dos definiciones fundamentales que sirven de sostén teórico respecto a la división sexual del trabajo y la categoría género.

En primer lugar, la división sexual del trabajo irrumpe a través de una perspectiva crítica en las ciencias sociales con los planteamientos de Engels y Marx durante el siglo XIX. De manera somera, se detecta que ambos sostuvieron que la división sexual del trabajo está dada por el rol preponderante que cumple la mujer en la vida doméstica, específicamente en el cuidado y la reproducción social. Asimismo, consideraron la propiedad privada como principal promotor de las oposiciones, y la diferencia de roles en la familia como condicionante en la reproducción de la desigualdad, donde la mujer tiende a ser más explotada en comparación al hombre. Posteriormente, emergen estudios feministas que profundizan y conceptualizan la división sexual del trabajo. En este sentido, Benería (1981) afirma que las diferencias basadas en los sexos se extienden por todos los campos de la sociedad, y que en escenarios particulares tiende a verse opacada o exacerbada no por cuestiones biológicas, sino más bien por una base socioeconómica que es promovida por el desarrollo productivo y reproductivo de las sociedades. Para la autora, existen tres focos para definir la división sexual del trabajo, a saber: control sobre las actividades reproductoras de la mujer, el papel de la mujer en la reproducción biológica y el cuidado, y la disminución de la participación de la mujer en la vida social pública y productiva debido a los dos factores anteriormente señalados (Benería, 1981).

En segundo lugar, respecto a la categoría género, cabe señalar que en los procesos históricos de la sociedad moderna se han establecido criterios de cambio en la cosmovisión respecto a los derechos de la mujer y del hombre, estableciendo demandas disímiles según el proceso histórico de la sociedad. En la década de los setenta, el feminismo académico anglosajón fomentó el uso de una nueva categoría y acuñó el concepto de género entendiéndolo como «un campo primario dentro del cual, o por medio del cual, se articula el poder» (Scott, 1990, p. 281). Se pretendía dar mayor énfasis a la realidad que viven las personas y sus cualidades subjetivas, superando así el determinismo biológico preponderante en los estudios, para así establecer un mayor análisis de la realidad en virtud de las demandas por los derechos de la mujer y la igualdad de género. A su vez, existían teóricos de la época que apuntaban a romper con la historia y cualquier determinismo cultural antes imaginado, cambiando así las concepciones societales existentes de la época, todo esto a partir de una teoría que quiebra con los preceptos 
desde las experiencias cotidianas. En esta línea, Lamas (1996) sostiene que la perspectiva de género implica reconocer la diferencia sexual de manera separada de las ideas y representaciones que se toman de referencia respecto a la diferencia sexual, lo cual conlleva pasar de las diferencias biológicas a las referencias socioculturales que se tienen sobre algo o alguien.

Según la perspectiva crítica señalada, tanto la organización estatal como el mercado actúan como instituciones que establecen patrones y reproducen la subordinación de la mujer basada en el modelo patriarcal. Millet (1975) señala que la organización social actual no habría cambiado en esencia, sino que solo en la apariencia, sobre el orden existente en las sociedades arcaicas bíblicas. Podría suponerse que el Estado y el mercado son más bien un reflejo de las desigualdades existentes dentro de los espacios en los que se desarrollan ambos sexos. Según cifras de la Organización Internacional del Trabajo, solo siete de cada diez mujeres con educación universitaria se encontraban dentro de la fuerza de trabajo, a diferencia de aquellas que tenían un índice de escolaridad inferior a los seis años, de las cuales ocho de cada diez se encontraban fuera del mercado laboral (Reinecke, 2006).

En virtud de lo anterior, la RSE puede comprenderse como «las acciones de una organización para responsabilizarse del impacto de sus actividades sobre la sociedad y el medio ambiente, donde estas acciones son consistentes con los intereses de la sociedad y el desarrollo sostenible» (Alvear, 2009, p. 4). Las dinámicas de transformación social permean las acciones de las empresas, donde el desarrollo sostenible y la realidad social actual aceleran la necesidad de generar cambios dentro de las medidas prácticas que las empresas deben realizar, considerando factores como la baja participación de las mujeres en el mundo laboral o diferencias de salario según sexo ${ }^{2}$.

A modo de antecedente, en un estudio realizado en Chile durante el periodo 1997-2006, se logra observar la precarización laboral femenina, sobre todo en lo que respecta al rango etario 20-24 años, donde la participación masculina era del $67,4 \%$ y en el caso de la mujer solo llegaba al 39,8\% (Jiménez, 2007). Este dato se asocia a la necesidad laboral que

2 Aunque en los últimos años ha aumentado la inserción en el mercado laboral, según el INE, al año 2017, un 45,8\% de las mujeres participa en el mercado laboral chileno. Según la Organización para la Cooperación y el Desarrollo Económicos (2015), las mujeres chilenas reciben un $15 \%$ menos de sueldo que los hombres. 
tiene la sociedad de libre mercado respecto a concebir la empresa como una institución por esencia generadora y fomentadora del trabajo.

Como se pudo observar en esta sección, los procesos sociales y sus manifestaciones dinámicas y cíclicas demandan en los tiempos actuales el compromiso social y la actualización en temáticas de género de sectores y grupos económicos que, en tiempos pasados, eran observados como periféricos o fuera del alcance para entablar canales de comunicación. En la actualidad, las empresas son convidadas a incorporar en su agenda política acciones que permitan considerar peticiones sociales para así avanzar en la participación, equidad, compromiso con el entorno y clima laboral de los y las trabajadoras. Sin lugar a duda, esta perspectiva requiere un tratamiento gradual e íntegro desde la RSE, como también desde el sistema público y la sociedad civil.

\section{PROCESOS DE SINDICALIZACIÓN DE LA MUJER CHILENA: LA EMERGENCIA DE TRANSFORMACIONES ESTRUCTURALES}

Las rutas utilizadas por las mujeres en su proceso de emancipación fueron de diversa envergadura, la más relevante para este caso se asocia al mundo laboral y sindical. Salazar y Pinto (2002) plantean que la primera oleada de mujeres relacionadas con mundo sindical se estableció durante los inicios del siglo XIX, principalmente por un grupo de mujeres altamente precarizadas y asociadas al «bajo pueblo».

Fue a través de la vía política que se expresó la organización colectiva de la mujer, particularmente mediante la asociación en las organizaciones sindicales, partidistas o mutualistas que luchaban por una reforma radical del sistema dominante, cobrando vital importancia las organizaciones sindicales de la época y estableciendo diferencias en la composición social de las mujeres ligadas a la participación política por cuestiones laborales.

Por una parte, existe la asociatividad feminista de las mujeres de clase alta y media ligadas a la elite a nivel de estudios, trabajo y salario, por otra parte, emergen las organizaciones de mujeres precarizadas que buscaban atenuar los problemas de la pobreza de las trabajadoras, de la vida proletaria, en pos de la generación de un espacio comunitario y de asociatividad. Finalmente, en esta época se logran aunar las demandas femeninas mediante diversas organizaciones intersectoriales, tal es el caso del Movimiento Pro-Emancipación de la Mujer Chilena (ME$\mathrm{MCH}$ ), que tiene como particularidad lograr articular a nivel nacional 
a las mujeres en el conjunto del territorio chileno desde el «activismo provincial», estableciendo demandas transversales sin distinción en su composición de clase (carácter multiclasista). El MEMCH emerge ${ }^{3}$ en la esfera política a principios del siglo XX (específicamente en 1935), bajo la dirección de Elena Caffarena, y dentro de sus principales reivindicaciones se encuentra la igualdad ante la ley, derecho a voto, control de la maternidad, derecho a la educación y el desarrollo de la mujer en todos sus aspectos (Brito, 2016).

Con la finalidad de conocer datos representativos de la actualidad del trabajo en Chile desde una perspectiva de género que contemple a las mujeres, a continuación, se presentan algunas cifras que permiten obtener una radiografía del escenario nacional.

En términos concretos, la tasa de participación, ocupación y desocupación según sexo y edad para el año 2016 (INE, 2017) muestra que la mujer en los últimos años ha tenido una evolución y participación histórica, no obstante, aún sigue siendo altamente inferior a la participación masculina en todos los rangos etarios, con un $23 \%$ menos que sus pares masculinos, escenario que se acentúa en los rangos etarios 15-24 años y 60 años o más, lo cual se agudiza en la tercera edad y en la juventud. En el caso de la tasa de ocupación, al año 2016 las brechas se reducen considerablemente; en los rangos etarios entre los 25-44 años y más de 60 años no se establecen grandes diferencias porcentuales, pues no superan al 1\%, más bien la diferencia se establece en el rango entre 15 y 24 años, con una diferencia no tan significativa del 3,2\%.

En cuanto a la organización sindical y la participación femenina en el Chile actual, cabe señalar que esta dimensión no se encuentra ajena a la realidad y las brechas antes mencionadas. La participación sindical en su conjunto ascendía el año 2006 al 11\%, y en el caso de la negociación colectiva las cifras son aún más alarmantes, con el 8,6\% del empleo asalariado (Jiménez, 2007). En el caso particular de las mujeres, su participación sindical sigue siendo aún sosteniblemente más baja, tan solo con el 7,5\% para el año 2007.

Respecto a la cantidad de sindicatos, afiliación y dirigentes mujeres, y feminización en afiliación y dirigencias por subsector de intermediación financiera al año 2013, según la Dirección de Trabajo (Echeverría, 2014), se puede considerar que donde más afiliadas existen es en el subsector de los bancos, con 11.129 mujeres. El subsector con menor afiliadas es el de las administradoras de fondos de pensiones (AFP),

\footnotetext{
En su fundación, cobran importancia las ideas feministas de Marta Vergara.
} 
con solo 1.068 representantes femeninas. En el caso de la feminización del subsector, el que más alto porcentaje alcanza es el de los planes de seguros generales, con un $75,3 \%$, y el más bajo porcentaje corre por cuenta de los bancos. En el caso de las dirigentes mujeres ligadas al sector financiero, los bancos, con una cantidad de cuarenta mujeres, tienen la mayor proporción, y en el caso opuesto se exhibe las que pertenecen a los grupos financieros, solo con cuatro dirigentes sindicales.

Al observar las dinámicas laborales femeninas en diversos momentos de la historia, apreciamos que entre 1920 y 1982 hubo una participación que osciló en torno a $20 \%$ y $25 \%$, y es a mediados de la década del ochenta cuando se produce una inflexión importante en la participación laboral de las mujeres, después de haberse mantenido estable durante las dos décadas anteriores.

La participación laboral de las mujeres en Chile ha sido históricamente baja si se la compara con los demás países latinoamericanos, con una cifra actual de 48,6\% (INE, 2017). El promedio de los países de América Latina es de 52,8\% y el de los países de la Organización para la Cooperación y el Desarrollo Económicos (OCDE) es de 63,8\% (Weller, 2011). Lo mismo ocurre si se la compara con países similares, por ejemplo, en Argentina, el 54,9\% de las mujeres son activas laboralmente; en Uruguay, el 57,2\%; en Colombia, un 59,4\% y en Brasil, el $65 \%$. Se puede deducir que la vida laboral de las mujeres en la sociedad chilena aún se asocia al trabajo doméstico, encontrando resabios de sistemas de dominación y control ya detectados por teóricos de las ciencias sociales en el siglo XIX.

\section{LA EMPRESA Y SU ROL EN LOS NUEVOS TIEMPOS: DIVISIÓN SEXUAL, ECONÓMICA Y SOCIOCULTURAL}

Así como la economía crece y avanza en el escenario mundial, también se desarrolla y avanza la sociedad considerando las (no tan) nuevas reivindicaciones políticas. Tal es el caso de la concepción de familia, como institución fundamental e histórica de la sociedad donde comienzan a observarse las diferencias constitutivas entre hombres y mujeres, cuya génesis también se ha visto replanteada producto de las dinámicas de cambio y transformación que experimenta la sociedad occidental. A modo de antecedente, el total de hogares chilenos cuya única proveedora es mujer ha tenido un crecimiento sostenible durante los últimos quince años, lo que se refleja en los números: mientras en 
el año 1990 las cifras estaban cercanas al 20,2\%, para el año 2006 ya ascendía al 27,6\% (INE, 2017).

En cuanto a la capacitación laboral femenina, esta es menor en relación con la del hombre, mientras que en el año 2000 las cifras ascendían al 45,5\%, para el año 2005 alcanzó un 56\% (Quiñones, 2005). Respecto a la capacitación laboral de las mujeres, según el Servicio Nacional de Capacitación y Empleo (SENCE, 2018), se debe comprender que la capacitación es un medio para que las y los trabajadores logren acceder a mejores oportunidades de vida y trabajo, para esto, las empresas deben generar igualdad en el acceso a la capacitación entre sus trabajadores/ as; establecer criterios meritocráticos, técnicos y objetivos para la promoción del personal, evitando así cualquier tipo de discriminación, y, por último, realizar cursos y talleres de capacitación profesional en las comunidades aledañas para ayudar a las mujeres a enfrentar su ingreso al mercado laboral, lo anterior, según recomendaciones del programa de la Facultad Latinoamericana de Ciencias Sociales-Chile «Género y Equidad» (Rebufel, 2009).

Por parte de las empresas, aún queda camino por recorrer, ya que una parte importante de estas políticas no se han hecho parte de la solución (Horbath y Gracia, 2014; Onsalo, et al., 2013), producto de este cambio repentino, exponencial y en continuo avance por parte de la posición femenina en el espacio productivo. Así, parte de las empresas han colaborado en la discriminación social y laboral, quedándose más bien con la visión tradicional de la idea de familia, que puede encontrar asidero en la reproducción del imaginario social, donde se naturaliza el precepto respecto a la mujer y su relación casi indisoluble con lo privado y reproductivo.

Se pueden enumerar y argumentar una serie de problemáticas que dan cuenta de esta realidad, tales como: la asignación de roles de género, la organización familiar, el cuidado de los hijos, la segmentación ocupacional, estereotipos en la cualificación laboral por sexo, discriminación salarial, los supuestos costos extras que significaría la contratación de mujeres para el empleador, el embarazo, y los periodos pre y postnatal. Realidades que se tensionan respecto a las reivindicaciones de las mujeres en sus espacios de trabajo.

Como se pudo considerar en esta sección, uno de los principios de la RSE es la participación y compromiso de todos los grupos de interés ligados a las temáticas propias de la empresa, por lo cual, es importante 
que cuenten con un sindicato ${ }^{4} \mathrm{u}$ otras organizaciones representativas de las y los trabajadores, que sea participativo y que contemple instancias de diálogo y trabajo en directa relación y comunicación con la dirección de la empresa y las instituciones gubernamentales pertinentes. La misma negociación colectiva es una instancia que puede ser utilizada para establecer medidas de acción efectiva y que favorezcan el acceso de las mujeres al empleo, y la aplicación cierta del principio de igualdad de trato y no discriminación de las condiciones ante el trabajo. Por lo anterior, la RSE tiene un alto componente social que responde a las condiciones culturales, económicas y sociales de las trabajadoras, para ello, se debe considerar la realidad sociológica al momento de diseñar de manera íntegra el rol de las empresas en la sociedad por sobre determinismos económicos.

\section{Conclusiones}

A pesar de que el derecho general, y particularmente de las mujeres, a la no discriminación frente al empleo tiene respaldo normativo establecido en el Código del Trabajo, en la Constitución política chilena y en numerosos tratados internacionales sobre derechos humanos, como los planteados por la Organización Internacional del Trabajo (OIT) en su convenio 169. La discriminación histórica demuestra que el reconocimiento de la igualdad formal ante la ley, la fiscalización de su cumplimiento y la aplicación de la justicia por parte de los tribunales han sido insuficientes y no han logrado su objetivo. Por lo anterior, se debe dirigir la búsqueda de respuestas en la prevención, particularmente en la naturalización de las conductas discriminatorias, y en un compromiso de todos los agentes sociales involucrados en el proceso de integración, asumiendo la inclusión de las empresas. Además, velar por una labor principal y legal de abstenerse de discriminar, lo cual puede transformarse en un elemento sustantivo en la erradicación de la desigualdad de género desde la RSE, como agentes de cambio de políticas internas ligadas a la materia. Lo anterior se logra aportando soluciones, y proponiendo y abordando el problema social de la desigualdad de género y la división sexual del trabajo, accionando más allá de lo mínimo que la ley exige y aplicando medidas concretas orientadas a erradicar la discriminación,

4 Más allá de las tendencias ideológicas, los sindicatos son organizaciones históricas clave en el desarrollo y crecimiento de las organizaciones, que velan por la participación y el reconocimiento de las y los trabajadores. 
desde un cambio de la cultura organizacional propia de cada empresa. Por lo anterior, se requiere de un trabajo colaborativo, donde todos los grupos de interés involucrados en la temática (sindicatos, empresas, trabajadores, dirigencia y gobierno) participen.

En esta ausencia explícita de políticas elocuentes en lo que respecta a la abolición de todo tipo de discriminación de género y desigualdad laboral, se hace necesario que las organizaciones realicen en primera instancia un diagnóstico que les permita evidenciar actitudes, procedimientos y prácticas institucionales que delaten toda manifestación de prejuicios que redunden en discriminación. Frente al aumento de la sindicalización femenina ${ }^{5}$, no existe un crecimiento proporcional en las dirigentes mujeres, que hoy representan un cuarto del total. Las razones son variadas y aunque persiste un modelo masculino al interior de los sindicatos, las mujeres han irrumpido considerablemente en la esfera política, superando las barreras que históricamente las han mantenido al margen.

Por último, cabe señalar la necesidad preponderante de acelerar la discusión y de realizar nuevos estudios asociados a la temática de la división sexual del trabajo y la RSE, que permitan superar las limitaciones de este, particularmente de la discriminación «oculta» que existe en todas las ramas laborales en Chile, y la responsabilidad de los sectores públicos y privados.

\section{Bibliografía}

Alvear, C. (2009). Mujer, trabajo y responsabilidad social empresarial. Serie Documentos $\mathrm{N}^{\circ}$ 2, FLACSO, Chile.

Benería, L. (1981). Reproducción, producción y división sexual del trabajo. Mientras Tanto, 6, 47-84.

Brito, E. (2016). Sentidos y significaciones del archivo del MEMCH. Taller de Letras, 58, 101-109.

Caamaño, E. (2010). Mujer y trabajo: origen y ocaso del modelo del padre proveedor y la madre cuidadora. Revista de Derecho (Valparaíso), (34), 179-209.

Echeverría, M. (2014). Informe final: Estudios de la institucionalidad laboral y su vinculación con salarios bajos. Programa de las Naciones Unidas (PNUD), Área de la reducción de la pobreza y desigualdad.

Encuesta de Caracterización Socioeconómica (2015). «Encuesta CASEN 2015». Disponible en: http://observatorio.ministeriodesarrollosocial. gob.cl/casenmultidimensional/casen/casen_2015.php.

13\%, según la Encuesta de Caracterización Socioeconómica (CASEN, 2015). 
Fawaz, J. y Soto, P. (2012). Mujer trabajo y familia: Tensiones, rupturas y continuidades en sectores rurales de Chile central. La Ventana. Revista de estudios de género, 4(35), 218-254.

Fuentes, J.; Palma, A. y Montero, R. (2005). Discriminación salarial por género en Chile: Una mirada global. Estudios de Economía, 32(2), 133-157.

Horbath, J. y Gracia, A. (2014). Discriminación laboral y vulnerabilidad de las mujeres frente a la crisis mundial en México. Economía, sociedad $y$ territorio, 14(45), 465-495.

Instituto Nacional de Estadísticas (INE) (2017). Género y empleo, Enfoque Estadístico. Disponible en: http://historico.ine.cl/genero/files/estadisticas/pdf/documentos/enfoque-estadistico-genero-y-empleo.pdf.

Jiménez, M. (2007). Situación de la Mujer en Chile con una perspectiva de género. RESULTADOS DE LA ENCUESTA CASEN 2006. Santiago: Departamento de estudios, División Social, MIDEPLAN. Lamas, M. (1996). La perspectiva de género. Revista digital La Tarea, 8.

Millet, K. (1975). Política Sexual. México, DF: Aguilar.

Quiñones, M. (2005). Demandas de capacitación del sector financiero. Sesgos de género y evaluación por competencias. Revista Mujer y Desarrollo. Santiago de Chile: CEPAL.

Rebufel, V. (2009). Chile: Participación de la mujer en los fondos públicos de financiamiento en investigación científica y tecnología y algunas propuestas de intervención. Serie Documentos $\mathrm{N}^{\circ} 1$, FLACSO, Chile.

Reinecke, G. (2006). Chile, informe de empleo para el año 2006. Oficina Internacional del Trabajo (OIT), CEPAL.

SENCE (2018). Beca fondo cesantía año solidario 2017. Unidad de estudios, Servicio Nacional de Capacitación y Empleo.

Salazar, G. y Pinto, J. (2002). Historia Contemporánea de Chile. Volumen I. Santiago: LOM Ediciones.

Scott, J. (1990). El Género: Una categoría útil para el análisis histórico. México, DF: PUEG.

Weller, J. (2011). Panorama de las condiciones de trabajo en América Latina. Revista Nueva Sociedad, 232, 32-49. 


\title{
DIRECTIVOS GENERACIÓN CONFIANZA: PERSPECTIVA DE GÉNERO EN PYMES SECTOR SERVICIOS, BOGOTÁ D.C.
}

\author{
Marta Gisela Durán Gamba" \\ Luz Janeth Lozano Correa" \\ Myriam Sosa Espinosa** \\ Colombia
}

\section{INTRODUCCIÓN}

Las organizaciones, en un contexto altamente volátil y complejo, tienen el reto de vincular directivos cuyas habilidades de liderazgo favorezcan diálogos socialmente responsables con los públicos con quienes interactúan, siendo sus trabajadores uno de sus mayores activos para el crecimiento sostenible. Por ello, la influencia de los directivos tiene un papel central en el desarrollo de competencias que favorezcan el desempeño de las personas y la organización, como la confianza, considerada un capital intangible que incentiva una mayor competitividad organizacional propiciada por estos, al establecer acuerdos cooperativos y transparentes con sus stakeholders (Cegarra, Briones y Ros, 2005). Existe predominio del género masculino en los cargos directivos que representan las destrezas de un gerente efectivo. Sin embargo, los cambios organizacionales, demográficos, económicos y culturales generan situaciones que tienden a conformar un panorama gerencial más equitativo, diverso e incluyente que, a su vez, produce alternativas gerenciales con

Maestría en Psicología del Trabajo y las Organizaciones, Universidad Católica de Colombia. Correo electrónico: marthaduran@usantotomas.edu.co

* Maestría en Gestión de Organizaciones, Universidad EAN. Correo electrónico: luzlozano@usantotomas.edu.co

*** Maestría en Administración de Personal, Universidad de Guanajuato. Correo electrónico: myriamsosa@usantotomas.edu.co 
ventajas tanto para la directiva masculina como la femenina (Fletcher, 2004). Desde este contexto, y con base en un análisis empírico, la presente investigación cuestiona ¿cuál es la incidencia del género de los directivos en la generación de confianza en los colaboradores en pymes del sector servicios en Bogotá D.C.?

\section{FORMULACIÓN DEL PROBLEMA}

En un contexto global en el cual el mercado laboral experimenta un proceso de cambio vertiginoso, el mundo de los negocios a su vez ágilmente implementa importantes transformaciones en los requerimientos de los trabajadores en general y, particularmente, de sus directivos, debido a la diversidad de roles que estos desempeñan. De esta forma, tanto mujeres y hombres en cargos gerenciales se enfrentan a importantes retos, entre ellos, lograr el compromiso de sus colaboradores, desarrollar una cultura que facilite el alcance de objetivos y tomar decisiones enmarcadas en un comportamiento ético e incluyente, aspectos que repercuten directamente en los resultados a nivel organizacional, así como de los grupos de interés (Dickson, Smith, Grojean y Ehrhart, 2000; Gilli, 2011). Hay que señalar, además, que los directivos en su gestión están llamados a construir ámbitos de trabajo que promuevan el desarrollo de habilidades que conlleven a sus equipos a un mayor compromiso con su labor y a incrementar el nivel de desempeño. Por lo cual, la confianza se considera una capacidad estratégica en la interacción de los directivos, ya que esta facilita las relaciones con los equipos de trabajo, así como la participación, la cooperación, la comunicación, la motivación y el desarrollo de los mismos para el logro de objetivos comunes, obteniendo resultados sobresalientes (Dargam, 2011; GarcíaMarzá, 2004). Por lo tanto, esta investigación considera de gran relevancia comprender ¿cuál es la incidencia del género de los directivos en la generación de confianza en los colaboradores en pymes del sector servicios en Bogotá D.C.?

\section{MARCo TEÓRICO}

El marco de referencia de la presente investigación está conformado por los conceptos de confianza, género y dirección en pymes del sector servicios en Bogotá D.C., los cuales se describen a continuación. 


\section{CONCEPTO DE CONFIANZA}

El proceso de generación de confianza al interior de las organizaciones es susceptible a la influencia de distintos factores que pueden contribuir a su mejoramiento o deterioro. Uno de ellos es la diferencia en el género de los distintos colaboradores y directivos que forman parte de una determinada organización, que debe ser tomado en consideración para lograr un proceso óptimo en la generación de confianza, y así, fomentar espacios de alta productividad en el contexto de la capital colombiana. Rousseau, Sitkin, Burt y Camerer (1998) la definen en términos de las expectativas positivas que se tienen con respecto al comportamiento de otros, así como un cierto nivel de aceptación de vulnerabilidad, en la interacción social. Complementariamente, Covey y Merril (2007) consideran la confianza como una forma de fe. Mientras que Sabel (1993), por su parte, describe la confianza como la seguridad de que ninguna de las partes tomará ventaja sobre las vulnerabilidades de las otras. Estos postulados revelan una tendencia de los autores que han estudiado este tema por definirla en términos de dos factores fundamentales: la aceptación de un cierto nivel de vulnerabilidad y la existencia de unas expectativas acerca de la persona u organización en quien se confía. Como afirman estos autores, la confianza está presente en todas las relaciones humanas y en todas sus actividades. Así pues, la generación de confianza al interior de las organizaciones es un reto que los directivos enfrentan día a día.

Igualmente, es oportuno indicar que se habla de confianza cuando las interacciones de las personas generan intereses entre ellos, de tal manera que se conserva y prima el estímulo que da valor al sostenimiento mutuo de las relaciones. Esto se denomina «interés encapsulado», es decir, el interés de una persona persuade el de aquel con quien interactúa, lo que promueve la expectativa de mejorar y permanecer con la relación. Así mismo, se pueden describir algunas características propias que sustentan la confianza, como son los comportamientos recíprocos o de intercambio que traen beneficios mutuos en el sostenimiento de las relaciones, como lo argumenta Hardin $(1980,1991)$. Es importante asentar que la confianza se deriva de las motivaciones que permiten un beneficio potencial en el manejo de sus relaciones, como lo argumentan Luhman (1988), Rousseau, Sitkin, Burt y Camerer (1998). Por su parte Covey y Merrill (2007), al definir la confianza como un acto de fe, describen tres aspectos fundamentales en el desarrollo de la confianza, a saber: el carácter, 
la competencia, así como la relación entre el carácter y la competencia, las cuales hacen parte de la capacidad del individuo para lograr generar confianza en otros y así mismo, la traslada al contexto empresarial. Por lo tanto, la confianza es un activo intangible, y para efectos de la investigación, es importante considerar las relaciones de reciprocidad de los directivos con sus diferentes grupos de interés, estimando además las características personales como sus competencias de dirección para fortalecer el desempeño de las personas en sus organizaciones.

\section{CONCEPTO DE GÉNERO}

Tal como afirma Hernández (2006), el género constituye la categoría explicativa de la construcción social y simbólica, histórico-cultural de los hombres y las mujeres sobre la base de la diferencia sexual. Lagarde (2004, citada por Hernández, 2006) señala cinco dimensiones que contiene el género, las cuales se describen a continuación: a) la biológica: comprende el bimorfismo sexual constituido por los cuerpos humanos; b) la económica: en las sociedades existen actividades concebidas para las mujeres y otras para los hombres; esta dimensión tiene como indicador la feminización de la pobreza, de la agricultura, la prostitución, la discriminación económica y laboral en función del género; c) la psicológica: se refiere a la subjetividad individual a partir de un orden social que establece prácticas de relacionamiento; d) la social: implica las normas y prohibiciones que se convierten en tabú en el contexto donde emergen para cada sociedad; e) la política: comprende el conjunto de relaciones de poder en todos los ámbitos; en donde histórica y mayoritariamente en las sociedades los hombres les ha sido concedido mayor poder y las mujeres han mantenido subordinación en todo sentido. Es preciso señalar que estas conforman el marco de referencia conceptual para la presente investigación, para el caso de género.

\section{Concepto De DiRección}

Entre los objetivos principales con los que se crea una empresa está el logro de resultados de naturaleza económica, para lo cual es de gran relevancia conseguir que todas las personas que forman parte de este contexto aporten sus capacidades y conocimientos, a fin de generar valor y mejoras constantes que conlleven al éxito al largo plazo. En este 
sentido, las personas que acceden a cargos directivos tienen una gran responsabilidad en cuanto al alcance de resultados colectivos de la organización, siendo pues indispensable que, tanto directivos como equipos de personas, desarrollen un ámbito que facilite asumir los retos que esto conlleva (Argandoña, 2014). Asimismo, las organizaciones actuales en un entorno de incertidumbre precisan contar con personas que puedan gestionar de forma eficaz teniendo presentes los distintos públicos con los que interactúan, por lo tanto, el liderazgo complementa la función directiva, lo que conlleva responder de forma más efectiva ante el cambio, lo cual resulta determinante para el éxito o fracaso de su gestión (Kotter, 1999; Lambert, 1994). Por otra parte, cabe señalar que la misión central de un directivo en un cargo implica no solo los aspectos técnicos, sino también que integre los valores y las virtudes morales, así como la toma de decisiones convenientes para la organización y que conducen, en última instancia, al logro de objetivos, la rentabilidad, el estatus, la satisfacción de sus trabajadores, de sus clientes, así como de todos aquellos que participan activamente en la organización. Razón por la cual el directivo tiene el desafío de crear un clima de motivación y confianza que oriente, en especial a sus trabajadores, a obtener objetivos comunes trazados (Argandoña, 2014).

Complementariamente, es importante mencionar que algunas de las principales funciones que el directivo realiza tradicionalmente son las de planeación, organización, dirección y control. Sin embargo, dentro de la dirección propiamente dicha esta implica, además del mando, la motivación de quienes tiene a su cargo, lo que conlleva a realizar labores a fin de que la organización mantenga su curso. Estas labores son: a) estratégicas, es decir, las relacionadas con el logro de resultados y aporte de valor a la organización; b) ejecutivas, tienen que ver con participar los objetivos a los equipos de trabajo impulsando el logro a través de personas con las habilidades que conlleven a dicho fin y c) $d e$ liderazgo, se orientan básicamente a la motivación y desarrollo de las personas a nivel de la organización (Abadía, como se citó en Soriano Llobera y Cebrian Díaz, 2014).

\section{Capacidades del Directivo}

Algunas de las capacidades que caracterizan a los directivos y que les facilitan una mejor gestión a nivel integral en el ámbito organizacional son: exploración de su entorno, entender la estrategia de la 
organización, pensamiento gerencial, trabajo en equipo, negociación, liderazgo, logro de objetivos, proactividad, proyección social, habilidad personal (cómo aprender a escuchar, empatía y asertividad) e integridad personal (Guevara, según se citó en Hernández, Armenteros, Villanueva, Montalvo y Del Río Ramírez, 2016).

\section{LA DIRECCIÓN Y EL LIDERAZGO}

En aras de comprender la labor de un directivo, la cual suele confundirse con la del líder y en otros casos no se tiene claridad frente a la relación que existe, a continuación, se definen ambos conceptos.

Tanto el liderazgo como la dirección son conceptos diferentes que se dividen mediante una fina línea. Zaleznik (2004) señala que el líder se diferencia del directivo particularmente en que se preocupa por el significado que tienen las cosas para las personas, mientras que los directivos se preocupan más por cómo hacer las cosas. Para Yulk (1989), los contrastes esenciales entre directivos y líderes está dada esencialmente en que: los directivos ejercen responsabilidades de posición y autoridad, mientras que los líderes logran influir en el compromiso de las personas al interior de las organizaciones. Es decir, el directivo se enfoca en los procesos, y el líder se orienta principalmente en las personas. Adicionalmente, de acuerdo con Bennis y Nanus (como se citó en Boyatzis, 2008), es oportuno anotar que el liderazgo representa una autoridad informal que genera influencia e interacción en doble vía en pro de resultados comunes. La relación de carácter social del líder proporciona capital emocional y espiritual a quienes le rodean, motivando así el cambio y el desarrollo de los equipos, mientras que la dirección se apoya mayormente en la autoridad institucional, haciendo énfasis en recursos materiales y físicos, orientándose a la administración y a la gestión de la organización.

Es decir, la dirección encamina sus esfuerzos mayormente hacia enfrentar la complejidad, aportando orden y firmeza mediante las labores ya descritas; y el liderazgo, por su parte, facilita el cambio, por lo cual su contribución es equivalente a alinear a las personas a través de los distintos equipos, conduciéndolos hacia el logro de objetivos vinculados a la visión. No obstante, pese a las diferencias que se han procurado establecer, ambos son complementarios e implican propósitos distintos. Es decir, que más allá de la importancia que el liderazgo reviste, este complementa la dirección mas no la reemplaza, entendiendo que la 
dirección controla a fin de que los trabajadores dirijan sus esfuerzos hacia el rumbo correcto, mientras que el liderazgo impulsa mediante las emociones y las expectativas de los trabajadores para lograr dicho fin de forma comprometida y entusiasta. Entonces, se puede decir que tanto la dirección como el liderazgo generan balance y son necesarios para el funcionamiento efectivo de las organizaciones (Kotter, 1999, 2005).

\section{REVISIÓN DE LA LITERATURA}

Dado que el interés de la investigación se focaliza en la generación de confianza de los directivos desde una perspectiva de género, seguidamente se describen los hallazgos relacionados con el tema.

\section{CONFIANZA Y GÉNERO}

La confianza es un intangible presente en las organizaciones que tiene influencia en el liderazgo y no es ajena al género, tema que a nivel organizacional ha sido discutido ampliamente en la literatura. Croson y Gneezy (2009) realizaron un estudio compilatorio que se centra en una serie de juegos de confianza efectuado por otros investigadores, que confirman que las mujeres confían en menor o igual medida que los hombres; sin embargo, los niveles de confianza de las mujeres suelen ser más sensibles al entorno que las que poseen los hombres. Es de gran relevancia mencionar que estos juegos de confianza no están estructurados específicamente para explicar el comportamiento al interior de organizaciones o empresas, y muestran tendencias generales acerca del comportamiento de los individuos en distintas sociedades. Sin embargo, estas generalidades permiten realizar inferencias acerca de lo que se podría esperar al estudiar la influencia del género en el tema de la confianza al interior de las organizaciones. Igualmente, respecto a las diferencias de género en cuanto a la confianza, los resultados de encuestas, así como los resultados experimentales, evidencian que, en general, los hombres confían más que las mujeres. Estos resultados señalan que es menos factible que las mujeres crean que es posible confiar en la generalidad de las personas (Alesina y La Ferrara 2002; Glaeser, Laibson, Scheinkman y Soutter, 2000; Terrell y Barrett, 1979). Un número de investigaciones que se orientan mayormente hacia los experimentos económicos apoya esos resultados y concluye que los hombres confían más que las mujeres. 
Lo anterior se fundamenta en resultados que revelan que los hombres depositaron más dinero a sus oponentes en juegos económicos, siendo así más vulnerables aún a las acciones de la otra parte (Buchan, Johnson y Croson, 2006; Snijders y Keren, 1999). Así pues, podría decirse que existe una generalidad en la diferencia de la confianza entre los géneros: las mujeres confían menos que los hombres. Esto puede influir la dinámica de las interacciones sociales en general, así como en el caso particular de la generación de confianza en las organizaciones.

\section{CARgos directivos y GÉNERo en Colombia}

Aunque la intención del presente estudio no es analizar la desigualdad de género ni discriminación en el ámbito laboral, es inevitable al indagar la literatura encontrarse con un sinnúmero de publicaciones centradas en estos aspectos. En este orden se expondrá lo encontrado en relación con el género y ámbitos organizacionales y que se considera pertinente para el objeto de estudio de esta investigación. Dentro del contexto colombiano, la revista Dinero publicó en octubre de 2015 un artículo titulado "¿Las empresas que tienen mujeres en altos cargos directivos son más exitosas?». Cuestionamiento al que responde que tan solo el $35 \%$ de las empresas en Colombia tienen mujeres en posiciones de liderazgo, una cifra realmente baja considerando que hay estudios que revelan que las compañías lideradas por mujeres son más rentables que las que no, hasta en un $26 \%$. Así mismo, se ha identificado menor riesgo de bancarrota y corrupción, también condiciones más favorables a nivel de colaboración, comunicación e innovación cuando quienes lideran las organizaciones son mujeres. Este mismo artículo plantea que un estudio desarrollado por la firma Aequales realizó una encuesta en cuarenta empresas en Colombia para evaluar sus niveles de inclusión, cuyos resultados indican que existen diversos factores que mantienen la inequidad de género, tales como la falta de políticas y de un lenguaje inclusivo. Sin embargo, hay empresas que, según esta misma firma, se destacan por promover la igualdad de género, entre estas: 3M, Johnson \& Johnson y Citibank.

Por otra parte, el periódico Portafolio publicó en enero de 2015 un artículo titulado "¿En qué cargos las mujeres están mandando en Colombia?», en el cual plantean que Colombia, de acuerdo con la Organización Internacional del Trabajo (OIT), es el segundo país a nivel mundial con mayor número de trabajadoras de género femenino en 
cargos directivos. La investigación también evidencia que esta constante se presenta en áreas relacionadas con la gestión humana, así como con la comunicación; en cuanto a gerencia se refiere, su gran dificultad tiene que ver con la responsabilidad a nivel familiar. Según un reporte del diario El Espectador (2018), solo el 20\% de los cargos directivos son ocupados por mujeres, y el $35 \%$ se encuentran en cargos profesionales y de gerencia media. Hay que decir entonces que, paulatinamente, las organizaciones en el entorno colombiano han ido generando una mayor equidad en lo que se refiere a la participación del género femenino en el panorama directivo.

\section{CARgos DiRECTIVOS Y GÉNERO EN IbEROAMÉRICA}

En diversas investigaciones surgen importantes conclusiones que permiten ver que la realidad en los países latinoamericanos es muy similar a la de Colombia con relación al género y diversas variables en el ámbito organizacional. Así, por ejemplo, lo determinaron Carranza y Peralta (2012) en su estudio «Empleo y género: análisis de las preferencias de los empleadores como determinantes del acceso al empleo, el caso de la Ciudad de Córdoba, Argentina", quienes identificaron que los empleadores tienen ciertas preferencias con relación a la edad de hombres y mujeres que contratan, evidenciando inequidad, de modo que la demanda de empleos que especifican como criterio de clasificación la edad permiten identificar cuestiones elementales, tales como: las ofertas de empleo que señalan requerir personas menores de treinta y tres años comprenden un $25 \%$ del total de la demanda laboral de mujeres y solo un $19 \%$ de la de hombres. A su vez, se evidencia casi el doble de posibilidades laborales para hombres que para mujeres cuando se define que son opciones laborales que requieren personas mayores de cuarenta y tres años. Y, finalmente, concluyen que existe segregación ocupacional de género en el mercado, resultando que la mujer está limitada para acceder a determinados empleos.

Hay que agregar que Molina y Torrado (2012) afirman que son pocas las mujeres que tienen cargos directivos en grandes empresas en España, lo que deja a la luz una fuerte segregación de género en el mercado de trabajo en dicho país, independiente del nivel formativo. Así mismo, concluyen las mujeres suelen liderar grupos de entre una y veinte personas generalmente de su mismo sexo y en la medida en que los grupos aumentan de tamaño son liderados por hombres. Por otro 
lado, respecto al tema salarial se encontró que los hombres cobran más y se encuentran satisfechos con su remuneración, mientras que entre las mujeres ocurre exactamente lo contrario, es decir, ganan menos y reportan estar insatisfechas con su salario. Otro estudio realizado en España por García, García y Madrid (2012) concluye que las empresas dirigidas por mujeres suelen tener las siguientes características: son de menor tamaño, corresponden al sector servicios, cuentan con tecnología menos desarrollada y son principalmente empresas familiares. En cuanto a la literatura enfocada en género se encuentran afirmaciones respecto a que las mujeres se destacan por competencias como: fácil adaptabilidad a los cambios, disponibilidad para delegar, habilidad para motivar, habilidades comunicativas, intuición, espíritu innovador, aspiraciones formativas, empatía hacia los subordinados y gestión eficaz del tiempo. Competencias que no coinciden con los modelos tradicionales de liderazgo y que se han asociado con la gestión exitosa (Molina y Torrado, 2012); sin embargo, las conclusiones de este estudio plantean que las mujeres que acceden a la cúspide de las organizaciones tienden a reproducir características de liderazgo tradicionalmente asociadas a los hombres, de tal manera que muchas se identifican más con los hombres que con su propio sexo, lo que en ocasiones provoca reacciones de desagrado o desconfianza (Collison, Knights y Collinson, como se citó en Molina et al., 2012).

Por otro lado, en Chile los estudios reportan que la tasa de participación de la mujer en el mercado laboral es de 47,2\%, lo que es considerado bajo en relación con otros países. A nivel mundial, el índice para el 2010 es de 53,20\%, según el Banco Mundial. La nueva encuesta nacional de empleo (INE) en Chile plantea las razones por las que las mujeres se mantienen fuera de la fuerza laboral, por ejemplo, el $36,58 \%$ de las encuestadas lo hacen por causas familiares; a diferencia de los hombres, que lo hacen por motivos de estudio, con un 44,81\% (Gallegos, Guzmán, Saavedra y Silva, 2012).Adicionalmente, en Chile es común que la mujer abandone su carrera y trabajo luego de ser madre. Así mismo, a nivel mundial se observa que la participación femenina en cargos directivas es de alrededor un $24 \%$. Además, Chile cuenta con la ley de igualdad salarial (Ley 20348 de 2009, que otorga igualdad de remuneraciones entre hombres y mujeres). Así mismo Adler (como se citó en Molina et al., 2012) afirma que el número de multinacionales dirigidas por mujeres aumentará su competitividad, ya que independientemente de las diferencias o similitudes entre los estilos de liderazgo de 
hombres y mujeres, al contar con directivos de ambos sexos la empresa está aumentando su reserva de talento potencial. En general, se puede afirmar que lo que se identifica en Colombia en torno a la participación de las mujeres en cargos de dirección en las organizaciones no es muy distinto a lo que se encuentra en otros países de Iberoamérica.

\section{INFLUENCIA DEL GÉNERO EN LA DIRECCIÓN}

Como se ha mencionado, las organizaciones se encuentran inmersas en un entorno caracterizado por la complejidad e influido por cambios externos constantes frente a los cuales tienen el desafío de responder de forma ágil y efectiva; por lo cual, disponen de una diversidad de directivos que no solamente faciliten la optimización de recursos, sino que, a su vez, den lugar a una organización innovadora que se oriente a resultados estratégicos. Por tanto, el género es uno de los factores que determina diferencias importantes en la forma de dirigir los equipos de trabajo en las organizaciones. En este sentido, tradicionalmente las investigaciones señalan que existe una preponderancia del género masculino en cuanto se refiere a los cargos directivos, debido a que representa destrezas de un gerente efectivo (Koenig, Eagly, Mitchell y Ristikari, 2011). Motivo por el cual tienen una mayor representación los altos cargos directivos con respecto a las mujeres. Adicionalmente, el entorno social con regularidad ha atribuido al género masculino mayor poder, autoridad y capacidad para competir en su gestión. Sin embargo, es pertinente señalar que al género femenino se le han atribuido características de gran relevancia, como el hecho de mostrar gran interés en las relaciones de carácter más humano y social, sin hacer tanto énfasis en el concepto de poder y mando (Eagly, Wood y Dickman, como se citó en Ergun, García-Muñoz y Rivas, 2011).

Otros estudios han señalado el incremento de la participación del género femenino en los cargos de las jerarquías superiores en varios estamentos, lo cual indica que lentamente los estereotipos respecto a la dirección y los roles han ido sufriendo cambios, por cuanto las mujeres en su ejercicio directivo pueden reunir varias de las características de ambos géneros (Dasgupta y Asgari, 2004). Por lo anterior, el género femenino poco a poco ha ido superando los obstáculos para ocupar cargos directivos, siendo una promotora del trabajo en equipo, generando así cambios significativos en el concepto tradicional de la dirección basada en la autoridad. Igualmente se puede afirmar que las mujeres en 
su gestión en cargos directivos han aportado cambios de gran relevancia a las prácticas consideradas del liderazgo, en cuanto generan relaciones más colaborativas con sus colaboradores, incentivan a metas, influyen mediante sus características y desarrollan un liderazgo más interactivo, procurando disminuir los niveles jerárquicos debido a la socialización y proceso de carrera. En contraste con el género masculino, estos tienden mayormente a influir desde su posición y autoridad organizacional (Lipman-Blumen, 1996; Rosener, 1990). En este sentido, las mujeres dirigen de forma distinta al modelo tradicionalmente reconocido como masculino, razón por la cual se reconocen aspectos fuertes particulares en las mujeres, tales como establecer un balance entre lo racional y lo emocional, es decir, que en su trabajo directivo hacen uso simultáneo de lo cognitivo y lo afectivo, a esta característica propia de las mujeres en los niveles directivos se le ha denominado estilo femenino-natural (Loden, 1985; Helgesen, 1990).

Complementariamente, Cortese (2005) señala que las mujeres en los cargos directivos, y en ejercicio del rol de líderes especialmente, desarrollan un ámbito más grato para trabajar, teniendo presentes para ello los aspectos que proporcionen estabilidad emocional, e igualmente tomando decisiones oportunas y efectivas. Asimismo, desde los hallazgos de Abarca (como se citó en Arteaga y Ramón, 2009), las mujeres desarrollan relaciones menos jerárquicas, menos formales, son más orientadas a las personas, por lo cual desarrollan relaciones que permiten impulsar equipos de personas motivadas, con mayor autoconfianza, cooperación y trabajo en equipo. Del mismo modo, algunos otros aspectos que caracterizan el género femenino en su gestión directiva desde la perspectiva de Loden (1985; Helgesen, como se citó en Eagly, 2013) son: menor nivel control, trabajo colaborativo entre las personas en el contexto organizacional, altos niveles de desempeño, trabajo en equipo, resultados con calidad (el cual es de gran relevancia para este género), intuición y racionalidad, los cuales facilitan la resolución de problemas a nivel organizacional.

De otra parte, Cortese (2005) afirma que tanto los hombres como las mujeres tienen marcadas diferencias a la hora de asumir roles de dirección; en el caso de los hombres, estos se caracterizan por ser más competitivos en su gestión, por mantener relaciones más jerárquicas, es decir, más formales, pues se interesan principalmente en triunfar. En lo que respecta al estilo de resolver los problemas, esencialmente son racionales. Así mismo, hacen un énfasis mayor en el control, en la estrategia 
operativa, tienen una actitud no emocional y usan mayormente el razonamiento analítico. Se puede concluir desde esta perspectiva que cada uno de los géneros tiene aspectos diferenciales propios para la dirección de acuerdo con los diferentes tipos de organizaciones. En el caso del género femenino, puede afirmarse que la mujer en cargos directivos favorece la gestión de equipos más creativos y entidades más rentables. Así mismo, esta se reconoce por ser más participativa, menos autocrática, menos directiva, ética y con mayor desarrollo de habilidades sociales, lo que conlleva a considerar que la mujer puede interesarse mayormente por el bien público en el contexto organizacional (Eagly, 2013). En lo que respecta al género masculino, se evidenció mediante un estudio que, en el contexto de las organizaciones militares, a diferencia de otros tipos de organizaciones, el género masculino favorece el proceso de dirección, así como las prácticas asociadas al liderazgo. Mientras que las mujeres se considera que son más efectivas en el sector negocios y educación (Eagly, Karau y Makhijani, 1995; Paustian-Underdahl, Walker y Woehr, 2014).

\section{GÉNERO Y HABILIDADES DEL LIDERAZGO EN LA DIRECCIÓN}

Frente a las distinciones que se han hallado a este respecto, las mujeres se caracterizan mayormente por desarrollar las siguientes habilidades del liderazgo en cargos de dirección: a) realizan un trabajo más participativo enfocado en el grupo, basado en los valores y las competencias que facilitan el desarrollo de un buen clima de trabajo; b) se adaptan rápidamente a los contextos cambiantes; c) tienen actitud optimista frente a los desafíos; d) se orientan al trabajo en equipo para solucionar los problemas; e) son más flexibles; f) se enfocan en el cliente y en el aprendizaje constante; g) en habilidades de comunicación, son mayormente dadas a la escucha empática, lo que facilita relaciones más efectivas con el equipo; h) son dadas al diálogo en situaciones conflictivas, de modo que facilitan su resolución (Jorna Calixto, Castañeda Abascal y Véliz Martínez, 2016). En palabras de las citadas autoras, se ha evidenciado los hombres se caracterizan en su desarrollo de habilidades de liderazgo en cargos directivos por: a) trabajar más de forma unipersonal que con una visión enfocada en el equipo; b) tienen una visión más estratégica; c) se han asociado con la capacidad de innovación como habilidad del liderazgo. 


\section{DIRECCIÓN Y PERCEPCIÓN DE CONFIANZA POR PARTE DE LOS TRABAJADORES}

$\mathrm{Al}$ identificar los hallazgos respecto a la relación que existe entre los directivos y la percepción de confianza por parte de los trabajadores, las investigaciones de Whitener (2001) han confirmado que, cuando los trabajadores logran percibir una relación de confianza respecto a sus superiores inmediatos, se genera un incremento en el compromiso de estos últimos con respecto a su trabajo. Lo que, a su vez, representa una muestra del compromiso de los directivos con sus trabajadores y con la organización. Así mismo, Mayer y Gavin (2005) indican que las relaciones de confianza con los directivos repercuten en los comportamientos ciudadanos de los trabajadores tanto individual como de la organización, e inciden en la capacidad de estos últimos para enfocarse en el trabajo. Desde su perspectiva, Rich (como se citó en Brashear, Boles, Bellenger y Brooks, 2003) plantea que en cuanto el directivo como líder desarrolle la capacidad de crear ambientes de confianza, promueve un mayor compromiso por parte de sus equipos de trabajo. Lo anterior lo logra a través de comportamientos entendidos como veraces e íntegros, sin los cuales no podrán exigir lealtad, lo que a su vez conlleva a que se desarrolle un trabajo dentro de un promedio normal. Por su parte, Dirks (2000) indica que la confianza de los equipos de trabajo en sus directivos genera un efecto en el desempeño, lo que a su vez implica que estos acepten con mejor actitud tanto las actividades, metas, toma de decisiones roles, así como el esfuerzo que implica lograrlas, en ocasiones mediante arduo trabajo.

\section{Percepción de CONfianza entre los PARes}

Al respecto, Nedkovski, Guerci, De Battisti y Siletti (2017) evidenciaron en su estudio una correlación entre el clima ético organizacional (OEC por sus siglas en inglés) y la confianza de los colaboradores en sus pares, jefes y la organización en general. Existen tres tipos diferentes de climas éticos organizacionales, cada uno con una característica distintiva. El OEC benevolente, en el cual la percepción de los colaboradores es que sus colegas toman decisiones basándose en su preocupación por el bienestar de todos los miembros de la empresa; el OEC de principios, en el cual la percepción es que los colegas, teniendo en mente el bienestar de los demás, siguen cuidadosamente una serie de reglas, 
normas y lineamientos de la organización; y el OEC egocéntrico, en el que la percepción es que los colegas velan únicamente por el bienestar propio. Estas percepciones son relevantes en la generación de confianza al interior de la empresa. Los autores del texto indican que en otros estudios se ha encontrado que el OEC benevolente tiende a promover la confianza entre pares al interior de las organizaciones, así como en los supervisores (aunque en menor medida). Por otra parte, un OEC de principios promueve la confianza en los supervisores y en la organización como conjunto. Finalmente, encuentran que una OEC egocéntrico va en detrimento de la generación de confianza.

\section{PERCEPCIÓN DE LA CONFIANZA POR PARTE DE LOS COLABORADORES}

Cabe señalar que en las organizaciones es relevante identificar si existe confianza por parte de un colaborador en sus pares, o la de un líder en sus colaboradores y viceversa, pero igualmente evaluar la percepción de la misma. De acuerdo con Edelberg (2010), la confianza no solo debe existir, sino que además debe ser percibida por las partes involucradas. La percepción negativa acerca de la confianza que un jefe les tiene a sus subalternos puede generar serios problemas de clima organizacional y llegar a resultar en una alta rotación. Por su parte, García Cruz y Real Fernández (2013) indican que tanto el apoyo como la autonomía percibidos por el trabajador dan lugar a una motivación intrínseca que conlleva a realizar mayor esfuerzo y compromiso para lograr las metas a nivel de la organización. De esta forma, el apoyo y la autonomía implican un cierto nivel de confianza por parte de los superiores inmediatos o supervisores, y es evidente que los efectos de esta percepción sobre los colaboradores tienen un impacto positivo. Así pues, se entiende que las percepciones de los colaboradores acerca de la confianza moldean el comportamiento, la productividad y la reciprocidad de la confianza en los supervisores y la organización en general.

\section{IMPLICACIONES DE LA DIRECCIÓN, LAS HABILIDADES DEL LIDERAZGO Y EL GÉNERO}

De acuerdo con los planteamientos de Rincón, González y Barrero (2017), actualmente es un hecho que las mujeres apenas están representadas en puestos de alta dirección en empresas privadas e instituciones 
públicas en el mundo occidental, por lo que es pertinente también afirmar que en los niveles intermedios de la escala laboral y en puestos con un nivel medio de responsabilidad, hay un mayor equilibrio entre hombres y mujeres. Es así que el enfoque basado en las diferencias de género sugiere que las mujeres y los hombres tienen diferentes rasgos relacionados con las habilidades del liderazgo, que pueden explicar una menor presencia de mujeres en cargos que impliquen una mayor capacidad de decisión. En general, los rasgos asociados con los hombres han sido más valorados por los puestos de liderazgo. Sin embargo, diferentes autores indican que un liderazgo efectivo requiere una combinación de características asociadas tanto a hombres como a mujeres, como la inteligencia emocional, la asunción de riesgos, la empatía, la integridad o la capacidad de persuadir, motivar e inspirar a las personas, entre otros. Igualmente, otros estudios que evidencian importantes diferencias en la valoración de los subordinados respecto a la efectividad de sus líderes, dependiendo de si estos son hombres o mujeres, en el caso de Ayman, Korabik y Morris (2009) evaluaron el desempeño de los líderes por parte de sus subordinados, encontrando que fue significativamente menos positiva para las líderes femeninas con subordinados masculinos que para las líderes femeninas con subordinadas femeninas. Los subordinados de género masculino y como las de género femenino de los líderes masculinos calificaron su desempeño como igualmente efectivo, independientemente de sus niveles del estilo de liderazgo.

\section{Metodología}

La presente investigación se desarrolla en seis empresas pymes del sector servicios en Bogotá D.C., en la cual participan en total sesenta y dos trabajadores de dichas entidades, con un diseño muestral de tipo no probabilístico. Adicionalmente, se utiliza una metodología descriptiva y cuantitativa mediante la aplicación de una encuesta ajustada a las necesidades del estudio, a fin de identificar la incidencia de las características del género de los directivos en la generación de confianza en los colaboradores en pymes del sector servicios en Bogotá D.C. Es de precisar que el instrumento cuenta con una escala tipo Likert, que mide las habilidades de liderazgo del directivo, cuyo coeficiente Alpha de Crobach es del 0,983, siendo pertinente en lo que refiere a su fiabilidad y validez. Igualmente, consta de una segunda escala tipo Likert al final del instrumento, que facilita determinar el grado de pertenencia por 
parte de los empleados al manifestar si se sienten orgullosos de trabajar en la organización, si sienten los problemas de esta como propios y si sienten como si la organización fuese su casa. Por su parte, esta escala arrojó un coeficiente de Alpha de Crobach del 0,8601, por lo cual se puede concluir que la escala establecida para medir el grado de pertenencia por parte de los empleados es adecuada desde el punto de vista de su fiabilidad y validez.

\section{Resultados}

En el presente estudio, el 72,6\% de los encuestados fueron mujeres y el $27,4 \%$ restante hombres (véase cuadro 1 ).

CUAdRO I. CARACTERIZACIÓN PARTICIPANTES ENCUESTADOS

\begin{tabular}{|c|c|c|}
\hline \multicolumn{3}{|c|}{ SEXo DEL ENCUESTADO } \\
\hline Femenino & Masculino & Total general \\
\hline 45 & 17 & 62 \\
\hline
\end{tabular}

FuENTE: Elaboración PROPIA.

Ninguno de los equipos o áreas encuestadas superaba los veinte colaboradores, lo que coincide con la conclusión de Molina y Torrado (2012) respecto a que las mujeres suelen liderar grupos entre una y veinte personas, generalmente de su mismo sexo, y en la medida en que los grupos aumentan de tamaño son liderados por hombres. Las seis empresas incluidas en este estudio pertenecen al sector servicios y en las áreas un 67,7\% de los encuestados tienen como jefe inmediato a una mujer, lo que coincide en parte con la idea planteada por García, García y Madrid (2012), respecto a que las empresas dirigidas por mujeres suelen tener las siguientes características: son de menor tamaño, del sector servicios, cuentan con tecnología menos desarrollada y principalmente son empresas familiares.

En el transcurso de la revisión de la literatura se encontraron reportes que indican que solo el $20 \%$ de los cargos directivos son ocupados por mujeres, y el $35 \%$ se encuentra en cargos profesionales y de gerencia media (El Espectador, 2018). El presente estudio halló datos mucho más altos, de modo que el $67,7 \%$ de los encuestados tienen como jefe inmediato una mujer, el restante $32,3 \%$ un hombre (véase el cuadro 2): 
CUAdro 2. CARACTERIZACión SUPERIORES INMEDiATOS

\begin{tabular}{|c|c|c|}
\hline \multicolumn{3}{|c|}{ SEXo DE SU JEFE INMEDIATO } \\
\hline Femenino & Masculino & Total general \\
\hline 42 & 20 & 62 \\
\hline
\end{tabular}

FuENTE: ELABORACIÓN PROPIA.

Los jefes inmediatos en el presente estudio corresponden a gerencia media dentro de las organizaciones, lo que refleja cifras mucho más altas de presencia de mujeres en cargos de gerencia media a las reportadas por el diario en mención. Así mismo, se confirma que las pymes, tal como lo aseguran Franco, Urbano y Toledano (2012), representan una gran oportunidad en cuanto a la reducción de la inequidad de género en el país, particularmente en los ámbitos de participación en los cargos directivos de las mismas y en la introducción de oportunidades equitativas para ambos géneros. Este hecho se constata con la eficacia organizacional: el $57 \%$ manifiesta sentirse orgulloso de trabajar allí, el $35,5 \%$ siente los problemas de la organización como propios y el $45 \%$ siente la organización como si fuese su casa (véase gráfico 1). Por lo tanto, la confianza percibida es alta cuando esta variable se combina con las percepciones de género al interior de las empresas estudiadas.

Gráfico I. SENTIDo DE PERTENENCIA POR PARTE DE LOS TRABAJADORES, APROPIACIÓN DE LOS PROBLEMAS DE LA ORGANIZACIÓN Y LA ORGANIZACIÓN COMO SU CASA

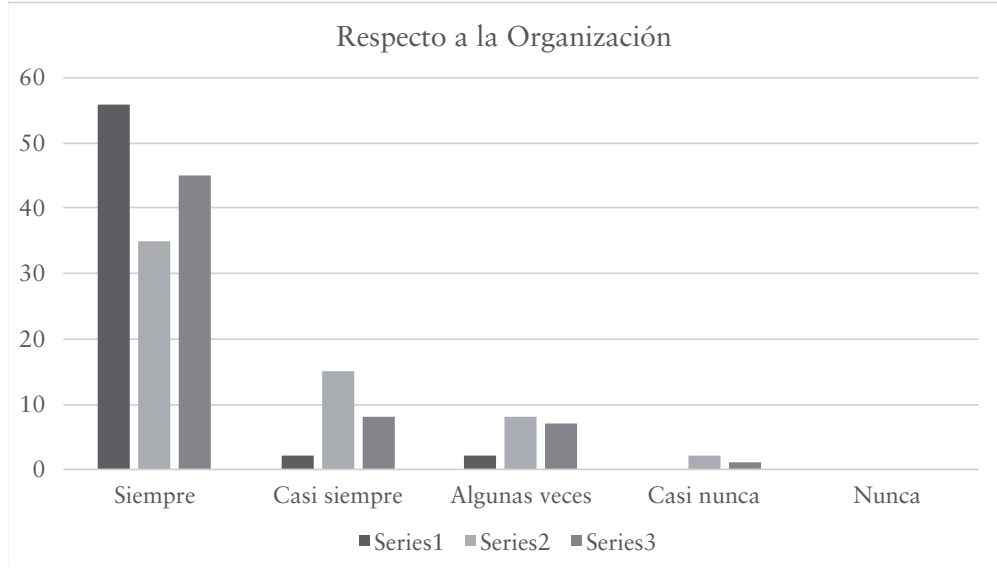


Serie 1. Sentido de pertenencia por parte de los trabajadores

Serie 2. Apropiación de los problemas de la organización

Serie 3. Siente la organización como si fuese su casa

Fuente: Elaboración PROPIA

Respecto a la evaluación de las habilidades de liderazgo de los jefes inmediatos, se observa una percepción muy favorable en casi todos los casos, con un promedio de aprobación del $65 \%$. Se identifican también algunas oportunidades de mejora respecto a las habilidades evaluadas, como lo son: recurrir a su autoridad y poder del cargo para impartir instrucciones, alinear las estrategias organizacionales con sus estrategias de gestión y dedicar espacios de tiempo para escuchar y relacionarse con el trabajador de forma personal, ya que demuestra interés en conocer sus necesidades como parte de su equipo. El porcentaje de aprobación de las habilidades de liderazgo constituye un aspecto positivo, considerando que el $72,6 \%$ de los encuestados fueron mujeres y el $27,4 \%$ hombres, identificando que las mujeres valoran positivamente las habilidades de sus líderes (véase gráfico 2). Lo anterior que coincide con las conclusiones de estudios tales como el de Ayman, Korabik y Morris (2009), quienes evaluaron el desempeño de los líderes por parte de sus subordinados, encontrando que fue significativamente menos positiva para las líderes femeninas con subordinados masculinos que para las líderes femeninas con subordinadas femeninas. Esto se asocia positivamente con la confianza, dado que las habilidades de liderazgo constituyen uno de los tres aspectos elementales en la generación de confianza, tal como lo plantean Guillén Parra, Lleó de Nalda y Marco Perles (2011) en el proceso de generación de confianza, entonces el depositante evaluará la confiabilidad del depositario en función de tres características: su habilidad, su benevolencia y su integridad.

Por otra parte, es indiscutible que el contexto organizacional de las pymes es altamente dinámico hoy en día. El hecho de concebir a las mujeres como actores que favorecen el desempeño de las personas trae consigo la posibilidad de considerar un panorama gerencial y empresarial alternativo que ofrece múltiples ventajas, tal como lo menciona Fletcher (2004); todas ellas directamente vinculadas con la generación de confianza. Hacerlo efectivamente es un reto que los directivos enfrentan diariamente, pero gestionarlo, desde la óptica diferencial de género, fortalece los comportamientos recíprocos y de intercambio que dan sustento a las relaciones interpersonales (Croson y Gneezy, 2009). 
A partir del análisis descriptivo del informe estadístico se destacan dos resultados fundamentales que sostienen la premisa anterior: el primero, que el 72,6\% de los encuestados fueron mujeres. Y el segundo, que el $67,7 \%$ de los encuestados tienen como jefe inmediato a una mujer.

En el contexto de esta investigación, se puede afirmar que según el estudio realizado por Edelberg (2010) y la sección de apoyo a las mujeres de la Organización de la Salud OMS (2015), se asegura que las empresas se benefician enormemente al aumentar las oportunidades en cargos de liderazgo para las mujeres, lo cual ha demostrado incrementar la eficacia organizacional. Lo que se comprobó en la presente investigación mediante la evaluación de las habilidades de liderazgo de los jefes inmediatos, cuyos resultados fueron favorables en todas las empresas estudiadas, con un promedio de aprobación del 65\%. En los casos referidos, las características propias del liderazgo efectivo están presentes, tales como delegación efectiva de tareas y asuntos, toma de decisiones, receptividad, respuestas de control convincentes, empatía, entre otros. Paralelamente, se discute que la percepción negativa de la confianza puede generar serios problemas en el clima organizacional y en la alta rotación del personal (Edelberg, 2010). Las percepciones de los colaboradores acerca de la confianza moldean el comportamiento, la productividad y la reciprocidad de las relaciones en los supervisores y la empresa en general. En palabras de García Cruz y Real Fernández (2013), tanto el apoyo y la autonomía percibidos por el trabajador conlleva a una motivación intrínseca que promueve tanto un mayor esfuerzo y compromiso en el logro de las metas organizacionales. En la presente investigación, la aplicación de la encuesta estableció las características de los jefes que facilitan el desarrollo de la percepción de la confianza en las relaciones de los colaboradores. Los resultados arrojaron que la percepción no varía ampliamente cuando el género es el principal determinante, cuando existe asociación de confianza relacionado con los beneficios de lograr metas organizacionales, así como con la percepción de asumir los problemas organizaciones como propios.

En contraste con las evidencias discutidas previamente, relacionadas con la influencia del género femenino en el desarrollo de relaciones de confianza y en la gestión de las pymes, es importante señalar que desde la perspectiva de la influencia del género masculino, en el análisis inferencial se encontró que el hecho de tener un jefe hombre aumenta la frecuencia con la que el colaborador percibe que su jefe le demuestra los beneficios de lograr metas organizacionales y que los colaboradores 
sienten los problemas de la organización/ área como suyas propias. Al respecto, Cortese (2005) señala que los hombres en su gestión directiva se caracterizan por ser más competitivos y orientados a triunfar, ya que representan destrezas de un gerente efectivo, lo cual supone el logro de metas organizacionales en algunos casos mediante el uso de su posición y autoridad organizacional (Koenig, Eagly, Mitchell y Ristikari, 2011; Lipman-Blumen, 1996; Rosener, 1990).

Adicionalmente, se ha evidenciado que los hombres trabajan de forma unipersonal más que con una perspectiva de equipo; su visión se enfoca en la estrategia organizacional y se han asociado con la capacidad de innovación y liderazgo (Jorna et al., 2016). Igualmente, Dirks (2000) indica que la confianza de los colaboradores en sus directivos incide en su desempeño, en cuanto estos asumen con mejor actitud tanto las actividades, metas, toma de decisiones y roles, generando un esfuerzo superior por lograrlos a través de su trabajo.

Por otra parte, el nivel educativo para el desarrollo de relaciones de confianza entre subalterno y superior inmediato presenta una relación significativa con respecto a comportamientos como: motivación para trabajar más arduamente para lograr metas alcanzables, generar confianza en cuanto es coherente con lo que dice y hace, capacidad de asumir sus errores y consecuencias cuando se equivoca, establecer una comunicación abierta, franca y respetuosa. Por lo anterior, puede afirmarse que el desarrollo de relaciones de confianza con sus directivos, en los comportamientos ciudadanos de los trabajadores a nivel individual y colectivo, incide en la capacidad de estos últimos para enfocarse en el trabajo (Mayer y Gavin, 2005).

Así mismo, hay que señalar que en cuanto el directivo como líder desarrolle ambientes de confianza, impulsa a un mayor compromiso en sus colaboradores. Por lo tanto, son fundamentales los comportamientos veraces e íntegros, sin los cuales no podrán exigir lealtad, lo que a su vez conlleva a que se desarrolle un trabajo. Con respecto a la organización se observa un sentido de pertenencia arraigado por parte de los trabajadores, ya que el 90,3\% manifiesta sentirse orgulloso de trabajar allí, el 58,6\% siente los problemas de la organización como propios y el $72,5 \%$ percibe a la organización como si fuese su casa.

Finalmente, es pertinente afirmar que la generación de relaciones de confianza de los directivos desde la perspectiva de comparación género en pymes del sector servicios de la ciudad de Bogotá D.C. ofrece diferentes beneficios, según se ha evidenciado y discutido en la presente 
investigación, lo cual permite dar respuesta a un entorno cambiante en términos de flexibilidad económica, aspectos demográficos, ambientes culturales diversos, entre otros, dando paso a un horizonte gerencial alternativo que ofrezca las ventajas de la labor directiva masculina así como femenina (Fletcher, 2004).

\section{Conclusiones}

La presente investigación ha comprobado empíricamente que la generación de relaciones de confianza desde la perspectiva de género en pymes sector servicios en la ciudad de Bogotá D.C. favorece el desarrollo organizacional y ofrece valor mediante un panorama gerencial diverso, que permite el ejercicio de las habilidades del relacionamiento y características propias tanto de los hombres como de las mujeres (Ayman, Korabik y Morris, 2009).

Por otra parte, pese a la predominancia que ha tenido el género masculino en los cargos directivos, así como el estereotipo que estos representan en cuanto a eficacia y éxito a nivel organizacional, es pertinente indicar que los resultados de la presente investigación muestran que las mujeres en el ejercicio directivo han desarrollado habilidades del liderazgo que les permiten trabajar de forma diferente con sus equipo debido a las prácticas que las caracterizan, las que fueron descritas previamente (Helgesen, 1990).

Igualmente, entre las características que particularizan la labor directiva de las mujeres, se puede afirmar que tienen predominancia en cargos directivos en empresas de menor tamaño, menos desarrolladas en cuanto a tecnología y de carácter familiar (García, García y Madrid, 2012). Además, la gestión directiva del género femenino se enfoca en grupos entre una y veinte personas de su mismo sexo, pero en cuanto aumenta el número de personas por grupo, las lideran hombres (Molina y Torrado, 2012).

Hay que agregar que las pymes del sector servicios representan una oportunidad, en cuanto disminuyen la inequidad de género e incrementan la eficacia organizacional (Franco, Urbano y Toledano, 2012). En el presente estudio, más de la mitad de los participantes reportaron tener como jefe inmediato una mujer, lo que promueve la eficacia en el ámbito laboral en cuanto desarrollan un mayor sentido de pertenencia, sienten los problemas de la organización como propios y consideran la organización como si fuese su casa en cuanto a compromiso se refiere. 
Para finalizar, se puede afirmar, según se encontró en la presente investigación concretamente, que el desarrollo de habilidades de liderazgo en directivos constituye un factor determinante en la construcción de las relaciones de confianza con respecto a los equipos de trabajo (Guillen et al., 2011). Pese a que a existe predominio del género masculino en los cargos directivos que representan las destrezas de un gerente efectivo. Sin embargo, los cambios organizacionales, demográficos, económicos y culturales generan situaciones que tienden a conformar un panorama gerencial más equitativo, diverso e incluyente que a su vez produce alternativas gerenciales con ventajas tanto para la directiva masculina como la femenina (Fletcher, 2004), según se ha discutido en la presente investigación.

\section{Bibliografía}

Alesina, A. y La Ferrara, E. (2002). Who trusts others? Journal of Public Economic 85, 207-234.

Argandoña, A. (2014). La ética en la empresa y la ética del directivo. IESE Business School, Universidad de Navarra, 1-11.

Arteaga, A. y Ramón, S. (2009). Liderazgo resonante según género. Multiciencias, 9(3).

Ayman, R.; Korabik, K. y Morris, S. (2009). Is transformational leadership always perceived as effective? Male subordinates' devaluation of female transformational leaders. Journal of Applied Social Psycho$\log y, 39(4), 852-879$.

Boyatzis, R. E. (2008). Leadership development from a complexity perspective. Consulting Psychology Journal: Practice and Research, 60(4), 298.

Buchan, N.; Johnson, E. y Croson, R. (2006). Let's get personal: an international examination of the influence of communication, culture, and social distance on other regarding preferences. Journal of Economic Behavior and Organization 60, 373-398.

Brashear, T. G.; Boles, J. S.; Bellenger, D. N. y Brooks, C. M. (2003). An empirical test of trust-building processes and outcomes in sales manager-salesperson relationships. Journal of the Academy of Marketing Science, 31(2), 189.

Carranza, J. P. y Peralta, P. I. (2012). Empleo y género: análisis de las preferencias de los empleadores como determinantes del acceso al empleo. El caso de la ciudad de Córdoba, Argentina. Nomadías, (16), 137-163.

Cegarra-Navarro, J. G.; Briones-Peñalver, A. J. y Ros-Sánchez, M. D. M. (2005). La confianza como elemento esencial para la mejora de la 
cooperación entre empresas: un estudio empírico en pymes. Cuadernos de Administración, 18(30).

Cortese, C. G. (2005). Learning through teaching. Management Learning, 36(1), 87-115.

Covey, S. y Merrill, R. (2007). El factor confianza. Barcelona: Paidós.

Croson, R. y Gneezy, U. (2009). Gender Differences in Preferences. Journal of Economic Literature, 47(2), 448-474.

Dargam, A. M. L. (2011). El rol de la confianza en las organizaciones a través de los distintos enfoques o pensamientos de la administración. Ciencia y sociedad, 36(3), 464-502.

Diario El Espectador (2018). Disponible en: https://www.elespectador.com/ economia/en-colombia-solo-el-20-de-las-mujeres-ocupan-cargosejecutivos-articulo-743281 (acceso: 2 de abril de 2018).

Dickson, M. W.; Smith, D. B.; Grojean, M. W. y Ehrhart, M. (2001). An organizational climate regarding ethics: The outcome of leader values and the practices that reflect them. The Leadership Quarterly, 12(2), 197-217.

Dasgupta, N. y Asgari, S. (2004). Seeing is believing: Exposure to counterstereotypic women leaders and its effect on the malleability of automatic gender stereotyping. Journal of Experimental Social Psychology, 40(5), 642-658.

Dirks, K. T. (2000). Trust in leadership and team performance: Evidence from NCAA basketball. Journal of applied psychology, 85(6), 1004.

Dickson, M. W.; Smith, D. B.; Grojean, M. W. y Ehrhart, M. (2001). An organizational climate regarding ethics: The outcome of leader values and the practices that reflect them. The Leadership Quarterly, 12(2), 197-217.

Eagly, A. H. (2013). Sex differences in social behavior: A social-role interpretation. Psychology Press.

Eagly, A. H.; Karau, S. J. y Makhijani, M. G. (1995). Gender and the effectiveness of leaders: a meta-analysis. Psychological bulletin, 117(1), 125.

Edelberg, G. (2010). Un buen jefe en las buenas y en las malas. Debates IESA, XV (1), 6-7.

Ergun, S.; García-Muñoz, T. y Rivas, M. F. (2011). Gender differences in economic experiments. Revista Internacional de Sociología, 70(1), 99-111.

Fletcher, J. K. (2004). The paradox of postheroic leadership: An essay on gender, power, and transformational change. The leadership quarterly, 15(5), 647-661.

Franco Ángel, M.; Urbano, D. y Toledano Garrido, N. (2012). Factores determinantes del dinamismo de las pymes en Colombia.

Gallegos, P. F.; Guzmán G. J.; Saavedra, C. C. y Silva, H. A. (2012). Participación de mujeres en cargos gerenciales: una investigación cualitativa de empresas financieras. Santiago: Universidad de Chile. 
García-Marzá, D. (2004). Ética empresarial del diálogo a la confianza. Madrid: Trotta.

García Cruz, J. y Real Fernández, J. C. (2013). Confianza como consecuencia del compromiso percibido: Implicaciones sobre el aprendizaje y la innovación. Cuadernos de Gestión, 13(1).

Glaeser, E.; Laibson, D.; Scheinkman, J. y Soutter, C. (2000). Measuring trust. Quarterly Journal of Economics, 115, 811-846.

Gilli, J. (2011). Ética y empresa. Valores y responsabilidad social en la gestión. Buenos Aires: Granica S.A.

Guillén Parra, M.; Lleó de Nalda, Á. y Marco Perles, G. S. (2011). Repensando la confianza como factor crítico en la gestión organizativa. Cuadernos de gestión, 11 .

Hardin, R. (1980). Social Science Information. En H. University, Social Sciencie Information (pp. 755-772). Baltimore: Hophins University.

Hardin, R. (1991). Trusting persons, trusting institutions. Strategy and choice, 185, 185-209.

Helgesen, S. (1990). The female advantage: Women's ways of leadership. Nueva York: Doubleday.

Hernández, G. Y. (2006). Acerca del género como categoría de análisis. Nómadas, Revista crítica de ciencias sociales y jurídicas, 13.

Hernández Barrera, D.; Armenteros Acosta, M. D. C.; Villanueva Armenteros, Y.; Montalvo Morales, J. A. y Del Río Ramírez, B. (2016). Competencias directivas en el sector industrial: Medición del desempeño en empresas de Coahuila, México (Management Competencies in the Industrial Sector: Performance Measurement Your Business Coahuila, Mexico).

Jorna Calixto, A. R.; Castañeda Abascal, I. y Véliz Martínez, P. L. (2016). Percepción de habilidades de liderazgo en hombres y mujeres para la dirección en salud en Cuba. Revista Cubana de Salud Pública, 42(1).

Johnson, J. y Schwabenland, C. (2013). Managing diverse identities at work. En A. M. R. y S. Perkins (Eds.), Organizational behaviour: People, process, work and human resource management (pp. 27-47). London: Kogan Page.

Koenig, A. M.; Eagly, A. H.; Mitchell, A. A. y Ristikari, T. (2011). Are leader stereotypes masculine? A meta-analysis of three research paradigms. Psychological Bulletin, 137, 616-642.

Kotter, J. (1999). Change leadership. Executive Excellence, 16(4), 16-17.

Kotter, J. P. (2005). Lo que de verdad hacen los líderes. Harvard Business Review, 83(11), 132-140.

Lambert, T. (1994). El liderazgo en un mundo empresarial rápidamente cambiante. Instrumentos claves para la gestión empresarial.

Lipman-Blumen, J. (1996). The connective edge: Leading in an interdependent world. San Francisco: Jossey-Bass. 
Luhmann, N. (1988). Familiarity, Confidence, Trust: Problems and Alternatives. En D. Gambetta (Comp.), Trust: Making and Breaking Cooperative Relations. Oxford: Basil Blackwell.

Loden, M. (1985). Femenin leadership or how to succeed in business without being one of the boys. Nueva York: Times-Books.

Mayer, R. C. y Gavin, M. B. (2005). Trust in management and performance: Who minds the shop while the employees watch the boss? Academy of management journal, 48(5), 874-888.

Molina, M. J. C. y Torrado, M. N. (2012). La mujer directiva en la gran empresa española: perfil, competencias y estilos de dirección. Estudios gerenciales, 28(124), 87-105.

Nedkovski, V.; Guerci, M.; De Battisti, F. y Siletti, E. (2017). Organizational ethical climates and employee's trust in colleagues, the supervisor, and the organization. Journal of Business Research, 71, 19-26.

Paustian-Underdahl, S. C.; Walker, L. S. y Woehr, D. J. (2014). Gender and perceptions of leadership effectiveness: A meta-analysis of contextual moderators. Journal of applied psychology, 99(6), 1129.

Organización Mundial de la Salud (2015). El «sexo» versus el «Género». Disponible en: http://www.who.int/mediacentre/factsheets/fs403/es/ (acceso: 23 de febrero de 2017).

Periódico El Portafolio (2015). Disponible en: http://www.portafolio.co/ internacional/cargos-mujeres-mandando-colombia-28412 (acceso: 5 de abril de 2017).

Revista Dinero (2015). Disponible en: https://www.dinero.com/empresas/ articulo/participacion-mujeres-altos-cargos-directos-colombiaamerica-latina/215142 (acceso: 12 de enero de 2017).

Riedl, R.; Hubert, M. y Kenning, P. (2010). Are there neural gender differences in online trust? An fMRI study on the perceived trustworthiness of eBay offers. Mis Quarterly, 34(2), 397-428.

Rincón, V.; González, M. y Barrero, K. (2017). Women and leadership: Gender barriers to senior management positions. Intangible Capital, 13(2), 319-386. Doi:10.3926/ic889

Rosener, J. B. (1990). Ways Woman lead. Harvard Business Review 68, 119-125.

Rousseau, D. M.; Sitkin, S. B.; Burt, R. S. y Camerer, C. (1998). Not So Different After All: A Cross-Discipline View of Trust. Academy of Management Review, 23(3), 393-404. doi:10.5465/amr.1998.926617

Sabel, C. F. (1993). Studied Trust: Building New Forms of Cooperation in a Volatile Economy. Human Relations, 46, 1133-1170.

Snijders, C. y Keren, G. (1999). Determinants of trust. En D. Budescu, I. Erev y R. Zwick (Eds.), Games and Human Behavior (pp. 355-386). Mahwah: Lawrence Erlbaum Associates. 
Dasgupta, P. (1988). Trust as a Commodity. En D. Gambetta, Trust: Making and Breaking Cooperative Relations. Oxford: Basil Blackwell. Soriano Llobera, J. M. y Cebrian Díaz, J. A. (2014). La formación del directivo: evolución del entorno económico y la comunicación empresarial.

Terrell, F. y Barrett, R. K. (1979). Interpersonal trust among college students as a function of race, sex, and socioeconomic class. Perceptual and Motor Skills.

Whitener, E. M. (2001). Do «high commitment» human resource practices affect employee commitment?: A cross-level analysis using hierarchical linear modeling. Journal of management, 27(5), 515-535.

Yukl, G. (1989). Managerial leadership: A review of theory and research. Journal of management, 15(2), 251-289.

Zaleznik, A. (2004). Managers and leaders: are they different? Clinical leadership \& management review: the journal of CLMA, 18(3), 171-177. 



\section{Sección III: \\ Responsabilidad Social de las cooperativas}





\title{
INFORME SOBRE EL ACCIONAR SOCIALMENTE RESPONSABLE DE UNA COOPERATIVA argentina. Caso CEB
}

\author{
Oscar Alcides Zapata" \\ Argentina
}

\section{INTRODUCCIÓN}

El tema Responsabilidad Social (RS) ha tenido una mayor consideración en los últimos años en la República Argentina, sin embargo, el conocimiento teórico es mayor que el conocimiento sobre las acciones destinadas a tratar cuestiones incluidas en la filosofía de la RS, razón por la cual resulta importante que se estudien casos como el aquí propuesto. La filosofía de la RS aspira a que las organizaciones impacten positivamente en la sociedad y en el medioambiente, resultando útil estudiar un caso indicando las acciones destinadas a generar dichos impactos (Gorrochategui, 2012).

La RS adquiere una mayor relevancia al considerar ciertas cuestiones referidas a desigualdades indignantes de todo tipo, entre otras: la discriminación de la mujer, el problema de la inserción laboral de los jóvenes y la pobreza extrema que provoca, entre otras cuestiones, la falta de oportunidad educativa y la dificultad de enfrentar problemas del medioambiente. Entonces, resulta necesaria la realización de acciones para revertir estas situaciones (Kliksberg, 2012). Asimismo, la suma de esfuerzos de las organizaciones socialmente responsable (OSR) teniendo en cuenta a los grupos de interés podría beneficiar a la comunidad (López Regalado et al., 2015). Por estas razones se considera interesante estudiar las acciones que realiza una OSR como aquí se propone.

Maestrando en Administración Pública FCE UBA (tesis en curso). Correo electrónico: oscar.zapata@posgrado.economicas.uba.ar 
En Argentina, debido a la ausencia de normativa que obligue a su realización, se considera que las acciones de RS son impulsadas por las OSR (Volpentesta, 2015).

La norma ISO 26000/2010 define a las OSR que se tienen en cuenta en el presente trabajo e indica que la RS es aplicable a cualquier tipo de organización, resultando entonces de aplicación a las cooperativas. Por sus valores éticos, que incluyen a la responsabilidad social (ACI, 1995), las cooperativas a priori son OSR, pero el accionar de una cooperativa determinada podría variar por la incidencia de los valores más o menos altruistas de sus integrantes (Caletti, 1986), aumentando el interés de su estudio como el aquí propuesto.

Se presenta un estudio de caso de la Cooperativa de Electricidad Bariloche Limitada (CEB), con el propósito de dar evidencia de la aplicación de la RS y su vinculación con los objetivos del desarrollo sostenible (ODS).

La metodología propuesta es exploratoria. Se relevan los datos aportados por la CEB, referidos a sus acciones socialmente responsables (programas/proyecto/actividad) en su primera Comunicación del Progreso (CoP), presentada por la misma ante el Pacto Global de Naciones Unidas (PG) en marzo de 2015 por el ejercicio 2014 —de acceso libre en internet-. Se analiza la información clasificada en cuatro áreas del Pacto Global (aspectos laborales, medioambiente, derechos humanos y ética) y luego se la vincula a los objetivos del desarrollo sostenible (ODS).

Previamente se expone un panorama sobre la adhesión a la iniciativa del PG en la República de Argentina, luego se expresan ciertos aspectos conceptuales sobre las entidades estudiadas, "cooperativas socialmente responsables» (CSR), y finalmente se brinda evidencia de la aplicación de la filosofía de la RS por parte de la organización estudiada (CEB).

\section{Panorama de ADHesión a la iniciativa Del PG en Argentina}

Con respecto a las adhesiones a la iniciativa del PG, se destaca que Argentina ocupa el octavo puesto mundial y el cuarto en América Latina, según las bases de datos del mismo Pacto Global. Los datos que se exponen en dicha base son los provistos por las organizaciones adherentes a la iniciativa. No obstante se sabe que existen críticas al Pacto Global de Naciones Unidas, las mismas están fuera del objetivo del presente trabajo y podrían ser la génesis de nuevos estudios. 
En el gráfico 1 se muestra la participación en la iniciativa del PG por parte de las organizaciones socialmente responsables (OSR) radicadas en la República de Argentina, donde se expone al sector público y al sector privado argentino. Se destaca que el ítem "Administración pública» se detalla excluyendo el tipo Academia, debido a que tiene su propio ítem. Se aclara que la cantidad de adhesiones en la República de Argentina correspondiente al sector privado es superior a la cantidad de organismos de la administración pública que adhieren a la iniciativa del PG. Se presenta el tema, pero el análisis de las adhesiones requiere de otro estudio que excede los objetivos del presente trabajo.

\section{Gráfico i. Adhesiones al PG en Argentina POR TIPO DE ORGANIZACIÓN}

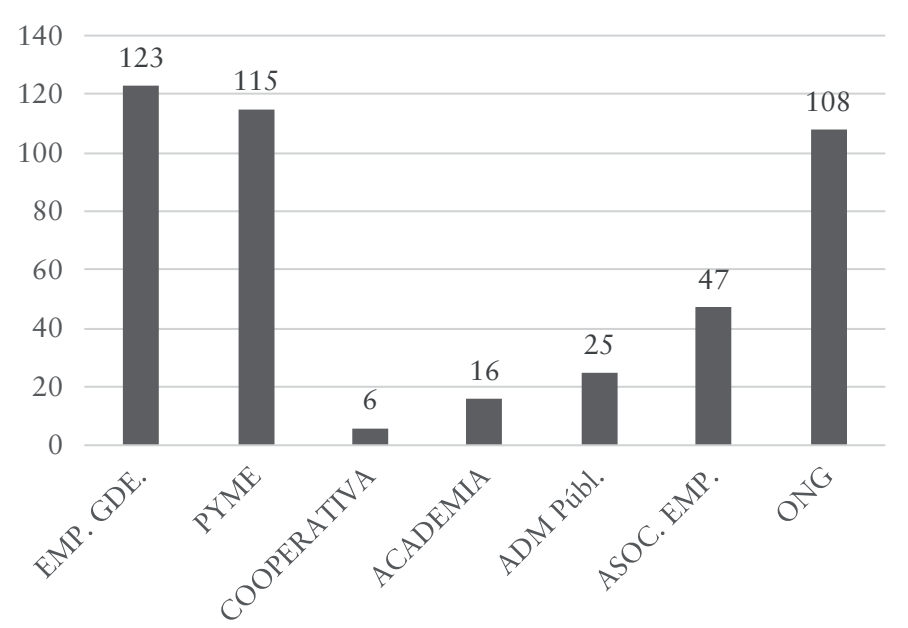

ELABORACIÓN PROPIA SEGÚN CONSULTA VÍA INTERNET EN BASE A DATOS DEL PG AL 30/04/I 8

Se destaca que la norma ISO 26000/2010 expresa que la RS es aplicable a cualquier tipo de organización. En el gráfico mencionado se observa que diferentes organizaciones adhieren a la iniciativa del PG y el mismo expresa ciertos lineamientos sobre responsabilidad social. Entonces, lo expresado en dicha norma ISO se cumple en Argentina porque en principio se aplica a distintos tipos de organizaciones, como puede verse que surge de dicho gráfico. 


\section{Panorama de las cooperativas argentinas ante el PG}

Surge del análisis del gráfico 1, que muestra la participación de los distintos tipos de OSR en la iniciativa del PG, la baja proporción de adhesiones del tipo de sociedades elegidas para su estudio: las cooperativas. Ahora bien, el interés en su estudio radica en sus características y valores éticos que incluyen a la responsabilidad social, y que a priori son entidades socialmente responsables (ACI, 1995).

Se detalla en el cuadro 1 con respecto a las cooperativas que adhieren a la iniciativa del PG y que están radicadas en la República de Argentina: la denominación de cada cooperativa argentina según la base de datos del PG al 30/04/18; tipo según PG; organización cooperativa o federación; actividad principal o sector donde opera y fecha de adhesión a la iniciativa.

Cuadro i. Cooperativas argentinas adHeridas

al Pacto Global ONU al 30/04/20I 8

\begin{tabular}{|c|c|c|c|c|}
\hline DENOMINACIÓN & Tipo & ORGANIZACIÓN & $\begin{array}{l}\text { ACTIVIDAD } \\
\text { PRINCIPAL }\end{array}$ & $\begin{array}{l}\text { FECHA } \\
\text { ADHES. }\end{array}$ \\
\hline $\begin{array}{l}\text { Cooperativa Eléctrica } \\
\text { Colon Bs. As. }\end{array}$ & $\begin{array}{l}\text { Asociación } \\
\text { comercial } \\
\text { local }\end{array}$ & Cooperativa & $\begin{array}{l}\text { Electricidad } \\
\text { - Servicios } \\
\text { Públicos }\end{array}$ & 14-10-2004 \\
\hline $\begin{array}{l}\text { Rio Uruguay } \\
\text { Cooperativa } \\
\text { de Seguros Ltda. }\end{array}$ & Compañía & Cooperativa & Seguros & $14-10-2004$ \\
\hline $\begin{array}{l}\text { La Agricola Regional } \\
\text { Cooperativa Limitada } \\
\text { Agropecuaria de } \\
\text { Consumo Y Servicios } \\
\text { Públicos }\end{array}$ & Compañía & Cooperativa & $\begin{array}{l}\text { Agropecuaria } \\
\text { y Servicios } \\
\text { Públicos }\end{array}$ & $15-08-2005$ \\
\hline $\begin{array}{l}\text { SanCor Cooperativas } \\
\text { Unidas Limitada }\end{array}$ & Compañía & Federación & Alimentos & $14-05-2010$ \\
\hline $\begin{array}{l}\text { Cooperativa de Obras } \\
\text { y Servicios Públicos de } \\
\text { Macachin Limitada }\end{array}$ & PYME & Cooperativa & $\begin{array}{l}\text { Electricidad } \\
\text { - Servicios } \\
\text { Públicos }\end{array}$ & 08-03-2013 \\
\hline $\begin{array}{l}\text { Cooperativa de } \\
\text { Electricidad Bariloche } \\
\text { Limitada }\end{array}$ & PYME & Cooperativa & $\begin{array}{l}\text { Electricidad } \\
\text { - Servicios } \\
\text { Públicos }\end{array}$ & $18-12-2013$ \\
\hline
\end{tabular}

Fuente: Elaboración propia, Sobre la base de datos del Pacto Global ONU al 30/4/I 8 
Se puede observar en dicho cuadro que seis sociedades cooperativas al 30 de abril de 2018 adhieren a la iniciativa del PG y que la mayoría de las cooperativas mencionadas tienen como actividad principal la prestación de servicios públicos, como es el caso de la organización objeto de estudio (CEB). Asimismo, la CEB, en las CoP's que presenta ante el PG, informa sobre su accionar socialmente responsable en forma clara para su análisis y dado que, según lo expone la CEB, realiza una de las actividades principales que efectúan la mayoría de las cooperativas adheridas al PG (servicios públicos). En consecuencia, se considera que el caso CEB resulta interesante para su estudio.

\section{Áreas del Pacto Global de Naciones Unidas}

Se destaca que la adhesión a la iniciativa del Pacto Global de Naciones Unidas es voluntaria y se da un marco de responsabilidad social, con sus diez principios que se basan en Declaraciones Universales aplicadas en cuatro áreas: a) derechos humanos; b) estándares laborales; c) medioambiente; d) ética/anticorrupción. Dichos principios, si bien no son de cumplimiento obligatorio, cuentan con cierto grado de consenso (United National Global Compact, 2015).

Con respecto a los derechos humanos, se considera pertinente considerar la Declaración Universal de Derechos Humanos dictada en París el 10 de diciembre de 1948, destacándose los siguientes preceptos: a) libertad e igualdad en dignidad y derechos; b) derecho a igual protección de la ley; c) derecho a un nivel de vida adecuado: salud, bienestar, vivienda, alimento, vestido y servicios sociales para subsistencia, etc. Protección de embarazo y de los niños; d) derecho a educación gratuita a nivel elemental fundamental. Nivel técnico y superior generalizado. Libertad de elección por parte de los padres; e) libertad de gozar de las artes y del progreso científico.

\section{Cooperativas}

Se considera que la esencia de las cooperativas es el servicio al costo desprovisto del fin de lucro. Son entidades fundadas en el esfuerzo propio y la ayuda mutua, además, no tienen límites al máximo de asociados, la adhesión es voluntaria, la responsabilidad es limitada, el voto es 
uno por asociado, aunque tenga varias cuotas sociales, y promueven el principio de integración cooperativa (Nilssen, 2010).

Es útil realizar una comparación para dar una mejor visión conceptual. Se destaca que la intención de permanencia en el mercado o en actividad en el tiempo es punto común en todo tipo de entidad. Ahora bien, si se comparan los fines de las entidades en estudio (cooperativas) con otros dos tipos de entidades (sociedades comerciales y asociaciones sin fines de lucro), surgen similitudes y diferencias. El fin interesado y patrimonial es el punto similar que las sociedades cooperativas tienen con las sociedades comerciales, pero las cooperativas no tienen fin lucrativo, en cambio las sociedades comerciales sí. La ausencia de lucro es el punto en común de las cooperativas con las asociaciones que no lo tienen, pero se diferencian en que las cooperativas sí tienen fin interesado y patrimonial, en cambio, las asociaciones no (Richard Efrain, 2007).

La entidad internacional más importante en el ámbito cooperativo, por la cantidad de cooperativas que la integran, es la Alianza Cooperativa Internacional (ACI), la que, en su Declaración sobre Identidad y Principios Cooperativos adoptados en Manchester en 1995, define que: «Una cooperativa es una asociación autónoma de personas que se han unido voluntariamente para hacer frente a sus necesidades y aspiraciones económicas, sociales y culturales comunes por medio de una empresa de propiedad conjunta y democráticamente controlada». Se destaca que los fundadores de las cooperativas creen en los valores éticos de honestidad, transparencia, responsabilidad social y preocupación por los demás (ACI, 1995).

\section{DEFINICIÓN DE COOPERATIVA SOCIALMENTE RESPONSABLE}

La norma ISO 26000/2010 expresa una definición de organizaciones socialmente responsables que tomamos junto a los principios del Pacto Global y así se obtiene la siguiente definición para este trabajo: cooperativa socialmente responsable (CSR) es la cooperativa que tiene en cuenta los impactos que generan cuando toman decisiones y realizan sus actividades que ocasionan en la comunidad en las cuatro áreas definidas por el Pacto Global de Naciones Unidas: derechos humanos; aspectos laborales; medioambiente y corrupción, priorizando: a) el cumplimiento de la legislación aplicable; b) el comportamiento ético; c) el desarrollo sostenible; d) las expectativas de los interesados; y e) llevan a la práctica la responsabilidad social en sus relaciones. 


\section{Objetivos de Desarrollo Sostenible (ODS). Programa de las Naciones Unidas para el Desarrollo}

Actualmente, dada la situación social y ambiental del planeta, se considera importante la producción de ciertos documentos destacados del año 2015, como lo son la aprobación por parte de Naciones Unidas de los diecisiete Objetivos del Desarrollo Sostenible (ODS) y la encíclica papal Laudato Si (Kliksberg, 2017).

Según el Programa de las Naciones Unidas para el Desarrollo (PNUD), los ODS son un llamado universal a la adopción de medidas para poner fin a la pobreza, proteger el planeta y garantizar que todas las personas gocen de paz y prosperidad.

Los diecisiete ${ }^{2}$ objetivos están interrelacionados porque las cuestiones de uno suelen estar vinculadas con las cuestiones de otro. Los ODS conllevan un espíritu de colaboración destinada a mejorar la vida de manera sostenible para las generaciones futuras. Proporcionan orientaciones y metas a adoptar por distintos países, según sus propias prioridades y los desafíos ambientales del mundo en general. Los ODS son una agenda inclusiva. Abordan las causas fundamentales de la pobreza y nos unen para lograr un cambio positivo en beneficio de las personas y el planeta.

El presidente del PNUD explicó que el corazón de la Agenda 2030 es erradicar la pobreza y el compromiso de no dejar a nadie atrás, y que se ofrece una oportunidad única para poner al mundo camino a un desarrollo sostenible, asegurando que refleja la razón por la cual se creó el PNUD.

\section{Planteamiento de la cuestión}

Las siguientes preguntas surgen en el caso analizado: ¿las acciones de RS que realiza la cooperativa analizada, CEB, contempla todos los Principios del Pacto Global de Naciones Unidas? ¿Existe una correlación con

2 Los ODS son: 1. Fin de la pobreza. 2. Hambre cero. 3. Salud y bienestar. 4. Educación de calidad. 5. Igualdad de género. 6. Agua limpia y saneamiento. 7. Energía asequible y no contaminante. 8. Trabajo decente y crecimiento económico. 9 . Industria, innovación e infraestructura. 10. Reducción de las desigualdades. 11. Ciudades y comunidades sostenibles. 12. Producción y consumo responsables. 13. Acción por el clima. 14. Vida submarina. 15. Vida de ecosistemas terrestres. 16. Paz, justicia e instituciones sólidas. 17. Alianzas para lograr objetivos. 
los ODS? ¿En este caso, sería viable producir una información que genere una visión útil para los interesados en las cuestiones de RS y los ODS?

Se estima que si existieran suficientes acciones por parte de todas las organizaciones de una comunidad con destino a solucionar determinadas cuestiones que trata la filosofía de la RS, podría mejorarse la situación actual de la sociedad y el medioambiente. Entonces se enfoca el estudio sobre las acciones destinadas a paliar o a resolver cuestiones de RS, tomando un caso puntual según la información de las CoP’s del Pacto Global de Naciones Unidas, en función de las áreas que el mismo establece, dando una visión que puede resultar útil a los interesados (Gorrochategui, 2012).

En Argentina, debido a la ausencia de normativa que obligue a su realización, se considera que las acciones de RS son impulsadas por las OSR (Volpentesta, 2015), el estudio de las acciones de RS que realiza la entidad estudiada resulta interesante para conocer cuáles son las actividades/proyectos/programas y considerar ciertas cuestiones relevantes (Klisberg, 2017) que se incluyen en los ODS, cuyo esfuerzo sumado al de otros OSR podría beneficiar a la comunidad (López Regalado et al., 2015). Por ello, se considera interesante estudiar las acciones que realiza una organización socialmente responsable (OSR), como aquí se propone.

En cuanto al territorio que puede influir el accionar socialmente responsable de la CSR analizada, se localiza en San Carlos de Bariloche y zonas aledañas, que desde el punto de vista de la responsabilidad social territorial, es el lugar donde puede impactar la entidad en cuestión y dar su esfuerzo coordinado por los sectores públicos o privados del territorio (Valdés Serrano et al., 2017). Vertido lo expuesto, cabe aclarar que está fuera del alcance de este estudio la coordinación con otras OSR de la zona de influencia de la CEB para determinar si la región es socialmente responsable, no obstante, conocer el aporte de una cooperativa de envergadura resulta importante en este caso.

En el presente estudio se pone atención a los datos disponibles del caso analizado: caso CEB, esta cooperativa presenta información en función de los lineamientos del PG, según consta en su CoP incluida en la base de datos del mismo pacto. Se analizan las acciones de RS que realiza la CEB (actividades/proyectos/programas), con el fin de atender problemas incluidos en la filosofía de la RS según los lineamientos del Pacto Global y su incidencia en determinados ODS. 


\section{Estudio DEL CASO CEB}

El presente caso CEB se encuentra en estudio (Zapata, 2017), se agrega a los análisis anteriores la bibliografía estudiada recientemente y constituye un aporte al conocimiento de la incidencia de las acciones de RS realizadas por una OSR en ciertos Objetivos del Desarrollo Sostenible (ODS).

Surge de dicho estudio que la CEB considera los siete principios cooperativos $^{3}$ en sus estatutos constitutivos. Se destaca que los estatutos muestran que se ha dado mayor prioridad a tres principios cooperati$\operatorname{vos}\left(2^{\circ}, 3^{\circ}\right.$ y $\left.4^{\circ}\right)$, una mediana consideración estatutaria a dos principios $\left(5^{\circ}\right.$ y $\left.6^{\circ}\right)$ y una menor consideración a los dos restantes $\left(1^{\circ}\right.$ y $\left.7^{\circ}\right)$. Dado que las cooperativas por definición son organizaciones socialmente responsables, la consideración de los principios cooperativos por parte de la CEB es un buen punto de partida para tenerla en cuenta como tal, en este trabajo cooperativa socialmente responsable (CSR).

Luego se realiza el estudio del accionar socialmente responsable de la CEB, conforme con los datos relevados de su primera CoP, presentada por la misma ante el Pacto Global de Naciones Unidas (PG) en marzo de 2015 por el ejercicio cerrado en junio/2014.

Se exponen a continuación las acciones (programa/proyecto/ actividad) realizadas por la CEB de acuerdo con los principios y las áreas del PG. Asimismo, para su análisis también se tiene en cuenta la Declaración de Derechos Humanos antes mencionada.

Luego, siguiendo la clasificación realizada según lineamientos del PG, se propone asignar el/los número/s de ODS incidido/s para cada acción socialmente responsable realizada por la CEB durante el periodo analizado, que es el ejercicio cerrado al 30 de junio de 2014, y luego haciendo referencia al ejercicio siguiente de corresponder.

\section{Área Derechos Humanos: PRINCIPIOS I Y 2}

Dentro de esta área se clasifica el accionar socialmente responsable de la CEB en función de los lineamientos del PG y la Declaración de Derechos Humanos mencionada, por tipo (capacitación; colaboración con

\footnotetext{
Los Principios Cooperativos son: I Membresía abierta y voluntaria; II Control Democrático de los Miembros; III Participación Económica de los Miembros; IV Autonomía e Independencia; V Educación, Formación e Información; VI Cooperación entre Cooperativas y VII Compromiso con la Comunidad.
} 
instituciones; comunidad con bajos recursos; contribución al personal y clima laboral; salud) y luego se lo vincula a los ODS, según se detalla.

Capacitación. Incidencia en los ODS 3, 4, 8 y 10, según el siguiente detalle:

- Proyecto Talleres Barriales y Capacitación en Cooperativismo. ODS incididos: 4 y 10.

- Programas nacionales INAES-Ingreso social con trabajo. ODS incididos: 4 y 8.

- Capacitaciones al personal. ODS incididos: 4 y 8.

- Capacitación en salud. ODS incididos: 3 y 4.

Colaboración con instituciones. Incidencia en los ODS 11 y 16, según se detalla:

- Colaboración con instituciones: ODS incididos: 11 y 16.

- Proyecto Bandera. ODS incididos: 11 y 16.

- Día de la Tradición. ODS incididos: 11 y 16.

Comunidad con bajos recursos. Incidencia en los ODS 7 y 10.

- Pilares comunitarios. ODS incididos: 7 y 10.

Contribución al personal y clima laboral. Incidencia en los ODS 10 y 16:

- Programa «Yo conozco a la CEB». ODS incidido: 16.

- Préstamos personales y anticipos de sueldos. ODS incidido: 10.

- Viviendas en Barrio Puerto Moreno. ODS incidido: 10.

Salud. Incidencia en ODS 3.

- Servicio de salud: jardín de infantes. ODS incidido: 3 .

- Servicio de salud-oftalmológico y audiométrico ODS incidido: 3

- Servicio de salud-inversión. ODS incidido: 3.

Se concluye que las acciones de RS de la CEB referida al área derechos humanos, en el caso estudiado, inciden en el cumplimiento en los ODS: 3, 4, 8, 10, 11 y 16. 


\section{Aspectos LABORALES: PRINCIPIOS 3 A 6}

Dentro de esta área se clasifica el accionar socialmente responsable de la CEB en función de los lineamientos del PG por tipo (sindical anticoacción; trabajo infantil; antidiscriminación; incentivo al personal) y luego se lo vincula a los ODS, según se detalla.

Sindical. Incidencia en los ODS 11 y 16, según el siguiente detalle:

- Libre actividad de la representación gremial. ODS incididos: 11 y 16.

- Realizar reuniones con distintos sindicatos vinculados a la CEB. ODS incididos: 11 y 16.

- Realizar negociaciones salariales. ODS incididos: 11 y 16.

- Tratar temas en comisiones laborales. ODS incididos: 11 y 16.

Anticoacción. Incidencia en ODS 16:

- Eliminar todo tipo de coacción en la CEB. ODS incidido: 16.

Trabajo infantil. Incidencia en los ODS 10, 11 y 16:

- Se establece no contratar menores en la CEB. ODS incididos: 10,11 y 16 .

Antidiscriminación. Incidencia en los ODS 10 y 16:

- Se establece no discriminar dentro del ámbito de la CEB. ODS incididos: 10 y 16.

Incentivo al personal. Incidencia en los ODS 9, 10 y 12:

- Programa ILUMINAR, referido a participación del personal en concurso de propuestas para implementar en la CEB. ODS incididos: 9, 10 y 12 .

Se concluye que las acciones de RS de la CEB referida al área Aspectos Laborales, en el caso estudiado, inciden en el cumplimiento en los ODS: 9, 10, 11, 12 у 16. 
Medioambiente: principios 7 a 9

Dentro de esta área se clasifica el accionar socialmente responsable de la CEB en función de los lineamientos del PG en Medioambienteenfoque y Medioambiente-promoción. Luego se lo vincula a los ODS, según se detalla.

Medioambiente-enfoque. Incidencia en los ODS 6 y 11, según se detalla:

- Realizar servicio de saneamiento CEB. ODS incididos: 6 y 11.

- Tratar los desagües cloacales. ODS incididos: 6 y 11.

Medioambiente-promoción. Incidencia en los ODS 6 y 11, según se detalla:

- Instalar planta depuradora compacta (10.000 habitantes) para mejorar el proceso. ODS incididos: 6 y 11.

- Implementar Sistema de Gestión de Calidad (SGC) según la norma ISO 9001:2008. ODS incididos: 6, 11 y 12.

- Proyecto Briquetas. ODS incididos: 11, 12 y 15.

Se concluye que las acciones de RS de la CEB referida al área Medioambiente, en el caso estudiado, inciden en el cumplimiento de los ODS: 6, 11, 12 y 15 .

\section{ANTICORRUPCIÓN O ÉTICA: PRINCIPIO IO}

Esta área/principio del PG, si bien no fue considerada en la CoP analizada por el ejercicio 2014, cabe destacar que luego de comparar con el ejercicio siguiente (2015), surge que la CEB ya incorpora la consideración del principio 10 que faltaba exponer en 2014. Por ello, se estima que la CEB brinda un mejor cumplimiento de la exposición de su accionar socialmente responsable, atendiendo todas las áreas que agrupan los 10 principios del PG.

En cuanto al ODS incidido, principalmente se considera el 16, destacándose la eliminación de todo tipo de corrupción y soborno como asimismo la transparencia en todos los niveles de la entidad analizada. 


\section{Resultados DE LA EVAluación}

Con respecto al grado de consideración de los Principios del Pacto Global por parte de la CEB por el ejercicio 2014, en general, se considera que esta CSR tiene en cuenta tres de las cuatro áreas correspondientes a los principios del PG. Para el ejercicio analizado era deseable que se agregara la información correspondiente al principio 10, que constituye la cuarta área del PG (ética o anticorrupción). No obstante, la misma no se esboza en la CoP 2014 y luego se corrige en el ejercicio siguiente (2015).

En cuanto a la relación del accionar de la CEB respecto de los objetivos del desarrollo sostenible (ODS), aunque al momento de la emisión de su CoP todavía los ODS no estaban establecidos, se puede notar que los distintos programas/proyectos/acciones tienen incidencia positiva (sea buscado o no) en determinados ODS: 3, 4, 6, 8, 9, 10, 11, 12,15 y 16 . Ello muestra que puede vincularse a las acciones socialmente responsables de la cooperativa analizada con la incidencia en los ODS por parte de la CEB.

\section{INFORME}

En función de la información provista al PG por parte de la organización socialmente responsable en estudio (CEB) y del análisis realizado, se estima que la sociedad cooperativa estudiada en este trabajo expone razonablemente las bases en sus estatutos constitutivos, incluyendo los preceptos éticos de las cooperativas, dado que considera en mayor o menor medida los principios cooperativos en sus estatutos, lo cual permite considerar que ha sido constituida como organización socialmente responsable en los términos de la normativa ISO 26000/2010.

Del análisis de su accionar expuesto en sus CoP’s cuya verificación no es objetivo del presente trabajo, surge que la CEB lleva adelante programas/proyecto/acciones dentro de la filosofía de la RS. Si bien en su primera CoP la CEB omite la información del cumplimiento del punto 10 (ética o anticorrupción), según su informe había cumplido con nueve de los diez principios del PG. Asimismo, en el ejercicio siguiente (2015), la CEB informa en su CoP que cumple con el principio omitido anteriormente, dando una mejor información sobre el cumplimiento de los principios del PG.

En cuanto al accionar de la CEB con respecto a los ODS, se observa en principio la incidencia sobre diez de los diecisiete Objetivos 
del Desarrollo Sostenible y en concordancia con lo mencionado por la PNUD, debido a la interrelación de los ODS, podría darse la incidencia sobre otros ODS. Si bien se requieren más datos para su análisis, puede mencionarse que la Capacitación en Salud, que informa la CEB en su CoP 2014, se relaciona con el tercero de los ODS: Salud y bienestar, que abarca la meta de aumentar la capacitación en salud, y también con el cuarto ODS: Educación de calidad, que abarca la meta de aumentar las posibilidades de educación en programas técnicos. También el programa de la CEB denominado Comunidad con bajos recursos, que se refiere a las facilidades dadas a quienes lo necesitan para la instalación de Pilares de energía eléctrica, por un lado se incide sobre el séptimo ODS, Energía asequible y no contaminante, que abarca la meta de garantizar el acceso universal a servicios de energía, y asimismo se impacta en el décimo ODS, Reducción de las desigualdades, que abarca la meta de potenciar y aumentar la inclusión social.

\section{Conclusiones}

El caso elegido, Cooperativa de Electricidad Bariloche (CEB), es una sociedad cooperativa de servicios que presenta información y adhiere a la iniciativa del Pacto Global de Naciones Unidas (PG), que posee una base de datos de libre acceso en internet de casi trece mil organizaciones de distinto tipo organizacional (empresas grandes, cámaras empresarias, pymes, administración pública, academias, ONG, cooperativas). Se aprecia en el presente trabajo que la filosofía de la Responsabilidad Social (RS) se aplica a distintos tipos de organizaciones, lo cual concuerda con lo expresado por la Norma ISO 26000/2010, que define a las organizaciones socialmente responsables (OSR), e indica que la RS es aplicable a cualquier tipo de organización. Se destaca que el estudio de casos contribuye al conocimiento del accionar de las OSR dentro de la filosofía de la RS, aspirando a que las organizaciones impacten positivamente en la sociedad y en el medioambiente (Gorrochategui, 2012). En este marco, se considera importante el análisis de las acciones para revertir ciertas cuestiones tratadas por la RS, como lo son las desigualdades indignantes de todo tipo (Kliksberg, 2012).

En cuanto a la sociedad cooperativa en general, se destaca que este tipo de organización se considera a priori OSR por sus valores éticos, que incluyen a la Responsabilidad Social (ACI, 1995). Luego, definimos a las cooperativas socialmente responsables (CSR) en función de la 
norma ISO 26000/2010 y de acuerdo con los lineamientos del Pacto Global mencionados. Ahora bien, se destaca que el accionar de una cooperativa determinada está incidida por los valores más o menos altruistas de sus integrantes (Caletti, 1986), lo que aumenta el interés de su estudio como el aquí propuesto.

En cuanto a la metodología de estudio, se aclara que se ha trabajado sobre la información provista por la CEB al PG de libre acceso en internet, y su verificación está fuera del alcance del presente trabajo, extrayendo los datos para su análisis sin auditarlos. Hecha esta salvedad sobre la información con la que se cuenta, se nota que la cooperativa realiza programas/proyectos/acciones dentro de la filosofía de la RS.

Se clasifica dicho accionar socialmente responsable en función del PG en cuatro áreas que se sintetizan en un cuadro (Derechos Humanos, Aspectos Laborales, Medioambiente, Anticorrupción/Ética), con el propósito de dar evidencia de la aplicación de la RS por parte de la CSR analizada y asimismo se vincula el accionar con los Objetivos del Desarrollo Sostenible.

Al respecto, la CEB para el ejercicio 2014 informa su accionar socialmente responsable dentro de las tres primeras áreas, pero en este estudio se estima que falta información respecto de la cuarta área (Anticorrupción/Ética), que hubiera sido interesante que lo informara, no obstante, se aclara en el siguiente ejercicio (2015), cuando incorpora información sobre su consideración de la ética dentro del marco del PG.

En cuanto a los ODS, se expone en el mismo cuadro el impacto positivo del accionar mencionado (acciones/programas/proyectos) sobre diez de los diecisiete $\operatorname{ODS}(3,4,6,8,9,10,11,12,15$ y 16), aclarándose que su incidencia positiva resulta vinculada a uno o más de los Objetivos de Desarrollo Sostenible. Por ejemplo, la Capacitación en Salud que informa la CEB en su CoP 2014 se relaciona con el tercero de los ODS (Salud y bienestar), que abarca la meta de aumentar la capacitación en salud, y también con el cuarto ODS (Educación de calidad), que comprende la meta de aumentar las posibilidades de educación en programas técnicos. Otro ejemplo es el programa de la CEB denominado Comunidad con bajos recursos, que se refiere a las facilidades dadas a quienes lo necesitan para la instalación de pilares de energía eléctrica; por un lado se incide sobre el séptimo ODS (Energía asequible y no contaminante), que abarca la meta de garantizar el acceso universal a servicios de energía, y asimismo, se impacta en el décimo ODS (Reducción de las desigualdades), que comprende la meta de potenciar y aumentar la inclusión social. 
Finalmente, se destaca que este trabajo puede servir de base para realizar un posterior estudio normativo para cubrir la ausencia de obligaciones en el marco de la RS (Volpentesta, 2015), los análisis referidos a la suma de esfuerzos de otras OSR atendiendo a los grupos de interés que podría beneficiar a la comunidad (López Regalado et al., 2015) y a los impactos territoriales (Valdés Serrano et al., 2017).

Se invita a realizar otras investigaciones similares sobre otras organizaciones que adhieren al Pacto Global de Naciones Unidas, destacando que la suma de las acciones dentro de la filosofía de la RS de las distintas organizaciones puede incidir positivamente en la comunidad y el medioambiente, como asimismo se invita a su difusión para motivar el accionar socialmente responsable de otras organizaciones para contribuir, dentro de nuestro alcance, a la construcción de un mundo mejor.

\section{BiBLIOGRAFÍA}

Alianza Cooperativa Internacional (1995). Definición de cooperativa, valores y principios cooperativos. Disponible en: http://ica.coop/en/ internationalco-operative-alliance.

Caletti, A. (1986). Iniciación, Desarrollo y Porvenir del Cooperativismo. Buenos Aires: Intercoop Editora Cooperativa Ltda.

Gorrochategui, N. (2012). Dimensión Social de la RSE. Buenos Aires: Ediciones Cooperativas.

Gorrochategui, N. (2012). Tesis Cumplimiento del Principio 10 del Pacto Global sobre Corrupción por Parte de las Empresas que Adhieren a la Iniciativa en la Argentina. Disponible en: http://www.econ.uba.ar/ www/servicios/biblioteca/bibliotecadigital/bd/tesis_doc/gorro.pdf.

Kliksberg, B. (2012). El informe Kliksberg: Escándalos éticos - C01: Los excluidos. Video Publicado el 18 de octubre de 2012. Disponible en: https://youtu.be/c0AFAtu7Ke0.

Kliksberg, B. (2017). Responsabilidad Social en un mundo turbulento. Buenos Aires: Jusbaires.

López Regalado, M.; Perusquía Velasco, J.; Valladares Icedo, O.; Villalón Cañas, R. y Ramírez Torres, M. (2015). En III SIRSO (Comp.), Responsabilidad Social de las Organizaciones (RSO): Avances y propuestas en América Latina (pp. 228-253). Chimbote: ULADECH Católica.

Nilssen, R. (2010). Capítulo XXVII. Las Sociedades Cooperativas. En R. A. Nilssen, Curso de Derecho Societario (pp. 507 a 539). Buenos Aires: ADHOC.

Pacto Global de Naciones Unidas. Listado de participantes. Disponible en: http://www.unglobalcompact.org/participants/search. 
Página 12 (2011). Biblioteca Bernardo Kliksberg. ¿Cómo enfrentar la pobreza y la desigualdad? Publicado el domingo 2 de octubre de 2011. Disponible en: https://pagina12.com.ar/diario/especiales/18-1781162011-10-02.html.

PNUD (2015). Disponible en: http://www.undp.org/content/undp/es/home/ sustainable-development-goals.html.

Richard Efrain, H. (1998). Sociedades Cooperativas. En Richard Efraín y Muiño, Derecho Societario. Buenos Aires: Astrea.

Valdés Serrano, E.; Moreno Garzón, L. y Bonilla Londoño, N. (2017). La Responsabilidad Social Territorial (RST) como enfoque para resignificar el estudio de las Prácticas de Responsabilidad Social de las Organizaciones (RSO). En IV SIRSO (Comp.), Responsabilidad Social de las Organizaciones (RSO): Aportes teórico-prácticos para lograr los Objetivos del Desarrollo Sostenible en América Latina (pp. 553-569). Bogotá: Universidad Santo Tomás.

Volpentesta, J. (2015). Procedimientos Administrativos en la Gestión de los Stakeholders. En III SIRSO, Responsabilidad Social de las Organizaciones (RSO): Avances y propuestas en América Latina, compiladores: Julio Benjamin Dominguez Granda, Nora Gorrochategui, Valmir Martins de Oliveira, Hery Chero Valdivieso (pp. 59-90). Chimbote: ULADECH Católica.

Zapata, O. (2017). Cooperativas Socialmente Responsables Argentinas Adheridas al Pacto Global: Caso Cooperativa de Electricidad Bariloche Limitada. II Encuentro Iberoamericano de Responsabilidad Social. Río Cuarto: UNRC. 



\title{
RESPONSABILIDAD SOCIAL EMPRESARIAL Y LA RENTABILIDAD EN LAS COOPERATIVAS DE AHORRO Y CRÉDITO DEL ECUADOR
}

\author{
Juanita García Aguilar" \\ Aníbal Altamirano Salazar" \\ Ecuador
}

\section{INTRODUCCIÓN}

La Responsabilidad Social Empresarial (RSE) surge debido a varios problemas que se asentaron en el siglo XX, tales como el trabajo infantil a gran escala, corrupción, insalubridad y el aumento de la pobreza, por esta razón, la sociedad inició un proceso de exigencia a las empresas para establecer políticas de RSE y, así, contribuir al bienestar social y al desarrollo sostenible (Vélez, 2011). La RSE contempla ciertos aspectos: ambiental, social y económico, reconociendo los intereses tanto de la sociedad como de accionistas y/o socios, empleados, proveedores y clientes. También, es considerada como una visión de negocios basada en valores éticos, gestión de la empresa, comunidad y el medioambiente, generando un mayor impacto en sus grupos de interés. Siendo esta una forma de gestión, se centra en la relación ética de la empresa

Máster Internacional en Administración de Empresas MBA, Universidad de la Fuerzas Armadas ESPE, Ecuador. Doctorando en Administración, Universidad Nacional de La Plata, Argentina. Docente-investigador del Departamento de Ciencias Económicas, Administrativas y de Comercio, Universidad de las Fuerzas Armadas ESPE, Ecuador. Correo electrónico: jcgarcia@espe.edu.ec

** Máster en Administración de Empresas MBA, Universidad Central del Ecuador. Doctorando en Administración, Universidad Nacional de La Plata, Argentina. Docente-investigador del Departamento de Ciencias Económicas, Administrativas y de Comercio, Universidad de las Fuerzas Armadas ESPE, Ecuador. Correo electrónico: waaltamirano@espe.edu.ec 
y la relación con el establecimiento de metas que ayuden al desarrollo sostenible de la sociedad.

En el último decenio y gracias a infinidad de circunstancias que ponen en peligro el desarrollo, la RSE cobra importancia. Así lo señalan los 17 Objetivos de Desarrollo Sostenible, cuyo propósito es erradicar la pobreza, proteger el planeta y asegurar la prosperidad para todos. Cada vez es mayor el número de organizaciones a nivel mundial que están adoptando estándares ambientales, económicos, sociales y políticos que garanticen la sostenibilidad propia y del entorno que les rodea.

No obstante la existencia de memorias o documentos que reflejan la aplicación de lineamientos, en especial el llamado «balance social» anual para la rendición de cuentas, pocas cooperativas han aplicado medidas contingentes que intentan cubrir ciertos pilares descritos por la RSE. Como, por ejemplo, proyectos de reforestación, alfabetización, campañas de salud, sin determinar los beneficios presentes y futuros o si constituyen acciones de responsabilidad social. De igual manera, la salud financiera de las organizaciones de este tipo es vital para hacer posible la sostenibilidad de las operaciones a largo plazo. Por lo tanto, es importante que las cooperativas pongan especial y continua atención sobre su situación económica y financiera, procurando proteger los intereses de todos los beneficiarios.

El sector cooperativo desempeña una importante función como intermediario financiero de fácil acceso para los ecuatorianos, lo cual se evidencia en el incremento de las operaciones reportadas en los últimos años. Según datos estadísticos publicados en el portal web de la Superintendencia de Economía Popular y Solidaria con corte al 30 de junio 2018, el Ecuador registra un total de 633 cooperativas de ahorro y crédito activas, las cuales incluyen aproximadamente a 6,9 millones de socios. Los activos registraron un saldo de USD 12.243 millones, incrementándose en $103 \%$ respecto al valor registrado a diciembre de 2012, mientras que la banca privada en el período de análisis registró un crecimiento del $40 \%$. Las entidades que conforman el segmento $1^{1}$ representan el $4,9 \%$ de las cooperativas y $74 \%$ de los activos. Las cifras

1 El artículo 447 del Código Orgánico Monetario y Financiero Ecuatoriano especifica que las cooperativas del Sector Financiero Popular y Solidario se ubicarán en los segmentos que la Junta de Política y Regulación Monetaria y Financiera determine. El segmento con mayores activos se define como segmento 1 e incluirá a las entidades con un nivel de activos superior a USD 80.000.000 (ochenta millones de dólares de los Estados Unidos de América); monto que será actualizado anualmente por la Junta aplicando la variación del índice de 
demuestran que en los últimos cinco años el sector creció notablemente, ocupando el segundo lugar en Latinoamérica después de Brasil (Superintendencia de Economía Popular y Solidaria, 2018).

El objetivo de la presente investigación es determinar la influencia de la RSE en la rentabilidad de las cooperativas de ahorro y crédito del Ecuador. El documento está organizado de la siguiente manera: en la primera sección se desarrolla el marco teórico de las variables de estudio. En la segunda parte se presentan algunos estudios empíricos realizados alrededor del mundo, que establecen la relación existente entre la RSE y la rentabilidad. En el tercer apartado se explica la metodología utilizada en la investigación. En la cuarta sección se colocan los resultados obtenidos y, finalmente, en el último apartado se dan a conocer las conclusiones.

\section{Adyacencia Al CONCEPTO DE RSE}

Las bases conceptuales de la RSE reposan en la antigua Roma y Grecia, donde fue posible visualizar ciertos indicios de principios fundamentales, como la filantropía y la caridad. Dichos principios han regido la vida de las sociedades que viven en comunidad, con la finalidad de hacer el bien social. La preocupación por socializar y comunicar la RSE en las organizaciones se aborda con mayor seriedad hace 129 años. Andrew Carnegie, fundador de U.S. Steel, basa la gestión de su empresa en dos principios fundamentales: caridad y custodia (Carnegie, 1889).

Cancino y Morales (2008) mencionan que a medida que el tiempo ha avanzado, diversos autores han incorporado más aristas al tema de la RSE. Esta variable ha sido analizada desde nuevas perspectivas y no solo desde el punto de vista de la repartición de utilidades que genera un negocio, o lo que se conoce como filantropía. La evaluación del desarrollo de los procesos productivos y el efecto que causan en las partes interesadas forman parte de las mismas. Pero la RSE ha sido fundamentada también con estudios que superan los enfoques netamente económicos o los intereses sociales o éticos. Se han producido teorías que no solo se enfocan en vincular la RSE con el cumplimiento económico o social de las organizaciones, sino que incluyen ambos, dando peso

precios al consumidor. El segmento 2 está conformado por aquellas cooperativas con un monto de activos mayores a USD 20.000.000 hasta USD 80.000.000. 


\section{de forma estratégica a las demandas diversas de los stakeholders para crear valor a largo plazo (Toro, 2006). \\ El cuadro 1 presenta el enfoque de cuatro teorías de RSE: instru- mental, integradora, de carácter político, y ética y moral en los negocios, que agrupan conceptos desde el punto de vista de diversos autores.}

\section{CuAdro i. Evolución CONCEPTUAL DE RSE}

\begin{tabular}{|c|c|c|}
\hline TEORÍA & Autores & CONCEPTUALIZACIÓN \\
\hline \multirow[t]{2}{*}{$\begin{array}{l}\text { Instrumental: enfo- } \\
\text { ques que consideran } \\
\text { la RSE como un } \\
\text { medio para alcanzar } \\
\text { resultados econó- } \\
\text { micos }\end{array}$} & $\begin{array}{l}\text { Friedman y la maxi- } \\
\text { mización de utilidad }\end{array}$ & $\begin{array}{l}\text { RSE recae en el uso de los recursos en acti- } \\
\text { vidades cuyo objetivo es la maximización de } \\
\text { los beneficios económicos para el accionista. } \\
\text { RSE entendida como actividad desligada de } \\
\text { las organizaciones y generar bienestar más } \\
\text { allá de las fronteras de las empresas. } \\
\text { RSE no corresponde una obligación para las } \\
\text { empresas ni un beneficio. } \\
\text { Accionistas anteponen su interés particular } \\
\text { al interés general. } \\
\text { Actividades socialmente responsables im- } \\
\text { ponen una carga injusta y costosa para el } \\
\text { accionista. }\end{array}$ \\
\hline & $\begin{array}{l}\text { Murray-Montamari } \\
\text { y el marketing } \\
\text { con causa }\end{array}$ & $\begin{array}{l}\text { RSE para obtener un beneficio positivo sobre } \\
\text { la imagen y reputación empresarial. } \\
\text { Actividades socialmente responsables se } \\
\text { justifican si generan beneficios asociados a la } \\
\text { marca de la empresa. } \\
\text { RSE para mejorar la satisfacción de los } \\
\text { consumidores, mejorar imagen, reputación, } \\
\text { aumentar lealtad, respeto, responsabilidad. } \\
\text { Generar valor a largo plazo a través de } \\
\text { actividades socialmente responsables desde } \\
\text { el punto de vista del marketing (MARM), } \\
\text { responder a intereses de la organización y su } \\
\text { público objetivo. }\end{array}$ \\
\hline $\begin{array}{l}\text { Integradora: enfo- } \\
\text { ques que contemplan } \\
\text { a la RSE para capta- } \\
\text { ción, identificación y } \\
\text { respuesta a deman- } \\
\text { das sociales, para } \\
\text { ganar mayor legiti- } \\
\text { midad social, acepta- } \\
\text { ción y prestigio }\end{array}$ & $\begin{array}{l}\text { Caroll y el modelo } \\
\text { de desempeño social } \\
\text { empresarial }\end{array}$ & $\begin{array}{l}\text { RSE debe tomar en consideración la cate- } \\
\text { goría económica, legal, ética y discrecional, } \\
\text { siendo desarrolladas durante el desempeño } \\
\text { del negocio. } \\
\text { RSE como herramienta que puede ser utiliza- } \\
\text { da por voluntad propia de las organizaciones } \\
\text { para producir bienestar en todas las áreas } \\
\text { posibles. }\end{array}$ \\
\hline
\end{tabular}




\begin{tabular}{|c|c|c|}
\hline TEORÍA & Autores & CONCEPTUALIZACIÓN \\
\hline & $\begin{array}{l}\text { Jones y la redefini- } \\
\text { ción de la responsa- } \\
\text { bilidad social } \\
\text { corporativa }\end{array}$ & $\begin{array}{l}\text { RSE como una forma de autocontrol que } \\
\text { engloba elementos legales o normativos, } \\
\text { incentivos altruistas y moral dominante en } \\
\text { la búsqueda de bienestar social de las orga- } \\
\text { nizaciones. } \\
\text { Las empresas poseen una obligación con la } \\
\text { sociedad en la que se desenvuelven. }\end{array}$ \\
\hline & $\begin{array}{l}\text { Wilcox y la teoría de } \\
\text { propiedad }\end{array}$ & $\begin{array}{l}\text { Empresas desarrollan sus actividades } \\
\text { centrando su accionar en el derecho a la } \\
\text { propiedad. } \\
\text { Para la toma de decisiones, las empresas } \\
\text { deben tomar en cuenta no solo a los } \\
\text { directivos, sino a otros grupos que tienen } \\
\text { responsabilidades sobre ella: empleados, } \\
\text { accionistas, clientes y consumidores. }\end{array}$ \\
\hline $\begin{array}{l}\text { De carácter político: } \\
\text { estudios que prestan } \\
\text { atención al poder } \\
\text { social que adquieren } \\
\text { las organizaciones }\end{array}$ & $\begin{array}{l}\text { Davis y la influencia } \\
\text { de las organizaciones } \\
\text { en la sociedad }\end{array}$ & $\begin{array}{l}\text { Las decisiones de negocio de una empresa } \\
\text { pueden afectar al medio en el cual se } \\
\text { desarrollan a medida que aumenta su } \\
\text { participación y tamaño. } \\
\text { Actividades de RSE practicadas por las } \\
\text { organizaciones pueden influir en el marco } \\
\text { cultural, político y económico que regulan su } \\
\text { desempeño. } \\
\text { El precio de la libertad social es su ejercicio } \\
\text { responsable. }\end{array}$ \\
\hline \multirow[t]{2}{*}{$\begin{array}{l}\text { Ética y moral en los } \\
\text { negocios }\end{array}$} & $\begin{array}{l}\text { Freeman y la teoría } \\
\text { de los stakeholders }\end{array}$ & $\begin{array}{l}\text { Acciones de las organizaciones afectan a } \\
\text { distintos actores. } \\
\text { La RSE es capaz de potenciar la ventaja } \\
\text { competitiva de las empresas. } \\
\text { Los stakeholders son cualquier grupo o } \\
\text { individuo que puede afectar los objetivos } \\
\text { de la organización o es afectado por las } \\
\text { actividades de la empresa. }\end{array}$ \\
\hline & $\begin{array}{l}\text { Freeman, responsa- } \\
\text { bilidad empresarial } \\
\text { y ética aplicada a las } \\
\text { empresas }\end{array}$ & $\begin{array}{l}\text { Aplicar principios éticos para la toma de } \\
\text { decisiones y acciones concretas. } \\
\text { Elaborar códigos de ética que regulen los } \\
\text { intereses de los involucrados. } \\
\text { Acciones de RSE basada en la ética para } \\
\text { lograr beneficios equitativos en un ambiente } \\
\text { saludable de trabajo y resultados eficientes y } \\
\text { satisfactorios. }\end{array}$ \\
\hline
\end{tabular}

Fuente: Elaboración Propia basada en Garriga y Melé (2004).

A partir de la década de los cincuenta comienzan a aparecer nuevas posturas respecto al significado de la RSE, Bowen (1953) la define 
como un conjunto de acciones que realizaban los altos ejecutivos de las compañías con valores y ética social. En los años sesenta y setenta, Davis (1975) la concibe como las decisiones que toma una empresa para buscar intereses propios y de la sociedad en la cual realiza sus actividades. Años después, aparece una de las más importantes e influyentes definiciones propuesta por Carroll (1979), que abarca las expectativas económicas, legales, éticas y voluntarias o filantrópicas que la sociedad tiene de las organizaciones en un determinado periodo. En su pirámide de RSE, la dimensión económica se encuentra en la base y sirve de apoyo para las demás (legales, éticas y filantrópicas). Según este enfoque, la rentabilidad es importante para soportar los demás aspectos de la RSE, pero la gestión para obtenerla se presenta por fuera de la misma (Blázquez y Peretti, 2012).

En la década de los ochenta aparece un concepto importante que tiene una relación muy fuerte con la RSE, los stakeholders, a quienes Freeman (1984) define como "cualquier individuo o grupo de interés que, de manera explícita o implícita; voluntaria o involuntaria; tenga alguna apuesta o pone algo en juego en la marcha de la empresa; y que si, por un lado, se ven condicionados, de manera más o menos directa, por la actividad de aquélla, pueden, a su vez, condicionarla» (pp. 5-7). Es decir, cualquier persona o grupo de personas que puedan influir en cumplir los objetivos que la empresa se ha planteado. También en estos años se dio un gran protagonismo a la ética como la mejor manera de autorregulación por parte de las compañías, en una época en la cual se vivía en Estados Unidos un capitalismo salvaje (Vélez, 2011).

En los años noventa, según Ortiz (2011), la RSE empieza a tomar importancia dentro de la sociedad mundial debido a la creación de organismos internacionales tales como Organización Mundial del Comercio, Banco Mundial, entre otras. Estos grupos sectoriales han impulsado la creación de normas, modelos e instrumentos para la aplicación de la RSE en las compañías a nivel mundial como una estrategia empresarial a largo plazo, logrando por medio de esto contribuir al desarrollo sostenible del área geográfica donde se sitúa.

Uno de los conceptos más aceptados en todo el mundo es el propuesto por la International Organization for Standarization (ISO) en el año 2010, que la define como la responsabilidad de las organizaciones de ejercer sus decisiones y actividades con ética y transparencia, en la sociedad y el medioambiente (Argandoña e Isea, 2011). El Centro Mexicano para la Filantropía (CEMEFI) lo precisa como algo inherente 
a la empresa, la cual ejecuta sus operaciones responsablemente en lo económico, lo social y lo medioambiental, tomando en cuenta los intereses propios y de los grupos relacionados, cuidando el medioambiente y la sustentabilidad a largo plazo (Cajiga, 2016). La Superintendencia de Economía Popular y Solidaria (2017) conceptualiza la responsabilidad social para entidades financieras como «el conjunto de actividades desarrolladas por voluntad de las organizaciones para servir a los sectores sociales».

Para Porto y Castromán(2006, citados por Barroso, 2007), todavía no se ha establecido una definición aceptada universalmente y no existe una institución con el aval para poder establecerla. Aún se la confunde con la buena voluntad, filantropía o instituciones que realizan actos de beneficencia, recalcando que socialmente responsable no es cumplir las obligaciones legales, sino un compromiso con recursos humanos, con el entorno en el que realiza sus actividades empresariales y en las relaciones con los stakeholders. En las cooperativas de ahorro y crédito del Ecuador predominan acciones relacionadas con la ética y la moral en los negocios, por cuanto realizan el proceso de intermediación financiera con recursos captados de terceros (stakeholders socios). Estos deben ser administrados a través de principios éticos al momento de la toma de decisiones, con la finalidad de obtener resultados positivos que permitan la sostenibilidad de las cooperativas en el tiempo.

\section{INSTRUMENTOS DE MEDICIÓN DE RSE}

La medición de la RSE puede ser interna (autoevaluación) o por intermedio de una entidad externa, cuyo objetivo es realizar un diagnóstico, control, verificación e impacto causado en la sociedad. Adicionalmente se conocerán las certificaciones que tiene una organización, nivel de cumplimiento y herramientas utilizadas para la evaluación de RSE (Estrada, 2014). Hoy en día existen algunas exigencias e instrumentos en el mercado que sirven para medir la RSE, los más relevantes que se están utilizando a nivel general en las organizaciones se presentan sintetizados en el cuadro 2. 
Cuadro 2. Instrumentos de medición de RSE

\begin{tabular}{|c|c|c|}
\hline INSTRUMENTOS & DESCRIPCIÓN & DimENSIÓN/INDICADORES \\
\hline ISO 26000 & $\begin{array}{l}\text { Proporciona una guía a las } \\
\text { organizaciones sobre los prin- } \\
\text { cipios, temas centrales relacio- } \\
\text { nados con la responsabilidad } \\
\text { social, y los métodos para } \\
\text { implementar los principios } \\
\text { de responsabilidad social en } \\
\text { las actividades diarias en una } \\
\text { organización, incluyendo aque- } \\
\text { llas actividades de involucra- } \\
\text { miento de stakebolders. }\end{array}$ & $\begin{array}{l}\text { 1. Medioambiente } \\
\text { 2. Derechos humanos } \\
\text { 3. Prácticas laborales } \\
\text { 4. Gobierno organizacional } \\
\text { 5. Prácticas de negocio justo/ } \\
\text { reglas de mercado } \\
\text { 6. Participación de la } \\
\text { comunidad } \\
\text { 7. Consumidores/responsa- } \\
\text { bilidad } \\
\text { del producto }\end{array}$ \\
\hline $\begin{array}{l}\text { Norma de } \\
\text { aseguramiento } \\
\text { AA1000 }\end{array}$ & $\begin{array}{l}\text { Evalúa, certifica y consolida } \\
\text { la credibilidad y calidad del } \\
\text { Informe de Sostenibilidad de } \\
\text { una organización, enfocándose } \\
\text { en sus principales procesos, } \\
\text { sistemas y competencias. Pro- } \\
\text { porciona los elementos clave } \\
\text { para lograr un proceso de ase- } \\
\text { guramiento. }\end{array}$ & $\begin{array}{l}\text { 1. Resultado organizacional } \\
\text { 2. Partes interesadas } \\
\text { 3. Políticas y metas } \\
\text { establecidas } \\
\text { 4. Aseguramiento público }\end{array}$ \\
\hline $\begin{array}{l}\text { Cuadro Central } \\
\text { de Indicadores } \\
\text { Sociales AECA }\end{array}$ & $\begin{array}{l}\text { Funciona para la creación de } \\
\text { los informes sobre Responsa- } \\
\text { bilidad Social Empresarial de } \\
\text { las pymes y preparación de los } \\
\text { indicadores detallados. }\end{array}$ & $\begin{array}{l}\text { Indicadores empleados, } \\
\text { clientes y accionistas }\end{array}$ \\
\hline $\begin{array}{l}\text { Global } \\
\text { Reporting } \\
\text { Initiative (GRI) }\end{array}$ & $\begin{array}{l}\text { Es una metodología que } \\
\text { aporta directrices para la } \\
\text { elaboración de memorias de } \\
\text { sostenibilidad, incluyendo los } \\
\text { impactos económicos, sociales } \\
\text { y ambientales de una empresa. } \\
\text { Para su elaboración se deben } \\
\text { considerar cuatro principios: } \\
\text { Materialidad, Participación de } \\
\text { los Grupos de Interés, Contex- } \\
\text { to de Sostenibilidad y Exhaus- } \\
\text { tividad. }\end{array}$ & $\begin{array}{l}\text { Indicadores específicos ca- } \\
\text { tegorizados en económicos, } \\
\text { ambientales y sociales }\end{array}$ \\
\hline
\end{tabular}


RESPONSABILIDAD SOCIAL EMPRESARIAL Y LA RENTABILIDAD EN LAS COOPERATIVAS DE AHORRO Y CRÉDITO DEL ECUADOR

\begin{tabular}{|c|c|c|}
\hline INSTRUMENTOS & DESCRIPCIÓN & DimENSIÓN/INDICADORES \\
\hline $\begin{array}{l}\text { Indicadores } \\
\text { Ethos de Res- } \\
\text { ponsabilidad } \\
\text { Social Empre- } \\
\text { sarial }\end{array}$ & $\begin{array}{l}\text { Estos indicadores buscan plan- } \\
\text { tear cómo la empresa puede } \\
\text { mejorar su desempeño en los } \\
\text { temas correspondientes desde } \\
\text { las distintas perspectivas. }\end{array}$ & $\begin{array}{l}\text { 1. Valores, transparencia y } \\
\text { gobernanza } \\
\text { 2. Público interno } \\
\text { 3. Medioambiente } \\
\text { 4. Proveedores } \\
\text { 5. Consumidores y clientes } \\
\text { 6. Comunidad } \\
\text { 7. Gobierno y sociedad }\end{array}$ \\
\hline $\begin{array}{l}\text { SGE 21: } 2008 \\
\text { Sistema de } \\
\text { Gestión Ética } \\
\text { y Socialmente } \\
\text { Responsable }\end{array}$ & $\begin{array}{l}\text { Permite establecer un Sistema } \\
\text { de Gestión Ética y Socialmente } \\
\text { Responsable en las organiza- } \\
\text { ciones. Debe ser contemplado } \\
\text { como una parte del sistema de } \\
\text { gestión de la organización. }\end{array}$ & $\begin{array}{l}\text { Alta dirección, clientes, } \\
\text { proveedores, entorno social, } \\
\text { entorno ambiental, inverso- } \\
\text { res, competencia }\end{array}$ \\
\hline $\begin{array}{l}\text { Guía del Pacto } \\
\text { Mundial }\end{array}$ & $\begin{array}{l}\text { Facilita un marco de trabajo } \\
\text { contextual para fomentar y } \\
\text { difundir la innovación, las so- } \\
\text { luciones creativas y las mejores } \\
\text { prácticas entre los participan- } \\
\text { tes. El Pacto Mundial cree en } \\
\text { las iniciativas voluntarias y los } \\
\text { sistemas regulatorios, cuando } \\
\text { se combinan, generan un po- } \\
\text { deroso impulso que favorece } \\
\text { el sentido de responsabilidad } \\
\text { cívica corporativa. }\end{array}$ & $\begin{array}{l}\text { 1. Derechos humanos } \\
\text { 2. Ámbito laboral } \\
\text { 3. Medioambiente } \\
\text { 4. Anticorrupción }\end{array}$ \\
\hline $\begin{array}{l}\text { Norma SA } \\
8000\end{array}$ & $\begin{array}{l}\text { Esta norma especifica los re- } \\
\text { quisitos de responsabilidad } \\
\text { social que permiten a una com- } \\
\text { pañía: a) desarrollar, mantener } \\
\text { y aplicar sus principios y sus } \\
\text { procedimientos con el objeto } \\
\text { de manejar aquellos asuntos } \\
\text { que están bajo su control o } \\
\text { influencia, b) demostrar a las } \\
\text { partes interesadas que sus } \\
\text { procedimientos y prácticas } \\
\text { están en conformidad con los } \\
\text { requerimientos impuestos por } \\
\text { la norma. }\end{array}$ & $\begin{array}{l}\text { Trabajo infantil, trabajos } \\
\text { forzados } \\
\text { Salud y seguridad laboral } \\
\text { Libertad de asociación y } \\
\text { derecho de negociación co- } \\
\text { lectiva } \\
\text { Discriminación } \\
\text { Gestión talento humano: } \\
\text { normativa, horario de traba- } \\
\text { jo, remuneración }\end{array}$ \\
\hline
\end{tabular}

Fuente: Elaboración PROPIA. 
Después de analizar los diferentes instrumentos para medir RSE, se consideró utilizar el Global Reporting Initative GRI G4. Su diseño fomenta la comparabilidad y calidad de la información sobre los impactos económicos, sociales y medioambientales de las organizaciones. La elaboración de informes de sostenibilidad basados en los estándares GRI proporciona una representación equilibrada y razonable de las contribuciones positivas y negativas de las organizaciones al cumplimiento de los objetivos de desarrollo sostenible. Tiene un total de noventa y un indicadores distribuidos en las tres dimensiones de la RSE, detallados en el cuadro 3.

Cuadro 3. Indicadores metodología GRI G4

\begin{tabular}{|c|c|c|}
\hline Dimensión & VARIABLES & $\begin{array}{c}\mathrm{N}^{\circ} \\
\text { INDICADORES }\end{array}$ \\
\hline \multirow[t]{4}{*}{ Aspecto económico } & Desempeño económico & 4 \\
\hline & Presencia en el mercado & 2 \\
\hline & Consecuencias económicas indirectas & 2 \\
\hline & Prácticas de adquisición & 1 \\
\hline \multicolumn{3}{|r|}{ Subtotal: 9} \\
\hline \multirow{12}{*}{$\begin{array}{l}\text { Aspecto } \\
\text { medioambiental }\end{array}$} & Materiales & 2 \\
\hline & Energía & 5 \\
\hline & Agua & 3 \\
\hline & Biodiversidad & 4 \\
\hline & Emisiones & 7 \\
\hline & Efluentes y residuos & 5 \\
\hline & Productos y residuos & 2 \\
\hline & Cumplimiento regulatorio & 1 \\
\hline & Transporte & 1 \\
\hline & General & 1 \\
\hline & Evaluación ambiental de proveedores & 2 \\
\hline & $\begin{array}{l}\text { Mecanismos de reclamación en } \\
\text { material ambiental }\end{array}$ & 1 \\
\hline \multicolumn{3}{|r|}{ Subtotal: 34} \\
\hline \multirow[t]{3}{*}{ Aspecto social } & Empleo & 3 \\
\hline & $\begin{array}{l}\text { Relaciones entre los trabajadores } \\
\text { y la dirección }\end{array}$ & 1 \\
\hline & Salud y seguridad en el trabajo & 4 \\
\hline
\end{tabular}


RESPONSABILIDAD SOCIAL EMPRESARIAL Y LA RENTABILIDAD EN LAS COOPERATIVAS DE AHORRO Y CRÉDITO DEL ECUADOR

\begin{tabular}{|c|c|c|}
\hline Dimensión & VARIABLES & $\begin{array}{c}\mathrm{N}^{\mathrm{O}} \\
\text { INDICADORES }\end{array}$ \\
\hline & Capacitación y educación & 3 \\
\hline & Diversidad e igualdad de oportunidades & 1 \\
\hline & $\begin{array}{l}\text { Igualdad de retribución entre mujeres y } \\
\text { hombres }\end{array}$ & 1 \\
\hline & $\begin{array}{l}\text { Evaluación de las prácticas laborales de los } \\
\text { proveedores }\end{array}$ & 2 \\
\hline & $\begin{array}{l}\text { Mecanismos de reclamación sobre } \\
\text { las prácticas laborales }\end{array}$ & 1 \\
\hline & Inversión & 2 \\
\hline & No discriminación & 1 \\
\hline & $\begin{array}{l}\text { Libertad de asociación y negociación } \\
\text { colectiva }\end{array}$ & 1 \\
\hline & Trabajo infantil & 1 \\
\hline & Trabajo forzoso & 1 \\
\hline & Medidas de seguridad & 1 \\
\hline & Derechos de la población indígena & 1 \\
\hline & Evaluación & 1 \\
\hline & $\begin{array}{l}\text { Evaluación de los proveedores en materia } \\
\text { de derechos humanos }\end{array}$ & 2 \\
\hline & $\begin{array}{l}\text { Mecanismos de reclamación en materia de } \\
\text { derechos humanos }\end{array}$ & 1 \\
\hline & Comunidades locales & 2 \\
\hline & Lucha contra la corrupción & 3 \\
\hline & Política pública & 1 \\
\hline & Prácticas de competencia desleal & 1 \\
\hline & Cumplimiento regulatorio & 1 \\
\hline & $\begin{array}{l}\text { Evaluación de la repercusión social de los } \\
\text { proveedores }\end{array}$ & 2 \\
\hline & $\begin{array}{l}\text { Mecanismos de reclamación por impacto } \\
\text { social }\end{array}$ & 1 \\
\hline & Salud y seguridad de los clientes & 2 \\
\hline & Etiquetado de los productos y servicios & 3 \\
\hline & Comunicaciones de mercadotecnia & 48 \\
\hline & Privacidad de los clientes & \\
\hline & Cumplimiento regulatorio & \\
\hline
\end{tabular}

Fuente: Elaboración propia, SObre la base De GRI G4 (2OI 5 ). 
La dimensión económica está conformada por cuatro variables y nueve indicadores que miden el flujo de capital entre los distintos grupos de interés y los principales impactos económicos que la organización tiene en la sociedad (sistemas locales, nacionales e internacionales). $\mathrm{El}$ aspecto medioambiental se refiere al impacto que pueden causar las organizaciones en los sistemas naturales vivos e inertes como los ecosistemas, suelo, aire y agua. Tiene doce variables y treinta y cuatro indicadores que cubren aspectos relacionados con los insumos (energía, agua), los productos (emisiones, efluentes y desechos), la biodiversidad, el transporte y la repercusión de productos y servicios, además de la conformidad y el gasto en materia ambiental. Por último, la dimensión social está relacionada con los efectos que provocan las operaciones de las empresas en los sistemas sociales en los que opera. Consta de treinta variables y cuarenta y ocho indicadores que evalúan las prácticas laborales y trabajo digno, derechos humanos, sociedad y responsabilidad sobre productos. En total suman noventa y un indicadores que constituyen una referencia internacional para aquellas organizaciones interesadas en presentar información sobre gobierno corporativo, desempeño y RSE.

\section{RENTABILIDAD}

Las empresas definen objetivos relacionados con crecimiento, productividad, innovación, económicos e incluso de servicio a la colectividad. Sin embargo, en todo análisis empresarial el centro de la discusión está en la polaridad entre la rentabilidad y el riesgo (liquidez o solvencia), siendo variables fundamentales que definen toda actividad económica y financiera de la empresa.

Gitman (2012) considera que la rentabilidad es el residuo positivo entre lo ganado y lo gastado, para lo cual se requiere incrementar las ventas y minimizar los costos mediante la correcta selección de insumos, mano de obra y cualquier costo indirecto. La rentabilidad también puede ser definida como el beneficio generado por una inversión, expresada en porcentaje. Sin embargo, el valor monetario percibido como consecuencia de la misma varía dependiendo del tiempo de colocación de la inversión. Aguirre, Prieto y Escamilla (1997) la definen como un objetivo económico a corto plazo que busca la obtención de beneficios positivos indispensables para el normal desarrollo de la empresa. En esta misma línea, Sánchez (2002) la conceptualiza como un objetivo que se 
plantea toda empresa como medida de rendimiento del capital invertido en su operatividad durante un período de tiempo. Podría decirse que la rentabilidad es el resultado de las decisiones que la administración de una empresa ha tomado en un determinado periodo de tiempo.

Los índices de rentabilidad miden la capacidad de la empresa para generar utilidades respecto la inversión realizada tanto en activos totales como capital contable. En el sector cooperativo, la rentabilidad se calcula utilizando dos indicadores: rentabilidad sobre el activo (ROA) y rentabilidad sobre patrimonio (ROE). El ROA evalúa el rendimiento producido por los activos, en mejor condición estarán aquellas empresas que reflejen porcentajes superiores al promedio del sector al que pertenecen y su tendencia sea creciente. Mientras que el ROE mide el rendimiento generado por el patrimonio durante un ejercicio contable y su interpretación es similar a la del ROA. Altamirano, Cruz, Villalba e Ipiales (2018), en una investigación para determinar un modelo de diagnóstico financiero para las cooperativas de ahorro y crédito, determinan que el ROA se calcula comparando el excedente neto con el promedio de activos y para el ROE se utiliza la razón excedente neto para el promedio del patrimonio.

\section{RSE Y LA RENTABILIDAD}

Durante el periodo comprendido entre los años 1983-2018, varios autores han realizado investigaciones para demostrar si existe una relación positiva, negativa o neutra, entre la RSE y la rentabilidad. Los resultados son diversos y la mayoría de los estudios se han realizado en Europa, pocos son los desarrollados en América Latina.

Ansoff (1983) fue uno de los primeros autores en determinar la relación entre la Responsabilidad Social y el rendimiento de las empresas, integrando en la formulación estratégica aspectos sociales y medioambientales. Cuando los clientes están dispuestos a pagar un precio superior al de la competencia por productos socialmente responsables, la RSE puede generar mayores ingresos a una empresa (Du, Bhattacharya y Sen, 2007; Yoon, Gurhan-Canli y Schwarz, 2006). De acuerdo con Giraldo (2008) y Ellis (2009), cuando las empresas mejoran su productividad, satisfacen a sus trabajadores, tienen un buen poder de negociación con sus proveedores y atienden a sus grupos de interés, hacen un buen uso de sus recursos, reducen los costos y consecuentemente incrementa su rentabilidad. 
Investigaciones realizadas por Margolis, Elfenbein y Walsh (2007), y Dixon-Fowler, Slater, Johnson, Ellstrand y Romi (2013) confirman que la Responsabilidad Social Empresarial tiene una correlación positiva con el desempeño financiero. En esa misma línea, Battaglia, Testa, Bianchi, Irald y Frey (2014), y Frynas y Yamahaki (2016) establecen que una organización que invierte en RSE tiene un mejor desempeño financiero, reflejado en productividad, liquidez y financiamiento.

Tsoutsoura (2004) realizó su investigación con empresas estadounidenses, concluyendo que existe una relación positiva y estadísticamente significativa entre ser socialmente responsable y su desempeño financiero. Por su parte, Valenzuela, Jara y Villegas (2014), en una investigación realizada a cincuenta y cinco empresas chilenas, determinaron que aplicar y divulgar prácticas de RSE influye positivamente en el desempeño financiero. Los estudios realizados por Karagiorgos (2010), Rodríguez (2015) y otros desarrollados en Europa, también confirman la relación positiva entre RSE y desempeño financiero. En esta misma línea de análisis, Martínez Fierro y Frías Aceituno (2015) concluyen que la RSE y el desempeño financiero tienen una relación directamente proporcional. Es decir, las empresas que invierten una mayor cantidad de recursos en RSE reflejan resultados positivos en el desempeño financiero.

Existen otras investigaciones que demuestran que la RSE tiene una relación negativa con el desempeño financiero de una empresa. La ejecución de proyectos de inversión en actividades de tipo social puede generar costos adicionales, lo cual conlleva a la disminución de la rentabilidad y afectando directamente los intereses de los accionistas (Nelling y Webb, 2009; Sadeghi, Arabsalehi y Hamavandi, 2016). Para Gras, Palacios y Hernández (2016), existe un impacto negativo al implementar prácticas de RSE y la generación de utilidades, debido a que las empresas se enfocan en tener mejores relaciones con sus partes relacionadas.

Por otro lado, Sadeghi et al. (2016), en su estudio realizado en empresas manufactureras concluyen que ninguna de las dimensiones de RSE influye en el rendimiento sobre el patrimonio; no obstante, la dimensión social en términos de clientes y trabajadores tiene una incidencia positiva y significativa en el rendimiento sobre el activo. Otras investigaciones indican que existe una relación neutral entre RSE y desempeño financiero, alegando que el entorno en el que operan las empresas es complejo y que por lo tanto no existe una relación simple entre estas dos variables (McWilliams y Siegel, 2000). En este sentido, Baird, Geylani y Roberts (2012), en su estudio determinaron 
que la relación entre RSE y desempeño financiero depende del tipo de empresa, industria a la que pertenece y factores situacionales externos. Finalmente, otros autores han concluido que no existe una relación significativa entre la aplicación de la RSE y el desempeño financiero de las empresas, ya sea porque no provoca pérdidas (Gémar y Espinar, 2015), o porque permite crear una buena imagen corporativa y mejores relaciones con sus partes relacionadas, pero no mayor lucro (Madorran y García , 2014; Lech, 2013).

De lo expuesto, existe evidencia empírica que comprueba la relación entre la RSE y la rentabilidad, en unos casos positiva, en otros, negativa, e incluso puede ser neutral. En la relación positiva, contar con productos socialmente responsables, prestar atención a los grupos de interés, invertir en RSE, incrementa la rentabilidad de las organizaciones y consecuentemente su desempeño financiero. La ejecución de proyectos de tipo social puede generar costos adicionales que disminuyen la rentabilidad y los intereses de los socios, reflejando una relación negativa. Por último, existen estudios que concluyen que no existe relación, por cuanto la rentabilidad de las organizaciones depende de varios factores situacionales externos. En este contexto, se pretende comprobar si las acciones de RSE influyen de manera positiva en la rentabilidad de las cooperativas de ahorro y crédito ecuatorianas.

\section{Metodología}

En la presente investigación se utilizó un estudio cuantitativo, diseño no experimental, realizado en las cooperativas de ahorro y crédito del Ecuador. Según información publicada al 31 de diciembre de 2017 en la Superintendencia de Economía Popular y Solidaria existen 671 cooperativas activas, agrupadas en cinco segmentos de acuerdo con sus activos totales. Para el desarrollo de este trabajo se tomaron en cuenta las cooperativas de los segmentos 1 y 2 , definiendo un universo de sesenta. Para determinar la muestra, se aplicó la fórmula del método de estimación simple para el Muestreo Irrestricto Aleatorio (Calero, 2003). Los parámetros definidos fueron: Población (N) 60 cooperativas, nivel de significación $(\alpha)$ 005, error (d) 0.,10, valor de la Probabilidad (P) 0,5, obteniendo como resultado treinta y siete cooperativas.

El instrumento de medición de RSE GRI G4 fue validado por expertos, que fueron seleccionados de acuerdo con los criterios establecidos por Skjong y Wentworth (2000): experiencia en la realización de 
juicios y toma de decisiones basada en evidencia o experticia (grados, investigaciones, publicaciones y premios), reputación en la comunidad, disponibilidad y motivación para participar e imparcialidad. Posteriormente se utilizó el método Delphi, que consiste en que cada experto realice su evaluación de manera individual y luego reciba las medianas obtenidas, para que reconsidere su juicio hasta que se logre un consenso (De Arquer, 1995). Procedimiento ratificado por Van Der Fels-Klerx, Gossens, Saaticamp y Horst (2002), que manifiestan que esta técnica permite obtener un alto nivel de interacción entre los expertos, evitando las desventajas de la dinámica grupal.

Se seleccionó a quince expertos que analizaron los reactivos del instrumento GRI G4S, considerando cuatro criterios de evaluación: representatividad, comprensión, interpretación y claridad. La escala utilizada fue de 1 al 3, siendo 1 la calificación más baja, y 3 la calificación más alta. Para analizar la representatividad, 1 significa nada representativo y 3 muy representativo; para el criterio comprensión, 1 señala que la pregunta resulta incomprensible y el 3 entendible; en la interpretación, en cambio, el 1 indica que puede tener varias interpretaciones y el 3 que tiene una única interpretación; por último, respecto a la claridad, el 1 establece nada claro y el 3 conciso (Crespo, D Ambrosio, Racines y Castillo, 2016). Finalmente, una vez consolidada las validaciones de cada experto, considerando el criterio establecido por Crespo y Moreta (2017), se dejaron las preguntas que sobrepasan el $75 \%$.

Los datos fueron sometidos a una evaluación multivariante, para el efecto se aplicó el Análisis Factorial Confirmatorio (AFC) y el Modelo de Ecuaciones Estructurales a fin de determinar las estimaciones de bondad de ajuste. También, se calculó el estadístico Alpha de Cronbach para establecer la confiabilidad del instrumento. Para el procesamiento de los datos se utilizó el software estadístico SPSS versión 24 y el programa AMOS versión 22. Las hipótesis planteadas en las investigaciones fueron las siguientes:

- H1: La dimensión económica de la RSE influye de manera positiva y significativa en la rentabilidad de las cooperativas de ahorro y crédito.

- H2: La dimensión medioambiental de la RSE influye de manera negativa y significativa en la rentabilidad de las cooperativas de ahorro y crédito. 
- H3: La dimensión social de la RSE influye de manera negativa y significativa en la rentabilidad de las cooperativas de ahorro y crédito.

\section{Resultados}

Antes de explicitar los resultados es importante detallar los indicadores con los cuales fueron medidos los constructos RSE y rentabilidad. La RSE está estructurada con tres dimensiones: Económica, Medio Ambiental y Social, determinadas con cuatro, once y cuatro variables, respectivamente. En cambio, el constructo Rentabilidad fue medido por dos indicadores: ROA y ROE. Luego se realizó el análisis de confiabilidad interna de los datos, para el efecto se utilizó el coeficiente Alpha de Cronbach, obteniéndose como resultado 0,861, lo que expresa un análisis de consistencia de alta fiabilidad, por cuanto el resultado de la escala supera el valor aceptable de 0,70 establecido por Luque (1997).

Posteriormente se realizó un análisis multivariante, a través del Modelo de Ecuaciones Estructurales, que es una herramienta avanzada por cuanto utiliza un conjunto de ecuaciones de regresión lineal para analizar las relaciones entre las variables (Armario y Cossio, 2001). A fin de no recurrir al lenguaje matemático, mediante un modelo gráfico denominado diagrama de camino (path diagrama) se representaron las relaciones entre las variables utilizando las cargas estandarizadas estimadas. En la figura 1 se presentan los resultados más importantes, la relación entre la dimensión económica de la Responsabilidad Social Empresarial y la rentabilidad es positiva $(0,52)$; las restantes dimensiones, social y medioambiental, señalan correlaciones negativas con la rentabilidad. Es decir, la dimensión económica de la RSE influye de manera aceptable en la rentabilidad de las cooperativas. 
Figura i. Estimación del Modelo de Ecuaciones Estructurales

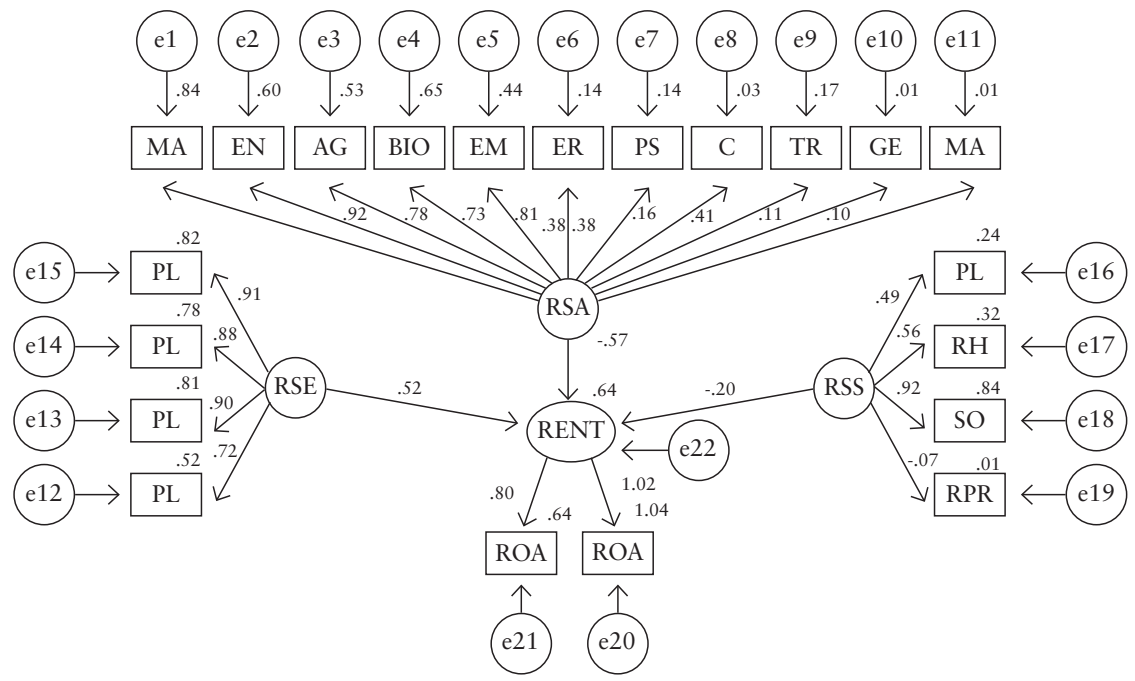

Para determinar si el modelo establecido es aceptable, se realizaron dos evaluaciones: ajuste global del modelo y ajuste del modelo estructural. En referencia al primer aspecto, los resultados se presentan en el cuadro 4.

Cuadro 4. Bondad de ajuste del modelo propuesto

\begin{tabular}{|l|l|l|l|}
\hline \multicolumn{1}{|c|}{ INDICADOR } & RESULTADO & \multicolumn{1}{|c|}{$\begin{array}{c}\text { NIVELES DE } \\
\text { ACEPTACIÓN }\end{array}$} & \multicolumn{1}{|c|}{ AUTOR } \\
\hline $\begin{array}{l}\text { Goodness of fit Index } \\
\text { (GFI) }\end{array}$ & 0,904 & Superior a 0,90 & $\begin{array}{l}\text { Jöreskog y } \\
\text { Sörbom, 1996 }\end{array}$ \\
\hline $\begin{array}{l}\text { Root Mean Square } \\
\text { Residual (RMSR) }\end{array}$ & 0,282 & $\begin{array}{l}\text { Valor más } \\
\text { próximo a cero }\end{array}$ & $\begin{array}{l}\text { Jöreskog y } \\
\text { Sörbom, 1996 }\end{array}$ \\
\hline $\begin{array}{l}\text { Root Mean Square Error } \\
\text { of Aproximation } \\
\text { (RMSEA) }\end{array}$ & 0,112 & $\begin{array}{l}\text { Valores inferio- } \\
\text { res a 0,08 }\end{array}$ & Steige, 1990 \\
\hline $\begin{array}{l}\text { Adjusted Goodness of fit } \\
\text { index (AGFI) }\end{array}$ & 0,863 & Superior a 0,90 & $\begin{array}{l}\text { Jöreskog y } \\
\text { Sörbom, 1996; } \\
\text { Hair et al., 1999 }\end{array}$ \\
\hline $\begin{array}{l}\text { Comparative Fit Index } \\
\text { (CFI) }\end{array}$ & 0,693 & $\begin{array}{l}\text { Valor más } \\
\text { próximo a 1 }\end{array}$ & Bentler, 1990 \\
\hline
\end{tabular}

Fuente: Elaboración PROPIA. 
Como se puede observar, los indicadores GFI, AGFI, CFI, RMRS y RMSEA que proporcionan la variabilidad explicada por el modelo, la media de los residuos entre la matriz inicial de datos y la estimada y el ajuste incremental del modelo, se encuentran dentro de los parámetros aceptables.

Para determinar el ajuste del modelo estructural, se utilizó el coeficiente crítico (CR) de las relaciones entre las variables latentes. Los resultados se presentan en el cuadro 5 .

Cuadro 5. Bondad de ajuste estructural

\begin{tabular}{|c|c|c|}
\hline RELACIONES & COEFICIENTE CRÍTICO & CARgAS ESTANDARIZADAS \\
\hline RSE-RENT & 2,377 & 0,52 \\
\hline RSA-RENT & $-3,058$ & $-0,57$ \\
\hline RSS-RENT & $-1,347$ & $-0,20$ \\
\hline
\end{tabular}

FuENTE: Elaboración PROPIA.

El coeficiente crítico de la relación RSE-RENT $(2,377)$ demuestra que existe incidencia positiva significativa entre la dimensión responsabilidad social económica y la rentabilidad, por cuanto su resultado supera el valor de +/- 1,96 establecido por Hair, Anderson, Tatham y William (1995), comprobando la H1. Para el caso de la relación RSA-RENT el CR es de -3,058, si bien es cierto supera el porcentaje establecido, es negativo, lo que implica que la dimensión de responsabilidad medioambiental incide de manera negativa y significativa en la rentabilidad, demostrando la $\mathrm{H} 2$. El resultado del CR de la relación RSS- RENT es de -1.347 , lo que establece una incidencia negativa pero no significativa entre la dimensión social y la rentabilidad, rechazando parcialmente la $\mathrm{H} 3$.

\section{CONCLUSIONES}

De acuerdo con los resultados obtenidos, se puede evidenciar que existe una relación positiva y estadísticamente significativa $(0,52$; $\mathrm{p}$-valor $<0,05)$ entre la dimensión económica de la RSE y la rentabilidad. En cuanto a la dimensión medioambiental $(-0,57$; p-valor $<0,05)$, se observa que tiene una relación negativa y estadísticamente significativa con la rentabilidad. En lo referente a la dimensión social $(-0,20$; p-valor $<0,05)$, con el resultado obtenido se demuestra que no influye en rentabilidad. 
Las cooperativas de ahorro y crédito deberían concentrar sus recursos y esfuerzos en la realización de proyectos relacionados con la dimensión económica de la Responsabilidad Social Empresarial. La transparencia de la información financiera, el correcto manejo de sus portafolios de inversiones y cartera, y la adecuada gestión integral de riesgos influyen positivamente en la rentabilidad. Debido a que los socios, al percibir un manejo financiero eficiente, deciden invertir sus recursos y acceder a los productos y servicios que ofrecen las cooperativas.

En cuanto a los proyectos de RSE desarrollados en las dimensiones medioambiental y social, como por ejemplo programas de reforestación, alfabetización, campañas de salud, generan costos adicionales que puede reducir los excedentes de manera significativa, por cuanto no garantizan que las personas beneficiarias de estos proyectos inviertan sus recursos en las cooperativas.

Con la finalidad de determinar las causas de la correlación negativa entre las dimensiones medioambiental y social con la rentabilidad, se deja abierta la posibilidad de una futura investigación para establecer si existen otros factores que inciden directa o indirectamente en esta relación.

\section{BiBLIOGRAFÍA}

Aguirre, J., Prieto, M. y Escamilla, J. (1997). Contabilidad de costos, gestión y control presupuestario, control de gestió, la función del controller. España: Cultural de Ediciones S.A.

Altamirano, A.; Cruz, M.; Villalba, N. e Ipiales, K. (2018). Modelo de diagnóstico para medir el desempeño financiero en las cooperativas de ahorro y crédito del Ecuador. Revista de investigación en modelos financieros, 124-146.

Ansoff, H. (1983). Societal strategy for the business firm. Advances in Strategic Management, 3-29.

Argandoña , A. e Isea, S. (2011). ISO 26000, una guía para la responsabilidad social en las organziaciones. IESE Business School, 11.

Armario, E. y Cossio, F. (2001). La orientación al mercado y el rendimiento esmpresarial: el caso de la banca comercial española. Cuadernos de gestión, 33-66.

Baird , P.; Geylani, P. y Roberts, J. (2012). Corporate social and financial performance re-examined: industry effects in a linear mixed model analysis, Journal of Business Ethics. Journal of Business Ethics, 367-388. 
Barroso, T. (2007). Responsabilidad social empresarial: concepto y sugerencias para su aplicación en empresas constructoras. Ingeniería Revista Académica Universidad Autónoma de Yucatán, 65-72. Disponible en: http://www.redalyc.org/pdf/467/46711307.pdf.

Battaglia, M.; Testa, F.; Bianchi, L.; Iraldo, F. y Frey, M. (2014). Corporate Social Responsibility and Competitiveness within SMEs of the Fashion Industry: Evidence from Italy and France. Sustainability, 872-893.

Blázquez, M. y Peretti, M. F. (2012). Modelo para gestionar la sustentabilidad de las organizaciones a través de la rentabilidad, adaptabilidad e imagen. Estudios Gerenciales, 40-50.

Bowen, H. (1953). Social Responsabilities of the Businessman (Primera edición ed.). New York: Harper and Row.

Cajiga, J. (2016). CEMEFI. Obtenido de El concepto de Responsabilidad Social Empresarial. Disponible en: https://www.cemefi.org/esr/images/stories/pdf/esr/concepto_esr.pdf.

Calero, A. (2003). Estadística III. La Habana: Félix Varela.

Cancino, C. y Morales, M. (2008). Responsabilidad Social Empresarial. Santiago: Departamento Control de Gestión y Sistemas de Información de la Facultad de Economía y Negocios de la Universidad de Chile. Carnegie, A. (1889). The Gospel of Wealth and Other Timely Essays. Filadelfia: The Unitarian Book-Room.

Carroll, A. (1979). A three-dimensional conceptual model of corporate performance. Academy of Management Review, 4(4), 497-505.

Crespo, G. y Moreta, M. (2017). Cómo medir la estrategia y planificación en las PYMES del sector de concesionarios de vehículos del Distrito Metropolitano de Quito. Yura relaciones internacionales, 1-22.

Crespo, G.; Ambrosio, G.; Racines, A. y Castillo, L. (2016). Cómo medir la percepción de responsabilidad social empresarial en la industria de gaseosas. Yura Relaciones Internacionales, 1-18.

Davis, K. (junio de 1975). Five Propositions for Social Responsibility. Business Horizons, 18.

De Arquer, M. (1995). Fiabilidad Humana: Métodos de cuantificación, juicio de expertos. Centro Nacional de Condicones de Trabajo.

Dixon-Fowler, H.; Slater, D.; Johnson, J.; Ellstrand, A. y Romi, A. (2013). Beyond «Does it pay to be green?'» A meta-analysis on moderators of the CEP-CFP relationship. Journal of business Ethics, 353-366.

Du, S.; Bhattacharya, C. y Sen, S. (2007). Reaping relational rewards from corporate social responsibility: The role of competitive positioning. International Journal of Research in Marketing, 224-241.

Ellis, A. (2009). The impact of corporate social responsability on employee attitudes and behaviours. Academy of Management Proceedings, 1-16. 
Estrada, G. M. (febrero de 2014). olade.org. Obtenido de Metodología para la implementación de acciones de RSE en empresas. Disponible en: http://www.olade.org/wp-content/uploads/2015/08/MetodologiaReplicable.pdf.

Freeman, E. (1984). Strategic Management: A Stakeholder Approach. Boston: Pitman.

Frynas, J. y Yamahaki, C. (2016). Corporate social responsibility: review and roadmap of theoretical perspectives. Business Ethics: A European Review, 258-285.

Garriga , E. y Melé , D. (2004). Corporate Social Responsability Theories: Mapping the territory. Revista IESE Insight Business Knowledge, 51-71.

Gémar, G. y Espinar, D. (2015). Communication about Corporate Social Responsibility practices and Return on Equity. Revista de Empresa Familiar, 7-15.

Giraldo, G. (2008). Responsabilidad Social Empresarial en Antioquía. Universidad Eafit, 38-59.

Gitman, L. (2012). Principios de administración financiera. México, DF: Pearson.

Gras, E.; Palacios, M. y Hernández, J. (2016). Investigating the relationship between corporate social responsability and earnings management: Evidence from Spain. Business Research Quarterly, 289-299.

Hair, J.; Anderson, R.; Tatham, R. y William, C. (1995). Multivariate Data Analysis with readings. London: Prentice Hall Inc.

Initative, G. R. (noviembre de 2015). Guía para la elaboración de memorias de sostenibilidad. Disponible en: https://www.globalreporting.org/ resourcelibrary/Spanish-G4-Part-One.pdf.

Karagiorgos, T. (2010). Corporate Social Responsibility and Financial Performance: An Empirical Analysis on Greek Companies. European Research Studies, 13. Disponible en: https://www.researchgate.net/ publication/287176601_Corporate_social_responsibility_and_financial_performance_An_empirical_analysis_on_Greek_companies.

Lech, A. (2013). Corporate Social Responsibility and Financial Performance. Theoretical and Empirical Aspects. VERSITA, 1-14. Disponible en: https://www.degruyter.com/view/j/cer.2013.16.issue-3/cer-20130018/cer-2013-0018.xml.

Luque, T. (1997). Investigación de Marketing. Barcelona: Ariel.

Madorran, C. y García , T. (2014). Corporate social responsibility and financial performance: the spanish case. revista de administración de empresas, 20-28.

Margolis, J.; Elfenbein, H. y Walsh, J. (2007). Does it pay to be good? A meta-analysis and redirection of research on the relationship between corporate social and financial performance. Academy of Management Meetings. 
Martínez Fierro, J. y Frías Aceituno, J. (2015). Relationship between sustainable development and financial performance: international empirical research. Business Strategy and the Environment, 20-39.

McWilliams, A. y Siegel, D. (2000). Corporate social responsibility and financial performance: correlation or misspecification. Strategic Management Journal, 603-609.

Nelling, E. y Webb, E. (2009). Corporate social responsibity and financial performance: the virtuous circle revisited. Review of quantitative finance and accounting, 197-209.

Ortiz, L. (29 de mayo de 2011). El Observador Económico. Obtenido de Evolución del concepto de Responsabilidad Social Empresarial (RSE): Disponible en: http://www.elobservadoreconomico.com/ articulo/1096.

Porto, N. y Castromán, J. (2006). Responsabilidad social: un análisis de la situación actual en México y España. Contaduría y Amdinistración, 67-87.

Rodríguez, M. (2015). Social responsibility and financial performance: The role of good corporate governance. ELSEVIER Business Research Quarterly, 137-151. Disponible en: http://www.sciencedirect.com/ science/article/pii/S2340943615000791.

Sadeghi, G.; Arabsalehi, M. y Hamavandi, M. (2016). Impact of corporate social performance on financial performance of manufacturing companies (IMC) listed on the Tehran Stock Exchange. International Journal of law and management, 634-659.

Sánchez, J. (2002). Análisis de rentabilidad de la empresa. 5 campus.com. Análisis contable. Disponible en: http://www.5campus.com/leccion/ anarenta (acceso: 26 de noviembre de 2018).

Skjong, R. y Wentworth, B. (2000). Expert Judgement and risk perception. Superintendencia de Bancos (s.f.). Superbancos. Disponible en: https://www. google.com/url? sa=t\&rct=j\&q=\&esrc=s\&source=web\&cd=1\&cad $=$ rja $\&$ uact $=8 \&$ ved $=0$ ahUKEwiUs $7 \mathrm{rb}-\mathrm{ZnXAhXH8CYKHaRyBaM}$ QFgglMAA\&url=http \%3A\%2F\%2Fwww.superbancos.gob.ec\%2 Fmedios\%2FPORTALDOCS\%2Fdownloads\%2Festadisticas \%2F Notas_Tecnicas_5.doc\&usg=AOvVaw3Ndmec6YK.

Superintendencia de Economía Popular y Solidaria (11 de julio de 2017). Cooperativas hacia la responsabilidad social. Disponible en: http:// www.seps.gob.ec/noticia-medio?cooperativas-hacia-la-responsabilidad-social (acceso: 20 de noviembre de 2017).

Superintendencia de Economía Popular y Solidaria (agosto de 2018). Boletín sector financiero popular y solidario. Disponible en: http://http://www.seps.gob.ec/documents/20181/789362/ Boleti \% C C 81 n +SFPS-Agosto+\%282\%29.pdf/ 
b302eced-7b88-423e-a7c5-ded5bad6e983? version=1.0 (acceso: 20 de noviembre de 2017).

Toro, D. (2006). El enfoque estratégico de la responsabilidad social corporativa: revisión de la literatura académica. Intangible Capital,338-358.

Tsoutsoura, M. (2004). Corporate Social Responsibility and Financial Performance. Center for Responsible Business UC Berkeley, 1-22. Disponible en: http://escholarship.org/uc/item/111799p2.

Valenzuela, L.; Jara, M. y Villegas, F. (2014). Prácticas de responsabilidad Social, reputación corporativa y desempeño financiero. RAE-Revista de Administração de Empresas, 55(3), 329-344. Disponible en: https://dialnet.unirioja.es/servlet/articulo?codigo=5131442.

Van Der Fels-Klerx, I.; Goseens, L.; Saaticamp, H. y Horst, S. (2002). Elicitation of quantitative data from a heterogeneous Expert Panel: Formal process and application in animal health. Risk Analisis, 22(1), 67-81.

Vélez, A. (2011). Un recorrido hacia la Resposnabilidad Social Corporativa. Revista Ciencias Estratégicas, 55-74. Disponible en: http://www. redalyc.org/articulo.oa?id=151322413004.

Yoon, Y.; Gurhan-Canli, Z. y Schwarz, N. (2006). The effect of corporate social responsibility (CSR) activities on companies with bad reputations. Journal of Consumer Psychology, 377-390. 


\section{SeCCIÓN IV: \\ Responsabilidad Social UNIVERSITARIA (RSU)}





\title{
LA SIMULACIÓN COMO ESTRATEGIA EDUCATIVA PARA LA ENSEÑANZA DE LA SUSTENTABILIDAD EN INGENIERÍA, EN FRBA (UTN)
}

\author{
Diana Rut Schulman" \\ Milena Ramallo"* \\ Hugo Alejandro Izaguirre*** \\ Argentina
}

\section{INTRODUCCIÓN}

A partir de considerar que las instituciones en general y las educativas en particular tienen la responsabilidad de incorporar el concepto de Desarrollo Sustentable en sus diseños curriculares, entendemos que, en el caso de la educación superior, se encarará también, y como corolario, la Responsabilidad Social tan anhelada en los ámbitos universitarios. Esta premisa se introduce con fuerza en la formación de ingenieros, dado que se está planteando una nueva concepción de ciencia y tecnología.

El objetivo de este trabajo es presentar los avances del proyecto de investigación «La enseñanza de la sustentabilidad en la formación de los ingenieros mecánicos. Una experiencia de innovación a partir de estrategias de simulación", que se desarrolla en la Facultad Regional Buenos Aires de la Universidad Tecnológica Nacional (UTN) Argentina, en el período 2016-2018.

Doctora en Ciencias Sociales, UTN FRBA, UNLu. Correo electrónico: dianarschulman@gmail.com

** Magíster en Ciencias Sociales con Mención en Educación, UTN FRBA. Correo electrónico: ramallo.milena@gmail.com

**** Licenciado en Tecnología Educativa, UTN FRBA. Correo electrónico: izagui@ gmail.com 
En el sentido teórico, se desarrollan aquí los avances respecto del estudio de las posiciones más destacadas en el tema de la sustentabilidad. En el sentido práctico, los resultados del trabajo de campo que se llevó a cabo durante el 2017, en la búsqueda y aplicación de nuevas estrategias de enseñanza para la ingeniería, tendientes a lograr una innovación de las prácticas docentes, basados en el construccionismo de Seymour Papert $(1987,1998)$.

Se describen también las primeras experiencias de simulación llevadas a cabo con estudiantes de ingeniería durante el cursado de la asignatura Ingeniería y Sociedad (ramo de primer año de la carrera de Ingeniería Mecánica) en 2017 y los resultados obtenidos.

Por último, las primeras conclusiones respecto del proyecto en curso, que busca contribuir en la construcción de una mirada de una ingeniería sustentable.

\section{ForMulaCión DEL PROBLEMA}

Los cambios que están aconteciendo en el orden económico, social y político en la sociedad del conocimiento desafían fuertemente la responsabilidad de las organizaciones sociales, sean estas empresariales o educativas. Se pone el acento en el conocimiento como posibilidad para alcanzar el desarrollo cultural, social, económico y ecológico de las comunidades y naciones. La preservación, el refuerzo y el incentivo de la misión y los valores de la educación superior demandan una fuerte revalorización en el logro del Desarrollo Sustentable (DS) y de la mejora de la sociedad en general. La pregunta por la responsabilidad de la universidad remite a una inquietud por aclarar cuál es su lugar en la esfera pública y cuál es el modelo de sociedad que está contribuyendo a construir. Así, la noción de DS convoca a las universidades a trascender de su propia mirada para generar vínculos con el entorno y colaborar con el aumento de capital social. La universidad como actor social tiene un papel fundamental y estratégico para que los ideales universales de igualdad, equidad y justicia sean una realidad. Pero ¿cómo formar ciudadanos que impulsen la sostenibilidad global e integral? El alcance que tiene dicha pregunta solo es posible valorarlo a la luz de las respuestas que recibe: de qué se están haciendo responsables, a quién o a quiénes están respondiendo, cómo lo están haciendo y al servicio de quién o quiénes están poniendo ese bien que atesoran. Si se asume como desafío que las universidades deberán alcanzar una clara visibilidad en los progresos para la comunidad 
universitaria y la sociedad, es necesario que sean claros los lineamientos de su responsabilidad con la sociedad y, consecuentemente, las funciones asociadas a los distintos ámbitos de su misión.

Los conceptos centrales utilizados como marco referencial del trabajo son el construccionismo y el desarrollo sustentable.

\section{Construccionismo}

Seymour Papert $(1987,1998)$ es referente destacado en el campo de la innovación educativa, pues desarrolló su teoría sobre el construccionismo basándose en los trabajos sobre constructivismo de Jean Piaget, del que se le considera discípulo, con quien trabajó en la Universidad de Ginebra. La teoría constructivista del aprendizaje de Piaget, quien realizó experiencias con el entorno y la cooperación que desarrollan la inteligencia individual del niño, caló profundamente en Papert. De dichas teorías recupera precisamente la noción de aprendizaje como una construcción de conocimientos. Así, supera la idea de la transmisión unilateral: el aprendizaje es más eficaz cuando forma parte de una actividad que el sujeto experimenta como la construcción de un producto significativo.

Papert sostiene que quien aprende es un diseñador, un descubridor de campos de conocimiento. Tanto en el enfoque de Piaget como en el de Vigotsky, los métodos de enseñanza valorados son similares: experiencias como los juegos en general y los de rol, donde se aprende enseñando o diseñando, los estudios de casos, aprendizajes guiados, cooperativos y colaborativos, etc. defienden la elaboración y la construcción, el aprendizaje mediante la experiencia.

Sobre dichos fundamentos, Papert desarrolla el construccionismo, estableciendo una línea de trabajo que le otorga a la tecnología un rol central tanto para la innovación como para el cambio en la educación. En este enfoque, entonces, se resalta la importancia de aprender haciendo: el conocimiento no puede ser transmitido, es el sujeto quien lo construye en acción. El docente cumple el rol de facilitador en la construcción de estructuras del conocimiento a partir de la actividad del estudiante. El objetivo fundamental de esta postura consiste en concebir el conocimiento como diseño y la tecnología como medio que permite realizarlo (Gros Salvat, 2002).

Entendemos que la universidad posee, entre otras, la responsabilidad de incorporar el concepto de Desarrollo Sustentable en sus diseños 
curriculares y que una metodología de enseñanza desde la perspectiva construccionista contribuiría para hacerlo.

\section{Estudios ACERCA DE LOS JUEGOS EN EL CAMPO EDUCATIVO}

El juego ha sido utilizado como un recurso educativo desde la antigüedad. Platón fue uno de los primeros en reconocer el valor práctico del juego, identificándolo con el culto sacro. Aristóteles, en el libro IV de la Ética, lo recomienda como actividad complementaria a la hora del descanso como una forma de aliviar el intelecto fatigado y como el camino para ensayar los ejercicios que los niños realizarán en edad más avanzada.

Con el paso del tiempo, diversas disciplinas - como la pedagogía, psicología, filosofía, entre otras- han aportado y potenciado las ventajas del juego en el ámbito educativo, dándole un lugar significativo en los procesos de enseñanza y aprendizaje. Algunos representantes de la pedagogía de los siglos XVII y XVIII han resaltado la importancia de la integración del juego a la educación y el impacto que brinda para el autoconocimiento, autodominio y ejercitación corporal. Por ejemplo, Rousseau destacó la posibilidad que el juego proporciona en términos de libertad y espontaneidad. Pestalozzi y Dewey han ido reconociendo en el juego un recurso complementario para las actividades que no presentan buenos resultados en el plano educativo, acercándose al aprendizaje activo (Valcarcel, 2011).

Después de la segunda mitad del siglo XIX, otros pensadores provenientes del campo de la psicología han brindado otros aportes, consolidando este campo de estudio. Distintas concepciones sobre cómo entenderlo permiten reconocer interpretaciones acerca del mismo:

- El juego habilita a consumir energías no utilizadas (Spencer, 1985);

- Relaja la mente después de tareas trabajosas (Lazarus, 1883);

- Supone ejercicios que preparan al sujeto para actividades que luego realizará en su vida adulta (Groos, 1901).

Las teorías más contemporáneas, ya avanzado el siglo XX, contribuyen a vincular más concretamente el juego con la infancia y la educación, teniendo un rol fundamental para el desarrollo cognitivo del niño. Winnicott define al juego en función de lo expresivo. A través de él, el niño expresa sus sentimientos, controla ansiedades, establece 
contactos sociales e integra su personalidad. Para Piaget, mediante el juego, el niño asimila lo que le llega del exterior y lo acomoda libre de ataduras a los fines de alcanzar su comprensión. Vigotsky también, como Piaget, rescata a la acción como origen del juego, pero aquí la presencia del mundo del adulto es necesaria para la construcción de su autonomía. De este modo, el mundo que lo rodea es fundamental para que logre su aprendizaje simbólico. Bruner realiza un aporte importante para pensar el juego en grupos, ya que este favorece tanto el desarrollo del lenguaje como el del pensamiento.

De las teorías psicológicas, Papert recupera la noción del aprendizaje como reconstrucción de conocimientos, proponiéndose superar la idea de ser una mera transmisión. Este autor sostiene que el aprendizaje es más eficaz cuando forma parte de una actividad que el sujeto experimenta como la construcción de un producto significativo.

Sus aportes se originan del modelo de estudiante como diseñador, enfatizando la importancia del aprendizaje por descubrimiento. Tanto en el enfoque de Piaget como en el de Vigotsky, los métodos de enseñanza valorados son similares: juegos, estudios de casos, aprendizaje guiado, juegos de rol, aprendizaje cooperativo, colaborativo, aprender enseñando, aprender diseñando, etc.

En los últimos treinta años, la proliferación de los juegos de simulación utilizados para el aprendizaje ha presentado múltiples variantes en función de sus objetivos, formas de aplicación y evaluación. En este sentido, hemos relevado experiencias interesantes, que muestran su aprovechamiento en tanto estrategia de enseñanza, señalando además una larga trayectoria en el campo educativo.

Ahora bien, no obstante la difusión de estas experiencias y sus evidentes implicancias, se ha podido constatar muy incipientemente la presencia de intervenciones pedagógico-didácticas que muestren la utilización de juegos de simulación y sus potencialidades dentro de esta casa de estudios.

\section{EL NUEVO PARADIGMA DE LA INGENIERÍA: \\ EL DESARROLLO SUSTENTABLE}

La idea del Desarrollo Sustentable ha impuesto un nuevo desafío a las universidades y más precisamente una nueva concepción de ciencia y tecnología. 
La construcción teórica del concepto de Desarrollo Sustentable comienza en la década del 60, aunque logra instalarse en los discursos a nivel internacional en 1992.

Siguiendo a Cambra Bassols (2008), el concepto de desarrollo sustentable se usa de modo errado y reduccionista cuando se refiere solo a la dimensión ambiental del desarrollo. También el concepto se fue desvirtuando con la pérdida de contenido reflexivo en el discurso político, económico y académico: tanto con los intereses de los sectores sociales más poderosos como con el entusiasmo humanitario de los que tenían buenas intenciones.

Más allá de estas difusas aplicaciones, la noción de sustentabilidad es muy antigua y ha sido practicada por culturas indígenas, como por ejemplo la civilización maya, a través de las terrazas de cultivo para aprovechar la fertilidad de suelos áridos.

La historia del desarrollo en su versión aún dominante, se origina después de la Segunda Guerra Mundial. La lógica fue extrapolar los éxitos logrados en Europa en el resto del mundo gracias al Plan Marshall: ideas económicas exitosas a regiones consideradas como subdesarrolladas. Esta concepción utilitaria pasa por alto la importancia de lo regional en materia de desarrollo. Para el modelo de desarrollo centrado en lo económico, las acciones se imponen desde fuera, no desde el interior de los grupos sociales. Y, fundamentalmente, se promueven desde los sectores más poderosos hacia los más desprotegidos. Este modelo no tiene en cuenta las posibilidades y necesidades propias de cada región, por el contrario, está vinculado a la acumulación de capital y consumo y toma de lo regional aquello que abunda naturalmente, sin proponerse potenciarlo. Tampoco prioriza su riqueza cultural específica.

En este sentido, Carlos Moneta (1994) hace mención a la idea de colonización que está implicada en este modo de moverse del capital. Las particularidades de las regiones y sus riquezas son aprovechadas por los poderes transnacionales, generando y profundizando desigualdades, tanto entre los países como al interior de cada uno de ellos.

Si sostenemos que la idea de desarrollo no debe acoplarse estrictamente a lo económico, y si en los ámbitos de lo político, económico, social y científico-tecnológico tiene como destinatario al ser humano y a la satisfacción de sus necesidades, entonces la vieja idea de desarrollo en términos puramente economicistas ya no es aplicable. Así lo entendió el Programa de Naciones Unidas para el Desarrollo (PNUD, 1999) cuando propuso un indicador que no sea solamente el ingreso 
per cápita. Las dimensiones de desarrollo sustentable comprenden, desde este nuevo punto de vista, aspectos culturales, éticos, políticos y económicos. Atienden desde dentro a la preocupación por responder a las necesidades y exigencias reales de cada región. En esta orientación se impulsa la descentralización, la participación local y comunitaria. Esta idea supera el enfoque medioambientalista y se instala en una dimensión que abarca lo humano por encima de los objetos de producción.

Un antecedente importante en la evolución del concepto fue el Informe Brundtland (Comisión creada en la Asamblea de Naciones Unidas en 1983). En él se manifiestan aspectos sobre el humanitarismo de los países desarrollados para ayudar a los más vulnerables y la posibilidad de incrementar los recursos básicos. Aquí se puso el énfasis en el Desarrollo Sustentable (DS), en relación con el trípode: entorno-equidad económica-equidad social. Se plantearon temas específicos como: la satisfacción de las necesidades físicas, psicológicas y sociales de los seres humanos; la respuesta a las necesidades primarias de las personas, como el alimento, la vestimenta, la salud, la vivienda, el trabajo y la educación; y también la distribución inequitativa de los recursos de la humanidad (Cambra Bassols, 2008).

En nuestros días, este tema continúa asumiendo una posición importante en la Agenda Política Internacional, asentada en la posibilidad de satisfacer las necesidades de las generaciones del presente respetando la equidad social y entre generaciones, el equilibrio de la ecología y el crecimiento económico sostenible (Marchetti, 2004).

\section{¿Por Qué el Desarrollo sustentable no es solo MEDIOAMBIENTALISMO?}

Desarrollo y medioambiente mantienen una relación que nadie discute. Sin embargo, es necesario superar la estrecha visión del medioambientalismo (Cambra Bassols, 2008) como único medio para alcanzar el desarrollo.

El proceso de industrialización se ha generado mediante una continua degradación del medio ambiente a nivel global, sin que se pudieran advertir las nocivas consecuencias sobre la humanidad. Si bien la conservación medioambiental es una responsabilidad de cada uno de los países, esto debe enmarcarse en un clima renovado de cooperación y solidaridad internacional promovidas por «mecanismos supranacionales». Esto les daría a las economías regionales posibilidades de acceso 
a recursos desarrollados a nivel global. Ejemplos en la búsqueda de ese diálogo han pretendido ser las conferencias que la ONU (Naciones Unidas) viene desarrollando hace más de tres décadas:

- En 1972 se celebra la primera Conferencia de Naciones Unidas sobre el Medio Humano (llamada posteriormente Cumbre de la Tierra de Estocolmo). Fue la primera vez que se asume la necesidad de definir una política internacional del medioambiente instaurando el Programa del Medio Ambiente de las Naciones Unidas.

- En 1983, la ONU creó la Comisión Mundial sobre el Medio Ambiente y el Desarrollo. En este marco se elaboró el Informe denominado «Nuestro Futuro Común», dirigido por Gro Harlem Brundtland, ex primera ministra de Noruega.

- En 1987, la Comisión Mundial del Medio Ambiente utilizó por primera vez la definición de desarrollo sustentable, entendiéndolo como «un desarrollo que satisfaga las necesidades del presente sin poner en peligro la capacidad de las generaciones futuras para atender sus propias necesidades».

- En 1992, la Cumbre de la Tierra, que tuvo lugar en Río de Janeiro, puso en discusión la noción de desarrollo sustentable, no solo restringida a aspectos medioambientales, buscando alcanzar un equilibrio justo entre las necesidades sociales, económicas y ambientales.

- En 1999, el Programa de Naciones Unidas para el Desarrollo (PNUD) planteó la necesidad de redefinir la idea de desarrollo. Debía separarse de criterios netamente economicistas. Aparece así el concepto de Desarrollo Humano (DH), entendido como un concepto complejo que vincula factores como la salud, el ingreso, la educación, el rol de la mujer, la situación del ambiente, entre otros. Este nuevo concepto integra y complementa al concepto de Desarrollo Sustentable. El DH se centra en la persona y la necesidad de satisfacer sus necesidades básicas. En el Índice de Desarrollo Humano (IDH) se reúnen tres dimensiones: salud —referida a la expectativa de vida al nacer-, educación —-midiendo la tasa de alfabetización y matriculación- y el ingreso —-modificando la medición anterior, en especial para países con valores de ingreso que superan la media mundial- (Capalbo, 2008).

- En 2002, en la Cumbre de la Tierra de Johannesburgo, se expuso la preocupación por el desilusionante resultado obtenido en la búsqueda por el desarrollo sustentable. La Asamblea General de las Naciones Unidas denunciaba el aumento de la pobreza 
y la degradación del medioambiente, advirtiendo la necesidad imperiosa de una cumbre de acciones y resultados, más que un nuevo debate filosófico político.

- En 2012, la Cumbre Río +20 se propuso lograr un acuerdo de mínimos plasmado en la definición del documento «El futuro que queremos». Los principales temas tratados fueron la reducción de la pobreza, la promoción de la equidad social y la necesidad de garantizar la protección del medioambiente. Los debates giraron alrededor de la construcción de una «economía ecológica» para alcanzar el desarrollo sustentable y sacar a la gente de la pobreza, y en cómo mejorar la «coordinación internacional» en este tema.

El análisis de estos documentos internacionales da cuenta de la relevancia de ampliar la noción de desarrollo sustentable. El término, en inglés sustainable development, plantea la idea de equilibro en el tiempo, la forma de encontrar los límites apropiados en el uso de los recursos humanos, económicos y naturales. Alude a las posibilidades de cada región o país de responder a sus propias necesidades. Es en este sentido en el que sostenemos la idea del concepto con referencia a un sistema específico de valores: la equidad, la responsabilidad, la toma de conciencia, el compromiso y la cooperación entre países.

\section{El Desarrollo Sustentable (DS) en la educación SUPERIOR}

Con la trascendencia del campo del Desarrollo Sustentable (DS) y de otros vinculados a él, entre ellos la Responsabilidad Social Empresaria (RSE), se ha planteado como un desafío a la educación superior la necesidad de su inclusión en la formación de los profesionales. Esto puede verse claramente con la generación de redes — como es el caso de la Red Iberoamericana de Universidades por la RSE- o los programas de Formadores en RSE, que tienen a su cargo reconocidos intelectuales como Bernardo Kliksberg. Se agrega a esta creciente significación e interés para la universidad el área de estudio y aplicación, que se conoce con el nombre de Responsabilidad Social Universitaria (RSU).

En los últimos veinte años, la UNESCO (en documentos de 1998 y de 2009) ha insistido en que la educación superior debe cumplir una misión social, garantizando calidad en la enseñanza, formación e investigación y brindando servicios a la sociedad. Se ha propuesto que desde 
las instituciones universitarias se generen conocimientos específicos que respondan a los problemas socioeconómicos, políticos y culturales de sus propios contextos.

El desarrollo sustentable también es hoy un eje fundamental dentro del programa general de la Naciones Unidas, conocido como «La agenda 2030 para el desarrollo sostenible», donde estipula que:

La Agenda 2030 se centra en las personas y es universal y transformadora, que los Objetivos de Desarrollo Sostenible y las metas son de carácter integrado e indivisible y conjugan las tres dimensiones del desarrollo sostenible económica, social y ambiental y que la Agenda es un plan de acción para las personas, el planeta y la prosperidad que también trata de fortalecer la paz universal en un concepto más amplio de la libertad, que será aplicado por todos los países y partes interesadas actuando en asociación de colaboración, y reafirmando además todos los principios reconocidos en la Agenda y que la erradicación de la pobreza en todas sus formas y dimensiones, incluida la pobreza extrema, es el mayor desafío a que se enfrenta el mundo y constituye un requisito indispensable para el desarrollo sostenible (ONU, 2015).

En el ámbito de la ingeniería se han logrado avances en cuanto a la formulación de principios, técnicas y normativas; estrategias que promueven opciones más amigables con el ambiente. Entre ellas, los principios de Hannover (Mac Donough, 2000); la Declaración de Shanghái «Ingeniería y Futuro Sostenible» (2004); los Principios guía para la Ingeniería para el Desarrollo Sostenible de la Real Academia de Londres (2005); el Manual para la Productividad Verde de la Organización de Productividad Asiática (2008), en el que se promueve y ejemplifica el uso de la Ecoeficiencia, Producción más limpia, Análisis del Ciclo de Vida, Ecodiseño, las Normas ISO 14000 y las 5R (reusar, reciclar, rechazar, reducir, recuperar).

Asimismo, en el informe de la Unesco (2013) «Programa de Acción Global para la Educación en Desarrollo Sostenible», se plantea que para alcanzar el DS es necesario no solo lograr consensos políticos, impulsos financieros o respuestas tecnológicas, sino además se requiere de una evolución en cómo actuar y pensar el tema. La educación es un factor decisivo para lograr ese cambio. En ese sentido, los objetivos del Programa de Acción Global son: a) reorientar la educación y el aprendizaje para que todas las personas tengan la oportunidad de adquirir conocimientos, competencias, valores y actitudes con los que puedan contribuir al desarrollo sostenible; y b) fortalecer la educación 
y el aprendizaje en todos los programas, agendas y actividades de promoción del desarrollo sostenible (UNESCO, 2013).

En Argentina, el ConFeDI (Consejo Federal de Decanos de Ingeniería) señala que es necesario definir claramente la misión de la universidad teniendo en cuenta la realidad actual nacional e internacional, traduciendo los conocimientos en acciones específicas que busquen mejorar la calidad de vida de la sociedad. Esta importancia también ha sido advertida desde la Ley de Educación Superior Nº 24521 (1995), cuando se propuso ampliar las funciones básicas de las instituciones universitarias.

Así, en una sociedad cada vez más globalizada y con exigencias cada vez más crecientes en busca del desarrollo, le cabe a la ingeniería un papel fundamental en lo que hace a la sostenibilidad y el cuidado del medioambiente, que requiere de profesionales con una visión amplia, abarcativa y sistémica del mundo, tanto en lo técnico como en lo social. En este esquema, las instituciones de enseñanza en ingeniería se constituyen en uno de los pilares del sistema, como consecuencia directa de la naturaleza y la vastedad del campo del conocimiento que generan y del que están en condiciones de transmitir (CONFEDI, 2010).

En 2014, en el marco del Congreso Mundial de Ingeniería, se presentaron los siguientes objetivos prioritarios: «Revalorizar el rol social de la Universidad en general, y de las carreras de Ingeniería en particular, para aportar al bienestar de la sociedad argentina en la cobertura de las necesidades básicas, condiciones necesarias para el desarrollo sostenible local y regional», y «Promover el Desarrollo Sostenible, mediante la participación activa de la Universidad como consultora natural de los poderes de los Estados provinciales, municipales y nacional, en la fijación de políticas públicas». Desde esta mirada, es imperiosa la necesidad de destacar que el rol de la ingeniería para el bienestar de la sociedad y su calidad de vida son condiciones necesarias para el desarrollo sostenible local y regional, asumiendo una visión amplia, abarcativa y sistémica del mundo, tanto desde el punto de vista técnico como desde el social.

Por su parte, la Comisión de Ingeniería Ambiental y Desarrollo Sustentable, perteneciente al Centro Argentino de Ingenieros (CAI), también postula una mirada del desarrollo sustentable, cuyo eje se focaliza en la relación ingeniería y cuidado del medioambiente. Algunos de sus propósitos conciernen al análisis de las «(...) actividades de los sectores de la economía con gran incidencia ambiental y social y potencial de riesgo para la salud humana y los ecosistemas; y a la planificación estratégica de desarrollo del país». Mediante un enfoque 
interdisciplinario, postulan «interpretar y difundir los criterios y principios del desarrollo sustentable, a través de documentos técnicos, de jornadas de discusión y difusión de temas específicos, y de informes que se le requieran, sobre el diseño y aplicación de herramientas de gestión ambiental» (CAI, 2018).

En la Universidad Tecnológica Nacional, y más precisamente en la Facultad Regional Buenos Aires, se está viviendo un proceso de cambio acerca de la visión de la ingeniería, el que comenzó a poner en evidencia la importancia de la incorporación de temas vinculados con el DS y la Responsabilidad Social. Este nuevo horizonte interpela a la ingeniería. Esta interpelación tiene varias consecuencias, una de ella es la ya establecida inclusión en el currículo de materias sobre medioambiente, si bien es esta todavía una inclusión técnica y reducida a lo ambiental; la otra es que abre a la reflexión sobre la vinculación ingeniería-sociedad, ingeniería-epistemología-ingeniería-ética, en muchos lugares esta problemática aparece bajo el nombre de filosofía de la ingeniería.

La enseñanza del DS presenta un nuevo desafío en la formación de los ingenieros, profundizando la reflexión en la forma de entender a los proyectos de ingeniería, el perfil del ingeniero y a las relaciones entre la ciencia, tecnología y la sociedad (CTS) en sí.

En nuestros días, este tema continúa ocupando una posición central en la Agenda Política Internacional. La discusión se asienta en la responsabilidad de satisfacer las necesidades de las generaciones del presente sin descuidar la equidad social, los vínculos intergeneracionales, la atención a la ecología y el crecimiento económico sostenible, lo cual significa hacerse cargo de las necesidades de las generaciones futuras (Marchetti, 2004).

\section{Simulación y JUEGo: VÍnCUlos CON EL APRENDiZAJE}

La simulación es el proceso de diseñar un modelo basado en un sistema real y poder llevar a término experiencias con dicho modelo, a fin de comprender el comportamiento del sistema. Para poder entrar en la lógica de la simulación, lo cual implica entrar en la lógica del juego, es necesario disponer de una representación. A dicha representación se la denomina modelo: es la representación artificial de un fenómeno, proceso o acción real (De la Torre, 1997). 
Tomando como base lo mencionado, y desde una perspectiva profundamente pedagógico-didáctica, detallamos los pilares fundacionales para implementar los juegos de simulación como estrategia didáctica:

- Las estrategias de juegos de simulación poseen la capacidad de ofrecer un nivel intermedio de abstracción, intermedio porque la representación da cuenta de una abstracción del mundo real y es más concreta que las abstracciones de los modelos mentales; o sea, es «directamente manipulable».

- También, ofrecen una versión simple y más comprendida del mundo. O sea, que el sujeto que interactúa con un juego de simulación se le presenta un espacio de problema más reducido, es decir, con límites más definidos, tornándose más accesible para este.

- Claramente ofrecen oportunidades de desarrollar habilidades procedimentales. A su vez, también pueden ofrecer muy buenas condiciones respecto de lo económico y del riesgo en la práctica.

- Y, por último, dichos juegos de simulación como estrategia necesitan de un sujeto activo para resolver problemas en él, puesto que este llevará al estudiante a la formación de conjeturas, evaluación de hipótesis, inferencias, evaluación de evidencias, búsquedas controladas, etc.

Por tanto, los juegos de simulación como estrategia contribuyen al desarrollo de habilidades para resolver problemas de orden factual; evidenciándose de esta manera la importancia como herramienta para la formación de estrategias, habilidades y, en definitiva, competencias profesionales básicas y específicas que servirán de base para el futuro desempeño en el mundo real.

Participar de un juego de simulación permite que los estudiantes desarrollen capacidades de imaginación y de representación de realidades futuras, así como ensayar estrategias para resolver problemas y tomar decisiones, aprender nuevas y creativas técnicas para abordar situaciones ya conocidas y modificar e intercambiar roles y tareas. En palabras de Krain y Lantis (2006, p. 396), los ejercicios de simulación «mejoran la experiencia educativa ya que promueven el pensamiento crítico y las habilidades analíticas, ofreciendo a los estudiantes un nivel más profundo en la dinámica de intercambio político, el fomento de las competencias de comunicación oral y escrita y el fomento de la confianza de los estudiantes», beneficios que avalan de manera clara 
la utilización de estrategias y didácticas de enseñanza y aprendizaje, en donde el estudiante adquiera un mayor protagonismo e interacción con sus conocimientos, habilidades y compañeros de clase.

El hombre ha utilizado el juego como vehículo de socialización y entretenimiento, como estrategia para adquirir habilidades y destrezas que le permitan desempeñarse en la vida. En el ámbito de la universidad, la simulación a través del juego posibilita representar la esencia de una situación por su nivel de abstracción y luego de la misma, obtener conclusiones para comprender y aplicar en la vida. Seymour Papert, el inventor del lenguaje logo, entendió rápidamente que programar era una actividad creativa de aprendizaje y que podía ser aplicada a otros aspectos fuera del escenario del juego. Por eso propuso promover los usos de simuladores, para que los estudiantes aprendan a hacer hipótesis y así fomentar la experiencia de iniciación en el método hipotético-deductivo.

De acuerdo con Díaz (1999, p. 17), el constructivismo y el aprendizaje significativo plantean una mirada totalmente diferente a la tradicional, al señalar que:

el alumno selecciona, organiza y transforma la información que recibe de muy diversas fuentes, estableciendo relaciones entre dicha información y sus ideas o conocimientos previos; así, aprender un contenido quiere decir que el alumno le atribuye un significado, construye una representación mental a través de imágenes o proposiciones verbales o bien elabora una especie de teoría o modelo mental como marco explicativo de dicho conocimiento.

Desde este marco, entonces, la simulación es también un modo de convertir las ideas y las relaciones formales y abstractas en objetos concretos, tangibles, maleables y, por ello mismo, más rápidamente comprensibles. La idea de la teoría construccionista es que "razonamos haciendo": cuando llevamos adelante dichas actividades, estamos poniendo en juego energía creativa y elaborando modos de pensamiento nuevos, formas disímiles de ver las cosas. Algunas de ellas nunca podrían salir al exterior de otra forma, ya que, al objetivarse un pensamiento, aparece una novedad construida entre un modo formal y la capacidad de realizarlo en el exterior.

También es importante hacer hincapié en algunos aspectos relevantes del constructivismo en los procesos de formación universitaria, que avalan la importancia de desarrollar procesos de enseñanza y 
aprendizaje donde los estudiantes sean los artífices importantes de su propio proceso de formación profesional, convirtiendo a los docentes en guías de dicho proceso, en especial cuando el constructivismo, como postura del aprendizaje y la enseñanza, nos plantea «la existencia y prevalencia de procesos activos en la construcción del conocimiento por parte de un sujeto cognitivo aportante, que claramente rebasa a través de su labor constructiva lo que le ofrece su entorno» (Díaz, 1999, p. 14).

\section{¿POR Qué El Juego de Simulación es una Metodología INNOVADORA PARA LA ENSEÑANZA DE LA SUSTENTABILIDAD?}

Por la potencialidad que tienen las situaciones vividas en juegos de simulación para interiorizar la información teórica, pero además por el valor para desarrollar competencias profesionales de modo creativo y favorecer la interacción y la reflexión a través de las propias acciones (De la Torre, 1997), consideramos que esta propuesta pedagógica para la formación de los ingenieros es la expresión de un enfoque que se sustenta en saberes integrados y articulados en la acción misma de la profesión. El ingeniero no solo debe saber, sino que también debe saber hacer. Este último no surge de la mera adquisición de conocimientos, sino que es el resultado de la puesta en funciones de una compleja estructura de conocimientos, habilidades y destrezas, que requiere ser reconocida expresamente en el proceso de aprendizaje.

En definitiva, buscamos generar prácticas pedagógicas que contribuyan a formar profesionales ingenieros con una profunda capacidad reflexiva sobre su accionar, puesto que cada decisión que pueda tomar supone un fuerte impacto en la realidad. Por ello, adherimos a la propuesta de Donald Schön (1992), citada por Daniel Feldman (1999):

(...) El elemento central de la formación de profesionales reflexivos es, según Schön, el practicum. El practicum consiste en generar una situación pensada y dispuesta para la tarea de aprender una práctica. Es un contexto parecido al mundo real de la práctica pero libre de sus presiones. En él los estudiantes se hacen cargo de sus proyectos que «simulan y simplifican la práctica». En el practicum, el trabajo combina el aprendizaje mediante la acción, las interacciones con pares y tutores y el aprendizaje experiencial y exige producir en tareas reales bajo la supervisión de un práctico veterano (Schön, 1992) (...). 
En este marco, la sustentabilidad pone de manifiesto una nueva manera de pensar la relación entre ciencia, tecnología e industria, asumiendo una concepción proactiva de la sociedad, con referencia a un sistema específico de valores: la equidad, la responsabilidad, la toma de conciencia, el compromiso y la cooperación. Todo esto supone la necesidad de desarrollar y aplicar nuevas estrategias cognitivas y metacognitivas para facilitar el proceso de aprendizaje. Las primeras requieren de la capacidad para reconocer y reflexionar críticamente las interrelaciones entre la ingeniería y la industria, comprendiendo la importancia del cambio tecnológico y sus consecuencias sociales, ambientales y éticas. Las segundas apuntan a la reflexión sobre el propio aprendizaje y aplican tanto a los conceptos como a los hábitos, actitudes y la toma de conciencia de que colaborar con la construcción de un mundo más solidario y más equitativo lo hace más habitable, por lo tanto, sustentable.

Es fundamental ofrecer un escenario pedagógico y de aprendizaje innovador, brindando nuevas maneras de interacción con los conocimientos y nuevas experiencias requeridas en la práctica profesional de la ingeniería. Una de las propuestas educativas que se basan en estos supuestos y que a nuestro entender pueden ayudar a la configuración de ese escenario, es la desarrollada por el construccionismo de Seymour Papert, quien resaltó la importancia del aprender haciendo: el conocimiento no puede ser transmitido, es el sujeto quien lo construye en acción. Desde ciertas teorías psicológicas, Papert recupera la noción del aprendizaje como reconstrucción de conocimientos, proponiéndose superar la idea de ser una mera transmisión. Este autor sostiene que el aprendizaje es más eficaz cuando forma parte de una actividad que el sujeto experimenta como la construcción de un producto significativo. El objetivo fundamental de esta postura consiste en concebir el conocimiento como diseño y la tecnología como medio que permite hacerlo (Gros Salvat, 2002).

Otro de los aspectos de su teoría sugiere que la utilización de conocimientos previos en la resolución de conflictos actuales es fundamental para la construcción de conocimientos nuevos. Lo dice así en uno de sus textos: «Para resolver un problema busca algo similar que ya comprendas». Este proceso de construcción hace que el aprendizaje sea significativo para el aprendiz, pero tanto el proceso de creación como el objeto construido deben ser compartidos con otros. Este vínculo de aprendizaje y creación se produce cuando se habla con los otros, cuando 
se explica y se llevan adelante diagramas y esquemas (Badilla Saxe y Chacón Murillo, 2004).

A partir de la observación en los niños de sus experiencias de aprendizaje atravesadas por actividades de repetición, Papert (1987) pudo afirmar que «el aprendizaje no depende solo de encontrar mejores formas de que el docente enseñe, sino brindando a los alumnos mejores oportunidades de construir». El construccionismo, entonces, no solo es una teoría sobre cómo facilitar los aprendizajes. Es también un modo de convertir las ideas y las relaciones formales y abstractas en objetos concretos, tangibles, maleables y por ello mismo, más rápidamente comprensibles. La idea de esta teoría es que «razonamos haciendo", y en dichas actividades, liberamos energía creativa, modos de pensamiento y modos de ver las cosas que, de otra forma, nunca podrían salir al exterior, objetivarse conteniendo también, los modos de pensamiento de quien crea o construye.

Por su parte, hemos podido constatar la existencia de varios estudios y experiencias referidos al uso y aprovechamiento de estrategias de enseñanza y aprendizaje que ponen de manifiesto la vinculación entre la enseñanza de temáticas inherentes al desarrollo sustentable e intervenciones pedagógico didácticas basadas en simulaciones.

\section{LOS RESULTADOS DE LAS EXPERIENCIAS DE CAMPO}

En función de lo expuesto, se resalta que esta etapa experiencial posee como marco teórico la teoría construccionista de Seymour Papert.

Nuestra experiencia educativa se realizó en noviembre de 2017, en un curso de alumnos que durante ese año se encontraban cursando Ingeniería y Sociedad, asignatura que forma parte del primer año de la carrera de Ingeniería Mecánica.

La encuesta, diseñada e implementada para el análisis de la experiencia, fue administrada al grupo mencionado. Para la definición del perfil de la muestra se consideraron las siguientes variables: sexo, edad, carrera en la que se desempeñaban, si realizaban alguna actividad laboral y turno de cursada. 


\section{OBSERVACIONES GENERALES SOBRE LA APLICACIÓN DE LOS JUEGOS DE SIMULACIÓN}

Se observó a los alumnos muy motivados por participar del juego desde el comienzo y dicha motivación y entusiasmo se mantuvieron a lo largo del mismo. Al analizar los comportamientos de los alumnos, como motivante aparece, en mayor medida, la idea de competencia entre ellos y la posibilidad de recibir un premio que incida en la nota final. También en algún caso se manifestó la posibilidad de relacionar los temas de la teoría en un caso práctico: el desafío de administrar bien los recursos y la posibilidad de tener que diseñar un producto.

Para los docentes, el desarrollo del juego fue una posibilidad concreta de ver a los estudiantes en movimiento, escena en la que afloraron cuestiones técnicas y criterios profesionales relacionados con la creatividad, la planificación estratégica, la ejecución, el control de un proyecto de negocios y el horizonte de posibilidades de innovación que abriga desde los primeros años los espíritus y las mentes de los estudiantes de ingeniería.

Cuando se les preguntó, a través de una encuesta posterior, los alumnos reconocieron encontrar similitudes entre el juego y el mundo real: los conflictos que se producen entre las diferentes áreas de una empresa -enfatizaron en el caso del área de marketing versus el área de ingeniería一, la innovación en técnicas de producción gracias al aprendizaje, el disponer de poco tiempo para tomar decisiones, la idea de hacer algo mejor o intentar ser mejor que la competencia, la idea de maximizar los beneficios.

Los docentes observamos que, inicialmente, los grupos debieron ponerse de acuerdo y dialogar para evaluar los pasos a seguir. Una vez decidido lo que harían, se observó un trabajo altamente cooperativo, con distribución ordenada de tareas, donde cada alumno logró concentrarse en su área. A pesar de las instrucciones dadas, algunos grupos decidieron organizar el trabajo de manera diferente. Si bien, originalmente, el juego solicitaba específicamente la definición de los roles, no se pudo distinguir con claridad el de cada uno: ningún estudiante sobresalió especialmente dirigiendo o dando órdenes. Todos trabajaron de manera más o menos uniforme y consultándose entre ellos.

El clima de aula fue de trabajo, respeto mutuo, compromiso y seriedad. Se observó a los alumnos muy involucrados en la actividad, distendidos y motivados por el objetivo que debían alcanzar. Si bien comprendían que estaban involucrados en un juego, prácticamente no se 
escucharon chistes o bromas. A diferencia de la experiencia en la sesión de prueba, en la versión definitiva no se observó gran rivalidad, sino un fuerte compromiso por cumplir con calidad la producción encomendada. Tampoco se observó apresuramiento por tratar de producir y vender. No parecían interesados en asumir grandes riesgos, sino más bien en cuidar el capital entregado.

La observación de la dinámica de trabajo permite confirmar la importancia de realizar experiencias innovadoras en las aulas universitarias, donde raramente ocurren. En la prueba piloto, los alumnos conversaban acerca de los roles que asumiría cada uno, se los vio implicados en la tarea de decidir la calidad del producto y en cumplir el objetivo del juego. En la experiencia final se pudo distinguir que se involucraron más en el diseño del producto, es decir, en el modo de resolver el problema, que en el resultado concreto del juego, que era generar la mayor cantidad de ventas posibles.

Es importante mencionar que la experiencia de simulación constó de dos partes. Una primera etapa donde se utilizaron los juegos LEGO y que se desarrolló a través de tres fases: diseño, implementación y evaluación de la experiencia. Una segunda etapa que se desarrolló a partir de un juego de roles.

\section{PRIMERA EXPERIENCIA: ESTRATEGIA DE SIMULACIÓN CON USO DE JUEGOS LEGO}

Las actividades que formaron parte de la experiencia fueron pensadas teniendo en cuenta el desarrollo de competencias profesionales generales y específicas propias del ingeniero en el marco del CONFEDI, los conocimientos previos de los estudiantes, los objetivos del PID, los entornos formativos vinculados a la formación de ingenieros, etc.

Para llevar adelante la experiencia y lograr con éxito los objetivos, se propuso a los estudiantes un plan de trabajo que consistió en leer las consignas detenidamente, realizar una memoria técnica y sistemática, evaluar los recursos necesarios, exponer los problemas encontrados, indicar posibles soluciones, tener en cuenta la factibilidad y viabilidad de cada proyecto realizado y exponer las conclusiones de cada experiencia con la máxima precisión posible.

Después del plan de trabajo, se les presentó como primera actividad el Desarrollo de la problemática 6A del Kit 9632 de LEGO Education. 
Los objetivos generales que se tuvieron en cuenta estuvieron orientados a que los estudiantes:

- Logren construir la balanza mecánica expuesta en los Manuales de Trabajo del Kit 9632 de LEGO Education.

- Analicen y logren comprender el funcionamiento del dispositivo construido.

- Realicen ensayos sencillos con el dispositivo.

- Indiquen posibles aplicaciones del dispositivo.

- Generen propuestas de mejora sobre lo trabajado.

Los objetivos propuestos estuvieron orientados conforme al desarrollo de la siguiente propuesta de trabajo:

1. Construir la propuesta del Manual 6A del Kit 9632 (pasos 1 al 8).

2. Realizar una breve memoria descriptiva de lo realizado (incluir croquis).

3. Realizar una breve descripción del funcionamiento del dispositivo construido.

4. Exponer los ensayos básicos realizados con el dispositivo.

5. Indicar posibles aplicaciones del dispositivo.

6. Indicar los problemas encontrados y soluciones adoptadas en cada caso.

7. Realizar una propuesta de mejora del dispositivo (incluyendo croquis).

8. Realizar una apreciación grupal a modo de conclusión respecto de todo lo trabajado.

\section{RESUlTADOS DE LAS ENCUESTAS SOBRE}

\section{LA PRIMERA EXPERIENCIA CON LEGO}

Luego de la experiencia con los juegos LEGO, los alumnos completaron una encuesta que nos permitió reflexionar acerca de sus puntos de vista y apreciaciones.

En todas las encuestas analizadas, los alumnos rescataron dos cuestiones: un aspecto al que hicieron referencia se centró en el trabajo en equipo que tuvieron que realizar para poder resolver la actividad. El segundo aspecto que más rescataron es haber podido llevar a cabo una actividad que los acercó al mundo empresarial, donde deberán tomar decisiones y asumir la división de las tareas. 
En la mayoría de los casos, casi el 90\% de los alumnos expresó que la mayor cantidad de habilidades que se pusieron en práctica fueron: el análisis y la síntesis que debieron hacer para lograr comprender las instrucciones, la solución de los problemas planteados, el armado del dispositivo, la aplicación de los conocimientos disponibles para la práctica concreta, la habilidad para trabajar en forma autónoma a la hora de asumir responsabilidades y sus consecuencias como el trabajo en equipo, tener que asumir una actitud de liderazgo para organizar y planificar, tener capacidad para la crítica y la autocrítica, el deber de gestionar la información, sentir motivación y el registro de la importancia de poseer habilidades personales e interpersonales para lograr los objetivos.

A partir del análisis de las encuestas, nos parece que la experiencia para los alumnos fue muy positiva. Descubrieron aprendiendo de maneras menos convencionales que como lo hacen habitualmente. En la expresión de los estudiantes, la práctica educativa «los acercó a lo que podría ser el mundo real una vez que termine la carrera». Fue comprendido que debían encarar la actividad en equipo, prestar atención a las opiniones de cada uno, escucharse, delegar y administrar de manera activa y participativa.

\section{SEgunda EXPERIENCIA: ESTRATEgIA DE SIMULACIÓN CON USO DE JUEGOS DE ROLES}

La segunda parte de la experiencia consistió en un juego de roles, en el que los alumnos tenían que representar ser miembros de la junta directiva de una empresa que se dedica a la fabricación de paneles solares, en un pueblo donde no llega la electricidad de forma tradicional. Los objetivos de aprendizaje propuestos son:

- Generar actitudes y comportamientos responsables para la toma de decisiones dirigidas al logro de un desarrollo culturalmente plural y físicamente sostenible;

- Comprender la necesidad de proteger el medio y la biodiversidad;

- Comprender la relevancia que tienen nuestras acciones - lo que hacemos o dejamos de hacer- y construir una visión global de las medidas en las que podemos implicarnos, tomando como guía las nociones de consumo responsable, actividad profesional y acción ciudadana. 
Los integrantes de la junta directiva ocuparon los lugares principales dentro de la empresa: a)presidente, b) vicepresidente, c) tesorero, d) ingeniero a cargo, y e) CEO o director/a ejecutivo/a. Estos miembros debían votar acerca de si su empresa tomaría la decisión de realizar una política social en donde brinde paneles solares a los habitantes de la comunidad a bajo costo (instalación), reduciendo sus márgenes de ganancia casi al mínimo, o si, por otro lado, mantenía la lógica de la ganancia empresaria y proponía la venta a la comunidad los paneles solares a precio de mercado, con el objetivo de aumentar los márgenes de rentabilidad de la compañía. Asimismo, y antes de pasar a la votación, el presidente de la firma compartió un documento que le ha llegado acerca de las posibilidades de llevar a la práctica el proyecto y las consecuencias que conllevaría para lograr el desarrollo sustentable. Este documento podía ser usado por los integrantes de la junta como forma de justificar su voto, o, por el contrario, también podrá ser rebatido en el debate de la junta acerca de las dificultades que podría ocasionar a la empresa la implementación de las políticas que marca dicho documento. Cada miembro de la junta debía fundamentar su voto de forma escrita, de acuerdo con el rol que cumple en la empresa, para que quede asentado en el acta de la compañía.

\section{RESUlTADOS DE LAS ENCUESTAS SOBRE \\ LA SEGUNDA EXPERIENCIA CON JUEGO DE ROLES}

Todos los alumnos encuestados destacaron la importancia del trabajo en lo que refiere a buscar una solución en conjunto. En este caso no era resolver un problema práctico, sino asumir un debate y tomar una posición concreta sobre una problemática. Todos coincidieron en que pudieron ponerse en el lugar de integrantes de una junta directiva de una empresa, tomar la decisión que consideraron más acertada y escuchar las opiniones y posturas de los demás.

En las habilidades que consideraron que se pusieron en juego a partir de la experiencia, la mayoría estuvo en sintonía con expresado luego de la actividad de los LEGO: análisis y síntesis de las instrucciones, la solución de problemas, la aplicación de los conocimientos disponibles en una práctica concreta, la capacidad de desplegar una postura tanto crítica como autocrítica, el compromiso ético, el tener que asumir actitudes de liderazgo, iniciativa y espíritu emprendedor, la preocupación por la 
calidad de los resultados, las habilidades interpersonales, el trabajo en equipo y la posibilidad de organizar y planificar.

Nuevamente, hay un porcentaje de respuestas que varían entre unos y otros en diferentes habilidades. La participación de los alumnos durante el juego fue aquí también muy activa y se observó interacción y discusión de diferentes puntos de vista, lo cual enriqueció ampliamente la experiencia.

\section{SÍNTESIS DE LOS RESULTADOS}

De ambas experiencias, podemos mencionar, a modo de síntesis, los siguientes resultados:

- Las experiencias desarrolladas muestran su aprovechamiento en tanto estrategia de enseñanza, en particular para el desarrollo de la temática del DS.

- Los estudiantes trabajaron de manera colaborativa y cooperativa en un clima acorde a grupos de trabajo propio de las actividades ingenieriles. Manifestaron entusiasmo al hacerlo y un alto grado de responsabilidad. Creemos, por tanto, que el trabajo en equipo es una dinámica enriquecedora para nuestros estudiantes universitarios, a pesar de no ser una práctica habitual.

- Los estudiantes se sintieron fuertemente motivados al momento de resolver cada problemática propuesta. Por lo tanto, podemos afirmar que las prácticas innovadoras que apelen a juegos de roles, intercambios y debates son valoradas para lograr un aprendizaje significativo. Se pudo observar que cada estudiante participó activamente en el desarrollo de las problemáticas presentadas. Creemos que la participación activa de los estudiantes construye conocimiento nuevo y los prepara para espacios y desafíos que deberán enfrentar fuera de la universidad.

- Se pudo observar que cada estudiante pudo desarrollar competencias básicas propias de la labor de un ingeniero, tales como: trabajo en equipo, planificación de tareas para el desarrollo de problemáticas, redacción de informes de trabajo, etc. Consideramos que dichas actividades son realizadas cotidianamente por nuestros estudiantes. Sin embargo, en actividades educativas innovadoras, como las que hemos llevado adelante, se realizan con mayor conciencia y compromiso, tanto para los estudiantes como para los profesores. 
- Es necesario definir con claridad la misión de la universidad atendiendo a la realidad actual de nuestro país y del contexto internacional, traduciendo los conocimientos en acciones específicas que mejoren la calidad de vida de la sociedad. En este sentido, la enseñanza del DS contribuirá a este objetivo.

\section{CONSIDERACIONES FINALES}

En primer lugar, el análisis de la idea de desarrollo sustentable fue fundamental para no caer en un reduccionismo, tal como ocurre en algunos ámbitos con la ciencia y la tecnología. Una de las cuestiones principales que tuvimos presentes al momento de trabajar el concepto de desarrollo sustentable es que no solo se encarga de analizar la problemática sobre el medioambiente. Si bien, en los orígenes del concepto se lo asociaba exclusivamente al medioambiente, hoy en día el término abarcó un conjunto más amplio de problemáticas sociales.

El desarrollo sustentable tiene como condición básica y fundamental que los recursos naturales no se agoten ni se deterioren, lo cual implica estar comprometidos y actuar solidariamente con las generaciones actuales y con las que aún no están presentes en el planeta. Para hacer posible esto, es necesario que cambien las formas actuales de extracción, producción y consumo de recursos naturales por parte de la sociedad. Voces por una benevolencia con la naturaleza, la ética de la producción y sus usos y la sostenibilidad reclaman otros modos de vida marcados por la calidad, acompañados de una nueva conciencia y cooperación con el ambiente natural, social y cultural de cada población.

El Desarrollo Sostenible ¿puede constituirse como nueva visión de la ingeniería? Es un desafío importante. Sabemos que se trata de un desarrollo especial, un desarrollo humano que se sustenta en la participación social y política, en la capacidad de poder tomar decisiones y en la libertad de las ideas, en la diversidad, pero al mismo tiempo en la unidad colectiva, en la igualdad de la sociedad, de etnias e identidades nacionales, de doctrinas y filosofías de vida; y que para alcanzar ese desarrollo se necesitarán medios comunitarios de aprendizaje mutuo, impulsados hacia la satisfacción de necesidades sinérgicas y la mejora de las potencialidades humanas.

Sin un cambio cultural, donde la sociedad civil no pueda reconsiderar sus prioridades, valores, estilos de vida, preferencias inclinadas 
por el consumo basadas en la cantidad (y no en la selectividad), nos parece una vía sin solución y sin horizonte.

En segundo lugar, la aplicación del concepto de Desarrollo Sustentable dentro de la agenda de educación de la ingeniería sería un paso fundamental para ir abarcando las diferentes problemáticas que plantea el mismo. Entre ellas, podemos mencionar: desde la pobreza, la contaminación de ríos, lagos y arroyos, el cambio climático, las energías renovables, la producción de alimentos, la utilización de agrotóxicos para el suelo, las condiciones de vida, el problema de la urbanización, la distribución de la riqueza, etc. Es decir, todo un abanico enorme de grandes temáticas que son de amplio conocimiento en el mundo contemporáneo y que plantean desafíos pedagógicos a la hora de introducirlos en la enseñanza superior.

Ahora bien, ¿cómo logramos introducir todos estos temas a fin de que el ingeniero incorpore las diferentes problemáticas que plantea esta agenda? Para ello, es imprescindible enfocarnos en la idea de que la enseñanza del desarrollo sustentable no es un cúmulo de conceptos abstractos que no nos competen como ciudadanos. Es preciso empezar a formar bajo la idea de que es necesario ser consciente de la gravedad y del carácter global de los problemas que presenta el mundo contemporáneo.

A partir de esto, podemos pensar algunas áreas en donde la enseñanza pedagógica en la universidad y la formación de ingenieros se puedan cruzar constantemente, de forma tal que los diferentes problemas planteados anteriormente sean parte integral de la formación profesional.

De esta manera, se plantea una renovación de las relaciones entre la Ciencia, Tecnología y Sociedad (CTS) y el Desarrollo Sustentable (DS), para poder realizar una enseñanza que nos permita pensar el mundo que queremos y hacia dónde vamos. Por ejemplo, la ciencia y la tecnología podrían empezar a dar algunas respuestas a estos problemas. Existe, por supuesto, un consenso general acerca de la necesidad de dirigir los esfuerzos de la investigación e innovación hacia el logro de tecnologías favorecedoras de un desarrollo sostenible, incluyendo desde la búsqueda de nuevas fuentes de energía al incremento de la eficacia en la obtención de alimentos, pasando por la prevención de enfermedades y catástrofes, el logro de una maternidad y paternidad responsables o la disminución y tratamiento de residuos, el diseño de un transporte de impacto reducido, etc. Dar prioridad a tecnologías orientadas a la satisfacción de necesidades básicas y que contribuyan a la reducción de las desigualdades, como, por ejemplo: 
- Fuentes de energía limpia (solar, geotérmica, eólica, fotovoltaica, mini-hidráulica, mareas, sin olvidar que la energía más limpia es la que no se utiliza) y generación distribuida o descentralizada, que evite la dependencia tecnológica que conlleva la construcción de las grandes plantas.

- Incremento de la eficiencia para el ahorro energético (uso de bombillas fluorescentes de bajo consumo o, mejor, diodos emisores de luz LED; cogeneración, que supone la obtención simultánea de energía eléctrica y energía térmica útil, aprovechando para calefacción u otros usos el calor que habitualmente se disipa).

- Aplicar el Principio de Precaución (también conocido como de Cautela o de Prudencia), para evitar la aplicación apresurada de una tecnología, cuando aún no se ha investigado suficientemente sus posibles repercusiones, como ocurre con el uso de los transgénicos o de las nanotecnologías.

Si bien estos pueden ser algunos de los ejemplos que se pueden establecer en la relación entre ciencia, tecnología, sociedad y desarrollo sustentable, también debería profundizarse en la democratización de todos los espacios donde esto se ponga en juego. Empezando, principalmente, por los espacios que los diferentes Estados le brindan a esta mirada. Si bien desde hace mucho tiempo la Organización de las Naciones Unidas viene trabajando en la idea de pensar el desarrollo sustentable, muy pocos Estados lo están llevando a cabo. Dos de los Estados más grandes y poderosos del planeta están haciendo muy poco hoy en día en el cuidado del medioambiente, así como poner la ciencia y la tecnología al servicio de la comunidad. Estamos hablando de China y EE.UU. Mientras que el primero es uno de los mayores contaminantes del planeta, el segundo se ha retirado del Protocolo de París (una iniciativa para reducir la producción de gases con efecto invernadero) y emplea la mayoría de sus gastos destinados a ciencia y tecnología en la construcción de arsenales bélicos cada vez más poderosos.

Si no tomamos en cuenta la importancia de los problemas por los que hoy está atravesando el mundo contemporáneo y no utilizamos todos los recursos científicos y tecnológicos a la mejora de los mismos, estamos hablando entonces de un mundo que seguirá siendo completamente desigual y donde las diferencias entre los Estados y su posible desarrollo serán cada vez más grandes. 


\section{BIBLIOGRAFÍA}

Cambra Bassols, J. de (2008). Desarrollo y Subdesarrollo del Concepto de Desarrollo: Elementos para Una Reconceptualización. En L. Capalbo (Comp.), El resignificado del desarrollo (pp. 77-104). Buenos Aires: UNIDA-Ciccus.

Capalbo, L. (2008). Desarrollo: del dominio material al dominio de las ilimitadas potencialidades humanas. En L. Capalbo (Comp.), El resignificado del desarrollo (pp. 17-57). Buenos Aires: UNIDA-Ciccus. Chacón Murillo, A. y Badilla Saxe, E. (2004). Construccionismo\&58; Objetos para pensar, entidades públicas y micromundos. Actualidades investigativas en educación, 4(1), 1-12.

CONFEDI (2010). La formación de Ingenieros para el desarrollo sostenible. Aportes para el Congreso Mundial de Ingeniería.

D’Angelo, C. (2008). La Organización de Cooperación de Shanghái. Hacia un nuevo orden político y económico internacional.

De la Torre, S. (1997). Creatividad y formación: identificación, diseño y evaluación. Trillas.

Feldt, A. G. (1972). The Community Land Use Game. New York: The Free Press.

Feldman, D. (1999). Ayudar a enseñar: relaciones entre didáctica y enseñanza. Buenos Aires: Aique.

Gros Salvat, B. (2002). Constructivismo y diseños en entornos virtuales de aprendizaje. Revista de Educación, 328, 225-247. Disponible en: http://www.mecd.gob.es/dctm/revista-de-educacion/articulosre228/ re3281310861.pdf?documentId=0901e72b8125940d (acceso: marzo de 2014).

Groos, K. (1901). The play of man [El juego en el hombre]. Nueva York: Appleton.

Lázarus, M. (1883). Concerning the fascination of play [En cuanto a la fascinación del juego]. Berlín: Dummler.

Ley de educación Superior No 24521 de 1995. Disponible en: http://infoleg. mecon.gov.ar/infolegInternet/anexos/25000-29999/25394/texact. htm (acceso: marzo de 2014).

Marchetti, P. (2004). La génesis del concepto de desarrollo sustentable y su materialización en América Latina. Revista Argentina de Humanidades y Ciencias Sociales, 2, 2.

Balboa, C. H. y Somonte, M. D. (2014). Economía circular como marco para el ecodiseño: el modelo ECO-3. Informador técnico, 78(1), 82-90.

Moneta, C. (1994). Reglas del juego. América Latina, Globalización y Regionalismo. Buenos Aires: Corregidor. 
ONU, Cf, O. D. D. S. (2015). Transforming our world: The 2030 agenda for sustainable development.

Papert, S. (1987). Desafío a la mente: Computadoras y Educación. Buenos Aires: Galápagos.

(1998). Study of Educational Impact of the LEGO Dacta Materials INFOESCUELA MED [Estudio del impacto educacional del material Dacta LEGO]. Disponible en: http://cache.lego.com/downloads/ education/infoescuela.pdf (acceso: marzo de 2014).

Shirts, G. R. (1970). Stapower. La Jolla: Western Behavioral Sciences Institute.

Spencer, H. (1985). Principios de psicología. Madrid: Espasa-Calpe.

Sterman, J. D. (1984). Instructions for running the Beer Distribution Game D-3679 [Instrucciones para ejecutar la distribución del juego de la cerveza D-3679]. Systems Dynamics Group, MIT, E60-383, Cambridge. (1992). Teaching Takes Off - Flight Simulators for Management Education [Enseñanza despega - Simuladores de vuelo para Gestión de la Educación]. The Beer Game. OR/MS Today.

Taylor, J. y Walford, R. (1978). Learning and the Simulation Game [El aprendizaje y el Juego de Simulación]. Milton Keynes: Open University Press.

UNESCO (1998). Declaración Mundial sobre la Educación Superior en el Siglo XXI: Visión y Acción y Marco de Acción Prioritaria para el Cambio y el Desarrollo de la Educación Superior, artículo 2, 9 de octubre de 1998. Disponible en: http://www.unesco.org/education/ educprog/wche/declaration_spa.htm (acceso: marzo de 2014).

(2009). Conferencia Mundial sobre la Educación Superior: La nueva dinámica de la educación superior y la investigación para el cambio social y el desarrollo - París, Comunicado 5-8 de julio de 2009. Disponible en: http://unesdoc.unesco.org/ images/0018/001832/183277s.pdf (acceso: marzo de 2014).

Valcarcel, C. (2011). Los juegos, una alternativa en la enseñanza del español como lengua extranjera. Revista Cuadernos de Educación y Desarrollo, 3, 28. Disponible en: http://www.eumed.net/rev/ced/28/ colv.htm (acceso: marzo de 2014).

Winnicott, D. (1972). Realidad y juego. Buenos Aires: Granica.

Zapata Jaramillo, C. M. (2007). Tutorial: Uso de Esquemas Preconceptuales para la generación automática de Diagramas de Clases, Comunicación y Máquina de Estados. En: Memorias de las VI Jornadas de Ingeniería del Software e Ingeniería del Conocimiento (pp. 469471). Lima. 


\title{
RESPONSABILIDAd SOCIAL UNIVERSITARIA Y VINCULACIÓN CON EL MEDIO: CONSTRUCCIÓN DE UNA METODOLOGÍA PARA DESARROLLAR PROYECTOS DE $A+S^{*}$
}

\author{
Gracia Navarro Saldaña" \\ Verónica González Navarro"** \\ Jorge Maluenda Albornoz $z^{m * * *}$
}

Chile

\section{INTRODUCCIÓN}

Según la Comisión Mundial de Medioambiente y Desarrollo (1987, citado en González y Avilez, 2015), el Desarrollo Sostenible (DS) se define como el proceso mediante el cual se satisfacen las necesidades económicas, sociales y medioambientales de la generación actual sin poner en riesgo la satisfacción de las mismas en las generaciones futuras.

En septiembre de 2015, los líderes del mundo adoptaron la agenda 2030, en la cual se definen 17 Objetivos para el Desarrollo Sostenible (ODS) y 169 metas. Estos ODS para 2015-2030 conllevan una agenda de sostenibilidad que busca, por una parte, completar aquello que los Objetivos de Desarrollo del Milenio (ODM) no lograron, y por otra, abordar las causas de fondo de la pobreza y la desigualdad, la necesidad

\footnotetext{
Este trabajo se contextualiza en el convenio entre Avina, Masisa, la Ilustre Municipalidad de Cabrero y la Universidad de Concepción, Chile, para la validación del índice de Progreso Social (IPS) en la comuna de Cabrero. Corresponde a un producto específico del equipo de trabajo de la Universidad de Concepción.

** Doctora en Educación, Universidad de Concepción. Correo electrónico: gnavarro@udec

*.** MSc Sustainable resources, University College London. Universidad de Concepción. Correo electrónico: mariavgonzalez@udec.cl

**** Magíster en Política y Gobierno, Universidad de Concepción. Correo electrónico: jorgemaluenda@udec.cl
} 
universal de un desarrollo que beneficie a todas las personas, el cambio climático, el consumo sostenible, la innovación y la importancia de la paz y la justicia para todos. Es una agenda que ofrece un plan de acción para el trabajo conjunto de gobiernos, empresas, organizaciones civiles y personas, trabajo que releva en forma específica en el objetivo número 17: alianzas para lograr los objetivos (Boza, 2015).

En el desarrollo sostenible, todos los actores de la sociedad tienen un rol que desempeñar y, en el caso de las universidades, lo hacen a través del ejercicio de su responsabilidad social. Una universidad socialmente responsable está comprometida con una docencia, investigación y gestión, realizadas en estrecha vinculación con el medio o alianza social para el bien común; en el ámbito de la docencia esta alianza se puede implementar y fortalecer a través de la estrategia metodológica de aprendizaje y servicio (Navarro, Vaccarezza, González y Catalán, 2015), la que se constituye, además, en una herramienta para formar profesionales socialmente responsables, capaces de hacer alianzas sociales para el bien común.

El presente trabajo se realiza en la Universidad de Concepción y tiene como propósito describir y evaluar, desde los participantes, la metodología construida para diseñar proyectos de aprendizaje y servicio con una comunidad local (Cabrero).

\section{MARCO TEÓRICO}

La Responsabilidad Social (RS) es un constructo creado por y para la sociedad, por lo tanto, el concepto varía para cada grupo humano, lo que, según Díaz de Feliciano (2011, citado en Guedez, 2011), se refleja en la falta de una definición universalmente aceptada. Según Navarro (2006 y 2012), la Responsabilidad Social es la capacidad y obligación de las personas y de las organizaciones de responder ante la sociedad por sus acciones y omisiones en pos del bien común. Se expresa en compromiso con los demás y en una orientación de las actividades individuales y organizacionales en un sentido que contribuya a generar equidad para el desarrollo. En tanto comportamiento individual o actuación organizacional, la Responsabilidad Social se expresa a través de acciones prosociales, que contribuyen a la sobrevivencia y desarrollo humano, motivadas por el bien común, es decir, tienen la intención fundamental de beneficiar a sí mismo y a los demás; a la organización y a la sociedad. Una universidad socialmente responsable es aquella que, 
según Navarro (2017), tiene como misión contribuir a generar equidad para el desarrollo desde una gestión que logra equilibrar sus resultados sociales, ambientales y financieros, la formación de personas socialmente responsables, la investigación desde criterios de RS y la construcción de conocimiento sobre RS. Una universidad socialmente responsable evalúa el impacto de sus acciones en el bien común, fortalece aquellas que aportan y minimiza o disminuye aquellas que impactan negativamente.

Los problemas y necesidades que presenta la sociedad actual no pueden ser resueltos por un solo actor, se requiere cooperación sostenida en pos del bien común entre diferentes actores y para ella es fundamental la creación y mantención de alianzas sociales. Según Machado de Acedo (2011, en Guedez, 2011), el proceso de creación de alianzas cubre tres etapas: la exploración, el fomento y el mantenimiento de la alianza. La exploración implica identificar quién conducirá la alianza, los posibles socios, sus aportes y las negociaciones para llegar a acuerdos. El fomento de la alianza implica fomentar consensos para una visión y objetivos comunes; el compromiso de recursos, roles y responsabilidades y el fortalecimiento de la capacidad de los socios para mantener sus compromisos. El mantenimiento de la alianza requiere desarrollar herramientas de gestión y dirección, por ejemplo, la disposición para renegociar los términos en respuesta a limitaciones internas o externas; capacidad para seguir procedimientos acordados, habilidades para la comunicación continua y transparente, habilidades para monitorear y evaluar periódicamente el impacto de la alianza en el logro de sus objetivos.

Entre los efectos de las alianzas sociales para el DS, las investigaciones muestran aquellos que dicen relación con la focalización de las alianzas sociales en las necesidades humanas y la innovación para satisfacerlas (Everard, y Longhurst, 2017); la ampliación de los conceptos, conocimientos y prácticas cuando se construyen alianzas sociales, entre otros, aquellos relacionados con el valor y bien común (Rossignoli y Lionzo, 2018), la disposición de diferentes roles que son necesarios para lograr objetivos relacionados con el bien común, donde cada socio hace su aporte (Yan, Lin y Clarke, 2018); el logro de acuerdos para no poner en riesgo los ODS (Ruckert, Schram, Labonté, Friel, Gleeson y Thow, 2016). Por su parte, Hawkins (2014), en un estudio realizado en Australia, concluye que es importante ayudar a desarrollar en los niños, desde pequeños y a través de la literatura, habilidades para integrar redes de colaboración para el bien común, entre ellas, la conciencia y comprensión de temáticas como la justicia 
social, la capacidad de reflexión crítica y de participación en discusiones profundas sobre prejuicios sobre apariencia física, género, etnia, nivel socioeconómico y habilidades.

A nivel universitario, una estrategia metodológica que contribuye a formar profesionales socialmente responsables, capaces de generar y mantener alianzas sociales para el bien común, es el Aprendizaje y Servicio $(\mathrm{A}+\mathrm{S})$. Las definiciones de $\mathrm{A}+\mathrm{S}$ provenientes de autores anglosajones proponen al servicio como un medio para el aprendizaje, y al aprendizaje-servicio como una estrategia metodológica para aprender haciendo y/o aprender de la experiencia (Stanton, 1990, citado en Tapia, 2010). Con este se logran esfuerzos comunes para promover cambios que se esperan, para favorecer el aprendizaje individual, la valoración del aprendizaje colaborativo y la satisfacción personal con el proceso de aprendizaje (Furco y Moely, 2012). Su evaluación requiere que el estudiante demuestre competencias que aplicará en situaciones similares en su vida profesional (Raymond, Homer, Smith y Gray, 2013). Por su parte, Tapia (2010) sostiene que en el contexto latinoamericano, inicialmente se busca el aporte de estudiantes para responder solidariamente a desafíos que plantean la pobreza y la inequidad, y es frecuente que la valorización de las prácticas solidarias llegue en un segundo momento, cuando los educadores empiezan a reconocer su valor formativo. Según Cecchi (2016), el A+S es, quizás, la única reforma educativa que ha nacido en todas partes de abajo hacia arriba; en esta estrategia metodológica el estudiante pone en práctica procesos analíticos, de reflexión y sistematización de la información, lo que en definitiva demanda una mayor autonomía que otras estrategias; constituye una propuesta pedagógica basada en proyectos de cooperación, en que se vinculan docentes, estudiantes y miembros de comunidades, en torno a una actividad de trabajo que tiene por fin satisfacer necesidades sentidas por la comunidad. Según Tapia (2000), el aprendizaje y servicio atienden con igual énfasis a un alto nivel de respuesta a la demanda de la comunidad y a un aprendizaje de calidad para los estudiantes.

A nivel cognitivo y de procedimientos, es una estrategia que estimula la reflexión y evaluación constante de lo que se sabe respecto de un tema, ya que requiere la aplicación de conocimientos; habilidad que va más allá de la reflexión analítica, pues considera una serie de variables contextuales. Según MINEDUC (2007), el A+S es una forma de acercar a los jóvenes al mundo real, pues favorece una participación más profunda en la comunidad, colabora en el desarrollo de la 
responsabilidad personal y social, fortalece la autoestima, el emprendimiento, el liderazgo y, por sobre todo, permite que se desarrolle el sentido de creatividad e iniciativa.

Para aplicar el A+S, según Tapia (2003), se requiere de tres etapas y tres procesos fundamentales. Las etapas son: Conceptualización, diagnóstico y planificación; Construcción de alianzas, ejecución e implementación del servicio, y Evaluación y sistematización final. Los procesos son sistematización, reflexión y evaluación, los cuales son descritos desde su implementación en la Universidad de Concepción por Navarro, Vaccarezza, González y Catalán (2015):

La sistematización de la información consiste en un proceso analítico de recogida de datos y registros de todo tipo, que sirve para detallar y contextualizar el problema o situación que se está trabajando. Requiere de la capacidad de ordenar, jerarquizar, categorizar y secuenciar ideas, y por tanto, pone de manifiesto las habilidades asociadas a las competencias de comunicación y pensamiento crítico.

En el caso de la reflexión, el estudiante debe profundizar en el análisis, pero esta vez desde la propia formación disciplinar, poniendo de manifiesto cómo podrá contribuir a la solución del problema y qué habilidades que ya posee (entendido como capital humano) son necesarias para el logro de los objetivos; en la reflexión se practica tanto el juicio crítico como la Responsabilidad Social.

En el marco de los ODS, considerando que la formación de personas socialmente responsables, capaces de hacer alianzas para el bien común, se favorece con la estrategia metodológica de aprendizaje y servicio, y que no se dispone de una metodología local para diseñar proyectos de aprendizaje y servicio, el presente trabajo tiene como propósito describir y evaluar desde los participantes, la metodología construida para diseñar proyectos de Aprendizaje y Servicio con una comunidad local (Cabrero).

\section{MÉTOdo}

Se realizó un estudio cuali-cuantitativo en la unidad de investigación formada por la comunidad de Cabrero, académicos y estudiantes de la Universidad de Concepción; representantes del gobierno local; ONG y empresa privada. 


\section{ObJeTIVos específicos}

1. Diseñar e implementar una metodología para desarrollar las etapas del $\mathrm{A}+\mathrm{S}$ con una comunidad local.

2. Identificar necesidades de una comunidad local (Cabrero).

3. Formular propuestas consensuadas para satisfacer necesidades identificadas en una comunidad local.

4. Identificar la evaluación de la metodología utilizada para aprender y servir, en académicos y estudiantes.

\section{Muestra}

Se trabajó con tres muestras:

- Muestra 1: formada por 287 representantes de hogar de la comuna de Cabrero ${ }^{1}$.

- Muestra 2: constituida por 22 académicos y estudiantes de la Universidad de Concepción.

- Muestra 3: 45 representantes de la universidad, comunidad, gobierno local y empresa.

\section{Procedimiento}

El trabajo se realizó en cuatro etapas: a) exploración, fomento y mantenimiento de alianza social para el bien común; b) identificación de necesidades en la comunidad local; c) formulación de propuestas consensuadas para satisfacer necesidades consensuadas; d) evaluación desde participantes (valoración y aprendizajes).

\section{INSTRUMENTOS}

Se diseñó y aplicó entrevista estructurada en sus hogares, para identificar las necesidades en la muestra 1 ; entrevista electrónica para identificar la evaluación de la metodología utilizada para aprender y servir en la muestra 2 y grupos focales en la muestra 3, para identificar propuestas consensuadas para satisfacer las necesidades identificadas.

1 Para el análisis de datos, se consideraron tres estratos: los dos sectores urbanos reconocidos por el INE (2007), Cabrero urbano y Monte Águila urbano, y el sector rural de Cabrero. 


\section{ANÁLISIS DE DATOS}

Se realizó análisis cuantitativo de los datos de la muestra 1, específicamente de frecuencia y porcentajes, y análisis cualitativo de los datos de las otras dos muestras, para identificar y categorizar temáticas en las verbalizaciones.

\section{Resultados}

\section{EXPLORACIÓN, FOMENTO Y MANTENIMIENTO DE ALIANZA SOCIAL PARA EL BIEN COMÚN}

La metodología de trabajo utilizada para construir alianzas sociales para el diseño de proyectos de $\mathrm{A}+\mathrm{S}$ implicó un profundo trabajo colaborativo intersectorial, que involucró la alianza conformada por el gobierno local (municipio), la empresa privada, la ONG; la sociedad civil, con representantes de diferentes grupos sociales, y la academia (universidad), donde todos los actores colaboraron desde su rol en la sociedad. Para concretar este acuerdo se firma un convenio intersectorial que formalizó acciones conjuntas orientadas a cultivar la Responsabilidad Social, a través del trabajo coordinado y cooperativo en pos del desarrollo sostenible.

La universidad asume la conducción del equipo interinstitucional y se constituyen dos equipos de trabajo, ambos conducidos por una directora académica: un equipo académico formados en Responsabilidad Social, integrado por siete académicos pertenecientes a diferentes disciplinas, entre ellas: psicología, trabajo social, economía, enfermería, arquitectura, estadística, ingeniería. Asume la responsabilidad por el logro de los objetivos y tareas, planifica, dirige y supervisa el trabajo, maneja los recursos y hace informes respectivos. Un equipo ejecutor integrado por profesionales, formados en Responsabilidad Social y por estudiantes de pregrado (15) bajo su dirección, quienes tuvieron a su cargo la aplicación de instrumentos en la muestra 1.

Se constituye un comité comunal, integrado por doce representantes de diferentes sectores de la sociedad civil, gobierno local, empresa privada y universidad, que aceptaron aportar sistemática y cooperativamente a la implementación de la metodología para identificar necesidades y obtener información para facilitar la elaboración de políticas públicas, 
la asignación de recursos en la comuna y el diseño de propuestas para satisfacer necesidades.

Principios en que se basó el proceso implementado: ausencia de conflicto de intereses en la conducción; participación informada de la comunidad; especialización de los equipos de trabajo; rigurosidad en los procedimientos; equidad en la ponderación de los aportes; búsqueda de información profunda; validación a partir del trabajo cooperativo entre todos los grupos de interés, considerando aportes teórico-prácticos e interdisciplinarios y el conocimiento de la realidad. La validación de cada paso o etapa se realizó siempre en tres instancias: equipo ejecutor, comité comunal, equipo académico.

\section{IDENTIFICACIÓN DE NECESIDADES EN LA COMUNIDAD LOCAL}

Los resultados muestran la identificación de necesidades en la comunidad, que se clasifican en ocho categorías:

Necesidades relacionadas con agua y saneamiento. Se refieren al acceso a agua potable y la infraestructura necesaria para su obtención e incluye la calidad percibida por los ciudadanos respecto de este servicio. Los resultados mostraron que el 99,66\% de la población urbana tiene acceso al agua potable conectada a la red pública y un $75 \%$ en el sector rural. El abastecimiento rural es a través de sistemas de agua potable rural, o APR, que, a diferencia de la zona urbana, no son administrados por el Estado, sino por comités o cooperativas de APR, formados por integrantes de las mismas comunidades. Reportan baja calidad del agua potable de APR principalmente debido a falta de recursos económicos para mejorar su instalación, precaria infraestructura de los pozos para la abstracción del agua y falta de personal técnico que asesore a los comités de APR en mantención de los niveles adecuados de salubridad del agua potable.

Necesidades relacionadas con vivienda. Contemplan el acceso a vivienda con condiciones de habitabilidad; materialidad apropiada y accesibilidad, hacinamiento y satisfacción con ella. Un 12\% de los encuestados están insatisfechos con la vivienda. Existe importante proporción de viviendas, principalmente en sector rural, con materialidad deficiente, baja accesibilidad a distintos servicios: centros policiales, bomberos, áreas verdes, jardines infantiles y transporte público, los que afectan a la calidad de vida (gráfico 1 ). 


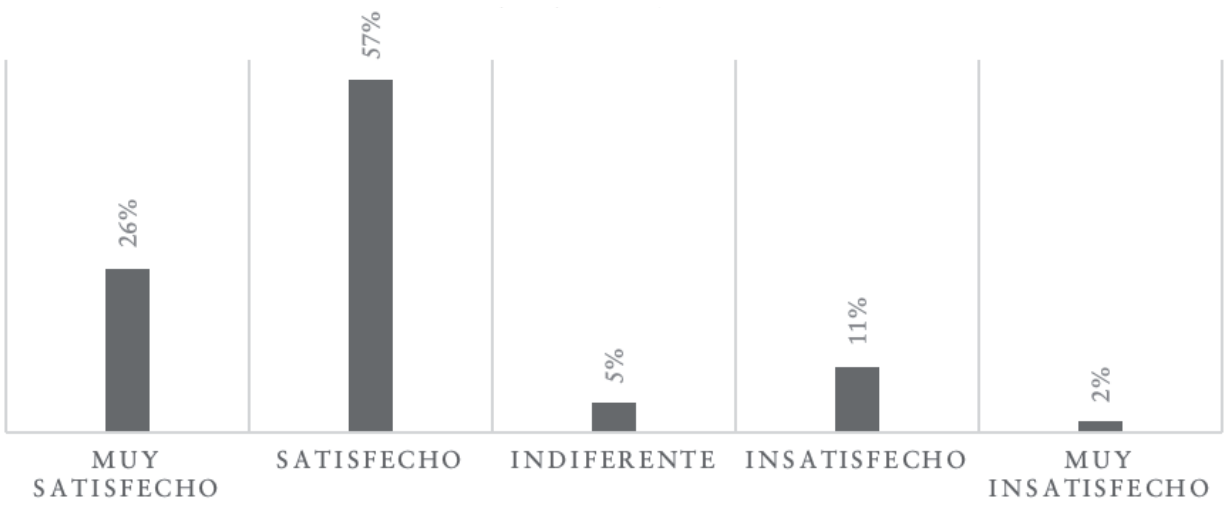

FuENTE: ELABORACIÓN PROPIA

Necesidades relacionadas con salud y bienestar. Incluyen acceso a atención de salud oportuna y de calidad; además, nivel de bienestar físico y mental en relación con la vida cotidiana y laboral. Los resultados muestran factores de riesgo potencial para la salud. Según los resultados, seis de cada diez personas no realizan ninguna actividad física, la que disminuye con la edad. Alto consumo de tabaco, especialmente en adultos jóvenes, y alta prevalencia de enfermedades crónicas en la población. Baja capacidad percibida para enfrentar problemas, baja autovalía; insatisfacción con el empleo en la adultez media y tardía y percepción de baja calidad en la atención recibida en los servicios de salud pública con tiempos de espera altos.

Necesidades relacionadas con seguridad personal. Se refieren al grado en que la persona siente que puede ejecutar tareas cotidianas sin riesgos para ella y su familia. Los resultados muestran alta preocupación por la delincuencia, específicamente por delitos en el hogar y en la calle, además de preocupación sobre la cobertura de salud (figura 1). Perciben como razones principales de la delincuencia la baja efectividad policial y presencia de grupos delictuales. Preocupación por la seguridad en carreteras de acceso y salida de la comuna debido a conducción imprudente, trabajos en la vía y falta de señalización apropiada. Reportan violencia infantil psicológica y física en colegios. 
Figura I. Situaciones QUE GENERAN MAYOR PREOCUPACIÓN ENTRE LOS ENCUESTADOS
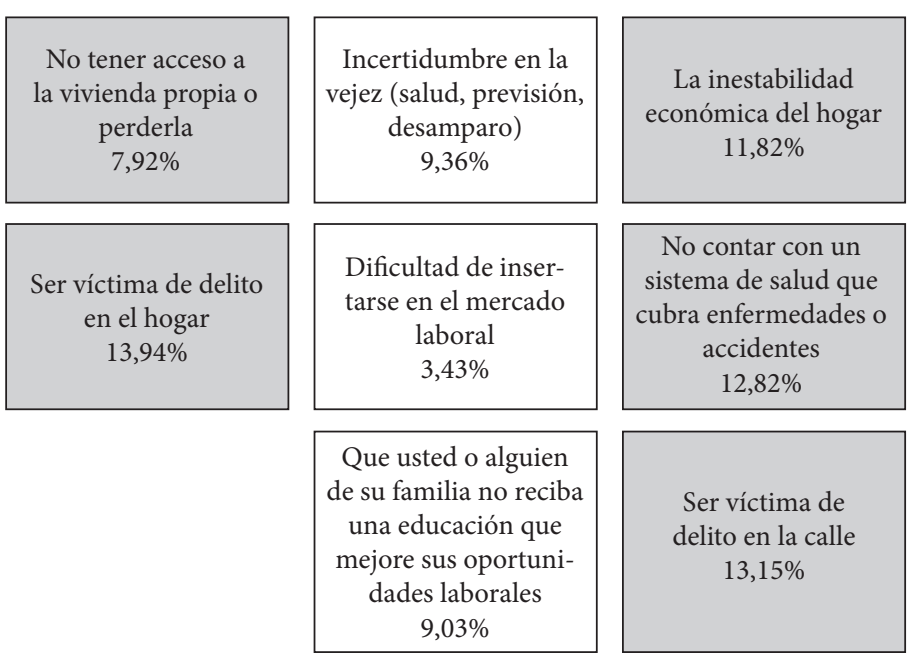

Ser víctima de delito en la calle $13,15 \%$
Que un miembro del grupo familiar caiga en el alcoholismo o la drogadicción $9,36 \%$

Perder el trabajo $9,14 \%$

FuENTE: ELABORACIÓN PROPIA

Necesidades relacionadas con el acceso a información y comunicaciones. Incluyen el nivel de acceso y dominio sobre tecnologías de la información y comunicaciones, y la calidad de los servicios asociados para dichos fines. Los resultados muestran que cuatro de cada diez personas no tienen acceso a computador en hogar y $46 \%$ no sabe usarlo. El dominio del computador disminuye con la edad, con nueve de cada diez adultos tardíos que no lo dominan. Seis de cada diez hogares no acceden a internet y tres de cada diez personas están insatisfechas con servicio de telefonía por mala señal.

Necesidades relacionadas con educación. Contemplan las expectativas de logro académico, posibilidad de acceder a educación y mejorar nivel educativo. Respecto del nivel instruccional, un $51,32 \%$ de la población comunal no terminó la enseñanza media. En general, los resultados muestran bajas expectativas de acceder a la educación superior, especialmente a educación superior de calidad. Existen diferencias entre los niveles educativos del sector rural y urbano, favoreciendo a este último.

Necesidades relacionadas con la sustentabilidad del ecosistema. Se refieren al grado de deterioro del ecosistema y áreas verdes públicas e identificación de factores que inciden en su deterioro. Perciben aspectos negativos en relación con el medioambiente de la comuna. Reconocen 
regular o mal estado de recursos naturales y como principales causas: contaminación humana, destrucción por acción humana y contaminación por industria.

Reportan como problemas ambientales que afectan a la comuna el manejo de desechos, emisión de gases invernaderos, y deforestación y contaminación de recursos hídricos. Ocho de cada diez personas perciben algún grado de deterioro medioambiental causado por: acciones de las empresas, falta de fiscalización y poca educación medioambiental. Los principales problemas ambientales del propio sector de residencia son la presencia de perros abandonados y la contaminación del aire.

Necesidades relacionadas con las oportunidades. Incluye las libertades políticas, libertades individuales, probidad judicial y discriminación. Según los resultados obtenidos, los mayores niveles de discriminación se presentan en relación con el nivel socioeconómico, sexualidad y sexo. Los encuestados perciben que la mayoría de las situaciones de discriminación se presentan al momento de buscar trabajo y al ser atendidos en los servicios públicos (figura 2).

Figura 2. Situaciones EN LAS QUe LOS ENCUESTAdos PERCiben MAYOR NIVEL DE DISCRIMINACIÓN

\begin{tabular}{|cccccc|}
\hline $\begin{array}{c}\text { Trato } \\
\text { Carabineros }\end{array}$ & $\begin{array}{c}\text { Servicios } \\
\text { públicos }\end{array}$ & Trabajo & Colegio & $\begin{array}{c}\text { Medios de } \\
\text { comunicación }\end{array}$ & Ciudadanía \\
$16,26 \%$ & $21,17 \%$ & $22,40 \%$ & $14,80 \%$ & $9,02 \%$ & $16,26 \%$ \\
\hline
\end{tabular}

FUENTE: ELABORACIÓN PROPIA

Tres de cada diez personas perciben que hay intimidación, soborno y persecución en el ejercicio de la campaña política, manipulación de resultados electorales y falta de fiscalización electoral. Tres de cada diez personas no concuerdan en que exista educación suficiente acerca de los procedimientos para votar y tampoco en que puedan surgir organizaciones políticas distintas con reales opciones de competir y con que puedan surgir minorías políticas. En cuanto a la probidad judicial, se observan bajos grados de acuerdo con el funcionamiento probo de la justicia. 
FORMULACIÓN DE PROPUESTAS CONSENSUADAS PARA SATISFACER NECESIDADES

Desde el trabajo cooperativo de los diferentes grupos de interés se logró construir un conjunto de propuestas consensuadas, para implementar proyectos de $\mathrm{A}+\mathrm{S}$ que aporten a satisfacer necesidades identificadas. Estas fueron clasificadas en siete categorías, para las cuales se presentan algunos ejemplos:

- Agua. Ejemplos: estudio de los problemas y soluciones hídricas en la comuna y apoyo académico a los profesionales de la municipalidad para concursar a fondos disponibles.

- Seguridad. Ejemplos: educar y empoderar a las comunidades sobre los planes de prevención del delito existentes; elaboración de una estrategia de recuperación de los espacios públicos en desuso.

- Educación. Ejemplos: diseño de propuestas para gestionar recursos para el acceso a educación superior fuera de la comuna: transporte, casas de acogida, redes de apoyo, etc.

- Relacionadas con oportunidades. Ejemplos: diseño de redes de intercambio de información entre comunidad y oferentes, para que diagnósticos y ofertas se basen en necesidades reales.

- Sustentabilidad del ecosistema. Ejemplos: diseño e implementación de planes de recuperación de espacios que sean foco de contaminación. Formar una red de monitores ambientales que ayuden a fiscalizar. Programas de esterilización y desparasitación de animales.

- Salud. Ejemplos: programas de educación y difusión para mejorar nutrición; programas para mejorar la actividad física-recreativa y el manejo del estrés.

- Información y comunicaciones. Ejemplos: programas para fortalecer habilidades de liderazgo y gestión en dirigentes de organizaciones sociales para canalizar necesidades hacia la autoridad; evaluación de los impactos en el paisaje rural de la presencia de antenas.

\section{EvAluaCión DESDE PARTICIPANTES}

Se identificaron sesenta y ocho respuestas en los participantes, a partir de las cuales se pudieron construir dos grandes categorías: 
valoraciones, con veintisiete respuestas $(39,7 \%)$ y aprendizajes, con cuarenta y una respuestas $(60,3 \%)$.

Respecto de las valoraciones, los resultados mostraron una alta valoración de estudiantes y académicos sobre cinco temas comunes: la metodología utilizada, la experiencia vivida, la vinculación con la comunidad, la oportunidad que el proceso significó y el trabajo entre diferentes organizaciones. Académicos valoraron, además, la posibilidad de trabajar interdisciplinariamente y construcción de alianzas para el desarrollo sostenible.

Respecto de los aprendizajes, resultados mostraron que académicos y estudiantes distribuyen sus respuestas entre aprendizajes de competencias académicas $(24,4 \%)$ y aprendizajes de competencias genéricas $(75,6 \%)$ en los estudiantes y académicos. Entre los aprendizajes de competencias académicas destacan el fortalecimiento del método científico, elaboración de informes verbales o escritos, resolución de problemas y comprensión del concepto de Responsabilidad Social y bien común. Entre aprendizajes de competencias genéricas destacan habilidades de comunicación interpersonal, habilidades sociales, la organización del tiempo, pensamiento crítico, trabajo en equipo y Responsabilidad Social.

\section{DisCUSIÓN Y CONCLUSIONES}

Se logró describir y evaluar desde los participantes, la metodología construida para diseñar proyectos de Aprendizaje y Servicio con una comunidad local (Cabrero). Específicamente, se diseñó e implementó una metodología para desarrollar las etapas del A+S, en la cual la construcción de alianza social para el bien común fue esencial; se identificó necesidades de una comunidad; se formuló propuestas consensuadas para satisfacerlas y se evaluó la metodología utilizada.

Los resultados permiten sostener, siguiendo a Navarro (2017), que la metodología utilizada es un instrumento para la Responsabilidad Social universitaria, en tanto fue útil para la gestión académica vinculada con el medio y construcción de alianzas sociales, para la formación de personas socialmente responsables y para la investigación desde criterios de Responsabilidad Social. Así también, constituye un aporte al desarrollo sostenible y en particular al ODS número 17.

Congruente con el planteamiento de Machado de Acedo (2011, en Guedez, 2011), el proceso de creación de la alianza para el bien común cubrió tres etapas: la exploración, el fomento y el mantenimiento. No 
obstante ello, de este trabajo queda claro que para el mantenimiento de una alianza para alcanzar los objetivos del desarrollo sostenible, es muy importante que las instituciones sean sólidas, estables y permanentes y que las alianzas con la comunidad requieren de instituciones confiables para ellas. Un aspecto que se debe fortalecer en las personas, en tanto representantes de organizaciones, es la disposición para renegociar los términos en respuesta a limitaciones internas o externas y las habilidades personales de los representantes para la comunicación continua y transparente, para la cooperación y reflexión crítica, lo que es coherente con el trabajo de Hawkins (2014) con niños de Australia.

La participación y trabajo cooperativo de todos los grupos de interés, para definir propuestas para satisfacer necesidades de la comuna, demostraron el interés por involucrarse en las acciones que se desprendan de este proceso, tal como se observó también en las impresiones reflejadas. La organización en grupos de discusión, que consideraron representantes de los distintos grupos de interés cuya vinculación era directa con el tema específico de discusión y análisis por área temática, permitió conectar a los representantes para la formulación de acciones conjuntas en relación con sus áreas de dominio e interés, además de calibrar las ponderaciones de los aportes, de modo que todos estuviesen apropiadamente representados en los resultados. Lograr propuestas consensuadas en al menos ocho categorías de necesidades mostró, en coherencia con los planteamientos de Everard y Longhurst (2017), que la alianza social favoreció la focalización en las necesidades de la comuna y la innovación desde el trabajo cooperativo para satisfacerlas. Así también, los aprendizajes logrados, según la percepción de académicos y estudiantes, se condicen con lo postulado por Rossignoli y Lionzo (2018) respecto del logro de una ampliación de los conceptos, conocimientos y prácticas cuando se construyen alianzas sociales, entre otros, aquellos relacionados con el valor y el bien común.

El A+S resultó ser una estrategia metodológica apropiada para lograr esfuerzos comunes para la formación profesional en competencias disciplinares y genéricas en estudiantes de pregrado y, a la vez, identificar necesidades en una comunidad y hacer propuestas para contribuir a satisfacerlas. También resultó útil en la valoración del aprendizaje colaborativo y la satisfacción personal con el proceso de aprendizaje, como lo plantearon Furco y Moely (2012), y en la vinculación de docentes, estudiantes y miembros de comunidades, en torno a la detección de sus necesidades sentidas por la comunidad y formulación de propuestas 
consensuadas para satisfacerlas, lo que concuerda con lo planteado por Cecchi (2016).

Se concluye la adecuación de la metodología construida para establecer alianzas sociales para el bien común. Por una parte, para la formación en competencias disciplinares y genéricas en estudiantes de pregrado, para el fortalecimiento del trabajo interdisciplinario y vinculado a la comunidad en académicos; por otra parte, para contribuir a la identificación de necesidades de las comunidades y construir cooperativamente propuestas para satisfacerlas y, por otra, para aportar a los objetivos del Desarrollo Sostenible, en particular el número 17.

\section{BiBLIOGRAFÍA}

Boza, M. E. (2015). Tiempos de co-responsabilidad: La agenda 2030 y la Cátedra Iberoamericana de Responsabilidad Social y Desarrollo Humano Sostenible. En Avances en educación de responsabilidad social y desarrollo sostenible en Iberoamérica (pp. 4-8). Universidad de Concepción, PNUD.

Cecchi, N. (2006). Aprendizaje servicio en educación superior. La experiencia latinoamericana. Presentación Seminario Internacional Responsabilidad Social Universitaria: Aprendizaje Servicio. Caracas.

Díaz de Feliciano, M. (2011). La Responsabilidad Social Empresarial: Un constructor social. En V. Guedez (Comp.), RSE-Visiones Complementarias. Hacia un Modelaje Social. Editorial Alianza.

Everard, M. y Longhurst, J. W. (2017). Reasserting the primacy of human needs to reclaim the «lost half» of sustainable development. Science of the Total Environment, 621, 1243-1254.

Furco, A. y Moely, B. (2012). Using learning communities to buildfaculty support for pedagogical innovation: a multi-campus study. The Journal of Higher Education, 83(1), 128-153.

González, V. y Avilez, M. P. (2015). Indicadores de responsabilidad social empresarial para el sector forestal: Una guía para avanzar en materias de desarrollo sostenible. En Avances en educación de responsabilidad social y desarrollo sostenible en Iberoamérica (pp. 28-45). Universidad de Concepción, PNUD.

Hawkins, K. (2014). Teaching for social justice, social responsibility and social inclusion: a respectful pedagogy for twenty-first century early childhood education. European Early Childhood Education Research Journal, 22(5), 723-738. DOI: 10.1080/1350293X.2014.969085

INE (2007). Regio del Bio-bio: División político administrativa y censal.

Disponible en: http://www.inebiobio.cl/archivos/files/pdf/DivisionPoliticoAdministrativa/biobio.pdf. 
Machado de Acedo, C. (2011). Responsabilidad social empresarial y alianzas trisectoriales. En V. Guedez (Comp.), RSE-Visiones Complementarias. Hacia un Modelaje Social. Editorial Alianza.

Ministerio de Educación (2007). Manual de aprendizaje servicio. Gobierno de Chile.

Navarro, G. (2006). Comportamiento socialmente responsable. En Responsabilidad social universitaria, una manera de ser universidad, teoría y práctica de la experiencia chilena. Santiago: Proyecto Universidad Construye País.

(2012). Moralidad y responsabilidad social; bases para su desarrollo y educación. Concepción: Universidad de Concepción.

(2017). Responsabilidad social universitaria, en las universidades del siglo XXI. Anuari de Psicología de la Universidad Valenciana de Psicología, 18, 1, 203-211.

Navarro, G.; Vaccarezza, G.; González, M. y Catalán, R. (2015). Construcción de conocimiento en educación superior: Educación de competencias genéricas en la Universidad de Concepción (Chile). Concepción: Sello editorial Universidad de Concepción.

Raymond, J.; Homer, C.; Smith, R. y Gray, J. (2013). Learning through authentic assessment: An evaluation of a new development in the undergraduate midwifery curriculum. Nurse Education in Practice, 13, 471-476.

Rossignoli, F. y Lionzo, A. (2018). Network impact on business models for sustainability: Case study in the energy sector. Journal of Cleaner Production, 182, 694-704.

Ruckert, A.; Schram, A.; Labonté, R.; Friel, S.; Gleeson, D. y Thow, A. (2016). Policy coherence, health and the sustainable development goals: a health impact assessment of the Trans-Pacific Partnership. Critical Public Health, 27(1), 86-96. DOI: 10.1080/09581596.2016.1178379

Stone, M. (Coord.) (1999). La enseñanza para la comprensión. Vinculación entre la investigación y la práctica. Buenos Aires: Paidós.

Tapia, M. (2000). La Solidaridad como Pedagogía. Buenos Aires: Ciudad Nueva.

(2003). El Aprendizaje-Servicio en América Latina: una aproximación. Disponible en: www.clayss.org.

Tapia, M. N. (2010). La propuesta pedagógica del «aprendizaje-servicio»: una perspectiva latinoamericana. Revista Tzhoecoen, 3, 5, 23-43. Edición especial de aprendizaje y servicio.

Yan, X.; Lin, H. y Clarke, A. (2018). Cross-Sector Social Partnerships for Social Change: The Roles of Non-Governmental Organizations. Sustainability, 10(2), 558. MDPI AG. Disponible en: http://dx.doi. org/10.3390/su10020558. 


\section{Sección V: \\ Responsabilidad Social \\ Pública (RSP)}





\title{
HerRAmienta de ANÁlisis DEL ROL GUBERNAMENTAL PARA PROMOVER LA RESPONSABILIDAD SOCIAL EN LA PRODUCCIÓN SOSTENIBLE DE LAS PYMES COLOMBIANAS
}

\author{
Luis Fernando Moreno Garzón" \\ Colombia
}

\section{INTRODUCCIÓN}

En el contexto empresarial colombiano, se pude observar que la política Pública Ambiental (PPA) diseñada sobre Responsabilidad Social Ambiental (RSA) no es tenida en cuenta por las pymes ${ }^{1}$. Si bien, el Ministerio de Ambiente y Desarrollo Sostenible de Colombia (MADS, 2010) considera la política de producción sostenible como un avance en la expedición de normas y la realización de campañas y capacitaciones, no lo hace en el logro de resultados concretos debido a barreras culturales. Para identificar esta brecha, es fundamental elaborar un instrumento que permita identificar y analizar en primera instancia las (PPA) relacionadas con las prácticas de (RSA) de los procesos productivos de los empresarios de las pymes colombianas. Esto servirá de marco para establecer los aspectos culturales de los empresarios pyme que inciden o no en la apropiación de prácticas de (RSA).

\footnotetext{
Doctorando en Administración de Empresas, Universidad Católica de Argentina. Docente de la Facultad de Administración de Empresas, Universidad Santo Tomás de Bogotá. Líder del Grupo de Investigación de Responsabilidad Social «GIRSA». Correo electrónico: luismoreno@usantotomas.edu.co

1 Son definidas en el marco de la Ley 905 de 2004 de Colombia, como toda unidad de explotación económica, realizada por persona natural o jurídica, en actividades empresariales, agropecuarias, industriales, comerciales o de servicios rurales o urbanos, que responde a los siguientes parámetros: a) planta de personal entre once y cincuenta trabajadores; b) activos totales por valor entre 501 y menos de 5.000 salarios mínimos mensuales legales vigentes.
} 
La presentación de esta herramienta comprende tres partes. La primera se vincula con el marco teórico relacionado con las políticas públicas, la Responsabilidad Social y el nexo que existe entre estos dos conceptos. La segunda parte, con una descripción de las herramientas utilizadas para la identificación de las PPA que promueven prácticas de RSA. Para finalizar, se presenta una herramienta que permite identificar las PPA para la promoción de RSA, relacionadas con la producción sostenible de las pymes.

\section{TEORÍAS DE LAS POLÍTICAS PÚBLICAS}

Existen tres grandes posturas teóricas relacionadas con las políticas públicas²: las teorías centradas en la sociedad (society-centered); las teorías centradas en el Estado (state centered) y las teorías mixtas o intermedias (Roth, 2002). En este último grupo se encuentran el neocorporativismo, el neoinstitucionalismo, el análisis de redes y la teoría de la acción; postulados que, con distinciones y variaciones, tratan de aprehender la sociedad como un tejido de interrelaciones complejas (Roth, 2002). La teoría de redes, o Networds Theory, se define como: los mecanismos de movilización de los recursos políticos en temas en los cuales las capacidades y la información necesarias para formular, decidir o implementar programas de acción pública. Son diseminados entre muchos actores públicos y privados, algunos con poder de veto (Roth, 2002, p. 40).

Desde este enfoque, se pueden identificar las redes de colaboración, apoyo, control e influencia que se construyen entre las instituciones, grupos e individuos que interactúan alrededor de las políticas públicas de producción y consumo (Lezaga, 1994; Roht, 2002). Desde esta perspectiva, en reemplazo de la crisis del Estado de bienestar, emerge el concepto de Estado relacional, que pretende dar una nueva lógica al rol de este y sus funciones.

Su legitimidad, si bien se relaciona con la legalidad, también incluye los principios de eficacia social y corresponsabilidad, determinados por

2 Para efectos de este artículo, se entiende la política pública como la existencia de un conjunto conformado por uno o varios objetivos colectivos, considerados necesarios o deseables, y por medios y acciones que son tratados, por lo menos parcialmente, por una institución u organización gubernamental, con la finalidad de orientar el comportamiento de actores individuales o colectivos para modificar una situación percibida como insatisfactoria o problemática (Roth, 2004). 
la capacidad del Estado de interlocución y de espacios de apertura a los intereses sociales, con el propósito de obtener resultados a través de otras organizaciones. Se trata de un concepto sistémico que se fundamenta en la sinergia de recursos, conocimientos y capacidades, en las relaciones entre el sector público y lo privado que se sitúa en el ámbito de la ética de la corresponsabilidad (Verniz y Mendoza, 2009).

Desde esta óptica, la corresponsabilidad es clave para el enfoque relacional por la existencia de objetivos comunes; la asunción de responsabilidades concretas en su consecución y la articulación efectiva de las responsabilidades asumidas por cada una de las partes. Esta relación implica la actitud sincera de diálogo y cooperación, donde el paradigma de la gobernanza adquiere un matiz especial en la lógica relacional de las políticas públicas (Lozano, 2007; Verniz y Mendoza, 2009).

Bajo esta perspectiva, gobernar ya no es sinónimo de gastar, sino de capacidad de liderazgo y de consenso para movilizar los recursos existentes, públicos y privados, en una sociedad para responder a las necesidades sociales. El término gobernanza, governance, surge por la necesidad de ir más allá de la palabra gobierno, government, demasiado ligada a los esquemas de decisión de los antiguos escenarios de los gobiernos y las organizaciones del sector público, predominantemente jerárquicos (Lozano, 2009; Longo, 2002 ).

En este contexto, la gobernanza hace referencia a los modelos de funcionamiento de la acción colectiva donde la jerarquía es, simplemente, uno más de los mecanismos que pueden pautear las relaciones entre múltiples actores o grupos de interés. Esta participación en la resolución de problemas que se consideren relevantes, o en función de los intereses colectivos, se constituye en la base para la construcción de la gobernanza del territorio y se convierte en un mecanismo eficaz para el desarrollo de la política pública (Lozano 2009; Valdés, Moreno; Bonilla, 2016). Cuestión que da cabida al concepto de la Responsabilidad Social en el marco de los Objetivos del Desarrollo Sostenible de Naciones Unidas.

\section{La Responsabilidad Social}

Desde la perspectiva de Melé y Garriaga (2004) existen tendencias y teorías de la Responsabilidad Social, los cuales agrupan en torno a los beneficios, la manifestación de las demandas sociales, el compromiso ético y el desempeño político. En este último grupo, también denominado de «Teorías Políticas», se concentran en el poder y el ejercicio responsable 
de las empresas en la sociedad en el ámbito político. Dentro del compendio de enfoques que conforman esta teoría, se destacan las relacionadas con el constitucionalismo corporativo, la teoría del contrato social integrador y la ciudadanía corporativa.

Las teorías relacionadas con el enfoque de ciudadanía corporativa se caracterizan por observar la Responsabilidad Social con fuertes nexos hacia la comunidad, local, asociaciones y preocupación por el medioambiente. Existe una visión equivalente a la Responsabilidad Social Corporativa (RSC), consecuencia de la globalización empresarial y su interdependencia (Garriaga y Merlé, 2004). Allí, los retos de gobernanza pasan a ser la máxima prioridad en respuesta al progresivo interés del contexto mundial. Esto implica un nuevo reto para las empresas que quieren ser responsables, puesto que los valores que acudían anteriormente han cambiado, dada la complejidad del entorno en que está inmersa; cuestión que les impone tener en cuenta en la toma de decisiones, criterios de actuación en contextos políticos, sociales y culturales divergentes entre sí (Volpentesta, 2016; Lozano, 2009).

Relacionar empresa con ciudadanía es considerarla como parte de la sociedad, con el propósito de participar socialmente a contribuir de forma voluntaria al desarrollo y bienestar de esa sociedad, más allá de la creación de riqueza (Melé, 2007). Para Lozano (2009), significa entender a la empresa desde un enfoque estrictamente empresarial, a partir de dos aspectos centrales. Uno, como actor con intereses y necesidades específicas, y otro, por la contribución a la gobernanza y al bien común. En esencia, la empresa debe apuntar a la integración de estos aspectos en la medida que estén presentes en su actividad cotidiana. "Desde esta perspectiva, hacer empresa es también hacer sociedad y de la manera como se lleve a cabo este hacer empresa, contribuye a su forma de hacer sociedad»(Lozano, 2009, p. 31).

En lo que respecta a los stakeholders, este enfoque de RSE implica un modelo de empresa más inclusivo, donde cada grupo de interés merece atención por lo que representa, esto es, pasar de observarlos como medios y fines, a considerarlos como agentes morales (Volpentesta, 2016). En este marco, la RSE se puede definir como «la integración voluntaria, por parte de las empresas, de las preocupaciones sociales y medioambientales, en sus operaciones comerciales y en sus relaciones con sus interlocutores» (Comisión Europea, 2001). Esta definición hace énfasis en dos aspectos: el qué y el cómo: «el qué» hace hincapié en el hecho de que las empresas deben asumir compromisos sociales y 
medioambientales en sus actuaciones; en cuanto «al cómo», ponen el acento en la voluntariedad (Lozano, 2006).

\section{LAS POLÍTICAS PÚBLICAS Y LA RSE}

A este punto, se ha hecho relación al enfoque de economía relacional, que plantea un Estado que promueva la gobernanza fundamentada en la corresponsabilidad. Esto, con el propósito de establecer relaciones colaborativas que motivan la sinergia entre los actores sociales para resolver sus necesidades más apremiantes. En este marco, se planteó la teoría de RSE de la empresa ciudadana, que entiende su rol como agente integrador entre el Estado y la sociedad en general, mediante el ejercicio responsable (social y medioambiental) en el ámbito político. Dicho esto, surge la siguiente pregunta: ¿cuál es el rol del Estado en la promoción práctica de la RSE?

Más allá de considerar una RSE impuesta por la ley, que la limita exclusivamente al cumplimiento de las regulaciones que la promueven, se requiere de un Estado con una visión integradora que desarrolle y diseñe acciones y políticas gubernamentales en el marco de la RSE (Cortina, 2010; Gilli, Gorrochategui y Martins, 2014 y 2011; Lozano, 2009; Melé, 2007; Sangustín, 2011). Esto es, un Estado interesado en promover una gobernanza que dinamice y facilite políticas que favorezcan la RSE. Para ello, es innegable la importancia de las iniciativas de orden nacional e internacional que promueven la RSE, el desarrollo de estándares obligatorios y voluntarios que lleva a las empresas a implementar prácticas de información, sustentadas en la creación de espacios de diálogo y de partenariado. En estos roles, los gobiernos y las administraciones públicas tienen un papel fundamental, difícilmente sustituible (Gilli; 2011; Gorrochategui y Martins, 2014; Lozano, 2009).

En este marco, el modelo de RSE de la Escuela Superior de Administración y Dirección de Empresas «ESADE» $(2005)^{3}$ considera que la promoción de prácticas de Responsabilidad Social debe enmarcarse en la perspectiva política de la Comisión Europea, que toma como elementos de referencia dos palabras clave: «fomentar «(desde la perspectiva

\footnotetext{
Actualmente denominada ESADE Business School. A esta se encuentran vinculados los profesores Lozano, Lezaga, Mendoza, Albarreda e Ysa, quienes han aportado desde sus investigaciones, elementos fundamentales para el análisis de las políticas públicas de las RSE.
} 
de las instituciones públicas) y de "contribución» (desde el punto de vista empresarial). Esta visión establece que el desarrollo de la RSE implica la capacidad conjunta de estos dos actores, cada uno desde su especificidad institucional (Lozano, 2009).

Así, cuando el énfasis se hace en las relaciones colaborativas entre el Estado, el mercado y la sociedad civil, la RSE se convierte en «una bisagra» desde la que se puede repensar el papel de la empresa en la sociedad; como «un elemento vertebrador», en el marco de una nueva perspectiva de gobernanza y sostenibilidad del Estado y la economía (Abarreda e Yza, 2005; Lozano, 2007). Desde esta lógica, los gobiernos han diseñado políticas en el marco de la RSE, no desde la obligatoriedad, sino desde la dinamización de prácticas de RSE que dan respuesta a las políticas (Lozano, 2007).

\section{HerRamientas de PPA PARA LA PROMOCIÓN DE PRODUCCIÓN SOSTENIBLE Y RSA}

A continuación, se detallan las herramientas o instrumentos que emplean los gobiernos para la producción sostenible y otros para la RSA. Con respecto a las primeras, se toma como referente la gestión ambiental, en la medida que busca equilibrar los aspectos vinculados con la toma de decisiones relacionadas con los recursos naturales y la contaminación ambiental con los elementos del desarrollo sostenible y sus componentes social, cultural y desarrollo económico ${ }^{4}$ (Van Hoof y otros, 2008).

\section{INSTRUMENTOS PARA LA PROMOCIÓN DE LA PRODUCCIÓN SOSTENIBLE}

Desde la perspectiva ambiental, las políticas públicas tienen el propósito de generar cambios en los gestores de las pymes en torno al impacto de sus decisiones en términos sociales, económicos y los ambientales. En este sentido, existen diferentes instrumentos diseñados para la promoción de la gestión ambiental.

4 En términos empresariales, se constituye en una variable ambiental que incluye, a nivel estratégico, el concepto de "producción más limpia», que se enfoca hacia procesos productivos, productos y servicios para reducir costos, incentivar la innovación tecnológica y reducir o mitigar riesgos en el ser humano y el medioambiente (Van Hoof y otros, 2008). 
Según Van Hoof y otros (2008) y Blackman y otros (2000), se pueden identificar los siguientes instrumentos:

Comando y control, buscan incentivar la implantación de medidas para el control de la contaminación, generalmente asociadas a las acciones de «fin de tubo ${ }^{5}$ ».

Incentivos económicos de tipo financiero para que el agente de la política tome su decisión basado en el esquema costo-beneficio ${ }^{6}$. Este instrumento es congruente con la lógica empresarial, cuyas decisiones están regidas por la variable económica. Su efectividad se observa en la medida en que los incentivos a la no contaminación sean permanentes y su análisis tenga en cuenta tanto los costos intangibles como tangibles (OECD, 2014).

Inversiones del gobierno, constituidas por instrumentos que le otorgan un mayor alcance de lo privado (él mismo incentiva la toma de decisiones empresariales puntuales). Se destaca el desarrollo de tecnologías limpias y/o las instalaciones comunes para el tratamiento de desperdicios. Su efectividad depende da la factibilidad administrativa y del costo $^{7}$ (OECD, 2014).

Basados en la información, en estos participan el regulador (Estado), el regulado (empresa) y otros grupos de interés (comunidad, clientes, proveedores, entre otros) que ejercen presión para el cumplimiento de la política. Estas acciones se evidencian en la magnitud y los efectos de las emisiones en relación con los cambios que se producen en la implantación de procesos de producción menos contaminantes, o la disposición adecuada de los desperdicios generados.

\section{INSTRUMENTOS PARA LA PROMOCIÓN Y DESARROLLO DE LA RSA}

A partir del enfoque de la economía relacional de Verniz y Mendoza (2009), la ESADE diseñó un modelo en el marco de la teoría de

5 Este es un enfoque de reacción y tratamiento también denominado de «etapa final», o del término en inglés «end of pipe», para referirse a las estrategias de tipo ambiental. «Son técnicas que intentan controlar la contaminación al final de la producción, cuando todos los desechos se han hecho y liberado por medio de una emisión o residuo» (Van Hoof, Monroy y Saer, 2008, p. 279).

6 En este caso dejará de contaminar si dicha acción es menos costosa que la de contaminar» (Van Hoof, Monroy y Saer, 2008, p. 17).

7 Los instrumentos deben ser coherentes con los recursos económicos, humanos y estructurales de las instituciones que llevan a cabo su seguimiento (OECD, 1991). 
Responsabilidad Social de ciudadanía corporativa. Desde esta perspectiva, la ESADE considera tres niveles de aproximación para identificar la acción gubernamental en la promoción de la RSE. El primer nivel se relaciona con los temas e instrumentos utilizados por el gobierno. El segundo se centra en los actores y los contextos, y el tercer nivel hace énfasis en los aspectos relacionales y estratégicos sobre la RSE.

En lo que respecta a la construcción de la herramienta que se propone, dadas sus características y propósitos, se tendrá en cuenta solo el "primer nivel», por tanto, se realizará una lista lo más exhaustiva posible sobre las políticas e instrumentos que se concretan en las medidas de políticas públicas que los gobiernos aplican para la promoción y desarrollo de la RSA (ver cuadro 1).

\section{HERRAMIENTA PARA IDENTIFICAR LAS PPA PARA LA PROMOCIÓN DE RSA, RELACIONADAS CON LA PRODUCCIÓN SOSTENIBLE DE LAS PYMES}

En el cuadro 1 se presenta la herramienta propuesta donde se fusionan los instrumentos PPA de Van Hoof y otros (2008) con el modelo de la RSE de la ESADE (2005). En este sentido, se integran los instrumentos de las políticas públicas relevantes para la promoción de la gestión ambiental con aquellos que promueven las prácticas de RSA. Esto se da en la compresión de la Responsabilidad Social entendida como una «bisagra» que dinamiza la relación colaborativa entre Estado, empresa y sociedad. 
HERRAMIENTA DE ANÁlisis DEL ROL GUBERNAMENTAL PARA PROMOVER LA RESPONSABILIDAD SOCIAL EN LA PRODUCCIÓN SOSTENIBLE DE LAS PYMES COLOMBIANAS

CuAdro i. INSTRumentos DE LA POLÍTICA DE GESTión AMBIENTAL APLICADOS A LA RSA

\begin{tabular}{|c|c|c|c|}
\hline $\begin{array}{c}\text { TIPO DE } \\
\text { INSTRUMENTO }\end{array}$ & Clasificación & DESCRIPCIÓN & $\begin{array}{c}\text { MEDIDAS DE POLÍTICA } \\
\text { PÚBLICA }\end{array}$ \\
\hline \multirow[t]{3}{*}{$\begin{array}{l}\text { Comando } \\
\text { y control }\end{array}$} & Directo & $\begin{array}{l}\text { Estándares de } \\
\text { emisiones. }\end{array}$ & $\begin{array}{l}\text { *Establecimiento y } \\
\text { promoción de marcos } \\
\text { reguladores globales. } \\
\text { "Redacción de informes } \\
\text { anuales de sostenibilidad. } \\
\text { "Fomento de publicación } \\
\text { de memorias. } \\
\text { "Regulación } \\
\text { medioambiental. } \\
\text { "Sanción a las malas } \\
\text { prácticas. } \\
\text { "Acreditación de prácticas } \\
\text { de RSA como indicador de } \\
\text { calidad de la gestión. }\end{array}$ \\
\hline & Indirecto & $\begin{array}{l}\text { Estándares de } \\
\text { tecnología (para } \\
\text { utilizar un tipo } \\
\text { específico). }\end{array}$ & $\begin{array}{l}\text { *Adaptación de los } \\
\text { acuerdos internacionales } \\
\text { sobre la RSA. } \\
\text { "Fomento a la } \\
\text { transparencia informativa. } \\
\text { "Fomento de actuaciones } \\
\text { empresariales sobre } \\
\text { RSA a la regulación } \\
\text { en sostenibilidad } \\
\text { medioambiental. }\end{array}$ \\
\hline & Directo & $\begin{array}{l}\text { "Impuestos } \\
\text { por unidad de } \\
\text { emisiones. } \\
\text { "Permisos } \\
\text { transables. }\end{array}$ & $\begin{array}{l}\text { *Regulación fiscal } \\
\text { favorable. } \\
\text { * Estímulos económicos } \\
\text { para empresas con RSE o } \\
\text { que demuestren mejoras } \\
\text { ambientales. } \\
\text { *Estímulos para que los } \\
\text { códigos ambientales hagan } \\
\text { referencia a los a los } \\
\text { acuerdos internacionales } \\
\text { e incluyan mecanismos de } \\
\text { evaluación y control de } \\
\text { RSA. }\end{array}$ \\
\hline
\end{tabular}




\begin{tabular}{|c|c|c|c|}
\hline $\begin{array}{c}\text { TIPO DE } \\
\text { INSTRUMENTO }\end{array}$ & Clasificación & Descripción & $\begin{array}{c}\text { MedidAS DE POLÍ́TICA } \\
\text { PÚBLICA }\end{array}$ \\
\hline $\begin{array}{l}\text { Incentivos } \\
\text { económicos }\end{array}$ & Indirecto & $\begin{array}{l}\text { Impuestos a } \\
\text { insumos o } \\
\text { productos } \\
\text { contaminantes. }\end{array}$ & $\begin{array}{l}\text { *Generación de sellos } \\
\text { ambientales para la } \\
\text { identificación por los } \\
\text { consumidores. } \\
\text { "Fomento de actuaciones } \\
\text { de RSA mediante líneas de } \\
\text { financiación a empresas. } \\
\text { "Promoción y financiación } \\
\text { de redacción de memorias } \\
\text { de sostenibilidad. } \\
\text { "Adopción de medidas } \\
\text { fiscales y de financiación } \\
\text { sostenibilidad favorables. } \\
\text { "Formulación de índices } \\
\text { de sostenibilidad y/o } \\
\text { RSA para cotización de } \\
\text { acciones en bolsas de } \\
\text { valores. }\end{array}$ \\
\hline \multirow{3}{*}{$\begin{array}{l}\text { Inversión } \\
\text { del gobierno }\end{array}$} & Directo & N.A. & \\
\hline & Indirecto & $\begin{array}{l}\text { Desarrollo de } \\
\text { tecnologías } \\
\text { limpias. } \\
\text { Instalaciones } \\
\text { comunes para el } \\
\text { tratamiento de } \\
\text { desperdicios. }\end{array}$ & $\begin{array}{l}\text { "Financiación } \\
\text { de programas de } \\
\text { investigación e innovación. } \\
\text { "Fomento de actuaciones } \\
\text { de RSA mediante líneas de } \\
\text { financiación a empresas. } \\
\text { "Asociaciones público- } \\
\text { privadas. } \\
\text { "Creación de fondos } \\
\text { gubernamentales para } \\
\text { iniciativas de RSA. }\end{array}$ \\
\hline & Directo & N.A. & \\
\hline
\end{tabular}


HERRAMIENTA DE ANÁlisis DEL ROL GUBERNAMENTAL PARA PROMOVER LA RESPONSABILIDAd SOCIAL EN LA PRODUCCIÓN SOSTENible DE LAS PYMES COLOMbIanAS

\begin{tabular}{|c|c|c|c|}
\hline $\begin{array}{c}\text { TIPO DE } \\
\text { INSTRUMENTO }\end{array}$ & ClasificaCióN & DESCRIPCIÓN & $\begin{array}{c}\text { MEDIDAS DE POLÍTICA } \\
\text { PÚBLICA }\end{array}$ \\
\hline $\begin{array}{l}\text { Basado en la } \\
\text { información }\end{array}$ & Indirecto & $\begin{array}{l}\text { Programas para } \\
\text { dar a conocer } \\
\text { públicamente } \\
\text { el desempeño } \\
\text { ambiental de la } \\
\text { empresa. }\end{array}$ & $\begin{array}{l}\text { *Fomento del intercambio } \\
\text { y la difusión de buenas } \\
\text { prácticas y casos } \\
\text { ejemplares en el marco de } \\
\text { las pymes. } \\
\text { "Fomento de la } \\
\text { investigación universitaria } \\
\text { y entre universidades, } \\
\text { empresa y gobierno. } \\
\text { *Asistencia técnica a las } \\
\text { empresas en sus esfuerzos } \\
\text { por aplicar la RSA. } \\
\text { "Fomento o creación de } \\
\text { una red de promoción de } \\
\text { prácticas de RSA. } \\
\text { *Promoción de los } \\
\text { estándares ambientales. } \\
\text { *Promoción del diálogo } \\
\text { y la cooperación entre las } \\
\text { empresas y sus grupos de } \\
\text { interés. } \\
\text { *Ejemplo de las empresas } \\
\text { públicas mediante su } \\
\text { práctica empresarial. } \\
\text { *Certificaciones. } \\
\text { *Reconocimiento de } \\
\text { la RSA a las mejores } \\
\text { prácticas. } \\
\text { *Establecimiento de } \\
\text { espacios de diálogo entre } \\
\text { los grupos de interés. }\end{array}$ \\
\hline
\end{tabular}

Fuente: Elaboración propia sobre la base de Blackman (2000), ESADE (2005), Van Hoof, Monroy y Saer (2008).

En cuanto al empleo de esta herramienta, es importante tener en cuenta que existen instrumentos cuya aplicación dependerá del contexto en el cual se desarrolla la política. La relación de los instrumentos ambientales con las medidas de política pública de RSA puede quedar condicionada a los programas ambientales que contempla la herramienta. Asimismo, podrán existir casos donde las medidas de RSA estarán vinculadas o combinadas a diferentes clases de instrumentos. 


\section{Conclusiones}

Se espera que la herramienta propuesta permita:

- Establecer la relación entre la producción sostenible, la responsabilidad social y las políticas públicas ambientales que las promueven en el marco de la gobernanza.

- Identificar los instrumentos para el fomento de producción sostenible en términos socialmente responsables, de acuerdo con las particularidades de los sectores productivos de la economía.

- Describir las medidas de las políticas públicas de RSA que fomenta el Estado para el cumplimiento puntual de políticas públicas de producción sostenible.

- Observar el énfasis y/o prioridades que hacen las políticas públicas ambientales para la promoción ambiental de las pymes, en términos legales, tributarios, inversión estatal e información.

En definitiva, esta herramienta se podría llegar a convertir en un medio poco utilizado para identificar el rol del Estado, con el objeto de observar la forma como se propician cambios o no en los tomadores de decisión de las pymes, en la lógica relacional de las políticas públicas y la RSA.

Esta propuesta tiene como trasfondo promover su aplicabilidad en diferentes contextos de la política pública ambiental y su relación con la promoción de la Responsabilidad Social de las pymes. Esto permitirá establecer su utilidad más allá de la discusión teórica que se plantea en este trabajo.

\section{BiBLIOGRAFÍA}

Aguilar, L. (2006). Gobernanza y Gestión Pública. México: Fondo de Cultura Económica.

Lozano, Albareda, L. e Ysa, T. (2005). ¿Qué pueden hacer los gobiernos para promover la Responsabilidad Social de la Empresa (RSE)? CIRIECEspaña. Revista de Economía Pública, Social y Cooperativa, 53, 5364. Disponible en: http://www.redalyc.org/articulo.oa?id=17405305.

Lozano, J. (2006). De la responsabilidad social de la empresa (RSE) a la empresa responsable y sostenible (ERS). Papeles de Economía Española, (108), 40-60.

Albareda, L.; Lozano, J.; Midttun, A.; Perrini, F. y Tencati, A. (2009). The Role of Government in Corporate Social Responsibility. En: Z. Boda, 
L. Fekete y L. Zsolnai (Eds.), Ethical Prospects Economy, Society and Environment (pp. 103-149). New York: Springer.

Arroyo, J. (2012). Promover al Promotor: El Estado ante la Responsabilidad Social Empresarial. Católica's Working Paper. Series CENTRUM, 09(4), 1-17. Disponible en: http://centrum.pucp.edu.pe/pdf/working_paper_series/CERES_WP2012-09-0004.pdf.

Blackman, A.; Newbold, S.; Shih, J. y Coock, J. (2000). The benefits and costs of informal sector pollution control: mexican Brick Kilns. Discussion paper (pp. 00-46). Resources for the future Washington D.C. Comisión de las Comunidades Europeas (2001). Libro Verde: Fomentar un marco europeo para la responsabilidad social de las empresas (presentado por la Comisión). Bruselas, 18 de julio de 2001. COM (2001), 366 final, en: http://www.oiss.org/atprlja/?Libro-verde-sobreResponsabilidad.

Congreso Nacional de la República de Colombia. Ley 905 de 2004 para el Fomento de la Micro, Pequeña y Mediana Empresa, las MIPYMES. Disponible en: http://businesscol.com/empresarial/pymes/.

Cortina, A. Justicia Cordial. Madrid: Trotta.

Decreto 482. Política de Producción Sostenible para Bogotá, D.C. Bogotá, Colombia, 30 de diciembre de 2003. Disponible en: http://www. alcaldiabogota.gov.co/sisjur/normas/Norma1.jsp?i=11272.

Garriga, E. y Mele, D. (2004). Corporate Social Responsibility Theories: Mapping the Territory. Journal of Business Ethics 53, 51-71. Ó Kluwer Academic Publishers. Printed in the Netherlands. Disponible en: https://link.springer.com/article/10.1023\%2FB\%3ABU SI.0000039399.90587.34.

Gilli, J. (2011). Ética y empresa: valores y responsabilidad social en la gestión. Buenos Aires: Granica.

Gorrochategui, N. y Martins, V. (2015). Notas sobre Responsabilidad Social Empresarial en América Latina a comienzos del siglo XXI. En N. Gorrochategui, V. Martins, J. Domínguez y H. Chero, Responsabilidad Social de las Organizaciones (RSO): Avances y Propuestas en América Latina. Trujillo: Universidad Católica de Los Ángeles de Chimbote.

Longo, F. e Ysa, T. (Edit.) (2008). Los escenarios de la gestión pública del siglo XXI. Barcelona: Ediciones Bellaterra Navas de Tolosa, Escolad'Administración Pública de Catalunya.

Lozano, J. (2007). Promoción pública de la responsabilidad social empresarial. Ekonomiaz: Revista Vasca de Economía, (65), 108-127. Disponible en: http://www.ogasun.ejgv.euskadi.eus/r51-.

Lozano, J. (2009). La empresa ciudadana como empresa responsable y sostenible. Madrid: Trotta.

Lozano, J. M.; Albareda, L.; Ysa, T; Marcuccio, M. y Roscher, H. (2005). Los gobiernos y la responsabilidad social de las empresas. Políticas públicas más allá de la regulación y la voluntariedad. Barcelona: Granica, Norma. 
Melé, D. (2007). Responsabilidad social de la empresa: una revisión crítica a las principales teorías. Ekonomiaz, 56, 50-67. Disponible en: https:// dialnet.unirioja.es/servlet/articulo?codigo $=2533611$.

Mendoza, X. y Vernis, A. (2008). El Estado relacional y la transformación de las administraciones públicas. En F. Longo y T. Ysa (Edit.), Los escenarios de la gestión pública del siglo XXI (pp. 41-66). Barcelona: Ediciones Bellaterra Navas de Tolosa, Escolad'Administración Pública de Catalunya.

OECD/ECLAC (2014). OECD Environmental Performance Reviews: Colombia 2014. OECD Publishing. Disponible en: https://www. cepal.org/es/publicaciones/evaluaciones-del-desempeno-ambientalcolombia-2014.

Roth, A. (2002). Politicas Públicas: formulación, implementación y evaluación. Bogotá: Ediciones Aurora.

Roth, A. (2004). El Estado relacional y la transformación de las administraciones públicas, La evaluación de políticas públicas en Colombia: una mirada crítica a partir de las prácticas evaluativas oficiales de los programas de la «Red de Apoyo Social». Revista del CLAD Reforma y Democracia [en línea] 2009, (Octubre). Disponible en: http://www.redalyc.org/articulo.oa?id=357533676007.

Sanagustín, M. (2011). Valores y ética empresarial: Un enfoque sociológico. Madrid: Trotta.

Valdés, E.; Moreno L. F. y Bonilla, N. (2016). La Responsabilidad Social Territorial (RST) como enfoque para resignificar el estudio de las Prácticas de Responsabilidad Social de la Organizaciones (RSO). En N. Gorrochategui, V. Martins, A. Hernández y L. Moreno (Eds.), Responsabilidad Social de las Organizaciones (RSO): aportes teórico prácticos para lograr los objetivos del desarrollo sostenible en América Latina (pp. 553-569). Bogotá D.C.: Ediciones USTA.

Van Hoof, B. (2005). División de Desarrollo Sostenible y Asentamientos Humanos de la CEPAL. Políticas e instrumentos para mejorar la gestión ambiental de las Pymes en Colombia y promover su oferta en materia de bienes y servicios ambientales. División de Desarrollo Sostenible y Asentamientos Humanos medio ambiente y desarrollo S E R E. Santiago de Chile: Naciones Unidas.

Van Hoof, B.; Monroy, N. y Saer, A. (2008). Producción más limpia: paradigma de la gestión ambiental. Bogotá: Alfaomega.

Volpentesta, R. (2016). Método de integración de Stakeholders a proceso de toma de decisiones de las empresas. En N. Gorrochategui, V. Martins, A. Hernández y L. Moreno (Eds.), Responsabilidad Social de las Organizaciones (RSO): aportes teórico prácticos para lograr los objetivos del desarrollo sostenible en América Latina (pp. 89108). Bogotá D.C.: Ediciones USTA. 


\title{
Principios de Responsabilidad Social: UNA MIRADA DESDE EL CONTROL
}

\author{
Daniela Alejandra Giordano" \\ Argentina
}

\section{INTRODUCCIÓN}

El objetivo de este artículo consiste en reflexionar sobre prácticas para integrar la responsabilidad social a las organizaciones desde la función del control (interno o externo) en la Administración Pública Nacional en la Argentina, considerando los principios y materias de la Responsabilidad Social enmarcados en la norma ISO 26000.

El estudio abarca tres partes. En la primera se describe el marco teórico y la efectúa un relevamiento acerca de los avances en materia normativa en la Administración Pública Nacional en la Argentina, integrando los principios de Responsabilidad Social a través de las prácticas de control, para lo cual se brinda una guía de trabajo específica en esta materia que pueda ser aplicada en las organizaciones. Para finalizar, se efectúan algunas recomendaciones finales y también se sientan futuras líneas de trabajo.

\section{Responsabilidad SOCIAL, POLÍTICAS PÚBlicas Y GOBERNANZA MODERNA}

Partiendo del concepto de gobernabilidad y democracia, Camou (1995) hace referencia a que si en el primer cuarto de siglo se vio nacer la creciente certidumbre según la cual «el mercado no lo podía todo", el último cuarto de siglo, en cambio, alumbró la convicción opuesta, «el Estado tampoco lo puede todo». Luis F. Aguilar indica que, ante

* Magíster en Administración Pública, Universidad de Buenos Aires. Correo electrónico: dragiordano.dg@gmail.com 
los problemas de eficacia directiva de los gobiernos, dos han sido las líneas generales de respuesta: la gobernabilidad y la gobernanza. De esta manera, la gobernabilidad es una cuestión que se plantea solo en el ámbito del gobierno, con referencia al gobierno y no atañe en ningún modo a la sociedad que, por definición, es ingobernable, limitada o destinada a conflicto y crisis, o que es "subdesarrollada", carente de las capacidades básicas para asegurar su supervivencia y bienestar (Aguilar, 2010). Por otra parte, la gobernanza es un concepto postgubernamental más que antigubernamental de gobernar y quiere significar un nuevo proceso directivo, en tanto la definición y efectuación de los objetivos sociales son resultado de un nuevo tipo de relación entre gobierno y sociedad, que no es dominado por gobierno y que, por ello, tampoco puede ser en modo de mando y control, dada la independencia política de los actores sociales y su fuerza relativa en virtud de los recursos que poseen y de los que el gobierno carece (Aguilar, 2010).

Longo (2010) sostiene que resulta evidente que la gobernanza posee también una significación que va más allá de lo descriptivo y se relaciona con la aspiración a una acción pública de calidad. En esas líneas, él menciona que existen al menos tres perspectivas en torno a esta aproximación: la que relaciona la gobernanza con la calidad de la democracia, la que la vincula con la capacidad para resolver problemas colectivos y la que considera su papel de garantía para los mercados y el buen funcionamiento de la sociedad civil. Lau (2005) se refiere a la buena gobernanza como un concepto poderoso por sí mismo, tanto en países desarrollados como en desarrollo, por las promesas de sus beneficios. Con una estructura de incentivos dentro de un sistema basado en el desempeño, y haciendo este sistema transparente y con rendición de cuentas para todos los grupos de interés (jugadores), se puede reducir la corrupción, incrementar la eficiencia gubernamental y mejorar la distribución de los recursos públicos. Además, el agregar mecanismos para la retroalimentación y la participación promete no solo mejores políticas, sino también una mejor implantación e instrumentación de estas, mayor confianza de la ciudadanía en el gobierno y un mejor ambiente para los negocios y la inversión.

Natera (2004) efectúa una revisión bibliográfica en la que distingue ocho campos de desarrollo de la perspectiva de la gobernanza: a) en el ámbito de la gestión pública; b) en el ámbito del análisis de políticas públicas; c) en el ámbito de la economía política; d) en el ámbito de la gestión empresarial; e) en el ámbito de las relaciones internacionales; 
f) en el ámbito de la estrategia de algunas organizaciones internacionales; g) en ámbito del terreno de la política urbana, y h) en el ámbito de la actual Unión Europea.

Longo (2010) y Aguilar (2010) definen cinco ejes que, conjuntamente considerados, ofrecerían el panorama completo de la gobernanza de un país: a) las instituciones políticas; b) las instituciones de justicia; c) las instituciones de mercado; d) la gestión pública, y e) la sociedad civil. Dado que en este trabajo se analiza el ámbito de la gestión y análisis de las políticas públicas, se resaltan los factores que inciden sobre la gestión pública y sobre la sociedad civil. En cuanto a los primeros, se sintetizan los expuestos por dicho autor: a) el desarrollo de capacidades de coordinación estratégica; b) la economía, eficiencia y eficacia en la provisión de los servicios ofrecidos (valores de referencia); c) la calidad en el empleo público (profesionalización, igualdad de trato); d) la corresponsabilidad; e) la evaluación y control de los resultados (controles internos y externos en la gestión presupuestaria, evaluación de resultados de la gestión); f) la rendición de cuentas (responsabilización y accountability); g) la transparencia (protección del patrimonio público, gestión de compras públicas, estructuras y su funcionamiento, capacidad fiscal); h) la evaluación pública (imparcialidad, discrecionalidad). En cuanto a los segundos, los factores que hacen a la sociedad civil hacen a cuestiones relacionadas con: a) la calidad del servicio ofrecido; b) la participación de los stakeholders en el proceso de gestión de las políticas públicas. Siguiendo las ideas de Longo, Aguilar (2010) sostiene que el proceso de gobernar tiene una estructura institucional y técnica. Los componentes institucionales de la gobernanza institucional son los mismos expuestos por el autor anterior. Por otra parte, los componentes técnicos son: a) el sistema cienciatecnología, b) la política pública, c) las finanzas públicas y d) la administración pública. El mismo autor sostiene que, si el proceso directivo carece de alguna o algunas de las cinco capacidades institucionales, y de las cuatro capacidades técnicas o simplemente no las ejerce en modo correcto y suficiente, la consecuencia probable será que la sociedad no tendrá orientación ni capacidad, se entrampará en problemas sin respuesta y se encaminará más bien al desorden y la decadencia (Aguilar, 2010). La estructura institucional y técnica demarca el alcance de las capacidades gubernamentales, lo que el gobierno puede hacer, pero el aprovechamiento cabal de las capacidades, su empleo eficaz, depende de las prácticas administrativas y políticas que pongan en práctica los gobernantes, del 
tipo de relaciones que establezcan y estabilicen con los varios sectores de la sociedad, particularmente con aquellos que por los recursos que poseen son necesarios y relevantes para resolver los problemas sociales crónicos y alcanzar los futuros deseados (Aguilar, 2010).

Lorenzo de Membiela (2009) enumera los cinco principios sobre los cuales se fundamenta la estrategia instruccional mencionada en el libro blanco sobre la gobernanza europea: a) apertura, b) participación, c) responsabilidad, d) eficacia y e) coherencia. Por su parte, UvalleBerrores (2012) expone ocho factores que influyen en la transformación funcional del Estado y la administración pública con base en el desarrollo que tiene la gobernanza democrática en la sociedad contemporánea, estos son: a) el vigor de lo público; b) las nuevas reglas del juego; c) la profesionalización del servicio público; d) los procesos de corresponsabilidad; e) el control de los resultados; f) la rendición de cuentas; g) la transparencia; y h) la evaluación pública.

La norma ISO 26000 establece como principios de responsabilidad social: la rendición de cuentas, la transparencia, el comportamiento ético, el respeto a los intereses de las partes interesadas, el principio de legalidad, la normativa internacional de comportamiento y los derechos humanos, mientras que las materias de Responsabilidad Social son: la gobernanza de la organización, los derechos humanos, las prácticas laborales, el medioambiente, las prácticas justas de operación, asuntos de consumidores, la participación activa y el desarrollo de la comunidad (ISO 26000, 2010). También en esa línea se encuentran los diez principios del Pacto Mundial en materia de derechos humanos, relaciones laborales, medioambiente, lucha contra la corrupción, que gozan de consenso mundial (Pacto Mundial de las Naciones Unidas, 2000).

A raíz del relevamiento bibliográfico, las propuestas realizadas en el marco de este trabajo se centran en el ámbito de la gestión y análisis de las políticas públicas y aquellos principios que inciden en materia de gobernanza moderna: a) el respeto por los intereses de las partes interesadas, que incluye la calidad de los servicios ofrecidos y la gestión del capital humano; b) el comportamiento ético, que incluye la eficiencia, eficacia y economía de las operaciones administrativas como así también el cuidado por el medioambiente; c) la transparencia; d) la rendición de cuentas, que incluye los procesos de evaluación y control como así también la corresponsabilidad; e) la gestión por resultados, que incluye aspectos de coordinación estratégica y otras actividades vinculadas con 
actividades sustantiva y de apoyo; f) la colaboración; g) la participación de los stakeholders en el proceso de gestión de políticas públicas.

\section{Materias de la Responsabilidad Social y CONTROL}

En la Argentina, el sistema de control de la Administración Pública Nacional se encuentra regulado por la Ley 24.156 de Administración Financiera y Control (B.O.:29/10/1992), estableciéndose un modelo de control integral e integrado sobre la base de los principios de economía, eficacia y eficiencia abarcando tanto el control interno como el externo. El control externo se realiza con el objetivo de que se adopten decisiones eficaces, económicas y eficientes en materia de gastos e ingresos del sector público y queda conformado por la Auditoría General de la Nación (AGN), que asiste técnicamente al Poder Legislativo, mientras que el control interno queda conformado por la Sindicatura General de la Nación (SIGEN) y las Unidades de Auditoría Interna (UAI) de cada jurisdicción, siendo sus objetivos principales: determinar la eficiencia y eficacia de las operaciones, la confiabilidad de la información y el cumplimiento de las leyes, reglamentos y políticas, y reducir riesgos que atenten contra los objetivos institucionales.

A continuación, se exponen las tendencias normativas vinculadas con aquellas materias de la Responsabilidad Social establecidos en la norma ISO 26000. Entendiéndose esta última como los asuntos específicos que las organizaciones públicas deben encarar para determinar su accionar de manera socialmente responsable.

\section{SOBRE LA GOBERNANZA DE LA ORGANIZACIÓN}

La evaluación del control interno o externo está dada por el análisis de aquellas medidas adoptadas por las autoridades máximas de las organizaciones públicas tendientes a evitar que los intereses individuales prevalezcan sobre los de la organización, tales como: la existencia de los códigos de conducta, el diseño de un mapa de riesgos de la organización, la implementación de instrumentos de rendición de cuentas y la gestión por resultados.

Un instrumento de rendición de cuentas adecuado en estos términos es el balance social. Sin embargo, los antecedentes en la legislación argentina ${ }^{1}$ establecen únicamente la obligatoriedad de realizar el mismo

$1 \quad$ Ley 25877 (B.O.: 19/03/2004). 
a determinados sujetos obligados, mientras que en abril del año 2012 se impulsó un proyecto de ley para que sea obligatorio su presentación para las organizaciones públicas, empresas estatales y aquellas en las que el Estado nacional posee participación accionaría, teniendo como objetivo darle protagonismo a la Responsabilidad Social, tema aún no ha sido resuelto. Por su parte, desde la Federación Argentina de Consejo Profesionales de Ciencias Económicas se generaron normas contables profesionales sobre el contenido del balance social, considerando las pautas establecidas en la guía para la elaboración de la Memoria de Sustentabilidad de Global Reporting Initiatives (GRI).

Otros de los temas que no debe descuidarse en el análisis de la gobernanza de la organización se vinculan con la rendición de cuentas en el uso de los fondos públicos, la aplicación del régimen de sumarios y recuperación patrimonial de los funcionarios públicos ${ }^{2}$, el de incompatibilidades y acumulación de cargos, funciones y/o pasividades ${ }^{3}$, el de ética en la función pública y el régimen de presentación de las declaraciones juradas patrimoniales integrales ${ }^{4}$ como así también el de conflicto de intereses ${ }^{5}$; el registro de obsequios a funcionarios públicos y viajes financiados por terceros ${ }^{6}$, y las competencias en materia de designaciones y contrataciones de personal ${ }^{7}$, el registro de convenios con universidades ${ }^{8}$, la autorización y aprobación de gastos y pagos ${ }^{9}$.

2 Decreto 467/1999 (B.O.:13/05/1999) de Reglamento De Investigaciones Administrativas; Decreto 1154/97 (B.O.: 11/11/19997) de responsabilidad patrimonial de funcionarios públicos.

3 Decreto 894/2001 (B.O.:13/07/1991) y modificatorias de régimen de incompatibilidades; Decreto 8566/1961 y normas modificatorias (B.O.: 26/09/1961) de régimen de incompatibilidades.

4 Ley 25188 (B.O.: 01/09/1961) sus modificatorias y complementarias de régimen legal de ética en el ejercicio de la función pública.

5 Decreto 202/2017 (B.O.: 22/03/2017) de procedimiento sobre conflicto de intereses; Resolución MJyDH 11-E/2017 (23/05/2017 de declaración jurada de intereses); Decreto 93/2018 (B.O.: 31/01/2018) de designación de personas con algún tipo de parentesco-criterios aplicables.

6 Decreto 1179/2016 (21/11/2016) de ética en el ejercicio de la función pública; Resolución MJyDH 18-E/2017 (B.O.: 10/08/2017 de instructivo para el registro de obsequios a funcionarios públicos).

7 Decreto 355/2017 (B.O.: 23/05/2017) de designaciones y contratación de personal; Decreto 619/2016 (B.O.:27/04/2016) de designaciones y contrataciones de personal.

8 Decreto 336/2016 (B.O.: 11/02/2016) y normas modificatorias. De registro de convenios con universidades y otras instituciones educativas.

9 Decretos reglamentarios 2662/1992 (B.O.: 31/12/1992) y normas modificatorias de competencias de funcionarios para autorización de gastos y pagos. 


\section{SOBRE LOS DERECHOS HUMANOS}

La evaluación del control interno o externo está dada por el análisis de aquellas medidas adoptadas por las organizaciones públicas tendientes a reconocer y respetar los derechos básicos de las personas humanas, considerando los principios de legalidad que rigen en la materia tales como el régimen de la discapacidad; las condiciones del medioambiente de trabajo y la igualdad de oportunidades.

El régimen de discapacidad deja en cabeza de las Unidades de Auditoría Internas la verificación del cumplimiento de las condiciones establecidas sus normas ${ }^{10}$, especialmente en la obligación de ocupar a personas con discapacidad que reúnan condiciones de idoneidad para el cargo, en una proporción no inferior al cuatro por ciento (4\%) de la totalidad de su personal, y a establecer reservas de puestos de trabajo a ser exclusivamente ocupados por ellas.

Es relevante, además, constar la conformación y verificación del funcionamiento de dos comisiones específicas previstas en el convenio colectivo general para la Administración Pública Nacional sobre medioambiente e igualdad de oportunidades, siendo las mismas la Comisión de Condiciones y Medio Ambiente de Trabajo (CyMAT) y la Comisión de Igualdad de Oportunidades y Trato (CIOT). En el caso de la CyMAT, se encuentran prácticas como la realización de exámenes preocupacionales para todos los trabajadores y exámenes médicos anuales; la existencia de un servicio de salud del trabajo o un prestador externo para la atención de urgencias según la cantidad de trabajadores, el cumplimiento de las leyes de higiene y seguridad y la de riesgos de trabajo ${ }^{11}$, la existencia de un plan de contingencia y evacuación aprobado. Para el caso de la CIOT, el cumplimiento de los principios de igualdad de trato y oportunidades; la promoción de la equidad de género, las políticas específicas para la integración efectiva de los agentes con discapacidad y la erradicación de la violencia laboral.

10 Ley 22431 (B.O.: 20/03/1981) reglamentado por el Decreto 312/2010 y la Resolución JGM 56/2010 (B.O.: 15/04/2010).

11 Ley 19587 reglamentado por el Decreto No 351/1979; Ley 24557 reglamentado por Decreto 1338/1996. 


\section{SOBRE LAS PRÁCTICAS LABORALES}

La evaluación del control interno o externo está dada por el análisis de aquellas medidas adoptadas por las organizaciones públicas vinculadas con el marco regulatorio del empleo público, siendo necesario enfocarse en auditorías integrales de gestión del capital humano relacionadas con todos los subsistemas, tales como el de planificación y organización de los recursos humanos, la gestión del empleo, la gestión del rendimiento, la gestión de la compensación, la gestión del desarrollo y la gestión de las relaciones humanas y laborales (Longo, 2002).

\section{Sobre El MEDIOAMBIENTE}

La evaluación del control interno o externo está dada por el análisis de aquellas medidas adoptadas por las organizaciones públicas tendientes a la protección y cuidado del medioambiente.

En estas líneas, tanto la Auditoría General de la Nación como la Sindicatura General de la Nación cuentan con documentos y herramientas de trabajo para su análisis, como así también han desarrollado capacitaciones encuadradas dentro de los diferentes principios que hacen a la responsabilidad social. Puntualmente, la SIGEN, a través de una resolución, establece una guía de apoyo para auditorías sobre medioambiente ${ }^{12}$, que considera tanto el cumplimiento de la legalidad vigente en materia de política ambiental nacional ${ }^{13}$ como así también aquellas sobre de higiene y seguridad y de riesgos del trabajo, brindando al mismo tiempo determinadas normas internacionales de comportamiento para analizar las prácticas sobre el medioambiente. Se trata de una herramienta de trabajo que sirve como guía para efectuar auditorías sobre el medioambiente, requiriendo analizar los siguientes aspectos: a) la caracterización de la organización y el análisis de los riesgos ambientales; b) la definición de una política ambiental; c) la registración de los pasivos ambientales; d) el relevamiento de normativas vigentes aplicables a la organización, y e) la enumeración de las acciones impulsadas por la organización relacionadas con el cuidado de los recursos y la seguridad e higiene en el trabajo.

12 Resolución SIGEN 74/2014 (B.O. 06/06/2014) de guía de auditorías ambientales.

13 Ley 25675 (B.O.:28/11/2002) de política ambiental. 


\section{SOBRE PRÁCTICAS JUSTAS DE OPERACIÓN}

La evaluación del control interno o externo está dada por el análisis de aquellas medidas adoptadas por las organizaciones públicas tendientes a favorecer los principios del comportamiento ético, la transparencia, la legalidad y la normativa internacional de comportamiento y las compras públicas sustentables.

Las medidas generadas para evaluar las acciones tendientes a disminuir la corrupción, siguiendo un comportamiento ético y responsable, se relacionan con algunos temas expuestos en la materia sobre la gobernanza de la organización: la existencia de procedimientos formalizados vinculados a la verificación de su cumplimiento por parte de los funcionarios obligados a presentar las declaraciones juradas patrimoniales integrales, como así también el relevamiento de los procedimientos de trabajo en materia de ética en el ejercicio de la función pública. La aplicación de la resolución de conflicto de intereses se puede verificar a través de la presentación de la declaración jurada de intereses por parte de toda persona que se presente a un procedimiento de contratación pública o de otorgamiento de una licencia, permiso, autorización, habilitación o derecho real sobre un bien de dominio público o privado del Estado; la constatación acerca de la actualización anual de la misma y a través del diseño de procedimientos, en caso de detectar la existencia de alguno de los supuestos previstos. Otra práctica es la vinculada con el registro de obsequios a funcionarios públicos y viajes financiados por terceros. A su vez, se puede relevar la realización de actividades de difusión relativas a los principios de ética y transparencia ${ }^{14}$, como así también con actividades de formación de líderes en la prevención de la corrupción.

Puntualmente, en materia de transparencia podemos destacar dos normas: la relacionada con el régimen de propaganda y publicidad, y la que se vincula con el acceso a la información pública y gobierno electrónico. En relación con el régimen de propaganda y publicidad existe una tarea específica de las Unidades de Auditoría Interna, para que releven acerca de la celebración de alguna contratación vinculada con dichos aspectos, todo conforme lo regulado por la norma específica ${ }^{15}$. En el régimen de acceso a la información pública se encuentran diferentes avances. Por un lado, los antecedentes normativos sobre el

14 Decisión Administrativa 1047/2017 (B.O.: 06/12/2017) de difusión sobre ética y transparencia.

15 Decreto 984/2009 y modificatorios (B.O.: 28/07/2009) de publicidad y propaganda; Circular SIGEN 2/2013 GnyPE. 
gobierno abierto ${ }^{16} \mathrm{y}$, por otro, sobre el acceso a la información pública ${ }^{17}$. En ese sentido, dentro del encuadre del gobierno abierto se establece el plan nacional y los planes sectoriales de gobierno electrónico, siendo la transparencia uno de los principios rectores, a través de la facilitación del acceso a los habitantes y ciudadanos de los actos de gobierno y la información pública mediante su publicación en internet, mientras que en la norma que regula el acceso a la información pública se reglamentan diferentes aspectos: a) audiencias públicas; b) publicidad de la gestión de los intereses; c) elaboración participativa de normas; d) acceso a la información pública; e) reuniones abiertas de los Entes Reguladores de los Servicios Públicos; f) el acceso libre y gratuito vía internet a la edición diaria de la totalidad de las secciones del Boletín Oficial de la República Argentina. Por último, la reciente Ley 27.275 (B.O.: 29/09/2016), que regula sobre el derecho de acceso a la información pública, menciona en su artículo 32 sobre la transparencia activa, estableciendo que los sujetos obligados con las excepciones previstas deberán facilitar la búsqueda y el acceso a la información pública a través de su página oficial de la red informática, de una manera clara, estructurada y entendible para los interesados y procurando remover toda barrera que obstaculice o dificulte su reutilización por parte de terceros. Asimismo, deberán publicar en forma completa, actualizada, por medios digitales y en formatos abiertos la información tipificada en dicho artículo.

A su vez, de manera complementaria se podrá verificar la aplicación de normativa intencional de comportamiento, tales como las prácticas recomendadas por las normas ISO de sistema de gestión ambiental; de responsabilidad social; de gestión energética y las normas Occupational Health and Safety Assessment Series (OHSAS) de gestión de salud y seguridad ocupacional. Estas últimas han sido diseñadas para ser compatibles con los estándares ISO de gestión de calidad y medioambiente, respectivamente (Resolución SIGEN 74/2014; 2014).

\section{SOBRE ASUNTOS DE CONSUMIDORES}

La evaluación del control interno o externo está dada por el análisis de aquellas medidas adoptadas por las organizaciones públicas tendientes

16 Decreto 378/2005 (B.O.: 28/04/2005) de plan nacional de gobierno abierto y planes sectoriales.

17 Decreto 1172/2003 (B.O.: 04/12/2003) de acceso a la información pública; Ley de acceso a la información pública 27275 (B.O.: 29/09/2016). 
a satisfacer a los beneficiarios de sus productos y servicios. Tales como información objetiva e imparcial, las prácticas justas de contratación, la protección de salud y seguridad de los consumidores, los servicios de apoyo y resolución de quejas, la protección y privacidad de sus datos.

En relación con este punto se puede verificar todo lo referente al cumplimiento del marco legal en materia de compras y contrataciones, haciendo énfasis en las compras públicas sustentables, aquellas normativas específicas tendientes a priorizar la contratación de determinados servicios con empresas u organizaciones públicas, tales como pago de haberes a través del Banco Nación; la carga de combustible con YPF; la contratación de pasajes aéreos para para viajes oficiales con la empresa Aerolíneas Argentinas y Austral. También abarca la supervisión del control interno en materia de tecnología de la información, la aprobación de los estándares tecnológicos (ETAP) y el modelo de política de seguridad de la información.

\section{SOBRE PARTICIPACIÓN ACTIVA Y DESARROLLO DE LA COMUNIDAD}

La evaluación del control interno o externo está dada por el análisis de aquellas medidas adoptadas por las organizaciones públicas tendientes al involucramiento y participación con sus partes interesadas.

La Auditoría General de la Nación en materia de participación cuenta con un programa de planificación participativa ligado a la colaboración ciudadana en el control de la gestión del Estado. Según la información disponible en la página web, el proceso de planificación participativa se reglamentó en el año $2014^{18}$. Los antecedentes datan desde el año 2002, periodo en el cual la AGN se acerca a las organizaciones de la sociedad civil para escuchar sus propuestas, lo cual derivó en la creación, en el año 2013, del Área de Participación Ciudadana, dependiente del Departamento de Relaciones Institucionales y Convenios. Las diferentes actividades mencionadas se derivan en el involucramiento en la realización de talles de trabajo, talleres temáticos, intermedios, de presentación de informes y encuentros anuales, como así también la convocatoria para discutir temas que puedan ser incorporados en su plan de acción anual, a fin de que se detecten temas de interés y se cumplan las recomendaciones. Otra medida de participación en materia de control interno son los comités de control; el programa de

18 Disposición AGN 98/2014 (abril 23 de 2017). 
fortalecimiento del sistema de control interno; el plan de compromiso de mejora de la gestión y el control interno; las normas particulares sobre la constitución y funcionamiento de los comités de control; la metodología de autoevaluación y diagnóstico de procesos como buena práctica de control interno ${ }^{19}$.

\section{ConClusión}

El objetivo de este trabajo consiste en reflexionar sobre prácticas para integrar la responsabilidad social a las organizaciones desde la función del control (interno o externo) en la Administración Pública Nacional en la Argentina, considerando los principios y materias de la Responsabilidad Social enmarcados en la norma ISO 26000.

Luego de haber procurado atender al objetivo general y los objetivos específicos, es también valioso continuar profundizado con más detalle en los temas relevados, a fin de generar una herramienta a través de la mirada multidisciplinaria de especialistas en toda las materias y principios de la Responsabilidad Social, bajo la mirada del enfoque de la gobernanza moderna. Lo anterior porque, fundamentalmente, este estudio constituye un recurso para las investigaciones que se encuadren dentro del ámbito de gestión de políticas públicas, dado que permite reflexionar sobre la función del control interno, y el rol de este último en términos de la gobernanza moderna y su vinculación con las partes interesadas.

Se observa entonces que el proceso de modernización del Estado y las nuevas herramientas gerenciales se encuentran instalándose en diferentes las líneas de acción que se trasladan y que abarcan los diferentes matices de la Responsabilidad Social. De esta manera es que se necesita encarar un plan de acción, de manera de poder alcanzar un buen gobierno basado en los principios de la gobernanza moderna. En función de lo expuesto en este trabajo se efectúan proposiciones que debe afrontar la organización en materia de gobernanza moderna, vinculadas con materias de Responsabilidad Social.

El respeto de los intereses de las partes interesadas se encuentra orientado a generar las condiciones básicas que hacen a la calidad en el servicio ofrecido, como así también a la calidad en la gestión del empleo público, buscando brindar una respuesta satisfactoria a todas las partes interesadas donde exista compromiso de las autoridades en

19 Resolución SIGEN 36/2011 (B.O.: 19/04/2011) de programa de fortalecimiento de control interno. 
el respeto por los intereses de las partes involucradas. La cooperación implica potenciar la sinergia, la interrelación y la generación de involucramiento entre las partes interesadas, apuntando a fortalecer los vínculos de cooperación interorganizacional como los intraorganizacional. La participación de los stakeholders intenta proveer, facilitar y brindar accesibilidad de los ciudadanos en cualquier instancia del proceso de gestión de políticas públicas, como también a incrementar la eficiencia en la comunicación con la ciudadanía e impulsar una administración más receptiva a sus demandas, a implantar mejoras organizativas que permitan incrementar la eficiencia de los procesos de gestión, y al uso de las tecnologías de la información y las comunicaciones.

Por su parte, el comportamiento ético abarca la producción de bienes y servicios con economía, eficiencia y eficacia, respetando los valores y derechos compartidos inmersos en la cultura de la sociedad para el logro del desarrollo sostenible, mientras que con la transparencia se busca generar las condiciones básicas para poner a disposición en forma clara, concisa y oportuna de toda aquella información sobre políticas y decisiones que requieran o afecten a sus partes interesadas, como así también dotar a la organización de los instrumentos necesarios para incrementar la eficiencia en la gestión de los recursos y servicios públicos.

La rendición de cuentas se relaciona con el impulso de la generación de explicaciones por parte de los funcionarios públicos, por las acciones u omisiones en el desempeño de las funciones conferidas en su cargo. De alguna manera, se pretende ir hacia una administración eficaz, innovadora y que rinda cuentas de su gestión, mientras que con la gestión por resultados se busca promover la utilización de un conjunto de herramientas orientadas a mostrar los resultados de la gestión. Implica la utilización de la planificación estratégica y la definición de un modelo de seguimiento y evaluación de resultados.

Sin embargo, se percibe un bajo grado de información disponible respecto a la existencia de métodos, instructivos o planes de auditoría enfocados en la gestión socialmente responsable de una organización pública. A continuación, se formulan las siguientes cuatro sugerencias relacionadas con acciones que deberían encarar los organismos de control, en materia de sus competencias. Ellas son: a) reforzar las actividades de control relacionadas con la temática; b) contratar auditores expertos o realizar capacitaciones integrales; c) generar nuevos métodos de revisión, y d) determinar criterios y estándares generalmente aceptados para la evaluación de una gestión socialmente responsable. 
La propuesta realizada es de manera preliminar, basándose en el relevamiento efectuado, y está sujeta a la dinámica propia de cada organización pública, su capacidad de autodiagnosticarse de manera objetiva y requiere de compromiso manifiesto por parte de los niveles superiores de la organización para establecer un plan de acción, ejecutarlo y efectuar el seguimiento permanente del mismo. La contribución a la función pública apunta a generar una cultura organizacional relacionada con los principios de la gobernanza moderna, reforzándose el rol del Estado como promotor de dichas políticas públicas, para estimular el comportamiento responsable y su rol fiscalizador en el cumplimiento de la legislación a través de la función del control interno y externo.

\section{BibLIOGRAFÍA}

Aguilar, L. F. (2006). Gobernanza y gestión pública. México: Fondo de Cultura Económica.

(2007). El aporte de la Política Pública y de la Nueva Gestión Pública a la gobernanza. Revista del CLAD Reforma y Democracia, 39, Caracas.

(2008). Gobernanza: normalización conceptual y nuevas cuestiones. Barcelona: Escuela Superior de Administración y Dirección de Empresas (ESADE), Cátedra de Liderazgos y Gobernanza Democrática.

(2010). Gobernanza: El nuevo proceso de gobernar. México: Fundación Friedrich Naumann para la Libertad.

Carmona, R. R. (s.f.). Nuevas formas de gobierno y gestión pública en el escenario local: Elementos y perspectivas para el estímulo de procesos concertados de desarrollo. Disponible en: http://www.ag.org. ar/3congreso/Ponencias/Carmona.pdf.

Cunill Grau, N. (2004). La democratización de la administración pública. Los mitos a vencer. Política y Gestión Pública. Buenos Aires: Fondo de Cultura Económica, Centro Latinoamericano de Administración para el Desarrollo.

Camou, A. (1995). Gobernabilidad y Democracia. México: Cuadernos del Instituto Federal.

Estévez, A. (s.f). Construcción de una matriz de actores para políticas públicas y proyectos dentro de un contexto de reforma de estado. Buenos Aires: Facultad de Ciencias Sociales. Disponible en: http:// www.polipub.org/documentos/matriz \%20de\%20actores.PDF. 
Fassio, A.; Pascual, L. y Suárez, F. (2004). Introducción a la Metodología de la Investigación Aplicada al Saber Administrativo y al Análisis Organizacional. Buenos Aires: Ediciones Macchi.

Federación Argentina de Consejo Profesionales de Ciencias Económicas (2012). Normas contables profesionales: balance social. Resolución técnica $N^{\circ} 36$. Buenos Aires, Consejo Emisor de Normas de Contabilidad y Auditoría (CENCYA). Disponible en: https://www.facpce. org.ar/web2011/Noticias/noticias_pdf/rt36.pdf.

Gaete Quezada, R. A. (2009). Participación de los stakeholders en la evaluación del comportamiento responsable de la gestión universitaria: perspectivas, obstáculos y propuestas. Trabajo presentado en XV Congreso de Asociación Española de Contabilidad y Administración de Empresas (AECA). Valladolid, España, septiembre. Disponible en: http://www.aeca.es/xvcongresoaeca/cd/6h.pdf.

Lau, E. (2005). Construyendo una nueva gobernanza a través del eGobierno: una visión de la OCDE. Revista del CLAD Reforma y Democracia, 31, Caracas.

Lorenzo de Membiela, J. B. (2009). Democracia, Gobernanza y desarrollo sostenible en la nueva gerencia pública. Revista Aragonesa de Administración Pública, 34, 325-342. Disponible en: https://dialnet. unirioja.es/servlet/articulo?codigo=3067113.

Longo, F. (2010). Ejes vertebradores de la gobernanza en los sistemas públicos. Un marco de análisis en clave latinoamericana. Revista del CLAD Reforma y Democracia, 46. Caracas. Disponible en: http:// itemsweb.esade.edu/idgp/longo.pdf.

Marradi, A.; Archenti, N. y Piovani, J. I. (2007). Metodología de las ciencias sociales. Buenos Aires: Emecé.

Natera, A. (2004). La noción de la gobernanza como gestión pública participativa y reticular. Documentos de trabajo "politica y gestión», 2. Madrid: Universidad Carlos III de Madrid. Departamento de política y sociología. Área de ciencia política y de la administración. Disponible en: http://e-archivo.uc3m.es/bitstream/handle/10016/590/ cpa040202.pdf;jsessionid=478FEBCA53A97D75B59DE2E6FDB5 A807? sequence $=1$.

Organización Latinoamericana y del Caribe de Entidades Fiscalizadoras Superiores. (2009). Declaración de Asunción sobre los principios de rendición de cuentas. XIX Asamblea General de la OLACEFSC. Asunción, Paraguay. Disponible en: https://www.agn.gov.ar/files/ files/Declaracion \%20Asuncion \%281\%29.pdf.

Organización Latinoamericana y del Caribe de Entidades Fiscalizadoras Superiores (2017). Declaración de Asunción sobre la seguridad presupuestaria y estabilidad financiera de las entidades de fiscalización superior. XXVII asamblea ordinaria OLACEFS. Asunción, Paraguay. Disponible 
en: https://www.agn.gov.ar/files/files/Declaracio \%CC $\% 81$ n $\% 20$ de $\% 20$ Asunci\%C3\%B3n\%20XXVII.pdf.

Piccard, A. (2011). ¿Cuáles son los enfoques que explican el juego de los actores en el proceso de políticas públicas? Cuadernos de Polibun. org, 6. Buenos Aires: Asociación civil para el estudio de políticas públicas participativas (Polipub). Disponible en: http://polipub.org/ documentos/cuaderno\%20nro.\%206.pdf.

Rofman, A. (2007). Participación de la sociedad civil en políticas públicas: una tipología de mecanismos institucionales participativos. Trabajo presentado en la VI Conferencia Regional para América Latina y el Caribe: Salvador de Bahía, Brasil. Disponible en: http://www.periodicos.adm.ufba.br/index.php/cgs/article/viewFile/9/6.

Santos Alba de, C. G.; Gálvez González, S. y Guzmán Campos, N. E. (2011). Guía sobre los aspectos generales, citas y referencias para la redacción de acuerdo al Manual de publicaciones de la American Psychological Association, 3 (Español, Trad.). Universidad de Guadalajara. Disponible en: http://repositorio.cucea.udg.mx/jspui/ bitstream/123456789/34/1/PDF.

Scarano, E. R. (2004). Manual de redacción de escritos de investigación $\left(1^{\mathrm{a}}\right.$. ed). Buenos Aires: Ediciones Macchi.

Uvalle-Berrones, R. (2012). La administración pública en los imperativos de la gobernanza democrática. Convergencia. 19 (60), 111-144. Toluca: México. Disponible en: http://www.scielo.org.mx/scielo. php?script=sci_arttext\&pid=S1405-14352012000300004.

Villarreal Martínez, M. (2006). Mecanismos participativos en el diseño, formulación e implementación de leyes, políticas y programas sobre envejecimiento. Política y Desarrollo, 70. Santiago: Centro Latinoamericano y Caribeño de Demografía (CELADE), División Población de la CEPAL. Disponible en: http://www.eclac.org/publicaciones/ xml/3/27963/lcl2542e-P.pdf.

Volpentesta, J. (2011). La Responsabilidad social empresaria. En Gestión de la Responsabilidad Social Empresaria: Visión, misión, objetivos $y$ estrategias ( $2^{\mathrm{a}}$ ed.). Buenos Aires: Ediciones Buyatti.

\section{MATERIAL Legal}

Honorable Congreso de la Nación Argentina (1992, 29 de octubre). Ley 24146 de administración financiera y control de administración financiera y de los sistemas de control del sector público nacional. En Boletín oficial de la nación, B.O.: 29/10/1992 (en línea). Argentina: Honorable Congreso de la Nación Argentina. Disponible en: http:// www.infoleg.gob.ar. 
Honorable Congreso de la Nación Argentina (1999, 01 de noviembre). Ley 25188 de régimen legal de ética en el ejercicio de la función pública. En Boletín oficial de la nación, B.O.: 01/11/1999 (en línea). Argentina: Honorable Congreso de la Nación Argentina. Disponible en: http://www.infoleg.gob.ar.

Honorable Congreso de la Nación Argentina (1999, 08 de octubre). Ley 25154 marco de regulación del empleo público Nacional. En Boletín oficial de la nación, B.O.: 08/10/1999 (en línea). Argentina: Honorable Congreso de la Nación Argentina. Disponible en: http:// www.infoleg.gob.ar.

Honorable Congreso de la Nación argentina (2004, 19 marzo). Ley 25.877 de reforma laboral. Boletín oficial de la nación, B.O.: 19/03/2004 (en línea). Argentina: Honorable Congreso de la Nación Argentina. Disponible en: http://www.infoleg.gob.ar.

Honorable Congreso de la Nación Argentina (2016, 29 de septiembre). Ley 27.275 de acceso a la información pública. En Boletín oficial de la nación, B.O.: 29/09/2016 (en línea). Argentina: Honorable Congreso de la Nación Argentina. Disponible en: http://www.infoleg.gob.ar.

Poder Ejecutivo Nacional de Argentina (2002, 09 de agosto). Decreto 1421/2002 reglamentario de la ley 25154. En Boletín oficial de la nación, B.O.: 09/08/2002 (en línea). Argentina: Poder Ejecutivo nacional. Disponible en: http://www.infoleg.gob.ar.

Poder Ejecutivo Nacional de Argentina (2003, 04 de diciembre). Decreto $1172 / 2003$ de acceso a la información pública. En Boletín oficial de la nación, B.O.: 04/12/2003 (en línea). Argentina: Poder Ejecutivo Nacional. Disponible en: http://www.infoleg.gob.ar.

Poder Ejecutivo Nacional de Argentina (2005, 28 de abril). Decreto 378/2005 de gobierno electrónico. En Boletín oficial de la nación, B.O.: 28/04/2005(en línea). Argentina: Poder Ejecutivo Nacional. Disponible en: http://www.infoleg.gob.ar.

Poder Ejecutivo Nacional de Argentina (2016, 21 de noviembre). Decreto 1179/2016 reglamentación de la ley de ética en el ejercicio de la función pública sobre Registro de Obsequios a Funcionarios Públicos y Viajes Financiados por Tercero. En Boletín oficial de la nación, B.O.: 21/11/2016 (en línea). Argentina: Poder Ejecutivo Nacional. Disponible en: http://www.infoleg.gob.ar.

Poder Ejecutivo Nacional de Argentina (2017, 22 de marzo). Decreto 202/2017 de procedimiento sobre resolución de conflicto de intereses. Boletín oficial de la nación, B.O.: 22/03/2017 (en línea). Argentina: Poder Ejecutivo Nacional. Disponible en: http://www.infoleg.gob.ar.

Poder Ejecutivo Nacional de Argentina (2018, 31 de enero). Decreto 93/2018 de criterios aplicables para la designación de personas con algún tipo vinculo de parentesco. En Boletín oficial de la nación, 
B.O.: 31/01/2018 (en línea). Argentina: Poder Ejecutivo Nacional. Disponible en: http://www.infoleg.gob.ar.

\section{PÁginas Web CONSUlTadas}

Auditoría General de la Nación (AGN): https://www.agn.gov.ar/ Global Reporting Incitatives (GRI): https://www.globalreporting.org/ Información legislativa y documental (INFLOG): http://www.infoleg.gov.ar/ Pacto Mundial, Red Española: https://www.pactomundial.org/ Sindicatura General de la Nación (SIGEN): http://www.sigen.gov.ar/ 


\section{ÍNDICE DE PERCEPCIÓN DE TRANSPARENCIA PARA LA OBRA PÚBLICA}

Carlos Nelson Rubin"

Argentina

\section{INTRODUCCIÓN}

A fines del siglo XX surge el fenómeno de la Gran Corrupción, un flagelo que es el resultado de muy altas concentraciones de poder y dinero, asociado con el crimen organizado, en un mundo conectado. En general, comprende una extensa red de corrupción que involucra a las máximas autoridades del país donde se origina, los principales grupos políticos del momento y poderosos grupos económicos empresariales e industriales, tanto del país origen como del exterior. La Gran Corrupción comenzó en los 70, con los casos emblemáticos de Indonesia (Mohamed Suharto), Filipinas (Ferdinand Marcos) y Nigeria (Sani Abacha). Con el tiempo se ha ido propagando, logrando en los 90 estar a escala mundial. En Latinoamérica, los casos de Perú, Venezuela, Guatemala, Honduras, Brasil y Argentina son claros ejemplos de ello.

En 1993, Peter Eigen funda Transparency International (TI), una ONG con sede en Berlín que promueve la transparencia y la responsabilidad en el desarrollo internacional, que hoy ya tiene capítulos nacionales en más de cien países. TI se constituye en una coalición transnacional en contra de la Gran Corrupción, decidida a enfrentar la impunidad, identificando, denunciando y buscando una sanción para los corruptos, y lograr la reparación de las víctimas. Actualmente, en muchos países hay falta de voluntad política, y resulta necesario acudir en forma directa a la llamada reserva moral de las instituciones para emprender campañas anticorrupción.

Doctor en Ciencias Económicas-Administración, Universidad de Buenos Aires. Correo electrónico: cxrubin@gmail.com. 
Según Olivera Prado (2003), la Gran Corrupción, por un lado, es normativa de alta nocividad social, es decir, se realiza en los niveles normativos y legislativos de la sociedad en su conjunto, implica la gestación de normas dolosas por intereses creados y afecta las reglas de juego social como intereses colectivos y/o la moral social objetiva. Por otro lado, es sistémica, es decir, afecta a la totalidad del sistema político, hasta llegar a un estado paralelo, o infraestado, alojado en el interior del Estado que asume el rol de fachada.

Con frecuencia, la Gran Corrupción toma acción en las obras públicas donde participan inmensos recursos económicos, como es el caso de las grandes obras de construcción. En estos casos, produce la cartelización de la obra pública, protagonizada por grandes empresas de construcción que actúan con gran impunidad, bajo la total protección del gobierno y del poder político.

La Gran Corrupción es un fenómeno que generalmente logra la impunidad absoluta.

Dada su naturaleza, generalmente permanece impune, pues la justicia se revela incapaz de sancionar a los responsables. En esta última categoría normalmente caen la corrupción política, la corrupción pública para favorecer a agentes privados y la corrupción financiera en todas sus expresiones, particularmente el lavado de activos. Es lamentable, pero en ese sentido, la impunidad se ha convertido en un lugar común alrededor del mundo. (Ugaz, 2015)

Lord Acton es un conocido historiador y político inglés del siglo XIX, a quien se atribuye la afirmación: «El poder tiende a corromper y el poder absoluto corrompe absolutamente». Él mismo decía: «Dinero es poder». En esta misma línea, cabe destacar que, a fines del siglo XX, el poderoso empresario argentino Alfredo Yabrán expresó: «Para mí el poder es impunidad».

En 2015, la Comisión Económica para América Latina y el Caribe (CEPAL), de las Naciones Unidas, acordó con los países un Plan de Desarrollo Global, consistente en la implementación de 17 Objetivos de Desarrollo Sostenible (ODS), cuya finalidad es erradicar la pobreza, hacer frente al cambio climático y construir sociedades pacíficas e inclusivas para 2030. En particular, el Objetivo 16, «Paz, Justicia e Instituciones Sólidas», meta 16.6, requiere "crear, a todos los niveles, instituciones eficaces y transparentes que rindan cuentas». 
La Gran Corrupción obstaculiza la construcción de sociedades inclusivas, lesionando la finalidad de los ODS. Si los gobiernos contaran con instituciones transparentes, la cartelización de la obra pública no debería alcanzar los altos niveles actuales, debido al monitoreo, control y penalización. Más aún, si consideramos que el involucramiento de la sociedad es una acción muy positiva, resulta necesario mantenerla informada adecuadamente.

Por lo tanto, sería muy útil contar con un modelo que describa y cuantifique la transparencia de la gestión pública. Estaría respaldado por el siguiente esquema axiomático:

- No se puede administrar lo que no se puede gestionar.

- No se puede gestionar lo que no se puede controlar.

- No se puede controlar lo que no se puede medir.

- No se puede medir lo que no se puede describir.

Indudablemente, constituye un verdadero desafío el diseño de una herramienta que describa y cuantifique con nitidez, de 0 a 100, un concepto tan abstracto y sutil como es la percepción de la transparencia de la gestión pública. Este planteamiento es tan complejo como necesario y se nutre de las afirmaciones de dos grandes hombres de ciencia.

Galileo Galilei (1564-1642): «Mide lo que se pueda medir; y, lo que no, hazlo medible».

Lord William Thomson Kelvin (1824-1907) expresó:

Si puedes medir lo que estás hablando, y expresarlo en números, sabes algo al respecto; pero si no puedes medirlo, no podrás expresarlo en números y entonces tu conocimiento será escaso e insatisfactorio; podrá ser el principio del conocimiento, pero apenas habrás avanzado en tus pensamientos en el estado de la ciencia, cualquiera que sea el tema que se trate.

Transparencia Internacional produce el Índice de Percepción de la Corrupción (IPC), el cual es una referencia mundial anual en materia de corrupción. Usa una escala de 0 a 100, donde 0 es altamente corrupto y 100 es muy transparente. Clasifica a 180 países y territorios, por sus niveles percibidos de corrupción en el sector público, según la opinión de expertos y empresarios. Esta información, si bien es sólida y de muy buena calidad, no resulta funcional para quien quiera realizar un seguimiento pormenorizado de la evolución de la transparencia a través del año, desglosado por localidades de interés. 
El modelo propuesto genera información mensual sobre la transparencia en todos los lugares que se desee monitorear, basándose en un esquema tan sólido como sencillo y auditable. Esta información, muy probablemente, pueda capturar el interés de la sociedad interesada en el bienestar futuro de sus hijos, de sus nietos y de la sociedad humana en su conjunto.

El modelo concentra la información en una matriz denominada mapa de transparencia, cuyas columnas son las etapas del proceso y cuyas filas, las variables perceptuales de la transparencia. Por cada elemento de la matriz, el experto evalúa el grado de vulnerabilidad y aplica una penalidad, dando lugar a la matriz de penalidades. El resultado final es el Índice de Percepción de Transparencia. Usa una escala de 0 a 100 , donde 0 es altamente vulnerable y 100 es altamente transparente.

\section{Marco metodológico}

La obra/compra pública constituye un proceso que se desarrolla en etapas, dentro del triángulo sociedad civil-Estado-empresa. La sociedad civil demanda al Estado, la ejecución de una obra para cubrir una necesidad pública; el Estado programa la obra, con la participación y consenso de la misma; el Estado genera la documentación necesaria para especificar la obra, a fin de invitar a las empresas interesadas en la ejecución de la misma; el Estado analiza las ofertas recibidas y selecciona al oferente ganador; por último, la empresa ejecuta la obra, bajo el control del Estado.

La gestión del Estado cumple una misión esencial, dado que escucha e interpreta la demanda de la sociedad civil; traduce técnicamente la necesidad, en el marco de los recursos disponibles y el estado del arte; analiza las ofertas en forma responsable, objetiva y equitativa; selecciona la oferta ganadora; elabora el contrato de la obra pública; controla su ejecución, en cuanto a su ritmo de avance, cumplimiento técnico y costo, tanto durante su ejecución como a su término. En este contexto, el modelo es la herramienta que evalúa la transparencia de la gestión pública, en relación con una obra pública dada, etapa por etapa, con un índice de 0 a 100.

\section{MAPA DE TRANSPARENCIA}

El modelo realiza un estudio de tipo cualitativo descriptivo, enfocado en la gestión de los funcionarios públicos, en relación a las 
obras públicas. Como estrategia, utiliza un sistema de penalidades, es decir, define los tipos de debilidades que afectan la transparencia de la gestión, evalúa su grado de vulnerabilidad y aplica una penalidad, de 0 a 100, en cada caso. Para mostrar la transparencia de la gestión se recurrió a un mapa que concentra los diferentes tipos de debilidades en las distintas etapas de la obra.

El trabajo se basa en una publicación de la Organización Poder Ciudadano (Arcidiácono et al., 2006), un estudio de percepción sobre las vulnerabilidades del Sistema Nacional de Contrataciones Públicas, en el cual se utiliza un mapa de riesgos sobre contrataciones públicas nacionales, cuyo análisis metodológico fue realizado por Karina Kalpschtrej. En dicho estudio, la noción de riesgo se define en función de las vulnerabilidades del sistema, en el sentido de la transparencia y eficiencia en las contrataciones públicas, así como de la eficacia en una compra pública. También se consultó otra publicación de Poder Ciudadano sobre la transparencia y control social en las contrataciones públicas (Arenoso, 2006).

El modelo utiliza un mapa funcional a sus objetivos, llamado mapa de transparencia, el cual consiste en una matriz de 4x6 elementos, constituida por cuatro etapas de la obra pública (columnas) y seis variables perceptuales (filas), que representan los tipos de debilidad.

Las variables perceptuales fueron concebidas con el fin de ser aplicadas en todas las etapas de la obra pública y dar lugar a respuestas unívocas. Para ello, las variables definen dominios perceptuales mutuamente excluyentes, cuya unión integra el espacio involucrado con la transparencia de la gestión pública. A continuación, se presenta su denominación, abreviatura, significado y el tipo de grado de vulnerabilidad.

- Prontitud (PRON): aptitud del funcionario público para actuar con diligencia, en todo lo concerniente a facilitar la normal evolución de la obra pública. El grado de vulnerabilidad se mide en relación con el grado de negligencia mostrado por el funcionario.

- Competencia (COMP): formación específica básica requerida al funcionario público, asignado en una etapa dada de la contratación pública. La vulnerabilidad se mide en relación con el grado de incompetencia del funcionario en su gestión.

- Discrecionalidad (DISC): potestad del funcionario público para decidirse, a su solo juicio, por una opción, entre otras igualmente válidas, con un criterio razonable. La vulnerabilidad se mide 
en relación con el grado de insensatez con que el funcionario justifica su decisión.

- Acceso (ACCE): deber del funcionario público de asegurar la libertad que tiene toda persona para acceder, recibir, investigar y difundir toda información pública. La vulnerabilidad se mide en relación con el grado de restricción de la ciudadanía al acceso de la información referida.

- Participación (PART): responsabilidad del funcionario público para permitir la intervención de la ciudadanía, en el diseño, ejecución y control de la obra pública. La vulnerabilidad se mide en relación con el grado de aislamiento de la ciudadanía en los aspectos señalados.

- Control (CONT): aptitud del funcionario público para inspeccionar el desarrollo de la obra pública, detectar irregularidades y aplicar las sanciones correspondientes establecidas por la norma. La vulnerabilidad se mide en relación con el grado de incapacidad del funcionario, tanto para penalizar los errores cometidos, como para prevenir los errores a futuro.

Las etapas marcan los dominios constructivos de la obra pública y permiten realizar un análisis nítido del proceso en estudio. Se presenta su denominación, abreviatura y alcance.

- Programación (PROG): definición y aprobación del proyecto.

- Pliego (PLIE): confección de las especificaciones técnicas de la obra.

- Selección (SELE): llamado a licitación, recepción y análisis de las ofertas, selección de la oferta ganadora y confección del contrato de la obra.

- Ejecución (EJEC): compra de materiales, proyecto y construcción de la obra.

Lo antes definido se muestra en el cuadro 1. 
Cuadro i. Mapa de transparencia

\begin{tabular}{|c|c|c|c|c|c|}
\hline \multicolumn{2}{|c|}{} & \multicolumn{3}{c|}{ ETAPAS DE LA OBRA } \\
\cline { 3 - 6 } \multicolumn{2}{c|}{} & PROG & PLIE & SELE & EJEC \\
\hline \multirow{4}{*}{} & PRON & & & & \\
\cline { 2 - 6 } & COMP & & & & \\
\cline { 2 - 6 } & DISC & & & & \\
\cline { 2 - 6 } & ACCE & & & & \\
\cline { 2 - 6 } & PART & & & & \\
\cline { 2 - 6 } & CONT & & & & \\
\hline
\end{tabular}

FuENTE: ElABORACIÓN PROPIA.

\section{Aplicación de penalidades (Pij)}

Para cada elemento del mapa de transparencia, el experto evalúa el grado de vulnerabilidad y define una penalidad determinada « $\mathrm{P}_{\mathrm{ij}}$ ", como se muestra en el cuadro 2.

Cuadro 2. Matriz de Penalidades

\begin{tabular}{|l|l|l|l|l|}
\hline & \multicolumn{1}{|c|}{ PROG } & \multicolumn{1}{c|}{ PLIE } & \multicolumn{1}{c|}{ SELE } & \multicolumn{1}{c|}{ EJEC } \\
\hline PRON & P11 & P12 & P13 & P14 \\
\hline COMP & P21 & P22 & P23 & P24 \\
\hline DISC & P31 & P32 & P33 & P34 \\
\hline ACCE & P41 & P42 & P43 & P44 \\
\hline PART & P51 & P52 & P53 & P54 \\
\hline CONT & P61 & P62 & P63 & P64 \\
\hline
\end{tabular}

Fuente: Elaboración propia.

En función de la incertidumbre del experto, cada penalidad podrá definirse ya sea con un valor o con un rango de valores. En la última opción, el experto utiliza un sistema de etiquetas lingüísticas, las cuales se corresponden con un rango numérico, como se indica en el cuadro 3. 
Sección V: Responsabilidad Social Pública (RSP)

CuAdro 3. Sistema de ETIQuetas lingüísticas

\begin{tabular}{|l|l|}
\hline \multicolumn{1}{|c|}{$\begin{array}{c}\text { Vulnerabilidad } \\
\text { ETIQUeta Lingüística }\end{array}$} & \multicolumn{1}{c|}{$\begin{array}{c}\text { Penalidad } \\
\text { RAnGo Numérico }\end{array}$} \\
\hline Alto (A) & $81-100$ \\
\hline Medio-Alto (MA) & $61-80$ \\
\hline Medio (M) & $41-60$ \\
\hline Medio-Bajo (MB) & $21-40$ \\
\hline Bajo (B) & $1-20$ \\
\hline Nulo (N) & 0 \\
\hline
\end{tabular}

FuENTE: ELABORACIÓN PROPIA.

Una vez definidas todas las penalidades « $\mathrm{P}_{\mathrm{ij}}$ ", se completa la matriz de penalidades, que se muestra en el cuadro 2 , donde cada penalidad es un número o un rango numérico.

\section{FACTORES DE INCIDENCIA $(\mathrm{KIJ})$}

Cada penalidad que evalúa el experto corresponde al grado de vulnerabilidad de un elemento dado en forma absoluta. En caso de que interese conocer la penalidad que le cabe a un elemento respecto de su etapa, corresponde considerar en qué grado incide dicho elemento en la etapa.

Lo anterior lleva a definir un factor de incidencia del elemento en la etapa, inferior a la unidad. Asimismo, la suma de los factores de incidencia de una etapa es igual a la unidad. De modo que, si deseamos conocer la penalización de una etapa, debemos sumar las penalizaciones recibidas en las seis variables de esa etapa, donde cada penalización estará afectada de su factor de incidencia. Por lo tanto, para calcular las penalizaciones de las etapas resulta necesario conocer los factores de incidencia $" \mathrm{~K}_{\mathrm{ii}}$ " para todos los elementos del mapa. El cuadro 4 muestra la matriz de factores de incidencia. 
Cuadro 4. Factores de incidencia

\begin{tabular}{|c|l|l|l|l|}
\hline & \multicolumn{1}{|c|}{ PROG } & \multicolumn{1}{c|}{ PLIE } & \multicolumn{1}{c|}{ SELE } & \multicolumn{1}{c|}{ EJEC } \\
\hline PRON & $\mathrm{K}_{11}$ & $\mathrm{~K}_{12}$ & $\mathrm{~K}_{13}$ & $\mathrm{~K}_{14}$ \\
\hline COMP & $\mathrm{K}_{21}$ & $\mathrm{~K}_{22}$ & $\mathrm{~K}_{23}$ & $\mathrm{~K}_{24}$ \\
\hline DISC & $\mathrm{K}_{31}$ & $\mathrm{~K}_{32}$ & $\mathrm{~K}_{33}$ & $\mathrm{~K}_{34}$ \\
\hline ACCE & $\mathrm{K}_{41}$ & $\mathrm{~K}_{42}$ & $\mathrm{~K}_{43}$ & $\mathrm{~K}_{44}$ \\
\hline PART & $\mathrm{K}_{51}$ & $\mathrm{~K}_{52}$ & $\mathrm{~K}_{53}$ & $\mathrm{~K}_{54}$ \\
\hline CONT & $\mathrm{K}_{61}$ & $\mathrm{~K}_{62}$ & $\mathrm{~K}_{63}$ & $\mathrm{~K}_{64}$ \\
\hline$\sum$ & 1 & 1 & 1 & 1 \\
\hline
\end{tabular}

FUENTE: ElABORACIÓN PROPIA.

Resulta práctico predefinir los factores de incidencia «Ki» para una obra pública típica. El cuadro 5 muestra una estimación tentativa, que podrá ser mejorada con la experiencia.

Cuadro 5. Factores de incidencia típicos

\begin{tabular}{|c|l|l|l|l|}
\hline & \multicolumn{1}{|c|}{ PROG } & \multicolumn{1}{|c|}{ PLIE } & \multicolumn{1}{|c|}{ SELE } & EJEC \\
\hline PRON & 0,1 & 0,2 & 0,2 & 0,2 \\
\hline COMP & 0,1 & 0,3 & 0,2 & 0,2 \\
\hline DISC & 0,1 & 0,1 & 0,3 & 0,1 \\
\hline ACCE & 0,3 & 0,1 & 0,1 & 0,1 \\
\hline PART & 0,3 & 0,2 & 0,1 & 0,1 \\
\hline CONT & 0,1 & 0,1 & 0,1 & 0,3 \\
\hline$\Sigma$ & 1 & 1 & 1 & 1 \\
\hline
\end{tabular}

FuENTE: Elaboración PROPIA.

\section{Penalidades ponderadas (Pij X Kij)}

Con las penalidades « $\mathrm{P}_{\mathrm{ij}}$ " y los factores de incidencia « $\mathrm{K}_{\mathrm{iij}}$ " se calculan los elementos de la matriz de penalidades ponderadas con el producto « $\mathrm{P}_{\mathrm{ij}} \mathrm{x} \mathrm{K}_{\mathrm{ij}} »$ del elemento en cuestión, como se muestra en el cuadro 6. La penalidad de la etapa «Pi» se calcula con la suma de las penalidades ponderadas de la columna correspondiente. En el caso de que la etapa contenga penalidades con rangos, la penalidad de la etapa será también 
un rango. En este caso, el experto podrá definir la penalidad de la etapa, o no, con un valor dentro del rango mencionado.

Cuadro 6. Matriz de PENAlidades PONDERAdAS

\begin{tabular}{|c|c|c|c|c|}
\hline & PROG & PLIE & SELE & EJEC \\
\hline PRON & $\mathrm{P}_{11} \times \mathrm{K}_{11}$ & $\mathrm{P}_{12} \times \mathrm{K}_{12}$ & $\mathrm{P}_{13} \times \mathrm{K}_{13}$ & $\mathrm{P}_{14} \times \mathrm{K}_{14}$ \\
\hline COMP & $\mathrm{P}_{21} \times \mathrm{K}_{21}$ & $\mathrm{P}_{22} \times \mathrm{K}_{22}$ & $\mathrm{P}_{23} \times \mathrm{K}_{23}$ & $\mathrm{P}_{24} \times \mathrm{K}_{24}$ \\
\hline DISC & $\mathrm{P}_{31} \times \mathrm{K}_{31}$ & $\mathrm{P}_{32} \times \mathrm{K}_{32}$ & $\mathrm{P}_{33} \times \mathrm{K}_{33}$ & $\mathrm{P}_{34} \times \mathrm{K}_{34}$ \\
\hline ACCE & $\mathrm{P}_{41} \times \mathrm{K}_{41}$ & $\mathrm{P}_{42} \times \mathrm{K}_{42}$ & $\mathrm{P}_{43} \times \mathrm{K}_{43}$ & $\mathrm{P}_{44} \times \mathrm{K}_{44}$ \\
\hline PART & $\mathrm{P}_{51} \times \mathrm{K}_{51}$ & $\mathrm{P}_{52} \times \mathrm{K}_{52}$ & $\mathrm{P}_{53} \times \mathrm{K}_{53}$ & $\mathrm{P}_{54} \times \mathrm{K}_{54}$ \\
\hline CONT & $\mathrm{P}_{61} \times \mathrm{K}_{61}$ & $\mathrm{P}_{62} \times \mathrm{K}_{62}$ & $\mathrm{P}_{63} \times \mathrm{K}_{63}$ & $\mathrm{P}_{64} \times \mathrm{K}_{64}$ \\
\hline $\mathrm{P}_{\mathrm{i}}$ & $\sum\left(\mathrm{P}_{\mathrm{i} 1} \times \mathrm{K}_{\mathrm{i} 1}\right)$ & $\sum\left(\mathrm{P}_{\mathrm{i} 2} \times \mathrm{K}_{\mathrm{i} 2}\right)$ & $\sum\left(\mathrm{P}_{\mathrm{i} 3} \times \mathrm{K}_{\mathrm{i} 3}\right)$ & $\sum\left(\mathrm{P}_{\mathrm{i} 4} \times \mathrm{K}_{\mathrm{i} 4}\right)$ \\
\hline
\end{tabular}

FUENTE: Elaboración PROPIA.

\section{Cálculo del Índice de Percepción de TRANSPARENCIA DE LA ETAPA (IPTE)}

El Índice de Percepción de Transparencia se calcula para cada etapa, en forma absoluta, restando de 100 las penalidades de la etapa «Pi», tal como se observa en el cuadro 7 .

Cuadro 7. Cálculo de IPTE

\begin{tabular}{|l|l|l|l|l|}
\hline & \multicolumn{1}{|c|}{ PROG } & \multicolumn{1}{c|}{ PLIE } & SELE & \multicolumn{1}{c|}{ EJEC } \\
\hline $\mathrm{P}_{\mathrm{i}}$ & $\sum\left(\mathrm{P}_{\mathrm{i} 1} \times \mathrm{K}_{\mathrm{i} 1}\right)$ & $\sum\left(\mathrm{P}_{\mathrm{i} 2} \mathrm{x} \mathrm{K}_{\mathrm{i} 2}\right)$ & $\sum\left(\mathrm{P}_{\mathrm{i} 3} \mathrm{KK}_{\mathrm{i} 3}\right)$ & $\sum\left(\mathrm{P}_{\mathrm{i} 4} \times \mathrm{K}_{\mathrm{i} 4}\right)$ \\
\hline IPTE $_{\mathrm{i}}=100-\mathrm{P}_{\mathrm{i}}$ & $100-\mathrm{P}_{1}$ & $100-\mathrm{P}_{2}$ & $100-\mathrm{P}_{3}$ & $100-\mathrm{P}_{4}$ \\
\hline
\end{tabular}

FUENTE: ELABORACIÓN PROPIA.

\section{Cálculo del Índice de Percepción de Transparencia de la Obra Pública (IPTOP)}

El Índice de Percepción de Transparencia de la Obra Pública (IPTOP) se obtiene con el promedio ponderado de los IPTE's de las etapas. Corresponde considerar el factor de peso "Wi», inferior a la unidad, que tiene dicha etapa en la obra. El cuadro 8 muestra la matriz de factores de peso «Wi». La obtención del IPTOP se muestra en la última fila de la tabla. 
Cuadro 8. CÁlculo de IPTOP

\begin{tabular}{|l|l|l|l|l|}
\hline & \multicolumn{1}{|c|}{ PROG } & \multicolumn{1}{c|}{ PLIE } & \multicolumn{1}{c|}{ SELE } & \multicolumn{1}{c|}{ EJEC } \\
\hline $\mathrm{W}_{\mathrm{i}}$ & $\mathrm{W}_{1}$ & $\mathrm{~W}_{2}$ & $\mathrm{~W}_{3}$ & $\mathrm{~W}_{4}$ \\
\hline IPTE $_{\mathrm{i}}$ & $\mathrm{IPTE}_{1}$ & $\mathrm{IPTE}_{2}$ & IPTE $_{3}$ & IPTE $_{4}$ \\
\hline IPTE $_{\mathrm{i}} \times \mathrm{W}_{\mathrm{i}}$ & $\mathrm{IPTE}_{1} \times \mathrm{W}_{1}$ & $\mathrm{IPTE}_{2} \times \mathrm{W}_{2}$ & $\mathrm{IPTE}_{3} \times \mathrm{W}_{3}$ & $\mathrm{IPTE}_{4} \times \mathrm{W}_{4}$ \\
\hline IPTOP & \multicolumn{4}{|c}{$\sum\left(\mathrm{IPTE}_{\mathrm{i}} \times \mathrm{W}_{\mathrm{i}}\right)$} \\
\hline
\end{tabular}

FUENTE: ElABORACIÓN PROPIA.

Resulta práctico predefinir los factores de peso «Wi» para una obra pública típica. El cuadro 9 muestra una estimación tentativa, que podrá ser mejorada con la experiencia.

Cuadro 9. Factores de peso típicos

\begin{tabular}{|l|l|l|l|l|}
\hline $\mathrm{W}_{1}$ & $\mathrm{~W}_{2}$ & $\mathrm{~W}_{3}$ & $\mathrm{~W}_{4}$ & $\sum \mathrm{W}_{\mathrm{i}}$ \\
\hline 0,1 & 0,2 & 0,2 & 0,5 & 1 \\
\hline
\end{tabular}

FUENTE: ELABORACIÓN PROPIA.

\section{Caso de APLICACión}

A los efectos de familiarizarse con la mecánica del cálculo, se procesa un ejemplo hipotético.

Se obtiene la siguiente matriz de penalidades.

Cuadro io. Ejemplo de matriz de penalidades

\begin{tabular}{|c|l|l|l|l|}
\hline & PROG & PLIE & SELE & EJEC \\
\hline PRON & B & 50 & B & B \\
\hline COMP & 85 & B & MB & 15 \\
\hline DISC & 15 & M & 10 & B \\
\hline ACCE & B & B & MA & 90 \\
\hline PART & MB & B & 15 & B \\
\hline CONT & B & 80 & B & MB \\
\hline
\end{tabular}

FUENTE: ElaboraCión PROPIA.

Se reemplazan las etiquetas lingüísticas por sus rangos numéricos (ver cuadro 11). 
CuAdro i I. EJEMPlo DE MATRIZ DE PENALIDAdES PONDERADAS

\begin{tabular}{|c|r|r|r|r|}
\hline & \multicolumn{1}{|c|}{ PROG } & \multicolumn{1}{c|}{ PLIE } & SELE & \multicolumn{1}{c|}{ EJEC } \\
\hline PRON & $1-20$ & 50 & $1-20$ & $1-20$ \\
\hline COMP & 85 & $1-20$ & $21-40$ & 15 \\
\hline DISC & 15 & $41-60$ & 10 & $1-20$ \\
\hline ACCE & $1-20$ & $1-20$ & $61-80$ & 90 \\
\hline PART & $21-40$ & $1-20$ & 15 & $1-20$ \\
\hline CONT & $1-20$ & 80 & $1-20$ & $21-40$ \\
\hline
\end{tabular}

FUENTE: Elaboración PROPIA.

Se toman los factores de incidencia típicos del cuadro 5 y se los procesa con los rangos del cuadro 11, como se indica en el cuadro 6. El resultado se muestra en el cuadro 12, donde se completa el procesamiento de la información obteniendo los IPTE's y el IPTOP. El experto ha procedido a convertir los rangos numéricos de $P i$ en un valor (variante 1). El resultado es un valor de 0 a 100.

Cuadro i 2. EJemplo de cálculo IPTE/IPTOP (VARIANTE I)

\begin{tabular}{|l|l|l|l|l|}
\hline & \multicolumn{1}{|c|}{ PROG } & \multicolumn{1}{c|}{ PLIE } & \multicolumn{1}{c|}{ SELE } & \multicolumn{1}{c|}{ EJEC } \\
\hline PRON & $0,1-2$ & 10 & $0,2-4$ & $0,2-4$ \\
\hline COMP & 8,5 & $0,3-6$ & $2,4-8$ & 3 \\
\hline DISC & 1,5 & $4,1-6$ & 3 & $0,1-2$ \\
\hline ACCE & $0,3-6$ & $0,1-2$ & $6,1-8$ & 9 \\
\hline PART & $6,3-12$ & $0,2-4$ & 1,5 & $0,1-2$ \\
\hline CONT & $0,1-2$ & 8 & $0,1-2$ & $6,3-12$ \\
\hline Pi & $16,8-32$ & $22,7-36$ & $13,3-26,5$ & $18,7-32$ \\
\hline Pi/experto & 27 & 31 & 22 & 28 \\
\hline IPTEi $=100-P i$ & 73 & 69 & 78 & 72 \\
\hline Wi $($ Tabla 9$)$ & 0,1 & 0,2 & 0,2 & 0,5 \\
\hline IPTEi $x$ Wi & 7,3 & 13,8 & 15,6 & 36,0 \\
\hline IPTOP & $\sum($ IPTEi $x$ Wi $)=72,7$ & & \\
\hline
\end{tabular}

FuENTE: ElABORACIÓN PROPIA.

Si luego del procesamiento de las penalidades, el experto decide no convertir las penalidades de un rango numérico a un valor (variante 2), 
el resultado dará un rango numérico, lo cual no le quita validez al método. Este caso se muestra en el cuadro 13.

Cuadro i 3. Ejemplo de cálculo IPTE/IPTOP (variante 2)

\begin{tabular}{|c|l|l|l|l|}
\hline & \multicolumn{1}{|c|}{ PROG } & \multicolumn{1}{c|}{ PLIE } & \multicolumn{1}{c|}{ SELE } & \multicolumn{1}{c|}{ EJEC } \\
\hline $\mathrm{P}_{\mathrm{i}}$ & $16,8-50$ & $22,7-36$ & $13,3-26,5$ & $18,7-32$ \\
\hline $\mathrm{IPTE}_{\mathrm{i}}=100-\mathrm{P}_{\mathrm{i}}$ & $83,2-50$ & $77,3-64$ & $86,7-73,5$ & $91,3-68$ \\
\hline $\mathrm{W}_{\mathrm{i}}($ Tabla $)$ & 0,1 & 0,2 & 0,2 & 0,5 \\
\hline $\mathrm{IPTE}_{\mathrm{i}} \times \mathrm{W}_{\mathrm{i}}$ & $8,32-5$ & $15,46-12,8$ & $17,34-14,7$ & $45,65-34$ \\
\hline $\mathrm{IPTOP}^{|c|} 66,5<\sum\left(\mathrm{IPTE}_{\mathrm{i}} \times \mathrm{W}_{\mathrm{i}}\right)<86,77$ \\
\hline
\end{tabular}

FUENTE: ElABORACIÓN PROPIA.

\section{Conclusiones}

El aspecto relevante de este trabajo es que presenta un modelo sencillo que cuantifica la transparencia de la gestión pública. Ello se logra mediante un conjunto de variables perceptuales, que son mutuamente excluyentes y que dan lugar a evaluaciones unívocas válidas para las distintas etapas de la obra pública. La metodología empleada es de simple ejecución y permite que el experto pueda realizar su tarea con comodidad. Asimismo, debido a la generalidad con que fue concebido, el modelo puede implementarse en cualquier país de América Latina, sin limitaciones, con la frecuencia necesaria.

A nivel instrumental, los coeficientes de incidencia podrían validarse, si sometiéramos la matriz de incidencias al método de recuperación de los efectos olvidados (Kaufmann y Gil Aluja, 1989). Las relaciones binarias entre las variables y las etapas de la obra se representarían por una matriz de incidencia borrosa rectangular, cuyo procesamiento permitiría que el experto tome conocimiento de los efectos indirectos que no tuvo en cuenta.

Otra posible mejora sería evaluar la vulnerabilidad con el concepto de Incidencia- $Z$.

Definimos la valuación de una incidencia $Z$, a un par ordenado de valuaciones $(\mathrm{A}, \mathrm{C})$, donde $\mathrm{A}$ es la valuación tradicional de una incidencia borrosa, realizada por un experto, y $\mathrm{C}$ es la valuación de la confiabilidad de A, realizada por el mismo experto, en el mismo acto. De modo que 
la valuación de una incidencia $\mathrm{Z}$ se identifica con dos datos numéricos subjetivos, A y C. (Rubín, 2017).

\section{BibliografíA}

Alconada Mon, H. (2018). La raíz (de todos los males). Buenos Aires: Planeta.

Alconada Mon, H. (2016). Entrevista de Hugo Alconada Mon a José Carlos Ugaz. Conversaciones en La Nación. Disponible en: https://www. lanacion.com.ar/1926795-jose-ugaz-la-argentina-padece-el-flagelode-la-gran-corrupcion.

Alconada Mon, H. (2015). La piñata. El ABC de la corrupción, de la burguesía nacional kirchnerista y del «capitalismo de amigos». Buenos Aires: Planeta.

Arcidiácono, P.; Rosenberg, G. y Arenoso, F. (2006). Contrataciones públicas vulnerables. $1^{\mathrm{a}}$ ed. Buenos Aires: Fundación Poder Ciudadano, Área Transparencia y Corrupción.

Arenoso, F. (2006). Manual de transparencia y control social en las contrataciones públicas. $1^{a}$ ed. Buenos Aires: Fundación Poder Ciudadano, Área Transparencia y Corrupción.

Astarita, M. (2014). Los usos políticos de la corrupción en la Argentina en los años noventa: Una perspectiva histórica. Revista Estado y políticas Públicas, 3. Disponible en: https://perio.unlp.edu.ar/sistemas/ biblioteca/files/Astarita_Martn.pdf.

Eigen, P. (2004). Las redes de la corrupción: La sociedad civil contra los abusos de poder. Editorial del Bronce.

Gilli, J. J. (2015). Aproximación ética al fenómeno de la corrupción. III SIRSO. Universidad Católica de los Ángeles de Chimbote (Lima)2014. Libro 2015, pp. 29-38. Disponible en: http://sirso.congresofan. uautonoma.cl/publicaciones/.

Kaufmann, A. y Gil Aluja, J. (1989). Modelos para la investigación de efectos olvidados. Santiago de Compostela: Editorial Milladoiro.

Kalpschtrej, K. (2015). Entre lo dicho y lo (no) hecho. Análisis del sistema de integridad local en CABA. Corrupción y Transparencia. Informe 2015 (pp. 283-315). Fundación Poder Ciudadano, $1^{a}$. Buenos Aires: Eudeba.

Klitgaard, R. (2015). Addressing Corruption together, Organización para la Cooperación y el Desarrollo Económicos (OCDE). Disponible en: https://www.oecd.org/dac/conflict-fragility-resilience/publications/ FINAL \%20Addressing \%20corruption $\% 20$ together.pdf.

(2012). Public-private collaboration and corruption En M. Pieth (Ed.), Collective Action on Anti-Corruption, Basel Institute 
on Governance (pp. 41-66). Basel. Disponible en: www.cgu.edu/ PDFFiles/Presidents\%20Office/Collaboration\%20and\%20Corruption \%202012.pdf.

(2000). Contra la corrupción. Revista Finanzas \& Desarrollo. Junio.

(1998). Healing sick institutions. En S. Borner y M. Paldam (eds.), The Political Dimension of Economic Growth: Proceedings of the IEA Conference held in San Jose, Costa Rica (pp. 335-347). Nueva York: St. Martin's Press. Disponible en: www.rand.org/pubs/ external_publications/EP19980006.html.

(1990). Controlando la corrupción. La Paz: Editorial Quipus. Klitgaard, R. et al. (2005). Choosing and using performance criteria. En R. Klitgaard y P.C. Light (Eds.), High-Performance Government: Structure, Leadership, Incentives (pp. 407-446). Santa Monica: The RAND Corporation. Disponible en: www.cgu.edu/include/ MG256-ch14.pdf.

Olivera Prado, M. (2003). Hacia reales políticas anticorrupción. Revista Probidad, 24, 1-12. Disponible en: http://mail.psf.org.pe/pipermail/ escuela_hco_psf.org.pe/attachments/20110508/32e590e3/attachment.pdf.

Rodríguez Collao, L. y Ossandon Widow, M. (2011). Delitos contra la función pública. Santiago: Editorial Jurídica de Chile.

Rubín, C. N. (2017). Mapas Z. Aplicación de los números Z en los mapas estratégicos. Trabajo de Tesis del Doctorado en Ciencias EconómicasAdministración. Universidad de Buenos Aires (UBA).

Sautú, R. (2004). Catálogo de prácticas corruptas: corrupción, confianza $y$ democracia. Buenos Aires: Lumiere.

Ugaz, J. C. (2015). Prólogo II. Corrupción y Transparencia. Informe 2015. Fundación Poder Ciudadano, $1^{\mathrm{a}}$ ed. Buenos Aires: Eudeba. 



\section{Sección VI: \\ Objetivos de Desarrollo \\ Sostenible}





\title{
ESTRATEGIAS DE GESTIÓN TERRITORIAL BAJO LOS PRECEPTOS DE LA RESPONSABILIDAD SOCIAL
}

\author{
Silvia Susana Vega" \\ Marcela Vanesa Céspedes" \\ Graciela Laplagne*** \\ Argentina
}

\section{INTRODUCCIÓN}

El presente trabajo da cuenta de los resultados obtenidos en el proyecto de investigación denominado "Bases estratégicas para la conformación de territorios socialmente responsables, departamento Jáchal, provincia de San Juan-Argentina», desarrollado durante los años 2016-2017'.

El objetivo principal fue formular lineamientos estratégicos que puedan ser aplicados a territorios emergentes, contribuyendo no solo a la formulación de proyectos innovadores que generen aportes al

\footnotetext{
Arquitecta. Docente investigadora (directora de proyecto). Magíster en Arquitectura en Zonas Áridas y Sísmicas, Universidad Nacional de San Juan. Correo electrónico: ssvega60@yahoo.com.ar

** Arquitecta. Docente investigadora (codirectora de proyecto). Magíster en Diseño, Domus Academy, Italia. Universidad Nacional de San Juan. Correo electrónico: lala75ar@gmail.com

*** Diseñadora industrial. Docente investigadora. Máster en Dirección Estratégica de Marketing, Universidad Nacional de San Juan. Correo electrónico: gralaplagne@yahoo.com.ar

1 Proyecto de investigación ejecutado en el Instituto Regional de Planeamiento y Hábitat (IRPHA), Facultad de Arquitectura, Urbanismo y Diseño, aprobado por la Universidad Nacional de San Juan. Autores: Mg. Arq. Silvia S.Vega, Mg. DI/ Arq. Marcela Céspedes, Ms.DI Graciela Laplagne, Arq. Jorge Ruiz, DI. Yanina Ruarte; DI. Natalia Cáceres, DI. Miguel Agüero, Srta. Melina de la Fuente, estudiante de Contador Público UNSJ.
} 
desarrollo económico local, sino también establecer las condiciones necesarias para construir el sentido de gobernanza y corresponsabilidad, base epistémica de la Responsabilidad Social(RS $)^{2}$ y los Territorios Socialmente Responsables (TSR). Ello, desde la perspectiva de entender a la «innovación» como un bien o servicio que cumple un rol fundamental para incentivar el crecimiento económico de las naciones, para potenciar la competitividad de las empresas y para mejorar la calidad de vida de la humanidad (Del Bono, 2015).

Hoy, el tema de la Responsabilidad Social ha superado la idea de asistencialismo y aunque tiene diversos principios, materias ${ }^{3}$, enfoques, definiciones y actores, supone el cumplimiento de principios éticos referidos necesariamente a cuatro aspectos o dimensiones: el legal, el económico, el ambiental y el social. A través de ellos se tiene en cuenta el cumplimiento de las normas y leyes, la elaboración de productos y servicios accesibles a la mayor parte de la comunidad, respetando el medioambiente y el uso de sellos de calidad ecológica, desarrollando proyectos que ayuden a mejorar la calidad de vida de las personas insertas en una comunidad.

Atento a las dimensiones enunciadas, se considera al territorio como un sistema complejo, de carácter multidimensional, con relaciones funcionales y valorativas de los recursos propios (Echeverri y Moscardi, 2005). Trasladando el concepto de RS a un enfoque territorial, se acuerda con Serrano García y Serrano López (2012, p. 77) en conceptualizar a los Territorios Socialmente Responsables como:

Proyecto de ciudad o de territorio, de carácter estratégico, basado en una visión compartida del futuro deseable, la creación de una cultura de corresponsabilidad y que, con un sistema de gobernanza participativa,

2 La Norma ISO 26000 «Guía de responsabilidad social» (2010) establece que «la RS es la Responsabilidad de una organización ante los impactos que sus decisiones y actividades ocasionan en la sociedad y el medioambiente, mediante un comportamiento transparente y ético que contribuya al desarrollo sostenible $(\ldots) »$.

3 Responsabilidad Social de las Organizaciones RSO (2013), citado por Gorrochategui y Kinen, que definieron los siguientes principios: rendición de cuentas, transparencia, comportamiento ético, respeto a los intereses de las partes interesadas, respeto al principio de legalidad, respeto a la normativa internacional de comportamiento, respeto a los derechos humanos. Asimismo, consideran como materias fundamentales: gobernanza de la organización, derechos humanos, prácticas laborales, medioambiente, prácticas justas de operación, asuntos de consumidores, participación activa y desarrollo de la comunidad (pp. 169-170). 
dé respuesta a los retos de sostenibilidad ambiental, crecimiento económico, empleo e inclusión social.

Además, estos autores proponen que un TSR se conforma como una coalición de empresarios, gobierno y organizaciones sociales, cumpliendo con el objetivo básico de lograr acuerdos y acciones coordinadas en favor del desarrollo local por parte de todos los actores sociales, a través de múltiples escenarios de alianzas público-privadas.

Desde este lugar, se ha pretendido la construcción de herramientas aplicables a territorios locales, que aporten respuestas coherentes y pertinentes a los desafíos actuales sobre equidad y mayor integración. Esta construcción exige trabajar a partir de la corresponsabilización, el involucramiento y el compromiso de todos los actores sociales. Ello implica acciones mancomunadas tanto en esfuerzos deliberados, como conscientes y organizados, para lograr las transformaciones territoriales sostenibles y socialmente responsables apropiadas.

Aún así, se evidencia que los gobiernos locales no aprovechan los beneficios de la implementación de estrategias innovadoras sobre los modelos de gestión.

\section{JÁCHAL, TERRITORIO EMERGENTE}

Se consideró como caso de estudio al departamento Jáchal, de la provincia de San Juan, por localizarse en un emplazamiento territorialmente estratégico, ya que integra a la microrregión productiva local, conteniendo el cruce de dos corredores principales de comunicación terrestre. Por un lado, de carácter internacional, el Corredor Ferroviario Bioceánico Central, que conecta Brasil, Argentina y Chile; y por otro, el corredor interregional, de integración turística, entre los departamentos Valle Fértil, Jáchal e Iglesia.

En contrapartida, es importante destacar que el conjunto de los departamentos alejados del asentamiento central de la provincia de San Juan ha quedado retrasado e inmerso en un contexto de condiciones adversas. Ello, tanto respecto de la producción, como de las infraestructuras y las comunicaciones, entre otros, donde el mercado no ha ofrecido alternativas superadoras, ni el sector público ha respondido a las necesidades y reclamos de la población. De este modo, la situación que se percibe en estos departamentos alejados es que solo se encuentran obstáculos al intentar trascender el ámbito local en el que se originan, desfavoreciendo la cohesión social y el desarrollo territorial de las microrregiones. 
Este problema, sumado a las fuertes problemáticas existentes en el desarrollo territorial de las diferentes regiones del país, nos lleva a plantear un proceso de construcción de propuestas apoyadas bajo los preceptos de la RS. Esto es, que la Responsabilidad Social se entiende como un deber al interior de las instituciones y organizaciones, no solo desde las presiones exteriores, sino desde el interior mismo, sobre la base de considerar la complejidad de aristas en los desequilibrios de los sistemas físico-ambiental, sociocultural, económico-productivo y político-institucional (Sepúlveda, 2008, p. 380).

En este sentido, la CEPAL sostiene:

Los factores que determinan esta situación son múltiples y diversos: coyunturales y estructurales, de carácter macro y micro, y de escala local, nacional y global. Los ámbitos en que se pueden enfrentar y transformar son igualmente diversos, y para ello pareciera indispensable utilizar el potencial creativo y todas las voluntades que están en el origen de este multicultural y variado continente. En la región existen experiencias de cómo enfrentar nuevos problemas, así como viejos problemas con novedosas soluciones (citado por Rodríguez Herrera y Alvarado Ugarte, 2008, p. 18).

De igual modo, la Fundación Kellogg destaca:

Dar voz a las personas que trabajan desde la propia comunidad, la sociedad civil, la empresa privada y el Estado, algunas a cargo de grandes programas públicos, otras de pequeños proyectos locales, todas ellas comprometidas con el avance social, es uno de los principales propósitos que persiguen la Comisión Económica para América Latina y el Caribe (CEPAL) y la Fundación W.K. Kellogg con el proyecto «Experiencias en innovación social en América y el Caribe» (citado por Rodríguez Herrera y Alvarado Ugarte, 2008, p. 18).

Estas experiencias concretas vinculadas a la innovación social impulsan a dar respuestas a cuestiones territoriales por considerarlas un área de vacancia epistémica, en relación con los preceptos de la RS, tanto en los ámbitos académicos como en las organizaciones públicas y privadas.

Por estas razones, este equipo de investigación reconoce que establecer estrategias de gestión conducentes hacia la viabilidad de procesos de 
desarrollo territorial, generados desde las propias demandas del entorno local, implica una novedosa mirada ante el desarrollo regional. Ello, pensando que los encargados o responsables de formular e implementar las políticas públicas debieran vincularse o asociarse con procesos de innovación social, para facilitar su concreción y recoger sus aportes.

Este proceso investigativo pretendió extender los comportamientos socialmente responsables a otras esferas; y que el debate sobre la RS se establezca como una política de Estado, cuyas normas generales permitan alcanzar los objetivos con un horizonte de cierta estabilidad y permanencia en el tiempo.

Esta propuesta implica asumir que las instituciones, tanto públicas como privadas, deben actuar de manera sostenible en diálogo con sus grupos de interés (stakeholders). Estos grupos abarcan una amplia variedad de actores, tales como empleados, comunidades locales, administración pública, visitantes y turistas, organizaciones no gubernamentales (ONG), empresas y proveedores. Esta nueva realidad permite reflexionar sobre los modos de gestión de los grupos de interés, a fin de promover una relación integral y estratégica para lograr la competitividad sostenible ${ }^{4}$.

\section{ANTECEDENTES DE UN MODELO DE GESTIÓN TERRITORIAL: EXPERIENCIA EMPÍRICA}

Las estrategias de gestión se plantean como instrumentos conducentes hacia la viabilidad de los procesos de desarrollo y transformación territorial socialmente responsables.

Estas estrategias se sustentan, entre otros, en los resultados del proyecto de investigación de los años 2014-2015, a través del «Modelo de gestión pública territorial para el departamento Jáchal. San Juan» (figuras 1 y 2). Dicho modelo concibe la idea de que el desarrollo local ha de pasar necesariamente por un abordaje integral, donde las acciones que se propongan debieran ser de carácter pluridimensional. De este modo, se convierte en una herramienta de organización y gestión mixta,

4 Aportes pertenecen a dos artículos: 1) Lazzari, L. y Moulla, P. (2015), «Un enfoque alternativo para la identificación y jerarquización de stakeholders», 2) Volpentesta, J. (2015), «Procedimientos administrativos en la gestión de los stakeholders» (extraídos de la compilación del III SIRSO-Avances y propuestas en América Latina. Responsabilidad Social de las Organizaciones (RSO). Octubre 2015. Editorial Universidad Católica los Ángeles de Chimbote. Trujillo, Perú. 
público-privada, inserto en una política de desarrollo adaptada a su realidad territorial, que entiende al territorio como una construcción social en la que coexisten diversas dimensiones.

Por otra parte, dicho modelo constituye una estructura organizacional que se contrapone a las implementadas en gestiones tradicionales, donde estas últimas plantean disposiciones híbridas que dificultan la implementación de políticas territoriales más democráticas.

En tal sentido, es dable destacar que toda política territorial debiera ofrecer la posibilidad de planteos prospectivos que promuevan gestiones sostenibles y responsables. De esta manera, podría afirmarse la idea de una articulación entre los diferentes actores sociales. Así, la prospectiva puede implicar que «hay varios futuros posibles»; comprender su significado y sus alcances resultan entonces indispensables para visualizar su eje central, que construye escenarios futuros de largo plazo para la sociedad, las regiones y las organizaciones.

Figura i. Vega, Silvia S. et al. Proyecto de Investigación (20I4-20i 5). ModeLO DE GESTIÓN PÚblica TERRITORIAL PARA EL DEPARTAMENTO Jáchal, SAN JUAN

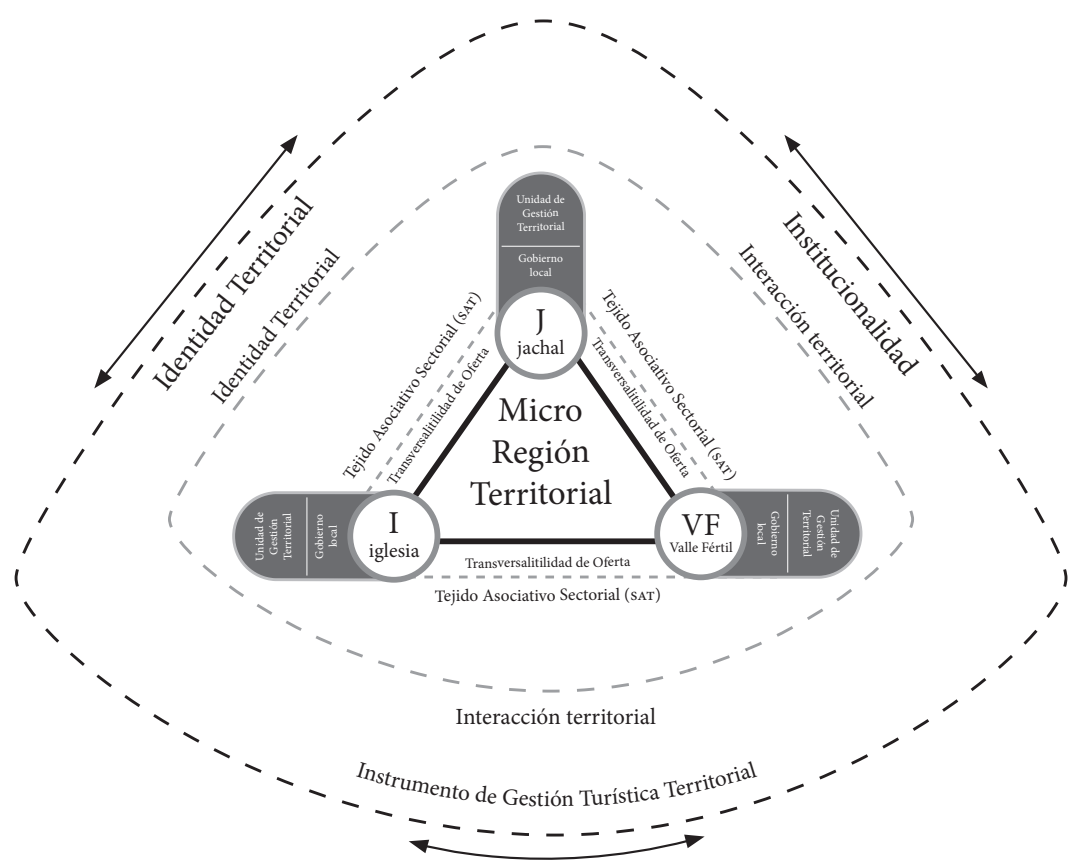

Marco Referencial Territorial

FuENTE: ElABORACIÓN PROPIA. 
Figura 2. Vega, Silvia S. et al. Proyecto de Investigación (20I4-201 5 ). MODELO DE GESTIÓN DE LA UNIDAD TERRITORIAL

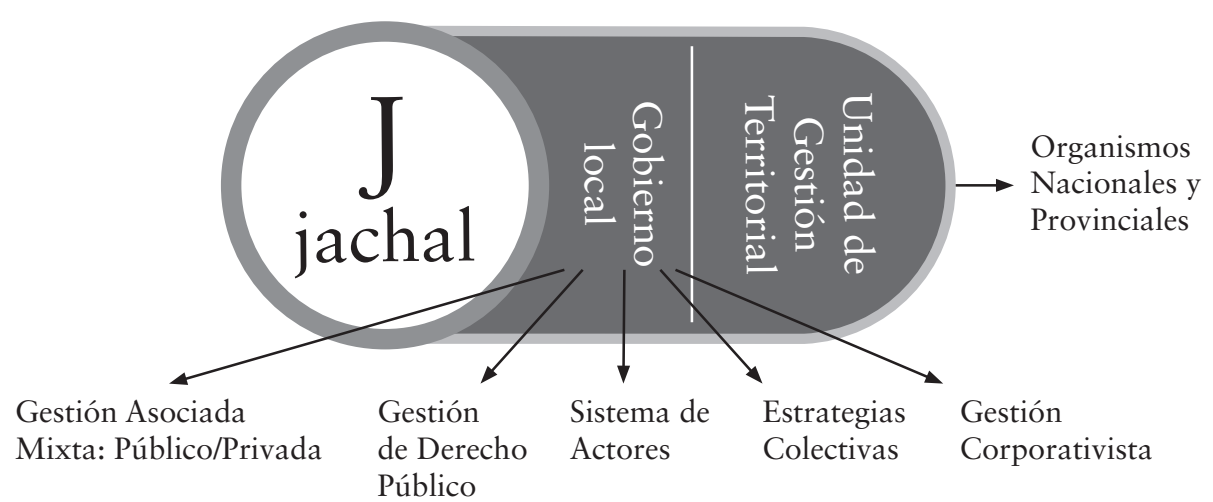

FuENTE: ElABORACIÓN PROPIA.

Como resultado de este proceso, se ha propuesto una serie de directrices para la implementación del modelo. Dichas directrices fueron presentadas al organismo local a través de un documento orientador, habiendo procurado profundizar en las recomendaciones para su implementación, en un marco de uso sustentable de los recursos naturales y culturales, y de respeto a la comunidad involucrada.

A modo enunciativo, se exponen a continuación algunos de los criterios considerados:

- La creación de una «Unidad de gestión territorial», cuyo rol es establecer una relación entre el organismo local y el resto de los organismos e instituciones públicas y privadas, así como un Consejo Consultivo para propiciar la participación del sector privado.

- La configuración de un sistema de gestión flexible, con apertura y adaptación a las necesidades futuras, derivadas de cambios en el entorno, como de la propia evolución del modelo.

- El fraccionamiento de las vocaciones territoriales desde una perspectiva de transversalidad, que conforme un tejido asociativo sectorial, teniendo como base la exaltación de los aspectos identitarios que caracterizan al territorio local.

- La implementación del modelo de gestión, a través del derecho público, atendiendo a las circunstancias específicas y sectoriales de cada municipio. 
- La optimización de la gestión para obtener la financiación adecuada, procurando apoyar las inversiones inteligentes y sustentables, y acompañando, fortaleciendo y monitoreando el efectivo desarrollo y compromiso del sector privado.

- El estímulo al fortalecimiento del tejido productivo local, estimulando especialmente a los microemprendimientos.

- El favorecimiento para la creación de una coalición de empresarios, gobierno y organizaciones sociales, cumpliendo con los siguientes objetivos básicos: lograr acuerdos y acciones coordinadas en favor del desarrollo local; implementar acciones para que su ejecución sea llevada a cabo por parte de todos los actores sociales; configurar esquemas de realización a través de múltiples escenarios conformados mediante alianzas público-privadas.

\section{ESCENARIOS TEMPORALES DE REFERENCIA}

Este modelo innovador desarrollado, que traspasa a los modelos tradicionales, ayudó a convalidar y darle sustento a la investigación, habiendo considerado a su vez el análisis de los diversos antecedentes que existen a nivel provincial, nacional e internacional en torno a estas problemáticas. A este respecto, se adjuntan los siguientes antecedentes:

A nivel provincial, se destaca la existencia de un Convenio entre la Universidad Nacional de San Juan y el Municipio de Jáchal, situación que ayuda a sustentar las acciones propuestas.

A nivel regional, la Sociedad Argentina de Planificación Territorial (SAPLAT), en el «II Encuentro Regional Nuevo Cuyo», realizado en San Juan, Argentina (2016), ha establecido los principios de su planificación urbano-territorial, los que han servido de marco normativo para la formulación de nuevas estrategias.

A nivel nacional, el Plan Nacional del Ministerio de Ciencia, Tecnología e Innovación Productiva, a través del «Plan Argentina innovadora 2020», que diseñó e implementó políticas públicas para la promoción de procesos asociativos y redes de investigación multidisciplinarias, y para el mejoramiento de la articulación del sistema nacional de innovación.

A nivel de la región latinoamericana, entre las experiencias analizadas se resaltan, por una parte, la desarrollada por el Instituto de Prospección, Innovación y Gestión del Conocimiento, de la Universidad del Valle, Cali, Colombia; y, por otra, aquellas abordadas en el «II Foro de Quito. Ciudades y Organizaciones Responsables», llevadas a cabo por 
iniciativa del Consejo Metropolitano de Responsabilidad Social, cuyo objetivo fue agrupar empresas e instituciones socialmente responsables del Distrito Metropolitano de Quito, Ecuador.

Finalmente, a nivel de la región europea, se destaca el trabajo llevado a cabo por el Municipio de España Castellón de la Plana, comunidad Valenciana, España, concretado en la propuesta denominada «Castellón, hacia un Territorio Socialmente Responsable: Las cláusulas sociales en la contratación pública».

Estos antecedentes, en sus distintos ámbitos académicos y gubernamentales, se han considerado base substancial para respaldar los avances de este equipo de investigación, y poder dar así respuestas apropiadas a las demandas de los gobiernos locales; entre ellas, se enfatizan aquellas previstas en torno a la necesidad de articular un sistema de investigación científicotecnológico, por un lado, y a los requerimientos de un desarrollo productivo, cultural y educativo de la región, por otro.

\section{¿Cómo Se Valida la propuesta?}

La metodología implementada responde a un proceso prospectivo, con una visión integral e interdisciplinar que incorpora los preceptos de la Responsabilidad Social, ya que se la ha considerado una estrategia de gestión territorial inclusiva y sostenible que permite involucrar y movilizar a todas las partes interesadas en el desarrollo.

La investigación abordada ha aplicado modelos de tipo cualitativo y cuantitativo (Cook y Reichardt, 2005), incorporando acciones de análisis documental, indagación en terreno y consultas a grupos de interés. El proceso llevado a cabo ha evidenciado una dinámica reflexiva acerca del valor y la pertinencia de los bienes identificados, y de los temas que son capaces de incidir en el desarrollo sustentable de un territorio.

Se han llevado a cabo distintas instancias metodológicas. Inicialmente se tomaron como base los resultados obtenidos en el proyecto de investigación «Modelo de gestión pública territorial para el departamento Jáchal, San Juan», desarrollados por parte del actual equipo de investigación. Se han considerado las premisas obtenidas en el diagnóstico socialproductivo realizado. Se aplicó un método descriptivo que ha permitido caracterizar la realidad departamental en sus dimensiones físico-natural, político-institucional, económica, social y cultural. Se debe destacar que en el análisis desarrollado se han abordado las escalas macro (nación), meso (provincia) y micro (departamento). 
La actual investigación ha profundizado en el abordaje del diagnóstico inicial de las dimensiones físiconatural, sociocultural, económicoproductivo y político-institucional, a fin de definir patrones y variables del territorio que han determinado los «campos de actuación». Los mismos se abordaron a través del método «exploración de la estructura del problema». Así, este análisis ha permitido trazar una matriz de conexiones sobre la cual se indagan las oportunidades que presenta el territorio de estudio (figura 3).

Figura 3. MATRiz De CONEXiones

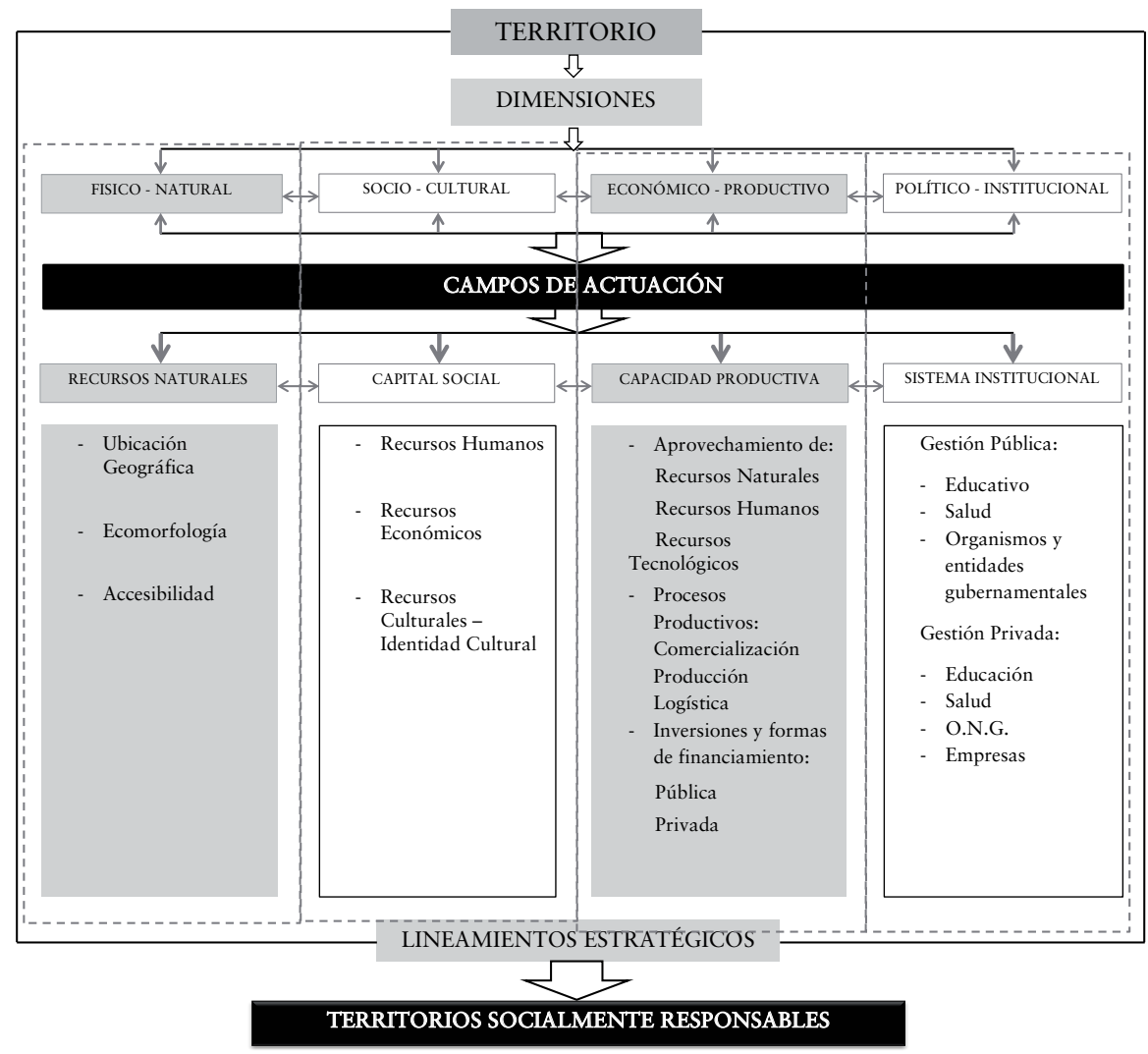

FUENTE: ELABORACIÓN PROPIA POR PARTE DEL EQUIPO DE INVESTIGACIÓN.

La segunda instancia se ha definido a través de un método prescriptivo, con la aplicación de procesos de « investigación-acción participativa». Se han analizado diversas fuentes, tales como documentos, 
trabajos de investigación, bibliografía especializada, entre otras, para establecer el marco cognitivo en el cual se inscribe el territorio de estudio.

Este proceso investigativo se ha complementado con la indagación y análisis de los datos secundarios que surgieron de las entrevistas a diferentes grupos de interés del departamento (stakeholders). Entre ellos se puede mencionar a instituciones que trabajan diariamente con la comunidad local, como son el Instituto Nacional de Tecnología Agropecuaria (INTA) y el municipio departamental; a artesanos, en particular los que integran la Feria Franca dependiente de la Municipalidad de Jáchal; a comerciantes, prestadores de servicios y a representantes de ONG que implementan programas locales o tienen sede en el departamento Jáchal.

Otra acción desarrollada ha sido la delineación de espacios de talleres participativos, con el fin de intercambiar ideas y lograr empatía con los protagonistas de la economía social, y con organizaciones que aportan al desarrollo local.

Estas experiencias, en su conjunto, han permitido vislumbrar las capacidades, los requerimientos y los niveles necesarios de alcanzar a nivel organizacional para que el departamento Jáchal pueda convertirse en un territorio socialmente responsable (TSR).

Una tercera instancia se ha concretado a través de la implementación del método evaluativovalorativo, el que se hace efectivo con la valoración entre los resultados del conjunto de actividades, acciones, tareas, flujo de trabajo, fundamentos y requerimientos relevados en relación con la correspondencia entre lo previamente planificado y la realidad contextual observada.

Se ha utilizado para este análisis la referencia muestral obtenida en los talleres participativos desarrollados y documentación relevada de las fuentes indagadas.

Atento al muestreo examinado, al análisis de las dimensiones territoriales preestablecidas y a los campos de actuación preconstituidos en la matriz de conexiones, se ha posibilitado la determinación de los conflictos y potencialidades emergentes del territorio de estudio. El entrecruzamiento de los datos obtenidos por medio del análisis crítico de sus problemáticas y potencialidades específicas ha permitido definir las jerarquías y la valoración de ellos.

Una vez culminada la valoración de los recursos territoriales, a partir de la identificación de los aspectos más relevantes, se ha elaborado un listado con las «ideas fuerza» más emblemáticas y provocativas que caracterizan a la región. Se plantea la transformación de los conflictos 
detectados en potencialidadesoportunidades, a fin de facilitar la definición de estrategias de gestión para convertir al departamento Jáchal en un TSR.

A modo de ejemplo, se expone una de las etapas procedimentales realizadas una vez detectados los conflictos y potencialidades del territorio "caso de estudio". Se ha considerado la implementación metodológica para cada uno de los campos de actuación investigados, tanto para el entrecruzamiento de conflictos, como para sus potencialidades y la interacción entre estos (cuadros 1 y 2). El resultado de las jerarquías obtenidas por un lado y las valoraciones de estos por otro, ha permitido compararlos y obtener un gráfico síntesis que denota la interacción que provocan estos conflictos o potencialidades en relación con territorio (gráfico 1).

CuAdro i. CAMPo de aCtuación: CAPACIDAd PRODUCTIVA-JERARQUizaCión A TRAVÉS DE MATRICES

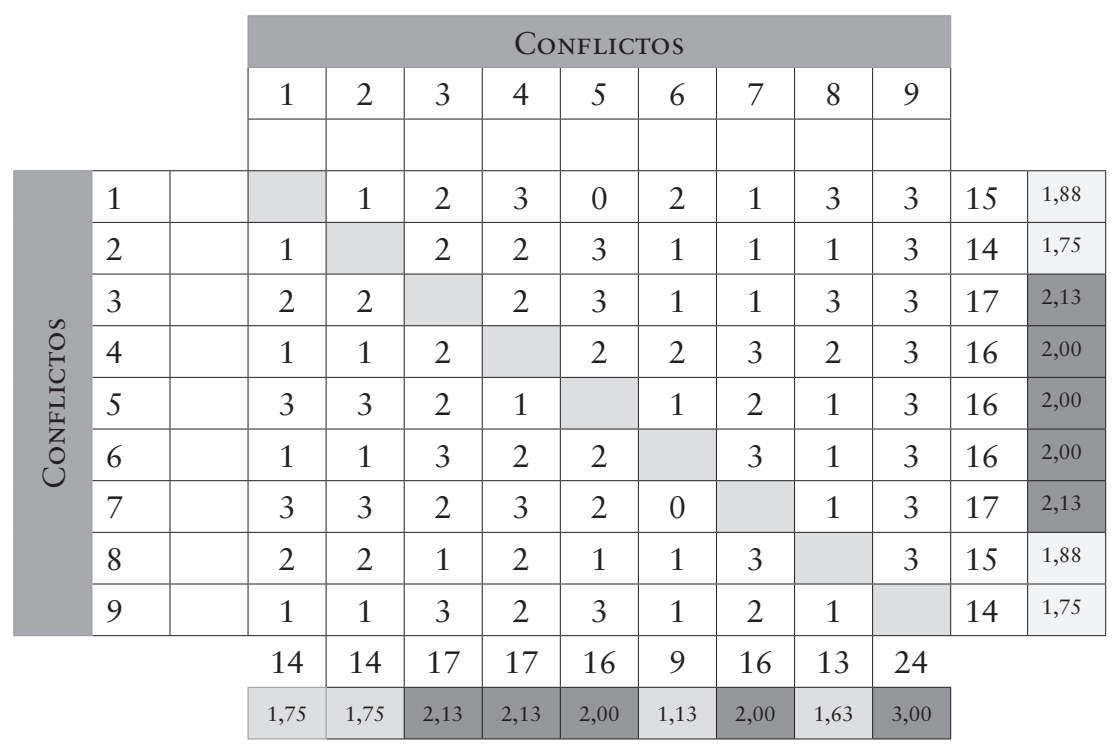




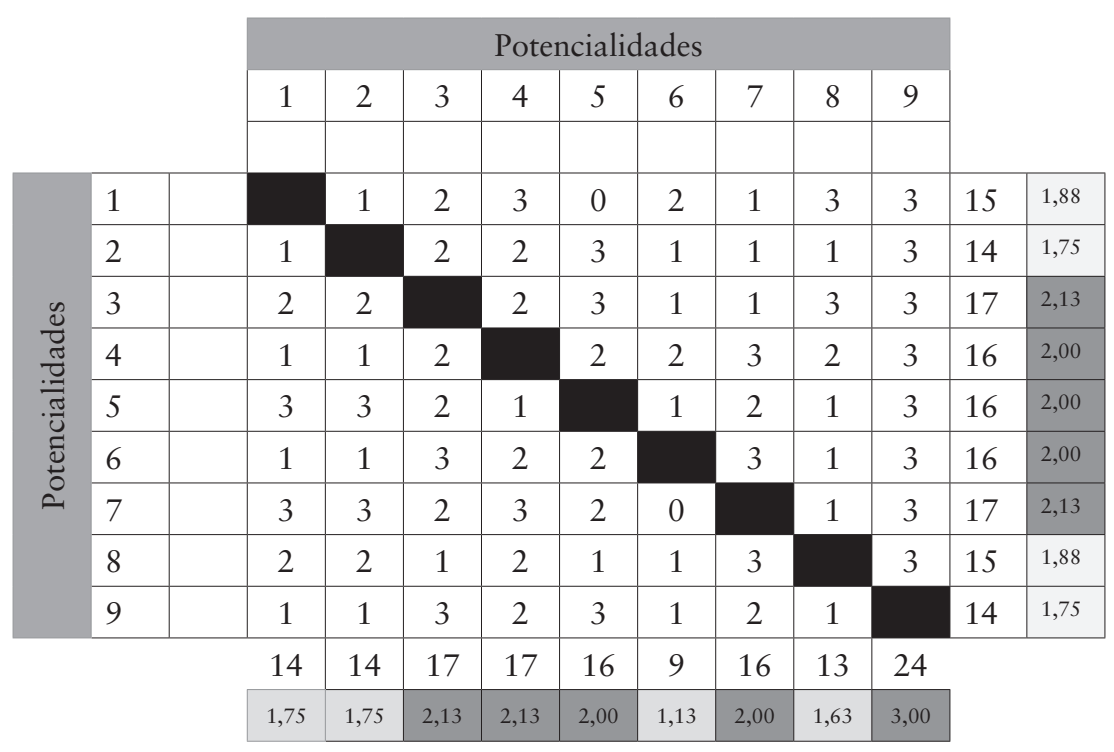

FUENTE: ELABORACIÓN PROPIA.

CUADRO 2. CAMPO DE ACTUACIÓN: CAPACIDAD PRODUCTIVA-VALORACIÓN

\begin{tabular}{|c|c|c|}
\hline $\mathrm{N}^{\circ}$ & POTENCIALIDADES & VALORACIÓN \\
\hline 5 & & 2,13 \\
\hline 7 & & 2,13 \\
\hline 6 & & 2,00 \\
\hline 1 & & 1,88 \\
\hline 8 & & 1,75 \\
\hline 9 & & 1,75 \\
\hline 2 & & 1,75 \\
\hline 3 & & 1,75 \\
\hline
\end{tabular}


Sección VI: Objetivos de desarrollo sosteniblede la Responsabilidad Social

\begin{tabular}{|c|c|c|}
\hline $\mathrm{N}^{\circ}$ & CONFLICTOS & VALORACIÓN \\
\hline 5 & & 2,13 \\
\hline 7 & & 2,13 \\
\hline 6 & & 2,00 \\
\hline 1 & & 1,88 \\
\hline 8 & & 1,75 \\
\hline 9 & & 1,75 \\
\hline 2 & & 1,75 \\
\hline 3 & & 1,75 \\
\hline
\end{tabular}

FUENTE: ElABORACIÓN PROPIA.

Gráfico i. CAMPo dE ACTUACIÓN: CAPACIDAD PRODUCTIVA. VisibilizaCióN COMPARATIVA ENTRE CONFLICTOS- ENTRE POTENCIALIDADES
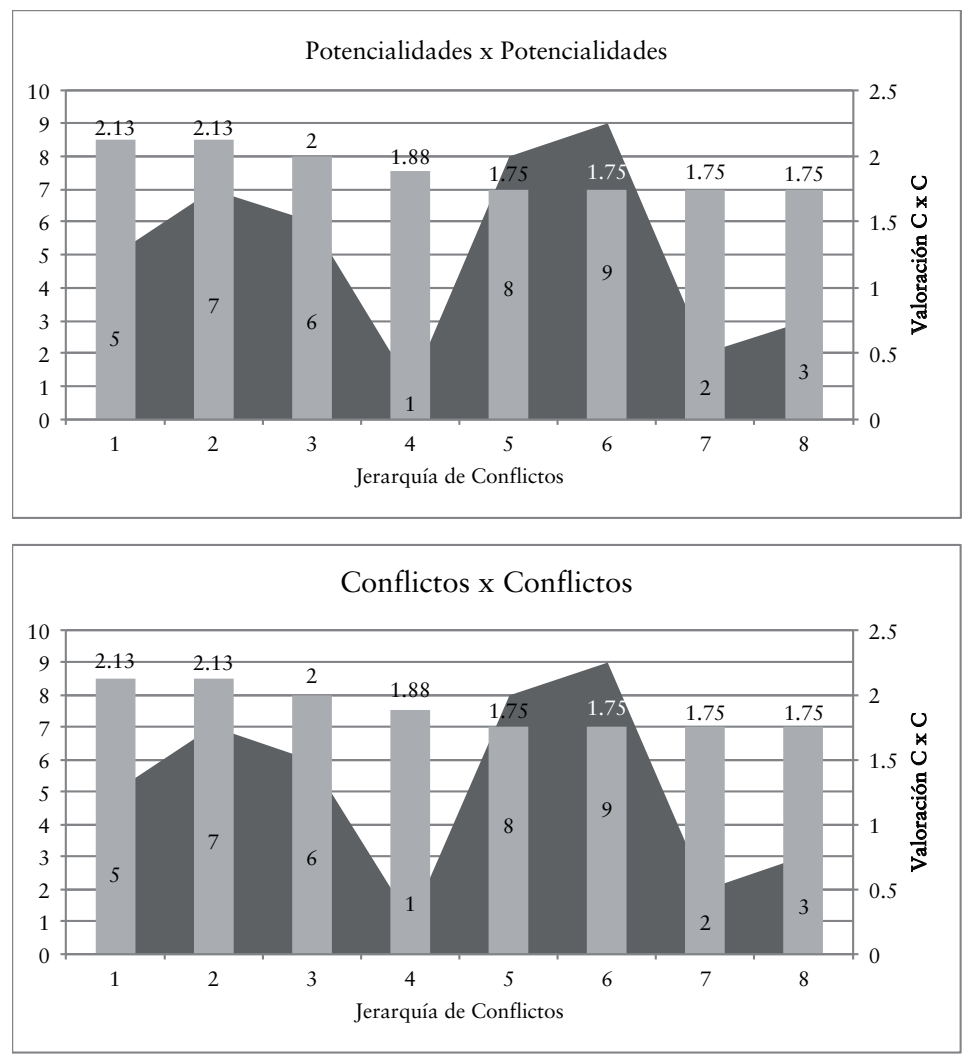

FuENTE: ElABORACIÓN PROPIA. 
Por último, se ha considerado una instancia propositiva que, a través del desarrollo del proceso metodológico enunciado, posibilita la construcción de encuadres programáticos y la preidentificación de proyectos para llevar adelante las ideasfuerza emergentes del territorio. De este modo, y a partir de esta instancia, se diseñaron los lineamientos estratégicos que permitirían la conformación y el desarrollo de Jáchal, con la correspondencia en calidad y sustentabilidad de un territorio socialmente responsable (TSR).

\section{VAlores POTENCIALES DEL PROCESO INVESTIGATIVO}

Como resultado de la presente investigación, y desde el campo epistemológico de la Responsabilidad Social, se ha construido un marco cognitivo apropiado para delinear las estrategias necesarias que permitan la conformación del departamento Jáchal como caso de estudio, en un territorio socialmente responsable.

Las herramientas construidas en el proceso metodológico, tales como el patrón de conexiones, la matriz de interacciones y la escala de valoración, son replicables a cualquier territorio posible de ser intervenido, teniendo en cuenta que son instrumentos de actualización permanente y que dan como resultado un proceso continuo de valoración de escenarios prospectivos vinculados a la visión de futuro.

En tal sentido, es dable destacar que sobre esta base cognitiva es factible la formulación de estrategias que podrán dar origen a la conformación de un TSR. Estas estrategias, con una visión compartida del futuro deseable, la creación de una cultura de corresponsabilidad y con la implementación de un sistema de gobernanza participativa, podrían dar respuesta adecuada a los retos de sostenibilidad ambiental, crecimiento económico, empleo e inclusión social, que demanda una región para conformarse como territorio socialmente responsable.

\section{REFLEXIONES FINALES}

En cuanto a las principales metas alcanzadas y resultados obtenidos, cabe mencionar que la presente investigación se ha abordado desde una visión prospectiva, y sobre la base conceptual y epistémica de la Responsabilidad Social, con el fin de plantear lineamientos estratégicos 
que permitan la construcción de escenarios que faciliten la conformación de territorios socialmente responsables (TSR).

Desde el convencimiento logrado por este equipo de investigación, en afirmar que es posible alcanzar el desarrollo integral, inclusivo y sostenible de una región, implementando estrategias de gestión que permitan, por un lado, la viabilidad de articulaciones dinámicas entre las diferentes dimensiones que conforman un territorio, y, por otro, conseguir el involucramiento y trabajo mancomunado de todos los grupos de interés en pos de lograr una consolidación estructural que favorezca la cohesión de la comunidad de dicho territorio.

Los resultados obtenidos en esta línea investigativa han de servir de insumo para otras investigaciones sobre esta temática; tal es el trabajo llevado a cabo actualmente por el presente equipo: «Estrategias innovadoras para la formulación de proyectos de carácter binacional entre San Juan, Argentina y Coquimbo, Chile. Desarrollo territorial socialmente responsable». Esto demuestra que los resultados logrados se convierten en un instrumento de utilidad práctica en la gestión de un territorio. Es un aporte a la interrelación entre la investigación académica y la gestión públicoprivada.

En síntesis, el proceso del presente trabajo de investigación da cuenta de cómo las asociaciones de conocimientos, creatividad, innovación y capacidad de respuesta de los grupos de interés de una localidad, en conjunto con el trabajo compartido de los profesionalesinvestigadores, y articulados ellos bajo los preceptos de la Responsabilidad Social, posibilitan el delineamiento de estrategias de gestión para abordar y comprender al territorio como un producto o servicio social emergente de la cultura que lo produce, contiene y consume.

Así, estas interrelaciones equilibradas de múltiples iniciativas y dimensiones permiten concebir al territorio como un entorno activo, dinámico, que facilita el cambio y estimula la transformación de una comunidad.

\section{BIBLIOGRAFÍA}

Cook, T. y Reichardt, C. (2005). Métodos cualitativos y cuantitativos en investigación evaluativa. Colección: Pedagogía. Traducción: Guillermo Solana. Título original: Qualitative and quantitative methods in evaluation research (C) SagePublications, Inc., 1982 - ISBN 84- 7112310-X. Madrid: Ediciones Morata, S. L. $1^{\text {a }}$ ed. 
Del Bono, T. (2015). Las innovaciones: conceptos introductorios y generales. San Juan: EFU, Editorial Universidad Nacional de San Juan.

Echeverri, P. y Moscardi, E. (2005). Construyendo el desarrollo rural sustentable en los territorios de México. Distrito Federal: Ediciones IICA. Instituto Interamericano de Cooperación para la Agricultura.

Gamba, L. (2012). Territorios y sujetos de la economía social y solidaria. Otra Economía, 6(10), 24-36. doi: 10.4013/otra.2012.

Lazzari, L. y Moulla, P. (2015). Un enfoque alternativo para la identificación y jerarquización de stakeholders. En N. Gorrochategui, V. Martins, J. Domínguez Granda y H. Valdivieso (Comps.), Responsabilidad Social de las Organizaciones. Avances y Propuestas en América Latina (pp. 39-58). Chimbote: Universidad Católica de Los Ángeles de Chimbote.

Ministerio de Infraestructura y Tecnología (2006). Dirección de Planeamiento y Desarrollo Urbano.

Gorrochategui, N. y Kinen, E. (2013). Implementación de la norma ISO 26000 en la materia, participación activa y desarrollo de la comunidad. Caso Municipalidad de Esperanza. Provincia de Santa Fe. En N. Gorrochategui, V. Martins y O. Licandro, Responsabilidad Social de las Organizaciones (RSO) Panorama de la agenda académica de América Latina Investigaciones, Casos y Reflexiones (pp. 169-183). Ciudad Autónoma de Buenos Aires: Ediciones Cooperativas.

Organización Internacional de Estandarización-ISO (2010). Norma Internacional ISO 26000. Guía sobre responsabilidad social, 2010. Suecia-Brasil: ISO.

Plan de Ordenamiento Territorial Urbano Rural 2006-2016. San Juan: Gobierno de San Juan.

Remolina, G. (2000). Hombre y Sociedad y Sociedad Civil y Estado. Fundación Social.

Rodríguez Herrera, A. y Alvarado Ugarte, H. (2008). Claves para la Innovación Social en América Latina y El Caribe. Santiago de Chile: Comisión Económica para América Latina y el Caribe (CEPAL) y la Fundación W.K. Kellogg.

Secretaría de Servicios Públicos/Ministerio de Infraestructura y Tecnología/ Dirección de Planeamiento y Desarrollo Urbano de San Juan (2008). Plan de Ordenamiento Urbano-Rural. San Juan 2006-2016. San Juan: Gobierno de San Juan.

Sepúlveda, S. (2008). Gestión del desarrollo sostenible en territorios rurales en Brasil.

Serrano García, J. y Serrano López, J. M. (2012). Guía para la incorporación de la responsabilidad social territorial en las políticas de empleo a nivel local. España: Grupo de consultoría estratégica Alquimia. Fondo Andaluz de Municipios para la solidaridad internacional (FAMSI). 
Sociedad Argentina de Planificación Territorial-SAPLAT (2015). Bases para una Agenda Nacional de Planificación Territorial, 2015. Buenos Aires, La Plata: SAPLAT.

Unión Europea/Fondo Social Europeo/Ministerio de Empleo y Seguridad Social (2009). Código Ético de Retos para los Territorios Socialmente Responsables. El Desarrollo sustentable: transformación productiva, equidad y medio ambiente. Santiago de Chile: Comisión Económica para América Latina y el Caribe (CEPAL).

Vega, S. S. (2015). Proyecto de Investigación: Modelo de Gestión Pública Territorial para el Departamento Jáchal. San Juan. Convocatoria 2014-2015. San Juan: Universidad Nacional de San Juan. Código SIGEVA: 80020130100331SJ.

Volpentesta, J. (2015). Procedimientos administrativos en la gestión de los stakeholders. En N. Gorrochategui, V. Martins, J. Domínguez Granda y H. Valdivieso (Comps.), Responsabilidad Social de las Organizaciones. Avances y Propuestas en América Latina (pp. 5989). Chimbote: Universidad Católica de Los Ángeles de Chimbote. 


\title{
AVAliAÇÃO DA SUSTENTABILIDADE DE MUNICÍPIOS BRASILEIROS PELOS OBJETIVOS DO DESENVOLVIMENTO SUSTENTÁVEL
}

\author{
Ronaldo Ferreira da Silva" \\ Leonardo de Lima Moura" \\ Luiz Octávio Gavião**** \\ Brasil
}

\section{INTRODUÇÃO}

Em 2015, a Cúpula das Nações Unidas para o Desenvolvimento Sustentável, adotou os Objetivos de Desenvolvimento Sustentável (ODS) que deverão orientar as políticas nacionais e as atividades de cooperação internacional nos próximos quinze anos (ONU, 2016).

A agenda contempla vários objetivos como erradicação da pobreza, segurança alimentar e agricultura, saúde, água e saneamento. Além disso, busca harmonizar progresso econômico, social e tecnológico com a natureza, reduzindo assim a degradação ambiental. Constituem-se de objetivos e metas universais que equilibram as três dimensões do desenvolvimento sustentável (econômica, social e ambiental) e envolvem os países desenvolvidos e os em desenvolvimento (Fukuda-Parr, 2016).

Os objetivos reforçaram a necessidade de ultrapassar a noção de desenvolvimento com foco apenas no crescimento econômico, inserindo o bem-estar e a redução da pobreza. O Produto Nacional Bruto (PIB) dá uma medida da riqueza agregada da economia, porém, a sua tradução

Doutorando em Sistemas de Gestão Sustentáveis, Universidade Federal Fluminense. Correo electrónico: ronaldorubanouff@gmail.com

** Doutorando em Engenharia Civil, Universidade Federal do Rio de Janeiro. Correo electrónico: leonardodelmoura@gmail.com

*** Doutor em Engenharia de Produção, Escola Superior de Guerra. Correo electrónico: luiz.gaviao67@gmail.com 
em termos de um padrão individual de prosperidade dependerá da distribuição da renda entre a população (Kageyama \& Hoffmann, 2006).

No mesmo sentido, o Triple Bottom Line (Elkington, 1997), propõe o dimensionamento da sustentabilidade nas dimensões econômica, social e ambiental. Nesta perspectiva, além da renda, o bem-estar humano também é caracterizado pelo acesso ao saneamento, saúde e educação (Junqueira, 2011; Hammer \& Pivo, 2017).

Embora tenha apresentado em 2016 o nono maior PIB do mundo, o Brasil ocupava em 2015 a 79a posição no ranking mundial do Índice de Desenvolvimento Humano (IDH) de 2016 (FMI, 2016; ONU, 2016). O país apresenta fortes desigualdades econômicas e sociais em seu território e a Região Nordeste, por exemplo, possui os menores índices de IDH, cerca de $55 \%$ das residências não possuem saneamento básico e a expectativa de vida é a menor do País. Participa com $18 \%$ da área total, $28 \%$ da população, mas menos de $14 \%$ do PIB nacional (Diniz, 2017).

Por outro lado, a Região Sul, mais industrializada, apresentou em 2015 um PIB per capita duas vezes maior que o da Região Nordeste e altos índices de IDH. Embora as regiões apresentem indicadores sócio econômicos diferentes, a atividade agropecuária responde de modo semelhante pela mão de obra ocupada (Martins, Lima \& Piffer, 2015).

Esta taxa de ocupação reflete o crescimento do agronegócio que vem aumentando sua participação no PIB do país, reduzindo a pobreza e garantindo a segurança alimentar. Entretanto, os avanços no campo têm como contrapartida os impactos no meio ambiente e, para que esta atividade mantenha sua expansão, será necessário considerar a utilização sustentável dos recursos naturais como um fator estratégico (Buainain et al., 2014).

A agricultura consome cerca de $70 \%$ da água disponível no mundo e grande parte é utilizada na irrigação e o uso intensivo compromete as reservas hídricas (Assouline et al., 2015).

Embora o Brasil detenha as maiores reservas de água doce do planeta, a oferta não é uniforme em todo o território e, mesmo regiões com grande disponibilidade hídrica como Sul e Sudeste, têm registrado períodos de escassez. Além disso, o uso é intensivo na agropecuária e, com o crescimento demográfico e o desenvolvimento econômico, as águas superficiais recebem cada vez mais resíduos oriundos das atividades humanas. Tal quadro se agrava no país devido aos indicadores pobres em saneamento que comprometem a qualidade dos mananciais (Carrera et al., 2018). 
Uma das principais causas de poluição dos recursos hídricos são as substâncias químicas e os fármacos vêm atraindo a atenção dos pesquisadores. Estas substâncias são excretadas pelos pacientes nos hospitais e residências e pelos animais em áreas de atividade agropecuária. Como são de difícil remoção, podem causar danos ao ecossistema. No Brasil, o problema é agravado porque os hospitais não precisam tratar os seus efluentes, lançando os despejos na rede de esgotos e muitos municípios não dispõem de redes de esgotamento sanitário suficientes (Gallo et al., 2012; Silva, 2016; Kummerer et al., 2016).

O desenvolvimento econômico e social é imprescindível para a melhoria da qualidade de vida, porém, os modelos adotados podem resultar em impactos ambientais. $\mathrm{Na}$ avaliação econômica tradicional do desenvolvimento, os custos ambientais ou externalidades negativas não são considerados (Proque, 2014). Os hospitais, por exemplo, são indispensáveis para garantir o acesso à saúde, porém, na perspectiva do desenvolvimento sustentável, seus efluentes podem contribuir para piorar o acesso ao abastecimento de água de qualidade constituindo uma externalidade negativa sob a perspectiva ambiental (Silva et al., 2017).

Neste cenário, é relevante a percepção do desenvolvimento dos municípios sob a ótica da sustentabilidade, avaliando-se os aspectos econômicos, sociais e ambientais pois o atendimento de muitas demandas sociais e econômicas pelas cidades provém do consumo de recursos naturais. Entretanto, a elaboração e adoção de índices ou indicadores que sejam capazes de abordar as três dimensões da sustentabilidade tem se configurado um desafio (Mori \& Yamashita, 2015).

O objetivo deste trabalho é verificar o nível de sustentabilidade de alguns municípios das Regiões Nordeste e Sul do Brasil, utilizando indicadores ambientais, econômicos e sociais associados ao cumprimento das metas dos ODS em relação aos recursos hídricos, saúde, renda, saneamento e segurança alimentar. Foram avaliados a coleta e tratamento de esgoto, a população, a atividade agrícola e pecuária e o acesso à água potável, além da quantidade de hospitais e de pacientes atendidos.

\section{Material e MÉTODos}

Trata-se de um estudo qualitativo - quantitativo no qual os indicadores de todos os municípios foram coletados através de pesquisa bibliográfica e documental e avaliados pela Composição Probabilística 
de Preferências (CPP), um método de apoio multicritério à decisão para estabelecer um ranking final de sustentabilidade.

$\mathrm{O}$ CPP é um Método de Apoio à Decisão Multicritério (MCDM) probabilístico, sendo desenvolvido por Sant'Anna (2002) e, mais recentemente, recebendo novas variantes (Sant'anna, 2015). Destina-se à solução de problemas cujos dados se caracterizam por duas ou mais alternativas, avaliadas quantitativamente em dois ou mais critérios. O método apresenta diversas variantes, sendo selecionado o modelo que melhor atenda ao objetivo da pesquisa. Assim, é possível aplicar o CPP para a ordenação e escolha de uma entre várias alternativas, para a classificação das alternativas em grupos de diferentes desempenhos, para a avaliação dinâmica entre períodos de tempo e para a avaliação de regularidade no desempenho das alternativas (Sant'anna et al., 2018).

Nesta pesquisa, os autores utilizaram a variante de decisão por eixos do CPP. Esse modelo é utilizado para problemas de ordenação das alternativas por pontos de vista da tomada de decisão, simulando quatro tipos de comportamento do decisor, com base em dois eixos. O eixo Progressista-Conservador exprime o desejo da escolha com referência à fronteira de melhores desempenhos (extremo Progressista) e o extremo Conservador simula a decisão que busca o afastamento da fronteira de pior desempenho. O eixo Pessimista-Otimista se refere ao desejo de avaliar o desempenho das alternativas sob todos os critérios (extremo Pessimista) ou de considerar o desempenho satisfatório da alternativa em ao menos um dos critérios (extremo Otimista). Assim, a decisão por eixos é capaz de definir quatro regiões que expressam os diferentes pontos de vista: Progressista-Pessimista (PP), Progressista-Otimista (PO), Conservador-Pessimista (CP) e Conservador-Otimista (CO) (Sant'anna, 2015). Esta pesquisa explorou o ponto de vista PP, tendo em vista a necessidade de avaliar os melhores desempenhos das alternativas sob todos os critérios, em função do contexto estabelecido ao problema.

A sequência de procedimentos utilizada para o estudo adotou os principais passos descritos por Pomerol e Barba-Romero (2012), partindo da definição do problema, escolha das alternativas, escolha dos critérios, composição da matriz de decisão e, por último, a aplicação do método.

Devido à dificuldade de quantificar preferências, nas condições reais em que cada análise deve ser aplicada, normalmente, espera-se imprecisão de medidas. Mecanismos para limitar a incerteza envolvem a redução de medidas a postos, a comparação das opções duas a duas e a utilização de limiares de indiferença. A redução a postos significa 
adotar a ordem ou ranking de cada alternativa em cada critério como fator de preferência. A incerteza é reduzida, porém a intensidade dessa preferência é também eliminada, pois se perde a medida de quanto uma alternativa é superior ou inferior às demais. A comparação duas a duas corresponde ao Processo de Análise Hierárquica (AHP), que tampouco requer o conhecimento do desempenho de cada alternativa. Por fim, os limiares de indiferença são comuns em alguns métodos da família ELECTRE, ampliando o nível de exigência para que uma alternativa seja preferível em relação a outra (Sant'anna et al., 2018). Nesta pesquisa, o método CPP compõe as preferências com abordagem diferente das supramencionadas, pois considera as possíveis regiões de decisão na estrutura de eixos. Dessa forma, todas as possibilidades de pontos de vista do decisor são aqui consideradas, com base no contexto e no objetivo do problema.

A amostragem dos municípios analisados foi constituída de vinte dois municípios localizados nos estados das Regiões Nordeste e Sul do país. Dados incompletos dos órgãos consultados determinaram a exclusão de outros municípios da pesquisa. De Alagoas (AL), foi escolhido o município de Arapiraca; da Bahia (BA), Feira de Santana, Juazeiro, Teixeira de Freitas e Vitória da Conquista; do Ceará (CE), Sobral; do Maranhão (MA), Imperatriz; de Pernambuco (PE), Caruaru, Garanhuns e Petrolina; do Paraná (PR), Cascavel, Londrina, Maringá, Pato Branco e Ponta Grossa; do Rio Grande do Norte (RN), Mossoró; do Rio Grande do Sul (RS), Bagé, Cruz Alta, Passo Fundo e Uruguaiana e de Santa Catarina (SC), Chapecó e Lages.

Para a avaliação dos municípios em relação às dimensões social, econômica e ambiental do TBL, foram definidos critérios aderentes aos objetivos do desenvolvimento sustentável da ONU. Foram escolhidos critérios que direta ou indiretamente expressassem o atendimento a estes objetivos e cuja disponibilidade de dados permitisse a elaboração do trabalho.

Para a avaliação da sustentabilidade dos municípios em relação à dimensão social, foram utilizados critérios de saúde e saneamento como quantidade de estabelecimentos hospitalares, de pacientes oncológicos atendidos pelo SUS e população atendida por água potável. Quanto maiores os valores dos três indicadores, melhor o desempenho do município na dimensão social.

Para a avaliação da sustentabilidade dos municípios em relação à dimensão econômica, os critérios utilizados foram o PIB per capita 
municipal, a quantidade de cabeças que compõem o rebanho e a área total cultivada no município. Quanto maiores os valores, melhor o desempenho do município na dimensão econômica. Cada critério, expresso na tabela 1, tem uma correspondência com um ou mais objetivos do desenvolvimento sustentável.

A avaliação da sustentabilidade dos municípios em relação à dimensão ambiental buscou o foco na utilização e contaminação dos recursos hídricos (ODS 6). Neste contexto, foram utilizados critérios que expressassem diretamente o atendimento a alguns objetivos do desenvolvimento sustentável como a população atendida por esgotamento sanitário, o volume de água consumido e o esgoto tratado no município. Quanto maiores os índices de atendimento e tratamento de esgoto, melhor o desempenho, porém, quanto mais água se consome, pior será a avaliação. Também foram considerados alguns indicadores utilizados nas outras duas dimensões que expressassem indiretamente os impactos causados no ambiente aquático, decorrente de atividades econômicas ou serviços exercidos nas cidades avaliadas. Desta forma, quanto mais pacientes oncológicos o município atender, quanto maior for a rede hospitalar, o PIB per capita, a área cultivada e o tamanho do rebanho, pior será o desempenho na dimensão ambiental.

TABELA I. CRITÉRIOS ESCOLHIDOS E SUA CORRESPONDÊNCIA COM OS OBJETIVOS DO DESENVOLVIMENTO SUSTENTÁVEL

\begin{tabular}{|l|l|l|l|l|l|}
\hline \multicolumn{2}{|c|}{ DIMENSÃo SOCIAL } & \multicolumn{2}{c|}{ DIMENSÃo ECONÔMICA } & \multicolumn{2}{c|}{ DIMENSÃo AMBIENTAL } \\
\hline \multicolumn{1}{|c|}{ CRITÉRIO } & \multicolumn{1}{c|}{ ODS } & \multicolumn{1}{c|}{ CRITÉRIO } & \multicolumn{1}{c|}{ ODS } & \multicolumn{1}{c|}{ CRITÉRIO } & \multicolumn{1}{c|}{ ODS } \\
\hline $\begin{array}{l}\text { Índice de } \\
\text { atendimento de } \\
\text { água }\end{array}$ & $\begin{array}{l}6.1 ; 6 . \mathrm{a} ; \\
6 . \mathrm{b}\end{array}$ & PIB per capita & $\begin{array}{l}8.2 ; 8.3 ; \\
8.4\end{array}$ & $\begin{array}{l}\text { Índice de } \\
\text { atendimento } \\
\text { de esgoto }\end{array}$ & $\begin{array}{l}6.1 ; 6.4 ; \\
6 . \mathrm{a}\end{array}$ \\
\hline $\begin{array}{l}\text { Total de pacien- } \\
\text { tes oncológicos } \\
\text { atendidos }\end{array}$ & 3.8 & Rebanho & $6.3 ; 12.4$ & $\begin{array}{l}\text { Índice de } \\
\text { esgoto tratado }\end{array}$ & 6.6 \\
\hline $\begin{array}{l}\text { Quantidade de } \\
\text { hospitais }\end{array}$ & $3.8 ; 3 . c$ & Área Cultivada & $\begin{array}{l}6.5 ; 6.6 ; \\
2.4\end{array}$ & - & - \\
\hline
\end{tabular}

FONTE: AUTORES.

As fontes para obtenção dos dados referentes aos critérios escolhidos foram o Sistema Nacional de Informações de Saneamento (SNIS), o Instituto Brasileiro de Geografia e Estatística (IBGE) e o Departamento de Informática do Sistema único de Saúde (SUS-DATASUS). 
Os critérios extraídos da base do SNIS (SNIS, 2016) com suas definições e unidades estão descritos na tabela 2.

TABEla 2. CRitérios do SNIS AdOTAdoS PARA A COMPOSIÇÃo DA MATRIZ DE DECISÃO E SUAS DEFINIÇÕES

\begin{tabular}{|l|l|l|l|}
\hline \multicolumn{1}{|c|}{ CRITÉRIO } & \multicolumn{1}{|c|}{ DEFINIÇão/FÓRMula } & UNIDADE & FONTE \\
\hline $\begin{array}{l}\text { Índice de Atendimento } \\
\text { Total de Água }\end{array}$ & $\begin{array}{l}\text { (População Total Atendida com Água } \\
\text { Potável / População Total) X 100 }\end{array}$ & Percentual & SNIS \\
\hline $\begin{array}{l}\text { Índice de Atendimento } \\
\text { Total de Esgoto }\end{array}$ & $\begin{array}{l}\text { (População Total Atendida por Esgota- } \\
\text { mento Sanitário / População Total) X 100 }\end{array}$ & Percentual & SNIS \\
\hline $\begin{array}{l}\text { Índice de Esgoto } \\
\text { Tratado }\end{array}$ & $\begin{array}{l}\text { (Volume de Esgoto Tratado / Volume de } \\
\text { Água consumida) X 100 }\end{array}$ & Percentual & SNIS \\
\hline $\begin{array}{l}\text { Volume de água } \\
\text { consumida }\end{array}$ & Volume de água consumida anualmente & $1.000 \mathrm{~m}^{3}$ & SNIS \\
\hline
\end{tabular}

FONTE: AUTORES.

Outra fonte de dados consultada e utilizada como base para as ações governamentais foi o IBGE - Cidades. Trata-se de uma ferramenta para obter informações sobre todos os municípios do Brasil num mesmo lugar e onde podem ser encontrados gráficos, tabelas, históricos e mapas que traçam um perfil completo de cada uma das cidades brasileiras (IBGE, 2016). Os critérios extraídos da base do IBGE com suas definições e unidades dos respectivos dados estão descritos na tabela 3 .

TAbela 3. Critérios do IBGE Adotados PARA A COMPOSIÇÃo DA MATRIZ DE DECISÃO E SUAS DEFINIÇÕES

\begin{tabular}{|l|l|l|l|}
\hline \multicolumn{1}{|c|}{ Critério } & \multicolumn{1}{|c|}{$\begin{array}{c}\text { DEFINIÇÃO/ } \\
\text { FÓRMUla }\end{array}$} & \multicolumn{1}{|c|}{ UnIDADE } & FONTE \\
\hline PIB & $\begin{array}{l}\text { Total da riqueza produzi- } \\
\text { da pelo município }\end{array}$ & R\$1,000,000,000.00 & IBGE \\
\hline $\begin{array}{l}\text { Área } \\
\text { Cultivada }\end{array}$ & $\begin{array}{l}\text { Área do município desti- } \\
\text { nada à produção agrícola }\end{array}$ & 1.000 ha & IBGE \\
\hline $\begin{array}{l}\text { Rebanho } \\
\text { Bovino }\end{array}$ & $\begin{array}{l}\text { Efetivo de cabeças de } \\
\text { gado criadas no municí- } \\
\text { pio }\end{array}$ & 1.000 cabeças & IBGE \\
\hline
\end{tabular}

FonTE: AUTORES.

As informações sobre assistência à saúde de cada município foram coletadas no sistema DATASUS que mantém uma base de dados nacional 
necessária ao processo de planejamento, operação e controle do SUS. A base disponibiliza dados sobre o atendimento na rede pública de saúde (DATASUS, 2016). Os critérios extraídos da base do DATASUS com suas definições e unidades dos respectivos dados estão descritos na tabela 4.

TABEla 4. CRitérios do DATASUS ADOTAdos PARA A COMPOSIÇÃo DA MATRIZ DE DECISÃO E SUAS DEFINIÇÕES

\begin{tabular}{|l|l|l|l|}
\hline \multicolumn{1}{|c|}{ CRITÉrio } & \multicolumn{1}{|c|}{$\begin{array}{c}\text { DEFINIÇÃo/ } \\
\text { FÓRMULA }\end{array}$} & UNIDADE & FONTE \\
\hline $\begin{array}{l}\text { Quantidade de hos- } \\
\text { pitais }\end{array}$ & $\begin{array}{l}\text { Total de estabelecimentos hos- } \\
\text { pitalares em funcionamento no } \\
\text { município }\end{array}$ & Unidades & DATASUS \\
\hline $\begin{array}{l}\text { Total de Pacientes } \\
\text { Oncológicos Aten- } \\
\text { didos }\end{array}$ & $\begin{array}{l}\text { Total de pacientes atendidos } \\
\text { pelas unidades de oncologia } \\
\text { do SUS no município }\end{array}$ & $\begin{array}{l}1.000 \\
\text { habitantes }\end{array}$ & DATASUS \\
\hline
\end{tabular}

FONTE: AUTORES.

\section{DelimitaÇÃo DA PESQUisa}

Para definição da amostra, foram utilizados os seguintes critérios de escolha: a) o município pertencer às regiões Nordeste e Sul do Brasil; b) fazer parte da rede de atendimento em oncologia do SUS; c) estar localizado no interior do estado; d) possuir atividade agropecuária. Para definição dos critérios, considerou-se indicadores relacionados ao potencial de contaminação, consumo e preservação dos recursos hídricos que estivessem disponíveis para consulta nas bases de dados no período de 2011 a 2015, último ano de atualização das bases de dados do IBGE e do SNIS.

\section{Resultados E Discussão}

O primeiro critério de avaliação dos municípios em relação à dimensão social é o índice de atendimento de água. Observando-se a tabela 5 , nota-se que 16 municípios apresentaram índices superiores a $90 \%$, expressando diretamente o avanço em direção ao pleno atendimento do objetivo 6.2 da agenda nas duas regiões. Dentre estes, Londrina, 
Maringá, Pato Branco, Ponta Grossa e Sobral alcançaram o objetivo da agenda com $100 \%$ da população atendida por água potável.

Os demais indicadores utilizados para a avaliação dos municípios na dimensão social estão relacionados ao acesso à saúde. O item 3.8 dos ODS prevê atingir a cobertura universal de saúde e o acesso a medicamentos e serviços de qualidade. O primeiro indicador é o total de pacientes oncológicos atendidos pela rede pública municipal, disponibilizado em unidades de saúde distribuídas pelos estados numa proporção de 1 (um) estabelecimento para cada 500.000 (quinhentos mil) habitantes.

As médias dos dados coletados de cada município no período estudado, segundo os critérios escolhidos foram inseridos em matrizes de decisão para as dimensões social, econômica e ambiental. A matriz de decisão da dimensão social é apresentada na tabela 5 .

TABELA 5. INDICADORES MÉdios DOS MUNiCÍPIOS NA DIMENSÃO SOCIAL

\begin{tabular}{|c|c|c|c|c|c|c|c|}
\hline \multirow[b]{2}{*}{ MunicíPIo } & \multicolumn{3}{|c|}{ INDICADORES } & \multirow[b]{2}{*}{ Município } & \multicolumn{3}{|c|}{ INDICADORES } \\
\hline & $\begin{array}{l}\text { Índice de } \\
\text { atendi- } \\
\text { mento de } \\
\text { água }\end{array}$ & $\begin{array}{l}\text { Pacientes } \\
\text { oncológicos } \\
\text { atendidos }\end{array}$ & $\begin{array}{l}\text { Unidades } \\
\text { de aten- } \\
\text { dimento } \\
\text { hospitalar }\end{array}$ & & $\begin{array}{l}\text { Índice de } \\
\text { atendimen- } \\
\text { to de água }\end{array}$ & $\begin{array}{l}\text { Pacientes } \\
\text { oncológicos } \\
\text { atendidos }\end{array}$ & $\begin{array}{l}\text { Unidades } \\
\text { de aten- } \\
\text { dimento } \\
\text { hospitalar }\end{array}$ \\
\hline Arapiraca & 94.02 & $27,838.40$ & 8 & Londrina & 100 & $116,739.40$ & 29 \\
\hline Bagé & 83.62 & $4,092.20$ & 3 & Maringá & 100 & 109,149 & 17 \\
\hline Caruaru & 93.06 & $90,818.20$ & 13 & Mossoró & 92.72 & $25,802.60$ & 11 \\
\hline Cascavel & 97.97 & $226,192.60$ & 19 & Passo Fundo & 99.05 & 106,077 & 10 \\
\hline Chapecó & 85.13 & 83,889 & 8 & Pato Branco & 100 & $30,381.60$ & 4 \\
\hline Cruz Alta & 97.79 & $3,445.80$ & 3 & Petrolina & 80.66 & $14,233.60$ & 9 \\
\hline $\begin{array}{l}\text { F. de } \\
\text { Santana }\end{array}$ & 90.61 & 52,014 & 28 & Ponta Grossa & 100 & $47,096.20$ & 13 \\
\hline Garanhuns & 96.09 & $2,261.80$ & 7 & Sobral & 100 & $25,428.60$ & 6 \\
\hline Imperatriz & 86.63 & $4,451.80$ & 9 & T. de Freitas & 78.88 & $1,882.40$ & 5 \\
\hline Juazeiro & 89.58 & $1,407.80$ & 10 & Uruguaiana & 94.5 & $57,015.20$ & 1 \\
\hline Lages & 96.77 & $6,079.20$ & 5 & $\begin{array}{l}\text { V. da Con- } \\
\text { quista }\end{array}$ & 98.68 & $69,587.20$ & 18 \\
\hline
\end{tabular}

FONTE: AUTORES. 
Observa-se que dentre os 22 municípios analisados, Cascavel apresentou a maior média de pacientes atendidos e dois municípios (Londrina, Maringá e Passo Fundo) atendem por ano uma quantidade de pacientes oncológicos pelo SUS próxima a 100.000. Dentre os municípios da região Nordeste, apenas Caruaru e Vitória da Conquista apresentaram um número de atendimento superior a 50.000. De acordo com o Instituto Nacional de Câncer (INCA), a estimativa de novos casos da doença para 2018 não difere muito entre as regiões: 117.280 para o Nordeste e 125.730 para o Sul (INCA, 2018). A diferença entre o total de atendimentos nos municípios nas duas regiões pode estar relacionada com diversos fatores como estrutura da atenção básica ou direcionamento de pacientes para outras unidades do estado.

O terceiro indicador utilizado para a avaliação da dimensão social é a quantidade de hospitais existente nos municípios o que reflete o nível de acesso aos serviços públicos de saúde. Os municípios que apresentam a maior quantidade média de hospitais são: Londrina (28), Feira de Santana (27) e Cascavel (22). Os que disponibilizam menos estabelecimentos são Bagé (3), Cruz Alta (4) e Uruguaiana (1), todos na Região Sul. A tabela 5 permite observar que existe um equilíbrio na oferta de hospitais públicos entre os municípios das duas regiões demonstrando um avanço em direção às metas do ODS 3.

Um dos itens considerados na dimensão econômica é o PIB per capita dos municípios. Os outros dois indicadores considerados na dimensão econômica estão relacionados à produção de alimentos pois a eliminação da fome e a garantia de acesso a alimentos a todas as pessoas fazem parte dos ODS.

Os critérios avaliados na dimensão econômica estão apresentados na tabela 6. Observa-se que os 7 municípios com maior PIB per capita situam-se na Região Sul. Entretanto, alguns municípios do Nordeste têm experimentado significativo crescimento como demonstram os PIB per capita de Imperatriz, Feira de Santana, Sobral e Petrolina. 


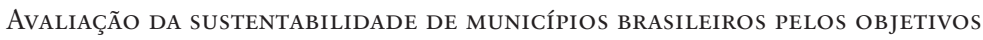
DO DESENVOLVIMENTO SUSTENTÁVEL

TABELA 6. INDICADORES MÉdios dos MUNICíPIOS NA DIMENSÃo ECONÔMICA

\begin{tabular}{|c|c|c|c|c|c|c|c|}
\hline \multirow[b]{2}{*}{ MunicíPIo } & \multicolumn{3}{|c|}{ INDICADORES } & \multirow[b]{2}{*}{ Município } & \multicolumn{3}{|c|}{ INDICADORES } \\
\hline & $\begin{array}{l}\text { PIB per } \\
\text { capita }\end{array}$ & Rebanho & $\begin{array}{c}\text { Área } \\
\text { cultivada }\end{array}$ & & $\begin{array}{l}\text { PIB per } \\
\text { capita }\end{array}$ & Rebanho & $\begin{array}{c}\text { Área } \\
\text { cultivada }\end{array}$ \\
\hline Arapiraca & $13,583.44$ & $1,914,973.00$ & $11,466.60$ & Londrina & $29,111.67$ & $2,231,397.00$ & $108,817.80$ \\
\hline Bagé & $16,517.85$ & $484,828.00$ & $36,149.20$ & Maringá & $34,008.00$ & $748,972.80$ & $47,779.40$ \\
\hline Caruaru & $15,759.74$ & $613,455.20$ & $1,643.20$ & Mossoró & $21,118.81$ & $972,331.00$ & $12,971.00$ \\
\hline Cascavel & $27,410.19$ & $5,258,049.00$ & $171,539.40$ & Passo Fundo & $34,290.35$ & $915,860.80$ & $47,113.80$ \\
\hline Chapecó & $34,138.41$ & $2,933,359.00$ & $23,384.60$ & Pato Branco & $32,295.35$ & $1,720,795.00$ & $51,460.00$ \\
\hline Cruz Alta & $37,790.85$ & $48,807.80$ & $127,622.20$ & Petrolina & $15,086.04$ & $398,654.00$ & $6,706.60$ \\
\hline $\begin{array}{l}\text { F. de San- } \\
\text { tana }\end{array}$ & $17,480.73$ & $1,849,478.00$ & $13,471.80$ & $\begin{array}{l}\text { Ponta Gros- } \\
\text { sa }\end{array}$ & $30,624.18$ & $652,105.80$ & $96,435.60$ \\
\hline $\begin{array}{l}\text { Garan- } \\
\text { huns }\end{array}$ & $12,807.80$ & $1,049,486.00$ & $3,665.40$ & Sobral & $17,234.90$ & $195,993.00$ & $12,221.60$ \\
\hline Imperatriz & $19,433.85$ & $118,296.40$ & 557.00 & T. de Freitas & $11,600.76$ & $162,033.60$ & $1,800.00$ \\
\hline Juazeiro & $12,116.56$ & $360,986.00$ & $21,567.80$ & Uruguaiana & $16,211.84$ & $575,839.00$ & $81,686.60$ \\
\hline Lages & $25,018.17$ & $193,377.20$ & $10,751.40$ & $\begin{array}{l}\text { V. da Con- } \\
\text { quista }\end{array}$ & $14,783.27$ & $903,088.60$ & $2,420.80$ \\
\hline
\end{tabular}

FONTE: AUTORES.

$\mathrm{O}$ agronegócio tem participação expressiva no PIB de todos os municípios avaliados e um dos indicadores é o porte do rebanho. Embora 3 municípios da Região Sul (Cascavel e Chapecó) disponham dos maiores plantéis, três municípios da Região Nordeste (Arapiraca, Feira de Santana e Garanhuns) estão entre os sete com rebanhos superiores a 1.000.000 de cabeças tabela 6) indicando que a pecuária tem importância econômica na região.

Os ODS também pretendem dobrar a produtividade agrícola e a renda dos pequenos produtores de alimentos. Neste sentido, a área cultivada é um indicador da existência de condições para o alcance deste objetivo. Nos municípios da Região Sul onde estão presentes grandes empresas do agronegócio, predominam as grandes extensões de terra cultivada ao contrário da Região Nordeste. Observa-se que os municípios de Cascavel, Cruz Alta, Londrina, Ponta Grossa, Pato Branco, Maringá, Passo Fundo e Bagé, todos da Região Sul, detém a maior parte das áreas cultivadas dentre todos os municípios avaliados (tabela 6).

A avaliação da dimensão ambiental tem como foco os recursos hídricos, utilizando indicadores que permitam avaliar diretamente o desempenho dos municípios em relação ao alcance do objetivo 6 dos 
ODS (melhorar a qualidade da água, aumentar o acesso ao saneamento e implementar a gestão integrada dos recursos hídricos). Neste sentido, foram avaliados indicadores diretos como o consumo de água, a cobertura da rede de coleta de esgotos e o índice de tratamento do esgoto. $\mathrm{E}$ também foram consideradas, como indicadores indiretos, as atividades avaliadas nas outras dimensões, para inferir a possibilidade de contaminação e consumo dos recursos hídricos decorrente destas atividades. Os critérios avaliados nesta dimensão estão apresentados na tabela 7 .

Nenhum dos 22 municípios analisados apresenta uma cobertura total de coleta de esgoto. Três (Londrina, Maringá e Ponta Grossa) coletam mais de $90 \%$ do esgoto produzido e nenhum município atinge o índice de $100 \%$ de tratamento de esgoto. O município de Arapiraca demonstra não realizar nenhum tratamento do esgoto, porém, é importante esclarecer que é a informação que consta na base de dados do SNIS (tabela 7).

O expressivo crescimento das cidades médias brasileiras nos últimos anos embute externalidades ambientais negativas como o crescente consumo de água potável. Observando-se a tabela 7, verifica-se que Londrina apresenta o maior consumo, cerca de dez vezes maior do que Cruz Alta.

TABELA 7. INDiCADORES MÉdios dos MUNiCíPIOS NA DIMENSÃo AMBIENTAL

\begin{tabular}{|c|c|c|c|c|c|c|c|}
\hline \multirow[b]{2}{*}{ MunicÍpio } & \multicolumn{3}{|c|}{ INDICADORES } & \multirow[b]{2}{*}{ MUNICÍPIO } & \multicolumn{3}{|c|}{ INDICADORES } \\
\hline & $\begin{array}{l}\text { Volume } \\
\text { água con- } \\
\text { sumida }\end{array}$ & $\begin{array}{c}\text { Índice de } \\
\text { esgoto } \\
\text { tratado }\end{array}$ & $\begin{array}{l}\text { Índice de } \\
\text { atendi- } \\
\text { mento de } \\
\text { esgoto }\end{array}$ & & $\begin{array}{l}\text { Volume } \\
\text { água con- } \\
\text { sumida }\end{array}$ & $\begin{array}{c}\text { Índice de } \\
\text { esgoto } \\
\text { tratado }\end{array}$ & $\begin{array}{l}\text { Índice de } \\
\text { atendi- } \\
\text { mento de } \\
\text { esgoto }\end{array}$ \\
\hline Arapiraca & $6,691.29$ & 0 & 21.43 & Londrina & $35,138.57$ & 82.88 & 96.11 \\
\hline Bagé & $7,909.77$ & 13.68 & 62.74 & Maringá & $22,316.38$ & 93.28 & 95.6 \\
\hline Caruaru & $11,821.42$ & 43.33 & 41.18 & Mossoró & $10,499.67$ & 37.89 & 40.74 \\
\hline Cascavel & $14,054.20$ & 78.78 & 76.02 & Passo Fundo & $10,160.89$ & 24.6 & 21.41 \\
\hline Chapecó & $6,961.49$ & 34.88 & 30.34 & Pato Branco & $3,901.63$ & 79.54 & 83.27 \\
\hline Cruz Alta & $2,948.84$ & 19.05 & 15.63 & Petrolina & $9,953.36$ & 68.14 & 56.21 \\
\hline $\begin{array}{l}\text { Feira de } \\
\text { Santana }\end{array}$ & $18,177.52$ & 70.55 & 49.72 & Ponta Grossa & $15,556.30$ & 82.16 & 93.67 \\
\hline Garanhuns & $4,763.78$ & 7.07 & 8.42 & Sobral & $9,976.69$ & 44.56 & 84.15 \\
\hline Imperatriz & $11,048.82$ & 78.96 & 24.77 & T. de Freitas & $4,755.79$ & 11.92 & 11.04 \\
\hline Juazeiro & $10,849.00$ & 34.71 & 63.61 & Uruguaiana & $5,208.46$ & 35.12 & 44.06 \\
\hline Lages & $8,942.56$ & 17.57 & 22.96 & $\begin{array}{l}\text { V. da Con- } \\
\text { quista }\end{array}$ & $11,070.77$ & 69.8 & 66.63 \\
\hline
\end{tabular}

FONTE: AUTORES 
Os dados coletados nos nove critérios adotados para as três dimensões não permitem inferir qual município obtém o melhor desempenho em nenhuma das perspectivas. Os municípios alternam posições nos diferentes critérios, o que reforça o argumento a favor do uso de um método MCDM, de forma a obter a ordenação dos municípios segundo o conjunto dos critérios. Além disso, os critérios não têm correlação entre si, ou seja, são independentes, o que constitui numa premissa para a aplicação do método escolhido. Assim, o município com melhor desempenho global representa uma solução satisfatória ao problema de pesquisa, ao invés de significar uma solução ótima.

$\mathrm{O}$ resultado do ranking dos municípios para as dimensões social, econômica e ambiental após a aplicação do método está consolidado na tabela 8 . Observando-se os resultados na dimensão social (tabela 8), verifica-se que Cascavel obteve a melhor posição, seguido de Maringá e Londrina. O CPP é um método não linear em que a diferença entre os escores do primeiro para o segundo colocado é maior do que a do segundo para o terceiro e assim por diante. Essas diferenças não lineares beneficiam os municípios com ótimas classificações em um ou dois indicadores como, por exemplo, Cascavel. De acordo com a tabela 5, o município liderou em «atendimento de pacientes oncológicos» e foi o terceiro em «unidades de atendimento hospitalar» embora tenha sido o oitavo em «atendimento de água». Por outro lado, Teixeira de Freitas que obteve a última colocação no ranking social, não se posicionou nas primeiras colocações em nenhum indicador. De acordo com os dados da tabela 6 , foi o último colocado em «atendimento de água», $17^{\circ} \mathrm{em}$ «unidades de atendimento hospitalar» e o penúltimo em «atendimento de pacientes oncológicos». 
Sección VI: Objetivos de desarrollo sosteniblede la Responsabilidad Social

Tabela 8. ORdenaÇão dos municípios NaS DIMENSÕES SOCIAL, ECONÔMICA E AMBIENTAL

\begin{tabular}{|c|c|c|c|c|c|c|c|}
\hline \multirow{2}{*}{ MunicíPio } & \multicolumn{3}{|c|}{ DiMENSÕES } & \multirow{2}{*}{ Município } & \multicolumn{3}{|c|}{ DiMENSÕES } \\
\hline & Social & Econômica & Ambiental & & Social & Econômica & Ambiental \\
\hline Arapiraca & 19 & 13 & 16 & Londrina & 3 & 3 & 21 \\
\hline Bagé & 21 & 12 & 8 & Maringá & 2 & 8 & 15 \\
\hline Caruaru & 9 & 18 & 13 & Mossoró & 15 & 14 & 10 \\
\hline Cascavel & 1 & 1 & 22 & Passo Fundo & 10 & 7 & 19 \\
\hline Chapecó & 14 & 6 & 18 & Pato Branco & 5 & 4 & 7 \\
\hline Cruz Alta & 16 & 2 & 20 & Petrolina & 12 & 19 & 1 \\
\hline F. de Santana & 7 & 10 & 17 & Ponta Grossa & 4 & 5 & 12 \\
\hline Garanhuns & 20 & 20 & 14 & Sobral & 8 & 17 & 2 \\
\hline Imperatriz & 11 & 16 & 4 & T. de Freitas & 22 & 22 & 5 \\
\hline Juazeiro & 18 & 21 & 9 & Uruguaiana & 13 & 9 & 6 \\
\hline Lages & 17 & 11 & 11 & $\begin{array}{l}\text { V. da } \\
\text { Conquista }\end{array}$ & 6 & 15 & 3 \\
\hline
\end{tabular}

FonTE: AUTORES.

Avaliando os resultados da ordenação na dimensão econômica pelo CPP (tabela 8), verifica-se que novamente Cascavel obteve a maior posição seguido de Cruz Alta e Londrina. Teixeira de Freitas mais uma vez ocupou a última posição enquanto Juazeiro se posicionou em penúltimo.

Assim como na avaliação da dimensão social, a líder Cascavel foi primeira colocada em dois critérios (área cultivada e rebanho) e oitava em PIB per capita (tabela 6). A segunda colocada, Cruz Alta foi primeira em PIB per capita e segunda em área cultivada. A terceira posição no ranking foi ocupada por Londrina que possui o oitavo maior PIB per capita, a terceira maior área cultivada e o terceiro maior rebanho (tabela 6). O posicionamento dos três primeiros colocados nas posições superiores de alguns critérios reforça a não linearidade do método que beneficia os municípios com ótimas classificações em um ou dois critérios.

$\mathrm{Na}$ ordenação dos municípios na dimensão ambiental, verifica-se que Cascavel, o município que liderou o ranking nas dimensões social e econômica, obteve a última posição enquanto Petrolina que foi a décima segunda colocada na dimensão social e décima nona na econômica, alcançou a primeira posição. 
Avaliando-se somente os indicadores diretos desta dimensão como consumo de água, atendimento e tratamento de esgoto (tabela 7), observa-se que este município tem o quinto maior volume de água consumida (14.054, $20 \mathrm{mil} \mathrm{m3)} \mathrm{e} \mathrm{os} \mathrm{sextos} \mathrm{melhores} \mathrm{índices} \mathrm{de} \mathrm{atendimento} \mathrm{de}$ esgoto $(76,02 \%)$ e esgoto tratado $(78,78 \%)$. Avaliando-se somente estes indicadores, o município estaria entre os dez melhores, entretanto, nesta dimensão foram considerados os impactos das atividades avaliadas nas outras dimensões. A consequência desta avaliação indireta é a mudança de posição de vários municípios que apresentaram bons índices de saneamento como, por exemplo, Cascavel mas que demonstram sofrer uma pressão significativa sobre os recursos hídricos decorrente do seu desenvolvimento econômico e social.

Neste contexto, a avaliação da sustentabilidade dos municípios nas três dimensões se constitui num complexo sistema de critérios em que cada indicador contribui de modo distinto para a avaliação final, e onde indicadores positivos para uma dimensão podem ser negativos para outra. A sustentabilidade em cada dimensão depende do desempenho nos critérios escolhidos, porém, na perspectiva do TBL, percebe-se que tais critérios podem parecer conflitantes quando o atendimento aos objetivos do desenvolvimento sustentável numa determinada dimensão implica num efeito que reduz o desempenho em outra dimensão.

Este cenário configura um argumento a favor do uso de um método MCDM, de forma a avaliar o conjunto de critérios em função dos possíveis conflitos, níveis de incerteza e independência entre os indicadores adotados e estabelecer uma ordenação que expresse o desempenho global de cada um dos municípios. Ao calcular as probabilidades conjuntas de cada município receber avaliações superiores e inferiores em relação aos demais, o método se mostrou capaz de estabelecer uma ordenação entre os três indicadores desta dimensão de modo coerente com os resultados obtidos para cada um individualmente.

Após a ordenação quanto aos critérios propostos nas dimensões social, econômica e ambiental, foi estabelecido um ranking dos municípios pela perspectiva do Triple Bottom Line, considerando o desempenho de cada um em todos os critérios simultaneamente. O resultado do ranking dos municípios para as três dimensões está consolidado na tabela 9 . 
Sección VI: Objetivos de desarrollo sosteniblede la Responsabilidad Social

TABEla 9. RANKING FINAL dos MUNICÍPIOS PELA PERSPECTIVA Do TRIPLE BOtTOM LINE

\begin{tabular}{|c|c|c|c|c|c|c|c|}
\hline MunicíPIO & PosiçÃo & Município & PosiçÃo & Município & PosiçÃo & Município & Posição \\
\hline $\begin{array}{l}\text { Pato } \\
\text { Branco }\end{array}$ & 1 & Uruguaiana & 7 & Mossoró & 13 & Cruz Alta & 19 \\
\hline $\begin{array}{l}\text { Ponta } \\
\text { Grossa }\end{array}$ & 2 & Londrina & 8 & Lages & 14 & Arapiraca & 20 \\
\hline Maringá & 3 & Imperatriz & 9 & $\begin{array}{l}\text { Passo } \\
\text { Fundo }\end{array}$ & 15 & Garanhuns & 21 \\
\hline $\begin{array}{l}\text { V. da } \\
\text { Conquista }\end{array}$ & 4 & Cascavel & 10 & Chapecó & 16 & $\begin{array}{l}\text { T. de Fre- } \\
\text { itas }\end{array}$ & 22 \\
\hline Sobral & 5 & $\begin{array}{l}\text { F. de } \\
\text { Santana }\end{array}$ & 11 & Juazeiro & 17 & - & - \\
\hline Petrolina & 6 & Caruaru & 12 & Bagé & 18 & - & - \\
\hline
\end{tabular}

FonTE: AUTORES.

Observando o ranking, verifica-se que Pato Branco ocupou o primeiro lugar entre os municípios estudados. O município foi o quinto mais bem avaliado na dimensão social, quarto colocado na dimensão econômica e sétimo na ambiental (tabela 8). Quando se analisa o desempenho médio em todos os critérios, este município obteve os melhores indicadores entre em 5 critérios. Possui o melhor atendimento e o segundo menor consumo de água, o quarto melhor índice de esgoto tratado, o quinto melhor atendimento de esgoto e o quinto melhor PIB per capita (tabelas 6 e 7).

Avaliando-se a influência dos indicadores econômicos e sociais sobre o desempenho na dimensão ambiental, observa-se que este município apresenta a terceira menor média de unidades de atendimento hospitalar e situa-se dentro da média em relação ao número de pacientes oncológicos atendidos (tabela 5). Possui a sétima maior área cultivada, e o sexto maior rebanho (tabela 6). Nenhum destes indicadores compromete sua posição na dimensão ambiental. Como obteve bom desempenho nas demais dimensões, no ranking final ocupou a primeira posição. O resultado confirma a premissa do método CPP de considerar o melhor desempenho das alternativas em todos os critérios e obter um escore final das alternativas beneficiando os municípios com ótimas classificações em um ou dois critérios.

A ordenação final dos municípios pode exemplificar a complexidade da avaliação da sustentabilidade na perspectiva do TBL. A 
sustentabilidade em cada dimensão depende do desempenho nos critérios escolhidos e eles podem ser conflitantes quando o atendimento aos objetivos do desenvolvimento sustentável numa determinada dimensão implica num efeito negativo que reduz o desempenho em outra dimensão.

Embora tenha apresentado indicadores econômicos e sociais robustos, o município de Cascavel ocupou as últimas posições em 4 dos indicadores diretos e indiretos considerados na dimensão ambiental. Como o método considera o melhor desempenho das alternativas em todos os critérios, estas diferenças influenciaram o desempenho final onde Pato Branco se posicionou nove posições acima de Cascavel que obteve uma posição intermediária no ranking final.

\section{Conclusão}

A utilização do método MCDM forneceu uma percepção de como as ações alinhadas ao ODS são heterogeneamente implementadas nos municípios do Nordeste e Sul do Brasil. Com base nos resultados, destaca-se que nenhum dos municípios analisados apresentou desempenho superior ou inferior em todos indicadores. Enquanto alguns municípios apresentaram um desempenho robusto com relação ao desenvolvimento econômico outros ainda se mantém distantes das metas de redução da pobreza. Quanto à perspectiva social, observou-se uma significativa disparidade na implantação de serviços básicos, principalmente no que se refere a existência de unidades hospitalares e o número de pacientes oncológicos atendidos. Com relação à dimensão ambiental, os resultados apresentados permitiram expressar os impactos negativos que o baixo índice de esgoto coletado e tratado tanto em municípios da Região Sul quanto da Região Nordeste podem ocasionar nas matrizes aquáticas e destacar os municípios mais suscetíveis ao comprometimento da qualidade das suas águas superficiais.

O estudo demonstra ainda que o alcance das metas dos objetivos do desenvolvimento sustentável impõe externalidades negativas e que diversos indicadores relacionados aos ODS podem servir de parâmetro para estimar possíveis impactos ambientais e direcionar o poder público para criar mecanismos de mitigação.

A avaliação final sob a perspectiva do Triple Bottom Line mostrou que obter um bom desempenho numa dimensão apenas não é suficiente para configurar um município como sustentável, reforçando a importância dos 
ODS para a integração da qualidade de vida da sociedade e da utilização responsável dos recursos naturais ao desenvolvimento econômico.

\section{REFERÊNCIAS}

Araújo, T. D. (2014). Nordeste: desenvolvimento recente e perspectivas. Um olhar territorial para o desenvolvimento: Nordeste. Rio de Janeiro: Banco Nacional de Desenvolvimento (BNDES), 540-560.

Assouline, S.; Russo, D.; Silber, A., \& Or, D. (2015). Balancing water scarcity and quality for sustainable irrigated agriculture. Water Resources Research, 51(5), 3419-3436.

Buainain, A. M.; Alves, E. D. A. da Silveira, J. M., \& Navarro, Z. (2014). O mundo rural no Brasil do século 21: a formação de um novo padrão agrário e agrícola. Brasília, DF: Embrapa.

BRASIL, Ministério do Meio Ambiente. Agência Nacional de Águas. Cadernos de capacitação em recursos hídricos. Brasília, 2011.

BRASIL (2016a). Sistem DATASUS. Acesso: 5 de maio de 2016, from http:// www2.datasus.gov.br/DATASUS/index.php.

BRASIL (2016b). Sistema Nacional de Informações sobre Saneamento (SNIS). Acesso: 2 de maio de 2016, from http://www.snis.gov.br/.

Carrera, J.; Arroyo, V.; Rojas, F., \& Mejia, A. (2018). Water security in Latin America: the urban dimension. Empirical evidence and policy implications from 26 cities. In Global Water Security (pp. 217-232). Singapore: Springer.

Diniz, C. C. (2017). Dinâmica regional e ordenamento do território brasileiro: desafios e oportunidades. Revista Catarinense de Economia, 1(1).

Elkngton, J. (1997). Cannibals with Forks: The Triple Bottom Line of Twenty-First Century Business. Capstone.

Fukuda-Parr, S. (2016). From the Millennium Development Goals to the Sustainable Development Goals: shifts in purpose, concept, and politics of global goal setting for development. Gender \& Development, 24(1), 43-52.

Gavião, L. O.; Sant'anna, A. P.; Lima, G. B. A.; \& Garcia, P. A. A. (2018). CPP: Composition of Probabilistic Preferences. R package version 0.1.0. https://CRAN.R-project.org/package=CPP, 2018.

Hammer, J., \& Pivo, G. (2017). The triple bottom line and sustainable economic development theory and practice. Economic Development Quarterly, 31(1), 25-36.

Instituto Nacional de Câncer José de Alencar Gomes da Silva (INCA) (2018). Estimativa 2018 - Incidência de Câncer no Brasil. Link: http://www1.inca.gov.br/estimativa/2018/. Acesso em 10/12/2018. 
Kageyama, A., \& Hoffmann, R. (2006). Pobreza no Brasil: uma perspectiva multidimensional. Economia e Sociedade, 15(1), 79-112.

Kümmerer, K., Haiß, A., Schuster, A., Hein, A., \& Ebert, I. (2016). Antineoplastic compounds in the environment-substances of special concern. Environmental Science and Pollution Research, 23(15), 14791-14804.

Martins, H. H.; Ferrera de Lima, J., \& Piffer, M. (2015). Indicadores de Base Econômica: uma aplicação para as Regiões Brasileiras. Caderno de Geografia, 25(43).

Mori, K., \& Yamashita, T. (2015). Methodological framework of sustainability assessment in City Sustainability Index (CSI): A concept of constraint and maximisation indicators. Habitat International, $45,10-14$.

ONU (2016). Organização das Nações Unidas. Agenda 2030 e os Objetivos de Desenvolvimento Sustentável (ODS). http://www.agenda2030. com.br/aagenda2030.php

Pomerol, J.-C., \& Barba-Romero, S. (2012). Multicriterion decision in management: principles and practice (Vol. 25). New York: Springer.

Proque, A. (2014). Externalidades do setor sucroalcooleiro: inserção de centrais co-geradoras a bagaço de cana. Revista Meio Ambiente e Sustentabilidade, 6, 3, 446-468.

Sant'anna, A. P. (2002). Aleatorização e composição de medidas de preferência. Pesquisa Operacional, 22, 1, 87-103.

Sant'anna, A. P. (2015). Probabilistic Composition of Preferences, Theory and Applications. New York: Springer.

Sant'Anna, A. P.; Lima, G. B. A.; Sant, L. A. D. F. P., \& Gavião, L. O. (2018). Two-Stage Composition of Probabilistic Preferences. Annals of Data Science, 1-33.

Silva, R. F.; Moura, L. L; Gavião, L. O.; Lima, G. B., \& Bidone, E. D. (2017). Avaliação dos municípios do Nordeste brasileiro pelos objetivos do desenvolvimento sustentável e o triple bottom line. Revista Verde de Agroecologia e Desenvolvimento Sustentável, 12(4), 717-728. 



\section{MicrogobernanZa PARA LOS EMPRENDIMIENTOS DE CALIDAD EN ECUADOR ACORDE AL OBJETIVO 8 de Desarrollo Sostenible}

Gino Geovanny Cornejo Marcos"

Ecuador

\section{LOS EMPRENDIMIENTOS INNOVADORES EN UNA ECONOMÍA POSTCAPITALISTA}

Es menester manifestar que después del fracaso de las economías planificadas, que se concretó con la caída del Muro de Berlín hace ya veintiocho años, y el gran avance de China, una economía de mercado regulada pasó a ser el modelo dominante, casi exclusivo, de organización de la sociedad. Al respecto, P. Samuelson (2010) señala que: "Los historiadores han encontrado que los factores fundamentales en el crecimiento económico de largo plazo incluyen mercados privados regulados como base de la mayor parte de la actividad económica» (p. 375). En esa misma dirección, el nobel Jean Tirole (2017) menciona: "Con las privatizaciones, la apertura a la competencia y la globalización el poder político ha perdido su influencia a favor del mercado» (p. 13). El hecho cierto es que la organización de la sociedad en los últimos tiempos ha descansado en la mano invisible (Smith, 1776) del mercado competitivo, en donde se aprovecha la búsqueda del interés personal para obtener la eficacia económica, y en la regulación del Estado, corrigiendo las fallas del mercado.

Pero ¿qué es lo que lo motiva al Estado a actuar en el mercado? Pues, generar el bien común, que se traduce en una igualdad de oportunidades. Se debe comprender que una sociedad desigual frena el

MBA Internacional, Universidad Politécnica de Cataluña UPC. Correo electrónico: gcornejo@ecotec.edu.ec 
crecimiento económico - léase desarrollo productivo- y el progreso social. El nobel J. Stiglitz señala que: «La desigualdad es la causa y la consecuencia del fracaso del sistema político y contribuye a la inestabilidad de nuestro sistema económico, lo que a su vez contribuye aumentar la desigualdad, una espiral viciosa en sentido descendente en la que hemos caído» (Stiglitz, 2012).

En este contexto, ¿'es socialmente suficiente que solo el Estado intervenga para la prosperidad de una nación? O ¿en la búsqueda del bien común y de generación de oportunidades deben solo los poderes públicos intervenir o, por el contrario, son las empresas o los emprendimientos los que también deberían adoptar un comportamiento socialmente responsable?

Pues bien, lo que se ha observado es que solo las empresas, sean estas pequeñas, medianas o la gran empresa, se han venido preocupando por ese comportamiento socialmente responsable; sin embargo, es necesario que los emprendimientos también se alineen a estos fundamentos, en los que se integren las preocupaciones sociales, del medioambiente y por sobre todo las económicas. Esta última, indudablemente es la parte medular de cualquier tipo de empresa y de la que va a depender no solo la subsistencia de la organización, sino también las otras dimensiones de índole social y ambiental.

No obstante, hay que considerar que en la actualidad, el libre accionar del emprendimiento basado en el mercado ha sido reemplazado por una nueva dinámica, que es la incorporación de las tecnologías de información, lo que ha corroído el sistema capitalista, base del modelo liberal y de la economía de mercado, pregonada por A. Smith en el siglo XVIII, bajo cuya filosofía emergió la idea de la mano invisible, en que el individuo busca su propio interés para, supuestamente, crear un beneficio colectivo. Al respecto, el autor norteamericano Paul Mason indica: «Una economía basada en la información por su tendencia misma a los productos de coste cero y a la debilidad de los derechos de propiedad intelectual, no puede ser una economía capitalista» (Mason, 2016).

Además, Mason seguidamente afirma que: «La tecnología de la información expulsa el factor trabajo del proceso de producción, destruye los mecanismos de formación de precios y favorece formas de intercambio no mercantiles. Y en último término, desgastará por completo el vínculo entre trabajo y valor». Lo descrito permite inferir que hoy se observan nuevos comportamientos en las empresas a nivel mundial y es 
por esto que el análisis del emprendimiento innovador, en el marco de un postcapitalismo, es un imperativo en América Latina y el Ecuador.

Lo señalado es simplemente una evidencia de lo que estaba sucediendo en el mundo, una transformación cualitativa del capitalismo, cuyo impacto se palpó con mayor énfasis a partir de la última década del siglo XX. Para evidenciar lo señalado, se puede observar el camino seguido por la tecnología. En la primera ola, con la introducción de los sistemas informáticos de gestión para el procesamiento de datos y las tecnologías de telecomunicaciones, comenzaron a aparecer nuevos términos: economía del conocimiento o sociedad del conocimiento, prácticamente estaba germinando una nueva forma de sociedad productiva muy diferente a la capitalista, puesto que se presentó una segunda ola, cuya característica estuvo dada por la difusión de internet con sus plataformas y buscadores, cuando se visualizó una mayor vinculación entre los consumidores y las empresas. Finalmente llegó la tercera ola, que R. Katz (2018) la describe:

La tercera ola — conformada por un conjunto de tecnologías llamadas de avanzada- permiten encarar una refundación de empresas tradicionales a partir de generación de nuevos modelos de negocio, la virtualización de estadios de la cadena de valor y una redefinición de las fronteras de eficiencia del negocio (p. 8).

Los países, a través de la sociedad que conforman, son testigos de que la economía ha tomado una nueva orientación, que tiene que ver con la innovación tecnológica, la cual ahora está en el centro del mecanismo de crecimiento de las naciones en el mundo. El valor agregado en el producto se sitúa en la actualidad, de manera exponencial, en la innovación. La riqueza de las naciones, que se basaban en los siglos pasados en la división del trabajo y en el uso de la maquinaria y la industria, ahora se extiende al uso de las tecnologías y el internet de las cosas.

Por lo visto, la innovación tecnológica sugiere definitivamente una cultura, visión, gestión e instituciones diferentes, las sociedades deben acoger estos nuevos condicionamientos y obligar a los gobiernos, a través de una buena educación, a animar al conjunto de la comunidad al emprendimiento.

El incremento de la productividad y competitividad de un país no depende solamente de las grandes empresas y de unas pequeñas 
y medianas empresas tradicionales, sino que esta se direccione a la creación de emprendimientos innovadores, que incorporen un gran valor agregado y no a iniciativas individuales que nazcan por necesidad, y lleguen a incrementar micros, pequeñas y medianas empresas MIPYMES, de bajo nivel de productividad, gran absorción de mano de obra no calificada, falta de compromiso social en sus inicios y una carencia de postulados de buena gobernanza acorde a algunos Objetivos de Desarrollo Sostenibles.

La realidad descrita no ha sido superada en Ecuador y Latinoamérica, lo corrobora un estudio de la CAF (2013): «Es el hecho que en América Latina existe una proporción muy significativa de empresas pequeñas y microemprendimientos informales» (p. 1). Este informe asegura además que: «Por ello la región se encuentra en una especie de trampa de informalidad y baja productividad».

En esta tesitura, para que lo sugerido tenga sentido, es necesario revisar algunos aspectos de los emprendimientos, conceptos y significados en el marco de una microgobernanza emprendedora. Factores internos y externos que lo limitan, como otras dimensiones que lo condicionan para lograr empresas innovadoras, competitivas y sobre todo sostenibles, que jueguen un papel preponderante en el desarrollo de los países, sintonizados con la Agenda 2030 de los Objetivos de Desarrollo Sostenible (ODS).

\section{EMPRENDIMIENTO Y GOBERNANZA: CONCEPTO Y SIGNIFICADOS}

Si en la región existe una mayoría de micros y pequeñas empresas de baja productividad, significa que la capacidad de gestión es precaria e insuficientemente preparada para ejercer emprendimientos de alta productividad. Es decir, que la acción de administrar o gobernar un emprendimiento no se lo realiza de manera adecuada, acorde a los nuevos paradigmas de crecimiento y generación de riqueza, articulados al uso de las nuevas tecnologías, tal como una buena gobernanza lo requiere. En todo caso, para que lo descrito tenga sentido, es preciso aproximarnos a los conceptos de emprendimientos y gobernanza.

En lo que respecta al emprendimiento, existen significados muy parecidos, por ejemplo, la Corporación Andina de Fomento (2013) en un estudio señala que «el emprendedor es aquella persona que puede ser 
capaz de visualizar nuevas demandas, con el propósito de producirlas mediante la creatividad y la innovación (p. 19).

Por otro lado, otro organismo internacional como el Banco Mundial indica que:

El emprendimiento comprende la entrada de empresas en mercados nuevos o ya establecidos (tanto nacionales como extranjeros), la introducción de productos nuevos en el mercado y los avances organizativos que permiten a las empresas mejorar la calidad o el precio de los productos o adoptar maneras de producir eficientes (p. 3).

A este concepto, le incorpora además otros elementos, en que el emprendimiento per se debe ser innovador, vinculado al crecimiento elevado, de gama alta y transformador. Y determina que hay que ser claros al distinguir entre este tipo de emprendimiento descrito y las iniciativas emprendidas por individuos autoempleados, cuyo potencial de crecimiento es bajo. En todo caso, los dos conceptos detallan que el punto central de un emprendimiento es la innovación, por lo que, con toda certeza, un emprendimiento puede lograr a consolidar otros ámbitos como el de generador de empleo y desarrollo social.

Por lo anotado, el hecho cierto es que el emprendimiento tiene una función transformadora en la sociedad, por la generación de empresa en la que se circunscribe y la cantidad de empleo que pueda generar. Pero en el contexto de creación de empresa, hay que tomar en consideración aquellos emprendimiento que se crean por necesidad —no encuentran opción de empleo y subsisten - y por oportunidad —está relacionado estrechamente con las condiciones estructurales que determina la capacidad de generar y crear conocimiento dentro de la sociedad-. Si bien es cierto que los primeros no tienen una gran connotación en el crecimiento económico de un país, los segundos consagran un efecto positivo.

En este contexto, se puede evidenciar y corroborar, mediante estudios de organismos internacionales, que en América Latina el espíritu emprendedor no es innovador, lo cual es una de sus grandes, profundas e insondables debilidades. En este punto, hay que agregar que la innovación está íntimamente ligada a la Investigación y Desarrollo $(\mathrm{I}+\mathrm{D})$ y a la incorporación de tecnología.

Según un estudio de la Secretaría Ibero Americana y la Facultad Latinoamericana de Ciencias Sociales (2011): «Países que tuvieron altas tasas de crecimiento, tuvieron paralelamente procesos de innovación 
o pusieron un énfasis muy fuerte en la innovación productiva. Los procesos de innovación se correlacionaron con el crecimiento a largo plazo» (p. 114). Y este no es el caso de la región, donde coexisten una gran cantidad de emprendimientos con escaso nivel técnico, que, en vez de ser un aporte al crecimiento económico, lo ralentizan.

Ahora bien, si se habla de emprendimiento e innovación y se afirma que las economías más dinámicas son innovadoras, toca conocer en dónde se encuentra Latinoamérica, y principalmente Ecuador. Es que la región está rezagada en aspectos relativos a innovación. Además, el país en el concierto mundial 2018 y en el marco de los emprendimientos, en lo que respecta a calidad y potencial, califica muy bajo. Por ejemplo, en «innovación del producto", las brechas de calificación son notorias, pues mientras la región y el resto del mundo tienen un puntaje que se aproxima a 0,50, Ecuador apenas llega a 0,29. En lo que concierne a la «internacionalización», las diferencias son también significativas, donde el país escasamente registra 0,07 y el resto del mundo, 0,38. Latinoamérica en este indicador posee 0,25 (GEDI, 2018).

Por lo anotado, se puede inferir que la calidad y el potencial del emprendimiento son el fiel reflejo de una economía muy poco dinámica, no generadora de empleo de alta productividad y no competitiva, donde sus emprendimientos no colocan sus productos o servicios en el exterior. Es evidente que una economía con un patrón de producción primaria, como la ecuatoriana, emerge de un esquema de bajos niveles de innovación y cambio tecnológico.

\section{EL EMPRENDIMIENTO EN EL CRECIMIENTO Y DESARROLLO ECONÓMICOS}

La senda intelectual planteada por el creador de la economía política y sintetizada por Samuelson (2010): «Smith fue el primer apóstol del crecimiento económico. En los albores de la revolución industrial señaló los grandes progresos que había experimentado la productividad gracias a la especialización y a la división del trabajo» (p. 30). En la actualidad se ven desbordadas por la incorporación de las tecnologías, la economía colaborativa y la existencia de plataformas digitales, que no hacen más que confirmar un postcapitalismo. La sociedad asiste a toda una corriente de pensamiento de destrucción creativa, término acuñado por el economista austríaco J. Schumpeter en 1942, según quien el cambio siempre necesita destruir algo viejo, que se reemplaza 
por algo nuevo, como ocurrió con los teléfonos celulares, que reemplazaron enormemente a las líneas telefónicas fijas, o la música digital, que convirtió a los acetatos en piezas para coleccionistas.

Este proceso de cambio fue realizado por emprendedores innovadores, bajo cuya dirección se erigieron nuevos campos del saber administrativo y de gestión, impulsados soberanamente y a los que obedece un sistema de gobernanza propio, en los que sus iniciativas se expanden a todo el tejido productivo, para coadyuvar a la generación de empleo permanente y ser partícipes del crecimiento y desarrollo económico, en clara sintonización con los preceptos de la meta 3 de los ODS8, que señala: «Promover políticas orientadas al desarrollo que apoyen las actividades productivas, la creación de puestos de trabajo decentes, el emprendimiento, la creatividad e innovación (...)» (Naciones Unidas, 2015).

\section{ORIGEN Y SIGNIFICADO DEL TÉRMINO «GOBERNANZA»}

Ahora bien, si se define a la gobernanza, en primera instancia este término aparece con mayor intensidad a fines del siglo pasado, como referencia al actual proceso de transformación del sector público, por lo que es importante definirlo. Según un reporte del Banco Mundial (2017), la gobernanza es:

El proceso a través del cual los actores estatales y no estatales interactúan para diseñar e implementar políticas dentro de un conjunto dado de reglas formales e informales que dan forma y están influidas por el poder. Este informe define el poder como la capacidad de grupos o individuos para hacer que otros actúen en interés de esos grupos e individuos y para generar resultados específicos (Banco Mundial, 2017).

Este concepto refleja el accionar de lo público con la participación de otros actores para la implementación de normas que direccionen el accionar de la sociedad. Asimismo, menciona al poder como el eje para la consecución de resultados.

Otra acepción la entrega Joan Prats, quien la define como:

El modo de gobernación característico de una sociedad compleja, diversa, interdependiente y dinámica en la que las Administraciones actúan con racionalidad limitada, el conocimiento se halla fragmentado entre diversos actores y 
la realización de los intereses generales depende de la calidad de la interacción entre las Administraciones Públicas, lo que podemos definir como gobierno multinivel y de éstas con las organizaciones de la sociedad civil y del sector privado (Prats, 2005).

Este concepto le da relevancia a la participación de la sociedad civil en la implementación de las políticas públicas, y sostiene la interrelación del mercado, el Estado y la sociedad.

En un concepto más elaborado, Quinteros (2014) cita a Aguilar $(2006$, p. 90$)$ y señala que la gobernanza es «el proceso mediante el cual los actores de una sociedad deciden sus objetivos de convivencia - fundamentales y coyunturales y las formas de coordinarse para realizarlos: su sentido de dirección y su capacidad de dirección». Esta explicación señala que lo que importa no es el gobierno en sí mismo, sino la acción de gobernar y que administraciones, ejecutivos y legislativos —el gobierno en sentido amplio- solo son trascendentes en función de lo que hacen con, desde y para otros actores sociales y económicos, antes que por y hacia sí mismos.

En cuanto a lo citado, se puede dilucidar que la gobernanza en esencia busca la interacción de los diferentes actores para la toma de decisiones que tengan como fin el bienestar de la comunidad.

Si bien es cierto el concepto de gobernanza no tiene una relación dialógica con una organización privada o emprendimiento, en su esencia, el término conlleva a desarrollar objetivos de convivencia fundamentales y coyunturales, donde lo que importa no es el gobierno en sí mismo, sino la acción de gobernar. De la misma manera, en este trabajo se pretende recoger esa esencia para trasladarla a la microgobernanza del emprendimiento, donde más que el emprendimiento en sí mismo, sea saludable para la economía, también sea trascendente su función de lo que hace, desde y para todos los actores involucrados, en este caso, de clientes, proveedores, accionistas, comunidad, entre otros.

Pues las acciones en las que los emprendimientos antes se creaban y operaban se quedan cortos frente a los nuevos desafíos a los que se enfrentan, donde no solo se debe ponderar el crecimiento de los mismos, sino que estos tienen que ver con criterios societales amplios e incluyentes, para lograr ese status de una microgobernanza del emprendimiento. Lógicamente que todo lo descrito corresponderá hacerlo en el marco institucional y organizacional correspondiente. 
Por lo tanto, en las complejidades de los conceptos anotados, se debe tener claro que el núcleo de la gestión de un determinado emprendimiento o una empresa es su gobernanza, en otras palabras, el hecho de ejercer el control y tomar las decisiones más importantes para configurar el desarrollo de la organización. Este desarrollo tiene que estar enmarcado en un criterio amplio, donde todos los actores de la actividad empresarial se activen en función de un bien común y donde los postulados del mercado se conviertan en un hecho histórico para volcarse en un nuevo tipo de actividad empresarial. Debe tener como base su Responsabilidad Social (RS) desde que nace el emprendimiento y no esperar a que se convierta en una micro o pequeña sin valores ni lineamientos de desarrollo productivo, que abarque no solo una dimensión económica, sino social y ambiental, tal como lo plantea el Objetivo 8 de los Objetivos de Desarrollo Sostenible ODS8. En esta misma dirección, A. Bárcena nos indica:

La RS está relacionada con una nueva forma de hacer negocios que apunta a conseguir aquello que se ha dado en llamar el triple resultado: tomar como marco de negocio el desarrollo sostenible, lo que significa ponderar equitativamente lo económico, lo social y lo ambiental en el proceso de toma de decisiones de la empresa (CEPAL, 2005).

En tal sentido, la dimensión económica no solo es lo importante en el marco del postcapitalismo o de la economía del conocimiento, pues en los nuevos tiempos inexorablemente tendremos que hacer algo por lo social y ambiental, ya que el mercado mal regulado por el Estado ha dejado una serie de elementos negativos, que tienen que ser observados muy detenidamente. En este punto es importante señalar que el mercado, si bien es cierto ha tenido una supremacía en el sistema económico mundial, ha convivido con la regulación del Estado, por lo que no se puede atribuir que la desigualdad y el daño ambiental son inherentes a un sistema capitalista, pues hay que tomar en consideración que el Estado siempre estuvo presente, más aún, es preciso tener claro que el mercado y el Estado son complementarios, el primero no podría sobrevivir ni cinco segundos sin el segundo (Varuofakis Yanis, 2016).

Lo descrito tiene su relevancia, puesto que el espíritu emprendedor debe funcionar, ineludiblemente, sobre la base de estos dos esquemas contrapuestos en teoría, pero en la praxis complementarios. El Estado, en el apoyo al emprendedor, debe ser de un enfoque multidimensional, 
en ámbitos ligados a la promoción de la innovación, al desarrollo del recurso humano, acceso al financiamiento y la capacitación de la mano de obra. Mientras que, por el lado del mercado, el estímulo a la producción debe atravesar a todo el tejido empresarial existente y en formación. Sin empresas grandes o medianas, sería complejo el potencial semillero de emprendedores. El ingenio de los creadores necesita de la visión empresarial del mercado para innovar y mejorar los procesos.

Es pertinente observar que el emprendedor, al ejercer su gestión, o sea, su acción de la toma de decisiones dentro de su iniciativa empresarial, no es dable que lo haga en el marco de las fuerzas del mercado, oferta y demanda, precios y ganancia, sino que esta tiene que abordarse en el marco de una responsabilidad social, puesto que, tal como se mencionó, la sociedad global transita hacia un nuevo modelo postcapitalista. En esta tesitura, es oportuno definir de antemano el término Responsabilidad Social como un mecanismo de dejar atrás a ese mercado cuya expresión ha sido el egoísmo y la falta de solidaridad, más aún cuando la infotecnología ha socavado el sistema capitalista.

La Responsabilidad Social Empresarial (RSE) es un término de vieja data. A finales del siglo XIX, por ejemplo, al constatar el escaso grado de implicación de los poderes públicos en los problemas sociales de la época, se desarrolló una serie de políticas sociales (salud, vivienda, subsidios familiares, etc.) en ciertos países europeos. El aumento de interés por la RSE es hoy superlativo en algunos países. Sin embargo, este concepto engloba acepciones similares. La Responsabilidad Social de las empresas puede ser concebida de dos maneras: la adopción de una visión a más largo plazo, compatible con el desarrollo sostenible; y el deseo de las partes implicadas en la empresa (trabajadores, clientes, inversionistas, gobierno y comunidad) de tener un comportamiento socialmente responsable.

Lo que pregona la RS es un modelo inclusivo, en que los actores anteriormente mencionados, denominados stakeholders, sean vistos como personas, ya que solo a partir de ahí se empieza por colocar a la ética y la responsabilidad como eje de una nueva forma de concebir a la empresa, y en la cual estos actores son partícipes de las bondades que puede generar un nuevo esquema de gestión de empresa. Para una apreciación más clara, la literatura ha definido de esta manera a los stakeholder:

El término stakeholder es un neologismo anglosajón que normalmente se encuentra en los términos de: interesado, de interés, o como parte interesada (International Organization 
for Standarization, ISO 26000). Los stakeholders son definidos como todas aquellas personas, grupos, empresas, comunidad y sociedad que tienen interés en la existencia y desarrollo de una empresa. Son interesados directos y/o indirectos con poder real o potencial para influir en las decisiones empresarias como por ejemplo: empleados, clientes, proveedores, accionistas/inversionistas, organismos públicos, asociaciones profesionales, grupos religiosos, comunidad, organizaciones de la sociedad civil, ONG's y el público en general (Volpentesta, 2015).

Es importante subrayar que la relación con los stakeholders deriva después de una relación de confianza, en ciertas sugerencias y demandas a tener en cuenta en la elaboración de los objetivos, políticas y estrategias de la empresa, tema que tiene que ser ampliado a los emprendimientos y no solo a las empresas formadas. De esta manera, el emprendimiento puede ser exitoso y en el futuro se organizará mejor para crecer, y enfrentará los desafíos asociados de una mejor manera.

Por tal motivo, el emprendimiento debe abordar desde su estado de formación temas que incluyan a los stakeholders. Al considerar esto, implica de manera ineludible un nuevo tipo de gerenciamiento, así como el feudalismo se estructuró por la obligación de servir a la burguesía y el capitalismo por el mercado, es viable que el postcapitalismo se estructure mediante la responsabilidad social, caso contrario, la desigualdad se agravará y la pobreza se radicalizará.

Cabe mencionar que es peligroso que en una economía postcapitalista, como la que se ha venido describiendo de a poco, los países o inversionistas que sepan atraer a los mejores actores de la economía digital puedan ser parte de la cadena de valor y tengan como objetivo incrementar su riqueza, mientras que los otros se quedarán viendo y les llegará una migaja, por lo que las brechas de desigualdad serán más evidentes. Sobre este aspecto, T. Piketty sostiene que:

El progreso tecnológico depende del ritmo de los inventos y de su puesta en práctica, lo que conduce a una demanda de calificaciones cada vez más fuerte. De ahí, la idea de una carrera o persecución entre educación y tecnología (y entre grupos sociales): si la oferta de calificaciones no crece al mismo ritmo que las necesidades de la tecnología, los grupos cuya formación educativa no creció lo suficiente reciben bajos salarios y obtienen empleos desvalorizados y la desigualdad respecto al trabajo crece aún más (Piketty, 2015). 
Lo que nos recuerda este autor es que la tecnología, paradójicamente, amenaza con forjar formas nuevas de exclusión.

\section{LA IMPORTANCIA DE LOS EMPRENDIMIENTOS DENTRO DE LOS ODS8}

Un emprendimiento bien direccionado, que implique creación de valor agregado, innovación y conocimiento, contribuye al crecimiento y desarrollo de un país y, por ende, a la creación de empleo de calidad, el éxito personal, además de una repercusión positiva en el mercado al producir beneficios. Estudios coinciden que las tasas de emprendimiento se han incrementado notablemente en los últimos años. De manera paralela, también ha aumentado el interés de organismos nacionales e internacionales - Banco Mundial, Corporación Andina de Fomentopor las complejidades del dinamismo que representa este segmento productivo en la sociedad y de la economía en su conjunto.

En este contexto, por la posibilidad de aportar al desarrollo económico y productivo y a la creación de empleo de calidad, a los emprendimientos se los ha colocado como un aspecto clave dentro del Objetivo 8 de los Objetivos de Desarrollo Sostenible.

\section{EL EMPRENDIMIENTO EN AMÉRICA LATINA Y ECUADOR}

Los emprendimientos marcan una complejidad de connotados efectos. Este tipo de iniciativas en América Latina y Ecuador no es ajeno a esta realidad, pero contrastan con las de los países desarrollados, en el sentido de que la mayor parte de los emprendimientos son por subsistencia y no por oportunidad, pues mientras en nuestra región se crean un alto número de negocios pequeños informales con muy bajo nivel de productividad, en los países industrializados es todo lo contrario, donde las iniciativas emprendedoras florecen al rigor de la educación que poseen y al marco institucional que las regula. La informalidad, como la falta de un emprendimiento sostenible y productivo, es evidente y recurrente en Ecuador y América Latina. Tanto es así, que el país mantiene una estructura dual y heterogénea (Colegio de Economistas, 2015), por un lado un mayor número de micros y pequeñas empresas $-99 \%$ del total $-\mathrm{y}$, por otro, grandes empresas que solo representan el $1 \%$ (INEC, 2010). 
La innovación y el emprendimiento deben ser actividades íntimamente relacionadas, pues no se puede hablar de emprendimiento sin mencionar la innovación. Al respecto, un informe titulado «Emprendimientos en América Latina desde la subsistencia a la transformación productiva», de la Corporación Andina de Fomento CAF (2013), menciona: «El proceso de innovación y creación de nuevos productos y mercados es liderado por emprendedores capaces de visualizar nuevas demandas» (p. 1).

Afianzando esta idea, en otro estudio del Banco Mundial se asevera que «es importante construir una clase emprendedora e innovadora en América Latina, de tal manera que puedan ser competitiva en el orden internacional, ya que al haber innovación, esta creará valor agregado y la economía será más competitiva» (Banco Mundial, 2014).

En Ecuador, si bien es cierto la Actividad Emprendedora Temprana en 2016 es la más alta de Latinoamérica (31,8\%), solo un $22 \%$ de los emprendimientos ha logrado transformarse en un negocio naciente (hasta tres meses de operaciones), el $11 \%$ en un negocio nuevo (tres y 42 meses) y 4,4\% en un negocio establecido (con más de tres años) (Global Entrepreneurship Monitor Ecuador, 2016). Asimismo, la mayoría de negocios son dedicados a los consumidores y no a la creación de valor agregado o transformación. Por lo descrito, se puede esclarecer que tal como está estructurada la consecución de establecer un negocio, denota una situación por resolver, pues los emprendimientos no son sustentables en el tiempo y no se incorporan a un sistema productivo.

Después de un período de bonanza en el Ecuador durante 20032014, cuando mejoraron los indicadores sociales, basados en los altos ingresos petroleros, tributarios y mayor endeudamiento, en la actualidad se hace necesario sostener lo que se ha alcanzado, pero el país tendrá que recurrir a sus propios medios y mejorar los niveles de productividad, pero la única forma de hacerlo es combinar el capital humano y físico que posee para maximizar la producción de bienes y servicios.

Sin embargo, ¿quiénes son los que podrían contribuir al crecimiento económico con una mayor productividad acorde a los Objetivos de Desarrollo Sostenible planteados por las Naciones Unidas? Pues son los denominados emprendedores; según indica el estudio «El emprendimiento en América Latina. Muchas empresas y poca innovación», del Banco Mundial (2015), el emprendedor es:

Un motor fundamental del crecimiento y desarrollo. Por lo que se puede inferir que los emprendedores no son una mera 
casualidad, sino son actores importantes del desarrollo. Estos juegan un papel crucial en la trasformación de las sociedades de ingresos bajos caracterizadas por la productividad (Banco Mundial, 2014).

El emprendimiento innovador, que es aquel que va a generar mayor productividad y por ende potencializará la generación de empleos, estará sometido en el tiempo al fracaso o al éxito del mismo. El estado en el que se pueda encontrar el emprendedor no va a depender solamente de su personalidad, su impetuosidad, su preparación, etc., sino que va a responder a ciertos factores que influirán en su nivel de productividad: la tecnología, el acceso a mercados y la gestión de su administración.

Hasta la década de 1990 del siglo pasado se creía que los postulados del crecimiento se basaban en la acumulación del capital, tal como lo sostenían los economistas clásicos, sin embargo, ese lineamiento explicaba solo en parte el crecimiento de las naciones, pues ahora es muy importante el progreso tecnológico. La tecnología de la información no es una dimensión más que nos llegó por azar y que dejaremos luego atrás sin más, como la máquina de vapor, sino que imbuye toda innovación futura de la dinámica: la biotecnología, los viajes espaciales, la reconfiguración cerebral, las nanotecnologías u otras muchas cosas que ni siquiera podemos imaginar aún. Hoy la innovación, tal como se lo manifestó en un párrafo anterior, se integra, a través de la tecnología, a la teoría del crecimiento económico. A decir del autor español Manuel Guisado (2013):

El mundo actualmente se encuentra inmerso en el núcleo de un proceso de cambio tecnológico muy profundo, dimanante de las pequeñas y persistentes innovaciones que se han venido produciendo a lo largo de las décadas precedentes, lo que ha dado lugar a una profunda e intensa revolución técnica económica (Guisado, 2009).

En contraposición a estos planteamientos idóneos para alcanzar un mayor crecimiento y mejor desarrollo acorde al ODS8 en América Latina, Ecuador no es la excepción, donde los emprendimientos son de subsistencia y de bajos niveles de productividad, lo que se ve reflejado en la estructura productiva, pues no se han desarrollado en la órbita del avance tecnológico. Predominan una mayor cantidad de micros, pequeñas y medianas empresas, que por lo general son de baja productividad. No obstante, según el Global Entrepreneurship Monitor 
Ecuador 2015, estudio realizado por la escuela Politécnica del Litoral ESPOL, en Ecuador, «a una escala reducida, comienzan a destacar emprendedores tecnológicos e innovadores cuyos negocios no solamente se orientan al mercado doméstico sino que están atendiendo mercados externos» (ESPOL, 2015).

En cuanto al acceso a mercados, otra condicionante del emprendimiento estará enmarcado en la capacidad que tenga de insertarse en el comercio mundial e internacionalizar su empresa. Pero estos elementos van a estar supeditados a la vez por los diferenciales de productividad que tenga la empresa o simplemente al alineamiento de una doctrina ideológica. Por lo general, economías menos dinámicas han promovido un proteccionismo, tal como ha sucedido en el Ecuador, movidos por la lógica de defender sus aparatos productivos y consiguientemente el empleo, pero no toman en consideración que la mayor integración comercial, como consecuencia de la evolución de la tecnología, ha facilitado una intensa fragmentación de los sistemas productivos. En las actuales circunstancias, una empresa exporta sus productos incorporando mercancías importadas.

El proteccionismo en Ecuador se enfocó precisamente en la necesidad de volver a un modelo parecido al de sustitución de importaciones, aplicado por la CEPAL en la década del 60 y 70 en la región como una nueva estrategia para el desarrollo, para lo cual fue vital el fortalecimiento de la industria nacional para el cambio de la matriz productiva.

Las políticas públicas en nuestro país, por el exceso de proteccionismo, no tuvieron un resultado tan aceptable, no estuvo claro el rol complementario del gobierno y del sector privado estos últimos años, que hubiese permitido desarrollar la producción y dinamizar el empleo. No se hizo hincapié en la necesidad de elevar la competitividad, ni en lo beneficioso de aprovechar las nuevas corrientes comerciales, en contraparte, se adoptó un enfoque hacia el mercado interno.

En un modelo proteccionista, la empresa no es sometida a la competencia. El Estado restringe las importaciones a pretexto de protegerla, pero no toma en cuenta que la competencia estimula en buena medida la innovación (Stiglitz, 2000). Al respecto, el nobel Jean Tirole es muy enfático al señalar que: «El Estado como árbitro de mercados, vela por la competencia, es garante de la innovación y de que los productos sean accesibles al consumidor» (Tirole, 2017). Como la innovación está estrechamente vinculada al emprendimiento, este va a depender de la calidad del entorno en el que se crea la empresa, por lo que el Estado 
debe ejerce una regulación inteligente, a decir de Tirole, «limitando el impacto negativo de la intervención sobre la innovación y la creatividad».

En lo que se refiere a la gestión del emprendedor, se verá reflejado en el nacimiento de una empresa y que a través del tiempo pueda ser sostenible, es decir, que podría convertirse en una micro, pequeña, mediana o gran empresa. Por ejemplo, en América Latina, Ecuador no es ajeno a esta realidad: la actividad emprendedora está marcada por la distribución de las empresas por su tamaño y en la región predominan las micros y pequeñas empresas informales y de baja productividad (CAF, 2013).

La heterogeneidad de la estructura productiva condiciona el mercado laboral. Un estudio de la CEPAL señala que: "Las estructuras productivas moldean las estructuras sociales y a la vez son moldeadas por ellas. Las características de los mercados laborales dependerán de la estructura productiva» (CEPAL, 2014). Esta apreciación puede ser relacionada específicamente con la precariedad del mercado laboral y el alto grado de informalidad que caracteriza al empleo en el Ecuador, donde casi el $60 \%$ de la mano de obra se encuentra desempleada o en el sector informal.

Es indudable que estos indicadores han llevado al Ecuador a poseer la tasa más alta de emprendimientos en el mundo y en Latinoamérica. Pero el hecho es que los emprendimientos no son sostenibles en el tiempo.

Diversos estudios han señalado que los motivos son variados, desde la falta de financiamiento hasta temas relacionados con la capacitación. Pero la evidencia empírica, si bien demuestra los aspectos ya mencionados, también es cierto que tiene que ver con una gobernanza que se direccione a sostener y fortalecer los pequeños emprendimientos, lo que se denominaría una microgobernanza que surja desde la esfera pública, encaminada justamente a darles a los emprendimientos en el Ecuador la debida importancia, no solo estimulando la actividad de manera aislada, sino direccionándola como una política de Estado, evaluando y monitoreando esta actividad por la cantidad de empleo que pueda generar, articulándola debidamente con los actores involucrados, en este caso los emprendedores, los institutos superiores de educación pública, la banca estatal y los promotores inmobiliarios.

Para ello, se necesita una microgobernanza que trascienda a estos aspectos. Si bien es cierto en el país, se han venido dando leyes para el apoyo a las micro, pequeñas y medianas empresas a través de diferentes leyes, como el Código Orgánico de la Producción, Comercio e Inversión 
y la Ley de la Economía Solidaria. En lo que se refiere a los emprendimientos, el gobierno ha impulsado programas, no obstante, no se han consolidado en un número significativo, puesto que el entorno macroeconómico e institucional y la falta de una buena educación superior no lo han permitido. El país sigue un círculo vicioso, de marcada heterogeneidad estructural, baja productividad, empleo precario, pobreza y desigualdad social, dificultades que no se han podido superar y que representan una tarea pendiente, por lo que se formularán lineamientos que ayuden a formular soluciones desde la perspectiva de una microgobernanza inteligente.

Sobre las circunstancias descritas, también hay que reconocer que la actividad emprendedora va a estar condicionada a aspectos claves como el entorno macroeconómico e institucional en el que se crean las empresas, puesto que la sostenibilidad de un emprendimiento depende sobremanera de estas dimensiones. Las instituciones influyen en el comportamiento y los incentivos en la vida real forjan el éxito o el fracaso de los países. El talento individual importa en todos los niveles de la sociedad, pero incluso este factor requiere un marco institucional para transformarse en una fuerza positiva. Ante estas eventualidades, se deberían establecer estrategias de microgobernanza, que redunden en la creación, impulso y fortalecimiento de emprendimientos, acorde al Objetivo 8 de los Objetivos de Desarrollo Sostenible. Para ello, es importante incorporar a las políticas públicas mecanismos que conlleven al afianzamiento de los emprendimientos, por medio de un apoyo a los gestores de los negocios en áreas administrativas, innovación, investigación, financiamiento, entre otros.

Por ejemplo, el fundador de Microsoft, Bill Gates, al igual que otras figuras legendarias, tenía una ambición y un talento intrínsecos, pero, en última instancia, respondía a incentivos. El sistema escolar estadounidense permitió que Gates y otros como él adquirieran un conjunto único de habilidades con las que complementar sus talentos. Las instituciones de este país permitieron que estos hombres crearan empresas con facilidad, sin enfrentarse a obstáculos infranqueables. El mercado laboral estadounidense les permitió contratar personal cualificado y el entorno de mercado relativamente competitivo posibilitó que ampliaran sus empresas y comercializaran sus productos. 


\section{DÉFICIT INNOVADOR DEL EMPRENDIMIENTO EN AMÉRICA LATINA}

El informe del Banco Mundial «Emprendimientos en América Latina» respecto al déficit innovador es determinante:

Las empresas de América Latina introducen productos nuevos con menos frecuencia que las empresas de otras economías similares, la gestión de los emprendedores de gama alta suele estar lejos de las mejores prácticas en el ámbito global, las empresas invierten poco en I + D y la actividad en materia de patentes está claramente por debajo de los niveles de referencia (Banco Mundial, 2014).

Las brechas de gestión se deben principalmente a las características de las empresas. En economías más avanzadas, los trabajadores poseen estudios universitarios, en contraste con las de América Latina, que por lo general son emprendimientos de baja productividad.

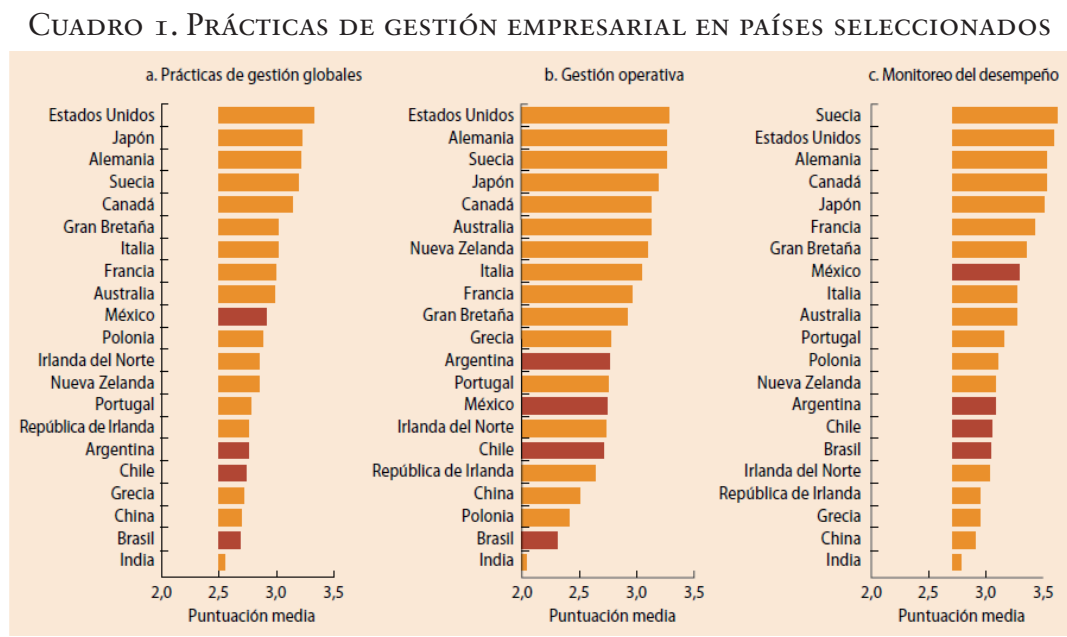

Fuente: Banco Mundial, Emprendimientos en América Latina.

Si se analiza el cuadro, las economías más eficientes del mundo precisan mejores prácticas de gestión en relación con algunos países de Latinoamérica. Estos últimos, según el estudio del Banco Mundial, tienen modelos de gestión más parecidos a los de China e India, lo cual refleja una brecha de gestión con relación a los países de ingresos altos, que es una desventaja competitiva.

Finalmente, un aspecto que no se debe dejar de analizar y que es de gran importancia es lo relativo a la internacionalización, en este 
aspecto, la capacidad de exportación de las pymes Latinoamericanas solo alcanza la mitad de los niveles registrados en Europa y son un tercio menores que las observadas en cuatro países de Asia oriental (OCDE-CEPAL, 2013).

\section{CONCLUSIONES Y RECOMENDACIONES}

Ecuador es el país con la más alta tasa de emprendimiento en América Latina. Surgen como necesidad y en su mayor parte no se consolidan en el tiempo, por lo que se hace necesario establecer estrategias tendientes a fortalecer la gestión de estas iniciativas, a fin de que se consoliden en el mercado interno y externo e incorporen suficiente cantidad de mano de obra de trabajo formal con salarios dignos, acorde a los postulados de los ODS8. Una política de apoyo al entorno del emprendimiento innovador es clave para mejorar la productividad del conjunto de la economía.

Poseer la tasa de emprendimiento más alta de la región no es motivo de orgullo para el Ecuador. La mayoría de los emprendimientos son por necesidad, puesto que existen altas tasas de subempleo que pasan a formar parte de una economía informal, que en poco contribuye a un desarrollo económico sostenido y, por ende, a los Objetivos de Desarrollo Sostenible. Por ser emprendimientos por necesidad, en su mayoría no aportan valor agregado. La Agenda de los Objetivos de Desarrollo Sostenible, dentro del Objetivo 8 asigna un papel destacado al desarrollo de los emprendimientos, al incluir metas como el impulso al empleo y la innovación.

Si nuestro país busca que el emprendimiento sea un puntal para el crecimiento y desarrollo, se requiere, en primer lugar, que desde Estado se generen condiciones para que el emprendimiento sea competitivo y logre un cierto grado de internacionalización.

Con la aplicación de una microgobernanza inteligente, los emprendimientos se convertirán en núcleos centrales de un crecimiento económico sostenido sobre la base de la productividad y no de la mayor intervención del Estado.

Un emprendimiento tiene que ser innovador por excelencia para crecer e incluso para sobrevivir.

El emprendedor no solo debe aprovechar las tendencias del siglo XXI en tecnología, sino también debe enfocarse en la productividad, lograr una relación favorable entre producción e insumos. La 
productividad supone efectividad y eficiencia, es decir, alcanzar objetivos y utilizar la menor cantidad de recursos.

El capitalismo se está transformando en algo cualitativamente diferente. Hoy es natural hablar de la economía del conocimiento, la sociedad de la información, el capitalismo cognitivo.

¿Cómo lograr el desarrollo del Ecuador? Pues con sostenibilidad económica: competitividad, innovación e internacionalización.

Una buena organización debe proponer todo un abanico de modos de gobernanza para que la estructura de la empresa pueda adaptarse a los retos que le plantea su contexto.

Por el hecho de que la empresa implica inversores, clientes, directivos, asalariados, necesariamente se asocia a una visión de estrategia sostenible.

\section{BiBLIOGRAFÍA}

Banco Mundial (2014). El emprendimiento en América Latina muchas empresas y poca innovación. Washington.

Banco Mundial (2017). World Development Report.

CAF (2013). Emprendimientos en América Latina desde la subsistencia a la transformación productiva. Bogotá.

CEPAL (2014). Pactos para la igualdad. Santiago de Chile.

CEPAL-DEVELOPMENTE CENTER-OCDE GTZ (2005). Gobernabilidad corporativa responsabilidad social y estrategias empresariales en América Latina. Bogotá.

Colegio de Economistas (2015). Cambio de la matriz productiva. QuitoEcuador: Edarsi.

ESPOL (2015). Global Entrepreneurship 2015. Guayaquil.

Global Entrepreneurship Monitor Ecuador (2016). Guayaquil-Ecuador.

Guisado M. (2009). Internacionalización de la empresa. Madrid: Pirámide. https://thegedi.org/countries/Ecuador. (26 de 6 de 2018). Global Entrepreneurship and Development Index.

INEC (2010). Censo económico. Quito-Ecuador.

Katz, R. (2018). Capital humano para la transformación digital en América Latina. Santiago de Chile.

Langyel, M. (2011). Innovación productiva desarrollo y gobernanza. América Latina y Caribe perspectivas de desarrollo y coincidencias para la transformación del Estado, (pp. 114). Flacso.

Mason, P. (2016). Postcapitalismo hacia un nuevo futuro. Buenos Aires: Paidós.

Naciones Unidas (2015). Objetivos de Desarrollo Sostenible. 
OCDE-CEPAL (2013). Perspectivas económicas de América Latina políticas de PYMES para el cambio estructural. Santiago de Chile.

Piketty, T. (2015). El capital en el siglo XXI. Fondo de Cultura Económica. Prats, Joan (2005). De la burocracia al management. Instituto de Cataluña. Samuelson, P. (2010). Economía. México: McGraw Hill.

(2010). Economía con aplicaciones a Latinoamérica. México: Mcgraw Hill.

Smith, A. (1776). La riqueza de las naciones. Madrid: Alianza Editorial.

Stiglitz, J. (2012). El precio de la desigualdad. Madrid: Prisa. (2000). Economía del sector. Barcelona: Antoni Bosh.

Tirole, J. (2017). La economía del bien común. Bogotá: Taurus-Penguin Random House.

Varuofakis, Y. (2016). Un plan para Europa. Bogotá: Icaria.

Volpentesta, R. (2015). Procedimientos administrativos en la gestión de los stakeholders. 



\title{
CAlidad DE Vida Y Responsabilidad SOCIAL EN NIÑOS INDÍGENAS MEXICANOS: CONDUCTA PROAMBIENTAL"
}

\author{
Santa Magdalena Mercado Ibarra"." \\ María Teresa Fernández Nistal ${ }^{* * *}$ \\ Joanna Mariby Cota Beltrán"**** \\ México
}

\section{INTRODUCCIÓN}

Según el Diario Oficial de la Secretaría de Medio Ambiente y Recursos Naturales (2009), en el territorio mexicano se cuenta con la presencia de población indígena en cada una de las entidades federativas, y el 90\% se encuentra ubicada en regiones biogeográficas ricas en flora y fauna, tanto del trópico húmedo, trópico seco, zonas templadas, desierto y semidesierto, que han favorecido al desarrollo de las culturas indígenas. Estas, al pertenecer a grupos minoritarios, carecen de una participación equitativa, lo cual ha provocado que sean hostigadas y tratadas de forma injusta; en adición a esto, han tenido que lidiar con una alta tasa de deterioro ambiental a lo largo de los años por el mal manejo de los recursos naturales que poseen. Como una alternativa de solución se propone analizar los lineamientos políticos para tener un acceso y control más eficientes, a fin de obtener un mejor aprovechamiento de los recursos naturales, brindar un apoyo a la población indígena para que se conozca el manejo sustentable de los recursos

Financiamiento con recursos PFCE 2018

* Doctora en Planeación Estratégica para la mejora del desempeño, Instituto Tecnológico de Sonora. Correo electrónico: mmercado@itson.edu.mx

*.* Doctora en Psicología, Universidad de Barcelona. Correo electrónico: mfernandez@itson.edu.mx

Investigadora, Instituto Tecnológico de Sonora. Correo electrónico: mariby. cobe@hotmail.com 
naturales y ecosistemas de sus territorios, promoviendo su participación en la gestión ambiental.

La Declaración de las Naciones Unidas sobre los Derechos de los Pueblos Indígenas (2007) resalta el artículo 29, que establece que tienen derecho a la conservación y protección del medioambiente y la capacidad productiva de sus tierras o territorios y recursos, por lo que los Estados deberán desarrollar programas de asistencia a los pueblos indígenas para asegurar esa conservación y protección. No obstante la lucha de los indígenas por mantener sus recursos y aprovecharlos de forma sustentable, siguen perdiendo sus territorios y su biodiversidad por el uso destructivo que se les da.

Por ejemplo, uno de los recursos naturales de mayor importancia es el agua, la que es un derecho universal. Para Mazabel y Mendoza (2012), los pueblos indígenas en México poseen sus propias normas acerca del agua y su manejo, incluye ritos, conocimiento sistemas de organización social, prácticas y símbolos. Según la Organización de las Naciones Unidas para la Educación, la Ciencia y la Cultura (UNESCO, 2003), algunas comunidades indígenas, dadas sus creencias espirituales y naturales, forman un vínculo entre el agua, el hombre y los animales. Debido a esto, muchas de las comunidades indígenas han tenido la necesidad de defender este recurso frente a instancias gubernamentales que no toman como prioridad sus derechos, con la finalidad de poder sostener sus costumbres y forma de vida. De forma general, se puede decir que las comunidades indígenas poseen valores espirituales frente al agua desde una perspectiva diferente que otro tipo de comunidades.

Peña (2004) plantea que el aprovechamiento del agua que se rige en México va de acuerdo al artículo 27 constitucional y su ley reglamentaria sobre aguas nacionales, puesta en vigor en el año 1992, la cual señala que la Comisión Nacional del Agua puede ejercer autoridad y administración de los recursos hídricos en el país. Esta forma de concentrar los recursos ha afectado de manera directa el derecho de los pueblos indígenas en el aprovechamiento de lagunas, ríos y manantiales, por ende, alteró la forma de vida de estas comunidades. No obstante los derechos que las comunidades indígenas poseen, para algunas de ellas resulta difícil poder ejercer su derecho al agua potable y otros servicios de este tipo; es decir, muchas de las comunidades sufren carencias ante el uso humano del agua, siendo este un derecho fundamental. En el año 2000, un $42 \%$ de las viviendas indígenas no contaban con agua entubada y un $70 \%$ no podía 
acceder a servicios de saneamiento, lo cual ocasionó el resurgimiento de enfermedades como cólera y tifoidea en estas regiones.

Para poder respetar los derechos de los indígenas, no solo del agua sino de los recursos naturales, se debe trabajar en tres direcciones: primero se debe establecer un marco jurídico que se comprometa a reconocer de manera plena estos derechos, después trabajar en la inclusión de representantes indígenas en la toma de decisiones en cuanto a la gestión del agua y, por último, trabajar en una coalición social que ayude a expandir la voz de todos aquellos ciudadanos que al igual que los indígenas se encuentran desfavorecidos (Peña, 2004).

\section{SER SOCIALMENTE RESPONSABLE}

Lo anteriormente expuesto se relaciona con ser socialmente responsable, puesto que se debe ser consciente del daño que nuestros actos pueden ocasionar a cualquier individuo o grupo social, hacia su entorno físico y social (Schwald, 2004). Las concepciones en torno a la Responsabilidad Social han pasado desde un compromiso exclusivamente económico, que implica hablar de beneficio máximo alcanzado por la oferta de bienes y servicios, hasta la visión donde se asume una responsabilidad frente a la sociedad, entre ello y de gran relevancia la promoción del cuidado del medioambiente (Cabrera, 2006).

Responsabilidad Social es una filosofía que tiene como pilares fundamentales valores éticos y morales, cuya principal incidencia se manifiesta en nuestros actos y de qué manera estos pueden afectar o dañar a otra persona o a un determinado entorno social (Mori, 2009).

Se debe tener cuidado en organizar acciones de Responsabilidad Social orientadas bajo la percepción del voluntariado o la filantropía porque no es sostenible en el tiempo, es discutible en sus impactos, de poca relación con la organización misma, y siempre interpretable de distintos modos en cuanto a las reales intenciones que la animan. Los elementos voluntaristas pueden ser pasajeros, directivos y temporales, lo que imposibilitaría el acceso al bienestar comunal que debe ser trabajado en un proceso de fortalecimiento continuo, por lo que aun cuando objetivamente las carencias existen, mientras no sean percibidas psicológicamente y no se produzca el deseo de satisfacerlas, los programas no producirán efectos esperados en la comunidad (Cantera, 2004).

Una alternativa destacada es la psicología comunitaria, que aborda el fenómeno de la participación como una acción socializadora y 
concientizadora que transmite, comparte y modifica patrones de conducta, es la suma de todas las participaciones, tanto de los miembros de la comunidad, con un beneficio en el crecimiento personal. Este principio asume que ninguna mejora, beneficio o cambio social es efectivo si no cuenta con la participación de los involucrados, desde el diseño del proyecto, hasta la implementación y evaluación de las acciones. Montero (2004) argumenta que la participación comunitaria tiene un efecto en el sentido de que es formativa, y de que desarrolla y fortalece a la sociedad civil, y por ende, aumenta la Responsabilidad Social.

Además de la importancia de la participación, se debe fomentar el compromiso. Strucas y Dunalp (2002) consideran que esto puede ayudar a establecer fuertes lazos entre las comunidades y la institución que residen en ellas, al generar ayuda y respaldo para la satisfacción de necesidades y al facilitar la interacción entre los miembros de la comunidad. Martínez (2008) considera que el trabajo comunitario no es solo para la comunidad, ni en la comunidad, ni siquiera con la comunidad, es un proceso de transformación desde la comunidad, soñado, planificado, conducido, ejecutado y evaluado por la propia comunidad.

En este sentido, los proyectos enmarcados en medioambiente, salud, educación, servicios básicos, nutrición o derechos humanos, además de mejorar el bienestar y calidad de vida, elevarían la sensación de control sobre sus vidas; comprensión crítica del medioambiente; participación y compromiso; unión de fortalezas y competencias individuales, y genera conciencia de causas y razones de lo que se quiere hacer (Mori, 2009). El Artículo XIII de la Comisión Interamericana de Derechos Humanos versa sobre el derecho a la protección del medioambiente y se plantea que los pueblos indígenas tienen derecho a un medioambiente seguro y sano, condición esencial para el goce del derecho a la vida y el bienestar colectivo (González, 2008).

Actualmente, el medioambiente, así como el cuidado de este, han sido de preocupación mundial, nacional y estatal; esto debido al gran deterioro ambiental que hemos provocado, manifestándose con daños desde muertes en especies, personas, así como dejando consecuencias perjudiciales de carácter permanente en suelos, agua, aire, entre otros. Según Contreras (2007), solo el $23 \%$ de la población mundial, que son los países industrializados, consumen el $80 \%$ de la producción mundial de energía comercial, el $79 \%$ del acero, el $85 \%$ del papel y el $86 \%$ de los metales no ferrosos. Destaca que se aceleran los procesos de concentración urbana, particularmente en los países del sur, donde el $90 \%$ 
del crecimiento poblacional tendrá un carácter urbano. La población urbana mundial pasará de 2.000 millones en 1985 a 5.100 millones en el 2025. Los límites de los recursos naturales (petróleo, madera, minerales, biodiversidad, etc.) indican que el actual modo de vida es insostenible. El consumo en constante expansión somete a tensión al medioambiente, con emisiones y derroches que contaminan la tierra y destruyen los ecosistemas. Se produce un agotamiento y la degradación en aumento de los recursos: la quema de combustibles fósiles se ha casi quintuplicado desde 1950; el consumo de agua dulce se ha casi duplicado desde 1960; la captura marina se ha cuadruplicado; el consumo de madera es ahora $40 \%$ superior a lo que era hace veinticinco años. Entre 1960 y 1998, mientras la población mundial se ha duplicado, las emisiones de $\mathrm{CO} 2$ lo han hecho por tres, el consumo de fertilizantes por cinco y la producción de energía por seis. Además, este nivel de consumo no repercute sólo en la naturaleza, sino también en la mayor parte de las personas.

En 2014, la Secretaría de Medio Ambiente y Recursos Naturales calificó como el peor desastre ambiental de la industria minera del país a la catástrofe ocasionada por la mina más grande del país, "Grupo México» en Cananea, Sonora, donde se derramaron cuarenta mil metros cúbicos de ácido sulfúrico en los ríos de Bacanuchi y Sonora (México), afectando a veinticuatro mil personas en seis municipios. En Cajeme, Sonora, las grandes empresas, así como los químicos que se producen en los campos agrícolas del valle del Yaqui, son algunas de las causas que elevan los índices de contaminación, y con ello hay un incremento de enfermedades entre sus habitantes, como por ejemplo, el cáncer (Lira y Millán, 2014).

\section{MARCO CONCEPTUAL}

Ante esta situación, ¿qué hacer?, ¿cómo hacer conciencia, por dónde empezar? La promoción del cuidado del medioambiente es una alternativa a la cual se debe de apostar. El niño en su desarrollo es influido y modifica su conducta en relación con su medio, relación que no se da en un grupo específico de edad, sino que se presenta a lo largo de su desarrollo y más allá de este periodo. En los niveles básicos (primaria) es más sencillo influir en el cambio comportamental de los niños, ya que tienen menos historia que incida en sus hábitos ya establecidos (Papalia, 2017). 
La educación es hoy por hoy la mejor forma de propiciar el tipo de pensamiento que se necesita para la responsabilidad ambiental e individual, e involucra a los centros de enseñanza por la responsabilidad que tienen de sentar las bases para formar personas comprometidas, éticas, responsables con el desarrollo de su comunidad, de su país y del mundo en general (Vélez y Cano, 2016).

Fraijo (2001) menciona un incremento en las creencias antiecológicas, lo que habla de las necesidades de propiciar a través de instrucción el cambio en esa visión; así como la importancia del desarrollo de programas de intervención basados en competencias de cuidado, que promuevan las conductas proambientales, contribuyendo a la formación de individuos conscientes de las necesidades que demanda el medioambiente, conocedores del problema, hábiles y motivados a resolverlos. Además, al estar trabajando con niños, y si se logra un cambio de actitud favorable en la población seleccionada, dicha educación trascenderá a sus hogares, logrando hábitos en pro del medioambiente. Al mismo tiempo, se obtendrán beneficios como la optimización de los recursos naturales, ya que se pretende generar valores y actitudes que van a aplicarse en el cuidado del ambiente.

Algunos estudios acerca de la formación de roles sexuales sugieren que las niñas adoptan desde muy temprano una percepción racional y comunitaria del mundo, mientras que los niños tienden a objetividad y controlar su ambiente, autodefiniéndose como entidades separadas de la naturaleza (Horrigan, 1989; Keller, 1985, citado por Velázquez, 2006); otros estudios reportan que las mujeres tienden a expresar mayores niveles de preocupación sobre los problemas ambientales, en comparación con los hombres (Nelkin, 1981; Slovic, 1992, citado por Sánchez, 2011).

Por su parte, respecto al conocimiento indígena sobre el medioambiente en Venezuela por Cebrián (2010), se encontró que los grupos indígenas, sobre todo los maestros, destacan la extinción de los animales, argumentando que la caza es uno de los factores de mayor relevancia en dicho acontecimiento.

Un trabajo desarrollado sobre educación ambiental en niños indígenas de Tabasco, México, tras aplicar programas de intervención bajo metodologías participativas, arrojó resultados positivos, en pro del cambio, y consolidación de una serie de valores y actitudes ambientales (Sánchez, 2011). 
En una investigación realizada por Mireles (2007) en el sur de Sonora, México, se encontró que los niños presentan una mayor adherencia a la postura de cuidado armonioso de la naturaleza, en contra de la postura de dominio y uso arbitrario de los recursos naturales, así mismo, se descubrieron datos con relaciones altamente significativas en variables como la percepción de los niños hacia el desastre natural (si los humanos se meten con la naturaleza siendo esto desastroso), así como abuso (si los humanos abusan de la naturaleza), donde la población sonorense considera de gran relevancia dicha situación.

\section{Овjetivo}

Bajo el contexto previo, el objetivo de este trabajo es evaluar las conductas en pro del cuidado del medioambiente de niños indígenas del sur de Sonora, México, con el fin de delinear estrategias de intervención que sean socialmente responsables y contribuir al bienestar personal y social.

\section{PuEblos INDÍGENAS Y MEDIOAMBIENTE}

Zurita (2015), en el comunicado de factores causantes de la degradación ambiental, argumenta que en América Latina se emiten diariamente cuarenta y un mil toneladas de residuos industriales peligrosos, sin que existan instalaciones adecuadas para recibir estos productores corrosivos, reactivos tóxicos e inflamables, provocando la generación de cáncer, múltiples enfermedades de piel, así como mutogénicos. Así mismo, México ocupa el cuarto lugar de deforestación en Latinoamérica, con un porcentaje anual del 1,3\%, según Cantú (2008).

Respecto al agua, se estima que cada día, muchas personas mueren como resultados de malos manejos en su tratamiento. Dos terceras partes de la población mundial carece de agua potable. En la mayor parte del mundo, el agua ha sido sobreutilizada; desechos industriales, basura y desperdicios agrícolas corren diariamente por los ríos y lagos envenenando las fuentes de agua. Complicándose un 19\% más en lugares donde las fuentes de agua son compartidas por dos o más países, por ejemplo, México y Estados Únicos, Guatemala y Belice (INEGI, 2015).

La herencia cultural y lingüística de los pueblos indígenas contribuye a la diversidad del mundo. Sus conocimientos y prácticas han 
mejorado el respeto por el medioambiente y los recursos naturales de las comunidades, seguridad alimentaria, salud y educación del mundo. El conocimiento de medicinas tradicionales de los pueblos indígenas, por ejemplo, ha contribuido enormemente a la protección no solo de la salud, sino de la flora y fauna tanto de los pueblos indígenas como de los no indígenas.

Por su parte, la DNUDPI (Declaración de las Naciones Unidas sobre los Derechos de los Pueblo Indígenas) manifiesta en el artículo 29: conservación y protección del medio ambiente, tierras y recursos, que los pueblos indígenas tienen derecho a que se proteja su medio ambiente, los gobiernos deben respetar y proteger el derecho de los pueblos indígenas a desarrollar y proteger sus tierras, aguas y otros recursos naturales, así mismo que debe haber un consentimiento previo e informado en caso de tirar algún material en sus tierras (UNICEF, 2013).

La preocupación por la conservación y protección del medioambiente se ha incorporado de manera general en los textos nacionales e internacionales más recientes. A nivel internacional, en el preámbulo del Convenio 169 de la OIT se hace una breve referencia a la importancia de este elemento para los pueblos indígenas, al reconocer la "particular contribución de los pueblos indígenas y tribales a la diversidad cultural, a la armonía social y ecológica de la humanidad y a la cooperación y comprensión internacionales» (Gaona, 2013, p. 144).

Según la Organización de las Naciones Unidas (2014), en el informe de las condiciones de vida de niños indígenas, en América Latina algunos países actualmente reconocen la posesión de las tierras y la personalidad jurídica de las comunidades indígenas, tal y como lo hace Chile en el artículo 12.2 de su Ley Indígena; Perú en su artículo 89 constitucional, y Ecuador — cuyo Estado reconoce los derechos colectivos al medioambiente de los pueblos indígenas en el artículo 57 constitucional-, o Bolivia, que en el artículo 30 constitucional reconoce y obliga a la titulación colectiva de las tierras indígenas.

En México se reconoce a las comunidades indígenas la autonomía para preservar la integridad de sus tierras y acceder al uso y disfrute preferente de los recursos naturales de los lugares que habitan y ocupan las comunidades, estipulando el mismo cuerpo legal un candado al requerir el necesario respeto a las formas y modalidades de propiedad y tenencia de la tierra establecidas constitucionalmente, lo cual nos remite al artículo 27 constitucional (Constitución Política, 2017). 


\section{RESPONSABILIDAd Social y MEdioAmbiente}

Existen muchos acuerdos, tratados y convenios de carácter voluntario en los que se comprometen a llevar a cabo acciones para frenar el desgaste ecológico. Entre ellas, la aplicación del reciclaje, evitar desechar residuos químicos en mares y ríos, evitar la quema de combustibles, contribuir a la reforestación, aprovechar la obtención de energía a través de recursos renovables. Simon Suat, director de la UICN (citado en Cantú 2008), comenta que «los seres humanos somos los guardianes de la Tierra y tenemos la responsabilidad de proteger las especies que comparten nuestro medio ambiente».

En la actualidad, se intenta educar para el ambiente a través de la modificación de las conductas y de la interacción consciente con este. Esta modalidad de la educación contempla el mejoramiento y la conservación del medio, lo cual implica la modificación de toda una gama de actitudes que tenemos respecto al mismo. La educación ambiental es una corriente de personamiento y acción de alcance internacional, pues la afectación al medioambiente es considerada problema social, de manera que en 1987, la educación ambiental se estableció como un proceso permanente en el cual los individuos y las comunidades adquieren conciencia de su medio y aprenden los conocimientos, valores, destrezas, experiencias y determinación que les capacite para actuar individual y colectivamente en la resolución de los problemas ambientales presentes y futuros.

Ramírez (2004), en su guía para la formulación y evaluación de programas de educación ambiental, afirma que un modelo para elaborar programas de educación ambiental debe considerar las siguientes fases:

- Planeación, que consiste en fijar el curso concreto de acción que ha de seguirse, estableciendo los principios que habrán de orientarlo, la secuencia de operaciones para realizarlo y la determinación de tiempo y números necesarios para su realización. Constituye el conjunto de decisiones para alcanzar lo que se desea en el futuro, sirviendo de guía para las decisiones inmediatas. Por lo tanto, un programa de intervención es el conjunto de actividades y proyectos previamente planeados, para el cumplimiento de metas.

- Participación: se puede dar cuenta de que la falta de participación comprometida de la gente provoca un declive en la intervención 
o proyecto impartido, por lo que fomentar la Responsabilidad Social será fundamental.

\section{MODElO CONCEPTUAL PARA PROGRAMAS DE EDUCACIÓN AMBIENTAL}

El modelo planteado por Vásquez (1993) visualiza a la formación ambiental con un papel importante en la comprensión de la conservación del medioambiente, en el que se reflexione sobre las consecuencias ante el impacto en los recursos naturales. La formación ambiental pretende cambiar esta visión, con los principios y actitudes que permitirán lograr una mejor convivencia con la naturaleza, además, esta concientización trascenderá a cambios en los aspectos sociales, psicosociales, socioeconómicos y políticos para la lucha de la conservación del medioambiente. El mecanismo propuesto por Vásquez es dar a conocer las causas principales del problema, tomar conciencia y actuar, así como formar un grupo de personas responsablemente sociales que congregue a los participantes activos en el proceso, con el objeto de organizar la intervención a cualquier grupo vulnerable, así como a toda persona que desee actuar en pro del medioambiente.

Por lo que el objetivo fue evaluar las conductas en pro del cuidado del medioambiente de niños indígenas del sur de Sonora, México, con el fin de delinear estrategias de intervención que sean socialmente responsables y contribuir al bienestar personal y social.

\section{Aspectos Metodológicos}

Participaron 36 niños indígenas con un rango de edad de 7 a 15 años, constituido por 25 mujeres y 11 hombres de una comunidad indígena del sur de Sonora. Se aplicó la escala de comportamiento proambiental originalmente elaborado por Kaiser (1998) a manera de registro observacional para padres de familia, posteriormente, validado por Corral, Fraijo y Tapia (2005), en niños de primaria con un promedio de edad de 11,5 años de Hermosillo, Sonora.

En esta investigación, y dado el contexto de aplicación con niños indígenas del sur de Sonora, se usó a manera de autoevaluación, pero a través de la técnica de entrevista complementado con imágenes y ejemplos, para facilitar la comunicación y diluir las barreras culturales. Así mismo, se ajustaron las opciones de respuesta de cinco, tales como 
«todos los días» (4), «casi todos los días» (3), «a veces» (2), «casi nunca» (1) y «nunca» (0), a cuatro opciones «todos los días» (4), «casi todos los días» (3), «a veces» (2), y «nunca» (1), esto debido a que los niños no identificaron la diferencia entre el «a veces» $\mathrm{y}$ "casi nunca».

Se llevaron a cabo análisis multivariados de las variables demográficas como sexo, edad, lugar de procedencia, así como las respuestas de la escala de comportamiento proambiental.

Se agruparon preguntas con el mismo criterio de indagación, y se relacionaron haciendo diferentes componentes que se describen enseguida:

- Componente 1, «conducta proambiental», que indagaba sobre el comportamiento en general de los niños indígenas en pro del ambiente.

- Componente 2, «interés ambiental», se explora el interés que tienen los niños por el medioambiente, manifestándose con propiciar conversaciones acerca del cuidado ambiental, comportamiento de lectura, así como gustando de programas acerca del cuidado del medioambiente.

- Componente 3, «cuidado de la energía eléctrica», que busca recabar información acerca de qué tan frecuentemente los niños cuidan la energía eléctrica cuando no está en uso.

- Componente 4, «conducta de desperdicio de agua», se investiga acerca de qué tan frecuentemente los niños dejan la llave abierta mientras no utilizan el agua.

- Componente 5, "conducta de tirar comida», indaga acerca de la frecuencia en que los niños tiran la comida cuando no les gusta, o bien cuando no tienen hambre.

- Componente 6, "conducta de tirar basura», se busca conocer con qué incidencia los niños tiran la basura en lugares inadecuados.

- Componente 7, «conducta de reciclaje», que valora la frecuencia con la que los niños utilizan materiales usados para la elaboración de trabajos o tareas.

- Componente 8, "percepción del daño de las personas hacia el medio ambiente», valora si los niños consideran que los humanos estamos dañando del medioambiente, así como la frecuencia con la que lo hacemos.

Finalmente, se procesó la información en el paquete estadístico SPSS versión 15.0, y se procesaron los resultados para la realización de los informes. 


\section{Resultados}

Con respecto a los resultados, como se muestra en el gráfico 1, a partir de la recolección de datos se obtuvo que el 69,4\%(25) de los participantes son mujeres y el $30,6 \%$ (11) son hombres.

Gráfico i. Sexo de los participantes en porcentajes

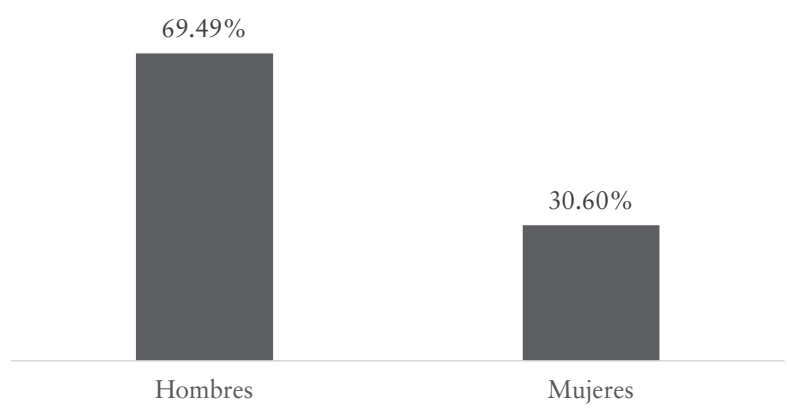

FuENTE: ELABORACIÓN PROPIA.

Como se muestra en el gráfico 2 , en cuanto a la edad de los participantes, el 30,6\% (11) tiene 9 años, el 27,8\% (10) tiene 12 años, el $11,1 \%$ (4) corresponde a los de 6 años, los de 11 años representan el $11,1 \%$ (4), el 5.6\% (2) representa a participantes de 10 años, el 5,6\% (2) a participantes de 7 y 8 años, el 2,8\% (1) al participante de 15 años y, por último, el 5,6\% (2) a los de 13 años. Existe una gran variedad de edades, desde los 6 a los 15 años, teniendo una media de 10 años.

Gráfico 2. EdAd de los PARTiCipantes EN PORCENTAJeS

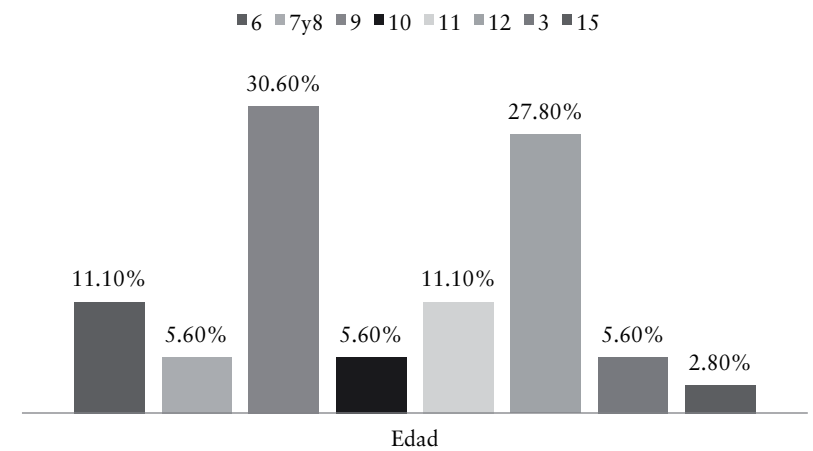


FuENTE: ELABORACIÓN PROPIA.

En el gráfico 3 se puede observar que el $56 \%$ de los niños caen dentro del rango medio de conductas en pro del medioambiente, lo cual significa que tienen conciencia en cuanto a la problemática ambiental y llevan conductas como cuidado de agua, tirar basura, entre otras, sin embargo, dicho comportamiento no siempre lo llevan a cabo el $44 \%$ bajo, el $0 \%$ alta. La puntuación en cuanto a los rangos estaba constituida de la siguiente manera: 1-10 = alto; 11-20 = medio; y, 21-30 = bajo. De acuerdo con estos resultados, se recomienda reforzar la conducta pro ambiental en general, debido a que el $0 \%$ manifestó llevar conductas medioambientales siempre. Además, gran parte de la población argumentó no tener cuidado del agua, suelo, aire, etc.

Gráfico 3. Manifestación de CONDUCTAS PROAMbientales

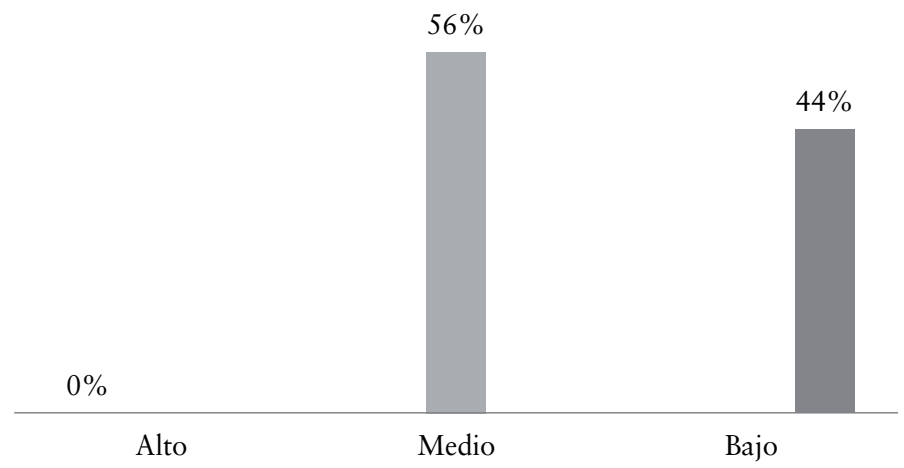

FuENTE: ELABORACIÓN PROPIA.

En el gráfico 4 se aprecia que el 3\% de la población presenta alto interés, manifestándose al hablar del tema, o investigando por sí mismos sobre este. En el valor medio se encontró una puntuación del $61 \%$, lo cual significa que tienen un interés propio en el cuidado del ambiente, manifestándose en gusto por lecturas, así como propiciar conversaciones sobre la problemática ambiental y los cuidados, mientras que el bajo interés ambiental lo representa el 36\%. La categoría fue constituida por rangos que van de 1-3 = alto; 4-6 = medio y 7-9 = alto. Por lo que se recomienda fomentar un interés hacia el cuidado del ambiente. 


\section{Gráfico 4. Porcentaje con Respecto al interés HACIA TEMAS PROAMBIENTALES}

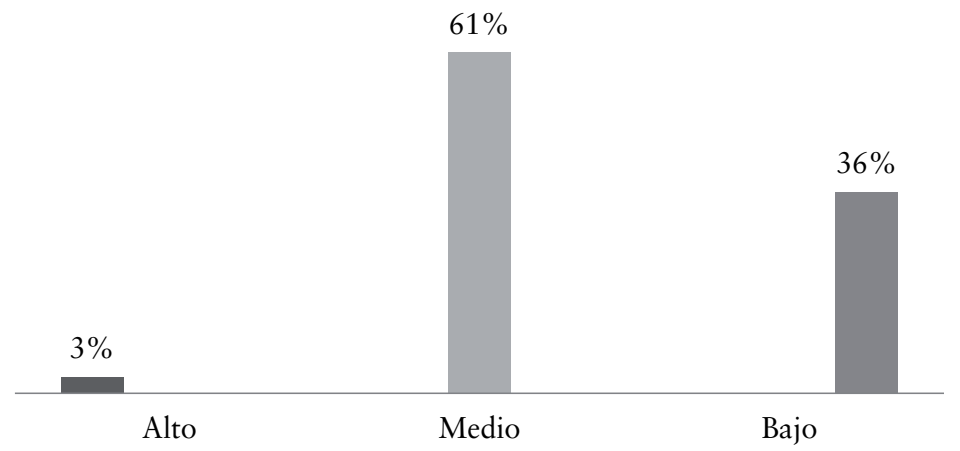

Fuente: Elaboración PROPIA.

El gráfico 5 representa el cuidado que los niños dicen tener hacia la energía eléctrica, manifestando dicha conducta con comportamientos como apagar las luces cuando no se utilizan, o cerrar el refrigerador cuando no esté en uso. En dicha categoría, se encontró que el $47 \%$ de los niños tienen cuidado medio, sin embargo, el $33 \%$ argumenta tener buen cuidado de la energía eléctrica. Un $0 \%$ de los participantes cayeron en el rango bajo. Los rangos establecidos estaban constituidos de la siguiente manera: $1-2=$ alto; $3-4=$ medio; $5-6=$ bajo.

Gráfico 5. Porcentaje Con Respecto al cuidado de la energía eléctrica $47 \%$

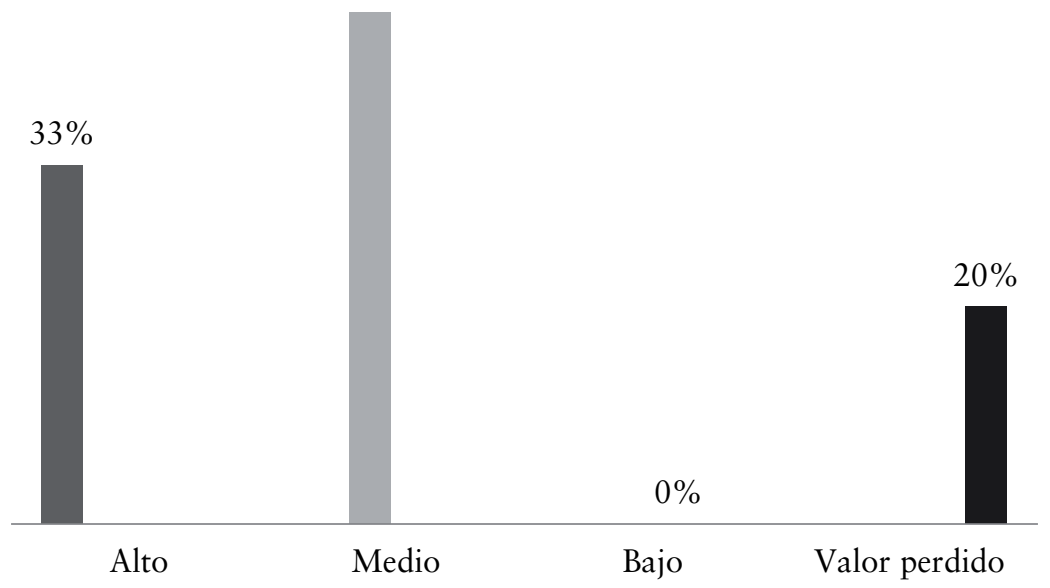

Fuente: ELABORACión PROPia. 
Como se puede observar en el gráfico 6 con respecto a la conducta del desperdicio de agua, el $58 \%$ de los niños argumentaron que nunca dejan la llave abierta mientras no la utilizan, sin embargo, el 31\% comentaron que solo lo hacen a veces, mientras que, en las categorías de todos los días y casi todos los días se obtuvo el $11 \%$. En esta categoría se recomienda reforzar la conducta del cuidado del agua.

Gráfico 6. Porcentajes CON RESPECTO A LA CONDUCTA

DE DESPERDICIO DE AGUA

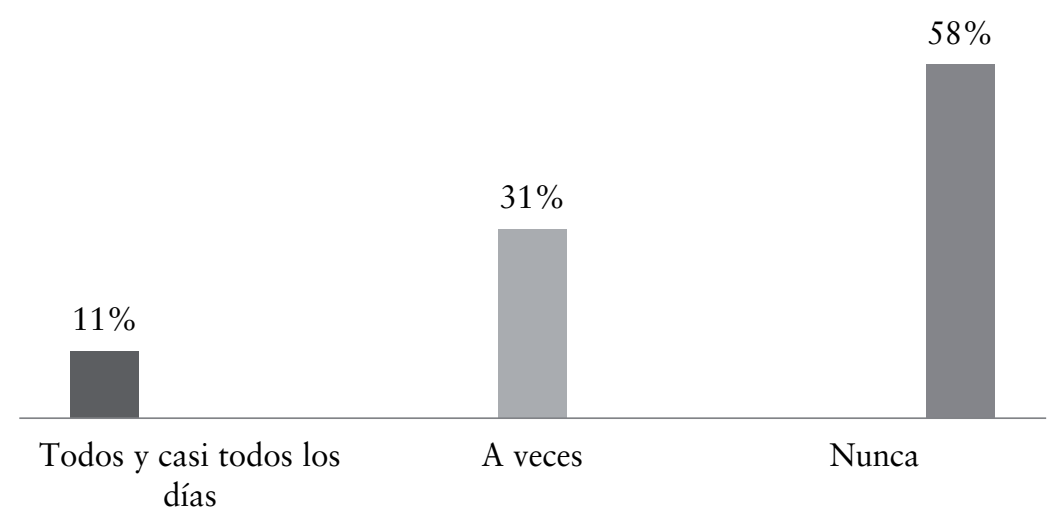

Fuente: ELABORACIÓN PROPIA.

El gráfico 7 representa la conducta de tirar residuos orgánicos como, por ejemplo, comida cuando al niño no le gusta, o bien, cuando está satisfecho. En esta categoría, el $61 \%$ de los niños argumenta nunca tirar la comida, sin embargo, el $36 \%$ comenta hacer dicha conducta a veces. Mientras que el 3\% manifiesta hacerlo todos los días. En esta categoría se recomienda reforzar la conducta de reusar residuos orgánicos. 
Gráfico 7. Porcentajes con respecto a la conducta DE TIRAR RESIDUOS ORGÁNICOS

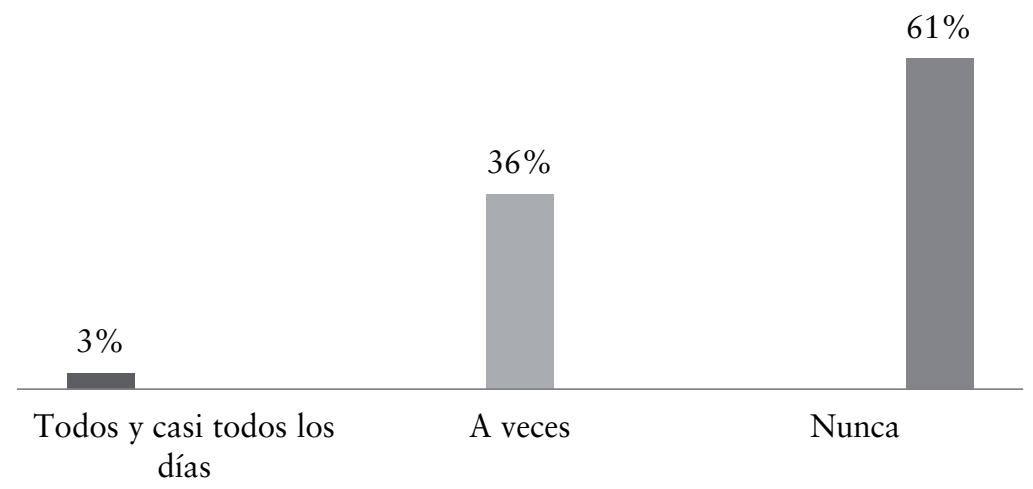

Fuente: ELABORACIÓN PROPIA.

El gráfico 8 representa la conducta de tirar basura, donde el 53\% de los encuestados argumenta que nunca tira basura en la casa. Mientras que el $47 \%$ comenta hacerlo a veces. Además, el $0 \%$ manifestó hacerlo todos los días o casi todos los días. En esta categoría se recomienda intervenir reforzando la conducta del desecho de basura en los lugares adecuados, así como de reutilizarla.

Gráfico 8. Porcentajes relativo a tirar basura

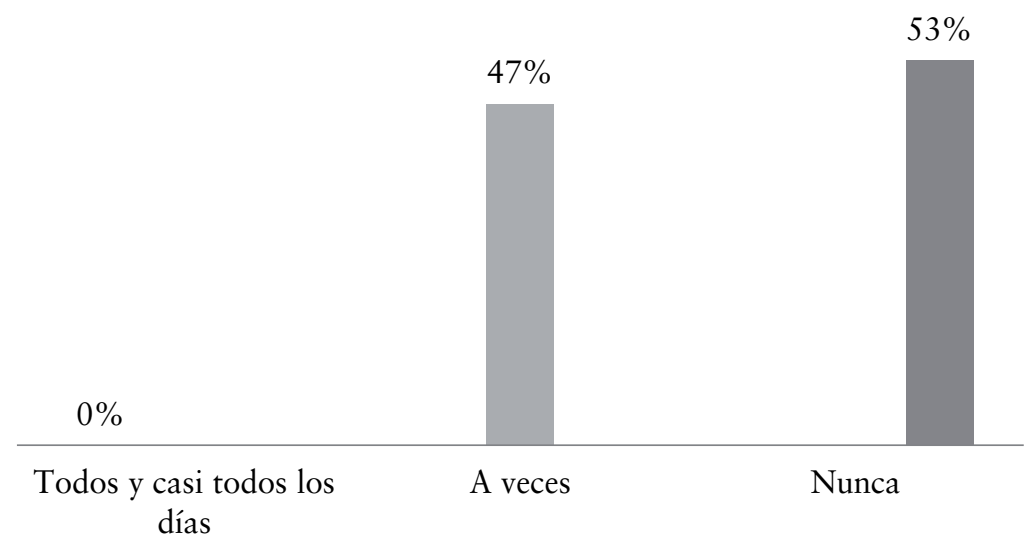

Fuente: Elaboración PROPIA. 
El gráfico 9 representa la conducta de reúso, en dicha categoría, el $45 \%$ de los niños comenta reutilizar materiales para la escuela solo a veces, sin embargo, el $25 \%$ explica nunca hacerlo, por su parte, el $22 \%$ argumenta reutilizar materiales casi todos los días y, siendo una minoría, el $8 \%$ dice hacerlo todos los días. En esta categoría se recomienda reforzar la conducta de reciclaje.

Gráfico 9. Porcentajes Con Respecto a la CONDUCta DE REÚSO DE MATERIAL

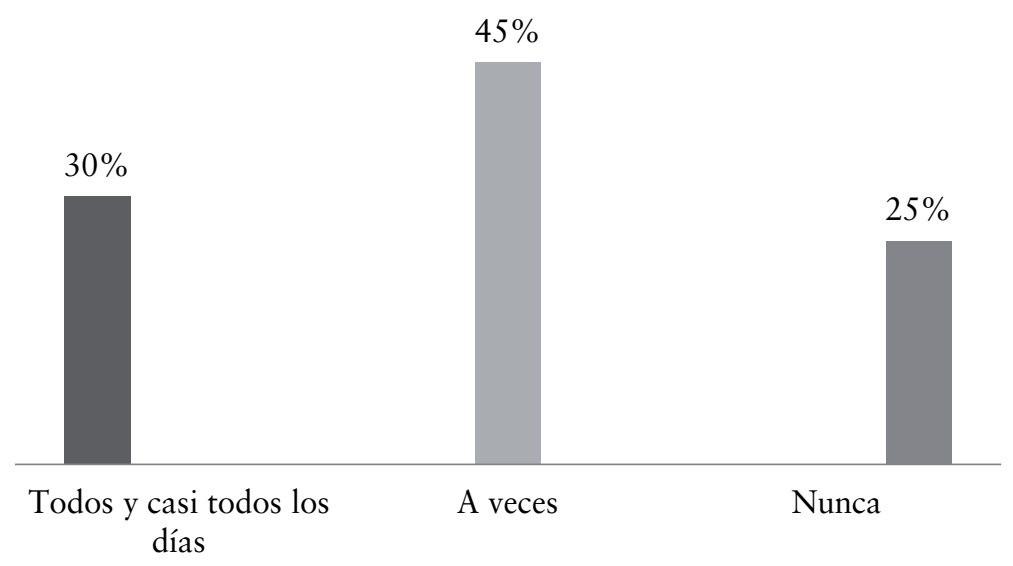

Fuente: Elaboración PROPIA.

El gráfico 10 considera la percepción de la frecuencia con que las personas dañan el medioambiente, en esta categoría, el $45 \%$ de los encuestados opina que las personas a veces dañan el medioambiente. El $25 \%$ comenta que dicho daño es hecho todos los días y el $6 \%$, casi todos los días. No obstante, el $30 \%$ de los encuestados consideran que los humanos no abusan de la naturaleza. En dicha categoría se recomienda dar conocimiento para concientizar en cuanto a este tema. 
Gráfico io. Percepción de frecuencia de daño DEL MEDIOAMBIENTE EN PORCENTAJES

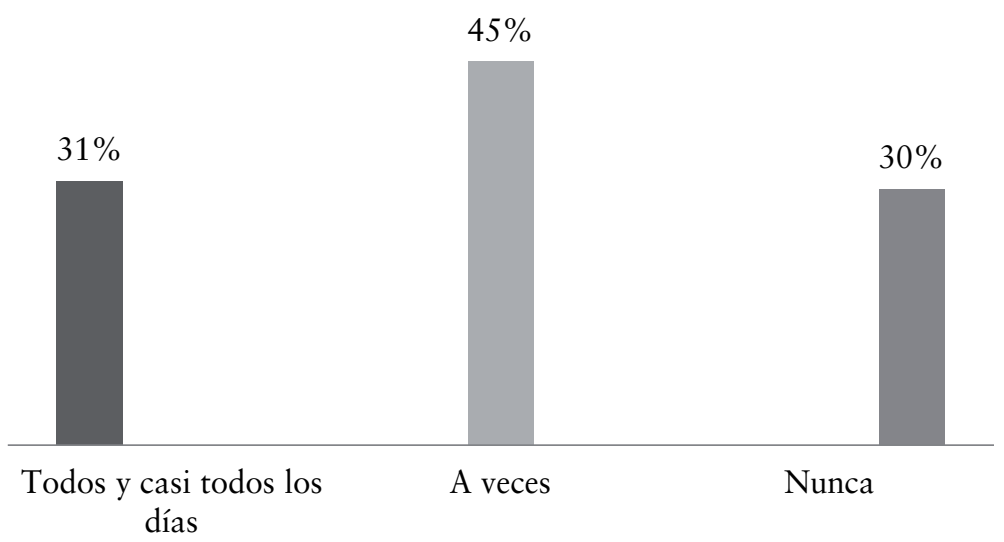

FuENTE: ELABORACIÓN PROPIA.

\section{Conclusiones}

Como se puede apreciar, el $61 \%$ de los participantes se ubica en el rango medio de conductas en pro del medio ambiente, lo cual significa que tienen consciencia de la problemática ambiental, y esto se ve reflejado en conductas de cuidado del agua como no dejar la llave abierta, el tirar la basura en su lugar, el reusar materiales, el no tirar alimentos, así como propiciar conversaciones sobre la problemática ambiental y sus posibles soluciones.. El tema del agua en las comunidades indígenas es relevante porque es un bien fundamental, no solo para las necesidades básicas humanas, sino porque es requerida para la agricultura, una de las actividades económicas vertebrales en la comunidad. Se requieren programas de intervención continuados en el que se trabaje con las nuevas generaciones, rescatando las tradiciones que están asociadas al respeto del medioambiente y la armonía con el ser humano.

Los cambios en el entorno exigen a las instituciones y organizaciones un comportamiento más comprometido con el ambiente, ya que se les reconoce responsabilidad no solamente en el ámbito social y económico, sino también en el ambiental. Debido a eso, las instituciones educativas desarrollan nuevos modelos de gestión en los cuales, desde su filosofía, valores y objetivos, se incluye la Responsabilidad Social, incorporando a grupos de interés y rediseñando el rol social de la universidad 
como un elemento que sirva de mejora en la calidad de las instituciones formadoras del talento humano (López, Zalthen y Cervantes, 2016).

Por su parte, Rincón (2013) asevera que los pueblos y las comunidades indígenas constituyen el más importante reservorio de la humanidad y el mayor impulso para la búsqueda de una civilización que revalorice el patrimonio humano y el desarrollo sustentable del planeta.

Hoy en día, el concepto de ambiente está ligado al de desarrollo, tal relación permite entender los problemas ambientales y su vínculo con el desarrollo sustentable, el cual debe garantizar una adecuada calidad de vida para las generaciones presente y futura (Wong, 1999, citado en Álvarez, 2009).

El gran problema medioambiental que se está presentando ha dado a lugar a diversas enfermedades, así como complicaciones o problemas en la salud.

Actualmente, existe un gran desgaste medioambiental que se ve reflejado en el crecimiento del agujero en la capa de ozono, la extinción de diversas especies, la disminución de áreas boscosas, así como un menor índice de agua disponible para el uso de los seres vivos, siendo preocupante para la supervivencia en un futuro de nuestra especie. Por los acontecimientos anteriormente descritos, es importante generar cambios conductuales, así como hacernos responsables por los daños hechos en el planeta. Sin embargo, es fundamental destacar que nuestra labor debe ser bajo la percepción de Responsabilidad Social.

\section{BiBLIOGRAFÍA}

Álvarez, P. y Vega, P. (2009). Actitudes ambientales y conductas sostenibles. Implicaciones para la educación ambiental. PSICODIDÁCTICA, 14 (2), 245-260.

Cantera, L. (2004). Psicología comunitaria de la Salud. Barcelona: UOC. Cantú, P. (2008). Deterioro ambiental y el futuro de la humanidad. Revista de salud pública, 5, (14), 30-35.

Cebrian, M. (2010). Conocimiento indígena sobre el medio ambiente y diseño de materiales educativos. Revista comunicar, 34(6), 115-124.

Contreras, F. (2007). Cultura verde: consejería del medio ambiente. Sevilla: Junta de Andalucía.

Declaración de las Naciones Unidas sobre los Derechos de los Pueblos Indígenas, 2007. Disponible en: http://www.un.org/esa/socdev/unpfii/ documents/DRIPS_es.pdf. 
Fondo de las Naciones Unidas para la infancia. UNICEF (2013). Declaración de las naciones unidas sobre los derechos de los pueblos indígenas para adolescentes indigenas. Disponible en: file:///c:/users/ lenovo $\% 20300 /$ desktop $/ 1 /$ declaracion $\% 20 \mathrm{de} \% 20$ las $\% 20$ naciones $\% 20$ unidas $\% 20$ sobre $\% 201$ los $\% 20$ derechos $\% 20$ indigneas.pdf.

Fraijo, B. (2001). La educación ambiental basada en competencias proecológicas: un estudio diagnóstico de requerimientos y acciones proambientales en niños de primer grado de primaria. Trabajo de grado, Maestría en investigación, Instituto Tecnológico, México.

Gaona P. G. (2013). El derecho a la tierra y protección del medio ambiente por los pueblos indígenas. Revista nueva antropología, 78, 141-161. González, G. F. (2008). OEA, medioambiente y desarrollo sostenible. Diálogo Político, 5, 99-108.

INEGI (2015). Estadísticas a propósito del día mundial del medio ambiente. Marzo 21, 2018, de Instituto Nacional de Estadística y Geografía. Disponible en: file:///c:/users/lenovo $\% 20300 /$ desktop/1/a \%20proposito $\% 20$ del $\% 20$ ambiente.pdf.

Lira, M. y Millán, E. (2014). Desastre Ambiental en Sonora. LA IZQUIERDA, 3-10.

López, M.; Zalthen, L. y Cervantes, M. (2016). La responsabilidad social universitaria desde la perspectiva del alumno. Ra Ximhai, 12 (6), 305-314.

Cabrera, G. (2006). La responsabilidad social de la empresa y las metas de desarrollo del milenio. EDUCARED (en línea). Disponible en: http://www.educared.edu.pe (acceso: 8 de abril de 2006).

Martínez, E. (2008). Trabajo comunitario: mitos y realidades. Talleres de trabajo comunitario y educación popular [en línea]. Disponible en: file:///c:/users/lenovo $\% 20300 /$ desktop/1/trabajo $\% 20$ comunitario $\% 20 y \% 20$ participacion, $\% 20$ mitos $\% 20 y \% 20$ realidades.pdf.

Mazabel, D. y Mendoza, A. (2012). Diversidad Cultural y Gestión del Agua: Lecciones desde una región de mazahua del Estado de México. Revista de Antropología Experimental, 30, 395-408.

Montero, M. (2005). Introducción a la psicología comunitaria. Buenos Aires: Paidós.

Mori, S. M. P. (2009). Responsabilidad social. Una mirada desde la psicología comunitaria. Revista Liberavit SciELO Analytics Perú. 15 (2) Disponible en: http://www.scielo.org.pe/scielo.php?script=sci_artte $\mathrm{xt} \&$ pid=S172948272009000200010.

ONU (2014). Informe sobre las condiciones de vida y cumplimiento de los derechos de niños, niñas y adolescentes indígenas. Organización Mundial de las Naciones Unidas. Disponible en: file:///c:/users/lenovo $\% 20300 /$ desktop/1/situacion $\% 20$ de $\% 20$ niños $\% 20$ indigenas.pdf. 
Organización de las Naciones Unidas para la Educación, la Ciencia y la Cultura (2003). El decenio de las naciones unidas para la educación con miras al desarrollo sostenible. Disponible en: http://unesdoc. unesco.org/images/0014/001486/148654so.pdf

Osios, R. (2015). La nueva filantropía o el negocio global de hacer el bien. Disponible en: file:///c:/users/lenovo $\% 20300 /$ desktop/1/la $\% 20$ nueva \%20filantropía \%20o\%20el\%20negocio \%20global\%20 de\%20hacer\%20el\%20bien..pdf.

Papalia, D. E. (2017). Desarrollo Humano. México: Porrúa.

Peña, F. (2004). Pueblos Indígenas y Manejo de Recursos Hídricos en México. Departamento de Antropología. Universidad de Chile. Revista Mad., 10, 1-2. Disponible en: http://era-mx.org/biblio/politica/ Pena2004.pdf.

Mireles, J. (2007). Sistema de creencias y conducta ambiental en niños de sexto de primaria; un estudio exploratorio. Trabajo de grado, Maestría en investigación. Instituto Tecnológico de Sonora, México. Ramírez, G. (2004). Guía metodológica para la formulación y evaluación de programas de educación ambiental bajo un enfoque participativocomprometido. Trabajo de grado, Licenciatura en Gestión Ambiental, Universidad Autónoma de Chapingo, México.

Rincón, Y. (2013). Pueblos Indígenas y Responsabilidad Social. Researchgate. Disponible en: file:///C:/Users/Lenovo\%20300/Downloads/3671361-1PBPueblosIndigenasyresponsabilidadSpocial.pdf.

Constitución Política de los Estados Unidos Mexicanos (2017) Cámara de Diputados del H. Congreso de la Unión (en línea). Disponible en: http://www.diputados.gob.mx/LeyesBiblio/pdf/1_150917.pdf (acceso: 5 de marzo de 2018).

Sánchez, K. (2009). Educación ambiental con niños indígenas yokot'an de olcuatitán, nacajuca Tabasco (en línea). México, Universidad Juárez Autónoma de Tabasco. Disponible en: file:///c:/users/lenovo\%20 300/desktop/1/educacion $\% 20$ ambiental $\% 20$ en $\% 20$ indigenas $\% 20$ de $\% 20$ tabasco.pdf.

Schwald, M. (2004). Responsabilidad social: Fundamentos para la competitividad empresarial y el desarrollo sostenible (Revista electrónica). Lima, Universidad del Pacífico. Disponible en: http://www.redalyc. org/pdf/686/681852611924010.pdf (acceso: 5 de marzo de 2018). Secretaría del Medio Ambiente y Recursos Naturales (2009). Programa de los Pueblos Indígenas y Medio Ambiente 2007-2012. México. Disponible en: https://cleancookstoves.org/binary-data/RESOURCE/ file/000/000/114-1.pdf (acceso: 27 de febrero de 2018).

Secretaría del Medio Ambiente y Recursos Naturales (2014). Desastre ambiental en Sonora, el peor de la minería en el país. Disponible en: http://www.drpconsultores.com/ 
semarnat-desastre-ambiental-en-sonora-el-peor-de-la-mineria-enel-pais/\#sthash.AdKus1ZZ.dpbs (acceso: 28 de febrero de 2018).

Strucas, R. y Dunalp, A. (2002). Comunidades en tiempo de flujo. Responsabilidad social. Una mirada desde la psicología comunitaria, 13, 183-193.

Unesco (1998). Conferencia mundial sobre la educación superior. Disponible en: http://www.unesco.org/education/educprog/wche/declaration_spa.htm (acceso: 25 de febrero de 2018).

Vásquez, G. (1993). Ecología y formación ambiental. España: Mc Graw Hill.

Velázquez, P. (2006). El desarrollo humano sustentable (DHS). Asociación ecológica de Bogotá. Disponible en: file:///C:/Users/Lenovo $\% 20300 /$ Downloads/2102Texto $\% 20 \mathrm{del} \% 20 \mathrm{art} \% \mathrm{C3} \% \mathrm{ADcu}$ lo-4165-1-10-20130219.pdf (acceso: 31 de marzo de 2018).

Vélez X. y Cano E. (2016). Los diferentes tipos de responsabilidad social y sus implicaciones éticas. Universidad Laica Eloy Alfaro de Manabí, Manta, Ecuador. Dom. Cien, 2, 117-126.

Zurrita, A. (2015). Factores causantes de degradación ambiental. International Journal of good conscience. Disponible en: file://c:/users/ lenovo $\% 20300 /$ desktop $/ 1 /$ factores $\% 20$ causantes $\% 20$ de $\% 20$ degradación \%20ambiental.pdf (acceso: 20 de marzo de 2018). 

Este libro se terminó de imprimir en Santiago de Chile, agosto de 2019

\section{Teléfono: 222238100 / ril@rileditores.com}

Se utilizó tecnología de última generación que reduce el impacto medioambiental, pues ocupa estrictamente el papel necesario para su producción, y se aplicaron altos estándares para la gestión y reciclaje de desechos en toda la cadena de producción. 
mérica Latina está trabajando para el logro de los Ob-
jetivos del Desarrollo Sostenible (ODS) con una orien-
tación multidimensional que transforme los modelos
tradicionales de desarrollo. Ello implica, a nivel organizacional, modificar la gestión en búsqueda de un arquetipo que conjugue la racionalidad técnica y la visión humanista. En este sentido, los principios y materias de la Responsabilidad Social (RS) ofrecen el marco adecuado para la gobernanza organizacional que contribuya a alcanzar algunas de las metas que se ha planteado la ambiciosa agenda internacional.

Los trabajos que se presentan en este libro son una muestra de la producción académica de América Latina sobre responsabilidad social, sustentabilidad y ODS. Sirven de referencia para la propia comunidad académica, con la finalidad de determinar sobre qué se está trabajando y cuáles son los temas aún no abordados. Las propuestas metodológicas y estratégicas son de utilidad, por su potencial de distinto tipo: a) potencial práctico, como instrumento de resolución de problemas; b) potencial de aplicación, por parte de quienes tienen responsabilidades de gerenciamiento en todo tipo de organizaciones, y c) potencial de innovación, por la utilidad metodológica que surge del propio diseño de un instrumento de gestión.

En tal sentido, la relevancia social de la incipiente producción académica de nuestra región quedará demostrada en la medida que los lectores de estas páginas capten las ideas centrales, las difundan y se conviertan paulatinamente en prácticas responsables para organizaciones concretas. 